Pehl

Implementation der Rasterfahndung 


\section{Kriminologische Forschungsberichte \\ Herausgegeben von Hans-Jörg Albrecht und Günther Kaiser}

Band K 140

Max-Planck-Institut für ausländisches
und internationales Strafrecht 


\title{
Die Implementation der Rasterfahndung
}

Eine empirische Untersuchung zur Anwendung, Umsetzung und Wirkung der gesetzlichen Regelungen zur operativen Informationserhebung durch Rasterfahndung

\author{
Dirk Pehl
}

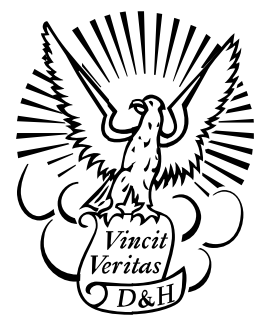

Duncker \& Humblot • Berlin 
Bibliografische Information der Deutschen Nationalbibliothek

Die Deutsche Nationalbibliothek verzeichnet diese Publikation in der Deutschen Nationalbibliografie; detaillierte bibliografische Daten sind im Internet über http://dnb.d-nb.de abrufbar.

DOI https://doi.org/10.30709/978-3-86113-092-5

Alle Rechte vorbehalten

(C) 2008 Max-Planck-Gesellschaft zur Förderung der Wissenschaften e.V. c/o Max-Planck-Institut für ausländisches und internationales Strafrecht

Günterstalstraße 73, 79100 Freiburg i.Br. http://www.mpicc.de

Vertrieb in Gemeinschaft mit Duncker \& Humblot GmbH, Berlin http://www.duncker-humblot.de Umschlaggestaltung: Ulrike Pehl

Druck: Stückle Druck und Verlag, Stückle-Straße 1, 77955 Ettenheim Printed in Germany

ISSN 1861-5937

ISBN 978-3-86113-092-5 (Max-Planck-Institut)

ISBN 978-3-428-12967-6 (Duncker \& Humblot)

Gedruckt auf alterungsbeständigem (säurefreiem) Papier entsprechend ISO 9706 
Für meine Eltern 



\section{Vorwort}

Die vorliegende Arbeit wurde im Sommersemester 2008 von der Rechtswissenschaftlichen Fakultät der Albert-Ludwigs-Universität Freiburg als Dissertation angenommen. Sie entstand während meiner Zeit als wissenschaftlicher Mitarbeiter am Max-Planck-Institut für ausländisches und internationales Strafrecht in Freiburg i. Brsg..

Mein besonderer Dank gilt an erster Stelle meinem Doktorvater und Direktor des Institutes, Herrn Prof. Dr. Dr. h.c. Hans-Jörg Albrecht, der es mir durch die Anstellung als wissenschaftlicher Mitarbeiter und die Nutzung der Institutslogistik ermöglichte, diese Arbeit durchzuführen. Bei der Anfertigung der Arbeit war er jederzeit bereit, sich engagiert mit meinen Überlegungen auseinanderzusetzen und so meinen Blickwinkel zu erweitern.

Mein Dank gilt weiter Herrn Prof. Dr. Wolfgang Frisch, der das Zweitgutachten zeitnah erstellt hat und damit erheblich zur Beschleunigung des Promotionsverfahrens beitrug.

Eine empirische Untersuchung bedarf auch immer der Unterstützung einer Vielzahl von Personen aus dem Forschungsfeld. So gilt mein Dank den Vertretern der Staatsanwaltschaften, für den nicht unerheblichen Aufwand bei der Identifizierung der dieser Untersuchung zugrunde liegenden Verfahren. Auch sei den Praktikern aus den Bereichen der Polizei und Justiz für die Teilnahme an den Expertengesprächen gedankt. Ihre offenen Angaben ermöglichten einen differenzierten Blick auf die Ergebnisse der Aktenanalyse. In diesem Zusammenhang möchte ich insbesondere meinen Ansprechpartnern bei der Bundesanwaltschaft und der Abteilung Operative Fallanalyse des Landeskriminalamtes Nordrhein-Westfalen danken.

Ein weiterer Dank sowohl für fachliche Diskussionen als auch für die gemeinsam verbrachte Zeit gilt meinem Freund und Kollegen im Max-Planck-Institut Herrn Dr. Benjamin Kurzberg. Herrn Dr. Volker Grundies danke ich für seine Geduld bei der Einführung in die Welt der Statistik. Des Weiteren gilt mein Dank Herrn Michael Knecht für die sorgfältige Durchsicht des Manuskripts und die zügige Drucklegung. Meiner Schwester Ulrike Pehl danke ich für die Gestaltung des Titelbildes.

Ein besonderes Dankeschön gilt Katrin Göpper. Sie stand mir während der gesamten Zeit der Erstellung dieser Arbeit verständnisvoll zur Seite und hat mich immer wieder durch aufmunternde Worte vorangebracht. Genauso wie meine Mut- 
ter übernahm sie die zeitintensive Arbeit des Korrekturlesens. Ohne sie hätte die Arbeit in der vorliegenden Form nicht entstehen können.

Dankbar bin ich für meine Eltern, die mich in jeder Hinsicht unterstützt haben. Die Anfertigung dieser Arbeit wäre ohne ihr Vertrauen in mich nicht möglich gewesen. Ihnen möchte ich diese Arbeit widmen.

Freiburg, im August 2008

Dirk Pehl 


\section{Inhaltsverzeichnis}

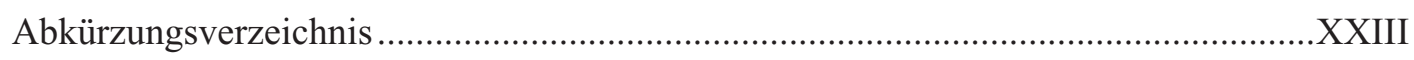

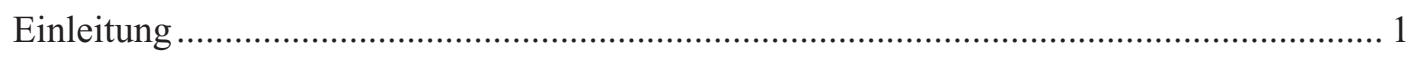

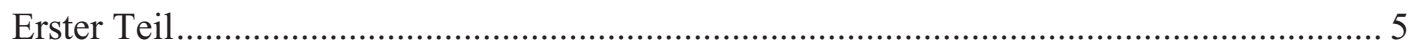

Grundlagen, Begriffsbestimmung und Stand der Forschung ............................................. 5

A. Der geschichtliche Hintergrund der Rasterfahndung ............................................. 5

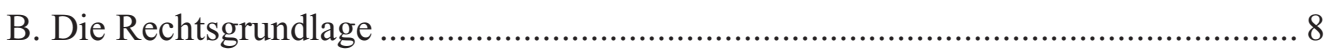

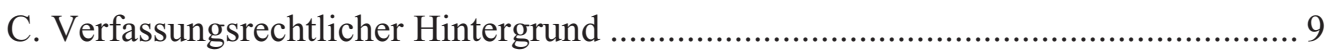

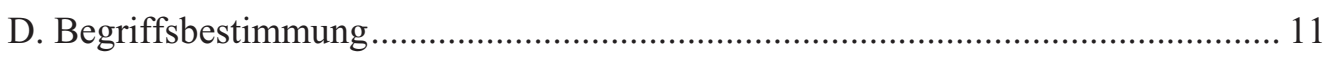

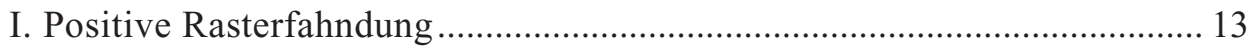

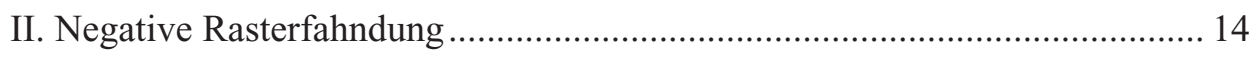

III. Stellungnahme zu den Formen der Rasterfahndung ................................... 14

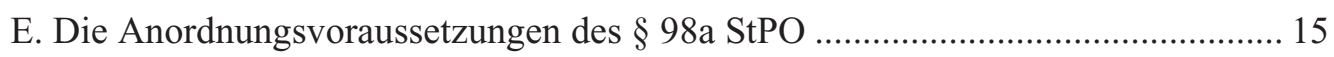

I. Zureichende tatsächliche Anhaltspunkte .......................................................... 16

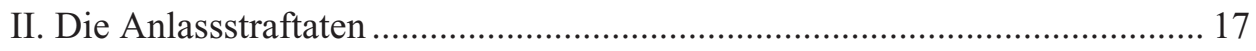

1. Straftaten auf dem Gebiet des unerlaubten Betäubungsmittelgesetzes oder Waffenverkehrs oder der Geld- und Wertzeichenfälschung ...... 18

2. Straftaten auf dem Gebiet des Staats- und Verfassungsschutzes............. 19

3. Straftaten auf dem Gebiet der gemeingefährlichen Straftaten................. 19

4. Straftaten gegen Leib oder Leben, die sexuelle Selbstbestimmung oder die persönliche Freiheit ................................................................ 20

5. Gewerbs- oder gewohnheitsmäßig begangene Straftaten........................ 20

6. Von einem Bandenmitglied oder in anderer Weise organisiert

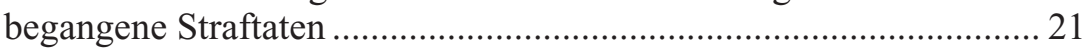

a. § 98a I S.1 Nr.6 1.Alt StPO ......................................................... 21

b. § 98a I S.1 Nr.6 2.Alt StPO......................................................... 23

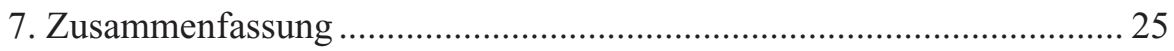

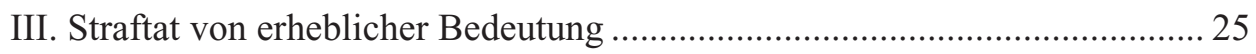

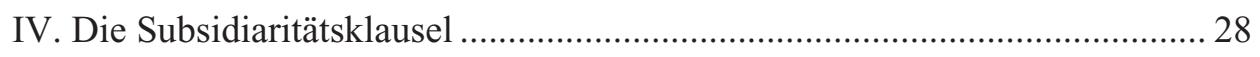

1. Verhältnis der Subsidiaritätsklauseln in der Strafprozessordnung ......... 29

2. Der Inhalt und das Verhältnis der beiden Alternativen innerhalb des $\S 98$ a I S.2 StPO zueinander ..................................................... 31

V. Die Mitwirkungspflicht der Speicherstelle .................................................. 33

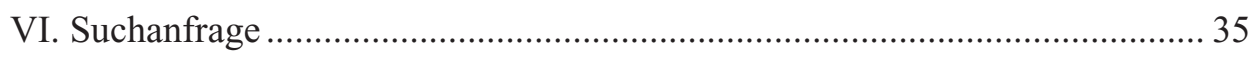

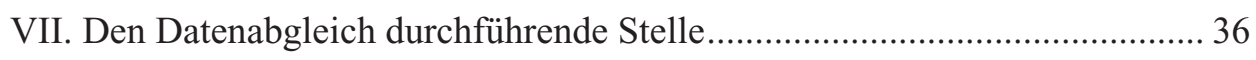

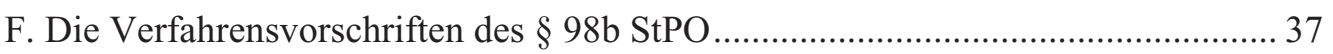


I. Die Annordnungskompetenz gem. § 98b I StPO ........................................ 37

II. Umfang der Prüfung und Entscheidungsgrundlage ...................................... 37

III. Anforderungen an Form und Inhalt der Anordnung .................................... 38

IV. Die Eilkompetenz der Staatsanwaltschaft nach § 98b I S.1 StPO ................ 39

V. Die richterliche Überprüfung der Eilanordnung ............................................ 40

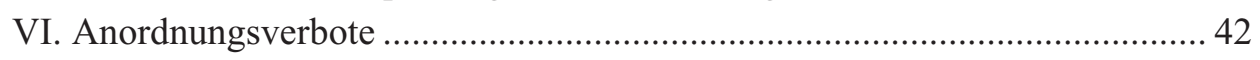

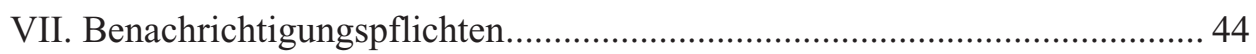

1. Benachrichtigung der Betroffenen ........................................................ 44

2. Benachrichtigung des Datenschutzbeauftragten..................................... 47

VIII. Verwertbarkeit der Erkenntnisse .............................................................. 48

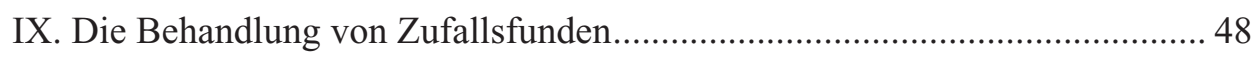

X. Rückgabe der Daten an die Speicherstelle und Löschung ............................ 50

G. Rasterfahndung nach den Polizei- und Sicherheitsgesetzen der Bundesländer ..... 51

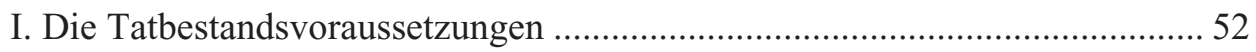

II. Abweichende Tatbestandvoraussetzungen in anderen Bundesländern .......... 55

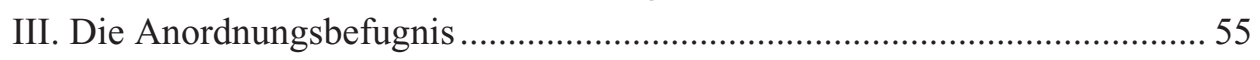

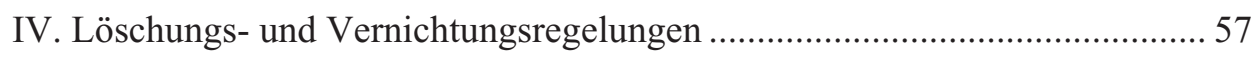

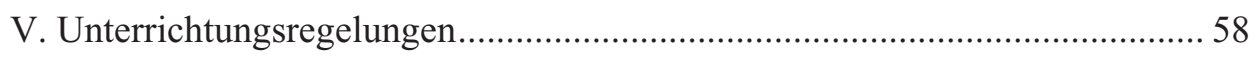

VI. Die polizeirechtliche Rasterfahndung in der Rechtsprechung...................... 58

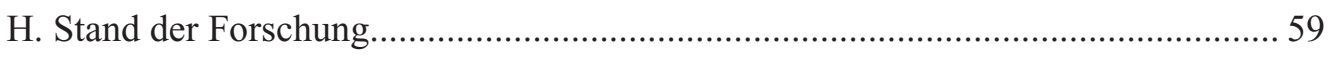

I. Rasterfahndung und organisierte Kriminalität (Graf 1997) ............................. 60

II. Rasterfahndung - Eine EDV-gestützte Massenfahndungsmethode im Spannungsfeld zwischen einer effektiven Strafverfolgung und dem Recht auf informationelle Selbstbestimmung (Siebrecht 1997)................. 61

III. Die Rasterfahndung nach § 98a StPO (Klever 2003) ................................... 62

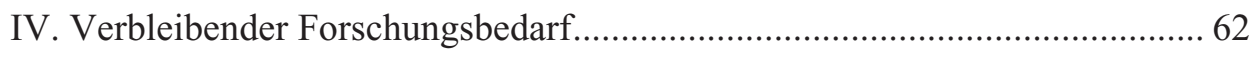

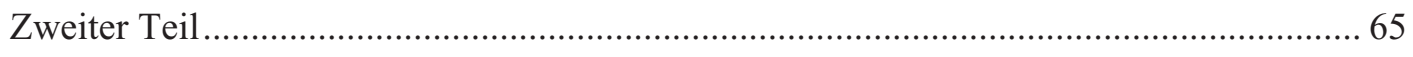

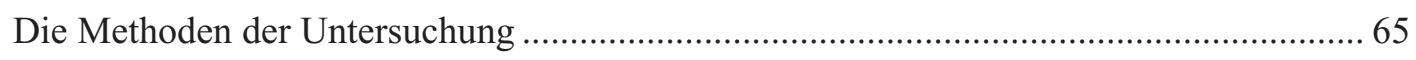

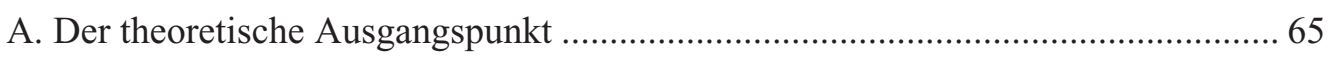

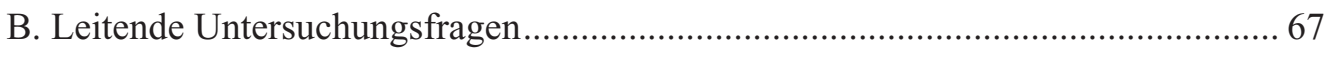

C. Die Wahl der Untersuchungsmethode............................................................... 73

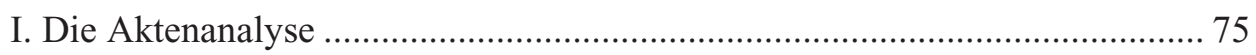

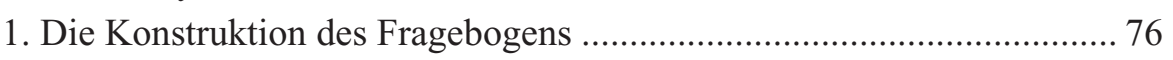

2. Die Identifikation der Verfahren .......................................................... 78

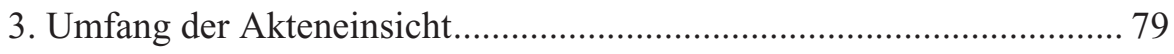

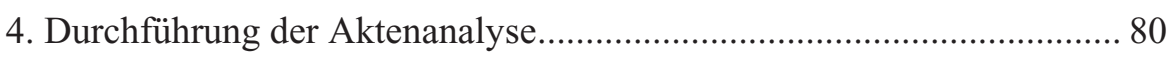

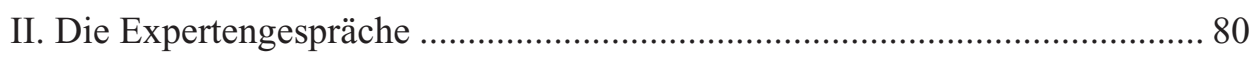

1. Auswahl der Gesprächspartner........................................................ 81

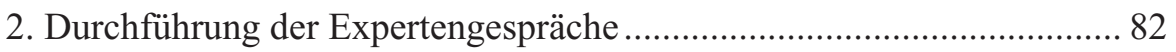

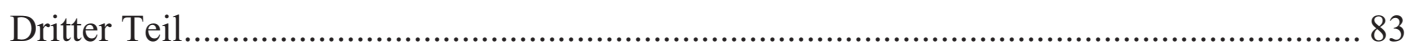

Die Ergebnisse der rechtstatsächlichen Untersuchung................................................. 83

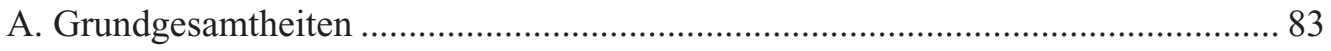

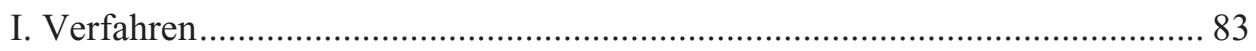


1. Verfahren mit Maßnahmen nach den $\S \S 98 \mathrm{a}, \mathrm{b}$ StPO ............................ 83

2. Verteilung der Verfahren auf den Zeitraum von 1990 bis 2005 ............. 83

3. Verteilung der Verfahren auf die Bundesländer....................................... 85

4. Verteilung der Katalogdelikte über die Verfahren .................................... 86

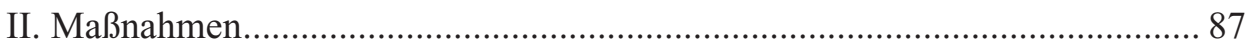

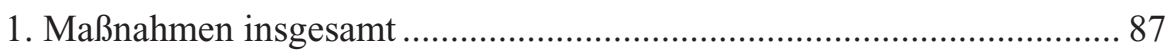

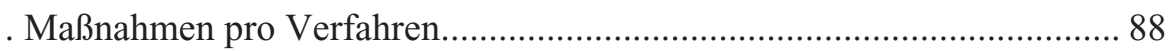

3. Verteilung der Katalogdelikte auf die Maßnahmen ................................... 88

4. Durchgeführte und nicht durchgeführte Maßnahmen ........................... 88

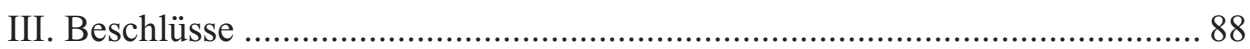

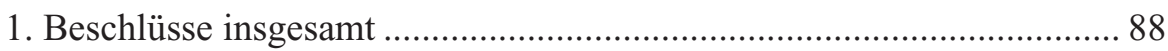

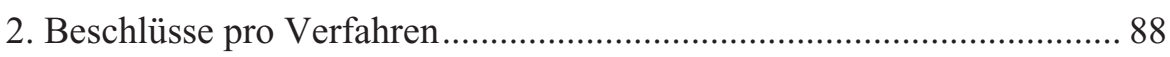

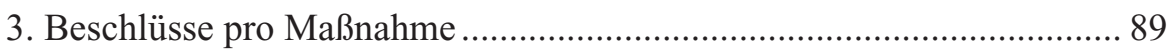

4. Verteilung der Katalogdelikte auf die Beschlüsse.................................. 90

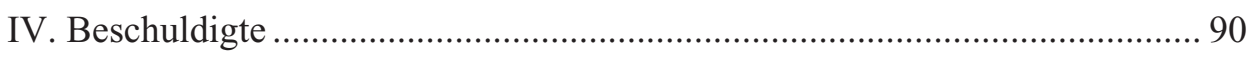

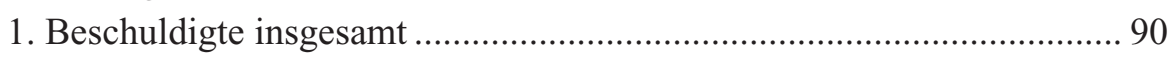

2. Beschuldigte pro Verfahren.................................................................. 91

B. Die Anordnung der Rasterfahndung gem. der $\S \S 98 \mathrm{a}, \mathrm{b}$ StPO ............................. 92

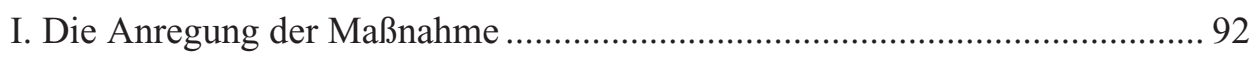

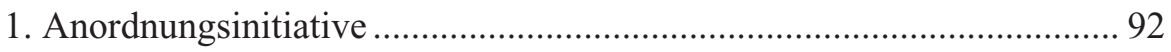

2. Ermittelnde Polizeidienststelle ......................................................... 92

3. Zeitraum zwischen der Ermittlungseinleitung und der Anregung.......... 93

4. Ermittlungsstand bei Anregung der Rasterfahndung.............................. 93

5. Begründung der Anregung ................................................................... 94

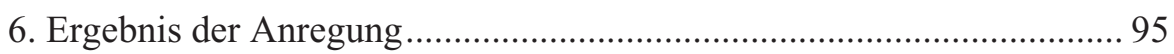

II. Die Beantragung der Maßnahme ................................................................ 95

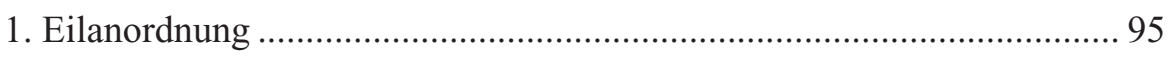

2. Zeitraum zwischen Anregung und Antrag............................................ 95

3. Ziele der Maßnahme laut staatsanwaltschaftlichem Antrag................... 96

a. Differenzierung positive und negative Rasterfahndung ................. 96

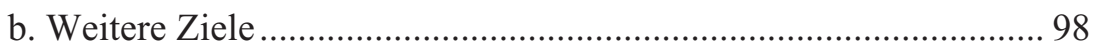

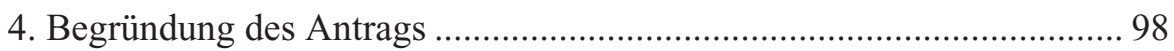

a. Kategorien und Kriterien für die Bewertung .................................. 98

b. Antragsbegründungen ............................................................. 100

c. Beispiel für eine substanzielle Begründung ................................... 101

d. Umfang der Antragsbegründungen ................................................ 102

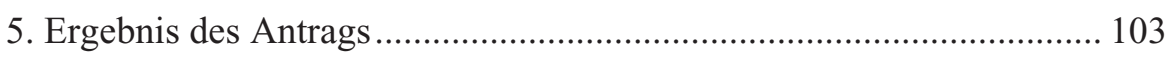

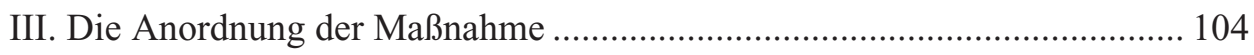

1. Zeitraum zwischen Antrag und Anordnung .......................................... 104

2. Zeitraum zwischen Anregung und Anordnung ..................................... 104

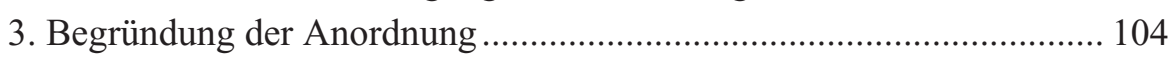

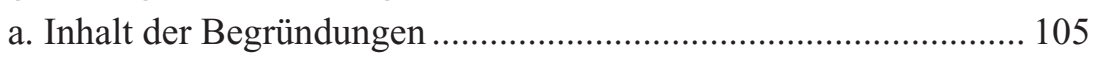

IV. Vergleich der Ergebnisse und Zusammenfassung.................................... 107 
1. Zeiträume zwischen Anregung, Antrag und Anordnung im Vergleich

3. Umfang der staatsanwaltschaftlichen und richterlichen

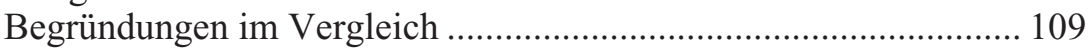

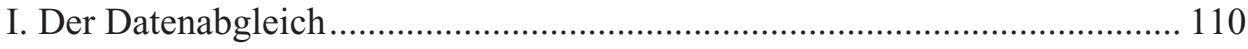

1. Zeitraum zwischen Anordnung und Durchführung.............................. 110

2. Für den Datenabgleich benötigte Zeit .................................................. 111

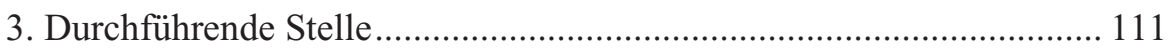

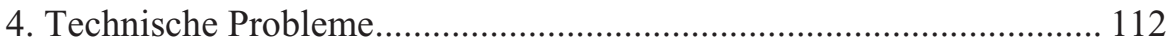

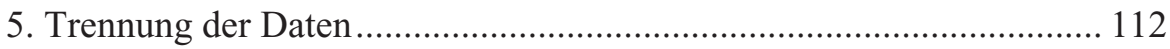

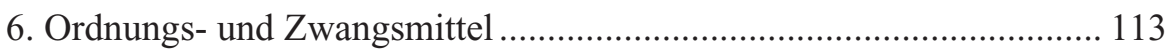

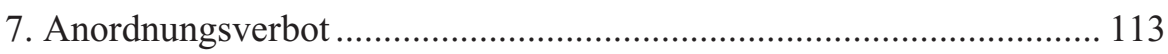

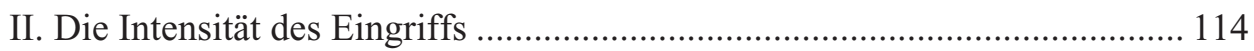

1. In den Datenabgleich einbezogene Datenbestände ............................... 114

2. Umfang der angeforderten und übermittelten Daten ............................. 114

3. Vom Datenabgleich betroffene Personen .............................................. 115

III. Nach der Durchführung des Datenabgleichs ............................................. 115

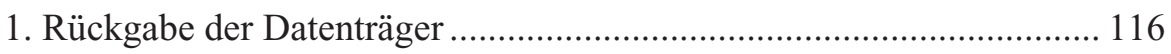

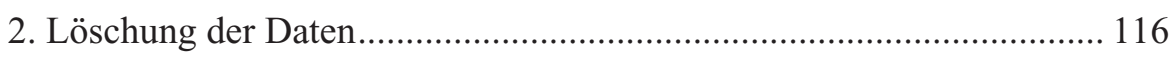

3. Verwendung der Daten zu Beweiszwecken in anderen Verfahren ...... 117

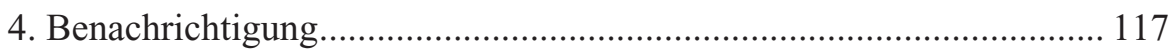

5. Meldung an den Datenschutzbeauftragten ............................................ 117

6. Kosten der Rasterfahndung ................................................................ 118

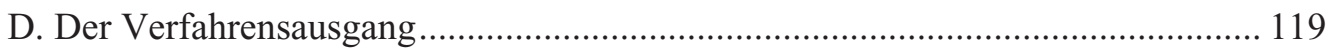

I. Verfahrensausgang bezogen auf die Verfahren............................................. 119

1. Inhalt der polizeilichen Abschlussberichte............................................ 119

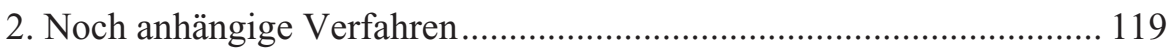

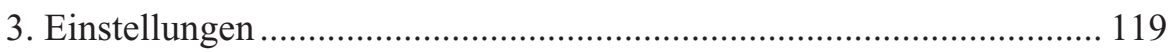

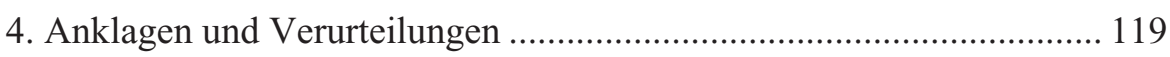

II. Verfahrensaugang bezogen auf die Beschuldigten .................................... 120

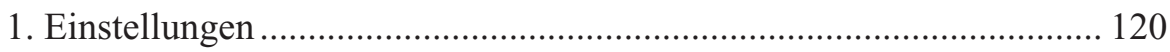

2. Anklagen und Verurteilungen ............................................................. 121

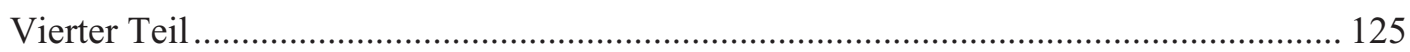

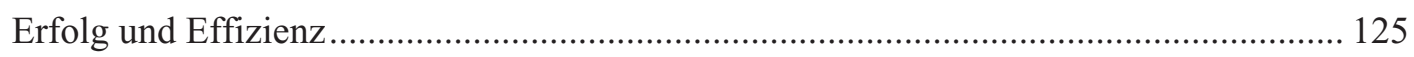

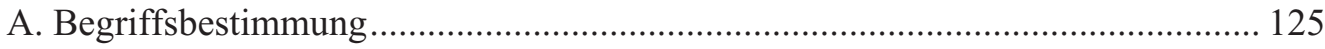

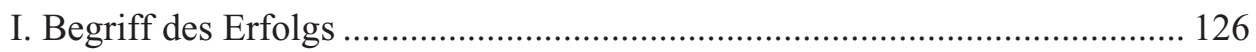

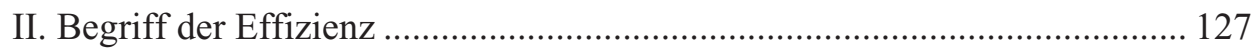

III. Erfolg und Effizienz der Rasterfahndung .................................................. 129

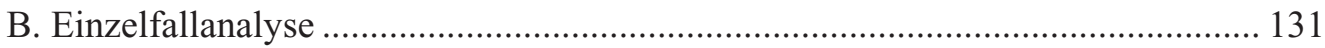

I. Verfahren 001 ……………………………………………………… 131

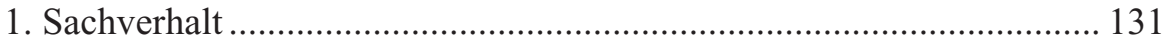

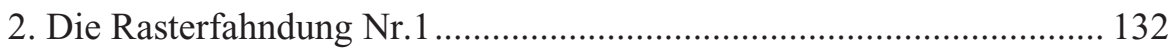

a. Ermittlungsstand und Ausgangslage .......................................... 132 


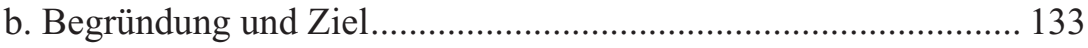

c. Durchführung und Ergebnis ....................................................... 133

d. Auswirkungen auf das Ermittlungsverfahren................................. 133

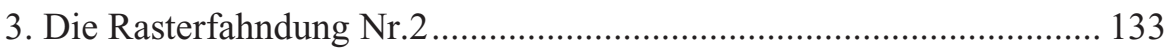

a. Ermittlungsstand und Ausgangslage ............................................ 133

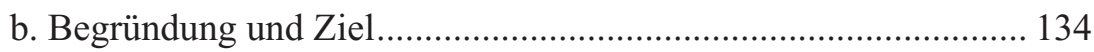

c. Durchführung und Ergebnis ....................................................... 134

d. Auswirkungen auf das Ermittlungsverfahren............................... 134

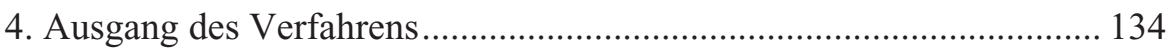

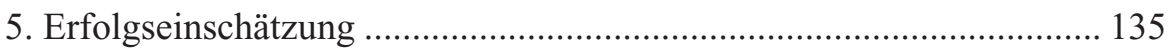

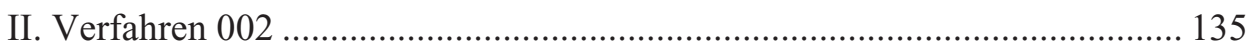

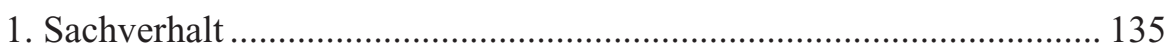

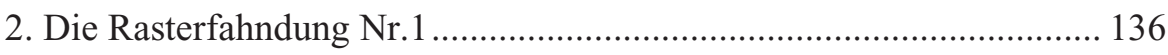

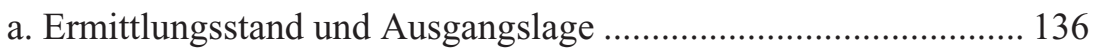

b. Begründung und Ziel................................................................. 136

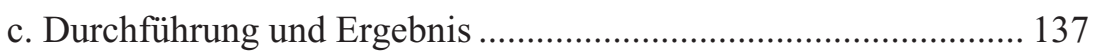

d. Auswirkungen auf das Ermittlungsverfahren................................. 137

3. Die Rasterfahndung Nr.2 …............................................................ 138

a. Ermittlungsstand und Ausgangslage .............................................. 138

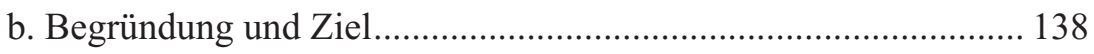

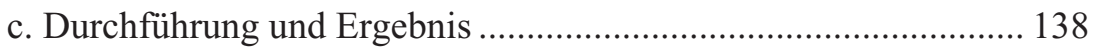

d. Auswirkungen auf das Ermittlungsverfahren................................ 139

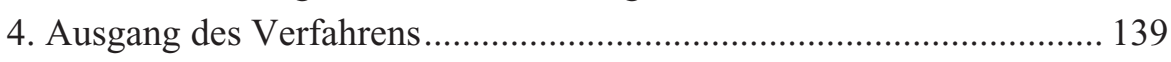

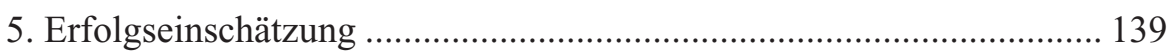

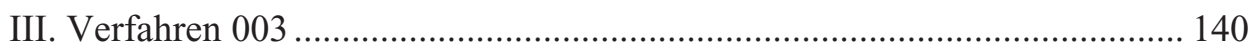

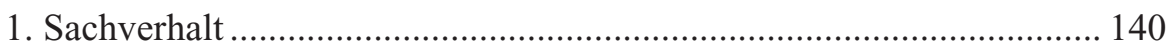

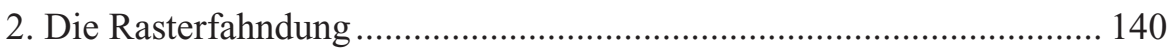

a. Ermittlungsstand und Ausgangslage ............................................ 140

b. Begründung und Ziel................................................................ 140

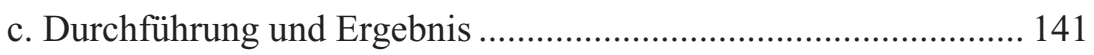

d. Auswirkungen auf das Ermittlungsverfahren................................. 141

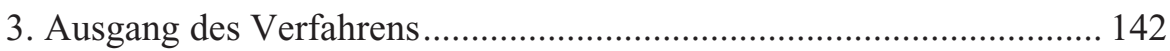

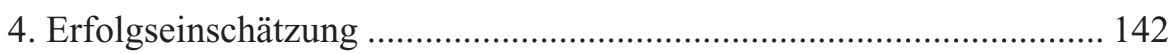

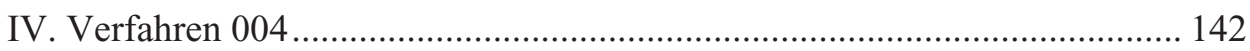

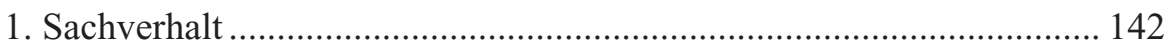

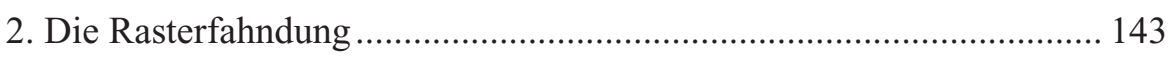

a. Ermittlungsstand und Ausgangslage ............................................. 143

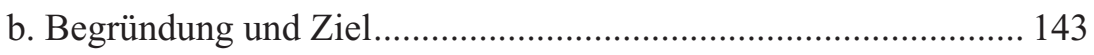

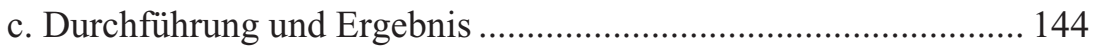

d. Auswirkungen auf das Ermittlungsverfahren................................. 144

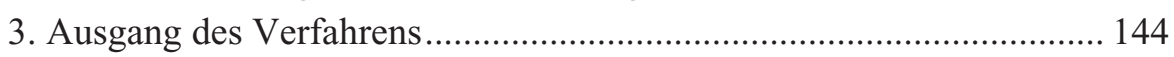

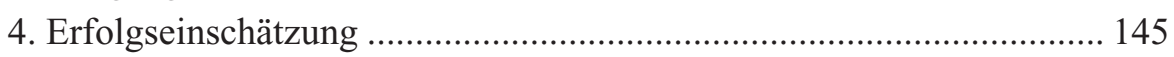

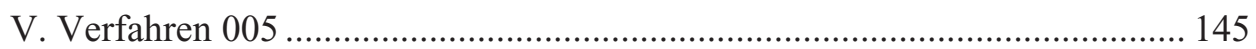




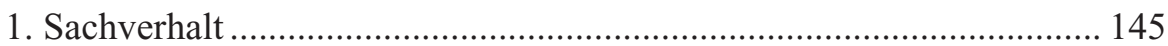

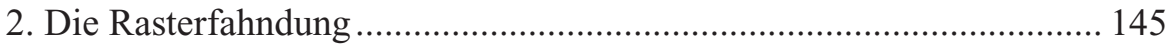

a. Ermittlungsstand und Ausgangslage .............................................. 145

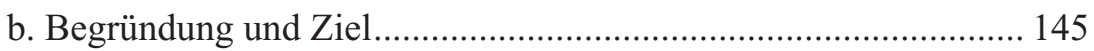

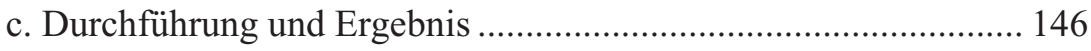

d. Auswirkungen auf das Ermittlungsverfahren............................... 146

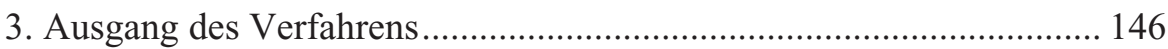

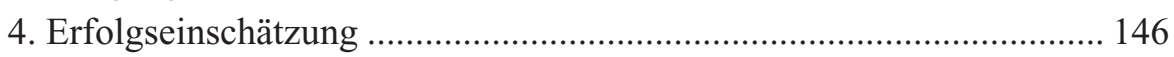

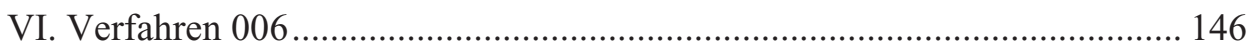

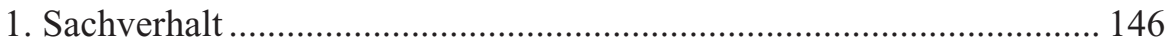

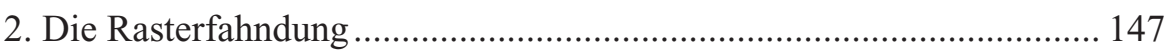

a. Ermittlungsstand und Ausgangslage ............................................. 147

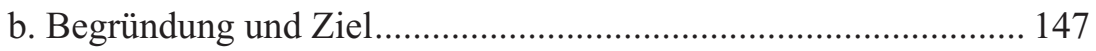

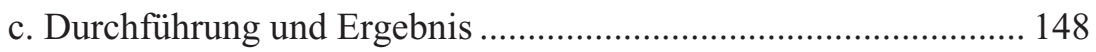

d. Auswirkungen auf das Ermittlungsverfahren................................. 148

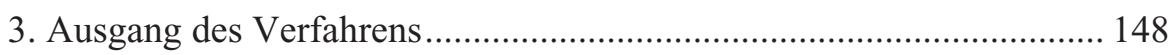

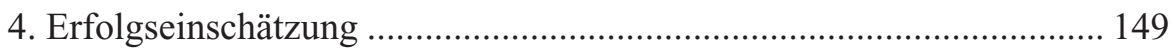

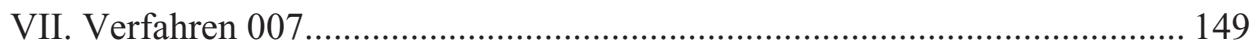

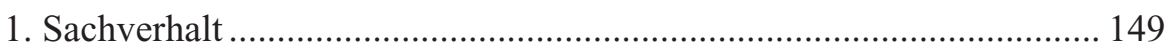

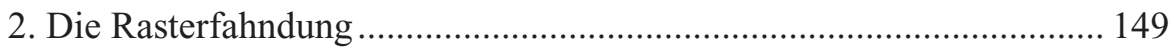

a. Ermittlungsstand und Ausgangslage ........................................... 149

b. Begründung und Ziel.............................................................. 151

c. Durchführung und Ergebnis ....................................................... 152

d. Auswirkungen auf das Ermittlungsverfahren............................... 152

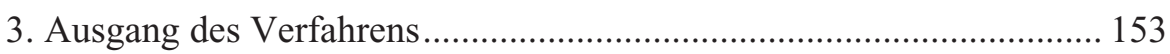

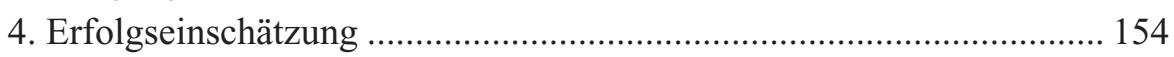

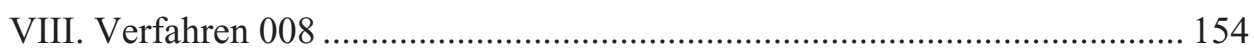

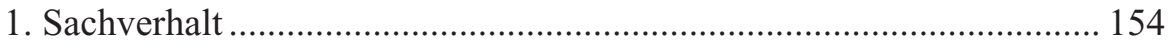

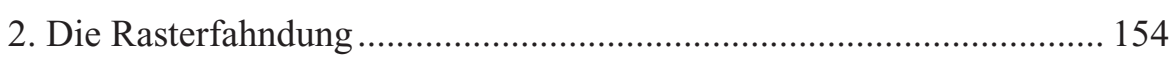

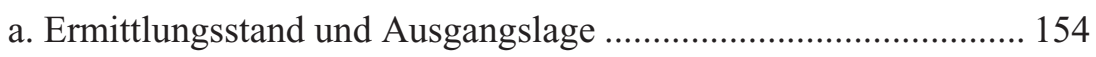

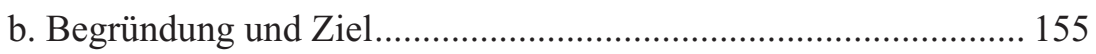

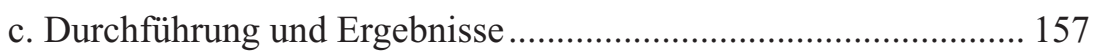

d. Auswirkungen auf das Ermittlungsverfahren................................ 157

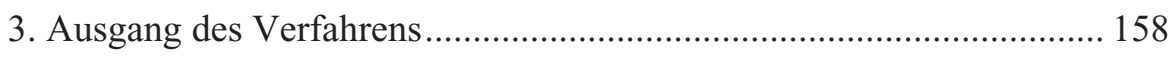

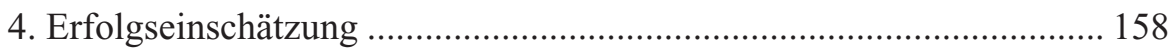

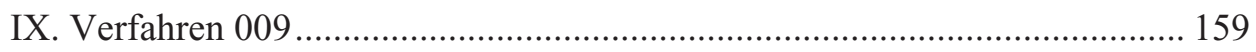

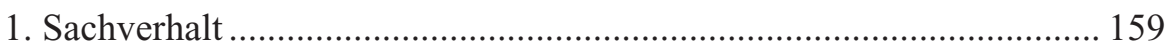

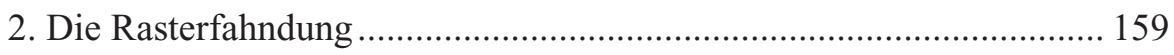

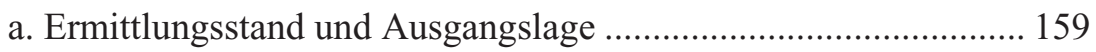

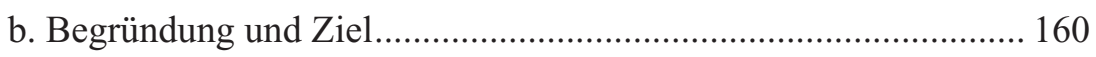

c. Durchführung und Ergebnis ....................................................... 161

d. Auswirkungen auf das Ermittlungsverfahren................................. 161

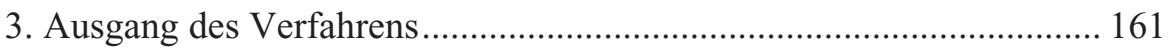




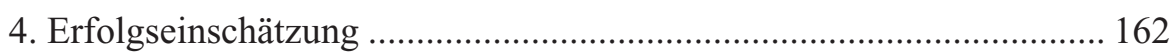

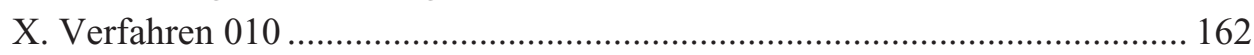

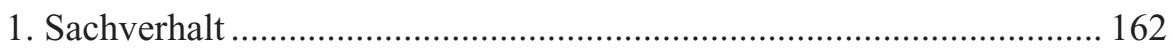

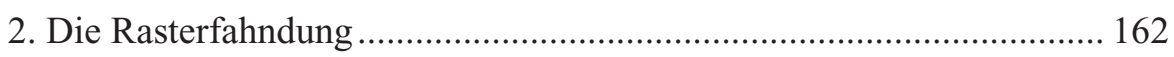

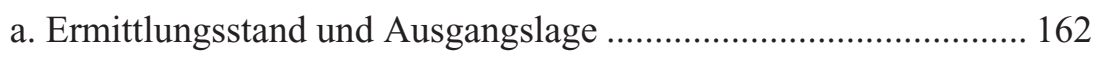

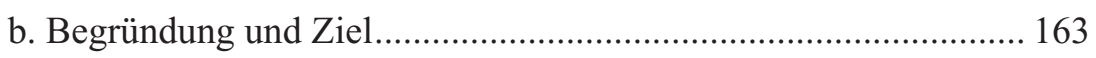

c. Durchführung und Ergebnis ....................................................... 164

d. Auswirkungen auf das Ermittlungsverfahren................................. 164

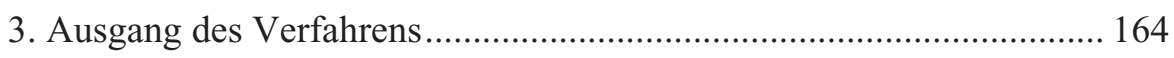

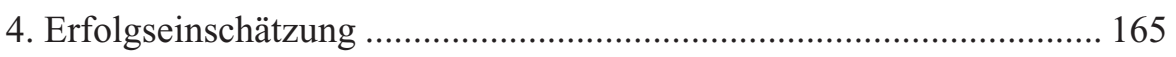

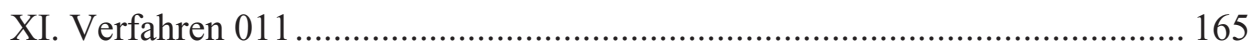

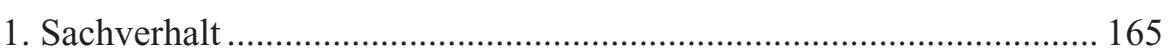

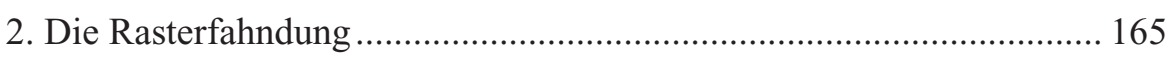

a. Ermittlungsstand und Ausgangslage .............................................. 165

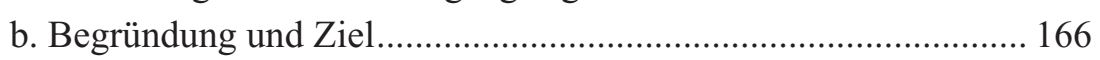

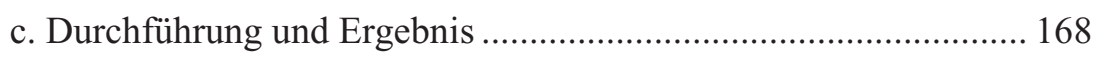

d. Auswirkungen auf das Ermittlungsverfahren................................ 169

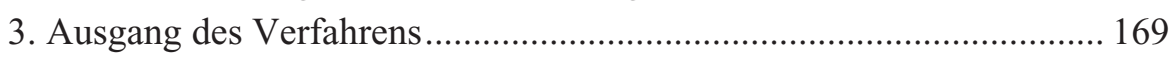

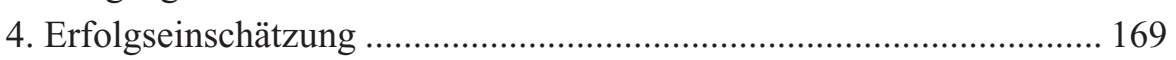

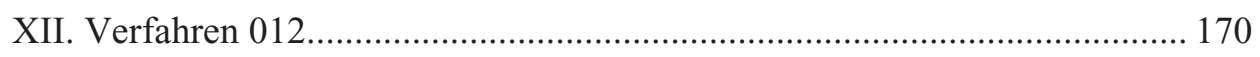

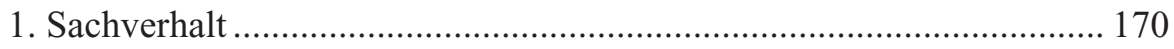

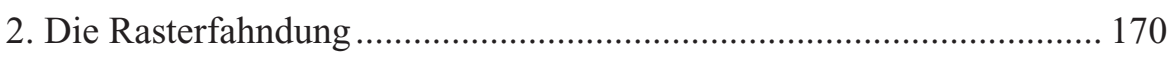

a. Ermittlungsstand und Ausgangslage .......................................... 170

b. Begründung und Ziel............................................................... 171

c. Durchführung und Ergebnis ....................................................... 171

d. Auswirkungen auf das Ermittlungsverfahren................................ 172

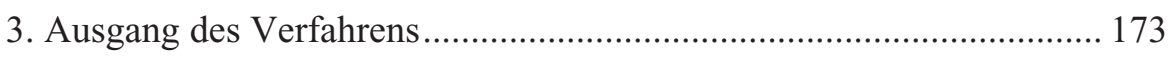

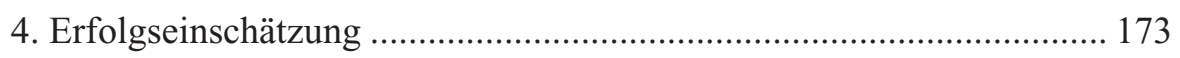

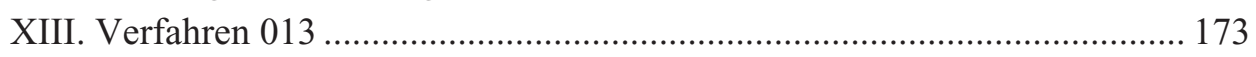

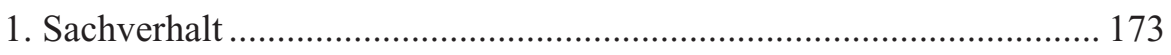

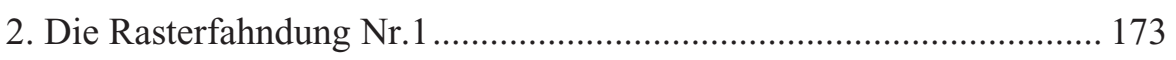

a. Ermittlungsstand und Ausgangslage ............................................ 173

b. Begründung und Ziel der ersten Rasterfahndung......................... 174

c. Durchführung und Ergebnis der ersten Rasterfahndung .............. 174

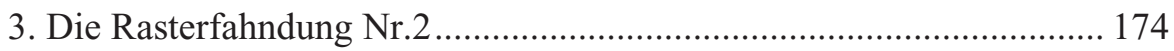

a. Begründung und Ziel der zweiten Rasterfahndung ...................... 174

b. Durchführung und Ergebnis der zweiten Rasterfahndung ........... 175

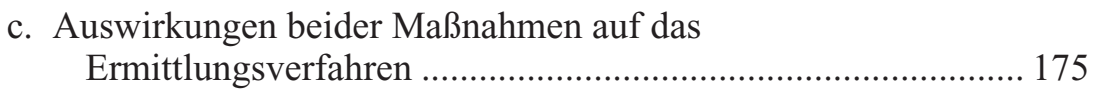

4. Ausgang des Verfahrens...................................................................... 175

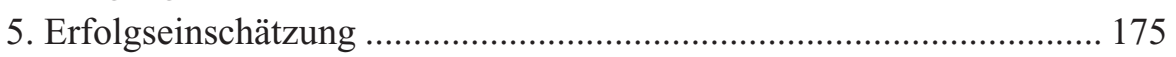

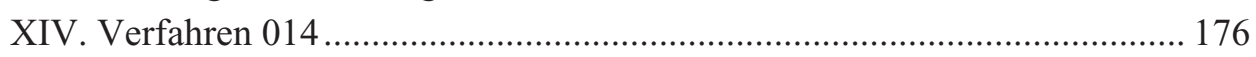

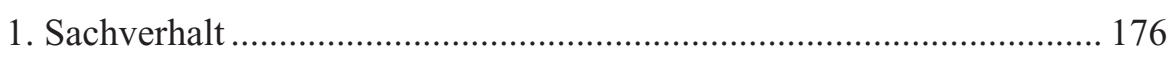




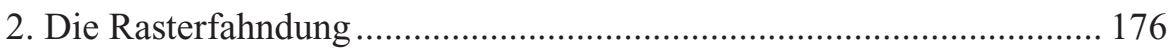

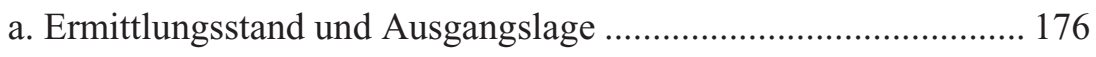

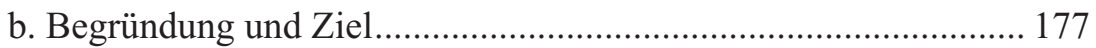

c. Durchführung und Ergebnis ......................................................... 178

d. Auswirkungen auf das Ermittlungsverfahren............................... 179

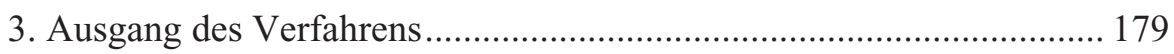

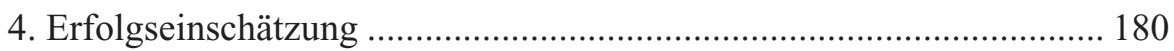

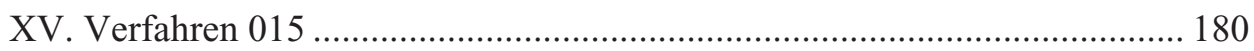

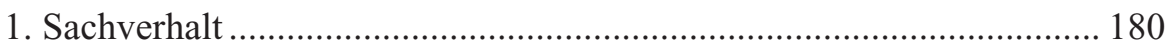

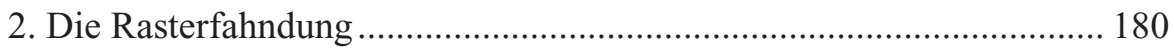

a. Ermittlungsstand und Ausgangslage ............................................ 180

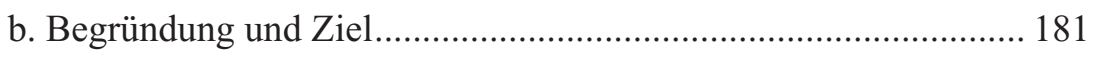

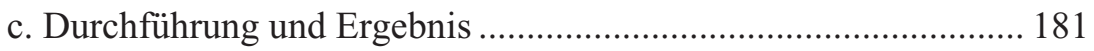

d. Auswirkungen auf das Ermittlungsverfahren............................... 181

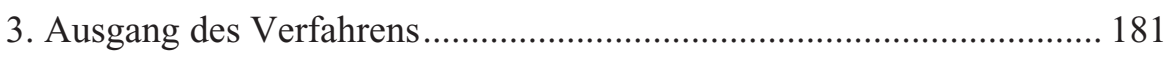

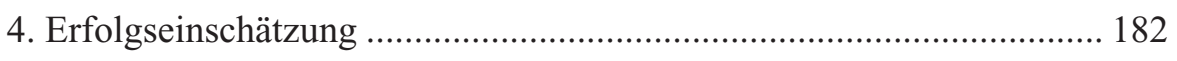

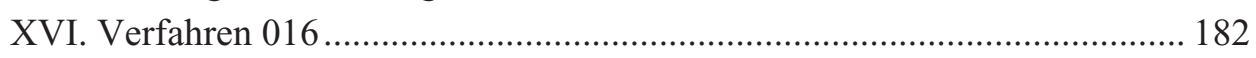

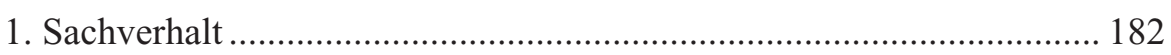

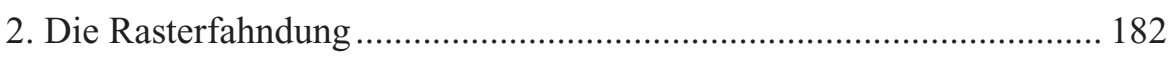

a. Ermittlungsstand und Ausgangslage ............................................ 182

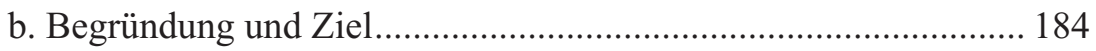

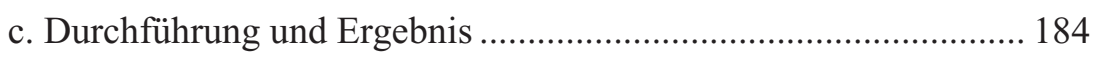

d. Auswirkungen auf das Ermittlungsverfahren............................... 184

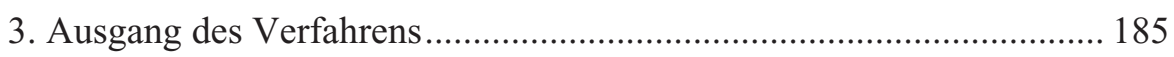

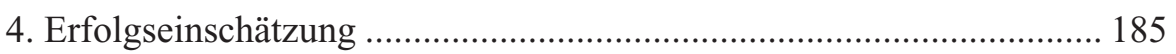

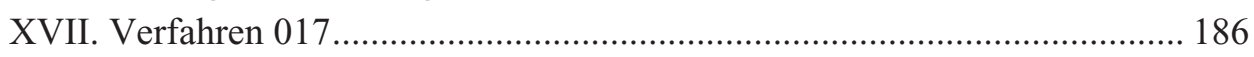

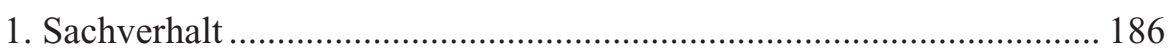

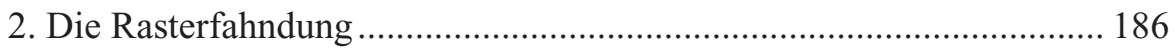

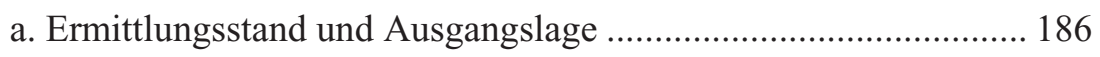

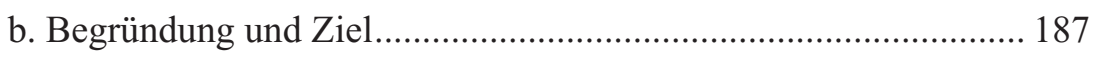

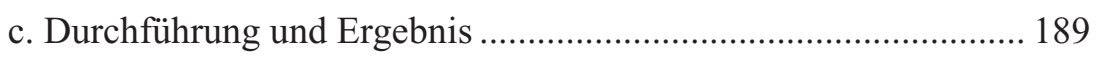

d. Auswirkungen auf das Ermittlungsverfahren................................ 190

3. Ausgang des Verfahrens.................................................................... 190

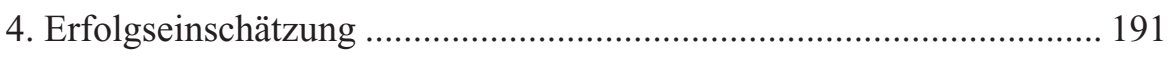

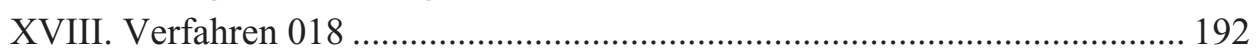

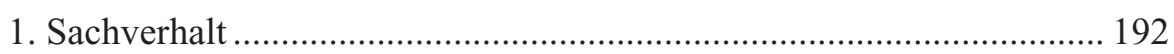

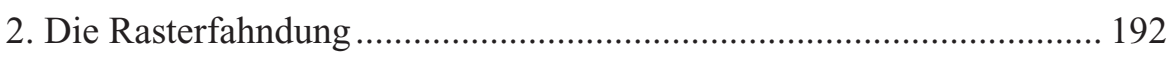

a. Ermittlungsstand und Ausgangslage ............................................ 192

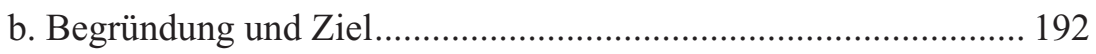

c. Durchführung und Ergebnis ......................................................... 193

d. Auswirkungen auf das Ermittlungsverfahren............................... 193

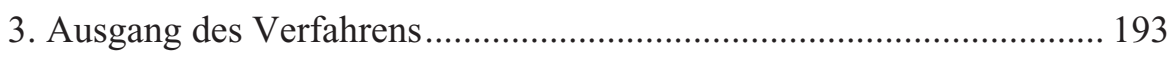

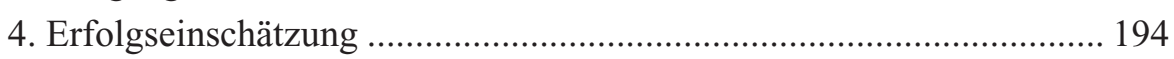




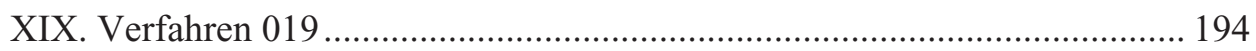

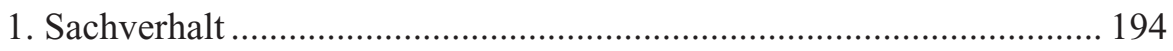

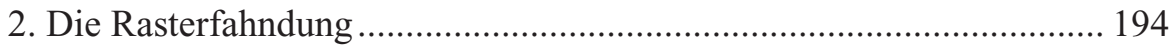

a. Ermittlungsstand und Ausgangslage ........................................... 194

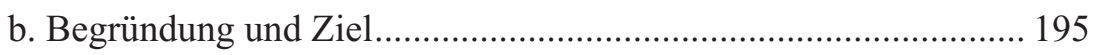

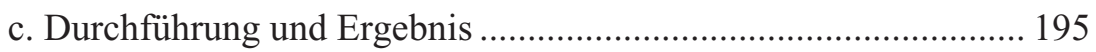

d. Auswirkungen auf das Ermittlungsverfahren............................... 196

3. Ausgang des Verfahrens ..................................................................... 196

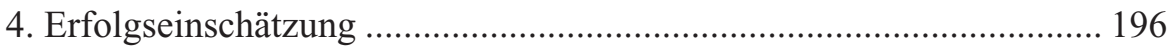

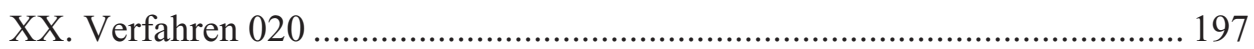

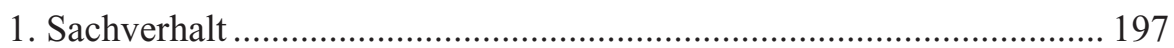

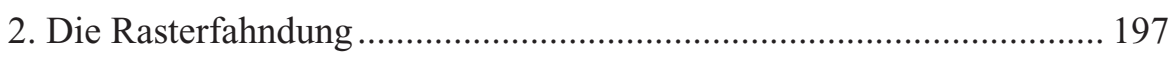

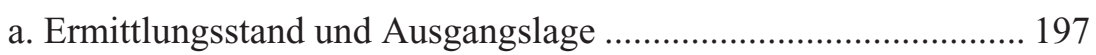

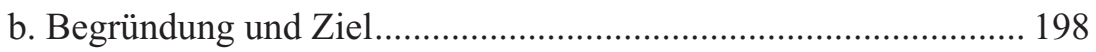

c. Durchführung und Ergebnis ......................................................... 198

d. Auswirkungen auf das Ermittlungsverfahren................................. 199

3. Ausgang des Verfahrens ................................................................ 199

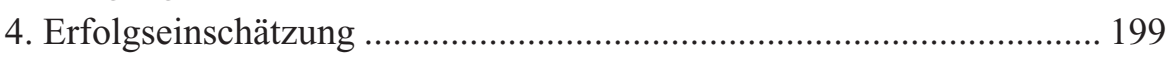

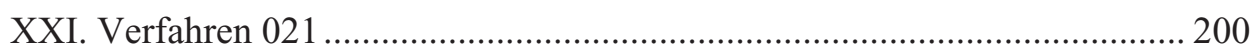

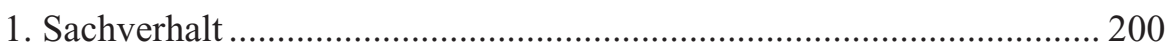

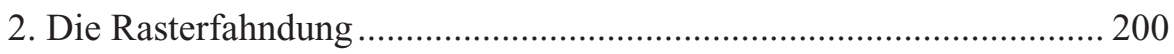

a. Ermittlungsstand und Ausgangslage .............................................. 200

b. Begründung und Ziel............................................................... 200

c. Durchführung und Ergebnis ........................................................ 201

d. Auswirkungen auf das Ermittlungsverfahren............................... 202

3. Ausgang des Verfahrens..................................................................... 202

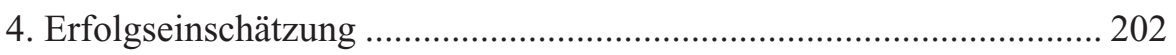

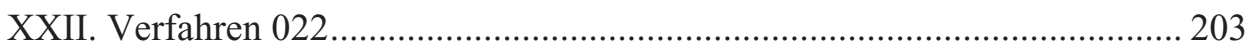

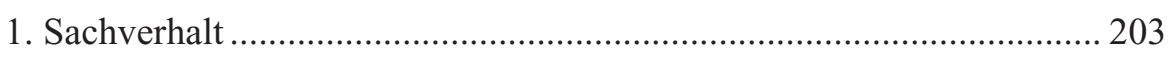

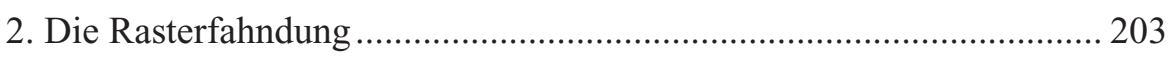

a. Ermittlungsstand und Ausgangslage .............................................. 203

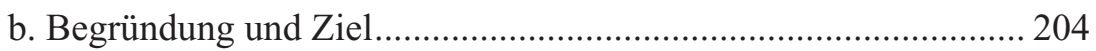

c. Durchführung und Ergebnis ......................................................... 205

d. Auswirkungen auf das Ermittlungsverfahren............................... 205

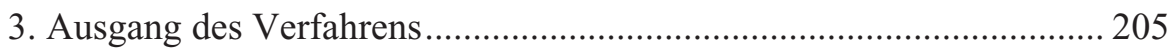

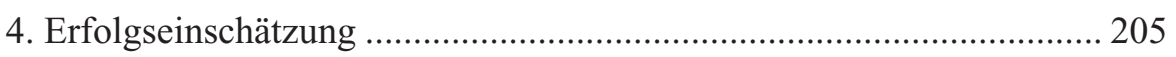

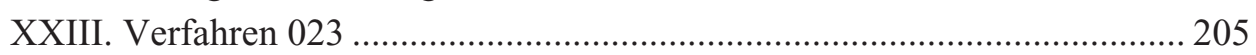

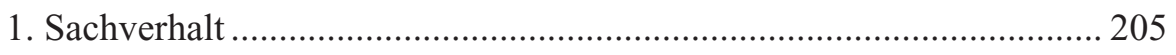

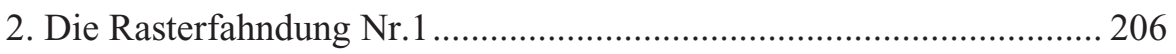

a. Ermittlungsstand und Ausgangslage ............................................... 206

b. Begründung und Ziel............................................................... 208

c. Durchführung und Ergebnis ........................................................ 209

d. Auswirkungen auf das Ermittlungsverfahren............................... 209 


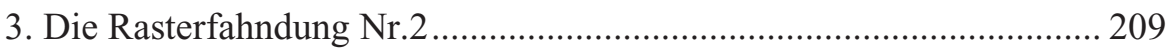

a. Ermittlungsstand und Ausgangslage ............................................ 209

b. Begründung und Ziel................................................................ 210

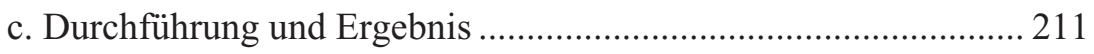

d. Auswirkungen auf das Ermittlungsverfahren............................... 212

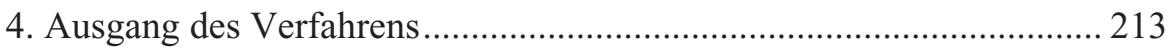

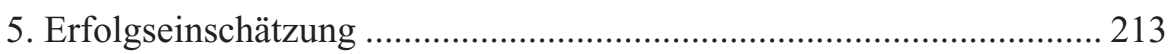

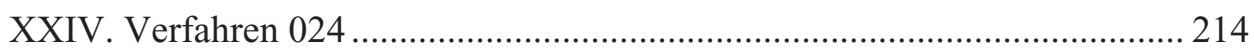

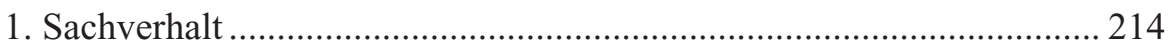

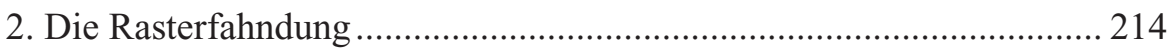

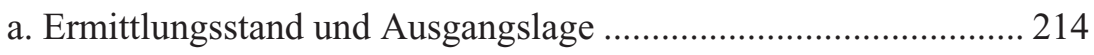

b. Begründung und Ziel............................................................. 214

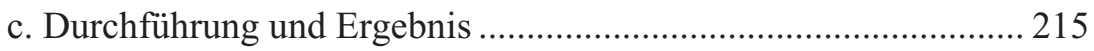

d. Auswirkungen auf das Ermittlungsverfahren.............................. 215

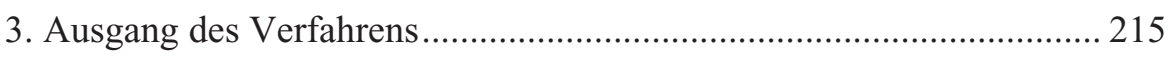

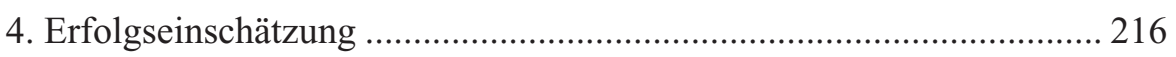

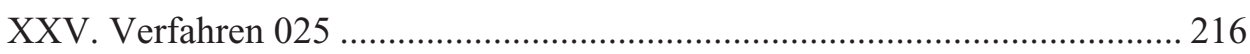

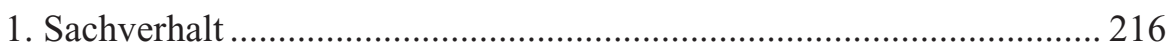

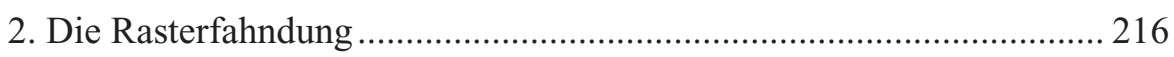

a. Ermittlungsstand und Ausgangslage …....................................... 216

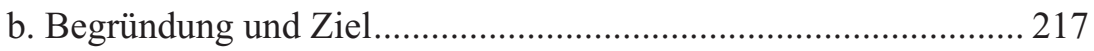

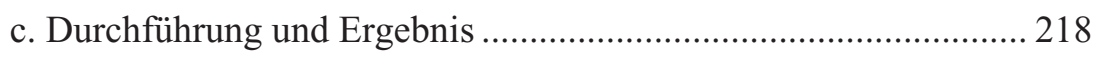

d. Auswirkungen auf das Ermittlungsverfahren................................. 219

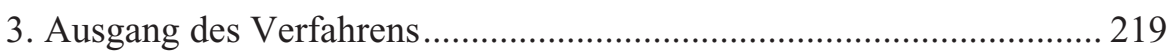

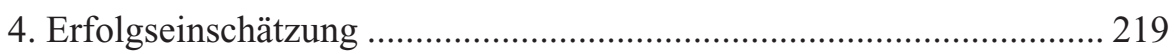

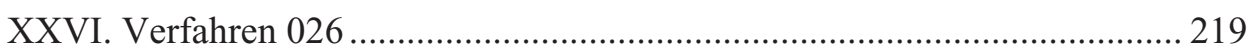

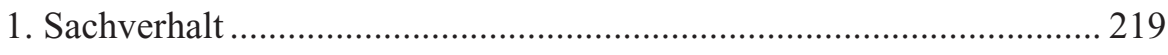

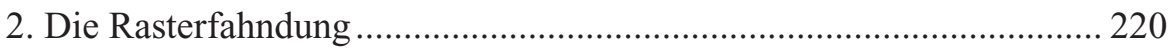

a. Ermittlungsstand und Ausgangslage ........................................... 220

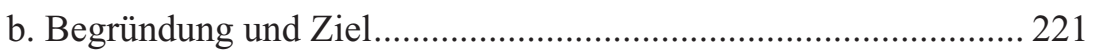

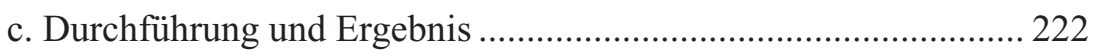

d. Auswirkungen auf das Ermittlungsverfahren................................ 222

3. Ausgang des Verfahrens................................................................... 222

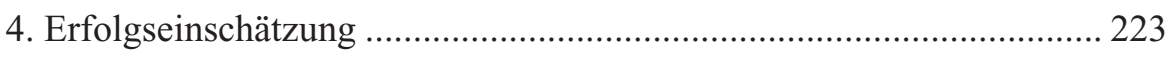

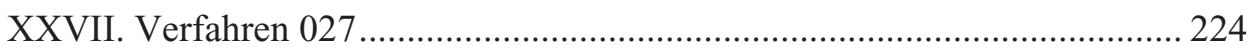

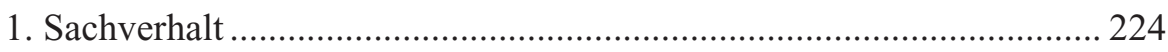

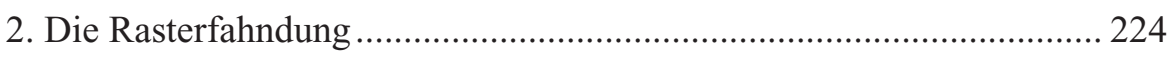

a. Ermittlungsstand und Ausgangslage ............................................ 224

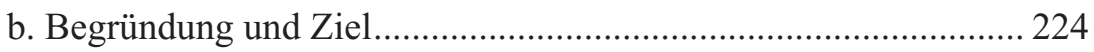

c. Durchführung und Ergebnis ....................................................... 225

d. Auswirkungen auf das Ermittlungsverfahren.............................. 226

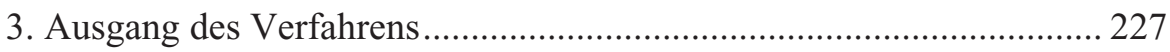

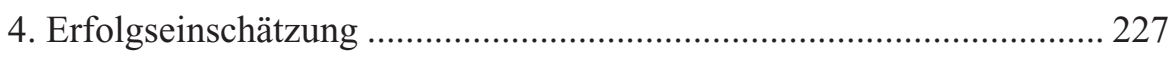


XXVIII. Die präventive Rasterfahndung nach dem 11. September 2001 ........ 227

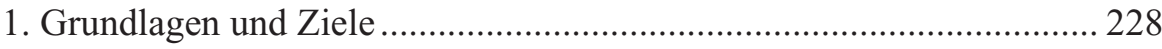

2. Die Rasterfahndung am Beispiel von Bayern....................................... 230

3. Die Rasterfahndung am Beispiel von Berlin ...................................... 231

4. Das Ergebnis der Rasterfahndung nach dem 11. September 2001 ....... 233

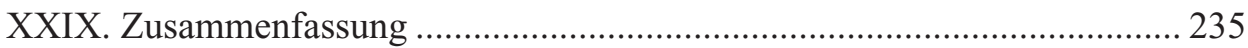

C. Die Ergebnisse der Untersuchung von Erfolg und Effizienz ............................. 236

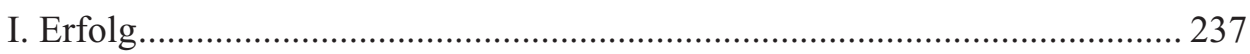

1. Operationalisierung des Erfolgs ...................................................... 237

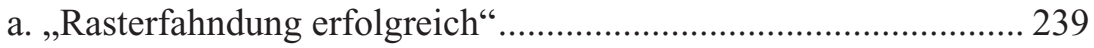

b. „Rasterfahndung bedingt erfolgreich“........................................... 239

c. ,Rasterfahndung nicht erfolgreich“.............................................. 239

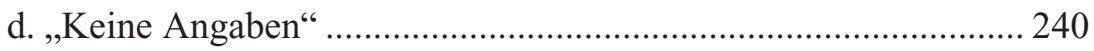

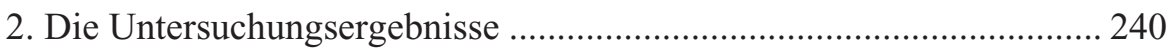

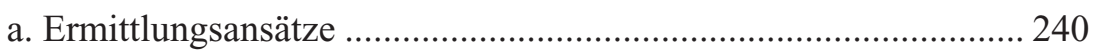

b. Weiterführende Ermittlungsmaßnahmen .................................... 240

c. Verteilung auf offene und verdeckte Ermittlungsmaßnahmen ..... 240

d. Anzahl der Prüffälle / Treffer....................................................... 242

e. Identifizierung von Beschuldigten................................................ 242

f. Identifizierung von Tatverdächtigen............................................ 243

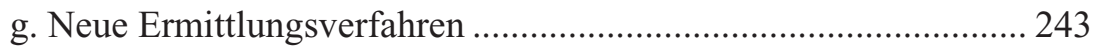

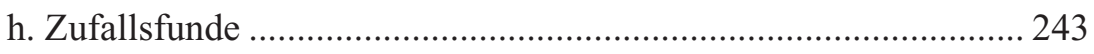

i. Aufklärung aufgrund der Erkenntnisse aus der Rasterfahndung... 243

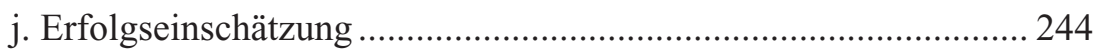

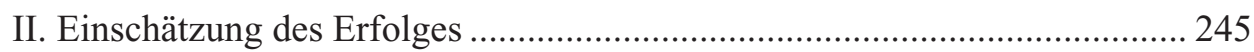

1. Erfolgseinschätzungen in den Verfahrensakten .................................. 245

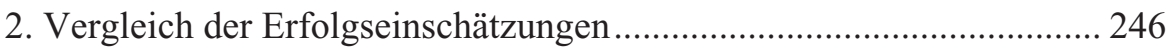

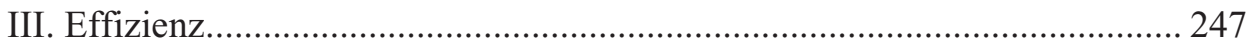

1. Operationalisierung des Effizienzbegriffs ......................................... 247

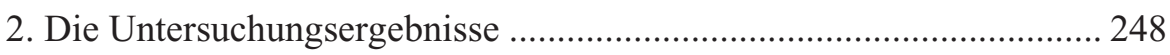

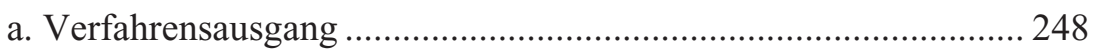

aa. Einstellungen erfolgsbezogen.................................................. 248

bb. Verurteilungen erfolgsbezogen .......................................... 249

b. Verteilung der Erfolge auf die Katalogstraftaten ......................... 249

c. Verteilung der Erfolge auf die verfolgten Ziele ........................... 251

aa. Verteilung der Erfolge auf die Differenzierung zwischen positiver und negativer Rasterfahndung .......................... 251

bb. Verteilung der Erfolge auf die weiteren Ziele.................... 252

cc. Zusammenfassung der Verteilung der Erfolge auf die

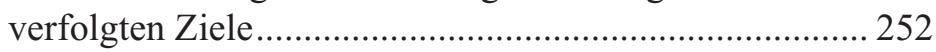

d. Die Rasterfahndung in Anklage, Hauptverhandlung und Urteil .. 253

aa. Die Rolle der Rasterfahndung in der Anklage................... 253

bb. Die Rolle der Rasterfahndung in der Hauptverhandlung ... 254 
cc. Die Rolle der Rasterfahndung im Urteil............................ 254

e. Die Rolle der Rasterfahndung im Rechtsmittelverfahren.............. 254

f. sonstige Effizienzkriterien .......................................................... 255

III. Erfolg und Effizienz der präventiven Rasterfahndung nach dem

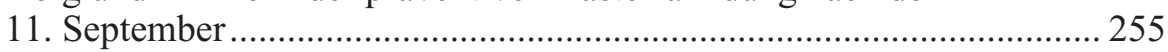

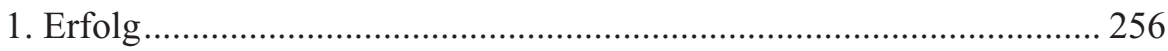

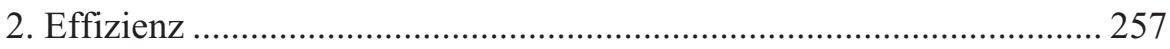

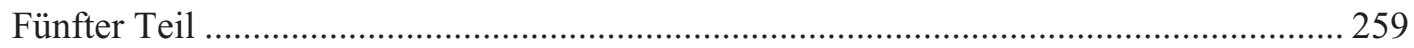

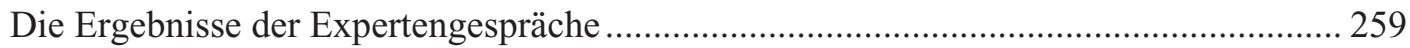

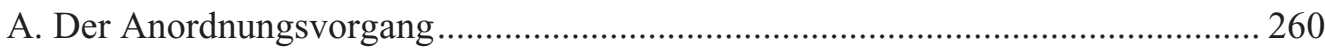

I. Entscheidungskriterien für die Anregung, Beantragung und Anordnung

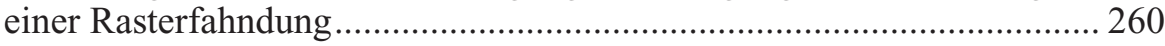

II. Das Vorliegen der gesetzlichen Voraussetzungen ...................................... 260

1. Einordnung einer Straftat unter den Katalog des § 98a I StPO ............ 260

2. Begründungsaufwand für das Merkmal der „Straftat von erheblicher

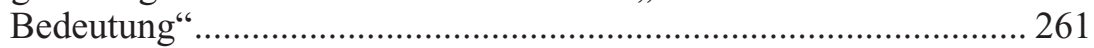

3. Die praktische Relevanz des Anordnungsverbots des § 98b I S.6

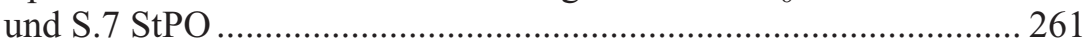

III. Informelle Abläufe im Rahmen des Anordnungsvorgangs ........................ 261

IV. Durchführung der Rasterfahndung aufgrund staatsanwaltschaftlicher Eilanordnung

V. Hierarchieverhältnis von Ermittlungsmaßnahmen und Standort der Rasterfahndung....

VI. Vorzüge der Rasterfahndung gegenüber anderen Ermittlungsmaßnahmen.

VII. Typisierung von Fallkonstellationen für die Durchführung einer Rasterfahndung...

VIII. Die Rolle der Rasterfahndung bei der Planung und Durchführung von DNA-Reihenuntersuchungen

IX. Die Rolle technischer, zeitlicher und wirtschaftlicher Erwägungen im

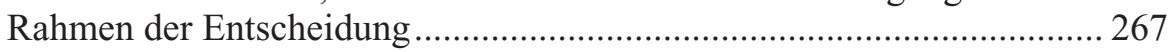

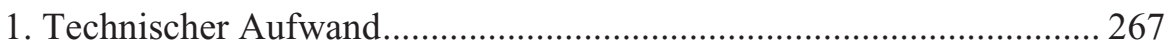

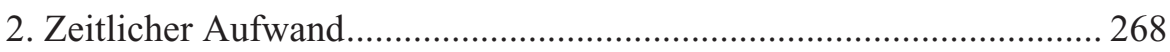

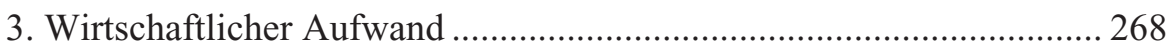

4. Häufigkeit der Erwägung einer Rasterfahndung vor dem Hintergrund des wirtschaftlichen, zeitlichen oder technischen Aufwands

B. Der Datenabgleich und das weitere Verfahren................................................... 270

I. Zusammenarbeit zwischen den datenführenden Stellen und den Strafverfolgungsbehörden im Hinblick auf die Akzeptanz der Maßnahme

II. Für die Rasterfahndung prädestinierte Datenbestände................................ 270

III. Die Bedeutung des Datenschutzes im Rahmen der Durchführung einer Rasterfahndung

IV. Die Benachrichtigungspflicht des § 98b IV StPO ..................................... 271

V. Löschung und Rückgabe der Datenträger.................................................... 272 
VI. Die Rolle der Rasterfahndung in der Hauptverhandlung ........................... 273

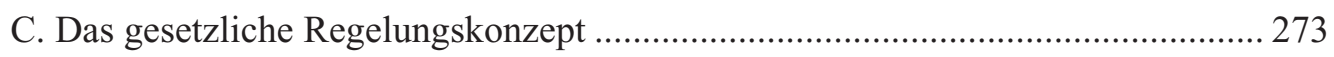

I. Unklarheiten bzgl. der gesetzlichen Ausgestaltung der Rasterfahndung ...... 273

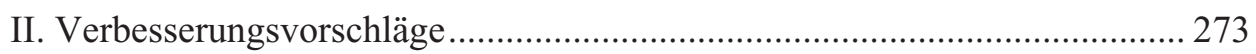

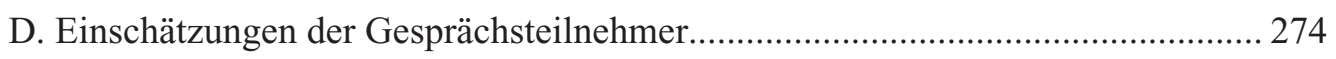

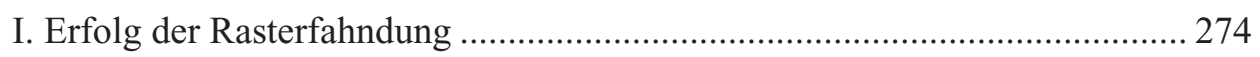

II. Die praktische Bedeutung der Maßnahme für die Tätigkeit der

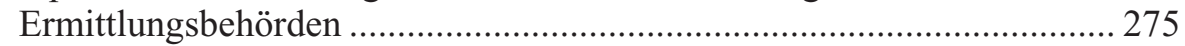

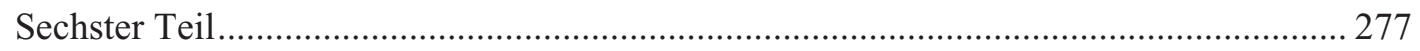

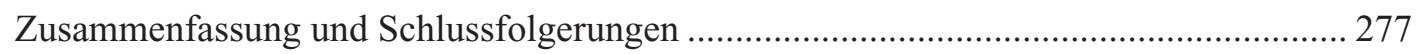

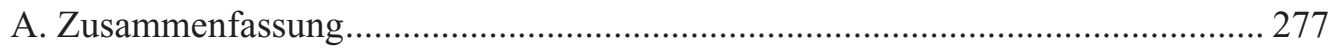

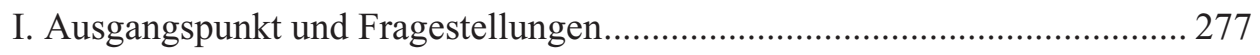

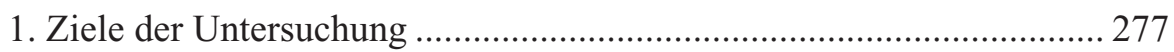

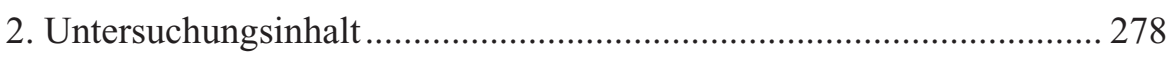

3. Die bisherige Forschung zur Rasterfahndung ................................... 278

4. Konzept und Durchführung der Untersuchung ................................... 279

II. Die Erkenntnisse der rechtstatsächlichen Untersuchung ............................ 279

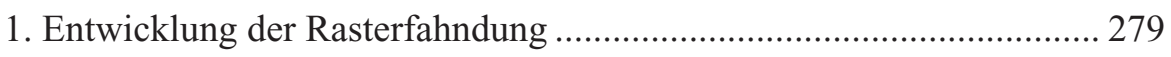

2. Charakter der untersuchten Verfahren.................................................. 280

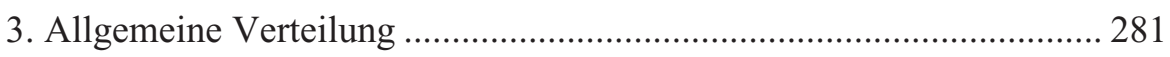

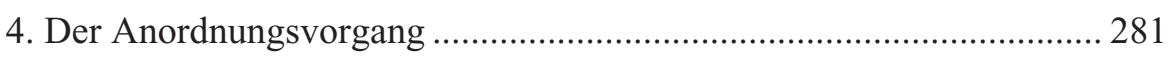

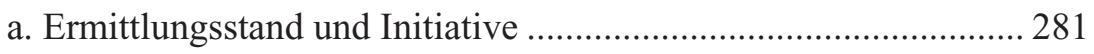

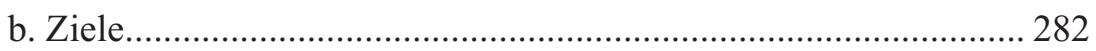

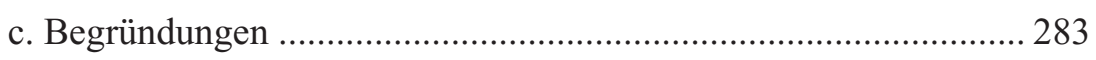

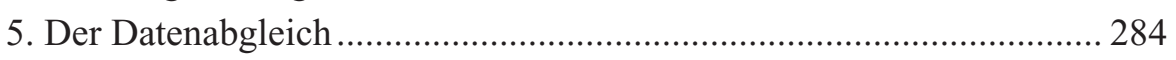

6. Intensität des Eingriffs....................................................................... 286

7. Weiteres Vorgehen nach dem Datenabgleich........................................ 286

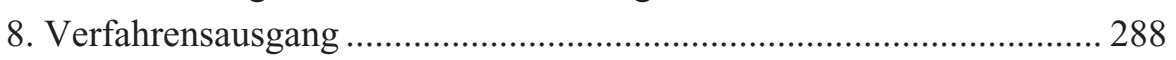

III. Die Ergebnisse der Evaluation von Erfolg und Effizienz.......................... 288

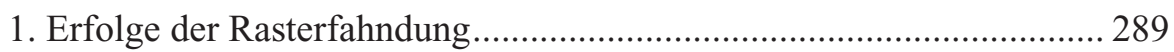

2. Ermittlungsansätze ........................................................................ 289

3. Erfolgseinschätzungen der Ermittlungsbehörden ................................ 290

4. Verteilung der Erfolge auf Katalogdelikte und verfolgte Ziele............ 290

5. Die Rolle der Rasterfahndung im Verfahrensausgang .......................... 291

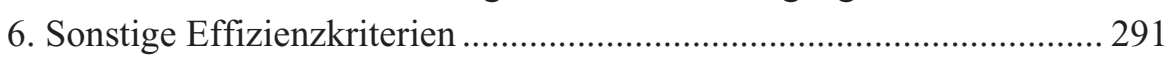

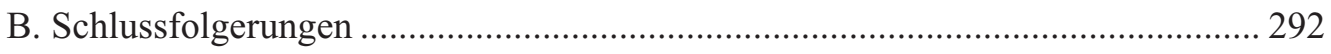

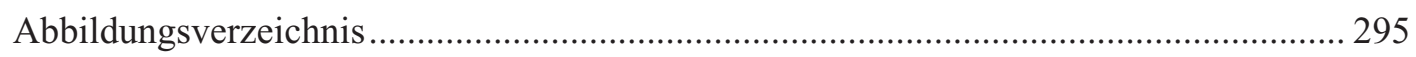

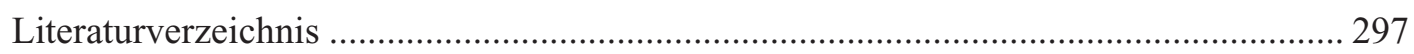





\section{Abkürzungsverzeichnis}

AG

Alt.

AMG

$\mathrm{AO}$

APIS

ASOG

AZR

BDSG

BEWAG

$\mathrm{BGH}$

BGHSt

BKA

BKAG

BR

BRD

BR-Drs.

BStatG

BT-Drs.

BtMG

BVerfG

BVerfGE

bzgl.
Arbeitsgruppe

Alternative

Arzneimittelgesetz

Abgabenordnung

Arbeitsdatei PIOS Innere Sicherheit

Allgemeines Gesetz zum Schutz der öffentlichen Sicherheit und Ordnung

Ausländerzentralregister

Bundesdatenschutzgesetz

Berliner Elektrizitätswerke AG

Bundesgerichtshof

Entscheidungen des Bundesgerichtshofs in Strafsachen

Bundeskriminalamt

Gesetz über die Errichtung eines Bundeskriminalpolizeiamtes

Bundesrat

Bundesrepublik Deutschland

Bundesratsdrucksachen

Bundesstatistikgesetz

Bundestagsdrucksache

Betäubungsmittelgesetz

Bundesverfassungsgericht

Entscheidungen des Bundesverfassungsgerichts

bezüglich 
BZRG

bzw.

ca.

CR

d.h.

DNA

DRiZ

DuD

ED

EDV

EK

EMA

etc.

FAG

FoR

gem.

GA

GG

Hrsg.

IGVP

IHK

INPOL

ISVB

i.V.m.

JA

$\mathrm{JuS}$

$\mathrm{JZ}$

KAN

KBA

$\mathrm{Kfz}$

KIV
Bundeszentralregistergesetz

beziehungsweise

circa

Computer und Recht

das heißt

deoxyribonucleic acid

Deutsche Richterzeitung

Datenschutz und Datensicherheit

Erkennungsdienst

Elektronische Datenverarbeitung

Ermittlungskommission

Einwohnermeldeamt

etcetera

Gesetz über Fernmeldeanlagen

Forum Recht

gemäß

Goltdammers Archiv für Strafrecht

Grundgesetz

Herausgeber

Integrationsverfahren der Polizei

Industrie- und Handelskammer

Informationssystem der Polizei

Informationssystem Verbrechensbekämpfung

in Verbindung mit

Juristische Arbeitsblätter

Juristische Schulung

Juristenzeitung

Kriminalaktennachweis

Kraftfahrtbundesamt

Kraftfahrzeug

Kommunale Informationsverarbeitung 


\begin{tabular}{|c|c|}
\hline KJ & Kritische Justiz \\
\hline $\mathrm{km}$ & Kilometer \\
\hline KPD & Kriminalpolizeidirektion \\
\hline KPI & Kriminalpolizeiinspektion \\
\hline Krad & Kraftrad \\
\hline KW & Konspirative Wohnung \\
\hline LKA & Landeskriminalamt \\
\hline Lkw & Lastkraftwagen \\
\hline $\mathrm{m}$ & Meter \\
\hline MEPolG & Ministerentwurf eines einheitlichen Polizeigesetzes \\
\hline MRK & Menschenrechtskonvention \\
\hline m.w.N. & mit weiteren Nachweisen \\
\hline NADIS & Nachrichtendienstliches Informationssystem \\
\hline NJW & Neue Juristische Wochenschrift \\
\hline Nr. & Nummer \\
\hline NRW & Nordrhein-Westfalen \\
\hline NStZ & Neue Zeitschrift für Strafrecht \\
\hline NVwZ & Neue Zeitschrift für Verwaltungsrecht \\
\hline OFA & Operative Fallanalyse \\
\hline $\mathrm{OK}$ & Organisierte Kriminalität \\
\hline OrgKG & $\begin{array}{l}\text { Gesetz zur Bekämpfung des illegalen Rauschgifthan- } \\
\text { dels und anderer Formen organisierter Kriminalität }\end{array}$ \\
\hline PAG & Polizeiaufgabengesetz \\
\hline POLAS & Polizeiauskunftssystem \\
\hline PolG & Polizeigesetz \\
\hline POLIS & Polizeiliches Informationssystem \\
\hline Pkw & Personenkraftwagen \\
\hline PostG & Postgesetz \\
\hline RAF & Rote Armee Fraktion \\
\hline RiStBV & $\begin{array}{l}\text { Richtlinien für das Strafverfahren und das Bußgeld- } \\
\text { verfahren }\end{array}$ \\
\hline
\end{tabular}


$\mathrm{RuP}$

SGB

SOG

sog.

Soko

StGB

StPO

StV

StVG

TKG

TÜ

u.a.

VEMEPolG

VICLAS

WStG

z.B.

ZEVIS

ZFER

ZFIS

ZPD

ZRP

ZSEG

ZStW
Recht und Politik

Sozialgesetzbuch

Gesetz über die öffentliche Sicherheit und Ordnung

so genannt

Sonderkommission

Strafgesetzbuch

Strafprozessordnung

Strafverteidiger

Straßenverkehrsgesetz

Telekommunikationsgesetz

Telefonüberwachung

unter anderem

Vorentwurf zur Änderung des Musterentwurfs eines einheitlichen Polizeigesetzes

violent crime linkage analysis system

Wehrstrafgesetz

zum Beispiel

Zentrales Verkehrsinformationssystem

Zentrales Fahrerlaubnisregister

Zeitschrift für Innere Sicherheit in Deutschland und Europa

Zentrale-Polizeitechnische-Dienste

Zeitschrift für Rechtspolitik

Gesetz über die Entschädigung von Zeugen und Sachverständigen

Zeitschrift für die gesamte Strafrechtswissenschaft 


\section{Einleitung}

Die vorliegende Untersuchung hat eine Evaluation der Anwendung und der Umsetzung der Rasterfahndung in ihren gesetzlichen Ausgestaltungen in den $\S \S 98 \mathrm{a}, \mathrm{b}$ StPO und den Polizei- und Sicherheitsgesetzen der Bundesländer zum Gegenstand. Die Rasterfahndung ist ein Ermittlungsinstrument, das in regelmäßigen Abständen Gegenstand rechtspolitischer Diskussionen ist. So war die Rasterfahndung von Beginn bis Mitte der achtziger Jahre häufig Thema in der Tagespresse und in juristischen Publikationen. ${ }^{1}$ Dabei wurden zunächst die fehlende Rechtsgrundlage für die Maßnahme und datenschutzrechtliche Aspekte kontrovers diskutiert. Sätze wie: „Jeder kann in Verdacht geraten, auch der Fromme und Frömmste, auch der Unauffälligste “2 veranschaulichen die anfänglichen Bedenken gegenüber der neuen Ermittlungsmethode. Letztmals hat die Rasterfahndung nach den Terroranschlägen des 11. September 2001 praktische Aufmerksamkeit erfahren und rechtspolitische Kontroversen ausgelöst. In diesem Zusammenhang sind Publikationen wie „Panik als Rechtsgrundlage““, „Neues aus der Mottenkiste ${ }^{64}$ oder „BKA rastert illegal“5 $\mathrm{zu}$ sehen, welche sich mit den Risiken, Chancen und Nutzen der Rasterfahndung in zugespitzter Form auseinandersetzen.

Die Rasterfahndung bewegt sich im Spannungsfeld zwischen dem Eingriff in das Recht auf informationelle Selbstbestimmung und einer effektiven Strafverfolgung. Entwickelt wurde diese Fahndungsmethode Anfang der 1970er Jahre. Sie wurde vornehmlich in der Strafverfolgung des RAF-Terrorismus eingesetzt. Die Rasterfahndung nutzt die Möglichkeiten der modernen Datenverarbeitung zur Strafverfolgung und zur Gefahrenabwehr. Da im Rahmen einer Rasterfahndung grundsätzlich alle registrierbaren Eigenschaften und Verhältnisse einer Person dazu geeignet sind, in einen merkmalsbezogenen automatischen Sortiervorgang einbezogen und miteinander verknüpft zu werden, wird sie als ein universell einsetzbares kriminalistisches Aufklärungsmittel bezeichnet. ${ }^{6}$ Kritiker sehen in der Rasterfahndung da-

\footnotetext{
${ }^{1}$ Siebrecht, CR 1996, 545, m.w.N.

2 Bull, S.242.

${ }^{3}$ Plöse, Betrifft Justiz 2002, 332.

${ }^{4}$ DRiZ Informationen..., DRiZ 2002, 9.

${ }^{5}$ Gehrken, FoR 2003, 28.

${ }^{6}$ Welp, in: Erichsen/Kollhosser/Welp (Hrsg.), Recht der Persönlichkeit, S.390.
} 
gegen eine Art Prestigeangelegenheit mit wenig praktischer Relevanz. ${ }^{7}$ Vor allem bei Datenschützern stößt sie im Hinblick auf die Frage der Verfassungsmäßigkeit auf erhebliche Bedenken. ${ }^{8}$

Dem steht jedoch die zunehmende Anerkennung der Fahndungsmethode in der Gesetzgebung gegenüber. Ihre Aufnahme in die Strafprozessordnung ( $\S \S 98 \mathrm{a}, \mathrm{b}$ StPO) fand sie durch das Gesetz zur Bekämpfung des illegalen Rauschgifthandels und anderer Erscheinungsformen der Organisierten Kriminalität (OrgKG) vom 15. 7. 1992. In den Polizei- und Sicherheitsgesetzen der Länder hat die Rasterfahndung in verschiedenen Ausgestaltungen ebenfalls Einzug gefunden. Mittlerweile enthalten alle Polizei- und Sicherheitsgesetze Vorschriften zum Datenabgleich. Teilweise wurden diese erst nach den Anschlägen vom 11. September 2001 eingefügt wurden.

Gegenstand wissenschaftlicher Untersuchungen war die Rasterfahndung bislang lediglich vereinzelt. Diese Untersuchungen setzten sich fast ausschließlich auf dogmatischer und theoretischer Ebene mit der Ermittlungsmaßnahme auseinander. ${ }^{9}$ Schwerpunkt der Analysen war insbesondere die Verfassungsmäßigkeit der Rasterfahndung. Eine empirische Datenbasis, die als Grundlage für eine rechtspolitische Diskussion zu genügen vermag, ist bislang jedoch vergeblich zu suchen.

Die vorliegende Untersuchung hat zum Ziel, eine solche Datenbasis zu schaffen. Es werden erstmals Implementations- und Evaluationsfragestellungen im Zusammenhang mit der Rasterfahndung empirisch aufgegriffen. Ziel und Anliegen dieser Untersuchung ist es, eine empirische Datenbasis für zukünftige rechtspolitische Diskussionen und Entscheidungen zu schaffen. Um die angestrebten Ziele zu erreichen, werden empirische Grundinformationen über die Einsatzpraxis und die Anwendungsstrukturen der Rasterfahndung und damit der tatsächliche Rechtszustand dargestellt. Darüber hinaus soll auch die Auswirkung der Rasterfahndung auf das Ermittlungsverfahren untersucht werden. Hierzu ist es notwendig, Erfolge und Schwierigkeiten des maschinellen Datenabgleichs aufzuzeigen und zu analysieren. Darauf aufbauend soll der Einfluss einzelner Faktoren auf die Effizienz der Ermittlungsmaßnahme evaluiert werden.

Voraussetzung für die Erreichung der verfolgten Ziele ist eine Evaluation der Anwendung der $\S \S 98 \mathrm{a}, \mathrm{b}$ StPO, ferner der entsprechenden Vorschriften der Polizeigesetze der Länder. Die vorliegende Untersuchung bedient sich dabei zweier Methoden der empirischen Sozialforschung. Bei diesen handelt es sich um die Aktenanalyse und die mündliche Befragung in der Form von leitfadengestützten Expertengesprächen. Im Mittelpunkt der Untersuchung steht die Aktenanalyse bereits abgeschlossener Ermittlungsverfahren, in denen eine Rasterfahndung durchgeführt

\footnotetext{
${ }^{7}$ Bäumler, in: Lisken/Denninger (Hrsg.), Handbuch des Polizeirechts, J Rn. 200.

${ }^{8}$ Bull, S.239ff.

${ }^{9}$ Siebrecht; Graf; Klever.
} 
wurde. Aufgrund der geringen Anzahl von vor allem im repressiven Bereich durchgeführten Rasterfahndungen ist die Analyse als Vollerhebung angelegt. Den zeitlichen Ausgangspunkt für die Vollerhebung der Daten zur repressiven Rasterfahndung bildet die Einstellung der Ermittlungsmethode in die StPO im Jahre 1992.

Den Zielen der Untersuchung entsprechend wird zunächst die Entstehungsgeschichte der Rasterfahndung dargestellt und der Stand der Forschung zur Rasterfahndung aufgearbeitet. Daran anknüpfend werden die gesetzlichen Regelungen erläutert. Gegenstand dieses deskriptiven Teils der Untersuchung sind sowohl die repressive Ausgestaltung der Rasterfahndung in den $\S \S 98 \mathrm{a}$, b StPO als auch die präventive Ausgestaltung der Ermittlungsmaßnahme in den Polizei- und Sicherheitsgesetzen der Bundesländer.

Auf der Grundlage der Erkenntnisse des Ersten Teils werden im Zweiten Teil der vorliegenden Untersuchung die Methoden der empirischen Studie dargestellt. Mithin werden die Auswahl der für die Untersuchung verwendeten Methoden begründet und konkrete Fragestellungen herausgearbeitet. Darüber hinaus wird der Gang der Untersuchung aufgezeigt.

Im Dritten Teil der Untersuchung werden die Ergebnisse der rechtstatsächlichen Untersuchung dargestellt. Im Mittelpunkt dieses Teils steht eine Bestandsaufnahme der Einsatzpraxis. Diese gibt einen grundlegenden Überblick über die Anwendung und die praktische Umsetzung der $\S \S 98 \mathrm{a}, \mathrm{b}$ StPO. Mithin stehen Fragen nach der Häufigkeit, der Intensität, der Dauer und des Zeitpunktes der Maßnahme innerhalb der einzelnen Verfahren im Vordergrund. Daran anschließend wird der Anordnungsvorgang untersucht. Hierbei stehen Fragen nach dem Einfluss von Polizei, Staatsanwaltschaft und Ermittlungsrichter im Entscheidungsprozess im Vordergrund. Von besonderem Interesse ist in diesem Zusammenhang die Begründung der Maßnahme durch die Beteiligten. Insbesondere die Kontrolle der Maßnahme in Form der Umsetzung des Richtervorbehalts soll eingehend untersucht werden.

Darüber hinaus ist auch die Durchführung der Maßnahme Gegenstand des rechtstatsächlichen Teils der Untersuchung. In diesem Zusammenhang stehen Fragen zum Durchführungszeitraum, zu technischen Problemen und zu den mit der Rasterfahndung verbundenen Kosten im Fokus der Untersuchung. Daneben werden auch die einbezogenen Datenbestände und der weitere Umgang der Ermittlungsbehörden mit den erlangten Daten untersucht. Ferner werden auch die Einhaltung von Rückgabe- und Löschungspflichten analysiert. Letztlich wird auch der Ausgang der betreffenden Verfahren einer eingehenden Betrachtung unterzogen.

Der Vierte Teil der Untersuchung befasst sich mit Fragen nach den Auswirkungen der Ermittlungsmaßnahme auf die weiteren Ermittlungen und den Ausgang des Ermittlungsverfahrens. Die Grundlage für diesen Teil bildet eine einzelfallbezoge- 
ne Erfolgsanalyse. Jedes der in die Untersuchung einbezogenen Verfahren wird einzeln beschrieben und analysiert. Darauf aufbauend wird die Effizienz der Rasterfahndung im Zusammenhang mit dem Einfluss einzelner Faktoren untersucht.

Im Fünften Teil werden die Ergebnisse der bundesweit durchgeführten Expertengespräche dargestellt. Diese ermöglichen eine Verifizierung der Erkenntnisse aus der Aktenanalyse. Darüber hinaus können Einschätzungen und Anregungen der Gesprächsteilnehmer erhoben werden. Letztlich werden im abschließenden Sechsten Teil die Ergebnisse der Untersuchung zusammengefasst und Schlussfolgerungen gezogen. Diese dienen als Grundlage für zukünftige rechtpolitische Diskussionen und Entscheidungen. 


\section{Erster Teil}

\section{Grundlagen, Begriffsbestimmung und Stand der Forschung}

\section{A. Der geschichtliche Hintergrund der Rasterfahndung}

In den Fokus der Diskussion rückte die elektronische Datenverarbeitung im Bereich der Polizei erstmals zu Beginn der sechziger Jahre. Zunächst wurden die generelle Anwendung von Datenverarbeitungsanlagen und die Möglichkeiten des Einsatzes elektronischer Datenverarbeitung im Rahmen von Ermittlungen diskutiert. Von deren Einsatz versprach man sich eine erhebliche Arbeitserleichterung. Eine Datenverarbeitungsanlage sollte für das kriminal-polizeiliche Aufgabengebiet zwei hauptsächliche Funktionen übernehmen. Sie sollte Daten speichern und vergleichen. Im Rahmen des Vergleichs sollten die zu erfragenden Daten in die Anlage eingegeben und mit bereits registrierten Daten abgeglichen werden. Bei festgestellten Übereinstimmungen sollten die Ergebnisse ausgeworfen oder herausgeschrieben werden. ${ }^{10}$ In der angeregten Vorgehensweise waren erste Ansätze zum automatischen Datenabgleich und damit auch zur Rasterfahndung erkennbar. Erstmals aufgegriffen wurde die Einführung der elektronischen Datenverarbeitung auf der Konferenz der Innenminister / -senatoren am 26. August 1966. Im Rahmen der Konferenz wurde die Erstellung eines Stufenplans beschlossen, nach welchem die Polizei von Bund und Ländern elektronische Datenverarbeitungsanlagen zur Intensivierung der Verbrechensbekämpfung einsetzen sollte. ${ }^{11}$

Es war Ende der siebziger, Anfang der achtziger Jahre, als Veröffentlichungen in der Presse über durchgeführte Datenabgleiche für gesteigerte Aufmerksamkeit sorgten. So wurde bekannt, dass sich die Ermittlungsbehörden der Rasterfahndung mehrfach mit unterschiedlichem Erfolg bedient hatten. Beispielhaft sind hier drei ausgewählte Rasterfahndungen zu nennen, die für besonderes Aufsehen sorgten. Dabei handelte es sich um die Rasterfahndungen zur Ergreifung von Heroinkurieren aus Fernost, ${ }^{12}$ zur Ermittlung terroristischer Erpresserkuriere ${ }^{13}$ und zur Ermittlung konspirativer Wohnungen von Terroristen. ${ }^{14}$

${ }^{10}$ So vorgeschlagen von Kaleth, Die Polizei 1962, 180.

${ }^{11}$ Ruwe, Die Polizei 1968, 376.

12 Himmelreich, 184: Als 1977/78 der Rauschgiftmarkt mit Heroin aus Fernost überschwemmt wurde, hat das BKA sich von allen europäischen Flugplätzen die Namen jener 
Der Einsatz der Rasterfahndung rief insbesondere auf Seiten der Datenschützer gesteigerte Aufmerksamkeit hervor. Diese sahen in der Ermittlungsmethode die Gefahr, „dass jeder in Verdacht geraten könne, auch der Fromme und Frömmste, auch der Unauffälligste. “15 In diesem Zusammenhang wurde auch auf die Stigmatisierungswirkung schon der bloßen staatsanwaltschaftlichen oder polizeilichen Ermittlungen hingewiesen. ${ }^{16}$ Auch wurde die Gefahr gesehen, dass das polizeiliche Informationsverhalten sich tendenziell der Kontrolle entziehen und über die Beobachtung sozialer Zusammenhänge, individueller Kommunikation und Lebensgestaltung zu einem verstärkten Normalisierungs- und Anpassungsdruck in der Gesellschaft führen würde. ${ }^{17}$

Dagegen sei die Anwendung aus Sicht der Ermittlungsbehörden notwendig, da die Erfahrungen aus der Bekämpfung terroristischer Gewalttaten ergeben hätten, dass die Täter bemüht seien, sich im Alltag möglichst unauffällig, konfliktfrei und somit nahezu umweltkongruent zu verhalten. Um diesen modernen Straftäter zu erkennen und seiner habhaft zu werden, sei es notwendig, dass sich die Polizei systematischer Fahndung und dabei insbesondere der Rasterfahndung bediene. ${ }^{18}$

Infolgedessen kam es zu emotional geführten Diskussionen zwischen Datenschützern auf der einen und Vertretern der Ermittlungsbehörden auf der anderen Seite. ${ }^{19}$ Von Letzteren wurde die Rasterfahndung als nahezu ,klinisch sterile Fahndungsform“ angesehen, die , erhebliche Verbesserungen im Menschenrechts- und

chinesischen und malayischen Einzelreisenden geben lassen, die ihre Flugroute auf Umwegen nach Amsterdam wählten, von dort aber schon nach kurzer Zeit wieder zurückflogen. So gelang es dem BKA, 350 Kuriere festzunehmen und damit die Heroinzufuhr aus Fernost fast völlig zu zerschlagen.

${ }^{13}$ Himmelreich, S.185: Im Entführungsfall Schleyer wurde festgestellt, dass die Erpresserbriefe in Paris am Gare du Nord durch Kuriere aufgegeben wurden. Daher wurden alle 20- bis 35-jährigen Benutzer der Nachtzüge nach Paris registriert. So konnten aufgrund anschließender konventioneller Ermittlungen aus den 3000 registrierten Nutzern zwei Kuriere herausgefiltert werden.

${ }^{14}$ Himmelreich S.185; Kruse, in Gropp (Hrsg.), Besondere Ermittlungsmaßnahmen zur Bekämpfung der Organisierten Kriminalität, S.153: Ausgangspunkt war die Erkenntnis, dass Terroristen für einen begrenzten Zeitraum Wohnungen angemietet und die Stromrechnung entweder unter falschem Namen bar oder durch den Vermieter beglichen hatten. Die Dateien von Strom-, Gas- und Wasserwerken in mehreren Großstädten wurden daraufhin mit anderen Dateien, u.a. dem Melderegister, INPOL und ZEVIS abgeglichen. Nach dem Abgleich blieb ein Personenkreis übrig, bei dem der Gemeldete nicht dem Zahler der Stromrechnung entsprach; weitere Fälle siehe Klever, S.11ff.

${ }^{15}$ Bull, S.242.

${ }^{16}$ Kühne, NJW 1979, 617.

${ }^{17}$ Simon/Taeger, JZ 1982, 141.

18 Ermisch, in: Bundeskriminalamt (Hrsg.), Möglichkeiten und Grenzen der Fahndung, S.70.

${ }^{19}$ Siehe zur Diskussion insbesondere die Stellungsnahmen zur Spiegelserie in: Bölsche, S.111 ff. 
Grundrechtsschutz zu bewirken“ imstande sei. ${ }^{20}$ Notwendige Eingriffe in Rechte des Bürgers würden gegenüber herkömmlichen systematisierten Fahndungen auf das notwendige Minimum reduziert. Mithin sei in diesem Ermittlungsinstrument ein wesentlicher Beitrag zur Realisierung des Datenschutzes zu sehen. ${ }^{21}$

Es lässt sich festhalten, dass die Diskussion zunächst durch die Frage nach der Eingriffsqualität der Rasterfahndung geprägt wurde, ${ }^{22}$ sich anschließend auf die Suche nach einer Ermächtigungsgrundlage verlagerte. Die Strafverfolgungs-behörden hatten Maßnahmen der Rasterfahndung auf die $\S \S 161$ I, 163 I, 160 I StPO gestützt und diese Vorschriften im Sinne einer allgemeinen Befugnisklausel ausgelegt. ${ }^{23}$ Ferner wurden als mögliche Ermächtigungsgrundlagen für die Durchführung von Rasterfahndungen $\S 94$ StPO, § 24 Bundesdatenschutzgesetz sowie das Gesetz über die Einrichtung eines Bundeskriminalamtes in Betracht gezogen.

Im Hinblick auf verfassungs- und datenschutzrechtliche Anforderungen vermochte jedoch keine dieser Normen als Ermächtigungsgrundlage zu überzeugen. ${ }^{24}$ Mit dem Volkszählungsurteil des Bundesverfassungsgerichts erhielt die Diskussion dann einen zusätzlichen Antrieb. Nach den Ausführungen des Bundesverfassungsgerichts umfasst das allgemeine Persönlichkeitsrecht des Art. 2 I GG in Verbindung mit Art. 1 I GG den Schutz des Einzelnen gegen unbegrenzte Erhebung, Speicherung, Verwendung und Weitergabe seiner persönlichen Daten. Das Grundrecht gewährleistet insoweit die Befugnis des Einzelnen, grundsätzlich selbst über die Preisgabe und Verwendung seiner persönlichen Daten zu bestimmen. Mithin bedürfen Einschränkungen einer verfassungsmäßigen gesetzlichen Grundlage, die dem rechtstaatlichen Gebot der Normenklarheit entsprechen muss. ${ }^{25}$ Gestärkt wurden durch dieses Urteil insbesondere die Forderungen der Datenschützer nach einer Ermächtigungsgrundlage für die Rasterfahndung.

Nach der Entscheidung des Bundesverfassungsgerichts dauerte es allerdings noch bis 1992, bis eine Ermächtigungsgrundlage ihre Aufnahme in die Strafprozessordnung fand. Die seitdem unveränderten $\S \S 98$ a und 98b StPO wurden durch das Gesetz zur Bekämpfung des illegalen Rauschgifthandels und anderer Erscheinungsformen der organisierten Kriminalität vom 15.07.1992, welches am 22.9.1992 in Kraft trat, eingeführt. ${ }^{26}$

\footnotetext{
${ }^{20}$ Herold, RuP 1980, 83.

${ }^{21}$ Ermisch, in: Bundeskriminalamt (Hrsg.), Möglichkeiten und Grenzen der Fahndung, S.71.

${ }^{22}$ Der Eingriffscharakter der Rasterfahndung wurde allerdings schnell zur herrschenden Meinung. So z.B. Wolter, GA 135 (1988), 49ff und 140; Krey/Haubrich, JR 1992, 312.

${ }^{23}$ Rogall, GA 132 (1985), 1 (5).

24 Wanner, CR 1986, 413f.

${ }^{25}$ BVerfGE $65,1 \mathrm{ff}$.

${ }^{26}$ Zum Gesetzgebungsverfahren siehe ausführlich: Siebrecht, S.27 ff. m.w.N.
} 


\section{B. Die Rechtsgrundlage}

Der automatische Datenabgleich zur Strafverfolgung findet seine gesetzliche Regelung in den $\S \S 98 \mathrm{a}, \mathrm{b}$ StPO. Darüber hinaus enthalten die Polizei- und Sicherheitsgesetze der Bundesländer Regelungen der Rasterfahndung für den präventivpolizeilichen Bereich. Die gesetzliche Ausgestaltung der Rasterfahndung betreffend, sind teilweise erhebliche Unterschiede in den Ländergesetzen festzustellen. Letztlich enthält auch das BKA-Gesetz Regelungen für die Datenerhebung und den Datenabgleich. Wobei die Rasterfahndung jedoch nicht ausdrücklich geregelt wird. Aufgrund der Aufgabenzuweisung als „Zentralstelle für das polizeiliche Auskunfts- und Nachrichtenwesen“ und „die Kriminalpolizei“ nach Art. 73 Nr.10, Art 87 I S.2 GG und $\S 1$ BKAG nimmt das Bundeskriminalamt jedoch eine Sonderstellung innerhalb der Polizeibehörden ein. ${ }^{27}$ In $\S 7$ BKAG findet die Datenerhebung ihre Rechtsgrundlage. Die Nutzung und Verarbeitung bereits erhobener Daten wird in $\S 28$ BKAG geregelt.

Gegenstand dieser Untersuchung ist die Rasterfahndung im Rahmen der Strafverfolgung. ${ }^{28}$ Mithin stehen die $\S \S 98 \mathrm{a}, \mathrm{b}$ StPO im Mittelpunkt. Nach diesen müssen für den automatischen Datenabgleich folgende Voraussetzungen vorliegen:

- Zureichende tatsächliche Anhaltspunkte

- Für eine Straftat von erheblicher Bedeutung

- Die Straftat muss zudem vom Katalog des $§ 98$ a I S.1 Nr.1-6 StPO erfasst sein

- Die Erforschung des Sachverhalts oder die Ermittlung des Aufenthaltsortes des Täters auf andere Weise muss erheblich weniger erfolgversprechend oder wesentlich erschwert sein

- Nach § 98b I S.1 StPO muss der maschinelle Datenabgleich durch einen Richter oder bei Gefahr im Verzug durch die Staatsanwaltschaft angeordnet werden.

Bei Vorliegen der Voraussetzungen können personenbezogene Daten von Personen, die bestimmte auf den Täter vermutlich zutreffende Prüfungsmerkmale erfüllen, mit anderen Daten maschinell abgeglichen werden. Ferner sind nach § 98a II StPO die speichernden Stellen zu Aussonderung und Übermittlung der angeforderten Daten verpflichtet.

\footnotetext{
${ }^{27}$ Gerling/Langer/Roßmann, DuD 25 (2001), 1.

${ }^{28}$ In einem Exkurs wird auf die gesetzliche Ausgestaltung der Maßnahme in den Polizei- und Sicherheitsgesetzen der Länder eingegangen. Zu den Voraussetzungen der Regelungen siehe: 1 . Teil G.
} 


\section{Verfassungsrechtlicher Hintergrund}

Bereits im Rahmen der Darstellungen zum geschichtlichen Hintergrund der Rasterfahndung wurde auf die Verfassungsmäßigkeit und das diesbezüglich bedeutsame Volkszählungsurteil des Bundesverfassungsgerichts eingegangen. ${ }^{29}$ Insofern soll hier lediglich ein kurzer Überblick über den verfassungsrechtlichen Hintergrund der Rasterfahndung gegeben werden. ${ }^{30}$ Zudem befasst sich die folgende Darstellung nur mit dem verfassungsrechtlichen Hintergrund der repressiven Rasterfahndung.

Im Rahmen der Rasterfahndung wird in einer Vielzahl von Fällen in das Grundrecht auf informationelle Selbstbestimmung, wie es sich aus Art. 2 I GG in Verbindung mit Art. 1 I GG ableitet, eingegriffen. ${ }^{31}$ Das Recht auf informationelle Selbstbestimmung gewährleistet die Befugnis des Einzelnen, grundsätzlich selbst zu entscheiden, ob und in welchem Umfang er Informationen über sich preisgibt. Der Einzelne wird gegen unbegrenzte Erhebung, Speicherung, Verwendung und Weitergabe seiner persönlichen Daten geschützt. ${ }^{32}$ Unter den Bedingungen der automatischen Datenverarbeitung gibt es kein ,belangloses“ Datum mehr, da auch eine für sich unerhebliche Information in Verknüpfung mit anderen Daten Rückschlüsse auf den Betroffenen ermöglicht. ${ }^{33}$

Allerdings ist das Recht auf informationelle Selbstbestimmung nicht schrankenlos gewährt. Der Einzelne muss Einschränkungen seines Rechts auf informationelle Selbstbestimmung im überwiegenden Allgemeininteresse hinnehmen. ${ }^{34}$ Dieses überwiegende Allgemeininteresse besteht im Bereich der repressiven Rasterfahndung in einer effektiven Strafverfolgung. Eine Einschränkung des Rechts auf informationelle Selbstbestimmung ist jedoch nur auf der Grundlage eines förmlichen Gesetzes möglich. ${ }^{35}$ Dieser Voraussetzung ist der Gesetzgeber mit den $\S \S 98 \mathrm{a}, \mathrm{b}$ StPO nachgekommen. Das Bundesverfassungsgericht hat in seinem Volkszählungsurteil allerdings darauf hingewiesen, dass Regelungen, welche das Recht auf informationelle Selbstbestimmung einschränken, dem rechtstaatlichen Gebot der Normenklarheit in besonderem Maße entsprechen und den Grundsatz der Verhältnismäßigkeit beachten müssen. Darüber hinaus ist der Gesetzgeber ausdrücklich dazu verpflichtet worden, der Gefahr von Verletzungen des Persönlichkeitsrechts,

\footnotetext{
29 Siehe 1. Teil A.

30 Ausführlich zur Verfassungsmäßigkeit der Rasterfahndung nach den $\S \S 98 \mathrm{a}, \mathrm{b}$ StPO siehe: Siebrecht, $35 \mathrm{ff}$.

${ }^{31}$ BT-Drs. 12/989, S.36.

32 BVerfGE 65, $1 \mathrm{ff}$.

33 BVerfGE 65, 1, 45.

34 BVerfGE 65, 1, 43f.

${ }^{35}$ Dreier, in: Dreier, Art.2 I Rn. 86.
} 
durch organisatorische und verfahrensrechtliche Vorkehrungen entgegenzuwirken. ${ }^{36}$

Der Gesetzgeber war sich des mit einer Rasterfahndung verbundenen Eingriffs in das Recht auf informationelle Selbstbestimmung einer Vielzahl von Personen bewusst. Um den Eingriff zu beschränken, wurde die Maßnahme an das Vorliegen einer der in $\S 98$ a I S.1 Nr1-6 StPO aufgezählten Deliktsgruppen gebunden. Zu diesen Deliktsgruppen gehören solche Straftaten, die für die Organisierte Kriminalität typisch bzw. nach Art ihrer Ausführung oder ihrer Auswirkung besonders schwerwiegend sind. ${ }^{37}$ An diesem Punkt setzt jedoch die Kritik in Bezug auf die gesetzliche Ausgestaltung der Rasterfahndung an. So wird der Katalog des § 98a I S.1 StPO als zu unübersichtlich angesehen. Aufgrund dessen sei die Ausgestaltung der Rasterfahndung vor dem Gebot der Normenklarheit nach teilweise vertretener Ansicht als verfassungswidrig anzusehen. ${ }^{38}$ Darüber hinaus wird die Vereinbarkeit der Rasterfahndung mit dem Verhältnismäßigkeitsgrundsatz in Frage gestellt. Indem der Gesetzgeber keine hohen Anforderungen für den Einsatz der Rasterfahndung vorgesehen hat, habe er bei der Formulierung der materiellen Einsatzvoraussetzungen den widerstreitenden Interessen nur unzureichend Rechnung getragen. ${ }^{39}$

Überwiegend wird die gesetzliche Ausgestaltung der Rasterfahndung jedoch als verfassungsmäßig angesehen. ${ }^{40}$ Diesbezüglich wird angeführt, dass der Verhältnismäßigkeitsgrundsatz durch die Subsidiaritätsklausel und die Begrenzung auf Straftaten von erheblicher Bedeutung in $\S 98 \mathrm{a}$ StPO ausreichend konkretisiert ist. ${ }^{41}$ Darüber hinaus hat der Gesetzgeber dem ohne Kenntnis des Betroffenen erfolgenden und dadurch besonders gravierenden Eingriff durch die Verfahrensvorschriften des $\S 98 \mathrm{~b}$ StPO Rechnung getragen. Mit $\S 98 \mathrm{~b}$ StPO wurden ausreichende organisatorische und verfahrensrechtliche Vorschriften geschaffen. ${ }^{42}$ Ihre strikte Einhaltung stellt eine wesentliche Sicherung des Rechts auf informationelle Selbstbestimmung dar. ${ }^{43}$ Folglich ist der Gesetzgeber damit allen Anforderungen des Bundesverfassungsgerichts für die Einschränkung des Rechts auf informationelle Selbstbestimmung nachgekommen. ${ }^{44}$ Insofern ist der der vom überwiegenden Teil vertretenen Ansicht zu folgen. Allerdings bedürfen die Anordnungsvoraussetzun-

\footnotetext{
36 BVerfGE 65, 1, 44.

${ }^{37}$ BT-Drs. 12/989, S.56.

38 Siebrecht, CR 1996, 548.

39 Graf, S.295.

40 Möhrenschlager, wistra 1992, 326; Schäfer, in: Löwe-Rosenberg, § 98a Rn. 14; Rudolphi, in Systematischer Kommentar, § 98a Rn. 3ff.

${ }^{41}$ Nack, in: Karlsruher Kommentar, § 98a Rn. 7.

42 Schäfer, in: Löwe-Rosenberg, § 98a Rn. 14.

${ }^{43}$ Lemke, in: Heidelberger Kommentar, § 98b Rn. 1.

$44 \mathrm{Zu}$ dem gleichen Ergebnis kommen auch: Schäfer, in: Löwe-Rosenberg, § 98a Rn. 14; Rudolphi, in Systematischer Kommentar, § 98a Rn. 3ff; andere Ansicht: Siebrecht, 179f.
} 
gen einer eingehenden Betrachtung unter dem Gesichtspunkt der VerfassungsmäBigkeit. Diesbezüglich ist auf die Ausführungen zu den Anordnungsvoraussetzungen des $\S 98 \mathrm{a}$ StPO und der Verfahrensvorschriften des $\S 98 \mathrm{~b}$ StPO zu verweisen. ${ }^{45}$

\section{Begriffsbestimmung}

Es ist zunächst notwendig, sich mit dem Begriff der Rasterfahndung und der dahinter stehenden Methode auseinanderzusetzen. Der Begriff setzt sich aus den Teilen Raster und Fahndung zusammen. Ein Raster wird definiert als ein System von (sich kreuzenden) Linien bzw. das dadurch gebildete System schmaler Streifen oder kleiner Flächen (Rasterpunkte). ${ }^{46} \mathrm{Im}$ Rahmen der Datenverarbeitung dient ein Raster zur digitalen Zerlegung oder Darstellung eines Bildes im weitesten Sinn. ${ }^{47}$

Überträgt man die allgemeine und die im Rahmen der Datenverarbeitung gängige Definition für Raster auf polizeiliche Ermittlungstätigkeit, so ist darunter ein Suchkriterium zu verstehen, mit dessen Hilfe aus einer Menge gegebener Informationen diejenigen ausgefiltert werden, an denen der Suchende ein Erkenntnisinteresse hat. ${ }^{48}$ Gerade in dieser Selektion von Erkenntnissen liegt der Kern polizeilicher Ermittlungstätigkeit. Die Polizei stützt sich bei ihrer Suche nach Tatverdächtigen und Tätern in der Regel immer auf das Vorhandensein oder Nichtvorhandensein bestimmter Merkmale. Daraus ergibt sich die Feststellung, dass die Polizei schon immer rasternd vorgegangen ist. ${ }^{49}$

Abstrakt betrachtet unterscheidet sich das Vorgehen im Rahmen der Rasterfahndung nicht von der klassischen Fahndung. Die Spezifikation der Rasterfahndung liegt in der mit dem Einsatz der EDV einbezogenen Menge der Daten, die auf konventionellem Wege gar nicht verarbeitet werden könnten, und der Gefahren, die die EDV durch ihre vielfältigen Nutzungsmöglichkeiten birgt. ${ }^{50}$ Mithin ist die Rasterfahndung keine neue kriminalistische Aufklärungsmethode, sondern lediglich ein Verfahren, dass mit einer bislang nicht bekannten Durchschlagskraft versehen wurde. $^{51}$

Es handelt sich bei der Rasterfahndung um eine spezifische Fahndungsmethode, die aus den Möglichkeiten der elektronischen Datenverarbeitung entwickelt wurde.

\footnotetext{
${ }^{45}$ Siehe unter 1. Teil E. und F.

${ }^{46}$ Meyers enzyklopädisches Lexikon, Band 19, S.589.

${ }^{47}$ Brockhaus-Enzyklopädie, Band 18, S.73.

${ }^{48}$ Welp, in: Erichsen/Kollhosser/Welp (Hrsg.), Recht der Persönlichkeit, S.389.

49 Sokol, in: Bäumler (Hrsg.), Polizei und Datenschutz, S.189.

${ }^{50}$ Riegel, ZRP 1980, 301.

${ }^{51}$ Welp, in: Erichsen/Kollhosser/Welp (Hrsg.), Recht der Persönlichkeit, S.390.
} 
Ihr liegt die Annahme zugrunde, der Verdächtige habe in den automatisiert geführten Dateien einzelne Spuren hinterlassen, deren Zusammenführung zu seiner Entlarvung beitrage. ${ }^{52}$ Dabei sind grundsätzlich alle registrierbaren Eigenschaften und Verhältnisse einer Person dazu geeignet, in einen merkmalsbezogenen automatischen Sortiervorgang einbezogen und miteinander verknüpft zu werden. ${ }^{53}$

Personenbezogen heißt in diesem Zusammenhang, dass sich alle Felder in dem Datensatz auf eine Person beziehen lassen. Entweder enthält der Datensatz selbst das Personenfeld oder es lässt sich die Beziehung zu einer Person über ein sog. Schlüsselfeld herstellen. Das Gesetz legitimiert aber auch Recherchen in unstrukturierten Datenbeständen, die die klassischen Datenbanken immer mehr verdrängen. So kann beispielsweise in elektronisch gespeicherten Geschäftsbriefen nach dem Vorkommen bestimmter Zeichenfolgen (Strings) gesucht werden. ${ }^{54}$

In den Gesetzesmaterialien wird die Rasterfahndung als maschinell ablaufende Überprüfung von Datenbeständen öffentlicher und nichtöffentlicher Stellen nach bestimmten Prüfungsmerkmalen (Rastern) umschrieben. Das Ziel der Maßnahme ist die Erlangung von Hinweisen und Spuren, die nach kriminalistischer Erfahrung zur Aufklärung der Tat beitragen können. ${ }^{55}$ Die erlangten Hinweise und Spuren können anschließend anhand von konventionellen Ermittlungen abgeklärt werden. $^{56}$

Dem Gesetz ist keine allgemeingültige Definition der Rasterfahndung zu entnehmen. So enthält § 98a I StPO keine Definition, sondern lediglich eine Umschreibung des Begriffs. Danach handelt es sich um einen maschinellen Datenabgleich von personenbezogenen Daten von Personen, die bestimmte, auf den Täter vermutlich zutreffende Prüfungsmerkmale erfüllen, mit anderen Daten. Ziel soll es sein, Nichtverdächtige auszuschließen oder Personen festzustellen, die weitere für die Ermittlungen bedeutsame Prüfungsmerkmale erfüllen. Den Polizeigesetzen der Bundesländer ist ebenfalls keine Definition zu entnehmen, sondern lediglich eine Umschreibung des Begriffs.

Das Gesetz kennt unterschiedliche Formen des maschinellen Datenabgleichs. In der Strafprozessordnung sind Regelungen zum maschinellen Datenabgleich in den $\S \S 98 \mathrm{a}, 98 \mathrm{~b}$ und 98c StPO enthalten. Die $\S \S 98 \mathrm{a}$ und 98b StPO betreffen den maschinellen Abgleich von Daten, auf die sich die Polizei zunächst Zugriff verschaffen muss. Dabei handelt es sich um den Abgleich von sog. polizei-externen Datei-

${ }^{52}$ Bäumler, in: Lisken/Denninger (Hrsg.), Handbuch des Polizeirechts, J Rn. 256.

${ }^{53}$ Welp, in: Erichsen/Kollhosser/Welp (Hrsg.), Recht der Persönlichkeit, S.390.

${ }^{54}$ Nack, in: Karlsruher Kommentar, § 98a Rn. 18.

${ }^{55}$ BT-Drs. 12/989, S.36.

56 Bäumler in: Lisken/Denninger (Hrsg.), Handbuch des Polizeirechts, J Rn. 257; so auch in den Gesetzesmaterialien vorgesehen BT-Drs. 12/989, S.36. 
en. ${ }^{57}$ Der $\S 98 \mathrm{c}$ StPO behandelt dagegen den Abgleich von Dateien, die sich bereits im Besitz der Polizei befinden (sog. polizei-interne Dateien). Diese Unterscheidung zwischen dem Abgleich von polizei-internen und polizei-externen Dateien ist auch den Polizeigesetzen der Bundesländer zu entnehmen. Beispielhaft soll an dieser Stelle das Polizeigesetz Baden-Württemberg genannt sein. Dieses unterscheidet in den $\S \S 39$ und 40 PolG zwischen dem Datenabgleich mit polizeilichen Dateien (§ 39 PolG) und dem Datenabgleich mit anderen Dateien (§ 40 PolG).

Darüber hinaus lässt sich bei der Rasterfahndung auch inhaltlich zwischen zwei Varianten differenzieren. So beschreibt § 98a I S.1 letzter Halbsatz StPO das Ziel der sog. negativen Rasterfahndung. Demnach sollen „Daten von Personen, die bestimmte ... Prüfungsmerkmale erfüllen ... mit anderen Daten maschinell abgeglichen werden, um Nichtverdächtige auszuschließen“. Die Formulierung: „... Personen festzustellen, die weitere für die Ermittlungen bedeutsame Prüfungsmerkmale erfüllen“, beschreibt die sog. positive Rasterfahndung. ${ }^{58} \mathrm{Im}$ Nachfolgenden werden die positive und die negative Rasterfahndung dargestellt, ihre Unterschiede herausgearbeitet und eine Bewertung abgegeben.

\section{Positive Rasterfahndung}

Wird ein Datenbestand aus den festgelegten und positiv festzustellenden Merkmalen gegen andere Dateien mit dem Ziel der Bildung einer neuen Datei aus den „Treffern“ abgeglichen, wird dies als positive Rasterfahndung bezeichnet. ${ }^{59}$ Ziel ist es, einen durch bestimmte Merkmale gekennzeichneten Täter als positives Ergebnis eines Datenabgleichs zu finden. ${ }^{60}$ Diese Merkmale können höchst unterschiedlich sein. Ist der Täter bereits namentlich bekannt, können dessen Name, Vorname etc. für den Datenabgleich verwendet werden. ${ }^{61}$ Auch können Merkmale wie Größe, Haarfarbe und Gestalt des mutmaßlichen Täters in den Datenabgleich miteinbezogen werden. ${ }^{62}$ Diese Erkenntnisse werden in eine Datei eingegeben und mit beliebig vielen anderen Dateien, in denen der Täter ebenfalls gespeichert sein könnte, abgeglichen. ${ }^{63} \mathrm{Kommt}$ es dabei zu Übereinstimmungen, werden die Personen herausgefiltert, die als sog. Schnittmenge die Merkmale erfüllen. ${ }^{64}$ In der Literatur wird für eine positive Rasterfahndung häufig der Abgleich von Daten mit Haftbefehl namentlich gesuchter Personen mit den

57 Die Begriffe polizei-interne Dateien und polizei-externe Dateien gehen auf Siebrecht zurück: Siebrecht, S.21.

${ }^{58}$ BT-Drs. 12/989, S.37.

59 Sokol, in: Bäumler (Hrsg.), Polizei und Datenschutz, S.190.

60 Wanner, S.16.

${ }^{61}$ Wanner, CR 1986, 220.

${ }^{62}$ Schäfer, in: Löwe-Rosenberg, § 98a Rn. 8.

${ }^{63}$ Kruse, in Gropp (Hrsg.), Besondere Ermittlungsmaßnahmen zur Bekämpfung der Organisierten Kriminalität, S.149.

${ }^{64}$ Nack, in: Karlsruher Kommentar, § 98a Rn. 2. 
von einem Einwohnermeldeamt gespeicherten Namen als Beispiel angeführt. Ziel dabei ist es, alle mit Haftbefehl gesuchten Einwohner eines Ortes zu ermitteln. ${ }^{65}$

\section{Negative Rasterfahndung}

Die positive Rasterfahndung versagt jedoch weitgehend bei der Bekämpfung des Terrorismus, der Rauschgiftkriminalität und des Organisierten Verbrechens. Die Straftäter in diesen Bereichen zeichnen sich durch die Anpassung an ihr Umfeld aus. Sie verhalten sich unauffällig und sozial konform. ${ }^{66} \mathrm{Im}$ Unterschied zur ,positiven“ Rasterfahndung setzt hier die Verbrechensbekämpfung nicht an dem kraft richterlichen Haftbefehls gesuchten Terroristen, sondern an einer Vielzahl loyaler Staatsbürger an, die aus ihrer Sicht mehr oder weniger zufällig Träger fahndungsrelevanter Merkmale sind. ${ }^{67}$ Durch aufeinander folgende Sortiervorgänge, jeweils bestimmt nach den zuvor festgelegten Kriterien, wird aus der Gesamtmenge von Ursprungsdaten letztlich ein sog. Bodensatz ausgesiebt, auf den die Summe aller Verhaltensmuster zutrifft. ${ }^{68}$

Kann nach dem Stand der Ermittlungen angenommen werden, dass ein bestimmtes Merkmal auf den Tatvorgang nicht zutrifft, so kann der Datenbestand mit diesem Suchkriterium abgeglichen werden. Die Treffermenge ist insofern negativ, als sie diejenigen Personen indiziert, die als „Nichtverdächtige“ aus den weiteren Ermittlungen auszuschließen sind. Demgegenüber wird die Restmenge von Personen gebildet, die zwar nicht unbedingt verdächtig, als Verdächtige aber nicht auszuschließen sind. ${ }^{69}$ Bei der negativen Rasterfahndung wird im Ergebnis nicht eine dritte Datei mit übereinstimmenden Daten erstellt, sondern es werden Daten des Ausgangbestandes bei Divergenz mit Vergleichsdaten gelöscht. ${ }^{70}$

\section{Stellungnahme zu den Formen der Rasterfahndung}

Im Ergebnis wird bei einer positiven Rasterfahndung eine neue Datei mit den herausgerasterten Personen erstellt, während bei der negativen Rasterfahndung lediglich Personen aus einer bestehenden Datei gelöscht werden. Folglich liegt der Unterschied nur in der positiven oder negativen Formulierung der Suchkriterien. ${ }^{71}$

${ }^{65}$ So z.B. von: Wanner, S.16; Kruse, in: Gropp (Hrsg.), Besondere Ermittlungsmaßnahmen zur Bekämpfung der Organisierten Kriminalität, S.149.

${ }^{66}$ Wanner, CR 1986, 220; Wanner, S.18.

67 Wanner, S.20. S.71.

${ }^{68}$ Ermisch, in: Bundeskriminalamt (Hrsg.), Möglichkeiten und Grenzen der Fahndung,

${ }^{69}$ Welp, in: Erichsen/Kollhosser/Welp (Hrsg.), Recht der Persönlichkeit, S.398.

${ }^{70}$ Kruse, in: Gropp (Hrsg.), Besondere Ermittlungsmaßnahmen zur Bekämpfung der Organisierten Kriminalität, S.149.

${ }^{71}$ Schäfer, in: Löwe-Rosenberg, § 98a Rn. 8. 
Ein praktischer Unterschied zwischen negativer und positiver Rasterfahndung besteht aber schon deshalb nicht, weil das Datenbankprogramm in der Regel die Suchanfrage ohnehin, gleich ob negativ oder positiv formuliert, in einen einzigen Maschinensprachebefehl nach den Regeln der Booleschen Algebra übersetzt. $^{72}$

Demzufolge ist die Unterscheidung von positiver und negativer Rasterfahndung von untergeordneter Bedeutung. Beide Begriffe umschreiben nur jeweils eine Seite eines einheitlichen Vorgangs. Aus einer Vielzahl möglicherweise relevanter Datensätze werden diejenigen herausgefiltert, unter denen sich möglicherweise der Täter befindet (positive Rasterfahndung), zugleich werden aber diejenigen Datenbestände gelöscht, auf die das Raster nicht zutrifft (negative Rasterfahndung). ${ }^{73}$ Beide Varianten sind kriminalistisch nur unter denselben Voraussetzungen sinnvoll. Der Abgleich muss eine ausreichend geringe Datenmenge produzieren, die praktikable weitere Ermittlungen ermöglicht. ${ }^{74}$

Letztlich ist die Unterscheidung auch datenschutzrechtlich von geringer Bedeutung, da in beiden Fällen zunächst Daten einer Vielzahl von Personen ohne deren Wissen herangezogen werden. ${ }^{75}$

\section{E. Die Anordnungsvoraussetzungen des § 98a StPO}

Wie bereits dargestellt wird die Rasterfahndung zur Strafverfolgung durch die $\S \S 98 \mathrm{a}, 98 \mathrm{~b}$ und 98c StPO geregelt. Diese wurden durch das Gesetz zur Bekämpfung des illegalen Rauschgifthandels und anderer Erscheinungsformen der Organisierten Kriminalität vom 15. Juli 1992 in die Strafprozessordnung eingeführt. Dabei betreffen die $\S \S 98 \mathrm{a}$ und 98b StPO den maschinellen Abgleich personenbezogener Daten, die - für andere Zwecke als Strafverfolgung erhoben - in Dateien anderer Stellen als Strafverfolgungsbehörden gespeichert sind, mit Hilfe fallspezifischer kriminalistischer Prüfkriterien (Raster). ${ }^{76}$ Davon zu unterscheiden ist der maschinelle Abgleich personenbezogener Daten nach § 98c StPO. Dieser regelt den maschinellen Abgleich personenbezogener Daten aus Strafverfahren mit anderen zur Strafverfolgung oder Strafvollstreckung oder zur Gefahrenabwehr gespeicherten Daten. Der Abgleich von polizei-internen Dateien ist nicht an besondere Eingriffsschwellen oder Anordnungskompetenzen geknüpft. ${ }^{77} \S 98 \mathrm{a}$ I StPO umfasst dem Wortlaut nach nur den maschinellen Datenabgleich. Dieser stellt den

\footnotetext{
72 Nack, in: Karlsruher Kommentar, § 98a Rn. 17.

${ }^{73}$ Bäumler in: Lisken/Denninger (Hrsg.), Handbuch des Polizeirechts, J Rn. 258.

${ }^{74}$ Welp, in: Erichsen/Kollhosser/Welp (Hrsg.), Recht der Persönlichkeit, S.398.

75 Sokol, in: Bäumler (Hrsg.), Polizei und Datenschutz, S.191.

${ }^{76}$ Hilger, NStZ 1992, 460.

${ }^{77}$ Rudolphi, in: Systematischer Kommentar, § 98c Rn. 1.
} 
Mittelpunkt der Rasterfahndung dar. Der Handabgleich ist als einfacher Ermittlungsvorgang nach $\S \S 161,163$ StPO zulässig, da er keinen Massenabgleich von Daten ermöglicht, sondern in der Regel nur wenige beschlagnahmefähige, weil beweisgeeignete Daten umfasst. ${ }^{78}$ Im Nachfolgenden werden die Anordnungsvoraussetzungen der Rasterfahndung anhand polizei-externer Dateien nach § 98a StPO dargestellt.

\section{Zureichende tatsächliche Anhaltspunkte}

Erste Voraussetzung für die Anordnung einer Rasterfahndung ist das Vorliegen zureichender tatsächlicher Anhaltspunkte dafür, dass eine der im Katalog des § 98a I S.1 StPO aufgeführten Anlassstraftaten begangen worden ist. Gefordert wird damit der sog. Anfangsverdacht, wie ihn jede Einleitung eines Strafverfahrens nach $\S 152$ II StPO voraussetzt. ${ }^{79}$ Der Anfangsverdacht wird sich in erster Linie auf die Tat selbst und den modus operandi beziehen und weniger auf eine bestimmte Person. ${ }^{80}$ Im Gegensatz zum klassischen Strafverfahrensrecht bildet der Verdacht gegen eine bestimmte Person also nicht den Ausgangspunkt, sondern im optimalen Fall, erst das Ergebnis der Ermittlungsmaßnahme. ${ }^{81}$ Es kann bei der Rasterfahndung also von einem Verfahren der gestuften Verdachtsgewinnung gesprochen werden. ${ }^{82}$

Die Anhaltspunkte müssen eine tatsächliche Grundlage haben, die darauf hindeutet, dass über die bloße allgemeine Möglichkeit der Begehung von Straftaten hinaus, gerade der zu untersuchende Lebenssachverhalt eine Straftat enthält. ${ }^{83}$ Keine zureichenden Anhaltpunkte liegen daher dann vor, wenn offensichtlich ist, dass weder die objektive noch die subjektive Tatbestandsseite irgendeiner Straftat erfüllt sein könnte. ${ }^{84}$ Ausreichend ist die Möglichkeit, dass nach kriminalistischer Erfahrung eine verfolgbare Straftat gegeben ist. ${ }^{85}$ Dagegen genügen bloße Vermutungen oder kriminalistische Hypothesen nicht, um einen Anfangsverdacht zu begründen. ${ }^{86}$

${ }^{78}$ Schäfer, in: Löwe-Rosenberg, § 98a Rn.5.

${ }^{79}$ Rudolphi, in: Systematischer Kommentar, § 98a Rn. 7; so auch von der Bundesregierung vorgeschlagen, die dies im Hinblick auf den engen Enumerativkatalog als gerechtfertigt sieht vgl. BT-Drs. 12/989, S.57.

${ }^{80}$ Nack, in: Karlsruher Kommentar, § 98a Rn. 11.

${ }^{81}$ Wittig, JuS 1997, 968.

82 Denninger, in: Hohmann (Hrsg.), Freiheitssicherung durch Datenschutz, S.158.

${ }^{83}$ Beulke, in: Löwe-Rosenberg, § 152 Rn. 25.

${ }^{84}$ Kammann, S.29.

85 Schoreit, in: Karlsruher Kommentar, § 152 Rn. 28; Bruns, in: Hirsch/Kaiser/Marquardt (Hrsg.), Gedächtnisschrift für Hilde Kaufmann, S.866.

${ }^{86}$ Schoreit, in: Karlsruher Kommentar, § 152 Rn. 31. 
Zureichend sind solche Anhaltspunkte, die es rechtfertigen, die Mittel der Strafverfolgungsbehörden einzusetzen und, wenn auch in geringem Maße, in die Rechtssphäre des Bürgers einzugreifen, um festzustellen, ob eine verfolgbare Straftat vorliegt und wer sie begangen hat. Es genügt eine gewisse, wenn auch noch geringe Wahrscheinlichkeit, bei der der Zweifel an der Richtigkeit des Verdachts noch überwiegen darf. ${ }^{87}$ Bei der Beurteilung der Frage, ob die Tatsachen zureichend sind, wird den Strafverfolgungsbehörden ein Beurteilungsspielraum zuerkannt. Dieser ist nur bedingt gerichtlich überprüfbar. ${ }^{88}$

Eine abstrakte, objektivierende Definition des Begriffs der „zureichenden tatsächlichen Anhaltspunkte“, die die Befugnisbegrenzung der Staatsanwaltschaft zur Einleitung von Ermittlungen konkretisieren würde, existiert nicht. Sie ist aufgrund der dem Verdachtsbegriff immanenten Subjektivität der Verdachtsbildung wohl auch technisch nicht zu bilden. ${ }^{89}$

\section{Die Anlassstraftaten}

Die ,zureichenden tatsächlichen Anhaltspunkte“ müssen sich auf eine der Anlassstraftaten aus dem Katalog des $\S 98$ a I S.1 StPO beziehen. Im Gegensatz zu anderen Katalogen, z.B. dem des $\S 100$ a StPO, werden im Katalog des $\S$ 98a I S.1 StPO keine bestimmten Straftatbestände aufgezählt. Vielmehr werden hier ganze Kriminalitätsbereiche oder Begehungsformen angeführt. ${ }^{90}$ Innerhalb dieses Kataloges ist die Anwendung auf Straftaten von ,erheblicher Bedeutung“ beschränkt. ${ }^{91}$ Das Auswahlsystem beruht somit auf einer Kombination von Generalklausel und Deliktsgruppen und kann daher als „Generalklausel mit katalogartigen Grenzen“ bezeichnet werden. ${ }^{92}$

Der Gesetzgeber wollte damit einen Deliktskatalog schaffen, der eine praxisgerechte und effiziente Handhabung ermöglicht. Er sah bei einer enumerativen Aufzählung die Gefahr, dass in einer Art Dauerdiskussion ständig neue Forderungen nach neuen Katalogdelikten gestellt werden könnten. ${ }^{93}$ Im Einzelnen handelt es sich bei den Anlassstraftaten um „Straftaten von erheblicher Bedeutung

- auf dem Gebiet des unerlaubten Betäubungsmittelgesetzes oder Waffenverkehrs, der Geld- oder Wertzeichenfälschung,

\footnotetext{
${ }^{87}$ Beulke, in: Löwe-Rosenberg, § 152 Rn. 23.

88 Weßlau, in: Systematischer Kommentar, § 152 Rn. 19.

${ }^{89}$ Eisenberg/Conen, NJW 1998, S.2241.

${ }^{90}$ Kruse, in: Gropp (Hrsg.), Besondere Ermittlungsmaßnahmen zur Bekämpfung der Organisierten Kriminalität, S.171.

${ }^{91}$ Meyer-Goßner, § 98a Rn. 5.

${ }_{92}$ Welp, in: Erichsen/Kollhosser/Welp (Hrsg.), Recht der Persönlichkeit, S.406.

${ }^{93}$ BT-Drs 12/2720, S.45.
} 
- auf dem Gebiet des Staatsschutzes ( $§ 74 a, 120$ des Gerichtsverfassungsgesetzes),

- auf dem Gebiet der gemeingefährlichen Straftaten,

- gegen Leib oder Leben, die sexuelle Selbstbestimmung oder die persönliche Freiheit,

- gewerbs- oder gewohnheitsmäßig oder

- von einem Bandenmitglied oder in anderer Weise organisiert

begangen“".

Von den Katalogtaten erfasst werden - wenn sie strafbar sind - auch der Versuch und der Versuch der Beteiligung. Darüber hinaus ist unerheblich, ob der Gesuchte als Täter oder Teilnehmer mitgewirkt hat. ${ }^{94}$

Dieser Katalog hat die Funktion, die Eingriffe in grundrechtlich geschützte Bereiche auf die Bekämpfung von schwerwiegender organisierter Kriminalität zu begrenzen. ${ }^{95}$ Ferner wollte der Gesetzgeber mit der Schaffung des Kataloges dem Grundsatz der Verhältnismäßigkeit entsprechen. ${ }^{96}$ Gerade vor diesem Hintergrund bedürfen jedoch die Nummern 1 bis 6 des in $\S$ 98a I StPO enthaltenen Kataloges einer eingehenden Erörterung.

\section{Straftaten auf dem Gebiet des unerlaubten Betäubungsmittelgesetzes oder Waf- fenverkehrs oder der Geld- und Wertzeichenfälschung}

In der Nr.1 des Kataloges hat der Gesetzgeber nicht die einzelnen Straftaten aufgeführt, sondern sie durch eine Generalklausel (,,auf dem Gebiete des...") umschrieben. Damit erfasst die Vorschrift nicht nur genau bestimmte Straftaten auf einem bestimmten Gebiet, sondern alle auf diesem Gebiet begangenen Straftaten. ${ }^{97}$ Diese Umschreibung darf jedoch nicht dahingehend verstanden werden, dass allein schon ein Zusammenhang mit Betäubungsmittelstraftaten usw. ausreicht. Dies wäre mit dem Wortlaut und der Umgrenzungsfunktion des Straftatenkatalogs nicht mehr zu vereinbaren. ${ }^{98}$

Im Wesentlichen enthält $\S$ 98a I S.1 Nr. 1 StPO die in $\S 100$ a S.1 Nr.3 und Nr.4 StPO, sowie die im achten Abschnitt des StGB genannten Delikte. ${ }^{99}$ Danach sind Anlassstraftaten auf dem Gebiet des Waffenverkehrs die $\S \S 51,52$ I Nr.1, Nr.2c

\footnotetext{
94 Schäfer, in: Löwe-Rosenberg, § 98a Rn. 16.

95 Siebrecht, CR 1996, 548.

96 Grunst, GA 149 (2002), S.219.

${ }^{97}$ Rudolphi, in: Systematischer Kommentar, § 98a Rn. 8.

98 Schäfer, in: Löwe-Rosenberg, § 98a Rn. 17.

${ }^{99}$ Lemke, in: Heidelberger Kommentar, § 98a Rn. 5.
} 
und Nr.2d, V, VI des Waffengesetzes, § 34 I - VI des Außenwirtschaftgesetzes oder $\S 19$ I - III, $\S 20$ I oder II, jeweils auch in Verbindung mit § 21, oder $\S 22 \mathrm{a} \mathrm{I} \mathrm{-}$ III des Gesetzes über die Kontrolle von Kriegswaffen. Ferner handelt es sich bei den Straftaten auf dem Gebiet des unerlaubten Betäubungsmittelgesetzes um eine Straftat nach einer in $\S 29$ III S.2 Nr.1 des Betäubungsmittelgesetzes in Bezug genommenen Vorschrift unter den dort genannten Voraussetzungen oder eine Straftat nach $\S \S 29 a$, 30 I Nr.1, 2, 4, 30a oder 30b des Betäubungsmittelgesetzes. Bei den Straftaten auf dem Gebiete der Geld- und Wertzeichenfälschung handelt es sich um die $\S \S 146$ bis 152 a StGB.

\section{Straftaten auf dem Gebiet des Staats- und Verfassungsschutzes}

Die Nr.2 des Kataloges der Anlassstraftaten beinhaltet eine Verweisung auf die $\S \S 74 \mathrm{a}$ und 120 GVG. Dabei handelt es sich um eine dynamische Verweisung. ${ }^{100}$ Dynamisch ist eine Verweisung, wenn sie auf die jeweils gültige Fassung eines anderen Gesetzes verweist. Was immer dann der Fall ist, wenn die Verweisung pauschal auf andere Paragraphen Bezug nimmt. ${ }^{101}$

Durch die Verweisung auf die $\S \S 74 \mathrm{a}$ und $120 \mathrm{GVG}$ wird wiederum auf weitere Straftatenkataloge verwiesen. Dadurch kommt es jedoch zu unübersichtlichen Kettenverweisungen. So verweist 98a I S.1 Nr.2 StPO u.a. auf $\S 120$ GVG, der seinerseits u.a. auf $\S 129$ a StGB verweist, der sich wiederum auf mehr als ein Dutzend weiterer Straftatbestände bezieht. ${ }^{102}$ Somit wird der Kreis der Straftaten nicht nur kompliziert, sondern auch wesentlich erweitert. ${ }^{103}$ Dies ist problematisch, da der Katalog der $\S \S 74 \mathrm{a}$ und $120 \mathrm{GVG}$ so umfangreich ist, dass keinesfalls aus dem Vorliegen einer der dort genannten Straftaten auf deren Erheblichkeit geschlossen werden kann. ${ }^{104}$

\section{Straftaten auf dem Gebiet der gemeingefährlichen Straftaten}

Von Nr.3 sind Straftaten auf dem Gebiete der gemeingefährlichen Straftaten erfasst. Dabei handelt es sich um die Straftaten des 27. Abschnitts des StGB, also die $\S \S 306$ bis 323c StGB. Erfasst sind damit nicht selten auch fahrlässige Straftaten wie z.B. in $\S 316$ und $\S 309$ StGB. Darüber hinaus ist die Frage, welche Delikte gemeingefährlich sind, vielfach noch ungeklärt. ${ }^{105}$ Hier gewinnt die Einschrän-

\footnotetext{
100 Rudolphi, in: Systematischer Kommentar, § 98a Rn. 8.

101 Schneider, Rn. 385.

102 Schäfer, in: Löwe-Rosenberg, § 98a Rn. 18.

103 Hassemer, KJ 1992, 69.

${ }^{104}$ Bäumler in: Lisken/Denninger (Hrsg.), Handbuch des Polizeirechts, J Rn. 270.

105 Rudolphi, in: Systematischer Kommentar, § 98a Rn. 8.
} 
kung, dass es sich um Straftaten von erheblicher Bedeutung handeln muss, besonderes Gewicht, indem geringfügige (fahrlässige) Verstöße etwa gegen § $316 \mathrm{StGB}$ eine Rasterfahndung nicht rechtfertigen können. ${ }^{106}$

\section{Straftaten gegen Leib oder Leben, die sexuelle Selbstbestimmung oder die persönliche Freiheit}

Die Nr.4 des Kataloges der Anlassstraftaten erfasst die Abschnitte 13 und 16 bis 18 des StGB und damit die $\S \S 174$ bis 184 a StGB sowie die $\S \S 211$ bis 241 a StGB. Auch hier kommen vielfach fahrlässige Straftaten in Betracht, ${ }^{107}$ so dass wiederum eine Korrektur über das Merkmal der Straftaten von erheblicher Bedeutung zu erfolgen hat. Erfasst werden aber auch die Straftaten im Amt nach $\S \S 340,343,345$ StGB oder $\S 30 \mathrm{WStG}$. Denn der Sinn des Straftatenkataloges ist nicht, die Zahl der betroffenen Delikte willkürlich zu begrenzen, sondern vielmehr, die mit der Rasterfahndung verbundenen Grundrechtseingriffe nur bei klar abgrenzbaren und wichtigen Straftaten zuzulassen. Entsprechendes muss auch für andere Delikte gelten, die neben zusätzlichen qualifizierenden Tatbestandsmerkmalen eines der Katalogdelikte umfassen. ${ }^{108}$

\section{Gewerbs- oder gewohnheitsmäßig begangene Straftaten}

Von Nr.5 werden alle gewerbs- oder gewohnheitsmäßig begangenen Straftaten in den Katalog aufgenommen. Ansatzpunkt ist hier also die Begehungsweise der Straftat. Nach dem eindeutigen Wortlaut werden demnach alle Delikte erfasst, sofern sie gewerbs- oder gewohnheitsmäßig begangen wurden. Mithin ist nicht erforderlich, dass die betreffenden Delikte die Gewerbs- oder Gewohnheitsmäßigkeit als Tatbestandsmerkmal oder Regelbeispiel enthalten. ${ }^{109}$

Dabei richtet sich das Verständnis der Begriffe gewerbs- und gewohnheitsmäßig nach den von der Rechtsprechung und dem Schrifttum zum Strafgesetzbuch entwickelten Kriterien. ${ }^{110}$ Danach handelt gewerbsmäßig, wer die Absicht hat, sich aus der wiederholten Tatbegehung eine fortlaufende Einnahmequelle von gewisser Dauer und einigem Umfang zu verschaffen. ${ }^{111}$

\footnotetext{
106 Pfeiffer, § 98a Rn. 2.

${ }^{107}$ Rudolphi, in: Systematischer Kommentar, § 98a Rn. 8.

108 Schäfer, in: Löwe-Rosenberg, § 98a Rn. 20.

109 Schäfer, in: Löwe-Rosenberg, § 98a Rn. 21.

${ }^{110}$ Lemke, in: Heidelberger Kommentar, § 98a Rn. 6.

111 BGH, NStZ 1995, 85.
} 
Dagegen ist der Strafgrund der Gewohnheitsmäßigkeit weitgehend ungeklärt. ${ }^{12}$ Kennzeichnend soll ein durch wiederholte Begehung erzeugter, eingewurzelter und selbständig fortwirkender Hang sein. ${ }^{113}$ So fordert die Rechtsprechung, dass der Täter sich an die Begehung von Straftaten ,so gewöhnt hat, dass ihm jeder weitere Förderungsakt gleichsam von der Hand geht, ohne dass es in diesem Augenblick für ihn noch zu einer Auseinandersetzung mit irgendwelchen sittlichen Bedenken kommt. ${ }^{114}$ Ferner wird vorausgesetzt, dass mindestens zwei Einzeltaten begangen worden sind. ${ }^{115}$

\section{Von einem Bandenmitglied oder in anderer Weise organisiert begangene Straftaten}

Letztlich ist die Rasterfahndung zulässig, wenn der Verdacht einer Straftat besteht, die von einem Bandenmitglied oder in anderer Weise organisiert, begangen worden ist. Aus $§ 98$ a I S.1 Nr.6 StPO ergeben sich somit zwei Alternativen.

\section{a. $§ 98$ a I S.1 Nr.6 1. Alt StPO}

Voraussetzung für die 1. Alternative des $\S$ 98a I S.1 Nr.6 StPO ist der Verdacht der Begehung einer Straftat durch ein Bandenmitglied. Kern dieser Alternative ist demnach der Begriff der Bande. Nach ständiger Rechtsprechung sollte für die Bande eine Verbindung von mindestens zwei Personen ausreichen. ${ }^{116}$ Um Abgrenzungsschwierigkeiten, insbesondere zur Mittäterschaft zu entgehen, forderte die Rechtsprechung ein über das bloße Individualinteresse hinausgehendes Handeln mit gefestigtem Bandenwillen. ${ }^{117}$ Dafür sollte kennzeichnend sein, dass sich ein Bandentäter im übergeordneten Interesse der bandenmäßigen Verbindung betätigt. $^{118}$

Im Gegensatz zu dieser Rechtsprechung hat der Große Senat für Strafsachen für den Begriff der Bande den Zusammenschluss von mindestens drei Personen vorausgesetzt, die sich mit dem Willen verbunden haben, künftig für eine gewisse Dauer mehrere selbständige, im Einzelnen noch ungewisse Straftaten zu begehen. ${ }^{119}$ Dabei ist ein gefestigter Bandenwille oder ein Tätigwerden in einem über-

\footnotetext{
112 Stree, in: Schönke/Schröder, vor § 52 Rn. 98f.

113 Stree, in: Schönke/Schröder, vor § 52 Rn. 98f.

114 BGH 15, 377, 380.

115 RGSt 58, 24, 25.

116 So zuletzt BGH, NJW 2000, $2907 \mathrm{ff}$.

117 BGH, NStZ 1996, 340.

118 BGH, NStZ 1996, 443.

119 BGH, NJW 2001, 2266; BGHSt 46, 321, 325.
} 
geordneten Bandeninteresse nicht erforderlich. Auch ein örtliches und zeitliches Zusammenwirken ist keine Voraussetzung. ${ }^{120}$ Damit schließt sich der BGH der im Schrifttum schon lange vorherrschenden Meinung zum Bandenbegriff an. ${ }^{121}$

Diese Auffassung erscheint vorzugswürdig, da sich die der Bande eigentümliche kriminogene Gruppendynamik erst entfaltet, wenn mindestens zwei Gleichgesinnte den Einzelnen majorisieren können. ${ }^{122}$ Bei nur zwei Mitgliedern bräuchte kein Beteiligter die Situation zu befürchten, als zahlenmäßige Minderheit einer in sich verschworenen, tatentschlossenen Gruppenmehrheit gegenüberzustehen. ${ }^{123}$ Vor allem aber kann ohne die Beschränkung der Bande auf mindestens drei Mitglieder nicht erklärt werden, worin der spezifische Unterschied zur mittäterschaftlichen Begehung liegen soll, der die deutlich höhere Strafe bei bandenmäßiger Begehung rechtfertigt. ${ }^{124}$ Somit stellt sich die Bande nach der neuen Rechtsprechung als eine Art Mittelding zwischen mittäterschaftlicher Verbindung und krimineller Vereinigung im Sinne des $\S 129 \mathrm{StGB}$ dar. ${ }^{125}$

Im Rahmen des § 98a I S.1 Nr.6 StPO ergibt sich unter Beachtung des Wortlautes, dass es unerheblich ist, welches Delikt begangen werden soll. Eine Katalogtat im Sinne des § 98a I S.1 Nr.6 StPO liegt nicht nur bei der Verwirklichung von Bandendelikten vor. Vielmehr können alle Delikte eine Katalogtat im Sinne dieser Vorschrift darstellen, wenn sie im Einzelfall von erheblicher Bedeutung und von einem Bandenmitglied begangen worden sind. ${ }^{126}$ Folglich liegt der Ansatzpunkt, für die Zulässigkeit der Rasterfahndung, in der Mitgliedschaft des Verdächtigen in einer Bande. Bandenmitglied ist, wer sich in die Organisation einfügt und ihren Regeln unterordnet, um zu ihrem Aufbau und Bestand beizutragen, ihre kriminellen Zwecke zu fördern und sich an ihren Straftaten - als Täter, Mittäter oder Teilnehmer - zu beteiligen. ${ }^{127}$ Darüber hinaus ist nicht erforderlich, dass Anhaltspunkte für eine Beteiligung der anderen Bandenmitglieder vorliegen, denn solche werden oft zu Beginn der Ermittlungen fehlen und sich erst mit Hilfe der Maßnahme ergeben. ${ }^{128}$

\footnotetext{
120 BGHSt 46, 321, 325. BGH, NJW 1970, 1802f.; Anmerkungen von Volk zu BGH, JR 1979, 428f.

122 Mitsch, §1 Rn. 254.

123 Hoyer, in: Systematischer Kommentar, § 244 Rn. 31.

124 Schmitz, in: Münchner Kommentar, § 244 StGB Rn. 38.

125 Joerden, JuS 2002, 330.

126 Schäfer, in: Löwe-Rosenberg, § 98a Rn. 25.

127 Mitsch, §1 Rn. 256.

${ }^{128}$ Hilger, NStZ 1992, 457ff.
}

${ }^{121}$ Schon vor der Entscheidung des Großen Senats für Strafsachen, für die Begrenzung des Bandenbegriffs auf mindestens drei Bandenmitglieder: Anmerkungen von Dreher zu 


\section{b. $\S 98$ a I S.1 Nr.6 2. Alt StPO}

Die 2. Alternative des $\S 98$ a I S.1 Nr.6 StPO enthält einen Auffangtatbestand für die Fälle, die nicht unter Nr.1 bis Nr.4 fallen und in denen auch nicht die Kriterien der Nr.5 und Nr.6 1. Alt. vorliegen, aber zureichende Anhaltspunkte dafür bestehen, dass hinter der Tat eine „Organisationsstruktur“ steht. ${ }^{129}$ Für eine solche Interpretation der Formulierung, ,in anderer Weise organisiert“" spricht auch, dass jede Straftat in irgendeiner Weise organisiert ist, sofern sie nicht spontan und im Affekt begangen wird. ${ }^{130}$ Dementsprechend kann mit dieser Formulierung nur eine Straftat aus dem Bereich der „Organisierten Kriminalität“ gemeint sein. Dies wirft jedoch Probleme auf, da der Gesetzgeber keine Definition der Organisierten Kriminalität in das OrgKG eingefügt hat. Es muss daher auf die „Gemeinsamen Richtlinien der Justizminister / -senatoren und der Innenminister / -senatoren der Länder über die Zusammenarbeit von Staatsanwaltschaft und Polizei bei der Verfolgung der Organisierten Kriminalität" vom Mai 1990 zurückgegriffen werden. Diese beinhalten folgende Beschreibung des Begriffs der Organisierten Kriminalität:

„Organisierte Kriminalität ist die von Gewinn- oder Machtstreben bestimmte planmäßige Begehung von Straftaten, die einzeln oder in ihrer Gesamtheit von erheblicher Bedeutung sind, wenn mehr als zwei Beteiligte auf längere oder unbestimmte Dauer arbeitsteilig

- unter Verwendung gewerblicher oder geschäftsähnlicher Strukturen

- unter Anwendung von Gewalt oder anderer zur Einschüchterung geeigneter Mittel oder

- unter Einflussnahme auf Politik, Medien, öffentliche Verwaltung, Justiz oder Wirtschaft

zusammenwirken. “'131

Das Problem einer solchen Definition lässt sich sofort erkennen. Werden die Begriffe Kriminalität und Gewalt aus der Definition herausgenommen, so verbleibt lediglich die Struktur wirtschaftlich ergiebiger Handlungen. Hierzu gehören Arbeitsteilung und damit Zusammenarbeit, wirtschaftliche Profite, Profitmaximierung, gewerbliche/geschäftliche Strukturen und Planung. Auch Einflussnahme auf Politik und Verwaltung, Globalisierung und internationale Verflechtungen zählen selbstverständlich zu den Kernelementen organisierten wirtschaftlichen Handelns. ${ }^{132} \mathrm{Zu}$ erkennen ist, dass die Organisierte Kriminalität, im Rahmen ihrer Tä-

\footnotetext{
129 Pfeiffer, § 98a Rn. 2.

${ }^{130}$ Bäumler, in: Lisken/Denninger (Hrsg.), Handbuch des Polizeirechts, J Rn. 272.

${ }^{131}$ Abgedruckt in: Meyer-Goßner, Anh 12 RiStBV, Anlage E Nr. 2.1.

${ }^{132}$ Albrecht, in: Deutsche Sektion der Internationalen Juristen-Kommission (Hrsg.), Organisierte Kriminalität und Verfassungsstaat, S.7.
} 
tigkeiten, mehr und mehr den Strukturen und Organisationsprinzipen der legalen Wirtschaft und Märkte folgt. ${ }^{133}$

Ferner ist aus der Definition erkennbar, dass es sich bei der Organisierten Kriminalität nicht um einen fest eingrenzbaren Straftatbestand oder eine Summe einzelner Straftatbestände, sondern um eine komplexe Form abweichenden Verhaltens handelt. ${ }^{134}$ Aus diesem Grund hat die „Gemeinsame Arbeitsgruppe Justiz/Polizei zur Strafverfolgung organisierter Kriminalität“ einen Katalog von generellen Indikatoren zur Erkennung OK-relevanter Sachverhalte sowie von für die Organisierte Kriminalität typischen Straftaten als Auslegungshilfe in die Richtlinien aufgenommen. ${ }^{135}$ Durch die Richtlinien werden von der organisierten Kriminalität ausdrücklich Straftaten des Terrorismus abgegrenzt. ${ }^{136}$

Die Besonderheiten der Kriminalitätsform lassen es geradezu unmöglich erscheinen, eine Begriffsbestimmung der Organisierten Kriminalität zu treffen, die das Phänomen der Organisierten Kriminalität sowohl umfassend kriminologisch umschreibt als auch in juristisch eindeutige Merkmale zur Schaffung von Rechtsgrundlagen fasst. ${ }^{137}$ Es bleibt festzuhalten, dass ein Rückgriff auf die Definition auch unter Einbeziehung der Auslegungshilfen erheblich Probleme birgt, die vor allen Dingen in ihrer Weite und Unbestimmtheit begründet liegen. So werden nahezu alle Elemente der Definition als interpretationsbedürftig angesehen. ${ }^{138}$

Allerdings zeichnet sich diese Definition dadurch aus, dass durch sie möglichst vielfältige OK-Variationen abgedeckt werden können. ${ }^{139}$ Auch verfahrenstechnisch ist die weite Definition notwendig, etwa für die Begründung von Zuständigkeiten und als Schwelle für die Durchführung aufwendiger Ermittlungsmaßnahmen, für die Inanspruchnahme zentraler Auswertungssysteme und besondere Informations-

${ }^{133}$ Kanther, in: Deutsche Sektion der Internationalen Juristen-Kommission (Hrsg.), Organisierte Kriminalität und Verfassungsstaat, S.59.

134 Gehm/Link, Kriminalistik 1992, 491.

135 Abgedruckt in: Meyer-Goßner, Anh 12 RiStBV, Anlage E Nr. 2.1. Dabei handelt es sich um: Rauschgifthandel und -schmuggel; Waffenhandel und -schmuggel; Kriminalität im Zusammenhang mit dem Nachtleben; Schutzgelderpressung; Unerlaubte Arbeitsvermittlung und Beschäftigung; Illegale Einschleusung von Ausländern; Warenzeichenfälschung; Goldschmuggel; Kapitalanlagebetrug; Subventionsbetrug und Eingangsabgabenhinterziehung; Fälschung und Missbrauch unbarer Zahlungsmittel; Herstellung und Verbreitung von Falschgeld; Verschiebung von hochwertigen Kraftfahrzeugen, LKW, Container- und Schiffsladungen; Betrug zum Nachteil von Versicherungen; Einbruchsdiebstahl in Wohnungen mit zentraler Beuteverwertung; Illegale Entsorgung von Abfall; Illegaler Technologietransfer.

${ }^{136}$ Kinzig, S.57.

137 Sieber/Bögel, S.372f.

${ }^{138}$ Kinzig, S.61.

139 Wittkämper/Krevert/Kohl, S.49. 
und Meldesysteme. ${ }^{140}$ Daher wird vor allem aus polizeilicher Sicht die mit der weiten Definition einhergehende Flexibilität hervorgehoben. ${ }^{141}$

\section{Zusammenfassung}

Aufgrund der außerordentlichen Weite des gesamten Katalogs des § 98a I S.1 Nr.1 bis Nr.6 StPO ist kaum noch überschaubar, welche Straftaten der Regelung unterfallen. Es sind auch keine gemeinsamen Merkmale der bezeichneten Straftaten erkennbar. ${ }^{142}$ Darüber hinaus sind die indizierten Straftaten weder für Organisierte Kriminalität noch für irgendeine andere konsistente Erscheinungsform realer Kriminalität „,ypisch“. 143 Letztlich kumulieren insbesondere in § 98a I S.1 Nr.5 und Nr.6 unbestimmte Rechtsbegriffe in einer für die Normenklarheit abträglichen Weise. ${ }^{144}$ So kann man zu dem Schluss kommen, dass ein so umfangreicher Katalog über den Bereich des Erforderlichen hinaus geht und deshalb nicht verhältnismäßig ist. ${ }^{145}$

Eine Korrektur dieses Zustandes kann nur im Wege der Auslegung des Merkmals der „Straftat von erheblicher Bedeutung“ und unter Anwendung des Verhältnismäßigkeitsprinzips im Rahmen der Subsidiaritätsklausel erreicht werden. Als Fazit zum Katalog des $\S 98$ a I S.1 StPO bleibt somit bestehen, dass die Auswahl der zur Rasterfahndung berechtigenden Straftaten, im Kern durch nichts weiter als den Begriff der erheblichen Tatbedeutung gesteuert wird. ${ }^{146}$

\section{Straftat von erheblicher Bedeutung}

Die außerordentliche Weite der gesetzlichen Regelung bedarf einer Korrektur. ${ }^{147}$ Dies hat der Gesetzgeber dadurch zu erreichen versucht, indem er neben dem Anfangsverdacht für das Vorliegen einer der Anlassstraftaten aus dem Katalog des $§ 98$ a I S.1 StPO die weitere Voraussetzung eingefügt hat, dass die Straftat von erheblicher Bedeutung sein muss. Der Begriff „Straftat von erheblicher Bedeutung“" wird in der Strafprozessordnung an unterschiedlichen Stellen verwendet. So setzen neben dem $\S 98$ a I S.1 StPO auch die $\S \S 100$ c I Nr.3 und 110a I StPO jeweils in Kombination mit einem unterschiedlichen Straftatenkatalog und der $\S 163 \mathrm{e}$ StPO ohne weiteren Zusatz jeweils eine Straftat von erheblicher Bedeutung

140 Kersten, ZFIS 1998, 132.

141 Kinzig, S.75.

142 Kruse, in: Gropp (Hrsg.), Besondere Ermittlungsmaßnahmen zur Bekämpfung der Organisierten Kriminalität, S.172.

143 Welp, in: Erichsen/Kollhosser/Welp (Hrsg.), Recht der Persönlichkeit, S.405.

144 Bäumler, in: Lisken/Denninger (Hrsg.), Handbuch des Polizeirechts, J Rn. 272.

145 Siebrecht, S.120.

146 Welp, in: Erichsen/Kollhosser/Welp (Hrsg.), Recht der Persönlichkeit, S.407.

${ }^{147}$ Rudolphi, in: Systematischer Kommentar, § 98a Rn. 10. 
voraus. ${ }^{148}$ Eine Definition des Merkmals ist in der Strafprozessordnung jedoch nicht enthalten.

Dies unterscheidet die Strafprozessordnung von einigen Polizeigesetzen der Länder. Beispielsweise wird der Begriff in $\S 22 \mathrm{~V}$ PolG Baden-Württemberg definiert. Danach sind Straftaten von erheblicher Bedeutung:

- Verbrechen,

- Vergehen, die im Einzelfall nach Art und Schwere geeignet sind, den Rechtsfrieden besonders zu stören, soweit sie

○ sich gegen das Leben, die Gesundheit oder die Freiheit einer oder mehrerer Personen oder bedeutende fremde Sach- oder Vermögenswerte richten,

○ auf den Gebieten des unerlaubten Waffen- oder Betäubungsmittelverkehrs, der Geld- oder Wertzeichenfälschung oder des Staatsschutzes ( $\S \S 74 \mathrm{a}$ und $120 \mathrm{GVG}$ ) begangen werden,

○ gewerbs-, gewohnheits-, bandenmäßig oder sonst organisiert begangen werden.

Auffällig ist hier, dass die Straftaten von erheblicher Bedeutung in $\S 22$ V PolG BW nahezu deckungsgleich mit dem Katalog der Anlassstraftaten in § 98a I S.1 StPO sind. Folglich hat das Merkmal in § 98a StPO praktisch keine eigenständige Bedeutung. Auf diese Legaldefinition kann daher nur begrenzt zurückgegriffen werden.

Mit der Einführung der Straftat von erheblicher Bedeutung in das Gesetz wurde auf ein im BR-E der 11. Wahlperiode verwendetes Merkmal zurückgegriffen. Dort wiederum war auf den Entwurf eines Strafverfahrensänderungsgesetz von 1989 des Bundesministers der Justiz zurückgegriffen worden. Hierin wird der Begriff „Straftat von erheblicher Bedeutung“ zwar nicht definiert, jedoch ausführlich wie folgt umschrieben:

„Unter dem Begriff der Straftat mit erheblicher Bedeutung sind solche Taten zu verstehen, die den Rechtsfrieden empfindlich stören und geeignet sind, das Gefühl der Rechtssicherheit der Bevölkerung erheblich zu beeinträchtigen. Danach muss es sich bei der Anlasstat um ein Delikt handeln, das mindestens der mittleren Kriminalität zuzurechnen ist. In den Fällen mittlerer Kriminalität ist dabei das besondere Maß des Unrechts nach Lage des konkreten Einzelfalles entscheidend, wobei es nicht so sehr auf den abstrakten Charakter des Straftatbestandes, sondern auf Art und Schwere der jeweiligen konkreten Tat gemäß der Verdachtslage bei Anordnung der Maßnahme ankommt. Die Beeinträchtigung des Rechtsfriedens oder der Rechtssicherheit kann sich etwa daraus ergeben, dass durch die Straftat bedeutsame

148 Bäumler, in: Lisken/Denninger (Hrsg.), Handbuch des Polizeirechts, J Rn. 269. 
Rechtsgüter, wie z.B. Leib, Leben, Gesundheit oder fremde Sachen von bedeutendem Wert, verletzt werden. Nach Lage des Einzelfalles können auch Eigentumsoder Vermögensdelikte mittlerer Kriminalität die genannte Voraussetzung erfüllen, insbesondere wenn es sich um Straftaten mit Seriencharakter und entsprechend erheblichem (Gesamt-) Schaden für die Allgemeinheit handelt.“ 149

Einigkeit besteht darin, dass die Anwendung der Rasterfahndung bei Fällen der einfachen Kriminalität ausgeschlossen ist. Demnach müsste die Anlasstat zumindest der mittleren Kriminalität zuzurechnen sein. ${ }^{150}$ Die Einschränkung auf Straftaten, die zumindest der mittleren Kriminalität zuzuordnen sind, ist jedoch ebenfalls nicht besonders hilfreich, da auch Straftaten der Massenkriminalität - etwa der Diebstahl bestimmter Autoradios oder Autoteile - Bestandteil organisierter Kriminalität und damit besonders gefährlich und durchaus von erheblicher Bedeutung sein können. ${ }^{151}$ Somit können Straftaten der einfachen Kriminalität nicht pauschal zu einem Ausschluss der Rasterfahndung führen.

Ein handhabbares Abgrenzungskriterium könnte ferner die Überlegung bilden, ob wegen der Tat Anklage beim Landgericht oder beim Oberlandesgericht erhoben werden müsste. Dieses Kriterium ist allerdings nur als hinreichende und nicht als notwendige Voraussetzung zu verstehen, da es auf die objektive Schwere der Tat und nicht auf das Maß der Schuld ankommt. ${ }^{152}$

Es lässt sich festhalten, dass wohl grundsätzlich alle Verbrechen - wenn es sich nicht um minderschwere Fälle handelt - erfasst werden. ${ }^{153}$ Darüber hinaus sollte, im Hinblick auf die Definition der Organisierten Kriminalität durch das OrgKG, ein Vergehen nur dann als Straftat von erheblicher Bedeutung aufgefasst werden, wenn sich die Schwere des Unrechts aus den Bezügen zu den Elementen und Strukturen Organisierter Kriminalität ergibt. ${ }^{154}$ Die Ansicht, wonach die Schwere des Unrechts und die Störung des Rechtsfriedens, bezüglich aller Katalogtaten, gerade durch die Organisierte Kriminalität zumindest mitgeprägt sein müssen, erscheint fraglich. ${ }^{155}$ Unter Beachtung dessen, dass ansonsten bis auf $\S$ 98a I S.1 Nr.6 1.Alt StPO (,,in anderer Weise organisiert") alle anderen Fälle des Straftatenkatalogs überflüssig wären, muss man hier zu dem Schluss kommen, dass diese Ansicht nicht mit dem Wortlaut der Vorschrift zu vereinbaren ist. ${ }^{156}$ Erforderlich ist in je-

\footnotetext{
149 BR-Drs. 74/90, S.79.

${ }^{150}$ Lemke, in: Heidelberger Kommentar, § 98a Rn. 9.

151 Schäfer, in: Löwe-Rosenberg, § 98a Rn. 27.

152 Nack, in: Karlsruher Kommentar, § 110a Rn. 21.

153 Möhrenschlager, wistra 1992, S.327.

154 Graf, S.95.

155 So Rudolphi, in: Systematischer Kommentar, § 98a Rn. 10, der dies für alle Katalogtaten fordert.

156 Schäfer, in: Löwe-Rosenberg, § 98a Rn. 27.
} 
dem Fall eine einzelfallbezogene Beurteilung unter Berücksichtigung des allgemeinen Verhältnismäßigkeitsprinzips. ${ }^{157}$

\section{Die Subsidiaritätsklausel}

Letztlich sieht $\S 98$ a I S.2 StPO vor, dass die Rasterfahndung nur angeordnet werden darf, ,wenn die Erforschung des Sachverhalts oder die Ermittlung des Aufenthaltsortes des Täters auf andere Weise erheblich weniger erfolgversprechend oder wesentlich erschwert wäre“. Durch diese Klausel wird der Ausnahmecharakter der Rasterfahndung betont. ${ }^{158}$ Es handelt sich um eine Subsidiaritätsklausel, wie sie die Strafprozessordnung seit Inkrafttreten des OrgKG für einige Ermittlungsmaßnahmen enthält.

Ziel von Subsidiaritätsklauseln ist die Begrenzung des Einsatzes von Ermittlungsmaßnahmen, die mit besonders schwerwiegenden Eingriffen in grundrechtlich geschützte Bereiche verbunden sind. ${ }^{159}$ Sie bestimmen dabei ein Subsidiaritätsverhältnis. Ein solches Subsidiaritätsverhältnis ist gegeben, wenn die Zulässigkeit einer Prozesshandlung, namentlich einer Ermittlungsmaßnahme, dergestalt in eine Relation zu anderen, dem gleichen Zweck dienenden Prozesshandlungen gesetzt ist, dass sie gegenüber diesen anderen Prozesshandlungen unter bestimmten Voraussetzungen, den Subsidiaritätsbedingungen, nur nachrangig zulässig ist. ${ }^{160} \mathrm{Ge}-$ braucht wird die Subsidiaritätsklausel in der Strafprozessordnung stets in einer alternativen Form. Es wird sowohl auf den Ermittlungserfolg als auch auf die Erschwernis seiner Gewinnung abgestellt. ${ }^{161}$ Dabei variiert die Ausgestaltung der Subsidiaritätsklausel in den unterschiedlichen Ermittlungsmaßnahmen der Strafprozessordnung.

Diese gesetzliche Ausgestaltung birgt einige Schwierigkeiten. Das Gesetz schweigt, gegenüber welchen Ermittlungsmaßnahmen die Rasterfahndung im Wege der Subsidiarität zurückzutreten hat. Subsidiarität soll immer dann gegeben sein, wenn das Ermittlungsziel, die Erforschung des Sachverhalts oder die Ermittlung des Aufenthaltsortes eines Tatverdächtigen, „auf andere Weise“ erreicht werden kann. Isoliert betrachtet wäre die Rasterfahndung demnach gegenüber allen anderen Ermittlungsmaßnahmen subsidiär. ${ }^{162}$ Daher stellt sich die Frage, in welchem Verhältnis die Rasterfahndung zu anderen Ermittlungsmaßnahmen steht, die eben-

${ }^{157}$ Nack, in: Karlsruher Kommentar, § 110a Rn. 21; Bottke, in: Geppert/Denicke (Hrsg.), Gedächtnisschrift für Karlheinz Meyer, S.43.

158 Pfeiffer, § 98a Rn. 3.

${ }^{159}$ Rieß, in: Geppert/Denicke (Hrsg.), Gedächtnisschrift für Karlheinz Meyer, S.389.

160 Rieß, in: Geppert/Denicke (Hrsg.), Gedächtnisschrift für Karlheinz Meyer, S.368f.

161 Krüger, in: Fachhochschule Villingen-Schwenningen, Hochschule für Polizei (Hrsg.), Gedächtnisschrift für Hagen Gülzow, S.39.

162 Welp, in: Erichsen/Kollhosser/Welp (Hrsg.), Recht der Persönlichkeit, S.410. 
falls Subsidiaritätsklauseln enthalten. Um diese Frage beantworten zu können, muss zunächst untersucht werden in welchem Verhältnis die einzelnen Subsidiaritätsklauseln zueinanderstehen. In einem weiteren Schritt bedürfen auch die beiden Alternativen innerhalb der Subsidiaritätsklausel des $\S$ 98a I S.2 StPO im Hinblick auf ihren Inhalt und ihr Verhältnis zueinander einer eingehenden Betrachtung.

\section{Verhältnis der Subsidiaritätsklauseln in der Strafprozessordnung}

Wie bereits dargelegt enthält die Strafprozessordnung für einige Ermittlungsmaßnahmen Subsidiaritätsklauseln. Es ist zunächst festzustellen, dass die Strafprozessordnung bei der auf den Erfolg abstellenden Tatbestandsalternative innerhalb der Klauseln drei Grade der Erfolgsminderung unterscheidet. Im Einzelnen sind dies:

- Weniger erfolgversprechend (z.B. § 100c I S.1 StPO)

- Erheblich weniger erfolgversprechend (z.B. $\S \S 98$ a I S.2, 163e I S.2 StPO) und

- Aussichtslos (z.B. $§ \S 100 a$ I S.1, 110a I S.2 StPO)

Zwischen den erfolgsorientierten Begriffen ,,aussichtslos” und ,erheblich weniger erfolgversprechend" besteht offensichtlich ein graduelles Verhältnis dergestalt, dass die zweite Formulierung ein deutlich geringeres Maß an fehlender Erfolgswahrscheinlichkeit der vorrangigen Maßnahme verlangt. ${ }^{163}$ Ein solches Rangverhältnis ist auch zwischen den Formulierungen ,erheblich weniger erfolgversprechend“ und „weniger erfolgversprechend“ gegeben. Im Gegensatz zum erfolgsorientierten Subsidiaritätsmerkmal stellt die zweite Alternative auf die Erschwernis bei der Beweisgewinnung ab. Auch im Rahmen des erschwernisorientierten Subsidiaritätsmerkmals enthält die Strafprozessordnung in den einzelnen Subsidiaritätsklauseln unterschiedliche Ausgestaltungen. Dabei wird zwischen zwei Erschwernisgraden, namentlich zwischen ,erschwert“ und „wesentlich erschwert“, unterschieden. Es erscheint jedoch nicht frei von Schwierigkeiten, aus diesem begrifflichen Rangverhältnis der erfolgsorientierten und der erschwernisorientierten Alternativen auf ein generelles Rangverhältnis der Ermittlungsmaßnahmen zu schließen.

Für ein solches Rangverhältnis würde die gesetzliche Ausgestaltung sprechen. Diese indiziert ein solches Rangverhältnis durch die unterschiedlichen Subsidiaritätsbedingungen, die nach dem Gesetz als Stufenfolge sich abschwächender Voraussetzungen zu verstehen sind. ${ }^{164}$ Dies würde bedeuten, dass die mit den Subsidiaritätsklauseln ausgestalteten Ermittlungsmaßnahmen zueinander in einem Subsidiaritätsverhältnis stehen. Danach wäre die Unterscheidung der Klauseln in einfache,

163 Rieß, in: Geppert/Denicke (Hrsg.), Gedächtnisschrift für Karlheinz Meyer, S.383 f.

164 Welp, in: Erichsen/Kollhosser/Welp (Hrsg.), Recht der Persönlichkeit, S.411. 
qualifizierte und strenge Subsidiaritätsklauseln ${ }^{165}$ auch maßgeblich für die Subsidiarität der Ermittlungsmaßnahmen zueinander. Für ein solches Verhältnis könnte angeführt werden, dass sie sich gegenseitig blockieren würden, wenn sie nicht in einem definierbaren Rangverhältnis zueinanderstünden. ${ }^{166}$ Ähnlich sieht dies der Bundesgerichtshof in seiner Rechtsprechung. Für ihn stellt sich das gesetzliche System der Subsidiaritätsklauseln als fein abgestimmt dar. Darüber hinaus erklärt er im Hinblick auf Abgrenzungsschwierigkeiten, dass die Übergänge notwendigerweise fließend und eine eindeutige von den subjektiven Einschätzungen und Wertungen des zur Entscheidung Berufenen unabhängige Grenzziehung nicht möglich ist. ${ }^{167}$

Andererseits zeigt die Ausgestaltung verschiedener eingriffsintensiver Maßnahmen mit ähnlich strukturierten Klauseln, dass es dem Gesetzgeber nicht darum geht, innerhalb dieser Gruppe eine Rangordnung aufzustellen. ${ }^{168}$ Ferner ergeben sich erhebliche Ungereimtheiten, wenn man die begriffliche Ausgestaltung nicht isoliert betrachtet, sondern den gesamten Tatbestand der einzelnen Ermittlungsmaßnahmen in die Betrachtung mit einbezieht. ${ }^{169}$ So ist dem Gesetz bei der bisherigen sehr pauschalen Gestaltung der Subsidiaritätsklauseln keine konkrete Rangfolge der Befugnisnormen zu entnehmen. ${ }^{170}$ Eine abstrakte Einteilung würde ignorieren, dass jeder einzelne Eingriff aufgrund der jeweils unterschiedlichen Umstände, unter denen er stattfindet, von ganz unterschiedlicher Stärke und Grundrechtsrelevanz ist. ${ }^{171}$ Vielmehr muss hier der verfassungsrechtlich gebotene Grundsatz der Verhältnismäßigkeit, der im Gesetz bereits bei der Schaffung des Straftatenkatalogs beim Erfordernis einer Straftat von erheblicher Bedeutung und beim Subsidiaritätsgrundsatz Ausdruck gefunden hat, in jedem Einzelfall als zusätzliche einschränkende Voraussetzung beachtet werden. Dabei sind das konkrete strafrechtli-

\footnotetext{
165 So die Unterteilung in Nack, in: Karlsruher Kommentar, § 100c Rn. 6.

166 Rieß, in: Geppert/Denicke (Hrsg.), Gedächtnisschrift für Karlheinz Meyer, S.383 f.

167 BGHSt 41, 31, 34.

168 Schäfer, in: Löwe-Rosenberg, § 110a Rn. 31.

169 Bernsmann/Jansen, StV 1998, 222, der ein schlüssiges Beispiel für diese Ungereimtheiten anführt: „Die Rasterfahndung nach $\S 98$ a StPO hat einen mit $\S 110 \mathrm{a}$ StPO vergleichbaren, wenn auch umfassenderen Straftatenkatalog. Der erforderliche Verdachtsgrad ist derselbe. Aber: Die Rasterfahndung steht unter dem Richtervorbehalt (\$98a I S.1 StPO); sie ist insgesamt also strengeren Voraussetzungen unterworfen als der Einsatz Verdeckter Ermittler. Warum ist dann aber die Subsidiaritätsklausel großzügiger?““

170 Krüger, in: Fachhochschule Villingen-Schwenningen, Hochschule für Polizei (Hrsg.), Gedächtnisschrift für Hagen Gülzow, S.40f; Schäfer, in: Löwe-Rosenberg, § 110a Rn. 31; so auch Meyer-Goßner, ZRP 2000, 348, der einen tieferen Sinn oder ein System hinter den Differenzierungen bezweifelt.

171 Bernsmann/Jansen, StV 1998, 220.
} 
che Gewicht der jeweils zu verfolgenden Tat, das Maß des Tatverdachts und der erwartete Erfolg gegen die Intensität des Eingriffs abzuwägen. ${ }^{172}$

Im Einzelfall ist danach zu fragen, welche Maßnahme in concreto den milderen Eingriff darstellt. ${ }^{173}$ Daraus lässt sich erkennen, dass die Rasterfahndung zulässig sein kann, wenn die Aufklärung zwar mit Hilfe einer anderen Maßnahme erreicht werden könnte, diese jedoch tiefer in den persönlichen Bereich Betroffener eingreifen würde. ${ }^{174}$ Sollte jedoch auch dieser Maßstab nicht zu einer Klärung führen, so wird man wegen des Grundsatzes der freien Gestaltung des Ermittlungsverfahrens die Wahl zwischen den Maßnahmen und gegebenenfalls auch deren kumulierten Einsatz in das pflichtgemäße Ermessen der Strafverfolgungsbehörden zu stellen haben. ${ }^{175}$ Dem Gesetz kann jedoch die generelle Wertung entnommen werden, dass es sich bei den mit diesen Subsidiaritätsklauseln versehenen Eingriffsbefugnissen um solche handelt, die eine gegenüber den klassischen Eingriffsbefugnissen der StPO gesteigerte Eingriffsintensität aufweisen, weshalb zunächst nach Möglichkeit den klassischen Ermittlungsmaßnahmen aus Verhältnismäßigkeitsgründen der Vorzug gebührt. ${ }^{176}$

Daher kann festgehalten werden, dass zunächst die Ermittlungsmaßnahmen den Vorrang genießen, die über keine Subsidiaritätsklausel verfügen. ${ }^{177}$ Bezüglich der Ermittlungsmaßnahmen mit Subsidiaritätsklausel lässt sich festhalten, dass es der Gesetzgeber versäumt hat, sofern er dies überhaupt vorgehabt haben sollte, ein Rangverhältnis deutlich zu machen. Somit hat unter Anwendung des Verhältnismäßigkeitsgrundsatzes diejenige Maßnahme den Vorrang, durch die im konkreten Einzelfall der gleiche Erfolg mit „voraussichtlich“ weniger beeinträchtigenden Mitteln erreicht werden kann.

\section{Der Inhalt und das Verhältnis der beiden Alternativen innerhalb des $\$ 98$ I I S.2 StPO zueinander}

Um eine Aussage über das Verhältnis der beiden Tatbestandsalternativen der Subsidiaritätsklausel in $\S$ 98a I S.2 StPO zu treffen, muss zunächst deren Inhalt geklärt und eingeordnet werden. Die erste Alternative des $\S 98$ a I S.2 StPO besagt, dass die Erreichung des Ermittlungsziels „erheblich weniger erfolgversprechend“ sein muss. Hier ist eine am Aufklärungserfolg und den Aufklärungsschwierigkeiten

172 Schäfer, in: Löwe-Rosenberg, § 98a Rn. 31; Wittig, JuS 1997, S.969, welche die Subsidiaritätsklausel als Konkretisierung des Verhältnismäßigkeitsgrundsatzes ansieht.

173 Schäfer, in: Löwe-Rosenberg, § 110a Rn. 31.

174 BT-Drs. 12/989 S.37.

175 Rieß, in: Geppert/Denicke (Hrsg.), Gedächtnisschrift für Karlheinz Meyer, S.388f.

176 Schäfer, in: Löwe-Rosenberg, § 110a Rn. 31.

177 Rieß, in: Geppert/Denicke (Hrsg.), Gedächtnisschrift für Karlheinz Meyer, S.368f, so z.B.: Vernehmungen, Auskunftsersuchen, kriminalistische Untersuchungen etc. 
orientierte Betrachtung erforderlich. ${ }^{178}$ Ergibt diese, dass mit Hilfe anderer zur Verfügung stehender Ermittlungsmaßnahmen die vollständige Aufklärung der Straftat nicht annähernd in demselben Maße erreicht werden kann, wie dies mit einer Rasterfahndung möglich erscheint, so darf diese eingesetzt werden. ${ }^{179}$ Als erheblich weniger erfolgversprechend wird man die Aufklärung auf andere Weise dann anzusehen haben, wenn aufgrund kriminalistischer Erfahrungen bei Unterlassen der subsidiären Maßnahme ein deutliches Aufklärungsdefizit prognostiziert werden kann, wobei eine Ex-ante-Betrachtung zugrunde zu legen ist. ${ }^{180}$ Bedenkt man, dass es sich bei der Abschätzung des Beweiserfolges ohnehin um eine Prognose handelt, so verlangt die graduelle Unterscheidung nach der fehlenden Erfolgswahrscheinlichkeit ein geradezu unrealistisches Differenzierungsvermögen. ${ }^{181}$ Denn wollte man erreichen, dass der Richter bei Beschlussfassung eine richtige Prognose trifft, müsste er im Einzelnen in die Ermittlungen der Polizei eingebunden werden. ${ }^{182}$ Der Richter ist hier vollständig auf die Unterrichtung durch die ohnehin kriminaltechnisch und kriminalistisch überlegene Kriminalpolizei angewiesen und kann im Grunde nur deren Bewertung nachvollziehen. So kann jedoch von einer wirksamen richterlichen Kontrolle nicht mehr gesprochen werden. ${ }^{183}$

Bei der Untersuchung der zweiten Alternative stellt sich die Frage nach der inhaltlichen Bedeutung des Begriffs ,wesentlich erschwert“. Einigkeit besteht über die Erfolgsunabhängigkeit des Merkmals. Der begriffliche Inhalt des Merkmals ist jedoch noch nicht näher bestimmt worden. ${ }^{184}$ So wird verlangt, dass ein Vergleich des Verfahrensaufwandes, der einerseits mit der Durchführung einer Rasterfahndung und andererseits mit der Vornahme alternativer Ermittlungshandlungen verbunden wäre, durchzuführen sei. ${ }^{185}$ Teilweise wird lediglich auf den Zeitaufwand abgestellt. Von einer wesentlichen Erschwernis wäre danach auszugehen, wenn die Benutzung anderer Methoden einen erheblich größeren Zeitaufwand erfordern und daher zu einer erheblichen Verfahrensverzögerung führen würde. ${ }^{186}$ Allerdings ist im Interesse einer wirksamen Verbrechensbekämpfung bei der Sachverhaltserforschung auch das Beschleunigungsgebot (Art. 6 I MRK) zu beachten. ${ }^{187}$ Hieraus

178 Pfeiffer, § 98a Rn. 3; Nack, in: Karlsruher Kommentar, § 98a Rn. 14.

${ }^{179}$ Hilger, NStZ 1992, S.460.

${ }^{180}$ Rieß, in: Geppert/Denicke (Hrsg.), Gedächtnisschrift für Karlheinz Meyer, S.384.

181 Krüger, in: Fachhochschule Villingen-Schwenningen, Hochschule für Polizei (Hrsg.), Gedächtnisschrift für Hagen Gülzow, S.39.

182 Meyer-Goßner, ZRP 2000, 348.

${ }^{183}$ Lilie, ZStW 111 (1999), 815f.

184 Vgl. Rieß, in: Geppert/Denicke (Hrsg.), Gedächtnisschrift für Karlheinz Meyer, S.385, der eine gewisse Ratlosigkeit bei der inhaltlichen Bestimmung des Merkmals konstatiert.

185 Welp, in: Erichsen/Kollhosser/Welp (Hrsg.), Recht der Persönlichkeit, S.409.

186 Graf, S.97.

${ }^{187}$ Rieß, in: Löwe-Rosenberg, § 160 Rn. 38. 
ergibt sich die Amtspflicht zur Ausschöpfung der gesetzlichen Möglichkeiten zur zügigen Verfahrensdurchführung. ${ }^{188}$ In Anbetracht dessen lässt es sich jedoch auch vertreten, den Zeitfaktor dem Ermittlungserfolg und damit der erfolgsorientierten Alternative zuzuordnen. ${ }^{189}$ Durch eine solche Zuordnung würde jedoch dem Merkmal „,wesentlich erschwert" eine eigenständige Bedeutung genommen. ${ }^{190}$ Aus diesem Grund kann bei der Definition des Merkmals nicht ausschließlich auf den Zeitaufwand abgestellt werden. Mithin sind sowohl der erforderliche Zeitaufwand, als auch der Verfahrensaufwand bei der Subsumtion eines Sachverhalts unter das Merkmal „wesentlich erschwert“ heranzuziehen. Damit liegt eine wesentliche Erschwernis vor, wenn mit anderen Aufklärungsmitteln erheblich mehr Zeit aufgewendet werden müsste oder diese zu wesentlich schlechteren Erkenntnissen über die Tat führen würden. ${ }^{191}$

Zum Verhältnis der beiden Alternativen bleibt festzuhalten, dass das Gesetz keiner der beiden einen Vorrang vor der anderen einräumt. Soweit die erfolgsorientierte und die erschwernisorientierte Subsidiaritätsbedingung alternativ zur Verfügung stehen, ist es für die Zulässigkeit der Maßnahme letztlich gleichgültig, ob die begründenden Umstände schwerpunktmäßig der einen oder der anderen Alternative zugeordnet werden können. ${ }^{192}$ Für den Fall, dass nur eine der Alternativen in Betracht kommt, wird man allerdings eine restriktivere Interpretation anzuwenden haben. ${ }^{193}$ Im Ergebnis wird durch die Kopplung der alternativen Subsidiaritätsmerkmale nur eine sehr geringe Anwendungshürde für die Rasterfahndung errichtet. ${ }^{194}$ Der anordnende Richter unterliegt aufgrund der großen Beurteilungsspielräume kaum einer sinnvollen Kontrolle. Somit bleibt festzuhalten, dass der ohnehin bei jedem Grundrechtseingriff zu beachtende Verhältnismäßigkeitsgrundsatz, der - so zeigt es das Bundesverfassungsgericht - gut justitiabel ist, gut ebenso Grundrechtsschutz zu bieten in der Lage ist. ${ }^{195}$

\section{Die Mitwirkungspflicht der Speicherstelle}

Die Absätze 2 bis 5 des $\S 98$ a StPO enthalten Mitwirkungspflichten, deren Adressat nach dem Wortlaut die „speichernde Stelle“ ist. Bei der „speichernden Stel-

188 Rieß, in: Löwe-Rosenberg, Einl. G Rn. 33.

189 Rieß, in: Geppert/Denicke (Hrsg.), Gedächtnisschrift für Karlheinz Meyer, S.385.

190 Siebrecht, S.122.

${ }^{191}$ Schäfer, in: Löwe-Rosenberg, § 98a Rn. 29.

192 Rieß, in: Geppert/Denicke (Hrsg.), Gedächtnisschrift für Karlheinz Meyer, S.386.

${ }_{193}$ So auch Rie $\beta$, in: Geppert/Denicke (Hrsg.), Gedächtnisschrift für Karlheinz Meyer, S.386, der dies jedoch nur für die erfolgsorientierte Alternative fordert.

194 Krüger, in: Fachhochschule Villingen-Schwenningen, Hochschule für Polizei (Hrsg.), Gedächtnisschrift für Hagen Gülzow, S.40.

195 Bernsmann/Jansen, StV 1998, 223. 
le" kann es sich sowohl um eine private als auch um eine öffentliche Stelle handeln, welche die benötigten Daten gespeichert hat. ${ }^{196}$ Da die Stelle allerdings nicht handlungsfähig ist, kommen als Adressat der gesamten Pflichten nur der oder die Gewahrsamsinhaber in Betracht. ${ }^{197}$ Der $\S$ 98a II StPO verpflichtet die speichernde Stelle, die für den Abgleich erforderlichen Daten aus den Datenbeständen auszusondern und den Strafverfolgungsbehörden zu übermitteln. Diese Verpflichtung beinhaltet jedoch keine Ermächtigung, neue Daten zum Zwecke der vorgesehenen Rasterung zu erheben. ${ }^{198}$

Voraussetzung für die Übermittlung ist zunächst die Aussonderung. Diese wird auf der Grundlage der Suchanfrage durchgeführt. Anhand der Suchanfrage werden die Datenbestände nach bestimmten Zeichenketten, numerischen Werten oder anderen digitalisierten Informationen wie z.B. Bildern durchsucht. Diejenigen Informationen, die mit der Suchanfrage übereinstimmen, werden dann in einem zweiten Schritt zu einer separaten Datei zusammengefasst. ${ }^{199}$ Unter Aussonderung ist demnach die Zusammenfassung von Datensätzen, Dateien oder relevanten Teilen von Dateien, die herausgefiltert wurden, zu einer separaten Datei, durch die speichernde Stelle zu verstehen. ${ }^{200}$ Ausführungen dazu, wie die darauf folgende Übermittlung durchzuführen ist, sind dem Gesetz nicht zu entnehmen. Es ist davon auszugehen, dass die Übermittlung in Form von EDV - Daten erfolgt. Diese müssten wiederum in einem Datenformat exportiert und übermittelt werden, das dem Datenformat der abgleichenden Stelle entspricht. ${ }^{201}$

Darüber hinaus ist die Übermittlung durch die speichernde Stelle auf die benötigten Daten zu beschränken. ${ }^{202}$ Eine Ausnahme hierzu enthält § 98a III S.1 StPO. Sollten danach die zu übermittelnden Daten von anderen Daten nur mit unverhältnismäßigem Aufwand zu trennen sein, sind auf Anordnung auch die anderen Daten zu übermitteln. Voraussetzung ist eine entsprechende gesonderte richterliche oder bei Gefahr im Verzuge auch staatsanwaltschaftliche Anordnung nach $\S 98 \mathrm{~b} \mathrm{I}$ StPO. ${ }^{203}$ Die Nutzung dieser nicht benötigten Daten ist nach $\S 98$ a III S.2 StPO unzulässig. Stellt sich jedoch heraus, dass auch diese Daten für die Rasterfahndung benötigt werden, so ist eine ergänzende Anordnung im Sinne des $\S 98$ b StPO erforderlich. ${ }^{204}$

\footnotetext{
196 Schäfer, in: Löwe-Rosenberg, § 98a Rn. 32; Meyer-Goßner, § 98a Rn. 9.

${ }^{197}$ Rudolphi, in: Systematischer Kommentar, § 98a Rn. 14.

198 Schäfer, in: Löwe-Rosenberg, § 98a Rn. 32.

${ }^{199}$ Nack, in: Karlsruher Kommentar, § 98a Rn. 2.

${ }^{200}$ Nack, in: Karlsruher Kommentar, § 98a Rn. 19.

${ }^{201}$ So Nack, in: Karlsruher Kommentar, § 98a Rn. 20.

202 Meyer-Goßner, § 98a Rn. 9.

${ }^{203}$ Meyer-Goßner, § 98a Rn. 9.

${ }^{204}$ Schäfer, in: Löwe-Rosenberg, § 98a Rn. 33.
} 
Nach $\S 98 \mathrm{a}$ IV StPO hat die speichernde Stelle, auf Anforderung der Staatsanwaltschaft, die den Abgleich durchführende Stelle zu unterstützen. Als Unterstützungshandlung kommt etwa die Übersetzung der herauszugebenden Dateien in ein kompatibles Format oder die Ermöglichung des Zugriffs auf Daten, die aus Gründen des Datenschutzes oder zur Wahrung von Betriebsgeheimnissen verschlüsselt sind, in Betracht. Ferner müssen den Strafverfolgungsbehörden gegebenenfalls Hardware, Software, Passwörter, Spezialwissen und/oder Personal zur Verfügung gestellt werden. ${ }^{205}$

Im Rahmen der Änderungen durch das Gesetz zur Bekämpfung des illegalen Rauschgifthandels und anderer Erscheinungsformen der Organisierten Kriminalität vom 15. Juli $1992 \mathrm{kam}$ es auch zur Aufnahme des $\S$ 98a StPO in den $\S 17$ a I des Gesetzes über die Entschädigung von Zeugen und Sachverständigen (ZSEG). In der Gesetzesbegründung wurde es als angemessen erachtet, dass die Personen, die unter Benutzung ihrer eigenen oder einer fremden Datenverarbeitungsanlage die Strafverfolgungsbehörden unterstützen, unter bestimmten Voraussetzungen entschädigt werden. ${ }^{206}$ Demnach kann die Speicherstelle für ihre Mitwirkung, nach den Voraussetzungen des $\S 17$ a I ZSEG, eine Entschädigung verlangen.

Letztlich gilt nach $\S 98 \mathrm{a}$ V StPO der $\S 95$ II StPO entsprechend. Demnach können gegen die speichernde Stelle die Ordnungs- und Zwangsmittel des $§ 70$ StPO für den Fall festgesetzt werden, dass diese sich weigert, die sich aus $\S 98 \mathrm{a}$ II - IV StPO ergebenden Pflichten zu erfüllen. Wird unzulässig Zwang ausgeübt, so kann daraus ein Verwertungsverbot abgeleitet werden. ${ }^{207}$ Der $\S 95$ II S.2 StPO beinhaltet eine Ausnahme für die Personen, die zur Verweigerung des Zeugnisses berechtigt sind.

\section{Suchanfrage}

Voraussetzung für die Aussonderung der Daten durch die speichernde Stelle und die anschließende Übermittlung ist zunächst die Formulierung einer Suchanfrage. Diese enthält die Vorgaben der Strafverfolgungsbehörde, welche Daten benötigt werden. Dabei handelt es sich um die auf den Täter vermutlich zutreffenden Prüfungsmerkmale. ${ }^{208}$ Vom Begriff des Täters werden alle Täterschafts- und Teilnahmeformen der $\S \S 25 f f$. StGB erfasst. ${ }^{209}$ In der Regel betreffen die Prüfungsmerkmale den Vor- und Nachname, das Geburtsdatum, die Anschrift und zusätzliche

\footnotetext{
${ }^{205}$ Schäfer, in: Löwe-Rosenberg, § 98a Rn. 34.

${ }^{206}$ BT-Drs. 12/989, S.50; OLG Stuttgart, NStZ 2001, 159.

${ }^{207}$ Schäfer, in: Löwe-Rosenberg, § 98a Rn. 36; Rudolphi, in: Systematischer Kommentar, $\S 98$ a Rn. 18.

${ }^{208}$ Nack, in: Karlsruher Kommentar, § 98a Rn. 16.

${ }^{209}$ Hilger, NStZ 1992, S.461, Fn. 56.
} 
Unterscheidungsmerkmale. ${ }^{210}$ Aus diesen Kriterien setzt sich dass sog. Verdächtigenprofil zusammen. Letztlich muss in der Suchanfrage auch festgelegt werden, mit welchen logischen Operatoren die einzelnen Prüfungsmerkmale des Verdächtigenprofils miteinander verknüpft werden sollen. ${ }^{211}$ Es bleibt festzuhalten, dass im Rahmen der Suchanfrage festgelegt wird welche Daten erhoben werden. Sie ist Grundlage für die Aussonderung durch die speichernde Stelle und den anschließenden Datenabgleich. Die Effektivität der Rasterfahndung dürfte damit in ganz erheblichem Maße von der Formulierung der Suchanfrage abhängen.

\section{Den Datenabgleich durchführende Stelle}

Fraglich ist, welche Stelle den Datenabgleich durchzuführen hat. Den Vorschriften der StPO ist, darüber nichts zu entnehmen. § 98a II StPO spricht nur davon, dass die speichernde Stelle die Daten an die Strafverfolgungsbehörden zu übermitteln hat. Die Durchführung der Rasterfahndungsmaßnahme dürfte derjenigen Strafverfolgungsbehörde obliegen, die dazu technisch am ehesten in der Lage ist. ${ }^{212}$ Möglich erscheint aber auch ein Abgleich durch die Speicherstelle, im Rahmen der Unterstützungspflicht nach § 98a IV StPO, die Beauftragung eines Sachverständigen oder die Nutzung der Einrichtungen einer EDV-Firma. ${ }^{213}$

Die mit der Rasterfahndung betrauten Beamten müssen eine spezielle Ausbildung auf dem EDV-Sektor besitzen. Dazu zählen in erster Linie Kenntnisse über Aufbau und Funktionsweise einzelner EDV-Anlagen sowie Umgang mit der gebräuchlichsten Software. ${ }^{214}$ Ob diese Voraussetzungen bei Beamten der Staatsanwaltschaft gegeben sind, erscheint fraglich. Vielmehr wird, aufgrund der Ausstattung, die Durchführung der Rasterfahndung im Regelfall der Polizei obliegen. ${ }^{215}$ In Betracht kommt allerdings eine Überwachung durch die Staatsanwaltschaft. ${ }^{216}$ Allerdings müsste die Staatsanwaltschaft dazu auch technisch und personell in der Lage sein. ${ }^{217}$

\footnotetext{
210 Schäfer, in: Löwe-Rosenberg, § 98a Rn. 11.

${ }^{211}$ Nack, in: Karlsruher Kommentar, § 98a Rn. 16.

212 Bäumler, in: Lisken/Denninger (Hrsg.), Handbuch des Polizeirechts, J Rn. 264.

${ }^{213}$ So auch Nack, in: Karlsruher Kommentar, § 98a Rn. 24.

214 Bär, S.47.

215 So auch Graf, S.101.

${ }^{216}$ Nack, in: Karlsruher Kommentar, § 98a Rn. 24.

217 So fordert Siebrecht, S.127, „,dass um das Defizit an tatsächlicher Verfahrensherrschaft nicht größer werden zu lassen, die Staatsanwaltschaften personell und sachlich so auszustatten sind, dass sie den Datenabgleich im Rahmen einer Rasterfahndung selbst vornehmen beziehungsweise hinreichend kontrollieren können. Auf diese Weise wird die Staatsanwaltschaft in die Lage versetzt, selbständig die Möglichkeiten und Gefahren einer Rasterfahndung beurteilen zu können.“
} 


\section{F. Die Verfahrensvorschriften des § 98b StPO}

\section{Die Annordnungskompetenz gem. $§ 98 b$ I StPO}

Nach $\S 98$ b I S.1 StPO darf die Rasterfahndung grundsätzlich nur durch den Richter angeordnet werden. Zuständig für die Anordnung im Ermittlungsverfahren ist der Ermittlungsrichter $(\S \S 162,169) .{ }^{218}$ Tätig wird der Ermittlungsrichter nur auf Antrag der Staatsanwaltschaft. Nach Erhebung der öffentlichen Klage ist das mit der Sache befasste Gericht zuständig. Darüber hinaus hat nach $\S$ 98b I S.1 StPO die Staatsanwaltschaft die Möglichkeit bei „Gefahr im Verzug“ die Rasterfahndung direkt anzuordnen. Bei diesem Anordnungsmodell, das durch das duale System von Richtervorbehalt und Eilkompetenz der Staatsanwaltschaft gekennzeichnet ist, handelt es sich um ein Regel-Ausnahmeverhältnis, bei welchem der Richter die Erstzuständigkeit besitzt. ${ }^{219}$

Sinn und Zweck des Richtervorbehaltes ist es, einen Ausgleich dafür zu schaffen, dass in erheblicher Weise in Grundrechte von Bürgern eingegriffen wird und dieser Eingriff in der Regel erfolgt, ohne zuvor rechtliches Gehör zu gewähren. ${ }^{220}$ So zielt der Richtervorbehalt nach der Rechtsprechung des Bundesverfassungsgerichts zur Durchsuchung im Sinne des Art. 13 II GG auf Kontrolle durch eine unabhängige und neutrale Instanz, der das Grundgesetz aufgrund ihrer persönlichen und sachlichen Unabhängigkeit und strikter Unterwerfung unter das Gesetz zuschreibt, die Rechte des Betroffenen im Einzelfall am besten wahrnehmen zu können. ${ }^{221}$ Es bestehen wenig Bedenken, die Ausführungen des Bundesverfassungsgerichts zur Sicherung des präventiven Rechtsschutzes auf gleichgeartete Ermittlungseingriffe zu übertragen. ${ }^{222}$ Allein in der Begründung der Übertragbarkeit bestehen unterschiedliche Auffassungen. ${ }^{223}$

\section{Umfang der Prüfung und Entscheidungsgrundlage}

Aus der Funktion des Richtervorbehalts folgt, dass der Richter im Ermittlungsverfahren ausschließlich die Rechtmäßigkeit der von der Staatsanwaltschaft gem. $\S 162$ StPO beantragten Anordnung der Rasterfahndung zu prüfen hat. ${ }^{224}$ Dagegen

\footnotetext{
218 Schäfer, in: Löwe-Rosenberg, § 98b Rn. 2.

219 Schnarr, NStZ 1991, $210 f$.

${ }^{220}$ Schäfer, in: Löwe-Rosenberg, § 98b Rn. 3.

221 BVerfG, NJW 2002, 1333.

222 So Amelung, NStZ 2001, 342f.

${ }^{223}$ So sieht Amelung, NStZ 2001, 342f. den Richtervorbehalt primär als präventiven Rechtsschutz für den faktisch unanwendbaren Art. 19 IV GG an; Nelles, S. 57, ist der Ansicht, dass sich der Richtervorbehalt als Rechtsschutsgarantie für den Betroffenen erklärt. Eines Umweges über Art19 IV GG bedarf es daher nicht.

${ }^{224}$ Rudolphi, in: Systematischer Kommentar, § 98b Rn. 4.
} 
darf der Ermittlungsrichter nicht die Notwendigkeit, die Zweckmäßigkeit und die Angemessenheit des Antrags der Staatsanwaltschaft nach $\S 162$ III StPO prüfen. ${ }^{225}$ Somit ist die Entscheidung, ob die Maßnahme ermittlungstaktisch geboten ist, im Aufgabengebiet der Staatsanwaltschaft $\mathrm{zu}$ sehen. Ob eine eingriffsintensivere Maßnahme getroffen werden soll, wenn auch eine andere erfolgversprechend erscheint, ist dagegen eine Frage der Verhältnismäßigkeit, die der Richter zu prüfen hat, und nicht eine Frage der Ermittlungstaktik. ${ }^{226}$ Dabei ist gegeneinander abzuwägen, wie stark durch die Ermittlungshandlung einerseits Grundrechte beeinträchtigt werden können, und andererseits, welche Bedeutung die öffentlichen Belange haben, die zur Beantragung der richterlichen Entscheidung geführt haben. ${ }^{227}$

\section{Anforderungen an Form und Inhalt der Anordnung}

Die Anforderungen an die Form der Anordnung legt $\S 98 b$ I S.4 StPO fest. So bedarf die Anordnung der Rasterfahndung der Schriftform. Bei Anordnung durch Fax, Telegramm oder E-Mail ist das Formerfordernis gewahrt. ${ }^{228}$ Auch die Verwendung von Formularen bei der Abfassung der Entscheidungsbegründung ist grundsätzlich nicht zu beanstanden. ${ }^{229}$

Aussagen über den Inhalt der Anordnung trifft $\S 98$ b I S.5 StPO. Danach muss die Anordnung zunächst den zur Übermittlung Verpflichteten, also den Verantwortlichen der Speicherstelle, beinhalten. Dabei empfiehlt es sich, die betreffende Person genau zu bezeichnen, da dieses Vorgehen den möglicherweise notwendigen Einsatz von Zwangsmitteln nach $§ 98 \mathrm{~b}$ II StPO erleichtert. ${ }^{230}$ Das Herausgabeverlangen richtet sich folglich gegen die Inhaber der tatsächlichen Sachherrschaft. Eine lediglich an die juristische Person gerichtete Anordnung ist als Aufforderung an die vertretungsberechtigten Organe umzudeuten. ${ }^{231}$

Des Weiteren ist die Anordnung auf die unbedingt benötigten Daten und Rasterkriterien, die genau zu bezeichnen sind, zu beschränken. ${ }^{232}$ So verlangt § 98b I S.4 StPO bei der Formulierung der betroffenen Daten größtmögliche Präzision. Dies liegt sowohl im Interesse der Ermittlungen, die nur dann sinnvolle Ergebnisse erbringen können, wenn die Ermittlungsansätze genau formuliert und datenverar-

\footnotetext{
225 OLG Düsseldorf, NStZ 1990, 144.

226 Schäfer, in: Löwe-Rosenberg, § 98 Rn. 16.

227 OLG Düsseldorf, NStZ 1990, 144.

228 Nack, in: Karlsruher Kommentar, § 100b Rn. 2.

229 Graf, S. 105.

230 Rudolphi, in: Systematischer Kommentar, § 98b Rn. 8.; Nack, in: Karlsruher Kommentar, §98b Rn. 3.

231 Schäfer, in: Löwe-Rosenberg, § 98b Rn. 11.

232 Hilger, NStZ 1992, S.461.
} 
beitungstechnisch umgesetzt werden, als auch der Schonung Dritter. ${ }^{233}$ So hat der Anordnende auf Grund der ihm vorliegenden Unterlagen zu prüfen, welche Prüfungsmerkmale im Einzelfall für die Rasterung benötigt werden. ${ }^{234}$ Da die Festlegung auf bestimmte Rastermerkmale jedoch unter anderem auch ermittlungstaktische Gesichtspunkte betrifft, kann der anordnende Ermittlungsrichter den Umfang der Maßnahme nur einschränken, wenn sie die vom Übermaßverbot gezogenen Grenzen überschreitet. ${ }^{235}$ Der Grund dafür liegt darin, dass dem Ermittlungsrichter eine Zweckmäßigkeitskontrolle nicht zusteht. ${ }^{236}$ Darüber hinaus sind die allgemeinen Anforderungen eines richterlichen Beschlagnahmebeschlusses zu beachten, insbesondere die Bezeichnung des Anordnungszwecks und der Tat, auf Grund derer die Rasterfahndung angeordnet wird. ${ }^{237}$

\section{Die Eilkompetenz der Staatsanwaltschaft nach § 98b I S.1 StPO}

Bei Gefahr im Verzug ist an Stelle des Richters, auch die Staatsanwaltschaft zur Anordnung der Rasterfahndung befugt. Diese Notkompetenz soll verhindern, dass durch die zeitraubende Einholung der richterlichen Entscheidung die Erfolgsaussichten des strafprozessualen Grundrechtseingriffs verloren gehen. ${ }^{238}$ Vom Ausdruck Staatsanwaltschaft sind sowohl die Bundesanwälte, die Staatsanwälte und die Amtsanwälte umfasst ( $§ 142$ I GVG). ${ }^{239}$ Anders als etwa bei der Beschlagnahme ( $§ 98$ StPO) und der Durchsuchung ( $\$ 105$ StPO) ist eine Anordnung durch Hilfsbeamte der Staatsanwaltschaft jedoch ausgeschlossen. ${ }^{240}$

Voraussetzung für die Möglichkeit, die Eilkompetenz wahrzunehmen, ist das Vorliegen von Gefahr im Verzug. Dies bedeutet, dass der Erfolg der Maßnahme durch die Verzögerung, welche die Erwirkung der richterlichen Entscheidung mit sich bringen würde, gefährdet wäre. ${ }^{241}$ Die bloße Möglichkeit eines Beweismittelverlustes genügt nicht. ${ }^{242}$ Maßgebend ist eine objektive Prognose auf der Basis der im Zeitpunkt des Einschreitens nach dem Stand der Ermittlungen bekannten Tatsachen. ${ }^{243}$ Dabei ist einerseits aufgrund des Grundrechtseingriffs der Begriff der Gefahr im Verzuge eng

233 Bäumler, in: Lisken/Denninger (Hrsg.), Handbuch des Polizeirechts, J Rn. 277.

${ }^{234}$ Hilger, NStZ 1992, S.461.

235 Siebrecht, S.130.

236 Siehe vorhergehender Abschnitt 1. Teil F.II.

${ }^{237}$ Nack, in: Karlsruher Kommentar, § 98b Rn. 3.

${ }^{238}$ Rudolphi, in: Systematischer Kommentar, vor $\S 94$ Rn. 77.

${ }^{239}$ Schäfer, in: Löwe-Rosenberg, § 98 Rn. 30.

${ }^{240}$ Schäfer, in: Löwe-Rosenberg, § 98b Rn. 4; Nack, in: Karlsruher Kommentar, § 98b Rn. 1.

${ }^{241}$ Schäfer, in: Löwe-Rosenberg, § 98b Rn. 5.

${ }^{242}$ Nack, in: Karlsruher Kommentar, § 98 Rn. 14.

${ }^{243}$ Rudolphi, in: Systematischer Kommentar, § 98 Rn. 10. 
auszulegen, andererseits ist aber auch der Zweck der Einräumung einer Eilkompetenz, also die Abwendung eines Beweismittelverlustes, zu berücksichtigen. ${ }^{244}$ Allerdings erscheint eine Sachverhaltskonstellation, in welcher ein drohender Beweismittelverlust im Rahmen einer Rasterfahndung durch die Nutzung der staatsanwaltschaftlichen Eilkompetenz abgewendet werden kann, kaum möglich. So ist die Rasterfahndung eine Ermittlungsmethode, die schon begrifflich als überhastete Eilmaßnahme kaum in Betracht kommt. Ihre Vorbereitung dürfte in aller Regel so viel Zeit beanspruchen, dass auch die Einschaltung des Richters noch möglich ist. ${ }^{245}$

Hat die Staatsanwaltschaft ihre Notkompetenz dennoch wahrgenommen und die Rasterfahndung selbst angeordnet, bedarf die Anordnung nach $\S$ 98b I S.2 StPO einer unverzüglich richterlichen Bestätigung. Unverzüglich heißt, dass der Antrag zu stellen ist, sobald dies möglich ist, unabhängig davon, wie weit bis dahin die Durchführung der Rasterfahndung gediehen ist. ${ }^{246}$ Nach $\S 98 \mathrm{~b}$ I S.3 StPO muss die richterliche Bestätigung innerhalb von drei Tagen erfolgen, da die Anordnung ansonsten außer Kraft tritt. Dies geschieht auch dann, wenn die Verzögerung von den Strafverfolgungsprozessen nicht verschuldet ist. ${ }^{247}$ Die Frist beginnt mit der staatsanwaltlichen Anordnung und nicht mit dem Beginn der Maßnahme zu laufen. ${ }^{248}$ Dabei ist der Tag der Anordnung nach $\S 42$ StPO allerdings nicht mitzurechnen. Auf die richterliche Bestätigung kann verzichtet werden, wenn der Aufklärungserfolg zwischenzeitlich anderweitig erreicht wurde. ${ }^{249}$

Ausgeschlossen ist die Eilkompetenz der Staatsanwaltschaft nach § 98b I S.5 StPO, wenn Daten übermittelt und gerastert werden sollen, die sich in den in $\S 98$ I S.2 StPO genannten Räumen befinden. Hier gilt nur die richterliche Anordnungskompetenz.

\section{Die richterliche Überprüfung der Eilanordnung}

In seiner Bestätigungsentscheidung entscheidet das Gericht in der Regel über die Rechtmäßigkeit der durch die Staatsanwaltschaft angeordneten Maßnahme und über die Fortdauer der Maßnahme. ${ }^{250}$ Die verspätete Bestätigung gilt als neue richterliche Anordnung, die mit dem Zeitpunkt des Eingangs bei der speichernden Stel-

244 Schäfer, in: Löwe-Rosenberg, vor § 94 Rn. 127.

245 Bäumler, in: Lisken/Denninger (Hrsg.), Handbuch des Polizeirechts, J Rn. 279; so auch Siebrecht S.132f. nach dessen Ansicht, die Rasterfahndung, aufgrund der erforderlichen Vorlaufzeit ohnehin nicht ad hoc durchgeführt werden kann und somit der Fall eines besonderen Eilbedürfnisses, das die Einholung einer richterlichen Entscheidung nicht zulassen würde, schwer vorstellbar sei.

246 Bäumler, in: Lisken/Denninger (Hrsg.), Handbuch des Polizeirechts, J Rn. 280.

${ }^{247}$ Rudolphi, in: Systematischer Kommentar, § 98b Rn. 6.

${ }^{248}$ Schäfer, in: Löwe-Rosenberg, § 98b Rn. 6.

${ }^{249}$ Nack, in: Karlsruher Kommentar, 3 98b Rn. 2.

${ }^{250}$ Schäfer, in: Löwe-Rosenberg, § 98b Rn. 6a. 
le wirksam wird. ${ }^{251}$ Strittig war bislang, ob auch die Annahme von Gefahr im Verzuge einer richterlichen Überprüfung unterliegt. So konnte nach überwiegender Meinung eine Überprüfung des Vorliegens von Gefahr im Verzuge unterbleiben. Begründet wurde dies damit, dass der Betroffene keinen Anspruch auf die Feststellung habe, dass die richterliche Anordnung rechtswidrig war. ${ }^{252}$ Dies würde jedoch bedeuten, dass die fehlerhafte Annahme von Gefahr im Verzuge keinerlei Einfluss auf die Verwertung eines so erlangten Beweismittels hätte. Dadurch würde es aber der Strafverfolgungsbehörde geradezu erleichtert Gefahr im Verzuge anzunehmen. ${ }^{253}$

Fraglich erscheint, ob diese Ansicht dem Rechtsschutzbedürfnis des Betroffenen ausreichend Rechnung trägt. ${ }^{254}$ Nach der durch die neuere Rechtsprechung des Bundesverfassungsgerichts und des Bundesgerichtshofs geschaffenen Rechtslage kann die bisher herrschende Meinung, nach welcher der Richter nicht das Vorliegen von Gefahr im Verzuge zu überprüfen hatte, nicht aufrechterhalten werden. Da die richterliche Überprüfung dem Ausgleich dafür dient, dass der Richtervorbehalt und damit der präventive Rechtsschutz nicht greifen konnten, erfolgt eine umfassende Rechtsüberprüfung dahin, ob die aufgrund der Eilkompetenz getroffene Maßnahme rechtmäßig war und ob auch im Zeitpunkt der richterlichen Entscheidung die Voraussetzungen noch vorliegen. ${ }^{255}$ Letztlich wurde gegen die Überprüfung des Vorliegens von Gefahr im Verzuge angeführt, dass nur derjenige, dem die Anordnung bei Gefahr im Verzuge anvertraut sei, ermessen könne, ob der durch Anrufung des Richters herbeigeführte Zeitverlust den Erfolg der Maßnahme beeinträchtigen könnte. ${ }^{256}$ Dem kann jedoch entgegengehalten werden, dass die mit dem Merkmal Gefahr im Verzuge geforderte objektive Prognose jeder und vor allem auch der Richter nachträglich treffen kann, sofern er sich nur in die Person des anordnenden Amtsträgers hineinversetzt. ${ }^{257}$

Vor dem Hintergrund, dass nun auch der Begriff Gefahr im Verzuge der richterlichen Überprüfung unterliegt, bleibt zu untersuchen, in welchem Umfang die Überprüfung möglich ist und wie sich die falsche Annahme des Vorliegens von Gefahr im Verzuge durch die Staatsanwaltschaft auf die Verwertbarkeit gewonnener Erkenntnisse auswirkt. Dafür ist zunächst näher auf die Rechtsnatur des Begriffs der Gefahr im Verzuge einzugehen. Als Voraussetzung für die entsprechende Kompetenz der Staatsanwaltschaft ist der Begriff auf der Tatbestandsseite der Norm angesiedelt. Schon deshalb ist er ermessens- und beurteilungsfeindlich und

\footnotetext{
${ }^{251}$ Schäfer, in: Löwe-Rosenberg, § 98b Rn. 6a.

${ }^{252}$ Graf, S.104.

253 Siebrecht, S.133.

${ }^{254}$ So Rudolphi, in: Systematischer Kommentar, § 98 Rn. 31.

255 Schäfer, in: Löwe-Rosenberg, § 98 Rn. 53.

256 Erstmals RGSt 23, 334; BGH JZ 1962, 610.

${ }^{257}$ Rudolphi, in: Systematischer Kommentar, § 98 Rn. 11.
} 
kann nur unbestimmter Rechtsbegriff sein. ${ }^{258}$ Als solcher unterliegt er in vollem Umfang gerichtlicher Überprüfung. ${ }^{259}$

Kann eine Bestätigung nicht erfolgen, weil Gefahr im Verzug zu Unrecht angenommen worden war, liegen aber jetzt die Voraussetzungen einer Rasterfahndung im Übrigen vor und beantragt die Staatsanwaltschaft deren Fortdauer, hebt das Gericht die staatsanwaltschaftlich angeordnete Maßnahme auf und erlässt einen neuen Beschluss ex nunc, bei dem es inhaltlich nicht an die staatsanwaltschaftliche Eilmaßnahme gebunden ist. ${ }^{260}$ Es bleibt die Frage, ob die bis zum Erlass des neuen Beschlusses erlangten Erkenntnisse einem Beweisverwertungsverbot unterliegen. Nach der überkommenen Auffassung, die bis zum Urteil des Bundesverfassungsgerichts zur Durchsuchung Bestand hatte, hätte die falsche Annahme von Gefahr im Verzuge keinen Einfluss auf die Verwertbarkeit der gewonnenen Daten gehabt. ${ }^{261}$ Dies hat so jedoch keinen Bestand mehr. Grundsätzlich gilt für die aufgrund der fälschlichen Annahme von Gefahr im Verzuge erlangten Daten ein Beweisverwertungsverbot. ${ }^{262}$ Dagegen unterliegen Erkenntnisse, die aufgrund zunächst zulässiger Rasterfahndung gewonnen worden sind, keinem Verwertungsverbot, sofern die Bestätigung unterbleibt oder versagt wird, weil die Voraussetzungen nicht mehr vorliegen oder die Maßnahme sich zwischenzeitlich erledigt hat, etwa weil der Täter ermittelt wurde. ${ }^{263}$

Im Ergebnis bleibt festzuhalten, dass die Änderung der Rechtsprechung des Bundesverfassungsgerichts und des Bundesgerichtshofes zur Durchsuchung auch erhebliche Auswirkungen auf andere Ermittlungsmaßnahmen gehabt hat. So hat sich im Rahmen der Rasterfahndung insbesondere der Streit über die Überprüfbarkeit des Begriffs der Gefahr im Verzuge durch den Ermittlungsrichter erledigt.

\section{Anordnungsverbote}

In den Sätzen 6 und 7 enthält $\S 98 b$ StPO einige Anordnungsverbote, die bestimmte Daten betreffen. So darf nach $\S 98$ b S.6 StPO die Übermittlung von Daten, deren Verwendung besondere bundesgesetzliche oder entsprechende landesgesetzliche Verwendungsregelungen entgegenstehen, nicht angeordnet werden. Hier handelt es sich etwa um besondere Amts- und Berufsgeheimnisse, sonstige spezialgesetzliche Verwendungs-, aber auch Übermittlungsverbote, die einen erhöhten

\footnotetext{
${ }^{258}$ Nelles S.299f; so auch Rudolphi, in: Systematischer Kommentar, § 98 Rn. 11.

259 Schäfer, in: Löwe-Rosenberg, § 98 Rn. 37.

${ }^{260}$ Schäfer, in: Löwe-Rosenberg, § 98b Rn. 6a.

${ }^{261}$ Siehe zum Urteil des BVerfG auch: 1. Teil, F.I.

262 Schäfer, in: Löwe-Rosenberg, § 98b Rn. 29.

${ }^{263}$ Lemke, in: Heidelberger Kommentar, § 98b Rn. 6.
} 
Schutz personenbezogener Daten bewirken sollen. ${ }^{264}$ Hierzu gehören insbesondere Daten, die dem Steuer-, Sozial-, Post- oder dem Fernmeldegeheimnis unterliegen. ${ }^{265}$ Beispielhaft sind hier $\S 51$ BRZG, $\S 85$ TKG, § 39 PostG, $§ 35$ SGB I, $\S$ 67 ff. SGB X, § 16 BStatG und $\S 30$ AO zu nennen.

Nach $\S 98 b$ I S.7 StPO ist $\S 96$ StPO im Rahmen der Rasterfahndung entsprechend anzuwenden. So braucht die zuständige Behörde Daten auch auf richterliche Anordnung hin nicht vorzulegen, wenn es sich um Datenbestände handelt, bei deren Bekanntgabe nach der Erklärung der zuständigen obersten Dienstbehörde dem Wohl des Bundes oder eines deutschen Landes Nachteile entstehen würden. Eine solche Sperrerklärung soll nur unter engen formellen und materiellen Voraussetzungen möglich sein, da sie als Einflussnahme einer Behörde auf ein Strafverfahren einen Eingriff in den Gang der Rechtspflege darstellt. ${ }^{266}$

Ferner darf nach § 98b I S.7 StPO in Verbindung § 98 I S.2 StPO die Übermittlung von Daten aus Räumen einer Redaktion, eines Verlages, einer Druckerei oder einer Rundfunkanstalt nur durch einen Richter angeordnet werden. Insoweit besteht folglich keine Eilkompetenz der Staatsanwaltschaft. So soll der grundrechtlich besonders sensible Bereich der Presse und insbesondere dessen erhöhte Störanfälligkeit geschützt werden. ${ }^{267}$ Letztlich verweist $§ 98$ b I S.7 StPO auf die $\S \S 96,97,98$ I S.1 StPO. Greift nach diesen Vorschriften ein Beschlagnahmeverbot ein, so entfällt bereits die Herausgabepflicht bezüglich der Daten. ${ }^{268}$ Im Rahmen dessen ist strittig, ob das Übermittlungsverbot dann nicht gilt, wenn ein Zeugnisverweigerungsberechtigter durch freiwillige Herausgabe auf das Beschlagnahme- und Verwertungsverbot verzichtet. Die Verwendung so erlangter Daten ist nach herrschender Meinung möglich. ${ }^{269}$ Die dafür unter anderem angeführte Begründung, es sei Sache des Zeugnisverweigerungsberechtigten, darüber zu entscheiden, ob er nach Abwägung widerstreitender Interessen sich zur Aussage entschließt, überzeugt jedoch nur wenig. ${ }^{270}$ Vielmehr kann in einem solchen Vorgehen ein Widerspruch zum rechtsstaatlichen Verfahren gesehen werden, da die Strafverfolgungsorgane einen Zeugnisverweigerungsberechtigten $\mathrm{zu}$ einem rechtswidrigen Geheimnisbruch veranlassen oder dabei unterstützen und dann die dadurch erlangten Beweismittel und Kenntnisse zum Nachteil des in seinen Grundrechten verletzten Beschuldigten verwenden. ${ }^{271}$

\footnotetext{
${ }^{264}$ Lemke, in: Heidelberger Kommentar, § 98b Rn. 4.

${ }^{265}$ Nack, in: Karlsruher Kommentar, § 98a Rn. 30.

266 Pfeiffer, § 96 Rn. 1.

267 Schäfer, in: Löwe-Rosenberg, § 98 Rn. 7.

${ }^{268}$ Rudolphi, in: Systematischer Kommentar, § 98a Rn. 15.

${ }^{269}$ So Schäfer, in: Löwe-Rosenberg, § 97 Rn. 55; Müller, in: Kleinknecht/Müller/ Reitberger, § 97 Rn. 24.

270 Z.B. von Schäfer, in: Löwe-Rosenberg, § 97 Rn. 55 als Argument angeführt.

${ }^{271}$ So Rudolphi, in: Systematischer Kommentar, § 97 Rn. 29.
} 
In die Betrachtung dieser Konfliktlage ist auch der Zweck des § 97 StPO mit einzubeziehen. Dieser dient dazu, die Umgehung des Zeugnisverweigerungsrechts, wie es sich aus $\S 53$ StPO ergibt, zu verhindern. ${ }^{272}$ Das Zeugnisverweigerungsrecht hat wiederum den Schutz des Vertrauensverhältnisses zwischen bestimmten Berufsangehörigen und denen, die ihre Hilfe und Sachkunde in Anspruch nehmen, zum Gegenstand. ${ }^{273}$ Im Rahmen des Zeugnisverweigerungsrechts ist darüber hinaus auch $\S 203$ StGB zu beachten. Dieser schützt zum einen das verfassungsrechtlich aus Art 2 I GG in Verbindung mit Art. 1GG abgeleitete Recht auf informationelle Selbstbestimmung und zum anderen das allgemeine Vertrauen in die Verschwiegenheit der Angehörigen bestimmter Berufe. ${ }^{274}$ Zumindest für den in $\S 203$ StGB genannten Personenkreis muss daher gelten, dass eine freiwillige Übermittlung von Daten, bezüglich derer eine Schweigepflicht besteht, nicht in Betracht kommen darf. ${ }^{275}$ Andernfalls würden sich diese Personen in einem kaum zu lösenden gesetzlichen Konflikt befinden, da sie einerseits zur Übermittlung verpflichtet werden könnten, sich aber gleichzeitig nach $§ 203$ StGB strafbar machen würden. Vor diesem Hintergrund und zum Schutz des Betroffenen kann eine freiwillige Herausgabe von Datenbeständen, die einem Beschlagnahmeverbot unterliegen, nicht in Betracht kommen. ${ }^{276}$

\section{Benachrichtigungspflichten}

$\S 98 b$ IV StPO beinhaltet Benachrichtigungspflichten, denen nach Durchführung der Rasterfahndung nachzukommen ist. Nach $\S 98 \mathrm{~b}$ IV S.1 StPO sind die durch die Rasterfahndung betroffenen Personen und nach § 98b IV S.2 StPO die Datenschutzbeauftragten zu benachrichtigen.

\section{Benachrichtigung der Betroffenen}

Bezüglich der Benachrichtigung der von der Rasterfahndung betroffenen Personen enthält $\S 98 b$ IV S.1 StPO einen Verweis auf $\S 163 d$ V StPO. Der $\S 163 d$ V StPO stellt eine so genannte Transparenzvorschrift dar. ${ }^{277}$ Danach sind die Betroffenen nach der Auswertung der Rasterfahndung zu benachrichtigen. Beschränkt wird die Benachrichtigungspflicht nach $\S 163 \mathrm{~d}$ V StPO auf die Personen, gegen die nach Auswertung der Daten weitere Ermittlungen geführt worden sind. Bei den

\footnotetext{
272 Pfeiffer, § 97 Rn. 1.

273 Meyer-Goßner, § 53 Rn.1.

274 Lenckner, in: Schönke/Schröder, § 203 StGB Rn. 3.

275 So auch Bäumler, in: Lisken/Denninger (Hrsg.), Handbuch des Polizeirechts, J Rn. 292.

276 Siebrecht, S.131 kommt ebenfalls zu diesem Ergebnis.

277 Pfeiffer, § 163d Rn. 7.
} 
weiteren Ermittlungen soll es sich um Ermittlungen konventioneller Art handeln. ${ }^{278}$ Als solche kommen beispielsweise die Vernehmung, die Anordnung oder der Vollzug von Zwangsmaßnahmen, Durchsuchungen, aber auch Nachforschungen im Umfeld der Person oder die bloße Einholung von Auskünften über sie in Betracht. ${ }^{279}$ Nicht benachrichtigt zu werden brauchen demnach alle Personen, deren Daten schon aufgrund der Auswertung gelöscht werden, weil sie weder als Verdächtige noch sonst als Beweisperson in Betracht kommen. ${ }^{280}$ Die Unterrichtung dieser Personen wird als zu aufwendig und nicht sinnvoll erachtet. ${ }^{281}$ Diesbezüglich bestehen allerdings verfassungsrechtliche Bedenken. ${ }^{282}$

Fraglich ist, inwieweit Personen, die als Merkmalsträger herausgerastert worden sind, der Benachrichtigungspflicht unterliegen. Um den Umfang einzugrenzen, muss der Zweck der Benachrichtigungspflicht betrachtet werden. Diese soll zum einen den Anspruch des Betroffenen auf rechtliches Gehör gewährleisten und zum anderen das Recht auf informationelle Selbstbestimmung garantieren. ${ }^{283}$ Mithin wird der Benachrichtigungspflicht auch ein selbstdisziplinierender Effekt zugeschrieben. ${ }^{284}$ Der mit ihr verbundene Verwaltungsaufwand soll der Behörde die Intensität ihres Grundrechtseingriffs vor Augen führen. ${ }^{285}$

Die Benachrichtigungspflicht bezieht sich auf Personen, bei denen die Auswertung tatsächlich einen Anfangsverdacht ergeben hat, der dann aber nicht erhärtet werden konnte. ${ }^{286}$ Für den Fall, dass sich der Anfangsverdacht erhärtet hätte, wären die Betroffenen als Beschuldigte ohnehin in der ersten Vernehmung unterrichtet worden ( $\S \S 136 \mathrm{StPO})$. Es bleibt festzuhalten, dass sich die Benachrichtigungspflicht grundsätzlich auf alle herausgerasterten Merkmalsträger beziehen sollte. Diesen sollte zumindest mitgeteilt werden, welche fahndungsrelevanten Vorgänge ihre Person betreffend durchgeführt worden sind und wie mit ihren personenbezogenen Daten weiter verfahren wurde. ${ }^{287}$ Darüber hinaus sollten die Betroffenen darüber unterrichtet werden, bei welcher Speicherstelle die Daten ausgesondert, welche Prüfungsmerkmale gerastert wurden und welche Stelle im Besitz der Daten

\footnotetext{
278 BT-Drs. 12/989, S.38.

279 Rieß, in: Löwe-Rosenberg, § 163d Rn. 79.

${ }^{280}$ Rieß, in: Löwe-Rosenberg, §163d Rn. 78.

${ }^{281}$ Schoreit, in: Karlsruher Kommentar, § 163d Rn. 44.

${ }^{282}$ So sieht Achenbach, in: Wassermann (Hrsg.), Kommentar zur Strafprozessordnung, $\S 163 d$ Rn. 29, in der ausbleibenden Unterrichtung von Personen, gegen die sich kein Tatverdacht ergeben hat, unabhängig davon, ob und in welcher Datei Daten weiterhin gespeichert sind, einen Verstoß gegen den grundrechtlich gewährleisteten Anspruch auf rechtliches Gehör (Art. 19 IV GG).

283 Siebrecht, S.140.

284 Graf, S.110.

285 Siebrecht, S.141; Graf, S.140.

286 Bäumler, in: Lisken/Denninger (Hrsg.), Handbuch des Polizeirechts, J Rn. 441.

287 So schon Wanner, S.227; Graf, S.110.
} 
war bzw. noch ist. ${ }^{288}$ An die Form der Benachrichtigung sind keine Anforderungen zu stellen. Sie ist formfrei, so dass sie im Rahmen einer Vernehmung erfolgen kann. Allerdings ist die Benachrichtigung aktenkundig zu machen. ${ }^{289}$ Empfehlenswert ist jedoch die Schriftform. ${ }^{290}$ Die Benachrichtigung muss darüber hinaus keine Begründung enthalten. Eine solche wäre aber nicht nur unter dem Gesichtspunkt einer bürgerfreundlichen Verwaltung von Vorteil. Mithin werden durch die Begründung auch eine Verunsicherung der Bevölkerung und die Strafverfolgungsbehörden unnötig belastende Rückfragen und Rechtsmittel verhindert. ${ }^{291}$

Strittig ist die Zuständigkeit für die Benachrichtigung. So wird vertreten, dass die Benachrichtigung Sache des Gerichts sei und eine Benachrichtigung durch die Staatsanwaltschaft nur in Betracht käme, wenn diese die Rasterfahndung selbst angeordnet habe. ${ }^{292}$ Diese Ansicht verkennt jedoch die besondere Sachnähe der Staatsanwaltschaft. Nur die Staatsanwaltschaft kann beurteilen, ob z.B. eine Gefährdung des Untersuchungszwecks droht. ${ }^{293}$ Daher muss hier die Zuständigkeit der Staatsanwaltschaft angenommen werden, die das Verfahren betreibt, in welchem die weiteren Ermittlungen vorgenommen worden sind. Diese kann mit der Benachrichtigung auch die Polizei beauftragen. ${ }^{294}$

Weiterhin kann nach $\S 163 \mathrm{~d}$ V StPO eine Benachrichtigung unterbleiben, wenn eine Gefährdung des Untersuchungszwecks oder der öffentlichen Sicherheit zu befürchten ist. Der Untersuchungszweck wird gefährdet, wenn zu befürchten ist, dass die Erforschung des Sachverhalts durch die Benachrichtigung in dem konkreten Verfahren beeinträchtigt wird. ${ }^{295}$ Eine Gefährdung der öffentlichen Sicherheit liegt darüber hinaus vor, wenn präventive, sicherheitspolitische Belange oder Ermittlungen in anderen Verfahren gestört werden könnten. ${ }^{296}$ Danach kann eine Unterrichtung insbesondere dann unterbleiben, wenn nicht allgemein bekannte Methoden der Verbrechensbekämpfung und dazu gehören bei der Rasterfahndung nicht nur das Institut als solches, sondern auch das angewandte Raster durch die Benachrichtigung bekannt und so für die Zukunft wirkungslos würden. ${ }^{297}$ In diesem Zusammenhang reicht der Wunsch, den allgemeinen Umfang des Einsatzes

\footnotetext{
288 Nack, in: Karlsruher Kommentar, § 98b Rn. 13.

289 Wolter, in: Systematischer Kommentar, $§ 163$ d Rn. 88.

290 Rieß, in: Löwe-Rosenberg, § 163d Rn. 81; Wolter, in: Systematischer Kommentar, $\S 163 \mathrm{~d}$ Rn. 88.

291 Schäfer, in: Löwe-Rosenberg, § 98b Rn. 28.

292 Meyer-Goßner, $\S 163$ d Rn. 25.

293 Schäfer, in: Löwe-Rosenberg, § 98b Rn. 27.

294 Rieß, in: Löwe-Rosenberg, § 163d Rn. 81.

295 Rieß, in: Löwe-Rosenberg, $\S 163$ d Rn. 80.

296 Wolter, in: Systematischer Kommentar, § 163d Rn. 90.

297 Schäfer, in: Löwe-Rosenberg, § 98b Rn. 25.
} 
von Rasterfahndungen nicht bekannt werden zu lassen, nicht aus. Ansonsten wäre die Transparenzvorschrift des $§ 163 \mathrm{~d}$ V StPO praktisch gegenstandslos. ${ }^{298}$

Vor dem Hintergrund, dass diese Vorschrift keine endgültige Frist vorsieht, nach welcher die Betroffenen auf jeden Fall informiert werden müssen, erscheinen die Einschränkungen verfassungsrechtlich bedenklich. ${ }^{299}$ Um diesen Mangel zu revidieren, könnte eine analoge Anwendung des $\S 101$ I StPO in Betracht kommen. ${ }^{300}$ Danach wäre eine Benachrichtigung nachzuholen, wenn die Gefährdung des Untersuchungszwecks oder der öffentlichen Sicherheit nicht mehr bestehen würde. $\mathrm{Ob}$ darin jedoch eine verfassungskonforme Interpretation des $\S 163 \mathrm{~d}$ V StPO zu sehen ist, ist allerdings mehr als fraglich. ${ }^{301}$ Darüber hinaus bleibt festzustellen, dass vor allem die Möglichkeit der Einschränkung der Benachrichtigungspflicht aufgrund der Gefährdung der öffentlichen Sicherheit von ihrem Regelungsgehalt nicht in die Strafprozessordnung passt. So sind die Verhütung von Straftaten, die Abwehr von konkreten Gefahren und die Wahrung der öffentlichen Sicherheit keine Aufgaben des Strafprozessrechts. ${ }^{302}$

\section{Benachrichtigung des Datenschutzbeauftragten}

Letztlich ist gemäß $§ 98 b$ IV S.2 StPO nach der Durchführung einer Rasterfahndung die für die Kontrolle der Einhaltung der Vorschriften über den Datenschutz bei öffentlichen Stellen zuständige Stelle zu unterrichten. Dabei handelt es sich um die Datenschutzbeauftragten der Länder und des Bundes. Eingeführt wurde diese Bestimmung auf Vorschlag der Bundesregierung. In der Begründung für diesen Vorschlag wurde angeführt, dass die Maßnahme der Rasterfahndung als Massendatenverarbeitung regelmäßig die Daten einer Vielzahl von Unbeteiligten erfasst und möglicherweise dazu führt, dass diese in den strafrechtlichen Kontrollprozess gelangen. ${ }^{303}$ Aufgrund der für den Bürger bestehenden Undurchsichtigkeit der Speicherung und Verwendung von Daten unter den Bedingungen der automatisierten Datenverarbeitung und auch im Interesse eines vorgezogenen Rechtsschutzes durch rechtzeitige Vorkehrungen ist die Beteiligung unabhängiger Datenschutzbeauftragter von erheblicher Bedeutung. ${ }^{304}$ So besteht insbesondere für die Betroffenen, die nicht benachrichtigt werden, keine Möglichkeit der Kenntnisnahme von der Rasterfahndung und einer damit einhergehenden Kontrolle.

\footnotetext{
${ }^{298}$ Rieß, in: Löwe-Rosenberg, § 163d Rn. 80; Graf, S.112.

${ }^{299}$ Kühne, Strafprozesslehre, Rn. 274.3.

300 So von Wolter, in: Systematischer Kommentar, § 163d Rn. 87; Rieß, in: LöweRosenberg, § 163d Rn. 80.

${ }^{301}$ So verneint von Achenbach, in: Karlsruher Kommentar, § 163d Rn. 30.

302 Rudolphi, in: Systematischer Kommentar, § 163d Rn. 90.

${ }^{303}$ BT-Drs. 12/ 989, S.57.

304 BVerfG, NJW 1984, 422 f.
} 
Der Realitätsgehalt der informationellen Selbstbestimmung hängt insofern auch und gerade von der Intensität und der Effizienz einer Kontrolle der Verarbeitungsprozesse durch die Datenschutzbeauftragten ab. ${ }^{305}$ Diese haben aber nicht die Rechtmäßigkeit der Rasterfahndung, sondern nur die Einhaltung datenschutzrechtlicher Vorschriften zu prüfen. ${ }^{306}$ Um dem Datenschutzbeauftragten diese Kontrollaufgabe zu erleichtern, müssen revisionsfähige Aufzeichnungen über die Rasterfahndung gefertigt werden. ${ }^{307}$ Ferner wird der Datenschutzbeauftragte besonders darauf zu achten haben, dass die Vorschriften über Datenrückgabe und Löschung erhobener Daten eingehalten werden. ${ }^{308}$

\section{Verwertbarkeit der Erkenntnisse}

Das Gesetz enthält keine Regelungen darüber, wie die gewonnenen Erkenntnisse zu verwenden sind. In der Regel werden aus den gewonnenen Daten weitere Ermittlungsansätze herzuleiten sein. ${ }^{309}$

\section{Die Behandlung von Zufallsfunden}

$\S 98 b$ III S.3 StPO enthält eine Regelung für die Verwendung der gewonnenen Daten im Rahmen von anderen Strafverfahren. Danach dürfen die durch den $\mathrm{Ab}-$ gleich erlangten personenbezogenen Daten in anderen Strafverfahren zu Beweiszwecken nur verwendet werden, soweit sich bei Gelegenheit der Auswertung Erkenntnisse ergeben, die zur Aufklärung einer in § 98a I S.1 bezeichneten Straftat benötigt werden. Es muss sich also um eine der Anlassstraftaten aus dem Katalog des $§ 98$ a I S.1 StPO handeln. ${ }^{310}$ Unter ,,andere Strafverfahren“ sind Verfahren wegen anderer prozessualer Taten im Sinne des $\S 264$ StPO zu verstehen. ${ }^{311} \S 98 \mathrm{~b}$ III S.3 StPO spricht ausdrücklich nur von einer Verwendung zu Beweiszwecken. Zu Beweiszwecken werden Erkenntnisse verwendet, wenn sie zur Klärung der Schuldoder Straffrage dienen. ${ }^{312}$

Strittig ist eine darüber hinausgehende Nutzung der Erkenntnisse für weitere Ermittlungsansätze, also außerhalb der Beweiszwecke für Straftaten, die nicht im Katalog des $\S 98$ a I S.1 StPO aufgeführt sind. Nach überwiegender Auffassung

\footnotetext{
305 Simitris, NJW 1984, 403.

306 Meyer-Goßner, § 98b Rn. 8.

307 Bäumler, in: Lisken/Denninger (Hrsg.), Handbuch des Polizeirechts, J Rn. 297.

308 Schäfer, in: Löwe-Rosenberg, § 98b Rn. 26.

309 Bäumler, in: Lisken/Denninger (Hrsg.), Handbuch des Polizeirechts, J Rn. 288.

$310 \mathrm{Zu}$ den Anlassstraftaten siehe: 1. Teil E.II.

${ }^{311}$ Hilger, NStZ 1992, 461; Schäfer, in: Löwe-Rosenberg, § 98b Rn. 24.

312 Schäfer, in: Löwe-Rosenberg, § 98b Rn. 24.
} 
dürfen die durch den Datenabgleich gewonnenen Erkenntnisse gleichfalls unbeschränkt verwendet werden, soweit sie als Ermittlungsansatz dienen. ${ }^{313}$ Für eine solche Nutzung würde zunächst einmal der Wortlaut des § 98b III S.3 StPO sprechen, welcher nur die Verwendung zu Beweiszwecken an das Vorliegen einer Katalogtat knüpft. Darüber hinaus wird die vom Bundesverfassungsgericht nicht beanstandete Rechtsprechung des Bundesgerichtshofes zur Verwertbarkeit der Erkenntnisse aus einer Telefonüberwachung nach $\S 100$ a StPO aufgrund der systematischen und rechtspolitischen Lage als Begründung herangezogen. ${ }^{314}$

Gegenstand dieser Rechtsprechung ist jedoch nur die Nutzung zu Beweiszwecken im Rahmen von Straftaten, die dem Katalog des $\S 100$ a StPO zu entnehmen sind. ${ }^{315}$ Eine Anwendung auf die Rasterfahndung erscheint daher zumindest fraglich. Vielmehr sind die Telefonüberwachung nach §100a StPO und die Rasterfahndung in Bezug auf die mit ihnen möglichen Ermittlungsergebnisse nur bedingt vergleichbar. So können Wortlautprotokolle und mitgeschnittene Telefongespräche leicht als Beweis verwendet werden.

$\mathrm{Zu}$ Beweiszwecken dürften die Ergebnisse von Rasterfahndungsmaßnahmen allerdings nur in den seltensten Fällen verwendbar sein. Vielmehr dienen sie in der Regel der Gewinnung von weiteren Ermittlungsansätzen. ${ }^{316}$ Wenn sich diese Ermittlungsansätze aber nicht auf den konkreten Verdachtsfall, der auch Anlass für den Einsatz der Rasterfahndung war, beziehen, so besteht hier die Gefahr einer allgemeinen Ausforschung. ${ }^{317}$ Die Strafverfolgungsbehörden könnten aus dem Ergebnis von Rasterfahndungsmaßnahmen Ermittlungsansätze selbst zur Aufklärung von Bagatelldelikten gewinnen. ${ }^{318}$ Die Wahrscheinlichkeit, dass solche Ermittlungsansätze im Rahmen der Rasterfahndung gewonnen werden, ist aufgrund der Einbeziehung einer Vielzahl von unverdächtigen Dritten sehr hoch. ${ }^{319}$ Darüber hinaus machen sich die Daten gewissermaßen selbständig und niemand kann deshalb sagen, zu welchem Zeitpunkt sie zu löschen sind. ${ }^{320}$ Entgegen der überwiegenden Auffassung ist daher eine Verwendung der gewonnenen Erkenntnisse für Straftaten, die nicht im Katalog des $\S 98$ a I S.1 StPO aufgeführt sind, abzulehnen.

313 Nack, in: Karlsruher Kommentar, § 98b Rn. 10; Lemke, in: Heidelberger Kommentar, $\S 98 b$ Rn. 12; so auch Graf, S.107; und Siebrecht, S.138.

314 So schon in der Gesetzesbegründung angeführt: BT-Drs 12/989, S.38; auch Siebrecht, S.138.

315 BGHSt 32, 10, 15; BGHSt 29, 23, $24 \mathrm{f}$.

316 Bäumler, in: Lisken/Denninger (Hrsg.), Handbuch des Polizeirechts, J Rn. 289.

317 Siebrecht, S.86.

318 Bäumler, in: Lisken/Denninger (Hrsg.), Handbuch des Polizeirechts, J Rn. 289.

319 Siebrecht, S.85.

${ }^{320}$ Hassemer, KJ 1992, 71. 


\section{Rückgabe der Daten an die Speicherstelle und Löschung}

Regelungen über die Rückgabe und die Löschung von Daten sind in $\S 98 \mathrm{~b}$ II S.1 und S.2 StPO enthalten. Der $\S 98 \mathrm{~b}$ III S.1 und S.2 StPO unterscheidet dabei zwischen der Rückgabe der Datenträger und der Löschung von Daten. Beide Maßnahmen stellen besondere Formen der Folgenbeseitigung bei Eingriffen in das Recht auf informationelle Selbstbestimmung dar. ${ }^{321}$ Der $\S 98 b$ III S.1 StPO sieht die unverzügliche Rückgabe der erhaltenen Datenträger, nach Beendigung des Datenabgleichs, an die betreffenden Speicherstellen vor. Werden die Daten ohne Datenträger, z.B. mittels Datenfernübertragung, überspielt, so gilt § 98b III S.2 StPO. Da die Rückgabe noch während des Ermittlungsverfahrens zu erfolgen hat, liegt sie in der Zuständigkeit der Staatsanwaltschaft. ${ }^{322}$

Fraglich ist, ob die Datenträger vor der Rückgabe an die übermittelnde Stelle zu löschen sind. Das Gesetz spricht nur von der Rückgabe der Datenträger, trifft aber keine Aussagen über deren Inhalt. Im Regelfall werden die Daten von der übermittelnden Stelle aus deren Gesamtdatenbestand herauskopiert. In einem solchen Fall dürfte diese jedoch kein berechtigtes Interesse an den selektierten Daten haben. Vielmehr würde die Rückgabe der Datenträger, einschließlich der darauf gespeicherten selektierten Daten Gefahren für das Recht auf informationelle Selbstbestimmung bedeuten, da die speichernde Stelle möglicherweise unsachliche Schlüsse bezüglich der erfassten Personen ziehen könnte. ${ }^{323}$ Daher sind die Datenträger vor der Rückgabe zu löschen. ${ }^{324}$ Ein solches Vorgehen ist auch durch den Wortlaut des $\S 98$ b III S.2 StPO gedeckt, der von Datenträgern und nicht von Daten spricht. $^{325}$

Ferner sind nach $\S 98$ b III S.2 StPO alle Daten, die auf andere Datenträger übertragen wurden, unverzüglich zu löschen, sobald sie für das Strafverfahren nicht mehr benötigt werden. Nach $\S 3$ V Nr.5 BDSG ist Löschen, das Unkenntlichmachen gespeicherter personenbezogener Daten. Die bloße Erschwernis des ,gezielten Zugriffs“" genügt nicht. ${ }^{326}$ Die Löschung erfolgt während des Ermittlungsverfahrens im Verantwortungsbereich der Staatsanwaltschaft, die diese anzuordnen und zu überwachen hat. ${ }^{327}$ Nach der Erhebung der Anklage entscheidet das mit der Sache befasste Gericht über die Löschung. ${ }^{328}$ Bezüglich der Löschung empfiehlt sich im Hinblick auf $\S 98$ b IV S.2 StPO die Errichtung eines Löschungsproto-

\footnotetext{
321 Siebrecht, S.136; Weichert, S.169.

322 Schäfer, in: Löwe-Rosenberg, § 98b Rn. 22.

323 Bäumler, in: Lisken/Denninger (Hrsg.), Handbuch des Polizeirechts, J Rn. 285.

324 Schäfer, in: Löwe-Rosenberg, § 98b Rn. 22.

325 So auch: Schäfer, in: Löwe-Rosenberg, § 98b Rn. 22.

326 Bäumler, in: Lisken/Denninger (Hrsg.), Handbuch des Polizeirechts, J Rn. 286.

327 Schäfer, in: Löwe-Rosenberg, § 98b Rn. 23.

328 Meyer-Goßner, § 98b Rn. 6; Schäfer, in: Löwe-Rosenberg, § 98b Rn. 23.
} 
kolls. ${ }^{329}$ Das Löschungsprotokoll bezieht sich nur auf die zur Rasterfahndung zur Verfügung gestellten Ausgangsdaten bzw. die diesbezüglichen Kopien, nicht jedoch auf das Ergebnis des Datenabgleichs. ${ }^{330}$ Auch etwaige zwischenzeitlich erstellte konventionelle Datenträger wie Computerausdrucke, schriftliche Aufzeichnungen etc. sind zu bereinigen bzw. zu vernichten. ${ }^{331}$ Andernfalls wäre die Löschpflicht obsolet.

Letztlich bedarf der Zeitpunkt der Löschung einer eingehenden Betrachtung. Diese hat nach § 98b III S.2 StPO unverzüglich, d.h. ohne schuldhaftes Zögern, zu erfolgen, wenn die Daten für das Strafverfahren nicht mehr benötigt werden. ${ }^{332}$ Für die Löschung gilt damit ein späterer Zeitpunkt als für die Rückgabe der Datenträger, denn die Daten können noch zur Beweisführung im Strafverfahren benötigt werden. ${ }^{333}$ Als Zeitpunkt für die Löschung kommt daher der rechtskräftige $\mathrm{Ab}$ schluss des Strafverfahrens in Betracht. Möglich erscheint aber auch eine darüber hinausgehende Aufbewahrung der Daten, um diese für den Fall einer Wiederaufnahme des Verfahrens zur Verfügung zu haben. ${ }^{334}$ Die strikte Löschungspflicht ist ein Ausgleich dafür, dass die Rasterfahndung in die Rechte völlig Unbeteiligter eingreift. Die Maßnahme, für welche die Personen keine vorwerfbare Ursache gesetzt haben, soll für sie keine weitergehenden Folgen haben. ${ }^{335}$ Vor diesem Hintergrund vermag die vage Möglichkeit eines Wiederaufnahmeverfahrens die zeitlich unbegrenzte Aufrechterhaltung des Eingriffs in das Grundrecht auf informationelle Selbstbestimmung nicht zu rechtfertigen. ${ }^{336}$ Mithin kann als spätester Zeitpunkt für die Löschung der Daten nur der rechtskräftige Abschluss des Strafverfahrens in Betracht kommen.

\section{G. Rasterfahndung nach den Polizei- und Sicherheitsgesetzen der Bundesländer}

Neben der Strafprozessordnung hat die Rasterfahndung ihren Einzug auch in die Polizei- und Sicherheitsgesetze der Bundesländer gehalten. So enthalten inzwischen alle Polizei- und Sicherheitsgesetze der Bundesländer Regelungen zur Ras-

\footnotetext{
${ }^{329}$ Hilger, NStZ 1992, 461, Fn.71.

${ }^{330}$ Schäfer, in: Löwe-Rosenberg, § 98b Rn. 23.

331 Bäumler, in: Lisken/Denninger (Hrsg.), Handbuch des Polizeirechts, J Rn. 286; anderer Ansicht Schäfer, in: Löwe-Rosenberg, § 98b Rn. 23.

332 Rudolphi, in: Systematischer Kommentar, § 98b Rn. 12.

${ }^{333}$ Nack, in: Karlsruher Kommentar, $\S 98 b$ Rn. 8.

334 So von Nack, in: Karlsruher Kommentar, § 98b Rn. 8 unter Hinweis auf: MeyerGoßner, § $100 \mathrm{~b}$ Rn. 8 vertreten.

335 Bäumler, in: Lisken/Denninger (Hrsg.), Handbuch des Polizeirechts, J Rn. 287.

336 So Siebrecht, S.136f, der nach Abschluss des Strafverfahrens die Persönlichkeitsbelange das Aufbewahrungsinteresse regelmäßig überwiegen sieht.
} 
terfahndung. ${ }^{337}$ Der Zeitpunkt der Aufnahme der Rasterfahndung in diese Gesetze ist jedoch in den einzelnen Bundesländern höchst unterschiedlich. Während die Rasterfahndung in einigen Bundesländern schon Anfang der neunziger Jahre ihre Aufnahme in die Gesetze fand, wurde die Notwendigkeit einer gesetzlichen Regelung in anderen Bundesländern erst nach den Anschlägen des 11. September 2001 gesehen. So kam es, dass die Rasterfahndung im Polizeigesetz Baden-Württemberg z.B. bereits in der Fassung vom 13.01.1992 enthalten war, sie in Schleswig Holstein dagegen erst mit Wirkung vom 19.10.2001 eingeführt wurde. ${ }^{338}$

Inhaltlich orientieren sich die Polizeigesetze bei der Ausgestaltung der Rasterfahndung an den strafprozessualen Fahndungsmaßnahmen der $\S \S 98 \mathrm{a}, \mathrm{b}$ StPO. ${ }^{339}$ Die Voraussetzungen, insbesondere die Zuständigkeiten für die Anordnung, differieren jedoch von Bundesland zu Bundesland. Im Folgenden sollen die Regelungen der Rasterfahndung in den Polizei- und Sicherheitsgesetzen der Bundesländer anhand eines beispielhaft ausgewählten Bundeslandes dargestellt werden. Als solches kommen jene Sicherheits- und Polizeigesetze in Betracht, die sich in ihrer Ausgestaltung an den Eingriffsvoraussetzungen des $\S 10 \mathrm{f}$ des Musterentwurfes eines einheitlichen Polizeigesetzes des Bundes und der Länder in der Fassung des Vorentwurfs zur Änderung des Musterentwurfs eines Polizeigesetzes (VEMEPolG) orientieren. Aufgrund dessen dient nachstehend § 31 SOG LSA als Beispiel. ${ }^{340}$ An den einschlägigen Stellen werden aber auch die Unterschiede zwischen den gesetzlichen Ausgestaltungen der Rasterfahndung in den einzelnen Bundesländern aufgezeigt.

\section{Die Tatbestandsvoraussetzungen}

Den einzelnen Vorschriften ist gemein, dass die Polizeibehörden von öffentlichen und nichtöffentlichen Stellen die Übermittlung von personenbezogenen Daten bestimmter Personengruppen aus Dateien, insbesondere Namen, Anschriften, Tag und Ort der Geburt sowie auf den Einzelfall bezogene zusätzliche fahndungsrelevante Suchkriterien zum Zweck des Abgleichs mit anderen Datenbeständen, verlangen können.

$337 \S 40$ PolG BW; § 45a Nds. SOG; § 31 PolG NRW; § 26 HSOG; Art. 44 PAG Bayern; § 47 ASOG Bln; § 47 SächsPolG; § 25d POG RP; § 36i BremPolG; § 46 PolG Bbg; § 23 PolDVG HH; § 44 SOG MV; § 37 SPolG; § 31 SOG LSA; § 44 ThüPAG; § 195a LVwG SH.

338 Auch Bremen und Niedersachsen, die bis zu diesem Zeitpunkt noch keine Notwendigkeit einer Regelung der Rasterfahndung sahen, haben erst nach dem 11. September 2001 nachgezogen. Gesetz zur Änderung des Bremischen Polizeigesetzes v. 25.10.2001, GVB1. Bremen, S.341; Gesetz zur Änderung des Niedersächsischen Gefahrenabwehrgesetzes vom 25.10.2001, Nds GVB1., S.664.

${ }^{339}$ Ruder/Schmitt, Rn. 496.

340 Die Anordnungsvoraussetzungen des $\S 31$ I SOG LSA finden sich unter anderem auch in $\S 47$ I ASOG Bln und $\S 31$ PolG NRW. 
Als Voraussetzung ist zunächst notwendig, dass die Maßnahme ,zur Abwehr einer gegenwärtigen Gefahr für den Bestand oder die Sicherheit des Bundes oder eines Landes oder für Leib, Leben oder Freiheit einer Person erfolgt". Eine Legaldefinition für den Begriff der gegenwärtigen Gefahr befindet sich in $\S 3 \mathrm{I} \mathrm{Nr}$. 3b SOG LSA. Hiernach ist dies: „eine Gefahr, bei der das schädigende Ereignis bereits begonnen hat oder unmittelbar oder in allernächster Zeit mit einer an Sicherheit grenzenden Wahrscheinlichkeit bevorsteht". Die Legaldefinition orientiert sich an der allgemeinen Begründung zum Musterentwurf eines einheitlichen Polizeigesetzes des Bundes und der Länder (ME PolG). Demnach ist die gegenwärtige Gefahr gekennzeichnet durch die besondere Zeitnähe und einen besonders hohen Grad an Wahrscheinlichkeit des Schadenseintritts. So muss der Schaden „sofort und fast mit Gewissheit" eintreten. ${ }^{341}$ Allerdings sind an die Wahrscheinlichkeit des Schadenseintritts und an die zeitliche Nähe umso geringere Anforderungen zu stellen, je größer und folgenschwerer der möglicherweise eintretende Schaden ist. ${ }^{342}$

Des Weiteren muss die gegenwärtige Gefahr entweder für den Bestand oder die Sicherheit des Bundes oder eines Landes oder für Leib, Leben oder Freiheit einer Person bestehen. Eine Legaldefinition für den Begriff der Gefahr für den Bestand des Bundes oder eines Landes kann $\S 92$ I StGB entnommen werden. Eine solche Gefahr ist demnach gegeben, wenn die Aufhebung der Freiheit von fremder Botmäßigkeit, die Beseitigung der staatlichen Einheit oder die Abtrennung eines zur Bundesrepublik gehörenden Gebietes droht. Folglich besteht eine gegenwärtige Gefahr für den Bestand des Bundes oder eines Landes in den Fällen der $\S \S 81,82$, und 92 StGB $^{343}$ Darüber hinaus kommt auch eine Gefahr für die Sicherheit des Bundes oder eines Landes in Betracht. Betroffen können in diesem Zusammenhang sowohl die innere als auch die äußere Sicherheit sein. Sicherheit meint die Gewähr, vor gewaltsamen Einwirkungen und Beeinträchtigungen aller Art geschützt zu sein, wobei für die äußere Sicherheit der Bestand des Staates in seinem Hoheitsgebiet, für die innere Sicherheit der im Einklang mit Gesetz und Verfassung sich vollziehende Wandel und Handel innerhalb der Staatsgrenzen im Vordergrund steht. ${ }^{344}$ Insofern besteht eine enge Verknüpfung mit den Prinzipien der freiheitlich demokratischen Grundordnung, so dass auch das ordnungsgemäße Funktionieren staatlicher Einrichtungen und der Schutz von Verfassungsorganen mit umfasst werden. ${ }^{345}$ Bezieht man den Begriff der Inneren Sicherheit als Schutzgut mit ein, so kommen ergänzend auch Staatsschutzverbrechen, terroristische Verbrechen oder Verbrechen und Vergehen der organisierten Kriminalität als Anwendungsfälle in Betracht. ${ }^{346}$

\footnotetext{
341 So gefordert von BVerwGE 45, 51, 58.

342 So KG-Berlin, NVwz 2002, 1540; OLG Düsseldorf, NVwZ 2002, 629 m.w.N.

343 Meixner/Martell, § 31 Rn. 3.

${ }^{344}$ Laufhütte, in: Leipziger Kommentar, § 92 Rn. 6.

345 Berg/Knape/Kiwor, § 47, II, B, 2.

346 Berg/Knape/Kiwor, § 47, II, B, 2.
} 
Jedoch gefährdet eine Gefahr für die öffentliche Sicherheit im Sinne des Polizeirechts nicht zwangsläufig die Innere Sicherheit der Bundesrepublik. ${ }^{347}$

Eine Legaldefinition für die Gefahr für Leib, Leben oder Freiheit einer Person enthält § 3 I Nr.3d SOG LSA. Es handelt sich danach um ,eine Gefahr, bei der eine nicht nur leichte Körperverletzung oder der Tod einzutreten droht". Diese muss wiederum gegenwärtig im Sinne des $§ 3$ I Nr.3b SOG LSA sein.

Letztlich müssen „Tatsachen die Annahme rechtfertigen, dass der Eingriff zur Abwehr der Gefahr erforderlich ist“. Die Formulierung „Tatsachen die Annahme rechtfertigen" verlangt in erster Linie den vorhandenen Tatsachenbefund, der sich hinsichtlich seiner objektiven, tatsächlichen Anhaltspunkte bezüglich der abzuwehrenden Gefahr auf die zu übermittelnden Daten bestimmter Personengruppen zu beziehen hat. Darüber hinaus bedarf es einer Einschätzung seitens der Polizei, ob durch den Abgleich der übermittelten personenbezogenen Daten bestimmter Personengruppen aus bestimmten Dateien eine der genannten Gefahren abgewehrt werden kann. Die Einschätzung geschieht in ähnlicher Weise wie bei der Gefahrenprognose. ${ }^{348}$ Mit der Formulierung soll zum Ausdruck gebracht werden, dass die Annahme, durch die Rasterfahndung könnten sachdienliche Hinweise erlangt werden, nicht bloß auf Mutmaßungen gestützt werden darf. ${ }^{349}$

Letztlich muss die Rasterfahndung auch verhältnismäßig sein. Insofern muss die Maßnahme erforderlich und geeignet sein, die Gefahr abzuwehren. ${ }^{350}$ Der Begriff der Erforderlichkeit ist hier in einem umfassenderen Rahmen zu sehen als im Rahmen des Verhältnismäßigkeitsprinzips, denn bei polizeilichen Einsätzen kommt gerade der Frage, ob die Maßnahme zur Gefahrenabwehr bzw. Straftatenbekämpfung auch wirkungsvoll ist, ein besonderes Gewicht $\mathrm{zu}^{351}$ Ferner hat sich die Erforderlichkeit dieser Anordnung auch unmittelbar auf die Erfolgsaussicht des Abgleichs zu beziehen. In diesem Rahmen ist die Fahndungshypothese, d.h. der Katalog von Merkmalen, die abgeglichen werden sollen, von besonderer Bedeutung. Deren Eignung muss, im Hinblick auf den Fahndungszweck, gegeben sein. ${ }^{352}$ Insofern kommt der Bestimmung von Störereigenschaften und Störungsmodalitäten in Verbindung mit der Einschätzung von Auskunftschancen bestimmter Datensammlungen eine entscheidende Bedeutung $\mathrm{zu}^{353}$

\footnotetext{
${ }^{347}$ Bäumler in: Lisken/Denninger (Hrsg.), Handbuch des Polizeirechts, J Rn. 716.

348 Berg/Knape/Kiwor, § 47, II, B, 1. aufgrund des identischen Wortlauts der Tatbestandsvoraussetzungen wird hier ergänzend auf die Kommentierung des Allgemeinen Sicherheits- und Ordnungsgesetzes Berlin zurückgegriffen.

${ }^{349}$ Koch, S. 190.

${ }^{350}$ Meister, JA 2003, 87.

${ }^{351}$ Koch, S.189, Fn. 777.

352 Meister, JA 2003, 87.

${ }^{353}$ Lisken, NVwZ 2002, 517.
} 
Die Maßnahme der Rasterfahndung kommt als Maßnahme der Gefahrenabwehr nur in Betracht, wenn sie das geeignete Mittel ist. Dies dürfte bei gegenwärtigen Gefahren nur in besonderen Ausnahmefällen gegeben sein. Gegenwärtige Gefahren erfordern entschlossenes Handeln statt Recherchieren in Datenbeständen. ${ }^{354}$ Nach neuerer Rechtsprechung zur Rasterfahndung haben sich der Gefahrenbegriff und die Gegenwärtigkeit derselben vor allem am Ausmaß des möglichen Schadens und dessen zeitlicher Nähe zu orientieren, um dessen Verhinderung es geht. ${ }^{355}$ Praktische Fälle dürften nur selten auftreten. Zu denken ist an Fälle, in denen die Gefahr länger andauert, etwa bei Entführungen oder Geiselnahmen. In diesen Fällen hat aber bereits die Strafverfolgung begonnen. ${ }^{356} \mathrm{Ob}$ in einer derartigen Situation - die nach allgemeinem Verständnis ein sofortiges polizeiliches Handeln erfordert und nicht die langwierige Anforderung und Verarbeitung von Daten - die Rasterfahndung ein geeignetes Mittel ist, wird zu Recht bezweifelt. ${ }^{357}$

\section{Abweichende Tatbestandsvoraussetzungen in anderen Bundesländern}

Im Rahmen der Tatbestandsvoraussetzungen sind durchaus erhebliche Unterschiede zwischen den einzelnen Bundesländern festzustellen. So ist die Rasterfahndung teilweise auch zulässig zur vorbeugenden Bekämpfung von Straftaten erheblicher Bedeutung ${ }^{358}$ sowie zur Abwehr bzw. zur Verhinderung dieser Delikte. ${ }^{359}$ In diesen Bundesländern werden die Bedingungen, insbesondere soweit sie sich auf die Eintrittwahrscheinlichkeit des Schadens beziehen, deutlich herabgesetzt. Fraglich erscheint insofern die Angemessenheit einer solchen Erweiterung. ${ }^{360}$

\section{Die Anordnungsbefugnis}

Auch was die Anordnung der Rasterfahndung betrifft, unterscheiden sich die einzelnen Bundesländer erheblich. Das Gesetz über die Öffentliche Sicherheit und Ordnung Sachsen-Anhalts sieht in $\S 31$ IV S.1 SOG LSA vor, dass die Rasterfahndung außer bei Gefahr im Verzug nur durch einen Richter auf Antrag des Behördenleiters oder eines von ihm Beauftragten angeordnet werden kann. Sollte Gefahr im Verzug vorgelegen haben, bedarf die Anordnung durch die Polizei nach § $31 \mathrm{IV}$ S.4 und S.5 SOG LSA der richterlichen Bestätigung innerhalb von drei Tagen. Insoweit gleicht die Anordnungsbefugnis derjenigen in der Strafprozessordnung.

\footnotetext{
354 Bäumler in: Lisken/Denninger (Hrsg.), Handbuch des Polizeirechts, J Rn. 717.

355 Seel, Die Polizei 2002, 193.

356 Bäumler in: Lisken/Denninger (Hrsg.), Handbuch des Polizeirechts, J Rn. 717.

357 Seel, Die Polizei 2002, 193.

358 in Baden-Württemberg.

359 in Bayern und Sachsen.

${ }^{360}$ Koch, S. 188.
} 
Diese sieht in $\S 98$ b I S.1 bis S.3 StPO ebenfalls die Anordnung durch den Richter vor und fordert bei einer Anordnung durch die Staatsanwaltschaft die richterliche Bestätigung innerhalb von drei Tagen.

Noch restriktiver ist die Anordnungsbefugnis im Polizeigesetz Nordrhein Westfalen geregelt. Durch $\S 31$ IV S.1 PolG NRW ist festgelegt, dass die Rasterfahndung nur auf Antrag des Behördenleiters durch einen Richter angeordnet werden darf. Entgegen dem SOG LSA ist hier also keine Anordnung bei Gefahr im Verzug durch den Behördenleiter mit anschließender richterlicher Bestätigung möglich.

In Baden-Württemberg weicht die Anordnungsbefugnis deutlich von den zuvor beschriebenen Bundesländern ab. Nach § 40 I S.1 PolG BW ist nur der Polizeivollzugsdienst berechtigt, die Übermittlung zu verlangen. Eine Beschränkung der Personen, die eine Rasterfahndung anzuordnen befugt sind, findet sich in $\S 40$ III S.1 PolG BW. Danach dürfen nur die in $\S 22$ VI PolG BW genannten Personen eine Rasterfahndung anordnen, wobei sie zusätzlich der Zustimmung des Innenministeriums bedürfen. Die Zustimmung des Innenministeriums muss bereits vorliegen, bevor das Übermittlungsverlangen gestellt wird. ${ }^{361}$ Bei den nach $\S 22$ VI PolG BW genannten Personen handelt es sich um den Leiter des Landeskriminalamtes, der Wasserschutzpolizeidirektion, einer Landespolizeidirektion, eines Polizeipräsidiums, einer Polizeidirektion oder eines Abschnittes. Wobei nach § 22 VI S.2 PolG BW die Leiter des Landeskriminalamtes, der Wasserschutzpolizeidirektion und der Landespolizeidirektionen die Anordnungsbefugnis auf besonders beauftragte Polizeibeamte des höheren Dienstes übertragen können. Der Behördenleitervorbehalt soll der hohen Eingriffsintensität Rechnung tragen. Recht- und Zweckmäßigkeit müssen sorgfältig geprüft werden, was Kompetenz und Weitsicht erfordert. ${ }^{362}$ Die Anordnung des Behördenleiters umfasst die gesamte Maßnahme, obwohl das Gesetz nur von der Anordnung des Abgleichs spricht. Danach hat bereits das Übermittlungsverlangen nur aufgrund einer Anordnung des Behördenleiters zu ergehen. ${ }^{363}$ Diese gesetzliche Ausgestaltung der Anordnungsbefugnis findet sich unter anderem im Polizeiaufgabengesetz Bayern, ${ }^{364}$ im Polizeigesetz des Freistaates Sachsen $^{365}$ und im Thüringer Gesetz über die Aufgaben und Befugnisse der Polizei. $^{366}$

Es lässt sich festhalten, dass die gesetzlichen Ausgestaltungen der Rasterfahndung in den einzelnen Bundesländern insbesondere bei der Anordnungsbefugnis erhebliche Unterschiede aufweisen.

\footnotetext{
361 Belz/Mußmann, § 40 Rn. 21.

362 Belz/Maußmann, § 22 Rn. 68.

363 Belz/Mußmann, § 40 Rn.20.

364 Art. 44 II S.1 PAG Bayern.

$365 \S 47$ III S.1 PolG Sachsen.

366 § 44 IV S.1 PAG Thüringen.
} 


\section{Löschungs- und Vernichtungsregelungen}

Auch im Rahmen der Löschungs- und Vernichtungsregelungen sollen zunächst auf die Ausgestaltung im SOG LSA eingegangen und im Anschluss Unterschiede zu anderen Bundesländern herausgestellt werden.

Regelungen, welche die Löschung und Vernichtung der Daten betreffen, enthält $\S 31$ III SOG LSA. Hiernach sind, sofern der Zweck der Maßnahme erreicht ist oder sich zeigt, dass er nicht erreicht werden kann, die übermittelten und im Zusammenhang mit der Maßnahme zusätzlich angefallenen Daten auf dem Datenträger zu löschen. Des Weiteren sind die Unterlagen, soweit sie nicht für ein mit dem Sachverhalt zusammenhängendes Verfahren erforderlich sind, zu vernichten. Allerdings unterbleibt die Löschung, wenn die Voraussetzungen des $\S 32$ VII SOG LSA gegeben sind. ${ }^{367}$ Unter Unterlagen sind alle Datenträger zu verstehen, die personenbezogene Daten enthalten, ohne die Voraussetzungen des Dateibegriffs nach $\S 2$ II DSG LSA zu erfüllen. Es handelt sich dabei beispielsweise um beschriftetes Papier, Ton- und Magnetbänder sowie Filme. Auch bezüglich deren Vernichtung ist $\S 32$ VII SOG LSA zu beachten. ${ }^{368}$

Ferner ist nach $\S 31$ III S.2 SOG LSA eine Niederschrift über die Löschung der Daten oder die Vernichtung der Unterlagen anzufertigen, welche nach $\S 31$ III S.3 SOG LSA gesondert aufzubewahren und durch technische und organisatorische Maßnahmen zu sichern ist. Unter gesonderter Aufbewahrung ist die Trennung vom Dateibestand oder den Akten zu verstehen, auf die sich die Niederschrift bezieht. ${ }^{369}$ Letztlich ist nach $\S 31$ III S.3 SOG LSA die Niederschrift am Ende des dem Jahr der Vernichtung der Unterlagen oder Löschung der Daten folgenden Kalenderjahres zu vernichten. Der § 31 III SOG LSA findet sich mit identischem Wortlaut ebenfalls in $\S 31$ III PolG NRW, in $§ 47$ III ASOG Berlin, § 26 III HSOG. § $40 \mathrm{IV}$ PolG BW hat den identischen Wortlaut wie § 31 III S.1 SOG LSA. Hier fehlen allerdings die Sätze 2 und 3, weshalb in Baden-Württemberg keine Niederschrift über die Löschung oder Vernichtung anzufertigen ist.

In Bayern ist die Anfertigung einer Niederschrift über die Löschung oder Vernichtung ebenfalls nicht erforderlich. Darüber hinaus ist Art. 44 III PAG Bayern weiter gefasst. Während in den anderen Polizei- und Sicherheitsgesetzen die Löschung oder Vernichtung unterbleiben kann, sofern die Daten oder Unterlagen nicht für ein mit dem Sachverhalt zusammenhängendes Verfahren erforderlich sind, gestattet Art. 44 III PAG Bayern diese Ausnahme, wenn die Daten nicht zur

\footnotetext{
367 Meixner/Martell, § 31 Rn. 12.

368 Meixner/Martell, § 31 Rn. 13.

${ }^{369}$ Meixner/Martell, § 31 Rn. 15.
} 
Verfolgung von Straftaten erforderlich sind. Es muss also kein Zusammenhang zu dem Verfahren bestehen, in dem die Rasterfahndung durchgeführt wurde.

\section{Unterrichtungsregelungen}

Abschließend sehen die Polizei- und Sicherheitsgesetze der Länder Unterrichtungspflichten vor. Nach $\S 31$ IV S.6 SOG LSA ist der Landesbeauftragte für den Datenschutz unverzüglich zu unterrichten. Die Unterrichtung betrifft das Ermittlungsersuchen und deren Gegenstand. ${ }^{370}$ Die unverzügliche, d.h., ohne schuldhaftes Zögern durchzuführende Unterrichtung des Landesbeauftragten für den Datenschutz sehen nahezu alle Polizei- und Sicherheitsgesetze vor. ${ }^{371}$

Des Weiteren sehen einige Gesetze die Unterrichtung von Personen vor, gegen die nach Abschluss der Rasterfahndung weitere Ermittlungen durchgeführt worden sind. So z.B. § 31 V PolG NRW. Vorraussetzung dafür ist jedoch, dass dies ohne Gefährdung der weiteren Datennutzung erfolgen kann. Letztlich unterbleibt die Unterrichtung, wenn wegen desselben Sachverhalts ein strafrechtliches Ermittlungsverfahren gegen die betreffende Person eingeleitet worden ist.

\section{Die polizeirechtliche Rasterfahndung in der Rechtsprechung}

Gegenstand der Rechtsprechung wurde die Rasterfahndung erst nach den Anschlägen des 11. September 2001 in New York und Washington. Grund dafür war die erstmalige flächendeckende Durchführung einer präventiven Rasterfahndung in Deutschland. Mitunter wird in diesem Zusammenhang auch von einem „Probelauf“ gesprochen. ${ }^{372}$ Die Gerichte hatten sich in erster Linie mit der Frage nach dem Vorliegen einer ,gegenwärtigen Gefahr“ zu befassen. Darüber hinaus waren auch die Rasteranordnung selbst und Fragen der Folgenbeseitigung Gegenstand gerichtlicher Entscheidungen. ${ }^{373}$

Von besonderer Bedeutung für die polizeirechtliche Rasterfahndung war die Entscheidung des Bundesverfassungsgerichts vom 4. April 2006. Gegenstand der Entscheidung war die Rasterfahndung nach dem 11. September 2001. Mit dieser Entscheidung erklärte das Bundesverfassungsgericht die Rasterfahndung der in $\S 31$ PolG NW geregelten Art für verfassungswidrig. Diese sei mit dem Grundrecht auf informationelle Selbstbestimmung nur dann vereinbar, wenn eine konkrete Gefahr für hochrangige Rechtsgüter wie den Bestand oder die Sicherheit des Bundes oder eines Landes oder für Leib, Leben oder die Freiheit einer Person gegeben wäre.

\footnotetext{
370 Meixner/Martell, $\S 31$ Rn. 15.

371 Beispielhaft seien hier $\S 40$ III S.2 PolG BW und Art. 44 II S.2 PAG Bayern genannt.

372 So Lisken, NVwZ 2002, 513.

373 Eine Übersicht über die gerichtlichen Entscheidungen enthält Bizer, DuD 2002, 309.
} 
Im Vorfeld der Gefahrenabwehr scheide die Maßnahme aus. Mithin sei eine allgemeine Bedrohungslage, wie sie im Hinblick auf terroristische Anschläge seit dem 11. September 2001 durchgehend bestanden habe, für die Anordnung der Rasterfahndung nicht ausreichend. Vorausgesetzt sei vielmehr das Vorliegen weiterer Tatsachen, aus denen sich eine konkrete Gefahr, etwa für die Vorbereitung oder Durchführung terroristischer Anschläge ergeben würde. ${ }^{374}$ Auf der Grundlage dieser Entscheidung wurden elf Bundesländer dazu aufgerufen, die gesetzliche Ausgestaltung der Rasterfahndung an die Rechtsprechung des Bundesverfassungsgerichts anzupassen.

\section{H. Stand der Forschung}

Bevor die Methoden und Ziele der vorliegenden Untersuchung dargestellt werden, ist es notwendig, den Stand der bisherigen Forschung zur Rasterfahndung aufzuzeigen. Besondere Ermittlungsmethoden, zu denen auch die Rasterfahndung zu zählen ist, haben sich in verschiedenen Formen mit der Ausweitung des strafrechtlichen Gefährdungs- und Risikostrafrechts sowie damit verbundener Aufklärungsprobleme entwickelt. ${ }^{375}$ Allerdings stehen die einzelnen Ermittlungsmethoden bislang nicht im Zentrum des Interesses der empirischen Rechtstatsachenforschung. ${ }^{376}$ Bzgl. einer ausführlichen Darstellung des empirischen Forschungsstandes zu besonderen Ermittlungsmethoden und zum strafprozessualen Ermittlungsverfahren ist auf die Untersuchung zur Telefonüberwachung nach den $\S \S 100 \mathrm{a}, \mathrm{b}$ StPO von Albrecht/Dorsch/Krüpe zu verweisen. ${ }^{377}$ Dort wird im Ergebnis festgehalten, dass die empirische Forschung zu strafrechtlichen Ermittlungen und insbesondere zu besonderen Ermittlungsmaßnahmen defizitär ist. ${ }^{378}$

Die Darstellung des Forschungsstandes zur Rasterfahndung wird auf drei Untersuchungen beschränkt. Dabei handelt es sich um die Untersuchungen von Graf, ${ }^{379}$ Siebrecht ${ }^{380}$ und Klever. ${ }^{381}$ Weitere Untersuchungen zur Rasterfahndung von Wan$n^{3} r^{382}$ aus dem Jahr 1985 und von Simon/Taeger ${ }^{383}$ aus dem Jahr 1981 befassen sich in erster Linie mit der Suche nach einer Ermächtigungsgrundlage und der Verfassungsmäßigkeit der Rasterfahndung. Da diese Fragestellung mit Einführung der

\footnotetext{
${ }^{374}$ BVerfGE 115, 320, 320.

375 Albrecht, Rechtstatsachenforschung, S.115.

376 Albrecht, Rechtstatsachenforschung, S.106.

377 Albrecht/Dorsch/Krüpe, S.110ff.

378 Albrecht/Dorsch/Krüpe, S.126.

379 Graf.

${ }^{380}$ Siebrecht.

381 Klever.

382 Wanner.

383 Simon/Taeger.
} 
$\S \S 98 \mathrm{a}, \mathrm{b}$ in die Strafprozessordnung 1992 obsolet geworden ist, kann insofern auf eine Darstellung der Untersuchungen verzichtet werden.

\section{Rasterfahndung und organisierte Kriminalität (Graf 1997)}

Die Untersuchung von Graf hat die Beschreibung und Bewertung der gesetzlichen Regelungen zur Rasterfahndung nach den $\S \S 98 \mathrm{a}$, b StPO zum Gegenstand. Ziel der Untersuchung war es, zur Klärung der Frage beizutragen, ob sich die gesetzlichen Regelungen zur Rasterfahndung als Bewältigungsstrategie zur Eindämmung der Organisierten Kriminalität eignen. Um dieses Ziel zu erreichen, wurde zunächst ein Überblick über die Lage der Organisierten Kriminalität in Deutschland gegeben und aufgezeigt, welche Probleme im Bereich staatlicher Reaktion auf Organisierte Kriminalität auftreten. Daran anschließend wurde die Rasterfahndung bzgl. ihrer Eignung zur Bewältigung Organisierter Kriminalität analysiert. Im empirischen Teil der Untersuchung wurden die Ergebnisse einer bundesweiten Befragung von Experten dargestellt. In die Befragung wurden 20 Experten miteinbezogen, die sich im Rahmen ihrer Tätigkeit mit der Fahndungsmethode beschäftigt hatten und mit dem erforderlichen Fachwissen ausgestattet waren. Letztlich war auch die Frage der Verfassungsmäßigkeit der gesetzlichen Ausgestaltung der Rasterfahndung Gegenstand der Untersuchung.

Graf kommt im Rahmen der Untersuchung zu der Erkenntnis, dass die Rasterfahndung aufgrund ihrer geringen Anwendungspraxis nicht zur kriminalistischen Alltagsarbeit zu zählen sei. ${ }^{384}$ Insbesondere aufgrund der negativen Ergebnisse der Rasterfahndung zweifelt Graf an der Wirksamkeit der Ermittlungsmethode als Bewältigungsstrategie zur Eindämmung der organisierten Kriminalität. Insbesondere sei der Beweis noch nicht erbracht, dass die Ermittlungsmaßnahme dazu in der Lage sei, Hintermänner der organisierten Kriminalität zu ermitteln. Ferner hätten technische, organisatorische und personelle Rahmenbedingungen der Rasterfahndung einen negativen Einfluss auf die Anwendungshäufigkeit. ${ }^{385}$ Im Hinblick auf die Verfassungsmäßigkeit der Rasterfahndung kommt Graf zu dem Ergebnis, dass die gesetzliche Ausgestaltung zwar dem Gebot der Normenklarheit entspricht, hinsichtlich des Verhältnismäßigkeitsgrundsatzes jedoch Bedenken bestehen würden. ${ }^{386}$

\footnotetext{
${ }^{384}$ Graf, S.304.

385 Graf, S. 305f.

${ }^{386}$ Graf, S.295.
} 


\section{Rasterfahndung - Eine EDV-gestützte Massenfahndungsmethode im Spannungsfeld zwischen einer effektiven Strafverfolgung und dem Recht auf informationelle Selbstbestimmung (Siebrecht 1997)}

Die Untersuchung von Siebrecht stellt die Rasterfahndung mit polizeifremden und polizeiinternen Daten in einen verfassungsrechtlichen und strafrechtlichen Kontext. Im Rahmen der Untersuchung wurden von Siebrecht insbesondere die vom Bundesverfassungsgericht im Volkszählungsurteil aufgestellten Grundsätze zur Einschränkung des Rechts auf informationelle Selbstbestimmung herangezogen. Anhand dieser Grundsätze wurden die Verfassungsmäßigkeit der gesetzlichen Ausgestaltung der Rasterfahndung sowie der Schutzbereich und die Grenzen des Rechts auf informationelle Selbstbestimmung analysiert. Darüber hinaus wurde die mit der Rasterfahndung verbundene Intensität des Eingriffs untersucht. Dabei stellte Siebrecht eine mit der Maßnahme verbundene Eingriffshierarchie fest. Nach seiner Ansicht sei die positive Rasterfahndung am eingriffsintensivsten. Gefolgt würde diese von der negativen Rasterfahndung in polizeifremden Dateien und der negativen Rasterfahndung in polizeiinternen Dateien.

Im Ergebnis stellt Siebrecht diverse Unzulänglichkeiten in der Ausgestaltung des Verfahrens der Rasterfahndung nach den $\S \S 98 \mathrm{a}$, b StPO fest. Der auslösende Verdachtsgrad sei zu niedrig und der Katalog der Anlasstaten sei zu unübersichtlich und zu unpräzise. Ferner sei die verwendete Subsidiaritätsklausel zu „weich“. Darüber hinaus seien die heranzuziehenden personenbezogenen Daten nicht näher beschrieben. Weitere Kritik übt Siebrecht an der restriktiven Ausgestaltung der Benachrichtigungspflichten und der nicht ausreichenden Beteiligung der Datenschutzbeauftragten. Des Weiteren würden Löschungsvorschriften für den Fall fehlen, dass Zufallsfunde in einem anderen Verfahren nicht mehr benötigt würden. Letztlich sei die Anordnungskompetenz der Staatsanwaltschaft überflüssig. ${ }^{387}$

In Anbetracht dessen hält Siebrecht die Rasterfahndung in ihrer Ausgestaltung in den $\S \S 98 \mathrm{a}, \mathrm{b}$ StPO für verfassungswidrig. Die Normierung verstoße gegen den Grundsatz der Normenklarheit, den Bestimmtheitsgrundsatz und das Verhältnismäßigkeitsprinzip. Vor dem Hintergrund der mit der Maßnahme ohnehin nur bedingt möglichen Fahndungserfolge erscheint eine verfassungskonforme Änderung der Normierung nicht angebracht. Vielmehr sei nach Siebrecht ein gänzlicher Verzicht auf die Rasterfahndung aus rechtspolitischer Sicht angezeigt. ${ }^{388}$

387 Siebrecht, S. 179.
388 Siebrecht, S. $180 \mathrm{f}$. 


\section{Die Rasterfahndung nach § 98a StPO (Klever 2003)}

Den Mittelpunkt der Untersuchung von Klever bildet eine verfahrens- und verfassungsrechtliche Begutachtung der Rasterfahndung nach § 98a StPO. Hierzu wird zunächst die Grundrechtsrelevanz von Datenerhebung und Datenverwendung erörtert und das Gesetzgebungsverfahren dargestellt. Anschließend befasst sich Klever mit dem Inhalt der gesetzlichen Regelung und den Anordnungsvoraussetzungen des $\S$ 98a StPO. Im Anschluss werden die $\S \S 98 \mathrm{a}$ ff StPO einer verfassungs- und verfahrensrechtlichen Würdigung unterzogen. Dabei kommt Klever zu dem Ergebnis, dass die Rasterfahndung nicht den Ansprüchen des Rechtsstaates genügt. Er ist der Ansicht, dass die gesetzlichen Begrenzungen der Eingriffsbefugnisse sowie die flankierenden verfahrensrechtlichen Schutzvorkehrungen keine genügende restriktive Wirkung entfalten würden. Klever bemängelt die bewusst unbestimmt gehaltene Wahl der Merkmale der Eingriffsnorm. Dadurch sei nahezu jede menschliche Betätigung in jeglichem Lebensbereich geeignet, ein Teil des strafprozessualen Datenabgleichs zu werden, sofern dies einer beliebigen kriminalistischen Hypothese dienen kann. ${ }^{389}$

Zur Behebung der Missstände schlägt Klever Änderungen der gesetzlichen Ausgestaltung vor. So solle sich der Verdachtsgrad an den $\S \S 111$ und 163d StPO orientieren. Darüber hinaus sollte auf den Katalog des $\S 98$ a StPO verzichtet werden. Vielmehr wäre eine Strafmassregelung besser geeignet. ${ }^{390}$ Ferner hält Klever die Subsidiaritätsklausel für verzichtbar, da ihre begrenzende Funktion durch den Grundsatz des mildesten Mittels ohnehin relativiert werde. Letztlich sei die Ausübung der richterlichen Kontrolle durch einen Einzelrichter nicht gewährleistet. Einer solchen stehe die Komplexität der Maßnahme entgegen. Aus diesem Grund sei die Einführung einer Kollegialentscheidung notwendig. ${ }^{391}$

\section{Verbleibender Forschungsbedarf}

Während Graf sich im empirischen Teil der Untersuchung allein auf die Befragung von 20 Experten aus dem Bereich der Strafverfolgungsbehörden stützt, bedienen sich Siebrecht und Klever ausschließlich sekundäranalytischer Zugänge. Mithin liegen keine gesicherten empirischen Informationen zur Rasterfahndung vor. Wenn Albrecht/Dorsch/Krüpe von Defiziten im Bereich der empirischen Forschung zu besonderen Ermittlungsmethoden sprechen, ${ }^{392}$ dann gilt dies in besonderem Maße für die Rasterfahndung.

\footnotetext{
389 Klever, S.179.

390 Klever, S.181f.

${ }^{391}$ Klever, S.182f.

392 Albrecht/Dorsch/Krüpe, S.126.
} 
Im Zusammenhang mit der Rasterfahndung gibt es bislang keine Studie, die Implementations- und Evaluationsfragestellungen verfolgt. Informationen über die Anwendungshäufigkeit liegen bislang ebenso wenig vor wie zu den Anwendungsstrukturen der Ermittlungsmaßnahme. Zudem gibt es keine Erkenntnisse zu den Auswirkungen einer Rasterfahndung auf das Ermittlungsverfahren. Insofern notwendige Untersuchungen von Erfolg und Effizienz sind bislang vergeblich zu suchen. 



\section{Zweiter Teil \\ Die Methoden der Untersuchung}

Im vorangegangenen Teil der Untersuchung wurden die Anordnungsvoraussetzungen der Rasterfahndung erörtert. In diesem Zusammenhang wurde auf die Defizite der gesetzlichen Ausgestaltung hingewiesen. Ferner ergab eine Untersuchung des Forschungsstandes zur Rasterfahndung, dass bislang keine gesicherten empirischen Informationen zu dieser Ermittlungsmaßnahme vorliegen. Auf dieser Grundlage werden im Zweiten Teil der theoretische Ausgangspunkt der Untersuchung, die leitenden Untersuchungsfragen und das Konzept der Untersuchung dargestellt.

\section{A. Der theoretische Ausgangspunkt}

Das Ziel empirischer Strafverfahrensforschung ist der Versuch, empirische Grundinformationen zur Beschreibung der Vorgänge und Abläufe im Strafverfahren zu beschaffen. ${ }^{393}$ Allgemein wird die empirische Forschung das Recht betreffend auch als Rechtstatsachenforschung bezeichnet. Gegenstand empirischer Erhebung sind Tatsachen, d.h. reale Sachverhalte. Aus der Fülle der realen Sachverhalte muss eine Untersuchung daher ihr besonderes Untersuchungsobjekt so exakt wie möglich abgrenzen. Diese Abgrenzung geschieht im Rahmen der Rechtsanwendung durch die Rechtsnorm selbst. ${ }^{394}$ Gegenstand dieser Untersuchung ist die Rasterfahndung, wie sie in den $\S \S 98 \mathrm{a}, \mathrm{b}$ StPO geregelt ist.

Aufgrund der Annahme, dass die Rasterfahndung im repressiven Bereich nur vereinzelt zur Anwendung kommt, wurde der vorliegenden Untersuchung ein qualitativer Ansatz zugrunde gelegt. Qualitativ-empirische Sozialforschung umfasst ein methodologisches und methodisches Spektrum verschiedener Ansätze einschließlich der dazugehörigen wissenschaftstheoretischen Begründungen. ${ }^{395}$ Aus diesem Spektrum wurde für die vorliegende Untersuchung die qualitative Inhaltsanalyse als Ansatz herangezogen. Sie ermöglicht die Aufdeckung der für den Un-

\footnotetext{
393 Albrecht, Rechtstatsachenforschung, S.9.

${ }^{394}$ Rehbinder, S.56f.

395 Garz/Kraimer, S.1.
} 
tersuchungsgegenstand relevanten Einzelfaktoren und die Konstruktion von möglichen Zusammenhängen zwischen diesen Faktoren. ${ }^{396}$

Während die herkömmliche Sozialforschung dabei den Prozess der Bildung von Hypothesen aus der eigentlichen empirischen Untersuchung ausklammert und diese lediglich deduktiv durch das empirische Forschungsvorhaben überprüfen lässt, tendiert die qualitative Sozialforschung dazu, sofern die Bildung von Forschungshypothesen nach dem herkömmlichen Verständnis überhaupt angestrebt wird, diese durch die empirische Untersuchung, d.h. induktiv zu gewinnen. Folglich kehrt die qualitative Sozialforschung die chronologische und inhaltliche Abfolge des Forschungsprozesses gegenüber der herkömmlichen Forschungsmethodologie um. Somit wird die Hypothesenbildung zu einem konstruktiven Teil des Forschungsprozesses. ${ }^{397}$ Nur so ist es möglich, aufgefundene Fakten, deren Existenz nicht von Beginn an in Rechnung gestellt wurde, und im Rahmen der Untersuchung entdeckte Hypothesen mit einzubeziehen. Dementsprechend werden der vorliegenden Untersuchung keine zu überprüfenden Hypothesen vorangestellt. Diese werden vielmehr erst auf der Grundlage der Datenauswertung herausgebildet. Stattdessen werden der Untersuchung leitende Untersuchungsfragen vorangestellt.

Das Anliegen dieser empirischen Untersuchung ist es, die Anwendung und Umsetzung der gesetzlichen Regelung der Rasterfahndung zu analysieren. Darüber hinaus sollen auch Auswirkung und Einfluss der Rasterfahndung auf das strafrechtliche Ermittlungsverfahren untersucht werden. Will man Aussagen über die Anwendung und Umsetzung der Rasterfahndung treffen und die Maßnahme bzgl. ihrer Effizienz bewerten, dürfen dabei nicht jene Ziele vernachlässigt werden, welche der Gesetzgeber als Begründung für die Aufnahme in die Strafprozessordnung angeführt hat. So wurde die Notwendigkeit der Ergänzung der Strafprozessordnung durch das OrgKG mit der Zunahme von Straftaten im Bereich des Rauschgifthandels und der organisierten Kriminalität begründet. Es sollte den Strafverfolgungsbehörden ermöglicht werden: „über die Peripherie der kriminellen Organisation hinaus in deren Kernbereich einzudringen, ihre Strukturen zu erkennen und zu zerschlagen und die hauptverantwortlichen Straftäter, die Organisatoren, Finanziers und im Hintergrund agierende Drahtzieher zu überführen.“ " 398 Begründet der Gesetzgeber, wie im Rahmen des OrgKG geschehen, den Eingriff in Individualrechte mit einem bestimmten empirisch fassbaren Nutzen, so bedarf der Gesetzesvollzug einer eingehenden Evaluation und Kontrolle. ${ }^{399}$ Um das angestrebte Ziel zu erreichen, bedient sich diese Untersuchung sowohl Fragestellungen aus dem Bereich der Implementationsforschung als auch der Evaluationsforschung. Während die Implementationsforschung dabei verstärkt auf eine Prozessbeobachtung abhebt, ist die Evaluationsforschung ergebnisorien

\footnotetext{
396 Mayring, S.20.

397 Göppinger, Kriminologie, S.55.

398 BT.Drs. 12.W. 989 S.21.

399 So auch Albrecht, Rechtstatsachenforschung, S.10.
} 
tiert. ${ }^{400}$ Eine umfassende Analyse kann dementsprechend nur durch die Verwendung von deskriptiven und evaluativen Fragestellungen, also einer Kombination beider Forschungsbereiche, gewährleistet werden.

Für die Anwendung und Umsetzung gesetzlicher Regelungen und politischer Programme bietet sich die Implementationsforschung als Bezugsrahmen an. Dieser liegt die Annahme zugrunde, dass politische Programme die Ergebnisse administrativen Handelns nur sehr unvollständig bestimmen, d.h., dass ihre Wirkung wesentlich von der Art der Durchführung abhängt. ${ }^{401}$ Insofern stehen die Erfassung realer Handlungsabläufe und die Erklärung auftretender Diskrepanzen zwischen Norm und Wirklichkeit im Mittelpunkt der Implementationsforschung. ${ }^{402}$ Die deskriptiven Fragestellungen betreffen die Initiierung und den Ablauf der Ermittlungen sowie den Ausgang der Strafverfahren. Es sollen Art und Umfang der Rasterfahndung und ihre Stellung im Verfahren untersucht werden. Insbesondere soll analysiert werden, welche Faktoren für die Anordnung und Durchführung der Rasterfahndung relevant sind. Mithin steht die faktische Umsetzung der gesetzlichen Regelung im Mittelpunkt der Fragestellungen. Letztlich geht es aber auch um eine Darstellung der Entwicklung der Rasterfahndung seit ihrer Einführung in die Strafprozessordnung.

Zur Untersuchung der Wirkung der gesetzlichen Regelung, insbesondere in Bezug auf den Erfolg und die Effizienz der Ermittlungsmaßnahme, war es notwendig, sich der Evaluationsforschung zu bedienen. Es soll festgestellt werden, in welchem Umfang die Rasterfahndung zu Erkenntnissen geführt hat, die unmittelbar oder mittelbar zur Verurteilung wegen Anlassstraftaten geführt hat. Ferner soll untersucht werden, welche der im Rahmen der Implementationsfragestellungen herausgearbeiteten Faktoren Einfluss auf den Erfolg und die Effizienz der Maßnahme haben.

\section{B. Leitende Untersuchungsfragen}

Wie bereits aufgezeigt, liefert die bisherige empirische Forschung ausschließlich eine auf Befragungen von Polizeibeamten basierende Beschreibung der Ermittlungsmaßnahme Rasterfahndung. Die betreffende Untersuchung von Graf datiert zudem aus dem Jahr 1997. ${ }^{403}$ Mittlerweile sind seit der Implementation der Rasterfahndung in die Strafprozessordnung über vierzehn Jahre vergangen. Gesicherte Erkenntnisse über die Anwendungshäufigkeit der Maßnahme liegen bislang nicht

\footnotetext{
400 Oswald, S.110.

401 Mayntz, in: ders. (Hrsg.), Implementation politischer Programme, 236.

${ }^{402}$ Hucke/Wollmann, in: Mayntz (Hrsg.), Implementation politischer Programme, S. 219; Mayntz, in: ders. (Hrsg.), Implementation politischer Programme, 236.

${ }^{403}$ Graf.
} 
vor. Daher ist es zunächst vorrangiges Ziel der Untersuchung, einen präzisen Überblick über Anwendungshäufigkeit, Entwicklung und Strukturen der Rasterfahndung nach den $\S \S 98 \mathrm{a}, \mathrm{b}$ StPO zu liefern.

Der erste Teil der Untersuchung soll zunächst einmal Basisinformationen zur Anwendungshäufigkeit der Rasterfahndung liefern. Darüber hinaus sollen Erkenntnisse über den Verlauf und die Struktur von Verfahren mit Maßnahmen nach den $\S \S 98 \mathrm{a}, \mathrm{b}$ StPO erlangt und dargestellt werden. Dabei stehen die folgenden Fragestellungen im Vordergrund:

1. In wievielen Verfahren wurde die Rasterfahndung nach den $\S \S 98 \mathrm{a}, \mathrm{b}$ StPO seit ihrer Einführung in die Strafprozessordnung im Jahr 1992 durchgeführt?

2. Wie verteilen sich die Verfahren auf den Zeitraum von 1990 bis 2005 ?

3. Wie verteilen sich die Verfahren auf die einzelnen Bundesländer?

4. Wie verteilen sich die Verfahren auf die Katalogtaten des $\S 98$ a I StPO?

5. Wie viele Maßnahmen wurden insgesamt angeordnet?

6. Wie viele Maßnahmen ergehen pro Verfahren?

7. Wie verteilen sich die Maßnahmen auf die Katalogdelikte?

8. Wie ist das Verhältnis von durchgeführten zu nicht durchgeführten Maßnahmen?

9. Wie viele Beschlüsse ergehen insgesamt?

10. Wie viele Beschlüsse ergehen pro Verfahren?

11. Wie viele Beschlüsse ergehen pro Maßnahme?

12. Wie verteilen sich die Beschlüsse auf die Katalogdelikte?

13. Gegen wie viele Beschuldigte richten sich die Verfahren insgesamt?

14. Wie viele Beschuldigte pro Verfahren?

Im Anschluss daran wird der Anordnungsvorgang dargestellt und analysiert. Es werden die Anregung der Maßnahme durch die Polizei und der staatsanwaltschaftliche Antrag untersucht. Dabei stehen die Begründung der Maßnahme und die mit ihr verfolgten Ziele im Mittelpunkt der Analyse. Daran anknüpfend soll die richterliche Anordnung analysiert und in Beziehung zum Antrag gesetzt werden. So ist es möglich, die Kontrolle der Maßnahme im Rahmen der Umsetzung des Richtervorbehaltes zu analysieren. Im Einzelnen ergeben sich hierzu folgende Fragestellungen:

1. Von wem geht die Anordnungsinitiative aus? 
2. Gibt es bei der Subsumtion unter die Katalogtatbestände Umgehungstendenzen?

3. Welche Polizeidienststelle führt die Ermittlungen durch?

4. Wie lang ist der Zeitraum zwischen der Einleitung der Ermittlungen und der Anregung der Maßnahme?

5. Wie ist der Stand der Ermittlungen zum Zeitpunkt der Anregung?

6. Wie werden die polizeilichen Anregungen begründet?

7. Welches Ergebnis hat die Anregung zur Folge?

8. Kommt es zur Anordnung der Maßnahme durch die Staatsanwaltschaft?

9. Welcher Zeitraum liegt zwischen Anregung und Antrag?

10. Welche Ziele werden mit der Maßnahme verfolgt?

11. Wird zwischen positiver und negativer Rasterfahndung unterschieden?

12. Wie werden die staatsanwaltschaftlichen Anträge begründet?

13. Setzt sich die Antragsbegründung mit der Subsidiarität der Maßnahme auseinander?

14. Welchen Umfang haben die Antragsbegründungen?

15. Welches Ergebnis hat der Antrag zur Folge?

16. Welcher Zeitraum liegt zwischen Antrag und Anordnung?

17. Welcher Zeitraum liegt zwischen Anregung und Anordnung?

18. Wie werden die richterlichen Anordnungen begründet?

19. Setzt sich die Begründung der Anordnung mit der Subsidiarität der Maßnahme auseinander?

20. Welchen Umfang haben die Anordnungsbegründungen?

21. Gibt es Übereinstimmungen und Unterschiede zwischen Anregung, Antrag und Anordnung?

Des Weiteren befasst sich dieser Teil mit der Durchführung der Maßnahme. Hierbei sollen Abläufe im Rahmen der Durchführung analysiert und auftretende Probleme dargestellt werden. Der Fokus richtet sich dabei auf den Durchführungszeitraum, technische Probleme und die Intensität des mit der Maßnahme verbundenen Eingriffs. Von besonderem Interesse sind letztlich auch die Datenbestände, in denen die Rasterfahndung durchgeführt wird. Diese sollen benannt und Parallelen zwischen den einzelnen Verfahren aufgezeigt werden. Mithin ergeben sich die folgenden Fragestellungen: 
1. Wurden Ordnungs- oder Zwangsmittel angeordnet, um die betreffenden Daten zu erlangen?

2. Welche praktische Relevanz besitzt das Anordnungsverbot des $\S 98$ a I S.6 StPO?

3. Welcher Zeitraum liegt zwischen Anordnung und Durchführung?

4. Wie viel Zeit wird für die Durchführung benötigt?

5. Wer führt den Datenabgleich durch?

6. Gibt es Hinweise auf technische Probleme?

7. Mussten die angeforderten Daten von anderen getrennt werden und war die Trennung möglich?

8. Welche Datenbestände werden in den Abgleich einbezogen?

9. Welchen Umfang haben die angeforderten Daten?

10. Wie viele Personen sind von dem Abgleich betroffen?

11. Werden die erlangten Datenträger im Anschluss an den Abgleich zurückgegeben?

12. Werden die Daten nach dem Abgleich gelöscht?

13. Ist eine Niederschrift über die Löschung analog $§ 100 \mathrm{~b}$ VI S.2 StPO gefertigt worden?

14. Werden die erlangten Daten gem. § 98b III S.3 StPO zu Beweiszwecken in anderen Verfahren verwendet?

15. Werden Personen, gegen die weitere Ermittlungen geführt worden sind, gem. § 98a IV. S.1 i.V.m. § 163d V StPO benachrichtigt?

16. Wurde die Rasterfahndung gem. $\S 98$ b IV S.2 StPO an den Datenschutzbeauftragten gemeldet?

17. Gibt es Informationen über Kosten der Rasterfahndungen?

Gegenstand des letzten Abschnitts dieses Teils ist die Untersuchung des Verfahrensausgangs. Dabei stehen sowohl der Verfahrensausgang bezogen auf das Verfahren als auch bezogen auf die Beschuldigten im Fokus der Untersuchung. Es ergeben sich folgende Fragestellungen:

1. Welchen Inhalt haben die polizeilichen Abschlussberichte?

2. Wie viele Verfahren sind eingestellt worden?

3. Wie häufig kam es zur Anklage und zur Verurteilung?

4. Gegen wie viele Beschuldigte sind die Verfahren eingestellt worden?

5. Wie viele Beschuldigte wurden angeklagt und verurteilt? 
Im zweiten Teil der Untersuchung stehen die Rolle der Rasterfahndung und ihre Bedeutung für das einzelne Ermittlungsverfahren im Vordergrund. Um dies zu gewährleisten, ist es notwendig, auf den Einzelfall einzugehen. Hierzu werden die Grunddaten und der Verfahrensverlauf der betreffenden Verfahren einzeln dargestellt und analysiert. Die Untersuchung konzentriert sich dabei zunächst auf Fragen nach dem Erfolg und der Effizienz der Maßnahme. Darüber hinaus sollen aber auch Zusammenhänge zwischen der Rasterfahndung und weiteren Ermittlungsmaßnahmen aufgezeigt und analysiert werden. Letztlich soll dieser Abschnitt aber auch einen zusammenfassenden Überblick über folgende Fragestellungen geben:

1. Wie häufig hat die Rasterfahndung neue Ermittlungsansätze zur Folge?

2. Welche Ermittlungsmaßnahmen bauen auf den neuen Ermittlungsansätzen auf?

3. Wie viele Treffer / Prüffälle sind zu verzeichnen?

4. Führt die Rasterfahndung zur Identifizierung von Beschuldigten?

5. Führt die Rasterfahndung zur Identifizierung von Tatverdächtigen?

6. Führen die Erkenntnisse zu neuen Ermittlungsverfahren?

7. Gibt es Zufallsfunde?

8. Werden die Taten aufgrund der Erkenntnisse aus der Rasterfahndung aufgeklärt?

9. Wie ist der Erfolg einzuschätzen?

10. Werden in den Verfahrensakten Aussagen über den Erfolg der Rasterfahndung gemacht?

11. Unterscheiden sich die Erfolgseinschätzungen von denen der Untersuchung?

12. Wie verteilen sich die Einstellungen und Verurteilungen auf die Erfolge?

13. Wie verteilen sich die Erfolge auf die Katalogtaten?

14. Wie verteilen sich die Erfolge auf die verfolgten Ziele?

15. Welche Rolle spielt die Rasterfahndung in Anklage, Hauptverhandlung und Urteil?

16. Welche Rolle spielt die Rasterfahndung im Rechtsmittelverfahren?

17. Welche weiteren Kriterien haben Einfluss auf die Effizienz der Rasterfahndung?

Neben den ersten beiden Teilen der Untersuchung sollen im dritten Teil Einschätzungen der mit der Durchführung von Rasterfahndungen betrauten Personen 
dargestellt werden. Die Einschätzungen betreffen einerseits zentrale Fragestellungen und andererseits solche, die sich erst im Rahmen der Untersuchung ergeben haben. Mit Hilfe der Fragestellungen dieses Abschnitts sollen die Ergebnisse der ersten beiden Abschnitte einer Überprüfung unterzogen werden. Darüber hinaus ist es möglich informationelle Abläufe im Rahmen der Anordnung und Durchführung der Rasterfahndung näher zu untersuchen. Mithin bilden Fragen zur Zusammenarbeit der Strafverfolgungsbehörden einen Schwerpunkt dieses Teils. Auch soll den Strafverfolgungsbehörden die Möglichkeit gegeben werden, neben ihren Einschätzungen zur Anwendungstauglichkeit der $\S \S 98 \mathrm{a}$, b StPO, auch Vorschläge bezüglich Verbesserungsmöglichkeiten, die gesetzliche Ausgestaltung der Rasterfahndung betreffend, machen zu können. Im Rahmen dieses Abschnittes soll demnach zu folgenden Fragen Stellung genommen werden:

1. Welche Entscheidungskriterien sind für die Anordnung der Rasterfahndung erheblich?

2. Bereitet die Einordnung einer Straftat unter den Katalog des $\S 98 \mathrm{a}$ I StPO in der Praxis Probleme?

3. Welcher Begründungsaufwand wird für das Merkmal der „Straftat von erheblicher Bedeutung" betrieben?

4. Spielen bei der Entscheidung für eine Rasterfahndung technische, zeitliche und wirtschaftliche Erwägungen eine Rolle?

5. Wie ist die Zusammenarbeit von Polizei, Staatsanwaltschaften und Gerichten im Hinblick auf Konflikte in Anregung, Antrag und Anordnung zu beurteilen?

6. Gibt es Fallkonstellationen, die sich typischerweise für die Durchführung einer Rasterfahndung eignen?

7. Spielt die Rasterfahndung bei der Planung und Durchführung von Massengentests eine Rolle?

8. Gibt es für die Rasterfahndung geradezu prädestinierte Datenbestände?

9. Welche Vorzüge hat die Rasterfahndung gegenüber anderen Ermittlungsmaßnahmen?

10. Ist eine Situation denkbar, in welcher die Rasterfahndung aufgrund einer staatsanwaltschaftlichen Eilanordnung durchgeführt werden kann?

11. Wie häufig wird eine Rasterfahndung erwogen, dann aber aufgrund z.B. zeitlicher, rechtlicher oder wirtschaftlicher Gründe nicht durchgeführt?

12. Welche Rolle spielen Fragen des Datenschutzes im Rahmen der Rasterfahndung?

13. Wie gestaltet sich die Zusammenarbeit zwischen der datenführenden Stelle und den Strafverfolgungsbehörden im Hinblick auf die Akzeptanz der Maßnahme? 
14. Wann ist nach der Einschätzung der Ermittlungsbehörden eine Rasterfahdung erfolgreich?

15. Wie wird die praktische Bedeutung der Maßnahme für die Tätigkeit eingeschätzt?

16. Gibt es Unklarheiten bzgl. der gesetzlichen Ausgestaltung?

17. Ist der Katalog des $\S 98$ a I StPO ausreichend?

18. Bedarf die gesetzliche Regelung Verbesserungen?

\section{Die Wahl der Untersuchungsmethode}

Um der Komplexität des Untersuchungsgegenstandes gerecht zu werden und die aufgeworfenen Untersuchungsfragen umfassend beantworten zu können, war es notwendig, eine Kombination aus mehreren Methoden der empirischen Sozialforschung zu wählen. Das Kernstück der Untersuchung bildet die Analyse von strafrechtlichen Verfahrensakten. Bei den ausgewählten Verfahren handelt es sich ausschließlich um solche, in denen eine Maßnahme nach $\S \S 98 \mathrm{a}, \mathrm{b}$ StPO durchgeführt wurde. Ergänzt wird die Aktenanalyse durch die Auswertung von Expertengesprächen. Für die Auswahl dieser Untersuchungsmethoden waren die im Folgenden dargestellten Überlegungen leitend.

Bei der Auswahl der Aktenanalyse als Untersuchungsmethode war zu beachten, dass diese nicht frei von Problemen und teilweise erheblichen Bedenken ausgesetzt ist, welche im Zweck der Erstellung von Akten begründet liegen. So muss stets der soziale und zeitliche Zusammenhang beachtet werden, dem die Akten ihre Entstehung verdanken. ${ }^{404}$ Strafrechtliche Verfahrensakten dienen der Dokumentation der über den Täter und die Tat gewonnenen Erkenntnisse, um Gewissheit darüber zu erlangen, ob das beschriebene Verhalten unter einen Straftatbestand subsumierbar ist und welche strafrechtlichen Sanktionen angemessen sind. ${ }^{405}$ Mithin steht die Sicherung der geordneten Durchführung des Verfahrens im Mittelpunkt. ${ }^{406}$ Dabei werden Aktivitäten der Strafverfolgungsinstanzen umso vollständiger und zuverlässiger in den Akten verzeichnet sein, desto höher der insbesondere durch Vorschriften des Strafprozessrechts bestimmte Grad der Formalisierung liegt. ${ }^{407}$

Die Bedenken bestehen darin, dass Akten die Wirklichkeit infolge selektiver Wahrnehmung der Realität durch die Aktenproduzenten und gefilterter Fixierung

\footnotetext{
${ }^{404}$ Rehbinder, S.70.

405 Albrecht, Strafzumessung und Vollstreckung bei Geldstrafen, S.54.

406 Kürzinger, Kriminologie, Rn.50.

407 Dessecker, S.188.
} 
des Wahrgenommenen in der Akte nur unvollständig und zudem durch die Sichtweise der Aktenersteller verzerrt wiedergeben. ${ }^{408}$ Gemessen an den der Akten innewohnenden Kommunikations-, Kontroll- und Legitimationsfunktionen kann insofern von einer Realität eigener Art gesprochen werden. ${ }^{409}$ Die Aktenproduzenten wählen aus der Fülle der Informationen der Wirklichkeit diejenigen aus, die unter einer Entscheidungsperspektive interessant sind. Mithin stellt sich die Aktenführung als ein Mittel zielgerichteter Erledigungsstrategie dar. ${ }^{410}$ Für die Entscheidungen der Instanzen ist jedoch das maßgebend, was in den Akten steht, so dass die Realität eigener Art als eine Realität der Entscheidungen angesehen werden kann. ${ }^{411} \mathrm{Da}$ in vorliegender Untersuchung gerade die Entscheidungswege zur Durchführung einer Rasterfahndung untersucht werden sollen, können die gegen die Aktenanalyse vorgebrachten Bedenken hier vernachlässigt werden. Es sollen in erster Linie die Begründungen, wie sie in polizeilichen Anregungen, staatsanwaltschaftlichen Anträgen und den richterlichen Beschlüssen vorkommen, untersucht werden. Hierfür ist ausschließlich die Aktenanalyse als geeignete Untersuchungsmethode heranzuziehen. Darüber hinaus konnten durch die Analyse von Anklageschriften, Hauptverhandlungsprotokollen und Urteilen Informationen über die Rolle der Maßnahme als Beweismittel gewonnen werden.

Mithin bietet die Aktenanalyse einige Vorteile gegenüber anderen Untersuchungsmethoden. So stehen die Quellen über vergleichsweise lange Zeiträume unverändert zur Verfügung. Hinzu kommt, dass sie - da unabhängig von einem Forschungsprojekt entstanden - durch dessen Durchführung nicht verzerrt werden können, was von Bedeutung für die Zuverlässigkeit der Datenerhebung ist. ${ }^{412}$ Darüber hinaus spricht für die Aktenanalyse auch, dass keine Interaktion zwischen Forscher und Untersuchtem besteht. Folglich können keine Verzerrungen durch eine Erhebungssituation auftreten. ${ }^{413}$

$\mathrm{Zu}$ beachten ist jedoch, dass lange nicht alles in den Akten erscheint, was für einzelne Entscheidungen wichtig ist. Zu den Strategien der Umgehung von schriftlichen Festlegungen gehören u.a. Telefongespräche, beiläufiges Fallenlassen von Informationen und der Aufbau eines informellen Beziehungsgefüges, ohne deren Regeldurchbrechungen wohl kaum eine formale Organisation funktionieren würde.

408 Dölling, in: Kury (Hrsg.), methodologische Probleme in der kriminologischen Forschungspraxis, S.269.

409 Dölling, in: Kury (Hrsg.), methodologische Probleme in der kriminologischen Forschungspraxis, S.270.

${ }^{410}$ Hermann, in: Kaiser/Kury/Albrecht (Hrsg.), Kriminologische Forschung in den 80er Jahren, S.864.

411 Steffen, S.92f.

412 Eisenberg, Kriminologie, § 13 Rn.31.

413 Friedrichs, S.317. 
Demgemäß enthalten Akten insbesondere dort Lücken, wo die Legitimation einer Entscheidung gefährdet ist. ${ }^{414}$

Im Rahmen der Aktenanalyse stellte sich heraus, dass neben polizeilicher Anregung, staatsanwaltschaftlicher Beantragung und richterlichem Beschluss nur wenige andere Dokumente Informationen über die Maßnahme enthielten. Detaillierte Berichte über die Durchführung der Rasterfahndung waren die Ausnahme. Erkenntnisse über die technische Umsetzung und damit einhergehende Schwierigkeiten konnten deshalb nur vereinzelt gewonnen werden. Mithin bestand die Notwendigkeit einer über die Aktenanalyse hinausgehenden Evaluation.

Geeignet, um die aufgeworfenen Fragen umfassend zu beantworten, war die Durchführung von Expertengesprächen. Nur so war es möglich, detaillierte Erkenntnisse über informationelle Abläufe im Zuge der Anordnung und Durchführung der Maßnahme sowie über die technische Umsetzung zu erlangen. Darüber hinaus konnten aus der Aktenanalyse erlangte Erkenntnisse hinterfragt und Entscheidungswege rekonstruiert werden. Letztlich bestand nur so die Möglichkeit, Einschätzungen der mit der Durchführung von Rasterfahndungen beauftragten Personen hinsichtlich Erfolgsaussichten und Anwendungstauglichkeit der Maßnahme zu evaluieren. Zur Evaluation der Einstellung von Personen steht allein die Befragung als Untersuchungsmethode zur Verfügung. ${ }^{415}$

Die empirische Untersuchung unterteilt sich in drei Teile. Der Dritte und Vierte Teil beruhen ausschließlich auf den aus der Aktenanalyse gewonnen Erkenntnissen. Demgegenüber sind im Fünften Teil die Erkenntnisse aus den Expertengesprächen dargestellt.

\section{Die Aktenanalyse}

Im Mittelpunkt der Untersuchung steht die Analyse von strafrechtlichen Verfahrensakten. Die durch Aktenanalyse betriebene systematische Gewinnung von Informationen aus Dokumenten ist die am häufigsten verwendete Methode zur Erlangung kriminologischer Erkenntnisse. ${ }^{416}$ Insbesondere zur Rekonstruktion von Entscheidungs- und Definitionsprozessen der Strafverfolgungsinstanzen kann die Analyse von strafrechtlichen Verfahrensakten herangezogen werden. ${ }^{417} \mathrm{Um}$ dem mit dieser Untersuchung verfolgten qualitativen Ansatz gerecht zu werden, wurde bei der Erstellung des Fragebogens, welcher im Rahmen der Aktenanalyse zur Anwendung kam, viel Wert auf die Verwendung von nicht standardisierten Freitextvariablen gelegt. Insofern steht es dem qualitativen Ansatz nicht entgegen,

\footnotetext{
414 Blankenburg, in ders. (Hrsg.), Empirische Rechtssoziologie, S.195.

415 Kürzinger, Kriminologie, Rn.55.

416 Kürzinger, Kriminologie, Rn.50.

${ }^{417}$ Dessecker, S.190.
} 
wenn die Aktenanalyse auch als die am häufigsten verwendete quantitative Untersuchungsmethode bezeichnet wird. ${ }^{418}$

Durch die Analyse von staatsanwaltschaftlichen Ermittlungsakten war es möglich, die Struktur der Verfahren zu untersuchen, in denen eine Rasterfahndung durchgeführt worden ist. So ließen sich den Verfahrensakten Informationen über den Verfahrensgegenstand und die eingesetzten Ermittlungsmaßnahmen entnehmen. Ferner konnten Erkenntnisse über den Beantragungs- und Anordnungsvorgang erlangt werden. Da Einsicht in die kompletten Verfahrenakten genommen wurde, war es auch möglich, die Auswirkungen der Rasterfahndung auf den Verfahrensausgang zu analysieren.

Die Auswertung der erlangten Daten erfolgte auf der Grundlage einer qualitativen Inhaltsanalyse. ${ }^{419}$ Die Darstellung der durch die Aktenanalyse erlangten Daten erfolgt in zwei Teilen. Dem ersten Teil liegt zunächst eine Bestandsaufnahme der Einsatzpraxis zugrunde. Es soll ein grundlegender Überblick über die praktische Umsetzung der gesetzlichen Regelungen zur Rasterfahndung gegeben werden. Darüber hinaus liefert dieser Teil Informationen über Häufigkeit, Intensität, Dauer und Zeitpunkt der Maßnahme. Auch technische Probleme im Rahmen der Durchführung und entstandene Kosten werden aufgezeigt. Im zweiten Teil stehen Fragen nach Effizienz und Erfolg der Ermittlungsmaßnahme im Vordergrund. Hierzu werden die ausgewerteten Verfahren dargestellt und einzeln auf Effizienz und Erfolg der Rasterfahndung untersucht.

\section{Die Konstruktion des Fragebogens}

Die im vorherigen Abschnitt beschriebene Vorgehensweise steht in enger Verknüpfung mit dem Grundprinzip der Messung, nämlich Informationen von Fall zu Fall vergleichbar zu machen. Ändert sich die Messmethode, d.h. die Fragestellung von Fall zu Fall, dann ist nicht mehr zu entscheiden, ob Unterschiede, die sich ergeben, auf Unterschiede der Messmethode (variierende Fragestellungen) oder auf tatsächliche Unterschiede der zu messenden Merkmale zurückzuführen sind. ${ }^{420}$ Zur Gewährleistung einer einheitlichen Datenerhebung wurde daher ein standardisierter Fragebogen erstellt. Ziel des Fragebogens sollte es sein, die aus der Akte gewonnenen Informationen so zu erfassen, dass eine Rekonstruktion des Sachverhalts zu einem späteren Zeitpunkt gesichert würde.

Es zeigte sich schon bei der Identifizierung von Verfahren mit durchgeführter Rasterfahndungsmaßnahme nach $\S \S 98 \mathrm{a}$, b StPO, dass mit einer geringen Fallzahl

418 So z.B. von: Hermann, in: Kaiser/Kury/Albrecht (Hrsg.), Kriminologische Forschung in den 80er Jahren, S.863ff.

${ }^{419}$ Siehe 2. Teil A.; Grundlegend zur qualitativen Inhaltsanalyse: Mayring, S.1ff.

${ }^{420}$ Schnell/Hill/Esser, S.323. 
zu rechnen war. Insofern war die Verwendung von nicht-standardisierten Freitextvariablen im Bereich von für den Forschungsgegenstand besonders interessanten Stellen angebracht. Zwar bedeutete dies einen nicht unerheblichen Aufwand bei der Auswertung, machte den konkreten Einzelfall aber gleichsam einer qualitativen Analyse zugänglich.

Zur Gewährleistung der Rekonstruktion der Verbindung zwischen Verfahren, Rasterfahndungsmaßnahme und Beschuldigten wurde der Fragebogen in fünf Module gegliedert. Hierbei handelt es sich um ein Verfahrensmodul, ein Beschuldigtenmodul, ein Modul die Anklage, Hauptverhandlung und das Urteil betreffend, ein Rasterfahndungsmodul und ein Modul bzgl. des Erfolges und der Effizienz der Rasterfahndung.

Den Mittel- und Verknüpfungspunkt der einzelnen Module bildet das Verfahrensmodul. Es enthält Variablen zum Verfahrensverlauf und zur Tatphänomenologie. Darüber hinaus konnten Informationen zum zeitlichen und organisatorischen Ablauf der Ermittlungen erfasst werden. Das Verfahrensmodul war für jedes Verfahren einmal auszufüllen.

Das Beschuldigten- und das Rasterfahndungsmodul wurden erstellt, um Verfahren mit mehreren Beschuldigten und mehreren Rasterfahndungsmaßnahmen detailliert abbilden zu können. Bereits bei der Auswertung des ersten Verfahrens zeigte sich, dass diese Vorgehensweise auf der einen Seite zwar einen größeren Aufwand bedeutete, andererseits aber deutlich übersichtlicher war. Im Rahmen des betreffenden Verfahrens wurden 58 Personen als Beschuldigte geführt, so dass das Beschuldigtenmodul dementsprechend 58-mal auszufüllen war.

Dem Beschuldigtenmodul wurde ein weiteres Modul mit dem Titel Anklage / Hauptverhandlung / Urteil zugeordnet. Dieses Modul war für jeden Beschuldigten dann auszufüllen, wenn gegen diesen Anklage erhoben wurde. Das Modul beinhaltete neben grundsätzlichen Variablen zu Anklage, Hauptverhandlung und Urteil auch Variablen zur Rasterfahndung. Hierdurch konnten Informationen über die weitere Verwendung der durch die Rasterfahndung erlangten Erkenntnisse erfasst werden.

Das Rasterfahndungsmodul stellt das für den Untersuchungsgegenstand relevanteste Modul dar. Auszufüllen war dieses Modul für jede getroffene Anordnung gem. $\S \S 98 \mathrm{a}, \mathrm{b}$ StPO. Auch für Beschlüsse, welche lediglich Ergänzungen darstellten, wurde das Modul ausgefüllt. So war es möglich, die Informationen aus den einzelnen Anordnungen detailliert und übersichtlich zu erfassen. Infolgedessen konnte es vorkommen, dass in einem Verfahren zwar nur eine Rasterfahndungsmaßnahme durchgeführt, aber mehrere Rasterfahndungsmodule ausgefüllt wurden. Inhaltlich lässt sich dieses Modul in vier Kategorien gliedern. Hierbei handelt es sich um die Bereiche Anregung, Antrag, Beschluss und Durchführung der Maßnahme. Um der Bedeutung dieses Moduls gerecht zu werden, war neben Variablen mit vorgegebenen Antworten die Verwendung von nicht-standardisierten Freitext- 
variablen angebracht. Hierdurch konnten größere Zusammenhänge zwischen Anregung, Antrag und Beschluss ausführlich erfasst werden. Letztlich war jeder durchgeführten Rasterfahndung ein Modul die Effizienz und den Erfolg betreffend zuzuordnen. Da sich dieses Modul auf die gesamte Maßnahme bezieht, war es auch im Falle von Ergänzungsbeschlüssen nur einmal auszufüllen.

Darüber hinaus wurde für jedes Verfahren eine umfassende Fallzusammenfassung erstellt. Diese ermöglichte, auf die Besonderheiten des Einzelfalles einzugehen, und unterstützte somit ebenfalls den qualitativen Zugang. Zusätzlich wurde für jede durchgeführte Rasterfahndungsmaßnahme ebenfalls eine abschließende Zusammenfassung erstellt.

Abbildung 1: Struktur des Fragebogens

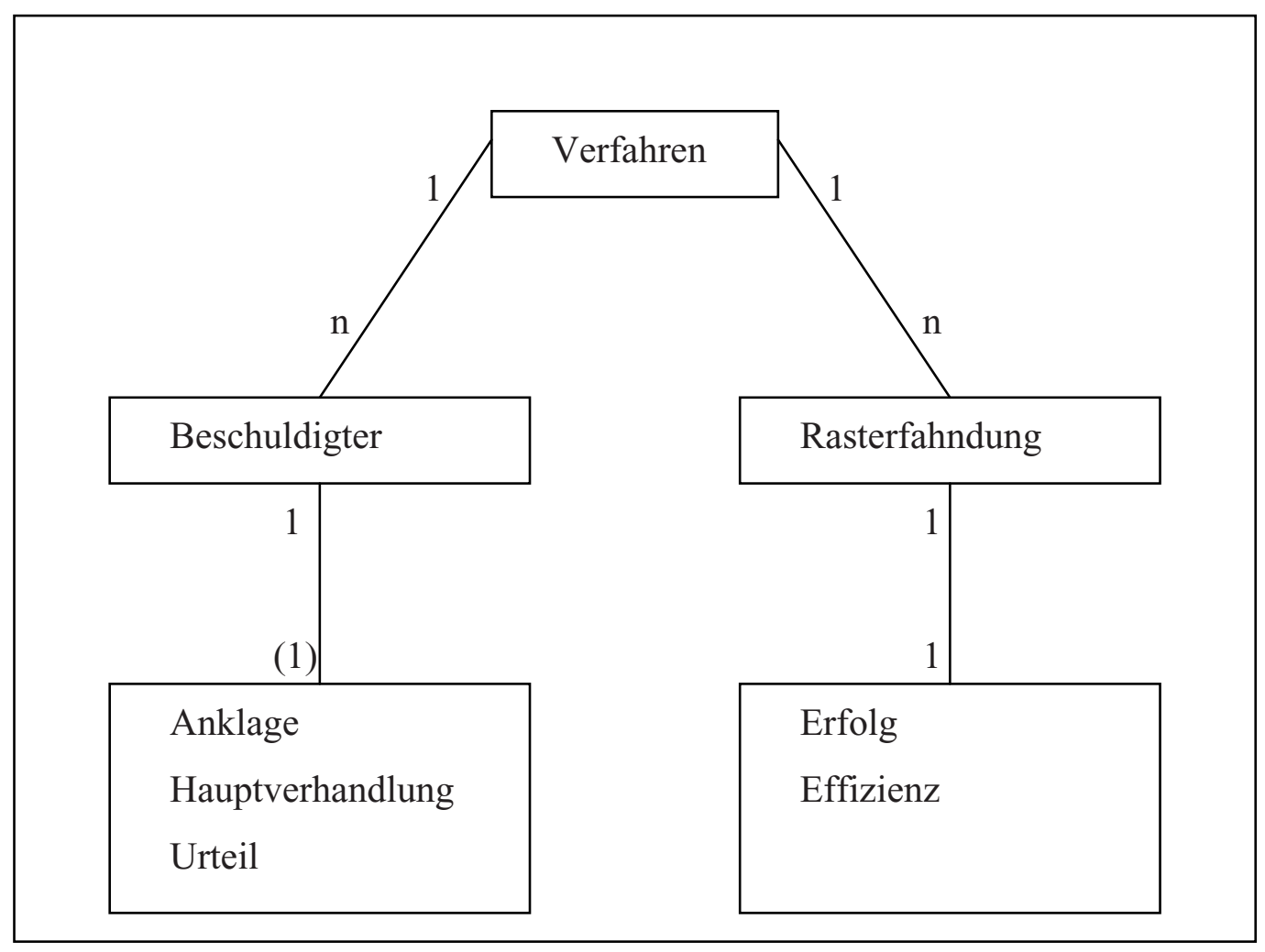

\section{Die Identifikation der Verfahren}

Aufgrund der zu erwartenden geringen Anzahl von Verfahren ist die Untersuchung als Vollerhebung angelegt. Ziel war es, alle Verfahren herauszufiltern, in denen eine entsprechende Maßnahme nach $\S \S 98 \mathrm{a}, \mathrm{b}$ StPO angeordnet und durchgeführt worden ist. Den zeitlichen Anknüpfungspunkt für die Datenerhebung bildet die Aufnahme der Fahndungsmaßnahme in die Strafprozessordnung im Jahr 1992. 
In einem ersten Arbeitsschritt zur Identifizierung der betreffenden Verfahren wurden zunächst die Datenschutzbeauftragten der einzelnen Bundesländer angeschrieben und um Auskunft darüber gebeten, ob Informationen über einschlägige Verfahren vorliegen. Dieses Vorgehen bot sich aufgrund der in $\S 98 \mathrm{~b}$ IV StPO normierten Unterrichtungspflicht an. Allerdings meldeten die Datenschutzbeauftragten unisono Fehlanzeige. In keinem Bundesland waren Maßnahmen nach den $\S \S 98 \mathrm{a}, \mathrm{b}$ StPO an die Datenschutzbeauftragten gemeldet worden.

Insofern bestand die Notwendigkeit, sich direkt an die einzelnen Staatsanwaltschaften zu wenden. Daher wurden zunächst alle Generalstaatsanwaltschaften und die Bundesanwaltschaft angeschrieben und um Mithilfe bei der Identifikation von entsprechenden Verfahren gebeten. Die Generalstaatsanwaltschaften leiteten das Ersuchen entweder an die Staatsanwaltschaften ihres Bezirkes weiter, oder regten an, sich direkt mit den Staatsanwaltschaften der betreffenden Bezirke in Verbindung zu setzen. Im letzteren Fall wurden die einzelnen Staatsanwaltschaften direkt angeschrieben.

Da die Verfahren innerhalb der Staatsanwaltschaften nach Delikten und nicht nach durchgeführten Ermittlungsmethoden archiviert werden, war eine Identifikation der betreffenden Verfahren erheblich erschwert. Von Vorteil für die Untersuchung war es, dass es sich bei der Rasterfahndung um eine Ermittlungsmaßnahme handelt, die den durchführenden Beamten häufig noch erinnerlich war. Darüber hinaus wurden im Rahmen der Expertengespräche Informationen über weitere Verfahren erlangt, die nicht von den Staatsanwaltschaften gemeldet wurden. Diese Verfahren konnten noch angefordert und in die Untersuchung aufgenommen werden. Durch diese zusätzliche Kontrolle der Ergebnisse der Anfragen an die Staatsanwaltschaften kann davon ausgegangen werden, dass die Anzahl von 30 identifizierten Verfahren mit Maßnahmen nach den $\S \S 98 \mathrm{a}$, b StPO nahezu einer Vollerhebung entspricht.

\section{Umfang der Akteneinsicht}

Von den 30 identifizierten Verfahren konnten lediglich 27 Verfahren in die Untersuchung einbezogen werden. Der Grund hierfür bestand darin, dass die übrigen

Verfahren noch nicht abgeschlossen waren und der Einsicht ermittlungstaktische Bedenken entgegenstanden.

In 5 der 27 Verfahren konnte nicht in vollem Umfang Einsicht genommen werden, da diese ebenfalls nicht abgeschlossen waren. Zusätzlich war in zwei dieser Verfahren auch der Datenabgleich noch nicht abgeschlossen. Allerdings konnten zumindest einige Grundinformationen über den Sachverhalt und die Rasterfahndungsmaßnahme erlangt und in die Untersuchung aufgenommen werden. Dies wurde dadurch ermöglicht, dass sich die ermittelnden Staatsanwaltschaften bereit erklärten, einen kurzen Fragebogen auszufüllen. Darüber hinaus wurden von diesen 
Verfahren Kopien der polizeilichen Anregungen, der staatsanwaltschaftlichen Anträge und der richterlichen Beschlüsse der Rasterfahndungsmaßnahme zur Auswertung übersandt. So war es möglich diese Verfahren im Rahmen des ersten Untersuchungsabschnittes beinahe vollständig in die Auswertung mit einzubeziehen. Dort, wo dies nicht möglich gewesen ist, wird im Folgenden jeweils darauf hingewiesen.

In den übrigen 21 Verfahren konnte vollständig in die staatsanwaltschaftlichen Ermittlungsakten Einsicht genommen werden. Der Umfang der Akten variierte von Verfahren zu Verfahren erheblich. Es wurden sowohl Akten mit einem Umfang von einigen hundert Seiten, als auch solche mit mehreren zehntausend Seiten ausgewertet.

\section{Durchführung der Aktenanalyse}

Die Aktenanalyse begann im Februar 2005. Aufgrund der Erkenntnisse aus den Expertengesprächen bzgl. weiterer Verfahren mit Maßnahmen nach den $\S \S 98 \mathrm{a}, \mathrm{b}$ StPO erstreckte sich die Aktenanalyse bis Oktober 2006. Der lange Zeitraum ermöglichte die Erfassung von Verfahren, in die zu Beginn der Aktenanalyse keine Einsicht gewährt werden konnte, da diese in der Zwischenzeit abgeschlossen waren.

Dem unterschiedlichen Umfang der Verfahrensakten entsprechend unterlag die Bearbeitungsdauer größeren zeitlichen Schwankungen. Von wenigen Stunden bis $\mathrm{zu}$ einer Woche nahm die Bearbeitung der einzelnen Verfahren in Anspruch. Die Einsichtnahme in die Verfahrensakten erfolgte teils in den Räumlichkeiten des Max-Planck-Institutes und teils in den Räumlichkeiten der betreffenden Staatsanwaltschaften. Letzteres war der Fall, wenn die Akten aufgrund ihres Umfanges nicht versandt werden konnten oder die Staatsanwaltschaften generell keine Akten postalisch weitergaben.

Mit der Auswertung der Verfahrensakten war lediglich der Verfasser dieser Untersuchung befasst. Dadurch war eine einheitliche Anwendung des Erhebungsinstruments gesichert. Zur Gewährleistung einer einheitlichen Auswertung war es darüber hinaus notwendig, die zu Beginn der Datenerhebung ausgewerteten Verfahren zu einem späteren Zeitpunkt nochmals auszuwerten. So war es möglich, diese nochmals zu kontrollieren und vorgenommene Modifikationen des Erhebungsinstruments zu berücksichtigen.

\section{Die Expertengespräche}

Im Rahmen der Aktenanalyse konnten praktische Erfahrungen der mit der Durchführung von Rasterfahndungen befassten Personen nicht berücksichtigt werden. Um die Ergebnisse der Aktenanalyse validieren und gegebenenfalls ergänzen zu können, war eine Befragung von Polizeibeamten und Staatsanwälten notwen- 
dig. ${ }^{421}$ Nur so war es möglich individuelles Detailwissen von Praktikern in die Untersuchung mit einzubeziehen. Mithin waren Erkenntnisse die Akzeptanz der Maßnahme betreffend nur im Rahmen von Expertengesprächen zu erlangen. Darüber hinaus konnten so auch Einschätzungen der Praktiker erlangt werden, was die mit der Maßnahme verbundenen Möglichkeiten betrifft. Letztlich bestand das Ziel der Expertengespräche auch darin, in Erfahrung zu bringen, inwiefern die gesetzliche Ausgestaltung der $\S \S 98 \mathrm{a}, \mathrm{b}$ StPO ausreichend ist oder möglicherweise Verbesserungen oder Ergänzungen bedarf. Die Auswertung der Expertengespräche basiert auf der Grundlage einer qualitativen Inhaltsanalyse. ${ }^{422}$

\section{Auswahl der Gesprächspartner}

Für die Gespräche wurden Experten der Polizei und der Staatsanwaltschaften ausgewählt. Voraussetzung für die Teilnahme an den Expertengesprächen waren konkrete Erfahrungen mit der Durchführung von Rasterfahndungen. Es war geplant, aus jedem Bundesland einen Staatsanwalt und einen Polizeibeamten in die Expertengespräche mit einzubeziehen.

Da sich im Rahmen der Aktenanalyse herausstellte, dass die Ermittlungsmaßnahme Rasterfahndung sehr häufig durch Mitarbeiter der Abteilung Operative Fallanalyse der Landeskriminalämter angeregt wird, wurden diese Personen als vorrangige Ansprechpartner ausgewählt. Mit der Bitte um Benennung eines Mitarbeiters der Abteilung Operative Fallanalyse wurde sich an die Landeskriminalämter gewandt.

Mangels durchgeführter Rasterfahndungen bestand jedoch nicht in jedem Bundesland die Möglichkeit, mit sachkundigen Mitarbeitern der OFA zu sprechen. In den betreffenden Bundesländern wurde dazu übergegangen, Mitarbeiter der Abteilung Staatsschutz der Landeskriminalämter in die Expertengespräche mit einzubeziehen. Voraussetzungen für die Auswahl dieser Personen waren Erfahrung im Bereich präventiv polizeilicher Rasterfahndung. Es stellte sich heraus, dass die Gespräche mit Mitarbeitern des Staatsschutzes sehr ergiebig waren. Aus diesem Grund wurde die Befragung ausgeweitet. Es wurden Mitarbeiter der Abteilung Staatsschutz auch in den Bundesländern in die Untersuchung miteinbezogen, in welchen bereits Mitarbeiter der Operativen Fallanalyse befragt worden waren.

Auch für den Bereich der Staatsanwaltschaften zeigte sich, dass nicht in jedem Bundesland Erfahrungen mit der Beantragung und Durchführung von Rasterfahndungen vorlagen. Insofern wurde verstärkt auf die aus der Aktenanalyse bekannten Staatsanwaltschaften zurückgegriffen. Hierbei stellte sich jedoch heraus, dass nicht in jeder der betreffenden Staatsanwaltschaften der zum Zeitpunkt der Beantragung

${ }^{421}$ Zur Auswahl der Befragung als Untersuchungsmethode, 2.Teil C.

422 Zur qualitativen Inhaltsanalyse siehe 2. Teil A. 
der Rasterfahndung zuständige Sachbearbeiter noch im Dienst war. Gründe hierfür waren beispielsweise die Versetzung oder die Pensionierung der betreffenden Personen. Daraus resultiert die deutlich geringere Anzahl von befragten Staatsanwälten. Aus den Erkenntnissen der Aktenanalyse wurde jedoch deutlich, dass der staatsanwaltschaftliche Antrag der Maßnahme in einem Großteil der Fälle sehr stark an die polizeiliche Anregung angelehnt war. Demnach liegt der Hauptaufwand der Begründungsarbeit bei Mitarbeitern der Polizei, so dass diese ohnehin von größerem Interesse für die Untersuchung waren.

Im Einzelnen stützten sich die Ergebnisse der Expertengespräche auf die Befragung von:

- Neun Mitarbeitern der Abteilung Staatsschutz der Landeskriminalämter

- Acht Mitarbeitern der Abteilung Operative Fallanalyse der Landeskriminalämter und des Bundeskriminalamtes

- Drei Kriminalbeamten

- Vier Staatsanwälten

\section{Durchführung der Expertengespräche}

Um eine einheitliche Durchführung der Expertengespräche zu gewährleisten, wurde ein Interviewleitfaden erstellt. Inhaltlich lässt sich dieser in fünf Teilbereiche gliedern. Im ersten Bereich standen Fragen zum Tätigkeitsprofil der teilnehmenden Gesprächspartner im Vordergrund. Der umfangreichste Bereich behandelte Fragen der Anwendung und Umsetzung der gesetzlichen Regelung der $\S \S 98 \mathrm{a}, \mathrm{b}$ StPO sowie der Zusammenarbeit der Strafverfolgungsbehörden im Rahmen der Anordnung einer Rasterfahndung. Daran schlossen sich Fragen zur Rolle der Rasterfahndung als Beweismittel in der Hauptverhandlung und zu Erfolg und Effizienz der Maßnahme an. Der letzte Bereich des Interviewleitfadens befasst sich mit dem präventiven Einsatz der Maßnahme. Für die Gespräche mit Mitarbeitern des Staatsschutzes wurden die einzelnen Fragen an die jeweilige gesetzliche Ausgestaltung der Rasterfahndung im Polizeigesetz des betreffenden Bundeslandes angepasst.

Die Befragung wurde im Oktober und November 2006 durchgeführt. Bis auf ein Gespräch, welches vor Ort stattfand, wurden alle Gespräche telefonisch durchgeführt. In einzelnen Fällen wurden die Gespräche aufgrund vorliegender Genehmigung der Gesprächspartner aufgezeichnet und anschließend transkribiert. Ansonsten wurden die Gespräche protokolliert. 


\title{
Dritter Teil \\ Die Ergebnisse der rechtstatsächlichen Untersuchung
}

\begin{abstract}
A. Grundgesamtheiten
Zu Beginn des rechtstatsächlichen Teils der Untersuchung werden die Grundgesamtheiten dargestellt. Die Darstellung gliedert sich in Ausführungen zu den Verfahren, zu den Maßnahmen und zu den Beschuldigten.
\end{abstract}

\section{Verfahren}

\section{Verfahren mit Maßnahmen nach den $\$ \S 98 a, b$ StPO}

Aufgrund der Anfragen an die Staatsanwaltschaften konnten 27 Verfahren identifiziert werden, in welchen eine oder mehrere Maßnahmen nach den $\S \S 98 \mathrm{a}, \mathrm{b}$ StPO durchgeführt worden sind. Bei diesen 27 Verfahren konnte überwiegend in die gesamten Verfahrensakten Einsicht genommen werden. Jedoch war bei einigen Verfahren keine komplette Akteneinsicht möglich, da diese sich noch im Stadium der Ermittlungen befanden oder eine umfangreiche Einsichtnahme aus datenschutzrechtlichen Gründen abgelehnt wurde.

Darüber hinausgehend konnten drei weitere Verfahren mit Maßnahmen nach den $\S \S 98 \mathrm{a}, \mathrm{b}$ StPO identifiziert werden. In diese Verfahren konnte jedoch keine Einsicht genommen werden, da diese sich ebenfalls noch im Stadium der Ermittlungen befanden.

\section{Verteilung der Verfahren auf den Zeitraum von 1990 bis 2005}

Zunächst soll untersucht werden, wie sich die Verfahren mit Anordnungen nach den $\S \S 98 \mathrm{a}, \mathrm{b}$ StPO auf die Zeitspanne seit Einführung in die Strafprozessordnung verteilen. Maßgebend für die Einordnung der Verfahren war das Datum des Einleitungsvermerks. Es konnte festgestellt werden, dass Maßnahmen nach den $\S \S 98 \mathrm{a}$, b StPO in Verfahren durchgeführt worden sind, deren Ermittlungen bis zu zwei Jahre vor der Einführung der Rasterfahndung in die Strafprozessordnung begonnen 
haben. Aus diesem Grund wurde für die Darstellung der Entwicklung die Zeitspanne auf die Jahre 1990 und 1991 ausgedehnt.

Abbildung 2: Entwicklung der Verfahren mit Anordnungen nach $\S \S 98 a, b \operatorname{StPO}(n=27)$

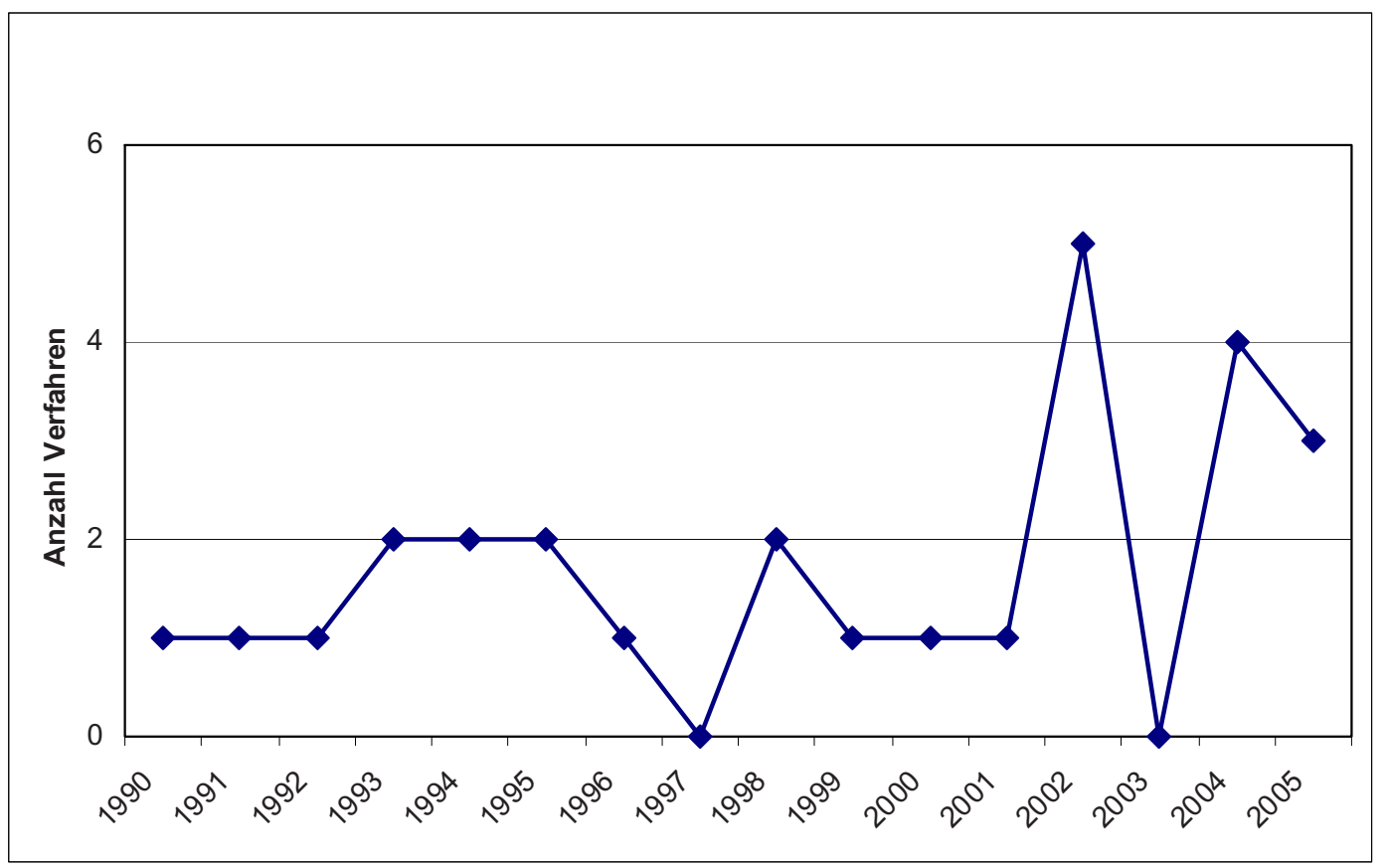

In den Jahren 1990 bis 2001 bewegte sich die Anzahl der Verfahren mit Maßnahmen nach den $\S \S 98 \mathrm{a}$, b StPO zwischen einem und zwei. Lediglich im Jahr 1997 wurde kein Verfahren eingeleitet, in dem es zur Durchführung einer Rasterfahndung kam. Ab dem Jahr 2002 war eine deutliche Zunahme von Verfahren zu erkennen, wobei im Jahr 2003 allerdings kein Verfahren zu verzeichnen war. Insgesamt wurden 12 der 27 Verfahren in den Jahren 2002 bis 2005 eingeleitet. Diese deutliche Zunahme der Verfahren mit Rasterfahndungen beruht auf mehreren Faktoren. So kommt in Betracht, dass die Akzeptanz der Ermittlungsmaßnahme bei den Strafverfolgungsbehörden seit ihrer Einführung in die Strafprozessordnung stetig ansteigt. ${ }^{423}$ Ein weiterer Grund ist die Zunahme von gespeicherten Daten in allen Lebensbereichen und damit verbundene Möglichkeiten, Abgleiche durchzuführen. Darüber hinaus hat es insbesondere im Bereich der für die Abgleiche notwendigen Software erhebliche Entwicklungen gegeben. Es kann festgehalten werden, dass der Grund für die Zunahme in einem Zusammenspiel der aufgezeigten Faktoren zu sehen ist.

${ }^{423}$ Dieser Annahme soll im Verlauf der Untersuchung anhand der Expertengespräche nachgegangen werden. Siehe hierzu: 5.Teil. 


\section{Verteilung der Verfahren auf die Bundesländer}

Die Verfahren mit Anordnungen nach den $\S \S 98 \mathrm{a}, \mathrm{b}$ StPO verteilen sich ungleich auf die Bundesländer. In sieben Bundesländern gab es kein Verfahren, in dem eine Rasterfahndung angeordnet wurde. Dagegen wurden in Nordrhein-Westfalen acht und in Bayern sechs Verfahren mit Anordnungen nach den $\S \S 98 \mathrm{a}$, b StPO geführt. In diesen beiden Bundesländern wurden damit mehr als 50\% der gesamten Verfahren geführt. Des Weiteren sind Hessen mit vier und der Generalbundesanwalt mit drei Verfahren hervorzuheben. Mithin verteilen sich 22 der 27 Verfahren auf drei Bundesländer und den Generalbundesanwalt.

Abbildung 3: Verteilung der Verfahren auf die Bundesländer ( $n=27)$

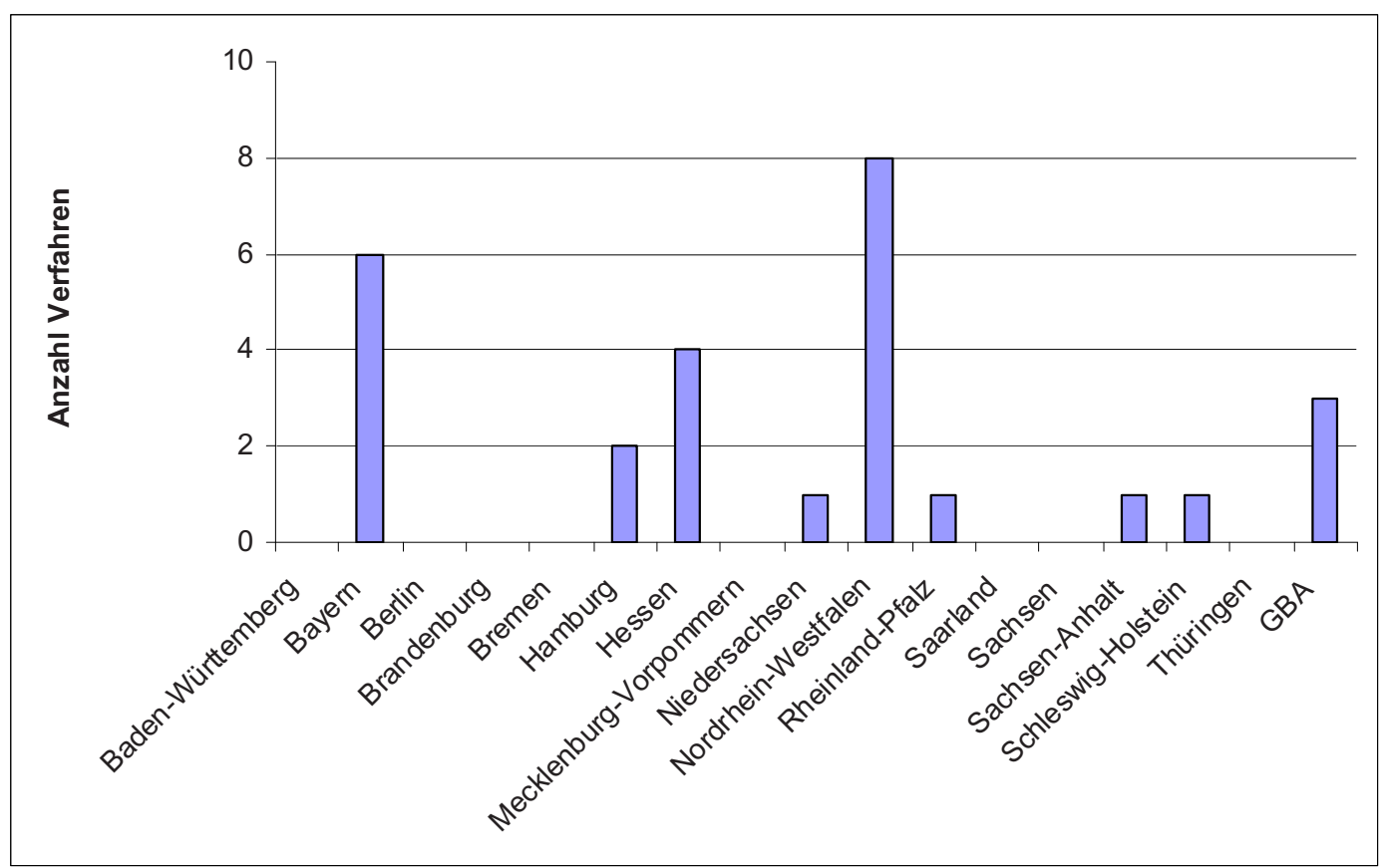

Bei den Bundesländern Bayern und Nordrhein-Westfalen handelt es sich um die bevölkerungsreichsten Bundesländer. ${ }^{424}$ Ferner liegen die beiden Bundesländer aufgrund dessen auch bei der Anzahl der Straftaten vor den übrigen Bundesländern. Da es in absoluten Zahlen gesehen in diesen beiden Bundesländern zu mehr Straftaten kommt, bieten sich auch mehr Ansatzpunkte für die Anwendung der Ermittlungsmaßnahme.

Aus der Aktenanalyse ergab sich darüber hinaus eine weitere Erklärung für die Verteilung der Verfahren. Bei einem Großteil der Verfahren aus den drei Bundesländern und des Generalbundesanwalts handelte es sich um solche, in denen die

${ }^{424}$ Nordrhein-Westfalen: 18 Millionen Einwohner; Bayern: 12,4 Millionen Einwohner. 
Ermittlungen mit der Unterstützung der betreffenden Landeskriminalämter und des Bundeskriminalamtes geführt worden sind. Dabei kam es mehrfach zur Anfertigung von Fallanalysen durch die Abteilungen Operative Fallanalyse. Diese Abteilungen gaben in den betreffenden Verfahren die Empfehlungen ab, eine Rasterfahndung durchzuführen. Die Erkenntnis aus der Aktenanalyse, dass sich die genannten Abteilungen offensichtlich mehr mit den Möglichkeiten der Ermittlungsmaßnahme auseinandergesetzt hatten als in den übrigen Bundesländern, sollte sich zusätzlich durch die Expertengespräche bestätigen. ${ }^{425}$

\section{Verteilung der Katalogdelikte über die Verfahren}

Bei der Verteilung der Katalogdelikte auf die Verfahren ist zu beachten, dass es zu Mehrfachnennungen gekommen ist. Es wurden in den 27 Verfahren 34 Nennungen von Katalogdelikten aufgenommen. In Verfahren, in denen es zu mehr als einer Anordnung kam, wurden in den Anordnungen keine unterschiedlichen Katalogdelikte angeführt. In zwei Verfahren stützten sich die Anordnungen auf drei Katalogdelikte und in drei weiteren Verfahren auf jeweils zwei Katalogdelikte. Die Kombinationen der Katalogdelikte bestehen aus Straftaten auf dem Gebiet des Staats- und Verfassungsschutzes, gemeingefährlichen Straftaten, Straftaten gegen Leib und Leben, Straftaten auf dem Gebiet des BtMG, als Bandenmitglied und in anderer Weise organisiert begangen Straftaten.

Gegenstand des einen Verfahrens aus der Deliktsgruppe des § 98a I S.1 Nr.1 StPO war eine Straftat auf dem Gebiet des Betäubungsmittelgesetzes. Daraus ergibt sich, dass keine der Anordnungen Straftaten auf dem Gebiet des Waffenhandels und auf dem Gebiet der Geld- und Wertzeichenfälschung zum Gegenstand gehabt hat. Auffallend ist die hohe Anzahl von Verfahren, in denen die Anordnungen unter Nennung einer Straftat des § 98a I S.1 Nr.4 StPO getroffen wurde. Diese 19 Verfahren schlüsseln sich in zehn Straftaten gegen Leib und Leben, fünf Straftaten gegen Leib und Leben in Kombination mit Straftaten gegen die sexuelle Selbstbestimmung, eine Straftat gegen die sexuelle Selbstbestimmung, zwei Straftaten gegen die persönliche Freiheit und eine Straftat gegen die persönliche Freiheit und gegen Leib und Leben auf. Bei den Straftaten gegen Leib und Leben handelt es sich ausnahmslos um Tötungsdelikte.

Der Kategorie gewerbs- und gewohnheitsmäßige Straftaten liegen vier Nennungen von gewerbsmäßigen Straftaten und einer Kombination von gewerbs- und gewohnheitsmäßigen Straftaten zugrunde. Der Kategorie Bandenmitglied oder in anderer Weise organisiert begangen liegen zwei Nennungen von in anderer Weise organisiert zugrunde.

${ }^{425}$ Siehe 5. Teil D. II. 
Abbildung 4: Verteilung der Katalogdelikte auf die Verfahren ( $n=34)$

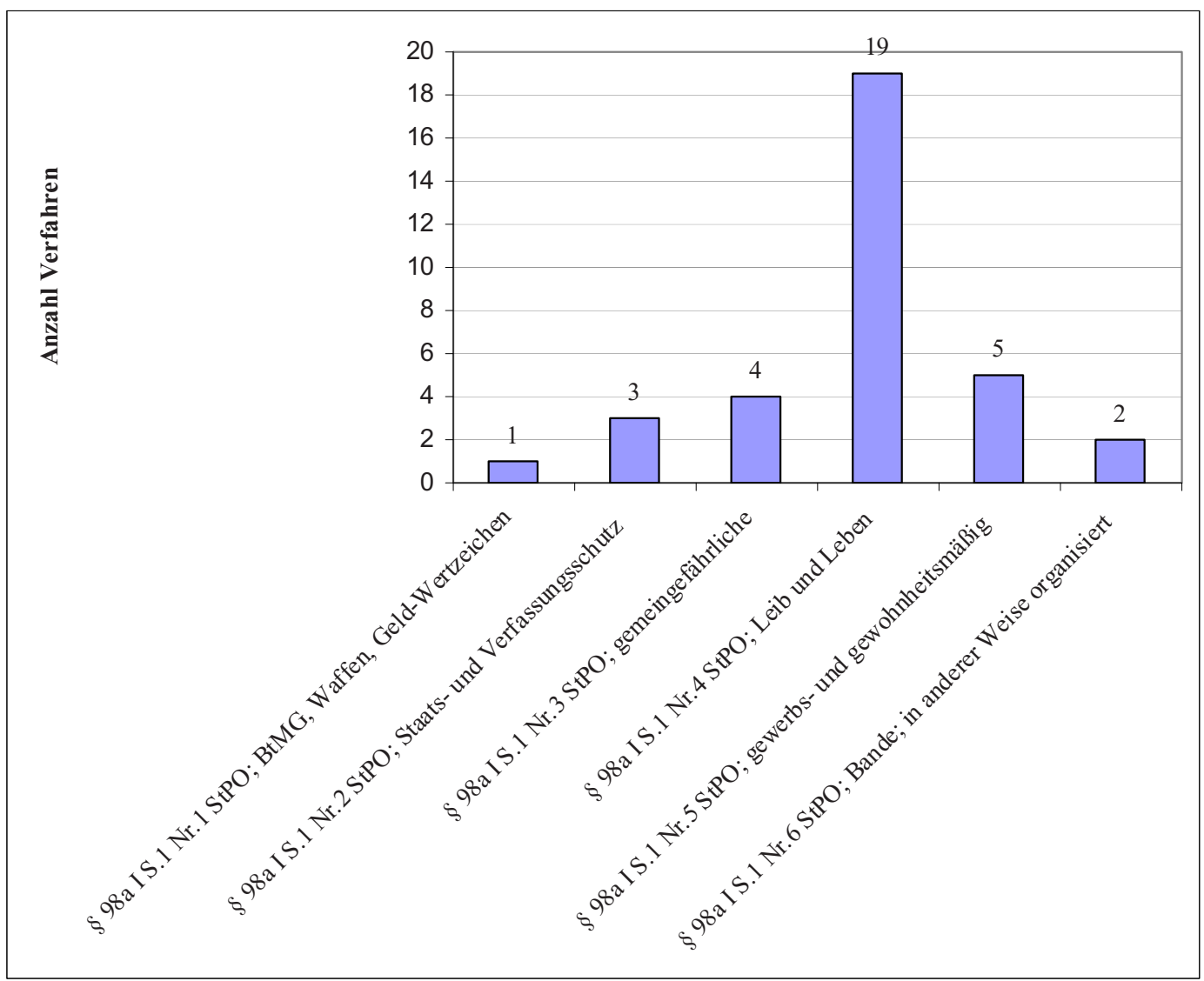

\section{Maßnahmen}

\section{Maßnahmen insgesamt}

Bei der Feststellung von Maßnahmen ergaben sich erhebliche Schwierigkeiten. Die einzelnen Maßnahmen setzen sich überwiegend aus mehreren Anordnungen zusammen. Häufig wurde für jeden Datenbestand, der in den Datenabgleich integriert werden sollte, ein separater Beschluss erlassen. Wenn die aufgrund dieses Beschlusses erhobenen Daten jedoch in einen Datenabgleich mündeten, wurde dieser Vorgang als eine Maßnahme gewertet. Auf der Grundlage dieser Wertung wurden in den 27 Verfahren 31 Maßnahmen nach den $\S \S 98 \mathrm{a}$, b StPO festgestellt.

Da Maßnahmen, welche in einem Verfahren durchgeführt worden sind, unterschiedliche Feststellungen nach sich ziehen können, bilden die $31 \mathrm{Maßnahmen} \mathrm{die}$ Grundgesamtheit für die überwiegende Anzahl der Untersuchungsabschnitte. Teilweise ist es jedoch notwendig, die Auswertung auf die Zahl der Verfahren zu stützen. Nur durch dieses Vorgehen ist es möglich, verfahrensspezifische Ausprägungen zu analysieren. 


\section{Maßnahmen pro Verfahren}

In 23 Verfahren wurde jeweils nur eine Maßnahme angeordnet. In den übrigen vier Verfahren wurden jeweils zwei Maßnahmen angeordnet. Es ist festzuhalten, dass in knapp $90 \%$ der Verfahren nur eine Maßnahme angeordnet wurde.

\section{Verteilung der Katalogdelikte auf die Maßnahmen}

Genauso wie bei der Verteilung der Katalogtaten auf die Verfahren ist auch bei der Verteilung der Katalogtaten auf die Maßnahmen zu beachten, dass es zu Mehrfachnennungen gekommen ist. Insgesamt kam es zu 41 Nennungen von Katalogtaten. Diese beziehen sich auf die 31 Maßnahmen. Mit 20 Nennungen bilden die Straftaten gegen Leib und Leben, die sexuelle Selbstbestimmung und die persönliche Freiheit die Majorität. Gemeingefährliche Straftaten und gewerbs- oder gewohnheitsmäßig begangene Straftaten bilden die Grundlage für je sechs Maßnahmen. Darüber hinaus werden Straftaten auf dem Gebiet des Staats- und Verfassungsschutzes viermal, als Bandenmitglied oder in anderer Weise organisiert begangene Straftaten dreimal und Straftaten auf dem Gebiet des BtMG zweimal angeführt. Es bleibt festzuhalten, dass die 20 Maßnahmen, welche auf der Nennung von Straftaten gegen Leib und Leben, die sexuelle Selbstbestimmung und die persönliche Freiheit beruhen, gemessen an der Gesamtzahl von 31 Maßnahmen fast $65 \%$ ausmachen.

\section{Durchgeführte und nicht durchgeführte Maßnahmen}

Von den 31 Maßnahmen konnten für 2 Maßnahmen keine Informationen darüber erlangt werden, ob es zur Durchführung des Datenabgleichs gekommen ist. Es handelt sich bei den zugrundeliegenden Verfahren um solche, die zum Zeitpunkt der Einsichtnahme in die Verfahrensakten noch nicht abgeschlossen waren. Die übrigen 29 angeordneten Maßnahmen sind durchgeführt worden.

\section{Beschlüsse}

\section{Beschlüsse insgesamt}

Wie zuvor aufgezeigt setzen sich die einzelnen Maßnahmen überwiegend aus mehreren Beschlüssen zusammen. Im Rahmen der Aktenanalyse konnten in den 27 Verfahren 62 Beschlüsse nach den $\S \S 98$ a, b StPO festgestellt werden.

\section{Beschlüsse pro Verfahren}

In $40 \%$ der Verfahren erging lediglich ein Beschluss nach den $\S \S 98 \mathrm{a}, \mathrm{b}$ StPO. Weitere $30 \%$ der Verfahren enthielten zwei Beschlüsse. Zu jeweils $11 \%$ konnten 
in den Verfahren drei und fünf Beschlüsse festgestellt werden. Letztlich enthielten jeweils $4 \%$ der Verfahren vier und sieben Beschlüsse. Daraus ergibt sich, dass in etwa $60 \%$ der Verfahren zwei und mehr Beschlüsse erlassen worden sind.

\section{Beschlüsse pro Maßnahme}

Bei der Betrachtung der Verteilung der Beschlüsse auf die Maßnahmen spiegelt sich deutlich wider, dass die einzelnen Maßnahmen große Unterschiede aufgewiesen haben. Insbesondere der Umfang der in den jeweiligen Datenabgleich einbezogenen Daten wirkt sich auf die Anzahl der Beschlüsse aus.

Abbildung 5: Beschlüsse pro Maßnahme (n=31)

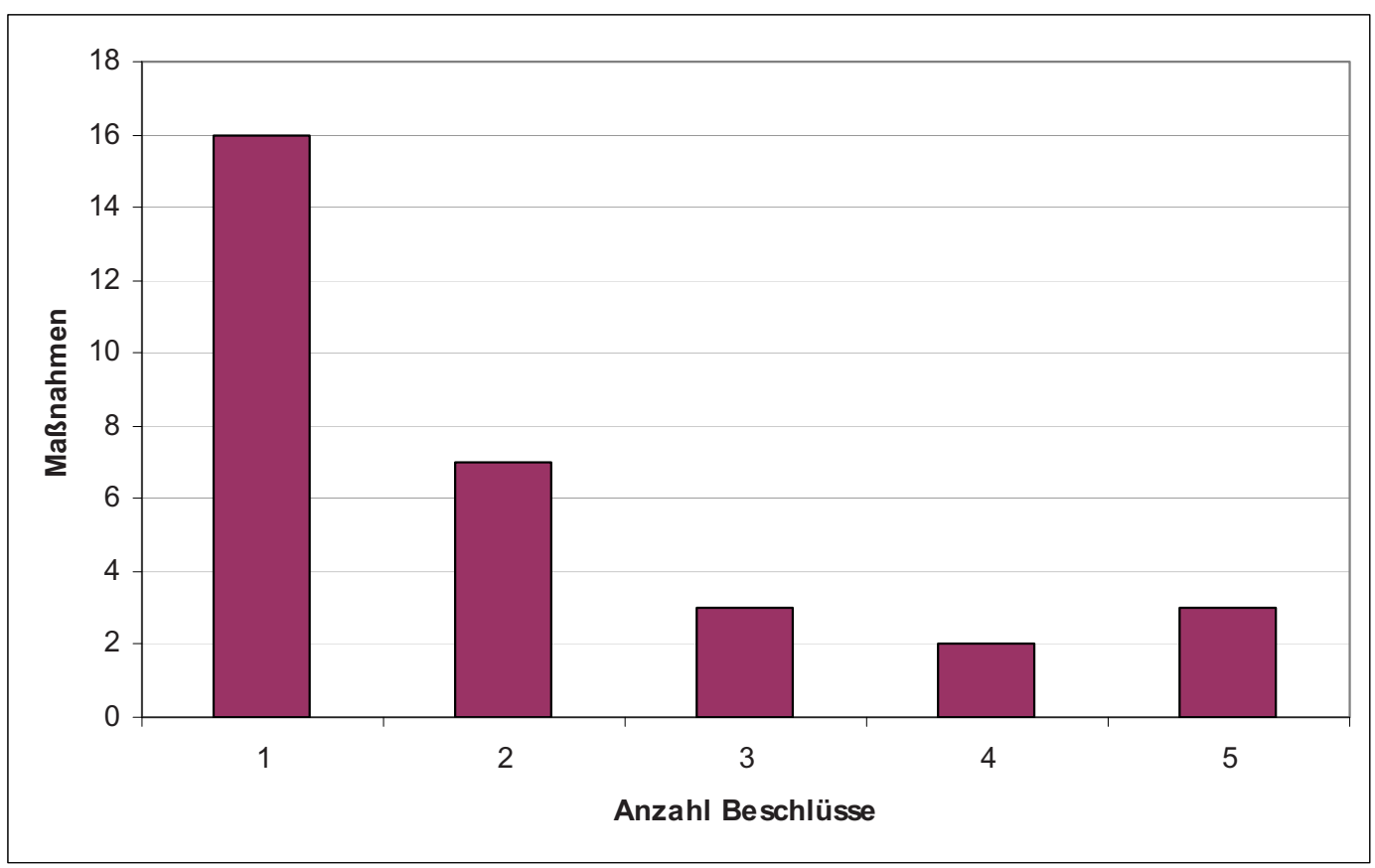

Wie bereits festgestellt, wurde für beinahe jeden Datenbestand, welcher in den Datenabgleich einbezogen werden sollte, ein separater Beschluss erlassen. Daraus ergibt sich, dass Rasterfahndungen, welche in umfangreichem Maße Daten einbeziehen, aus mehr Beschlüssen bestehen, als solche Maßnahmen, die nur wenige Daten in den Abgleich einbeziehen. Es zeigt sich, dass die 16 Maßnahmen, welche auf einem Beschluss beruhen, die größte Gruppe bilden. Bezogen auf alle $31 \mathrm{Maß-}$ nahmen macht diese Gruppe einen Anteil von mehr als $50 \%$ aus. Im Umkehrschluss bedeutet dies jedoch, dass die Gruppe von Maßnahmen, in denen zwei oder mehr Beschlüsse ergehen, ebenfalls beinahe $50 \%$ ausmacht. In sieben Fällen setzt sich die Anordnung der Maßnahme aus zwei Beschlüssen zusammen. Diese Maßnahmen machen einen Anteil von etwas mehr als $20 \%$ aller Maßnahmen aus. Drei 
weitere Maßnahmen setzen sich aus jeweils drei Beschlüssen und zwei Maßnahmen aus jeweils vier Beschlüssen zusammen. Letztlich basieren drei Maßnahmen auf jeweils fünf Beschlüssen.

\section{Verteilung der Katalogdelikte auf die Beschlüsse}

Auch bei der Verteilung der Katalogdelikte auf die Beschlüsse waren Mehrfachnennungen zu beachten. Auf die 62 Beschlüsse verteilen sich insgesamt 79 Nennungen von Katalogdelikten. Insgesamt enthielten 45 Beschlüsse Straftaten gegen Leib und Leben, die sexuelle Selbstbestimmung und die persönliche Freiheit. Diese wurden einzeln oder in Kombination mit anderen Katalogdelikten genannt. Jeweils zehnmal wurden Straftaten auf dem Gebiet des Staatsund Verfassungsschutzes sowie gewerbs- oder gewohnheitsmäßig begangene Straftaten in den Beschlüssen genannt. Darüber hinaus basierten acht Beschlüsse auf der Nennung von gemeingefährlichen Straftaten. Als Bandenmitglied oder in anderer Weise organisiert begangene Straftaten wurden viermal und Straftaten auf dem Gebiet des BtMG zweimal in Beschlüssen als Katalogdelikte angeführt.

\section{Beschuldigte}

\section{Beschuldigte insgesamt}

Eine Person wurde nur dann als Beschuldigter erfasst, wenn sich das Verfahren ausdrücklich gegen diese richtete. Dabei wurden auch die Personen erfasst, deren Verfahren vorzeitig abgetrennt oder eingestellt worden war. Dieses Vorgehen war erforderlich, um alle aufgrund der Rasterfahndung und der darauf basierenden weiteren Ermittlungen identifizierten Beschuldigten zu erfassen, auch wenn diesen die verfolgte Tat nicht nachgewiesen werden konnte. Vor dem Hintergrund, dass die Identifizierung eines Beschuldigten ein wesentliches Kriterium für die Beurteilung des Erfolges der Rasterfahndung darstellt, war es notwendig, diese Personen zu erfassen. Insgesamt konnten im Rahmen der Einsichtnahme in die Ermittlungsakten der 27 Verfahren 135 Beschuldigte festgestellt werden. Allerdings waren zu 29 dieser Beschuldigten keine Informationen $\mathrm{zu}$ erlangen. Beispielsweise wurde in einem Verfahren lediglich in einem Satz erwähnt, dass es im Verlauf der Ermittlungen 21 weitere Beschuldigte gegeben habe.

Von den 135 Beschuldigten lagen zu 96 Personen Angaben über das Alter vor. Die Altersstruktur lässt sich der nachfolgenden Abbildung entnehmen. Das Durchschnittsalter beträgt 35 Jahre. 
Abbildung 6: Altersstruktur der Beschuldigten in Jahren ( $n=96)$

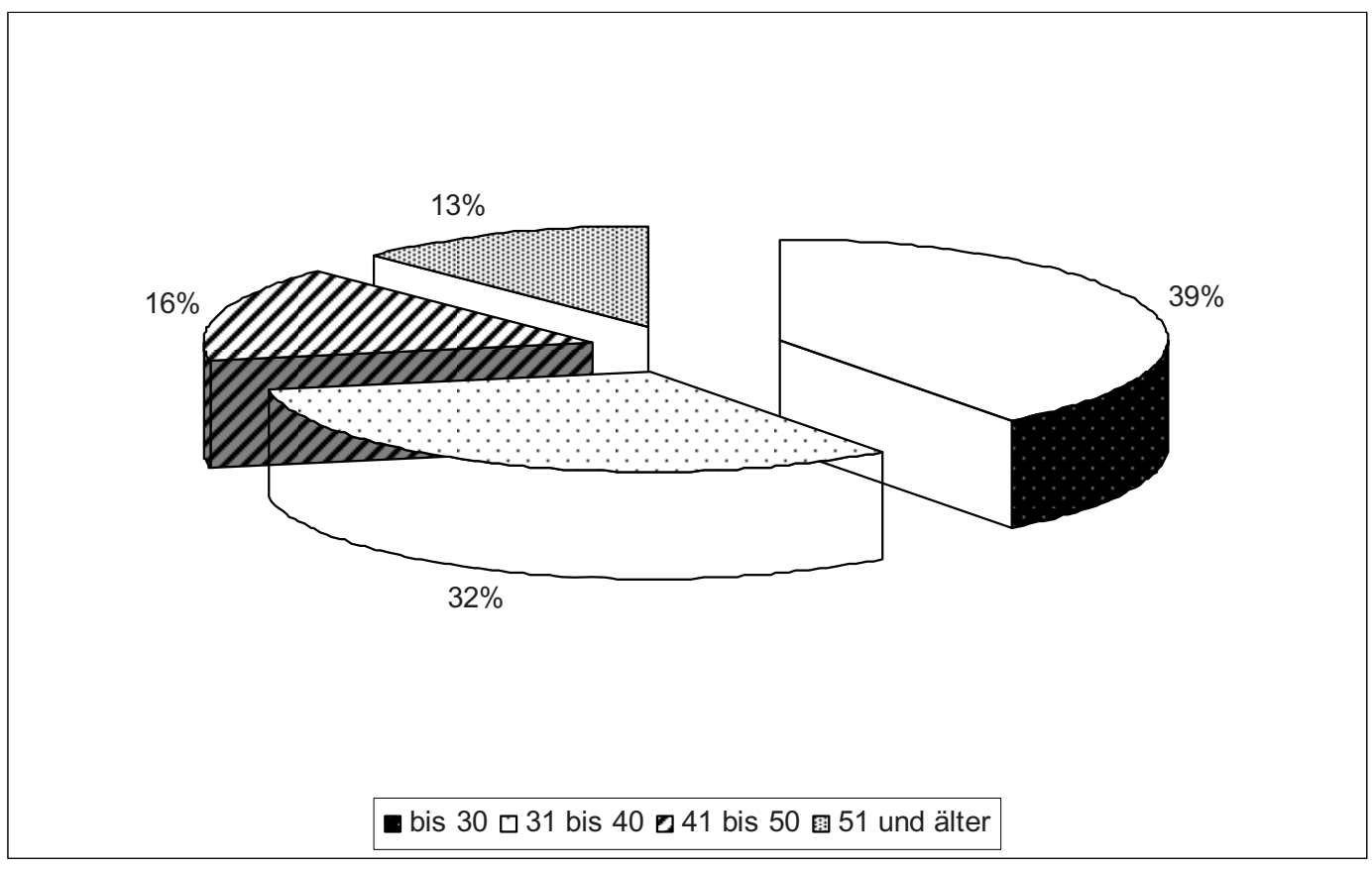

Angaben über das Geschlecht konnten nur über 93 der 135 Beschuldigten erlangt werden. Von diesen 93 Beschuldigten sind $67 \%$ männlich und $33 \%$ weiblich. Zu 82 der 135 Beschuldigten konnten Angaben über die Nationalität erlangt werden. Insgesamt verteilen sich die Beschuldigten auf lediglich acht verschiedene Nationalitäten. Mit etwas mehr als $50 \%$ bilden deutsche Staatsangehörige die größte Gruppe. Weitere $28 \%$ besitzen die thailändische und $11 \%$ die türkische Staatsangehörigkeit.

\section{Beschuldigte pro Verfahren}

In den von der Untersuchung erfassten 27 Verfahren konnten in 22 Verfahren Beschuldigte festgestellt werden. Bei den fünf Verfahren, in denen kein Beschuldigter festgestellt werden konnte, handelt es sich um solche, die noch nicht abgeschlossen oder erfolglos eingestellt worden waren. Darüber hinaus konnte in einigen Verfahren nur in die Teile der Verfahrensakten Einsicht genommen werden, die sich mit der Rasterfahndung befassten.

In zehn der Verfahren wurde lediglich eine Person als Beschuldigter geführt. In jeweils zwei Verfahren wurden zwei, drei und vier Personen als Beschuldigte geführt. Darüber hinaus richteten sich ein Verfahren gegen fünf, zwei weitere Verfahren gegen jeweils acht und ein Verfahren gegen neun Beschuldigte. Bei zwei Verfahren kommt es zu einer deutlichen Abweichung. In diesen werden einmal 21 und einmal 56 Personen als Beschuldigte geführt. Diese beiden Verfahren sind der Grund dafür, dass es zu einer schiefen Verteilung kommt. So liegt der Mittelwert bei fünf Beschuldigten pro Verfahren, während der Median bei einem Beschuldigten liegt. 


\section{B. Die Anordnung der Rasterfahndung gem. den §§ 98a, b StPO}

Gegenstand dieses Kapitels ist der Anordnungsvorgang. Es gliedert sich in drei Abschnitte. Zunächst wird die Anregung der Rasterfahndung analysiert. Daran anknüpfend werden die Beantragung und die Anordnung der Maßnahme untersucht. Als Grundgesamtheiten für die Untersuchungsschritte in diesem Kapitel dienen sowohl die 27 Verfahren und die 31 Maßnahmen als auch die 62 Beschlüsse, wie sie im vorhergehenden Kapitel dargestellt worden sind. Im Rahmen der verschiedenen Untersuchungsschritte wird jeweils angeführt, auf welcher Grundgesamtheit die Auswertung beruht.

\section{Die Anregung der Maßnahme}

Im ersten Abschnitt dieses Kapitels steht die Anregung der Maßnahme im Mittelpunkt der Untersuchung. Es wird untersucht, von wem die Initiative zur Anordnung der Maßnahme ausgeht und wie diese begründet wird.

\section{Anordnungsinitiative}

Mangels Angaben in den Verfahrensakten konnte nicht für jede der 31 Maßnahmen festgestellt werden, von wem die Initiative zur Anordnung ausging. Teilweise waren keine polizeilichen Vermerke, welche die Anregung der Maßnahme zum Gegenstand hatten, in den Verfahrensakten enthalten. Erkenntnisse konnten lediglich zu 26 Maßnahmen gewonnen werden. Bei diesen 26 Maßnahmen ging die Initiative ausschließlich von den ermittelnden Polizeidienststellen aus. Für die übrigen fünf Maßnahmen lagen keine polizeilichen Vermerke etc. vor.

\section{Ermittelnde Polizeidienststelle}

In 16 der 27 Verfahren war die Kriminalpolizei mit der Durchführung der Ermittlungen betraut. Die Kriminalpolizei war darüber hinaus in jeweils einem Verfahren gemeinsam mit dem betreffenden Landeskriminalamt und dem Bundeskriminalamt mit den Ermittlungen befasst. In einem weiteren Verfahren waren diese drei Ermittlungsbehörden gemeinsam mit den Ermittlungen betraut. Die Ermittlungen in drei weiteren Verfahren wurden ausschließlich durch Landeskriminalämter und in einem Verfahren durch das Bundeskriminalamt durchgeführt. Letztlich waren in zwei Verfahren Landeskriminalämter, Bundeskriminalamt und Landesverfassungsschutz mit den Ermittlungen befasst. Auffällig ist, dass in 11 der 27 Verfahren übergeordnete Ermittlungsstellen involviert waren. In den übrigen 15 Verfahren waren die Landeskriminalämter teilweise über die Erstellung von Fallanalysen beteiligt. Auch wurde der Datenabgleich zum Teil bei den Landeskriminaläm- 
tern durchgeführt, da die ermittelnde Kriminalpolizei nicht über die notwendige technische Ausstattung verfügte.

\section{Zeitraum zwischen der Ermittlungseinleitung und der Anregung}

Anknüpfungspunkt für die Feststellung der Zeiträume zwischen der Einleitung des Ermittlungsverfahrens und der Anregung der Maßnahme bilden die 31 Rasterfahndungen. Als Bezug für die Maßnahmen wurde das Datum der ersten Anregung gewählt. Die Anregungen von Ergänzungs- und Änderungsbeschlüssen werden hier nicht berücksichtigt. Fokussiert wird der Zeitraum, welcher zwischen dem Ermittlungsbeginn und der Einleitung der Rasterfahndung gelegen hat.

Von den 31 Maßnahmen konnten nur für 26 Maßnahmen polizeiliche Anregungen festgestellt werden. Für die übrigen fünf Maßnahmen waren keine Anregungen in den Verfahrensakten enthalten. Durchschnittlich betrug der Zeitraum zwischen der Einleitung des Ermittlungsverfahrens und der Anregung einer Rasterfahndung 291 Tage. Der deutlich aussagekräftigere Median liegt jedoch bei 62 Tagen. D.h., in $50 \%$ der Rasterfahndungen liegt der Zeitraum bei maximal 62 Tagen. Mithin liegt hier eine schiefe Verteilung vor, die noch verdeutlicht werden kann, indem weitere Werte betrachtet werden. So beträgt der Zeitraum zwischen der Einleitung und der Anregung bei $25 \%$ der Maßnahmen 15 Tage und weniger. Der Zeitraum erstreckt sich bei weiteren $25 \%$ der Maßnahmen auf 627 Tage und mehr.

Während der kleinste Zeitraum bei einem Tag lag, betrug das Maximum 1247 Tage. Bis auf die Zeiträume von sieben und 15 Tagen, welche jeweils zweimal festgestellt werden konnten, kamen die weiteren Zeiträume jeweils nur einmal vor. Daraus ergibt sich, dass die Rasterfahndung zu höchst unterschiedlichen Zeitpunkten innerhalb der Verfahren angeregt wurde. Zum Teil wurde die Maßnahme innerhalb der ersten acht bis neun Wochen angeregt. Allerdings waren auch Zeiträume von zwei bis drei Jahren bis zur Anregung nicht unüblich.

Die Verteilung verändert sich nur unwesentlich, wenn als Grundlage nur die ersten in den 27 Verfahren durchgeführten Rasterfahndungen herangezogen werden. Zwar beträgt der durchschnittliche Zeitraum dann nur noch 268 Tage, der Median liegt jedoch bei 58 Tagen und ist damit kaum verändert.

\section{Ermittlungsstand bei Anregung der Rasterfahndung}

Die Informationen bzgl. des Standes der Ermittlungen zum Zeitpunkt der Anregung der Rasterfahndung wurden anhand einer Freitextvariable erhoben. So war es möglich kurze Zusammenfassungen der bisherigen Ermittlungen aufzunehmen. Bei der Auswertung der erhobenen Daten zeigte sich, dass sich die verschiedenen Sachverhalte in lediglich drei Kategorien einordnen ließen. 
Die erste Kategorie bilden die Verfahren, in denen bislang alle Ermittlungen erfolglos verliefen. Hier sollten durch die Rasterfahndung neue Ermittlungsansätze erlangt werden. In diesen Verfahren war die Rasterfahndung das letzte zur Verfügung stehende Ermittlungsinstrument.

Die zweite Kategorie beinhaltet die Verfahren, in denen zwar alle Ermittlungen erfolglos verliefen, es aber sehr genaue Anhaltspunkte für die Rasterfahndung gab. Hierzu zählen insbesondere die Verfahren, in denen die Abteilung Operative Fallanalyse der betreffenden Landeskriminalämter eingeschaltet wurde. Deren Fallanalyse erbrachte in der Regel Ansatzpunkte für die Durchführung einer Rasterfahndung. Zum Teil sollte die Maßnahme als Grundlage für eine geplante DNAReihenuntersuchung dienen. In diesen Verfahren bildete die Rasterfahndung nicht das letzte zur Verfügung stehende Ermittlungsinstrument, sondern das den größten Erfolg versprechende.

In der dritten Kategorie von Verfahren waren die Ermittlungen dagegen schon sehr weit fortgeschritten. Häufig gab es bereits Tatverdächtige. Hier sollten durch die Rasterfahndung konkrete Fragestellungen beantwortet werden. In den betreffenden Verfahren spielte die Rasterfahndung eine lediglich untergeordnete Rolle. Zahlenmäßig verteilen sich die Verfahren zu gleichen Teilen auf die drei Kategorien.

\section{Begründung der Anregung}

Die Anregungen durch die ermittelnden Polizeidienststellen ließen sich bis auf eine Ausnahme durchweg als substanziell begründet beurteilen. Die 25 Anregungen setzten sich jeweils ausführlich mit dem vorliegenden Sachverhalt und den bereits durchgeführten Ermittlungen auseinander. Darüber hinaus wurde die Notwendigkeit des Einsatzes der Maßnahme dargelegt. Zusätzlich wurde in einigen Anregungen auch auf technische Voraussetzungen und Möglichkeiten des automatischen Datenabgleichs eingegangen. Mithin bildete die ausführliche Auseinandersetzung mit der Maßnahme die Regel innerhalb der Anregungen. Dagegen war die Anregung nur in einem Fall als formelhaft einzustufen. Hier wurde ausschließlich der Inhalt des $\S 98 \mathrm{a}$ StPO als Begründung wiedergegeben.

Lediglich was den Umfang der Anregung anging, ließen sich Unterschiede feststellen. Diese waren durch den Stand der Ermittlungen zum Zeitpunkt der Anregung bedingt. Bezogen auf die zuvor vorgenommene Kategorisierung der Verfahren konnte festgestellt werden, dass die Begründungen von Maßnahmen in Verfahren der dritten Kategorie den geringsten Umfang aufwiesen. Bei Maßnahmen in Verfahren der ersten Kategorie war der Umfang deutlich größer. Den größten Umfang wiesen die Maßnahmen in Verfahren der zweiten Kategorie auf. Grund hierfür war die Auseinandersetzung mit anderen Ermittlungsmaßnahmen. Darüber hinaus setzten sich diese Begründungen auch mit auf der Rasterfahndung aufbauenden Ermittlungsmaßnahmen wie z.B. DNA-Reihenuntersuchungen auseinander. 


\section{Ergebnis der Anregung}

Wie bereits dargelegt konnten nur für 26 der 31 Maßnahmen nach den $\S \S 98 \mathrm{a}, \mathrm{b}$ StPO polizeiliche Anregungen festgestellt werden. Von diesen hatten alle einen Antrag der Staatsanwaltschaft zur Folge. Mithin führten $100 \%$ der Anregungen zu einem entsprechenden Antrag.

\section{Die Beantragung der Maßnahme}

Im Rahmen der Aktenanalyse konnten für 30 der 31 Maßnahmen staatsanwaltschaftliche Anträge festgestellt werden. Bei einer Maßnahme fehlte ein Antrag der Staatsanwaltschaft. Im Rahmen der Untersuchung der staatsanwaltschaftlichen Anträge stehen zunächst die mit der Maßnahme verfolgten Ziele im Vordergrund. Im Anschluss daran werden die Begründungen eingehend analysiert. Dabei steht insbesondere die Auseinandersetzung der Staatsanwaltschaften mit der Subsidiarität der Maßnahme im Mittelpunkt.

\section{Eilanordnung}

In keinem der untersuchten Verfahren kam es zu einer Eilanordnung durch die zuständige Staatsanwaltschaft. Daraus ergibt sich, dass die $31 \mathrm{Maßnahmen} \mathrm{auf} \mathrm{ei-}$ ner richterlichen Anordnung beruhen. Weshalb es in den untersuchten Verfahren zu keiner Eilanordnung gekommen ist und ob eine solche überhaupt denkbar wäre, wird im Rahmen der Expertengespräche zu untersuchen sein. ${ }^{426}$

\section{Zeitraum zwischen Anregung und Antrag}

Für die Darstellung des Zeitraums zwischen der Anregung der Maßnahme und der Beantragung durch die Staatsanwaltschaft konnten nur die 26 der 31 Maßnahmen als Grundlage herangezogen werden, bei denen eine Anregung festgestellt wurde. Von den 26 Maßnahmen wurde in sechs Fällen der Antrag der Staatsanwaltschaft noch am gleichen Tag gestellt. Bei weiteren sieben Maßnahmen betrug der Zeitraum zwischen Anregung und Antrag nur einen Tag. Acht weitere Maßnahmen verteilen sich auf einen Zeitraum von zwei bis zehn Tagen. Darüber hinaus konnten Verfahren mit Zeiträumen von 20, 32, 40 und 47 Tagen festgestellt werden. Letztlich betrug der Zeitraum in einem Verfahren 82 Tage. In diesen Verfahren sind die Zeiträume durch die speziellen Problematiken der Einzelfälle begründet.

${ }^{426}$ Siehe 5. Teil A. IV. 
Der durchschnittliche Zeitraum zwischen Anregung und Antrag beträgt zehn Tage. Des Weiteren liegt der Median bei 1,5 Tagen. Demnach beträgt der Zeitraum bei $50 \%$ der Maßnahmen weniger als zwei Tage. Darüber hinaus liegt der fragliche Zeitraum bei $75 \%$ der Maßnahmen unter sieben Tagen. Diese Verteilung erweckt den Eindruck, dass der Einsatz der Maßnahme schon im Vorfeld abgeklärt wird. Danach würde der eigentliche Anordnungsvorgang lediglich einen formalen Akt darstellen. Dieser Eindruck bedarf der weiteren Analyse anhand der Expertengespräche. $^{427}$

\section{Ziele der Maßnahme laut staatsanwaltschaftlichem Antrag}

Von besonderem Interesse für die Untersuchung sind die mit den Maßnahmen verfolgten Ziele. Grundlage für deren Untersuchung bilden die 30 festgestellten Anträge. Im theoretischen Teil dieser Untersuchung wurde bereits auf die Unterscheidung zwischen positiver und negativer Rasterfahndung, wie sie der $\S 98 \mathrm{a}$ StPO vorsieht, eingegangen. In diesem Untersuchungsschritt soll analysiert werden, ob diese Unterscheidung eine praktische Relevanz besitzt. Darüber hinaus werden auch weitere mit der Rasterfahndung verfolgte Ziele untersucht.

\section{a. Differenzierung positive und negative Rasterfahndung}

In mehr als einem Drittel der Maßnahmen wurden im Antrag der Staatsanwaltschaft keine der beiden Alternativen des $\S 98$ a StPO als Ziele angeführt. Diese Maßnahmen verfolgen die Umsetzung genau definierter Ziele. Beispielsweise sollte mit einer Maßnahme in Erfahrung gebracht werden, ob ein Pkw mit einem bekannten Kennzeichen zu einer bestimmten Uhrzeit von der Polizei kontrolliert worden war.

Bei der Betrachtung der Verteilung ist auffällig, dass bei keiner Maßnahme der Ausschluss Nichtverdächtiger als Ziel angeführt worden ist. Der Grund hierfür dürfte darin liegen, dass der Ausschluss nichtverdächtiger Personen einen genau umgrenzten Personenkreis voraussetzt. In einem weiteren Drittel der Maßnahmen wurden beide Alternativen angeführt. Hierbei handelt es sich um Anträge, in denen neben konkreten Zielen der Text des $\S 98$ a StPO zumeist ergänzend angeführt wurde. Die Feststellung von Personen, die weitere für die Ermittlungen bedeutsame Prüfungsmerkmale erfüllen, wurde bei etwas weniger als einem Drittel der Maßnahmen als Ziel genannt.

${ }^{427}$ Siehe 5. Teil A. III. 
Abbildung 7: Differenzierung zwischen Positiver und negativer Rasterfahndung $(n=30)$

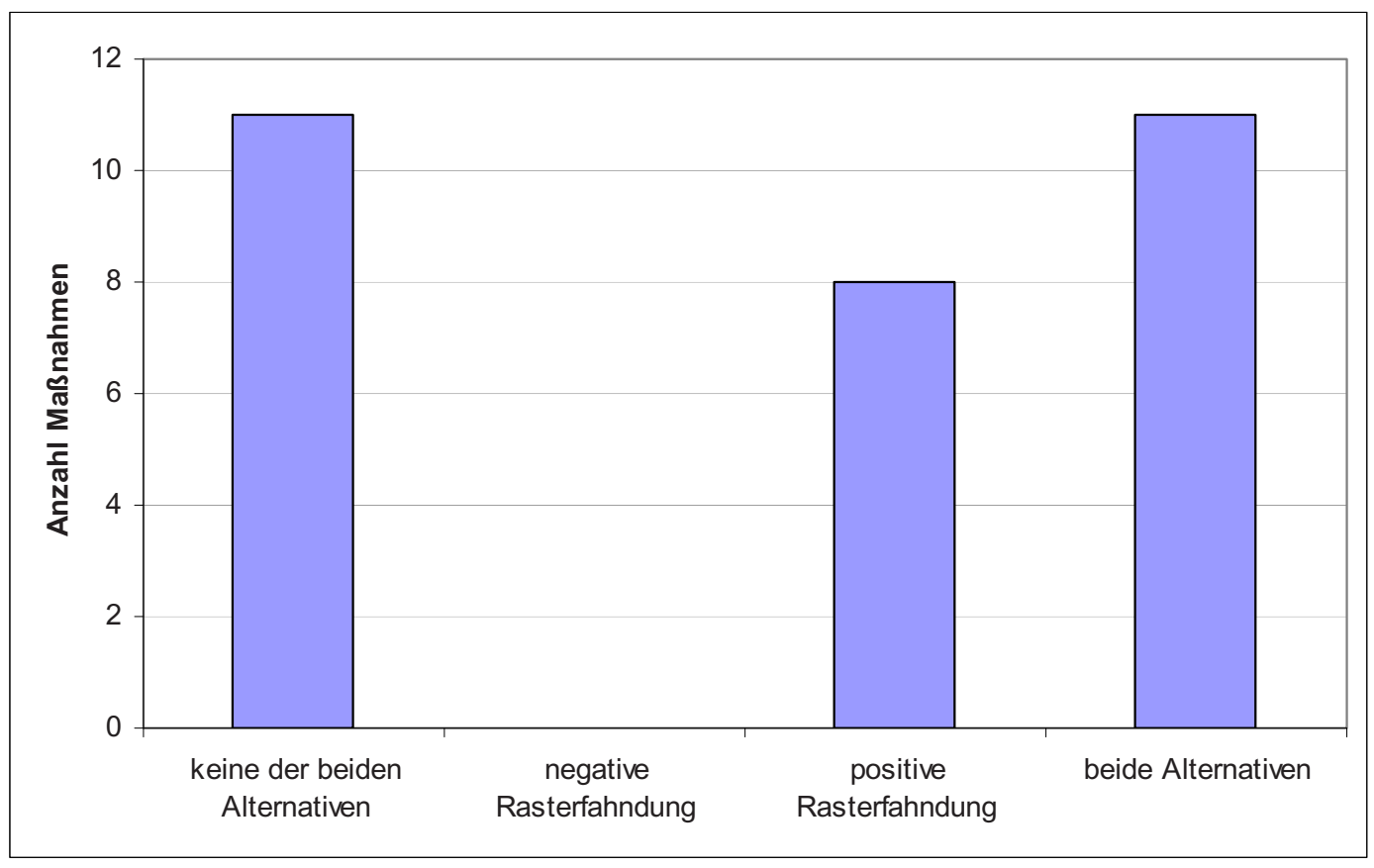

Abbildung 8: Weitere Ziele ( $n=26)$

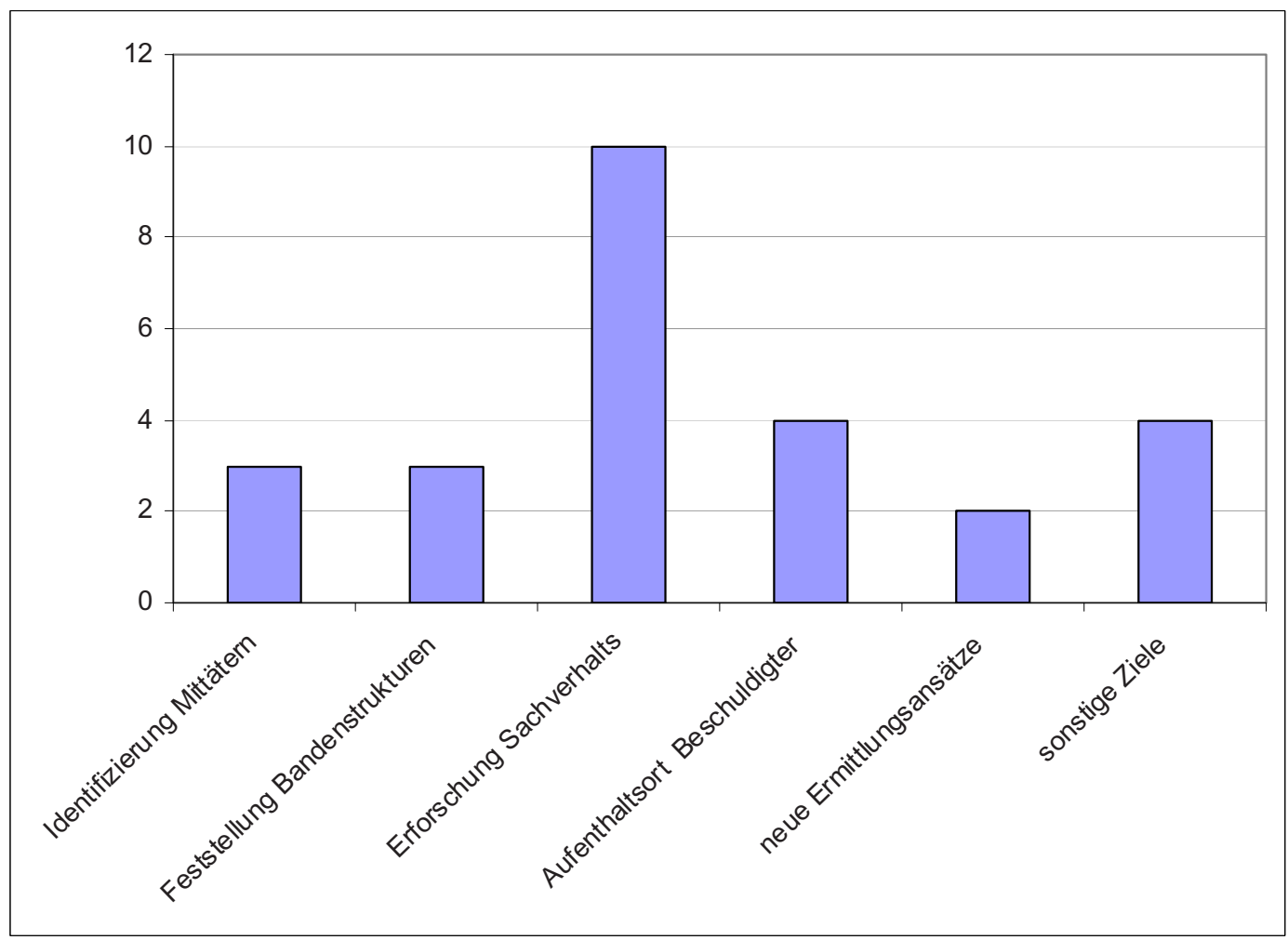


b. Weitere Ziele

Bei den weiteren Zielen handelt es sich um solche, die neben dem Ausschluss Nichtverdächtiger und der Feststellung von Personen, die weitere für die Ermittlungen bedeutsame Prüfungsmerkmale erfüllen, genannt worden sind. In gut $60 \%$ der Anträge wurden weitere Ziele angeführt. Knapp $40 \%$ der Anträge enthielten keine anderen Ziele als den Ausschluss Nichtverdächtiger und die Feststellung von Personen, die weitere für die Ermittlungen bedeutsame Prüfungsmerkmale erfüllen.

Bei der Verteilung der weiteren Ziele sind Mehrfachnennungen zu beachten. So wurden in den 19 Anträgen 26 Ziele angeführt. Mit zehn Nennungen bildet die Erforschung des Sachverhalts die mit Abstand größte Gruppe unter den weiteren Zielen. Die weiteren Nennungen verteilen sich gleichmäßig auf die übrigen Kategorien. Bei den sonstigen Zielen handelt es sich beispielsweise um die Feststellung einer Langzeit konspirativen Wohnung oder die Vorbereitung einer DNA-Reihenuntersuchung.

Nimmt man nicht die 19 Anträge mit weiteren Zielen, sondern alle 30 Anträge als Grundlage, so ergibt die Auswertung, dass in fast einem Drittel die Erforschung des Sachverhalts als Ziel angeführt wird.

\section{Begründung des Antrags}

Neben den mit der Rasterfahndung verfolgten Zielen sind die Begründungen der Rasterfahndung von besonderem Interesse für diese Untersuchung. Es soll analysiert werden ob und in welchem Umfang sich die antragende Staatsanwaltschaft mit der Subsidiarität der Maßnahme auseinandersetzt.

\section{a. Kategorien und Kriterien für die Bewertung}

Bei der Analyse der Begründungen der staatsanwaltschaftlichen Anordnungen ist zu beachten, dass sich den Verfahrensakten informelle Kontakte zwischen den mit der Anordnung befassten Stellen in der Regel nicht entnehmen lassen. Diesbezüglich stößt die Aktenanalyse an ihre methodischen Grenzen. ${ }^{428}$ Dementsprechend kann der tatsächlich vorgenommene Begründungaufwand nur im Rahmen der Expertengespräche untersucht werden. ${ }^{429}$

Eine rechtliche Beurteilung der Begründungen im Sinne einer Kontrolle wurde nicht durchgeführt. Bei der Bewertung der Begründungen wurde nur der formal dokumentierte Vorgang, wie er in den Verfahrensakten abgebildet war, herangezogen. Dabei lag der Einstufung der Begründungen in die Kategorien ausschließlich

\footnotetext{
428 Siehe 2. Teil C.

429 Siehe 5. Teil A. III.
} 
deren inhaltliche Qualität zugrunde. Hierzu wurden die Begründungen auf ihre Auseinandersetzung mit dem Sachverhalt, den Tatbestandsvoraussetzungen des $\S$ 98a StPO und alternativen Ermittlungsmaßnahmen analysiert. Die im Rahmen der Beurteilung verwendeten Kategorien und die für diese maßgeblichen Kriterien sind der nachfolgenden Tabelle zu entnehmen.

Abbildung 9: Kategorien und Kriterien für die Beurteilung der Begründungen

\begin{tabular}{|c|c|}
\hline Kategorie & Kriterien \\
\hline Formelhaft & $\begin{array}{l}\text { Wenn der Antrag } \\
\text { - } \quad \text { keine Begründung enthält } \\
\text { - } \text { nur mit einer Wiedergabe des } \\
\text { Sachverhalts begründet wird } \\
\text { - feststellt, dass die Vorausset- } \\
\text { zungen des } \S 98 \text { a StPO gegeben } \\
\text { sind }\end{array}$ \\
\hline Formblatt / Vordruck & $\begin{array}{l}\text { Für den Antrag wird ein Vordruck ver- } \\
\text { wendet. }\end{array}$ \\
\hline $\begin{array}{l}\text { Verweis auf Begründung der Polizei } \\
\text { (Anregung) }\end{array}$ & $\begin{array}{l}\text { Im Antrag wird auf die in der polizeili- } \\
\text { chen Anregung enthaltene Begründung } \\
\text { verwiesen. Darüber hinaus enthält der } \\
\text { Antrag keine weitere Begründung. }\end{array}$ \\
\hline Gesetzesformel & $\begin{array}{l}\text { Wenn der Antrag nur } \\
\text { - „Wenn die Erforschung des } \\
\text { Sachverhalts oder die Ermitt- } \\
\text { lung des Aufenthaltsortes des } \\
\text { Täters auf andere Weise erheb- } \\
\text { lich weniger Erfolg verspre- } \\
\text { chend oder wesentlich erschwert } \\
\text { wäre.“ } \\
\text { enthält }\end{array}$ \\
\hline Substanziell begründet & $\begin{array}{l}\text { Wenn im Antrag } \\
\text { - Auseinandersetzung mit anderen } \\
\text { Ermittlungsmaßnahmen bezo- } \\
\text { gen auf den Einzelfall } \\
\text { - } \\
\text { Auseinandersetzung mit der } \\
\text { Subsidiarität der Maßnahme }\end{array}$ \\
\hline
\end{tabular}




\begin{tabular}{|l|l|}
\hline Verweis auf Erstbegründung & $\begin{array}{l}\text { Wenn im Antrag lediglich auf die Be- } \\
\text { gründung eines vorhergehenden An- } \\
\text { trags verwiesen wird. }\end{array}$ \\
\hline Keine Angaben & $\begin{array}{l}\text { Wenn kein Antrag in den Verfahrensak- } \\
\text { ten vorhanden war. }\end{array}$ \\
\hline Kombination & $\begin{array}{l}\text { Wenn sich die Begründung aus mehre- } \\
\text { ren der zuvor genannten Kategorien } \\
\text { zusammensetzt. }\end{array}$ \\
\hline
\end{tabular}

\section{b. Antragsbegründungen}

Bei der Verteilung der Begründungen der Staatsanwaltschaften auf die Kategorien fällt zunächst auf, dass sich mehr als $50 \%$ der Anträge aus Kombinationen der übrigen Kategorien zusammensetzen. Mit einem knappen Drittel folgt die Kategorie „Substanziell begründet“. Demzufolge setzt sich ein Drittel der Anträge substanziell mit anderen Ermittlungsmöglichkeiten auseinander.

Die Kategorien „Verweis auf Erstbegründung“, „Begründung mit der Gesetzesformel“ und „Formelhaft" kommen dagegen seltener vor. Von einer Maßnahme fehlt der Antrag, so dass „keine Angaben“ festgestellt werden mussten. Die Kategorie „Verweis auf die Polizei Begründung“ konnte gar nicht festgestellt werden. Unter Aufschlüsselung der Kombinationen auf die übrigen Kategorien ändert sich dies jedoch deutlich.

In den 16 Anträgen, die sich aus Kombinationen verschiedener Kategorien zusammensetzen, konnten sechs unterschiedliche Kombinationen festgestellt werden. Diese setzen sich aus den Kategorien „Formelhaft“, „Begründung mit der Gesetzesformel“, „Verweis auf die Polizei Begründung“, „Substanziell begründet“ und „Verweis auf die Erstbegründung“ zusammen. Die Kategorien „Formelhaft“ und „Verweis auf die Erstbegründung“ kommen jeweils nur einmal vor. Demgegenüber konnten die „Begründung mit der Gesetzesformel“ in zwölf Anträgen, die Kategorie „Substanziell begründet“ in elf Anträgen und der „Verweis auf die Polizei Begründung" in neun Fällen festgestellt werden.

Bezieht man die Verteilung auf die Kategorien innerhalb der Kombinationen in die Betrachtung mit ein, so verändert sich das Bild deutlich. Insgesamt wurden zwei Drittel der Anträge substanziell begründet. Ferner wurde in knapp der Hälfte der Anträge die Gesetzesformel verwendet. Letztlich enthielt ein Drittel der Anträge einen Verweis auf die Polizei Begründung. Insbesondere der hohe Anteil an substanziellen Begründungen innerhalb der Anträge zeigt auf, dass diese sich mit den Voraussetzungen der Maßnahme in besonderem Maße auseinandersetzen. 
Abbildung 10: $\quad$ Begründungen der Staatsanwaltschaften nach Kategorien in \% $(n=30)$

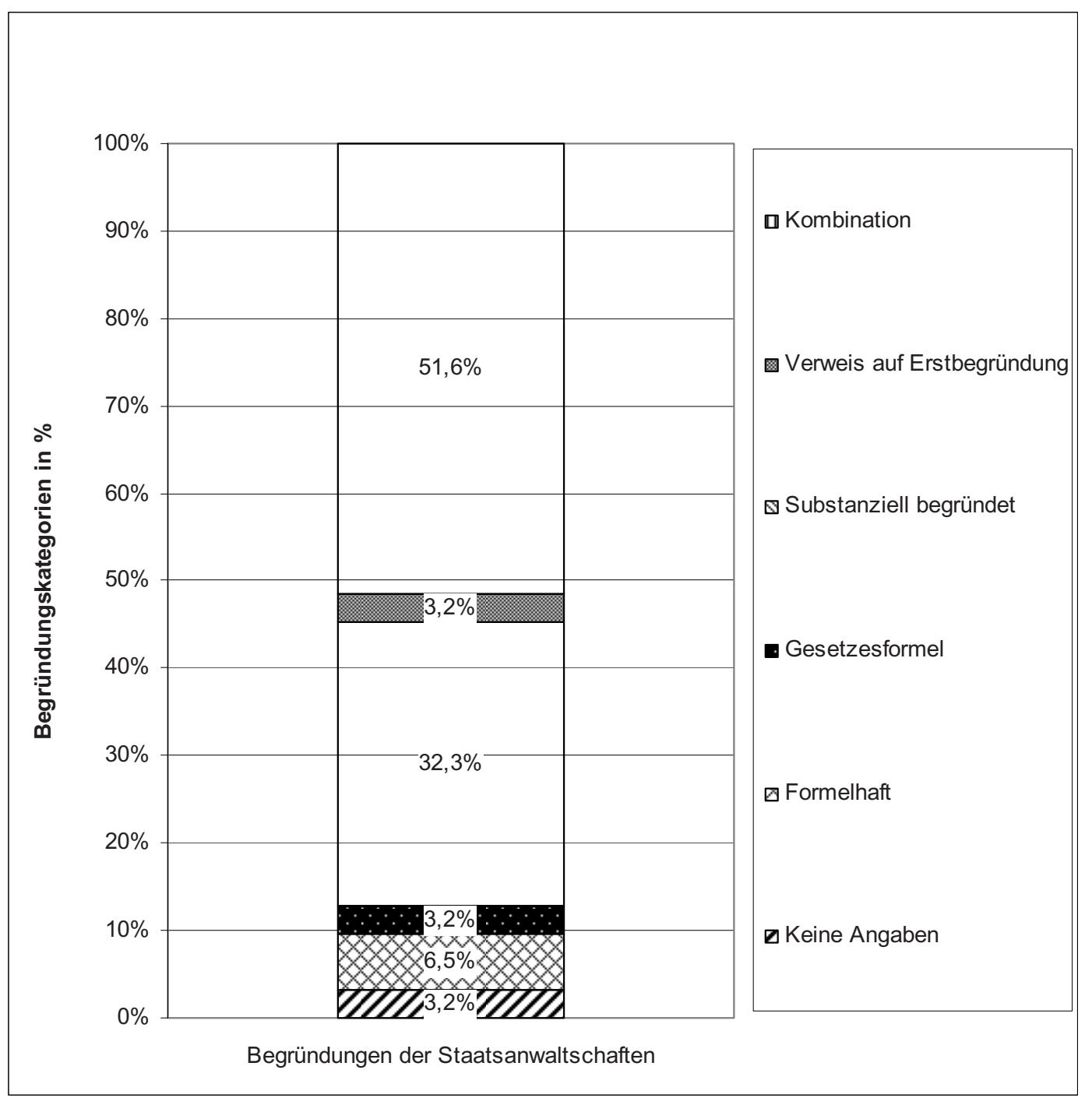

c. Beispiel für eine substanzielle Begründung

Inwiefern diese Annahme zutrifft, soll anhand eines Beispiels dargelegt werden. Ein Antrag wurde dann als substanziell begründet beurteilt, wenn er sich einzelfallbezogen mit den bisherigen Ermittlungsergebnissen und den Möglichkeiten der Rasterfahndung auseinandersetzte. Darüber hinaus musste sich der Antrag auch mit der Subsidiarität der Maßnahme auseinandersetzen. Unter Zugrundelegung dessen kann der folgende Antrag als Beispiel herangezogen werden.

„Gegenstand des vorliegenden Ermittlungsverfahrens ist ein schwerer Raub zum Nachteil der Spielbank in H. Nach dem bisherigen Stand der Ermittlungen liegen zureichende tatsächliche Anhaltspunkte dafür vor, dass die drei maskier- 
ten Täter von einem weiteren Mittäter kurz vor Tatbeginn mittels eines Handys oder aus dem Festnetz über die Gegebenheiten im Spielsaal informiert wurden. Zudem haben sich aufgrund der Tatausführung Parallelen zu Raubüberfällen auf Spielbanken in $\mathrm{K}$ und Bad $\mathrm{H}$ im Hinblick auf den modus operandi ergeben, die auch durch die übereinstimmenden Täterbeschreibungen verstärkt werden. Insoweit liegen zureichende tatsächliche Anhaltspunkte für eine Straftat von erheblicher Bedeutung vor, die gewerbs- oder gewohnheitsmäßig begangen worden ist. Die Übermittlung und der Abgleich der oben genannten Daten sollen dazu dienen, die Gesprächsteilnehmer des unmittelbar vor der Tat in $\mathrm{H}$ geführten Telefongesprächs zu ermitteln. Zudem sollen durch den Abgleich der Besucherlisten der verschiedenen überfallenen Spielbanken Nichtverdächtige ausgeschlossen und Personen festgestellt werden, die sich jeweils in engem zeitlichen Zusammenhang mit den Taten in den Spielbanken aufhielten und daher als Täter in Betracht kommen. Die Erforschung des Sachverhalts und die Ermittlung der Täter auf andere Weise erscheinen nicht möglich, da praktisch keine weiteren objektiven Beweismittel vorhanden sind. Die anzuordnende Maßnahme ist auch nicht unverhältnismäßig.“

Aus diesem Antrag wird deutlich, dass sich der größte Teil der Begründung mit den Möglichkeiten und Zielen der Maßnahme auseinandersetzt. Ausführungen zur Subsidiarität der Maßnahme werden dagegen lediglich am Ende der Begründung und auch nur formelhaft gemacht. Diese Feststellungen treffen auf einen Großteil der substanziell begründeten Anträge zu. Mithin wird in den staatsanwaltschaftlichen Anträgen die Subsidiarität der Maßnahme nur in geringem Umfang erörtert.

\section{d. Umfang der Antragsbegründungen}

Einen weiteren Faktor bei der Beurteilung der Begründung bildet der Umfang der Ausführungen. So ist es möglich, der wertenden Einstufung der Maßnahmen in die festgelegten Kategorien ein formales Kriterium zur Seite zu stellen. Sicherlich kann im Rahmen der Erhebung des Umfangs der Begründungen keine Aussage über deren Qualität getroffen werden. Allerdings ermöglicht der Umfang der Begründung einen Rückschluss auf den Begründungsaufwand. Bei der Feststellung des Umfangs der Begründungen wurden ausschließlich die Zeilen des mit „Gründe" überschriebenen Teils der Anträge zugrunde gelegt.

Von den 30 Anträgen weisen sieben Anträge einen Umfang von bis zu zehn Zeilen auf. Der Antrag mit dem geringsten Umfang bestand aus drei Zeilen. Weitere zehn Anträge haben einen Umfang zwischen zehn und 20 Zeilen. Darüber hinaus konnten vier Anträge mit bis zu 30 und weitere vier Anträge mit bis zu 40 Zeilen festgestellt werden. In drei Anträgen wurden bis zu 50 Zeilen verwandt. Auffällig sind zwei Anträge mit bis zu 100 und 110 Zeilen. Diese fallen aus der übrigen Verteilung deutlich heraus. Bei diesen beiden Anträgen handelt es sich um Anträge des 
Generalbundesanwaltes in zwei sehr umfangreichen Verfahren. Durchschnittlich beträgt der Umfang der Anträge 24 Zeilen. Der Median beträgt 15 Zeilen. Die Abweichung ist durch die beiden sehr umfangreichen Anträge des Generalbundesanwaltes bedingt. Insgesamt liegt der Umfang bei über $90 \%$ der Anträge unter 50 Zeilen.

Abbildung 11: Umfang der staatsanwaltschaftlichen Begründungen ( $n=30)$

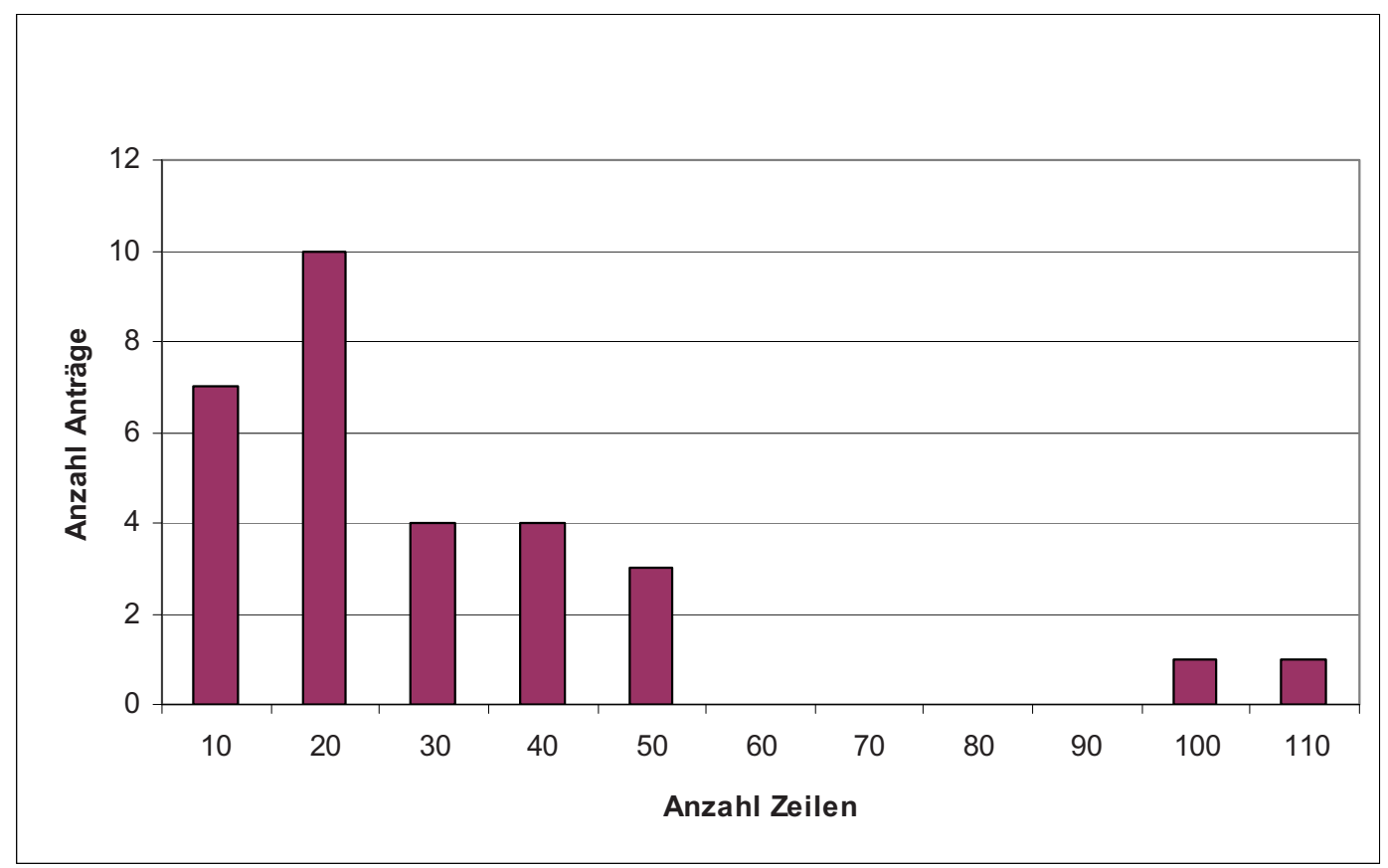

\section{Ergebnis des Antrags}

Die 30 Anträge führten zu über $80 \%$ zur Anordnung der beantragten Maßnahme. In zwei Fällen wurde die Maßnahme mit Änderungen und in weiteren zwei Fällen mit Ergänzungen angeordnet. Bei den Ergänzungen handelt es sich beispielsweise um zeitliche Befristungen. Insofern dient das folgende Beispiel zur Erläuterung. Mit der betreffenden Maßnahme sollten Daten eines Einwohnermeldeamtes aus dessen aktuellem Datenbestand und aus Datenbeständen für zurückliegende Zeiträume erhoben werden. Für die zurückliegenden Zeiträume enthielt der Antrag keine zeitliche Befristung. In der Anordnung wurde eine zeitliche Befristung auf einen zurückliegenden Zeitraum von fünf Jahren eingefügt.

In einem Fall wurde die beantragte Maßnahme durch das zuständige Amtsgericht abgelehnt. In Folge der Anfechtung durch die Staatsanwaltschaft wurde der ablehnende Beschluss durch das zuständige Landgericht aufgehoben und die Maßnahme angeordnet. 


\section{Die Anordnung der Maßnahme}

\section{Zeitraum zwischen Antrag und Anordnung}

Fünf der Anordnungen und damit $17 \%$ ergingen noch am selben Tag wie der Antrag. Mit neun Fällen und $30 \%$ bildet der Zeitraum von einem Tag zwischen Antrag und Anordnung die anteilsmäßig größte Gruppe. Insgesamt werden über $75 \%$ der Anordnungen innerhalb von fünf Tagen nach der Antragstellung getroffen. Der durchschnittliche Zeitraum zwischen Antrag und Anordnung beträgt vier Tage. Dagegen liegt der Median bei zwei Tagen. Demnach werden 50 \% der Maßnahmen innerhalb von zwei Tagen nach der Beantragung angeordnet.

Der durchschnittlich relativ kurze Zeitraum zwischen Antrag und Anordnung deutet daraufhin, dass es sich hier lediglich um einen formalen Vorgang handelt und die eigentliche Entscheidung innerhalb informeller Abklärungen im Vorfeld getroffen wird. Aufschlussreich für die Überprüfung dieser These könnten die in den Anordnungen angeführten Begründungen sein. Allein anhand der Aktenanalyse lässt sich diese These jedoch nicht überprüfen, so dass ihr im Rahmen der Expertengespräche nachzugehen ist. ${ }^{430}$

\section{Zeitraum zwischen Anregung und Anordnung}

Wie bereits dargestellt konnten den Akten nur 26 Anregungen entnommen werden. Insofern war es nur für diese $26 \mathrm{Maßnahmen} \mathrm{möglich,} \mathrm{den} \mathrm{Zeitraum} \mathrm{zwischen}$ Anregung und Anordnung festzustellen. Im Durchschnitt beträgt der Zeitraum zwischen Anregung und Anordnung 14 Tage. Der Median liegt dagegen bei sechs Tagen. Demnach werden $50 \%$ der Maßnahmen innerhalb von sechs Tagen nach der Anregung angeordnet. Der kleinste Zeitraum beträgt einen Tag. Demgegenüber beträgt der größte Zeitraum 101 Tage, was gleichzeitig die Abweichung des Median vom Durchschnittswert erklärt.

\section{Begründung der Anordnung}

In gleichem Maße wie die Begründungen der antragenden Staatsanwaltschaft sind auch die Begründungen der richterlichen Anordnungen der Rasterfahndung von besonderem Interesse für diese Untersuchung. Dabei steht insbesondere die Ausübung der richterlichen Kontrolle im Vordergrund. Wie bereits bei der Begründung der Anträge werden sowohl der Inhalt der Anordnung als auch deren Umfang in die Betrachtung einbezogen.

${ }^{430}$ Siehe 5. Teil A. III. 
Für die inhaltliche Bewertung der richterlichen Anordnungen wird auf die bereits im Rahmen der Beurteilung der Antragsbegründungen vorgenommenen Kategorisierung zurückgegriffen. Allerdings war diese um eine weitere Kategorie zu ergänzen. Hierbei handelt es sich um die Kategorie „wie Antrag ausgefertigt".

Abbildung 12: Erweiterung der Begründungskategorien aus Abbildung 9

\begin{tabular}{|c|c|}
\hline Kategorie & Kriterien \\
\hline Wie Antrag ausgefertigt & $\begin{array}{l}\text { Wenn } \\
\text { - die Anordnung im Wortlaut i- } \\
\text { dentisch mit dem Antrag ist } \\
\text { - ein von der Staatsanwaltschaft } \\
\text { vorgefertigter Beschluss ledig- } \\
\text { lich unterschrieben wurde }\end{array}$ \\
\hline
\end{tabular}

a. Inhalt der Begründungen

Bei der Verteilung der Anordnungsbegründungen auf die Kategorien zeigt sich ein anderes Bild wie bei den Antragsbegründungen. Die mit Abstand größte Gruppe bildet mit über $60 \%$ die Kategorie ,wie Antrag ausgefertigt““. Daraus lässt sich entnehmen, dass in knapp zwei Dritteln der Anordnungen die zuständigen Gerichte keine eigenen Ausführungen gemacht haben. Inhaltlich besteht zwischen den betreffenden Anträgen und Anordnungen kein Unterschied. Es wurden in 19 der 31 Anordnungen entweder die Beschlussausfertigungen der Staatsanwaltschaft unterschrieben oder abgeschrieben. Diese Verteilung unterstützt die im Rahmen der Ausführungen zum Zeitraum zwischen Antrag und Anordnung aufgestellte These, dass Staatsanwaltschaften und Gerichte im Vorfeld der Anordnung bereits auf informellem Wege in Kontakt treten und das Vorliegen der Voraussetzungen erörtern.

In fünf Anordnungen konnte eine substanzielle Begründung festgestellt werden. Darüber hinaus enthielten fünf Anordnungen Kombinationen aus mehreren Kategorien. Die Kombinationen setzten sich aus den Kategorien „Formelhaft“, „Vordruck / Formblatt“, „Begründung mit der Gesetzesformel“, „,Verweis auf die Polizei Begründung“ und ,substanziell begründet“ zusammen. In jeder der Kombinationen wurde auf die polizeiliche Begründung verwiesen. Letztlich waren zwei Anordnungen als formelhaft zu beurteilen. 
Abbildung 13: richterliche Begründungen nach Kategorien in \% (n=31)

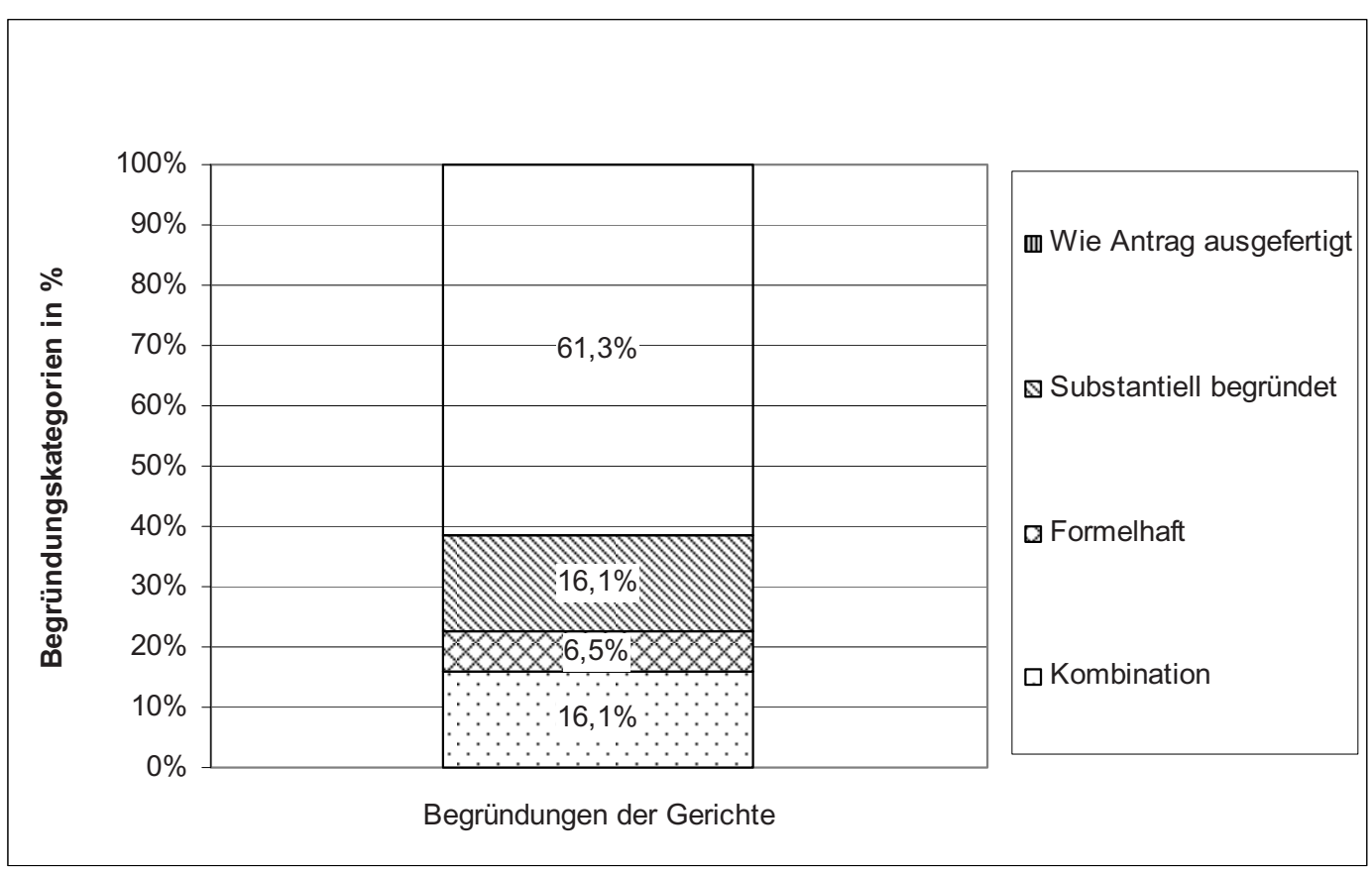

b. Umfang der Anordnungsbegründungen

Wie im Rahmen der staatsanwaltschaftlichen Anträge wurden auch die richterlichen Anordnungen nach ihrem Umfang untersucht. Auch hier wurden als formales Kriterium für die Beurteilung des Begründungsaufwandes die Zeilen der Anordnungsbegründung herangezogen. Es wurden lediglich die Zeilen des mit „Gründe“ überschriebenen Teils der Anordnungen berücksichtigt. Während das Minimum zwei Zeilen betrug, lag das Maximum bei 95 Zeilen. In sechs Fällen wurden die Anordnungen mit bis zu zehn Zeilen begründet. Die größte Gruppe bilden zwölf Anordnungen mit bis zu 20 Zeilen. Mit bis zu 30 Zeilen wurden weitere vier Anordnungen und mit bis zu 50 Zeilen drei Anordnungen begründet. Auf die Kategorien bis zu 40 Zeilen, bis zu 70 Zeilen und bis zu 90 Zeilen entfiel jeweils eine Anordnung. Auffällig sind drei Anordnungen mit bis zu 95 Zeilen Begründung.

Durchschnittlich haben die Begründungen einen Umfang von 30 Zeilen. Der Median liegt jedoch bei 16 Zeilen. Demnach beträgt der Begründungsumfang von $50 \%$ der Anordnungen 16 oder weniger Zeilen. Diese schiefe Verteilung ist durch die vier umfangreichen Anordnungen mit bis zu 95 Zeilen bedingt. Bei diesen handelte es sich um Anordnungen des Ermittlungsrichters am Bundesgerichtshof in den bereits geschilderten umfangreichen Verfahren des Generalbundeswalts.

Da weniger als $40 \%$ der Anordnungen aus eigenständigen Begründungen bestanden, kann diesen Ergebnissen im Gegensatz zu der Analyse des Umfangs der Antragsbegründungen nur ein geringer Aussagewert beigemessen werden. Wie im 
vorhergehenden Untersuchungsschritt festgestellt werden konnte, wurden in mehr als $60 \%$ der Anordnungen lediglich die Ausführungen der Staatsanwaltschaft übernommen.

\section{Vergleich der Ergebnisse und Zusammenfassung}

\section{Zeiträume zwischen Anregung, Antrag und Anordnung im Vergleich}

Bei der Betrachtung der Zeiträume zwischen Anregung und Antrag, Antrag und Anordnung sowie Anregung und Anordnung fällt auf, dass diese relativ gering sind. Aufgrund der schiefen Verteilungen bei den Ergebnissen wird hier nur auf den jeweiligen Median zurückgegriffen. ${ }^{431}$ Der Median des Zeitraums zwischen Anregung und Antrag liegt bei 1,5 Tagen. Mit einem Wert von zwei Tagen liegt der Median des Zeitraums zwischen Antrag und Anordnung nur wenig höher. Auch der Median von Anregung und Anordnung, der bei sechs Tagen liegt, zeigt auf, dass keine großen zeitlichen Abstände zwischen den einzelnen Schritten liegen. Dieses Ergebnis deutet daraufhin, dass dem Anordnungsvorgang bereits Erörterungen der Sach- und Rechtslage auf informellen Wegen vorangehen.

Die folgende Abbildung veranschaulicht die Verteilung der Zeiträume. Dabei fällt auf, dass es in keinem Fall zu einer Anordnung der Maßnahme am Tag der Anregung gekommen ist. Mithin liegt zwischen Anregung und Anordnung mindestens ein Tag. Insgesamt verteilen sich die Zeiträume zwischen Anregung und Anordnung gleichmäßiger als die Zeiträume zwischen Anregung und Antrag sowie Antrag und Anordnung. Bei diesen beiden Zeiträumen ist eine Konzentration auf den gleichen und den ersten Tag zu verzeichnen.

\section{Die Begründungen der Anregungen, der Anträge und der Anordnungen im Vergleich}

Bei den Begründungen von polizeilichen Anregungen, staatsanwaltschaftlichen Anträgen und richterlichen Anordnungen waren erhebliche Unterschiede festzustellen. Insbesondere die Betrachtung der Kategorie „Substanziell begründet“ ergab deutlich Unterschiede. Die Gesamtübersicht zeigt anschaulich, dass der Umfang der substanziellen Begründungen von der Anregung über den Antrag bis zur Anordnung stark abnimmt. Da die in den Kombinationen enthaltenen substanziellen Begründungen berücksichtigt werden müssen, ist die Abnahme jedoch nicht ganz so stark, wie sich in der Abbildung darstellt. Die Anregungen waren bis auf eine Ausnahme substanziell begründet. Einschließlich der Kombinationen enthielten nur noch knapp zwei Drittel der Anträge eine substanzielle Begründung. Von den Anordnungen waren nur noch weniger als $20 \%$ substanziell begründet.

${ }^{431}$ Siehe 3. Teil B. I.3., II.2. und III.1. 
Abbildung 14: Übersicht über die Zeiträume zwischen Anregung und Antrag, Antrag und Anordnung und Anregung und Anordnung

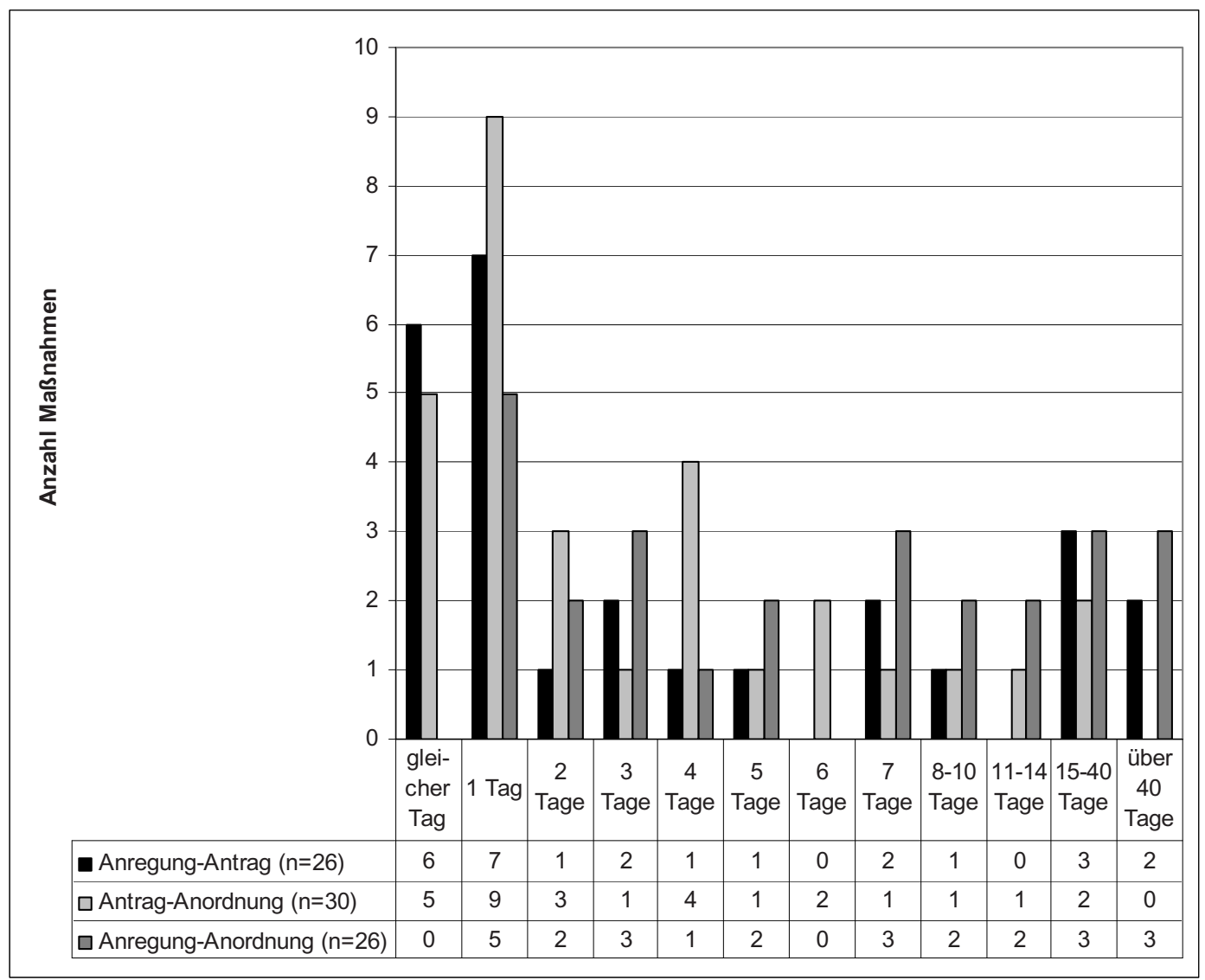

Bedenklich ist die große Zahl von Beschlussausfertigungen im Rahmen der Anordnungen. In $60 \%$ der Anordnungen übernahmen die Gerichte die staatsanwaltschaftlichen Begründungen, indem die Ausfertigungen unterschrieben oder abgeschrieben wurden. Das Vorliegen der Voraussetzungen der $\S \S 98 \mathrm{a}, \mathrm{b}$ StPO wurde durch die Gerichte demnach nicht mehr geprüft. Unter alleiniger Zugrundelegung der Ergebnisse der Aktenanalyse muss man zu dem Schluss kommen, dass die richterliche Kontrolle der Rasterfahndung nur unzureichend ausgeübt wird. Wie bereits im Rahmen der Untersuchung der richterlichen Begründung dargestellt, muss dieser Erscheinung im Rahmen der Expertengespräche nachgegangen werden. Nur so können informelle Abklärungen im Vorfeld der Anordnung erfasst und der tatsächliche Umfang der richterlichen Kontrolle untersucht werden. 
Abbildung 15: Prozentuale Verteilung der Begründungskategorien bei polizeilicher Anregung ( $n=26)$, staatsanwaltschaftlichem Antrag $(n=30)$ und richterlicher Anordnung $(n=31)$

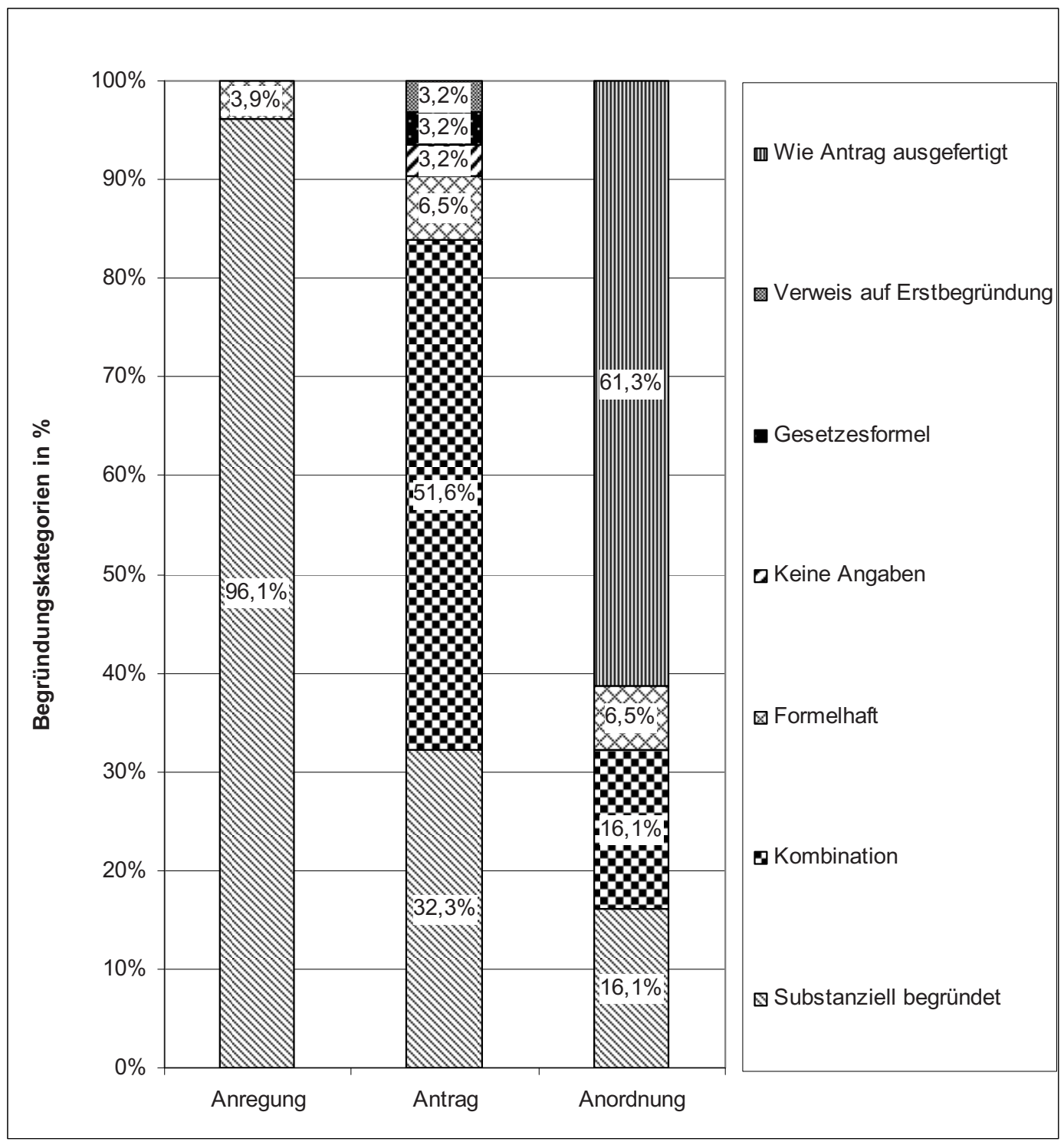

\section{Umfang der staatsanwaltschaftlichen und richterlichen Begründungen im Vergleich}

Aus der nachfolgenden Abbildung ist zu entnehmen, dass sich die Umfänge von staatsanwaltschaftlichen Anträgen und richterlichen Anordnungen nicht signifikant unterscheiden. Ausschlaggebend hierfür sind die mehr als $60 \%$ der Fälle, in denen lediglich eine Beschlussausfertigung durch das Gericht übernommen worden ist. 
Während der durchschnittliche Umfang der Antragsbegründungen 24 Zeilen betrug, waren dies bei den Anordnungsbegründungen 30 Zeilen. Der Median betrug bei den Antragsbegründungen 15 Zeilen und bei den Anordnungsbegründungen 16 Zeilen. Auch sind die Unterschiede geringfügig im Bezug auf den minimalen und maximalen Umfang.

Abbildung 16: Umfang staatsanwaltschaftlicher und richterlicher Begründungen im Vergleich

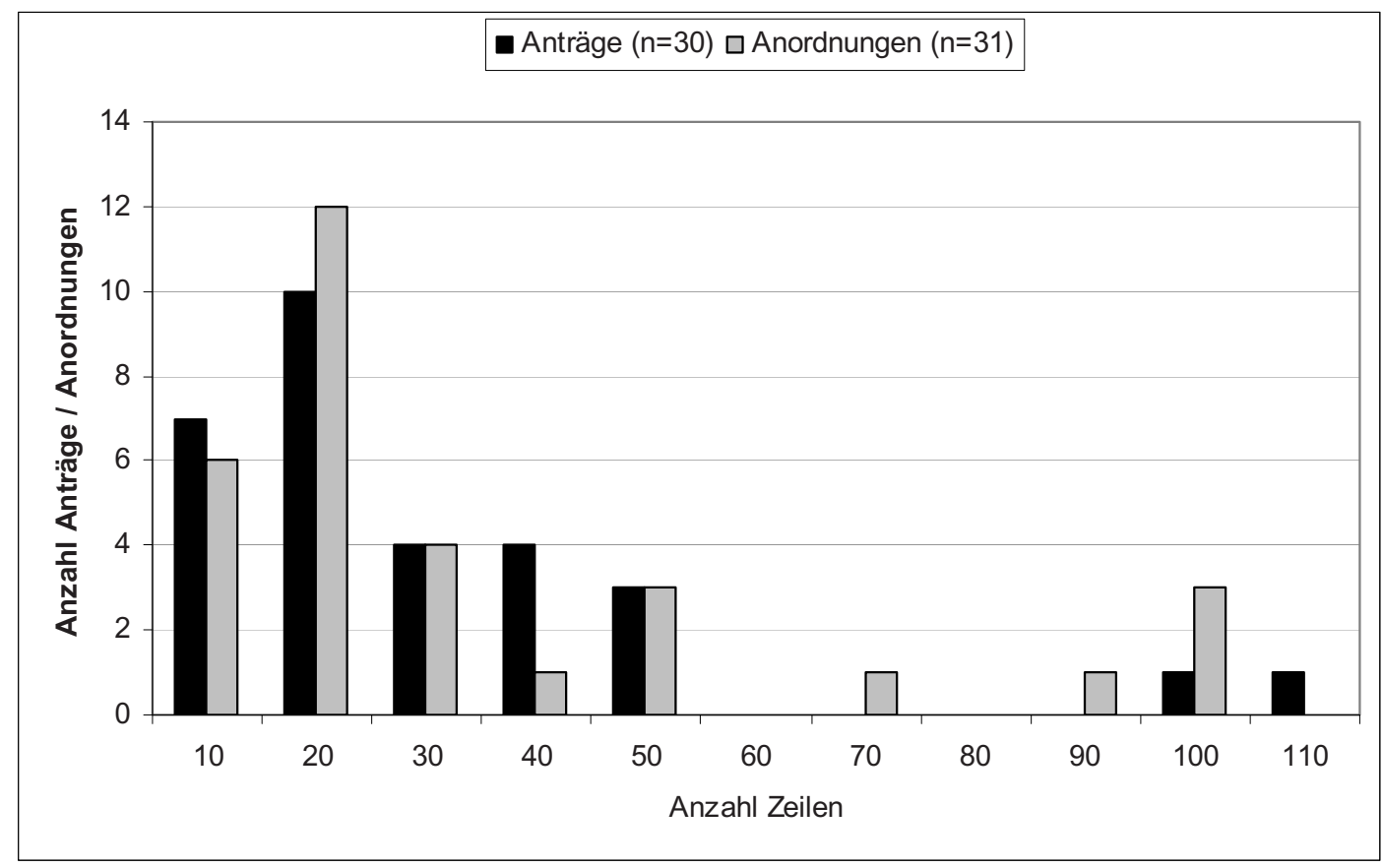

\section{Durchführung der Rasterfahndung gem. der §§ 98a, b StPO}

Im Dritten Kapitel dieses Teils der Untersuchung steht die Durchführung des maschinellen Datenabgleichs im Mittelpunkt. Von Interesse sind sowohl die Abläufe vor und während als auch nach dem Datenabgleich. Es sollen technische Probleme und die Intensität des mit der Maßnahme verbundenen Eingriffs dargestellt werden. Darüber hinaus befasst sich dieses Kapitel auch mit den betroffenen Datenbeständen und dem weiteren Vorgehen mit den erlangten Daten.

\section{Der Datenabgleich}

\section{Zeitraum zwischen Anordnung und Durchführung}

Bei der zeitlichen Umsetzung der richterlichen Anordnungen ergaben sich erhebliche Unterschiede zwischen den einzelnen Maßnahmen. Diese beruhten teilweise auf technischen Problemen. Aber auch die Einholung von Ergänzungs- und Erweiterungsanordnungen beeinflusste den Zeitraum zwischen der Anordnung der Maß- 
nahme und der Durchführung des maschinellen Datenabgleichs. Im Rahmen der Aktenanalyse konnten nur für 22 der 31 Maßnahmen Angaben über den Zeitpunkt des Datenabgleichs dokumentiert werden.

Die Spanne der Zeiträume lag zwischen -69 Tagen und 209 Tagen. In einem Verfahren wurde die Maßnahme erst nach der Durchführung beantragt. Insofern erklärt sich der Minuswert. In dem betreffenden Verfahren wurden die Daten erhoben und ein erster Abgleich durchgeführt. Anschließend wurde das Vorgehen zwischen ermittelnder Polizeidienststelle und Staatsanwaltschaft mit dem Ergebnis erörtert, dass es sich bei dem Datenabgleich um eine Rasterfahndung handeln würde, welche eine richterliche Anordnung voraussetze. Dieser Zeitraum bildet insofern eine Ausnahme.

Die übrigen Zeiträume lagen zwischen null Tagen und 209 Tagen. Durchschnittlich beträgt der Zeitraum zwischen Anordnung und Durchführung 40 Tage. Der Median liegt bei 26 Tagen. Demnach handelt es sich hier um eine schiefe Verteilung, da $50 \%$ der Maßnahmen innerhalb von 26 Tagen nach der Anordnung durchgeführt worden sind. Die Auswertung zeigt auf, dass die Maßnahme in der Regel einer längeren Vorbereitungszeit bedarf. Dies erklärt auch, weshalb es in keinem Fall zu einer Eilanordnung durch die Staatsanwaltschaft kam.

\section{Für den Datenabgleich benötigte Zeit}

Der für den Datenabgleich benötigte Zeitraum wurde in den ausgewerteten Verfahrensakten nicht hinreichend dokumentiert, so dass keine allgemeingültigen Angaben gemacht werden können. Es konnte den Verfahrensakten jedoch entnommen werden, dass der eigentliche maschinelle Datenabgleich keinen großen zeitlichen Aufwand erfordert. Im Normalfall wird für den Datenabgleich ein Tag benötigt. Der längste Zeitraum betrug eine Woche.

\section{Durchführende Stelle}

Für alle 31 Maßnahmen nach den $\S \S 98 \mathrm{a}, \mathrm{b}$ StPO konnte festgestellt werden, wer den Datenabgleich durchgeführt hat bzw. noch damit beschäftigt war. In einem Drittel der Maßnahmen war es die datenführende Stelle, welche den Datenabgleich durchgeführt hat. In den übrigen beiden Dritteln wurde der Datenabgleich durch die Polizei durchgeführt. Allerdings war es nicht in allen Fällen die ermittelnde Polizeidienststelle, welche den Datenabgleich durchgeführt hat. Teilweise wurden die Daten von der ermittelnden Polizeidienststelle an das betreffende Landeskriminalamt weitergeleitet und von diesem abgeglichen. In einigen richterlichen Anordnungen wurde die direkte Übermittlung der Daten an die zuständigen Landeskriminalämter angeordnet. In diesen Fällen wurden den ermittelnden Polizeidienststellen lediglich die Trefferlisten durch die Landeskriminalämter zugesandt. 


\section{Technische Probleme}

Als nicht unwesentlich bei der Durchführung von Rasterfahndung erwiesen sich technische Probleme. Im Rahmen von sieben Maßnahmen wurde in den Verfahrensakten ausdrücklich von technischen Problemen gesprochen. Damit kommt es in über $20 \%$ der Maßnahmen zu technischen Problemen. Da jedoch nicht zu allen Maßnahmen diesbezüglich Informationen festzustellen waren, muss davon ausgegangen werden, dass der tatsächliche Anteil von Maßnahmen mit technischen Problemen deutlich höher liegt. Diese Annahme basiert auf der Erkenntnis, dass die Verfahren ohne Angaben ihren Datenabgleich teilweise in den gleichen Datenbanken durchgeführt haben.

Das größte Problem bei der Durchführung von Rasterfahndung stellen die unterschiedlichen Formatierungen der abzugleichenden Dateien dar. Das Umschreiben der unterschiedlichen Formate in ein einheitliches Format erfordert einen erheblichen Zeitaufwand und birgt erhebliches Potenzial für technische Probleme. Bei zwei Maßnahmen waren diese Probleme so beträchtlich, dass es praktikabler war, den Datenabgleich anhand einer Einzelabfrage durchzuführen.

Darüber hinaus kam es im Rahmen einer Maßnahme während des Datenabgleichs zu einem vollständigen Datenverlust, weshalb die Daten erneut übermittelt werden mussten. Bei einer weiteren Maßnahme mussten aufwendige Sicherungskopien angefertigt werden, da auch dort die Gefahr eines vollständigen Datenverlustes bestand. In einem polizeilichen Vermerk zu dieser Maßnahme wurde darüber hinaus bemängelt, dass die zur Verfügung gestellte Software nicht mehr zeitgemäß sei.

Aber nicht nur Probleme im Bereich der Polizei, sondern auch EDV-Probleme bei den zur Übermittlung verpflichteten Stellen konnten festgestellt werden. Insbesondere die Einwohnermeldeämter arbeiteten mit stark veralteter Software. Ferner war die von den verschiedenen Einwohnermeldeämtern verwendete Software nicht identisch, so dass aufwendige Formatierungsarbeiten durchgeführt werden mussten. Auch was die Schreibweise von Namen, insbesondere ausländischer Personen anging, war die Erfassung durch die Einwohnermeldeämter nicht einheitlich. Diese Probleme mussten im Rahmen der Bearbeitung der Daten im Vorfeld des Datenabgleichs beseitigt werden. Bei einer Maßnahme wurde die technische Unterstützung einer privaten Softwarefirma benötigt, da die Probleme nicht durch die Polizei gelöst werden konnten.

\section{Trennung der Daten}

Die von der ermittelnden Polizeidienstelle angeforderten Daten mussten bei allen 31 Maßnahmen von anderen Daten getrennt werden. Dabei stand der Trennung in keinem Fall ein unverhältnismäßiger Aufwand im Sinne des $\S$ 98a III S.1 StPO entgegen. Demnach war es nicht notwendig die Übermittlung sog. Überhangdaten 
anzuordnen. Bei der Anordnung von drei Maßnahmen wurde jedoch die Unmöglichkeit der Trennung der Daten in Betracht gezogen. Aufgrund dessen wurde bereits in die Anordnung der Text des $\S 98$ a III S.1 StPO aufgenommen. Es sollten für den Fall des mit einer Trennung verbundenen unverhältnismäßigen Aufwandes auch die übrigen Daten übermittelt werden.

\section{Ordnungs- und Zwangsmittel}

Bei der Untersuchung der Verfahrensakten konnten für keine der Maßnahmen Informationen über die Anordnung von Ordnungs- oder Zwangsmitteln festgestellt werden. Mithin ist davon auszugehen, dass es im Rahmen von keiner der Maßnahmen zu einer solchen Anordnung gekommen ist. Lediglich in einem Verfahren wurden solche angedroht. In diesem Verfahren weigerte sich die datenführende Stelle, die angeforderten Daten zu übermitteln. Daraufhin beantragte die Staatsanwaltschaft eine neue Anordnung. Diese Anordnung enthielt den Namen der zuständigen Person innerhalb der verpflichteten Stelle und die Androhung eines Zwangsgeldes oder ersatzweise Haft. Aufgrund der neuen Anordnung übermittelte die datenführende Stelle die verlangten Daten umgehend, so dass es nicht zur Anordnung des Zwangsgeldes kam. Daraus ergibt sich, dass die datenführenden Stellen in großer Mehrheit den entsprechenden Anordnungen nachkommen und die Anordnung von Ordnungs- oder Zwangsmitteln eine untergeordnete Rolle spielt.

\section{Anordnungsverbot}

Im Rahmen der Untersuchung konnten lediglich im Zuge einer Maßnahme Hinweise auf ein Anordnungsverbot festgestellt werden. Ein im Verlauf der betreffenden Maßnahme angefertigter polizeilicher Vermerk enthielt den Hinweis darauf, dass die beim Kraftfahrtbundesamt angeforderten Daten nach dessen Ansicht einem Anordnungsverbot unterliegen würden. Die Zweckbestimmung des ZFER sollte der Datenübermittlung entgegenstehen, so dass diese gem. § $52 \mathrm{StVG}$ unzulässig sei. Das zuständige Amtsgericht wies jedoch eine Beschwerde des Kraftfahrtbundesamtes zurück. Daraufhin übermittelte das Kraftfahrtbundesamt die betreffenden Daten.

In den übrigen Verfahren konnten keine Hinweise auf ein Anordnungsverbot festgestellt werden. Insofern besitzt das Anordnungsverbot des $\S 98$ b I S.6 und S.7 StPO nur wenig praktische Relevanz. Insbesondere der Streit, ob ein Zeugnisverweigerungsberechtigter durch freiwillige Herausgabe auf das Beschlagnahme- und Verwertungsverbot verzichten kann, ist lediglich theoretischer Natur. ${ }^{432}$ Der Grund für die geringe Bedeutung des Anordnungsverbotes liegt in den

${ }^{432}$ Siehe 1. Teil F.VI. 
für die Datenabgleiche herangezogenen Datenbeständen. Hierbei handelt es sich in der Regel um solche, die keinem Anordnungsverbot unterliegen. ${ }^{433}$

\section{Die Intensität des Eingriffs}

\section{In den Datenabgleich einbezogene Datenbestände}

Bei der Betrachtung der in die Datenabgleiche einbezogenen Datenbestände weisen die einzelnen Maßnahmen deutliche Übereinstimmungen auf. So wurden in 15 der 31 Maßnahmen Daten von Einwohnermeldeämtern einbezogen. Damit bilden die Datenbestände der Einwohnermeldeämter in fast $50 \%$ der Maßnahmen einen Bestandteil der Rasterfahndung. Darüber hinaus wurden mehrfach Datenbestände des Kraftfahrtbundesamtes in die Datenabgleiche einbezogen.

Am häufigsten werden jedoch polizeiinterne Datenbestände in die Rasterfahndungen einbezogen. Dabei handelt es sich um die KAN-Bestände von Bund und Ländern, den IGVP-Datenbestand, die POLAS-Datenbank, die VICLASDatenbank, die Sexualstraftäterdatei des Bundeskriminalamtes sowie die APIS und NADIS-Datenbanken. ${ }^{434}$ Ferner werden in einigen Fällen Daten in die Rasterfahndung einbezogen, die zuvor mit Hilfe anderer Ermittlungsmaßnahmen erhoben worden sind. Bei den Ermittlungsmaßnahmen handelt es sich um Telefonüberwachungen, Auskunftserteilungen über Telekommunikationsverbindungsdaten, Ringalarmfahndungen und Observationen.

Letztlich werden auch nicht öffentliche Datenbestände in die Datenabgleiche einbezogen. Hier sind insbesondere Datenbestände von Banken, Kundendateien von Versandhandelsfirmen und anderen Geschäften sowie Mitarbeiterdaten von Firmen zu nennen. Wie und mit welchen Abfragen innerhalb dieser und der zuvor genannten Datenbestände recherchiert worden ist, wird im vierten Teil dieser Untersuchung dargestellt. Insofern kann an dieser Stelle eine ausführliche Beschreibung der Datenbestände unterbleiben.

\section{Umfang der angeforderten und übermittelten Daten}

Zum Umfang der angeforderten und übermittelten Daten konnten den Verfahrensakten nur sehr unterschiedliche Informationen entnommen werden. In einigen Fällen konnten lediglich Angaben über die Anzahl und die Art der übermittelten Datenträger festgestellt werden. Dabei handelte es sich um Magnetbänder, CDs

\footnotetext{
433 Siehe 3. Teil C.II.1.

434 Einen Sonderfall bilden die Abfragen in der Protokolldatei der Zentralen Polizeitechnischen Dienste des Landes Nordrhein-Westfalen. Hierzu siehe unten: 4. Teil.
} 
und Disketten. Bei den Maßnahmen, die durch die datenführenden Stellen durchgeführt wurden, kam es teilweise nur zur Übermittlung von Trefferlisten.

Häufig waren den Verfahrensakten nur Informationen über die Anzahl der übermittelten Datensätze zu entnehmen. Diese variierten in einer Größenordnung zwischen elf und 1.374.006 Datensätzen.

\section{Vom Datenabgleich betroffene Personen}

Als vom Datenabgleich betroffene Personen sind solche anzusehen, deren personenbezogene Datensätze in den Datenabgleich eingeführt worden sind. Diese personenbezogenen Datensätze ermöglichen einen Rückschluss auf die hinter den Daten stehenden Personen. Auch wenn der größte Teil der einbezogenen Datensätze nicht zu Treffern / Prüffällen im Rahmen des Datenabgleichs führt, so besteht doch die Möglichkeit dazu. Insofern können nicht ausschließlich die in den Treffermengen enthaltenen Datensätze und die dazugehörigen Personen als Betroffene der Maßnahme angesehen werden. ${ }^{435}$ Betroffen ist danach jeder, dessen Daten in einen Abgleich einbezogen werden.

Wie schon zuvor ausgeführt, konnten über den Umfang der Daten nur wenige Informationen gewonnen werden. Insofern können nur bedingt Aussagen über die Anzahl der von den Maßnahmen betroffenen Personen gemacht werden. Nicht für alle Maßnahmen lag die Anzahl der übermittelten und vom Datenabgleich betroffenen personenbezogenen Datensätze vor. Bei Zusammenfassung der Informationen ergibt sich eine Zahl von 2.633.721 personenbezogenen Datensätzen, welche in die Maßnahmen eingeführt worden sind. Mehrfachnennungen innerhalb der einzelnen Maßnahmen können bei der Gesamtzahl nicht berücksichtigt werden. Insgesamt dürfte die tatsächliche Anzahl der einbezogenen Datensätze jedoch deutlich höher liegen. Diese Vermutung ergibt sich bereits daraus, dass nicht zu allen eingeführten Datenbanken Informationen über die Anzahl der einzelnen personenbezogenen Datensätze vorlagen.

\section{Nach der Durchführung des Datenabgleichs}

Im Folgenden soll untersucht werden, wie im weiteren Verlauf der Ermittlungen mit den erlangten Datensätzen verfahren wird. Dabei stehen insbesondere die Rückgabe der Datenträger und die Löschung der Daten im Vordergrund. Aber auch die Verwendung der erlangten Daten zu Beweiszwecken in anderen Verfahren soll analysiert werden. Darüber hinaus soll aufgezeigt werden, ob und wann die Datenschutzbeauftragten Informationen über die Durchführung der Maßnahmen erhalten

${ }^{435}$ Zur Anzahl der Treffer / Prüffälle siehe 4.Teil.C.I.2.d. 
haben. Letztlich sollen auch die Kosten der Maßnahmen nicht unberücksichtigt bleiben.

\section{Rückgabe der Datenträger}

In $\S 98 b$ III S.1 StPO ist die unverzügliche Rückgabe der erhaltenen Datenträger nach Beendigung des Datenabgleichs an die betreffenden Speicherstellen vorgesehen. Bezüglich der Rückgabe der Datenträger waren den Verfahrensakten nur zu einem Drittel der Maßnahmen Informationen zu entnehmen. Für 21 Maßnahmen lagen keine Informationen über die Rückgabe der Datenträger vor. Dabei lag nur in wenigen Verfahren der Grund dafür in den noch andauernden Ermittlungen. $\mathrm{Ob}$ davon auszugehen ist, dass bei den übrigen Maßnahmen keine Rückgabe stattgefunden hat oder diese nur nicht in den Akten vermerkt worden ist, muss im Rahmen der Expertengespräche näher untersucht werden. ${ }^{436}$

Von den übrigen zehn Maßnahmen wurden in drei Fällen die Datenträger an die Stellen zurückgegeben, von der sie übermittelt worden sind. Ob diese zuvor gelöscht worden sind, konnte nicht festgestellt werden. ${ }^{437} \mathrm{Im}$ Rahmen der restlichen sieben Maßnahmen wurden zum Teil nur Trefferlisten übermittelt, so dass eine Rückgabe von Datenträgern nicht in Betracht kam. Darüber hinaus wurden die Datenträger zum Teil gelöscht und seitens der übermittelnden Stellen auf eine Rückgabe der Datenträger verzichtet.

\section{Löschung der Daten}

Ähnliche Erkenntnisse ergaben sich bei der Auswertung der Informationen über die Löschung der Daten. Auch hier waren nur für ein gutes Drittel der Maßnahmen Angaben festzustellen. Für 19 Maßnahmen waren keine Informationen über Löschungen verfügbar. Insofern können keine Aussagen darüber getroffen werden, ob die Daten nicht gelöscht oder die Löschungen nur nicht in den Verfahrensakten vermerkt worden sind. ${ }^{438}$

Die übrigen zwölf Maßnahmen verteilen sich zu gleichen Teilen auf die Kategorien „Daten gelöscht“ und „Daten nicht gelöscht“. Mithin konnte für sechs Verfahren die Information gewonnen werden, dass die Daten gelöscht worden sind. Dabei wurde nur in einem Fall eine Niederschrift über die Löschung gefertigt. In keinem Fall fand die Löschung der Daten unter der Aufsicht der Staatsanwaltschaft statt. Bei den sechs Maßnahmen, deren Daten nicht gelöscht worden sind, handelt es sich zum Teil um Maßnahmen aus noch nicht abgeschlossenen Verfahren.

\footnotetext{
436 Siehe 5. Teil B. V.

437 Bzgl. der Löschung der Datenträger vor der Rückgabe siehe 1. Teil F.X.

${ }^{438}$ Auch hier ist auf die Expertengespräche zu verweisen. Siehe 5. Teil B.V.
} 


\section{Verwendung der Daten zu Beweiszwecken in anderen Verfahren}

Über die Verwendung der erlangten Daten zu Beweiszwecken in anderen Verfahren waren den Verfahrensakten keine Angaben zu entnehmen. Insofern muss davon ausgegangen werden, dass es nicht zu einer solchen Verwendung kam. Einer Verwendung der Daten aus den 31 Maßnahmen zu Beweiszwecken in anderen Verfahren steht zudem deren stark auf den Einzelfall bezogener Charakter entgegen.

\section{Benachrichtigung}

Gemäß § 98b IV.1 StPO in Verbindung mit § 163d V StPO sind nach der Durchführung der Rasterfahndung die Personen zu benachrichtigen, gegen die weitere Ermittlungen geführt worden sind. Darüber hinaus sollten, wenn möglich, alle herausgerasterten Merkmalsträger (sog. Treffer / Prüffälle) benachrichtigt werden. ${ }^{439}$

Für mehr als die Hälfte der Maßnahmen konnten aus den Verfahrensakten keine Angaben über die Benachrichtigung der Betroffenen erlangt werden. Lediglich für drei Maßnahmen konnte festgestellt werden, dass die betreffenden Personen nach der Durchführung des Datenabgleichs benachrichtigt worden sind. Dabei handelte es sich um alle herausgerasterten Treffer / Prüffälle. Für zwei der Maßnahmen war es zudem möglich, die Benachrichtigung auch zeitlich zu bestimmen. In einem Fall wurden die betreffenden Personen 154 Tage und im zweiten Fall 410 Tage nach der Durchführung der Maßnahme benachrichtigt.

Für elf Maßnahmen kann festgehalten werden, dass die Personen, gegen die weitere Ermittlungen geführt worden sind, nicht benachrichtigt werden mussten. Dabei handelt es sich insbesondere um Personen, die aufgrund der Rasterfahndungen zur Abgabe einer Speichelprobe oder eines Vergleichsfingerabdrucks aufgefordert waren. Darüber hinaus waren auch Personen betroffen, die als Zeugen oder Beschuldigte vernommen worden sind. Bzgl. dieser Personen war eine gesonderte Benachrichtigung obsolet.

\section{Meldung an den Datenschutzbeauftragten}

Nach der Regelung des $\S 98 b$ IV S.2 StPO sind nach der Durchführung des Datenabgleichs die Datenschutzbeauftragten der Länder oder des Bundes zu benachrichtigen. Bei der Untersuchung der Verfahrensakten konnten nur vier Maßnahmen festgestellt werden, nach deren Abschluss der betreffende Datenschutzbeauftragte informiert worden ist. Für zwei der vier Maßnahmen konnten zudem zeitliche Angaben festgestellt werden. So wurden die Datenschutzbeauftragten einmal 172 Tage und in einem anderen Fall 477 Tage nach der Durchführung der Maßnahme be-

${ }^{439}$ Zur Begründung dessen, siehe 1. Teil F.VII.1. 
nachrichtigt. In beiden Fällen kann von einer zeitnahen und effektiven datenschutzrechtlichen Kontrolle nicht gesprochen werden.

Für die übrigen Maßnahmen lagen keine Informationen über die Meldung der Maßnahme an den Datenschutzbeauftragten vor. Der Frage, ob die Benachrichtigung tatsächlich nicht stattgefunden hat oder sie lediglich nicht in den Verfahrensakten vermerkt worden ist, muss im Rahmen der Expertengespräche nachgegangen werden. ${ }^{40}$ Bei ausschließlicher Heranziehung der Erkenntnisse aus der Aktenanalyse ergibt sich die Schlussfolgerung, dass die Meldung an die Datenschutzbeauftragten in der Regel unterbleibt. Dies würde bedeuten, dass eine Kontrolle der Einhaltung von datenschutzrechtlichen Vorschriften faktisch nicht erfolgt. Insbesondere für die Personen, die nicht benachrichtigt werden, besteht damit keine Möglichkeit, von der Maßnahme Kenntnis zu erlangen.

\section{Kosten der Rasterfahndung}

Bei der Untersuchung der Maßnahmen nach entstandenen Kosten konnten lediglich für eine Maßnahme Angaben festgestellt werden. Bei dieser stellte das Einwohnermeldeamt, welches zur Übermittlung von Daten verpflichtet worden war, eine Rechnung in Höhe von 225 DM aus. Die Gesamtkosten einer Maßnahme waren den Verfahrensakten in keinem Verfahren zu entnehmen. Mithin muss der Frage nach dem finanziellen Aufwand im Rahmen der Expertengespräche nachgegangen werden. ${ }^{441}$

Den größten Teil der Kosten einer Rasterfahndung dürften die Arbeitsstunden der mit der Durchführung betrauten Personen ausmachen. Insbesondere auftretende technische Probleme erfordern in der Regel einen erheblichen Arbeitsaufwand. Die damit verbundenen Kosten werden jedoch nicht in den Verfahrensakten aufgeführt. Allerdings enthielten die polizeilichen Vermerke vereinzelt Angaben über den Arbeitsaufwand. Bei der Durchführung einer Maßnahme kamen die Polizeibeamten auf einen Arbeitsaufwand von 554 Manntagen.

\footnotetext{
${ }^{440}$ Siehe 5. Teil B.IV.

${ }^{441}$ Siehe 5. Teil A.IX.3.
} 


\section{Der Verfahrensausgang}

\section{Verfahrensausgang bezogen auf die Verfahren}

\section{Inhalt der polizeilichen Abschlussberichte}

Die Untersuchung der Ermittlungsergebnisse stützt sich zunächst auf den Inhalt der polizeilichen Abschlußberichte. Von den 27 untersuchten Verfahren gab es nur in 18 Fällen Abschlußberichte. Die Ermittlungsakten der neun übrigen Verfahren enthielten keine Abschlußberichte oder Schlussvermerke. Es handelt sich dabei jedoch nicht um nicht abgeschlossene Verfahren, so dass angenommen werden muss, dass die Abschlußberichte lediglich nicht in den Verfahrensakten abgeheftet oder keine angefertigt worden sind. In 12 der 18 Abschlußberichte wurden die zugrunde liegenden Taten als aufgeklärt bezeichnet. Die weiteren sechs Abschlußberichte hatten die erfolglose Einstellung der Ermittlungen zum Inhalt.

\section{Noch anhängige Verfahren}

Weitere Informationen über den Ausgang der 27 Verfahren ließen sich sowohl aus staatsanwaltschaftlichen Verfügungen als auch aus rechtskräftigen Urteilen entnehmen. So konnte festgestellt werden, dass die Ermittlungen in fünf der untersuchten Verfahren noch nicht abgeschlossen waren. Insofern können keine Angaben über den Verfahrensausgang gemacht werden. Aus Medienberichten konnte jedoch die Information gewonnen werden, dass es in einem der Verfahren inzwischen zur Ergreifung eines mutmaßlichen Täters gekommen ist. Den Berichten zufolge sei die betreffende Person auch geständig. Da die Ermittlungen zum Zeitpunkt der Beendigung dieser Untersuchung noch nicht abgeschlossen waren, bestand keine Möglichkeit, erneut in die Verfahrensakten des betreffenden Verfahrens Einsicht zu nehmen.

\section{Einstellungen}

In acht Verfahren wurden die Ermittlungen eingestellt, weil keine Täter ermittelt werden konnten. In einem weiteren Verfahren hat sich der Täter der Festnahme durch Suizid entzogen. In diesem Sonderfall konnten dem verstorbenen Täter die Taten aufgrund von DNA-Spuren zugerechnet und daraus resultierend das Verfahren eingestellt werden.

\section{Anklagen und Verurteilungen}

In zwölf Verfahren führten die Ermittlungen zur Aufklärung der Tat und der Ergreifung von Tätern. In diesen Verfahren wurden die mutmaßlichen Täter angeklagt und verurteilt. Darüber hinaus wurde in einem weiteren Verfahren der Täter im Ausland gefasst und dort verurteilt. 


\section{Verfahrensausgang bezogen auf die Beschuldigten}

Wie bereits im Rahmen der Grundgesamtheiten dargestellt, wurden 135 Personen in den 27 Verfahren als Beschuldigte geführt. Vertiefende Informationen lagen jedoch nur zu 114 Beschuldigten vor.

\section{Einstellungen}

Von den 135 beschuldigten Personen wurden bei 106 Personen Angaben bzgl. der Verfahrenseinstellung oder der Anklageerhebung dokumentiert. Gegen 71 der 106 Beschuldigten wurden die Ermittlungen eingestellt. Bezogen auf diese Zahl der Personen, für welche der Verfahrensausgang bekannt ist, kann festgehalten werden, dass die Verfahren gegen fast $70 \%$ der Beschuldigten eingestellt wurden.

Bei der Verteilung der Einstellungen auf die Katalogdelikte zeigt sich zunächst, dass die größte Anzahl von Beschuldigten in Verfahren mit Kombinationen aus mehreren Katalogdelikten geführt worden sind. ${ }^{442}$ In dieser Gruppe sind auch die häufigsten Einstellungen zu verzeichnen. Bei der Betrachtung ist jedoch zu berücksichtigen, dass es sich bei 56 der unter der Kategorie „Kombination aus mehreren Katalogdelikten“ geführten Beschuldigten um beschuldigte Personen aus einem einzigen Verfahren handelt. Im Rahmen der Grundgesamtheiten wurde auf diese Beschuldigtengruppe bereits hingewiesen. Es handelt sich um die Beschuldigten aus dem untersuchten Verfahren, welchem Straftaten auf dem Gebiet des BtMG und Straftaten, die als Bandenmitglied und in anderer Weise organisiert begangen worden sind, zugrunde lagen. ${ }^{443}$

Neben den Kombinationen aus mehreren Katalogdelikten bilden die Beschuldigten in Verfahren mit Straftaten gegen Leib und Leben die zweitgrößte Gruppe. Mehr als ein Viertel der Personen werden aufgrund Straftaten gegen Leib und Leben als Beschuldigte geführt. Gegen die Hälfte dieser Beschuldigten wurden die Verfahren eingestellt. Aus der Analyse der Abbildung ergibt sich des Weiteren, dass keine Person allein aufgrund von Straftaten auf dem Gebiet des Staats- und Verfassungsschutzes, als Mitglied einer Bande oder in anderer Weise organisiert begangene Straftaten und Straftaten auf dem Gebiet des BtMG, des Waffenhandels und der Geld- und Wertzeichenfälschung, als Beschuldigter geführt worden ist.

442 Zur Verteilung der Katalogdelikte auf die Kombinationen sie oben unter Grundgesamtheiten (3.Teil A.I.4.).

${ }^{443}$ Bzgl. der hohen Anzahl von Beschuldigten bildet dieses Verfahren einen Sonderfall. Im Rahmen der Einzelfallauswertung wird dieses Verfahren unter Verfahren 001 dargestellt (4. Teil B.I.). 
Abbildung 17: Einstellungen und Katalogtat

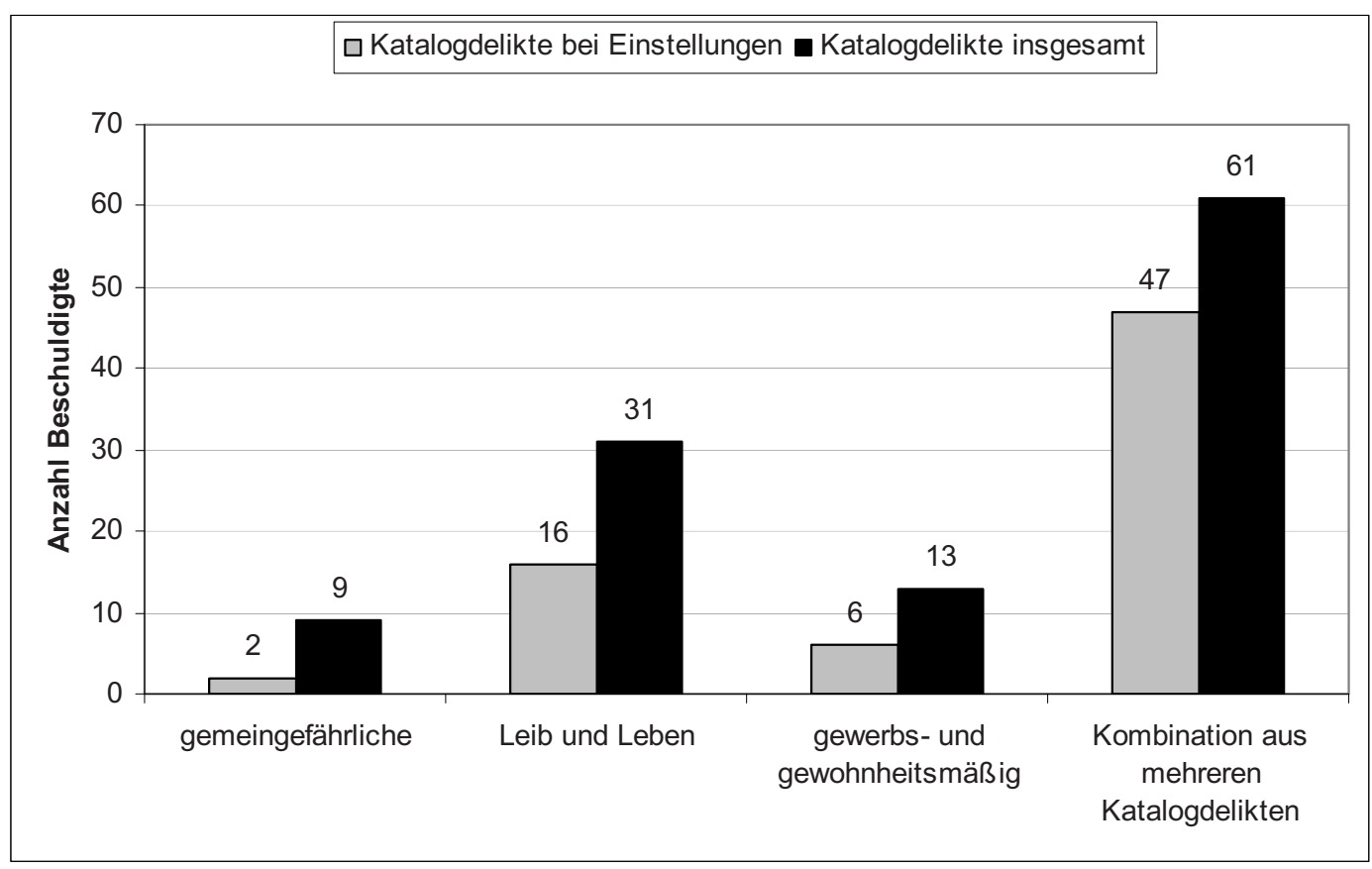

Die Verfahren gegen 60 Beschuldigte wurden gem. $\S 170$ II StPO eingestellt. Damit stützen sich fast $85 \%$ der Einstellungen auf diese Norm. In einem Fall wurde das Verfahren gegen die betreffende Person gem. $§ 153 \mathrm{a}$ StPO eingestellt. Die Verfahren gegen drei weitere Beschuldigte wurden gem. $§ 154 \mathrm{~b}$ StPO eingestellt. $\mathrm{Zu}$ sieben Beschuldigten waren keine Informationen über den Grund der Einstellung verfügbar.

\section{Anklagen und Verurteilungen}

Im Gegensatz zu den 71 Einstellungen kam es nur in 35 Fällen zu einer Anklage. Allerdings lagen nur zu 28 dieser Personen Angaben zur Anklage, zur Hauptverhandlung und zum Urteil vor. Von diesen 28 Personen wurde keine freigesprochen und gegen keine der Personen wurde das Verfahren in der Hauptverhandlung eingestellt. Mithin wurden alle 28 Personen verurteilt. 19 der Angeklagten wurden zu einer unbedingten Freiheitsstrafe verurteilt. Gegen fünf der Angeklagten wurden Bewährungsstrafen und gegen die übrigen vier Angeklagten wurden Geldstrafen verhängt.

Die Dauer der Freiheitsstrafen lag zwischen zehn Monaten und lebenslänglich. Die Dauer der Freiheitsstrafen, welche für 24 Beschuldigte verhängt worden sind, ermöglicht Rückschlüsse bzgl. der Art der Verfahren. Die Verfahren 
mit Maßnahmen nach den $\S \S 98 \mathrm{a}, \mathrm{b}$ StPO konzentrieren sich auf den Bereich der schweren Kriminalität. Legt man für die drei Beschuldigten, die zu lebenslangen Freiheitsstrafen verurteilt worden sind, eine Dauer von 15 Jahren zugrunde, ergibt sich eine durchschnittliche Freiheitsstrafe von über acht Jahren. Insgesamt liegen $50 \%$ der Freiheitsstrafen bei über neun Jahren. Insofern bestätigt sich die Annahme, dass die Rasterfahndung hauptsächlich in Verfahren der schweren Kriminalität angewandt worden ist.

Abbildung 18: Dauer der Freiheitsstrafen ( $n=24)$

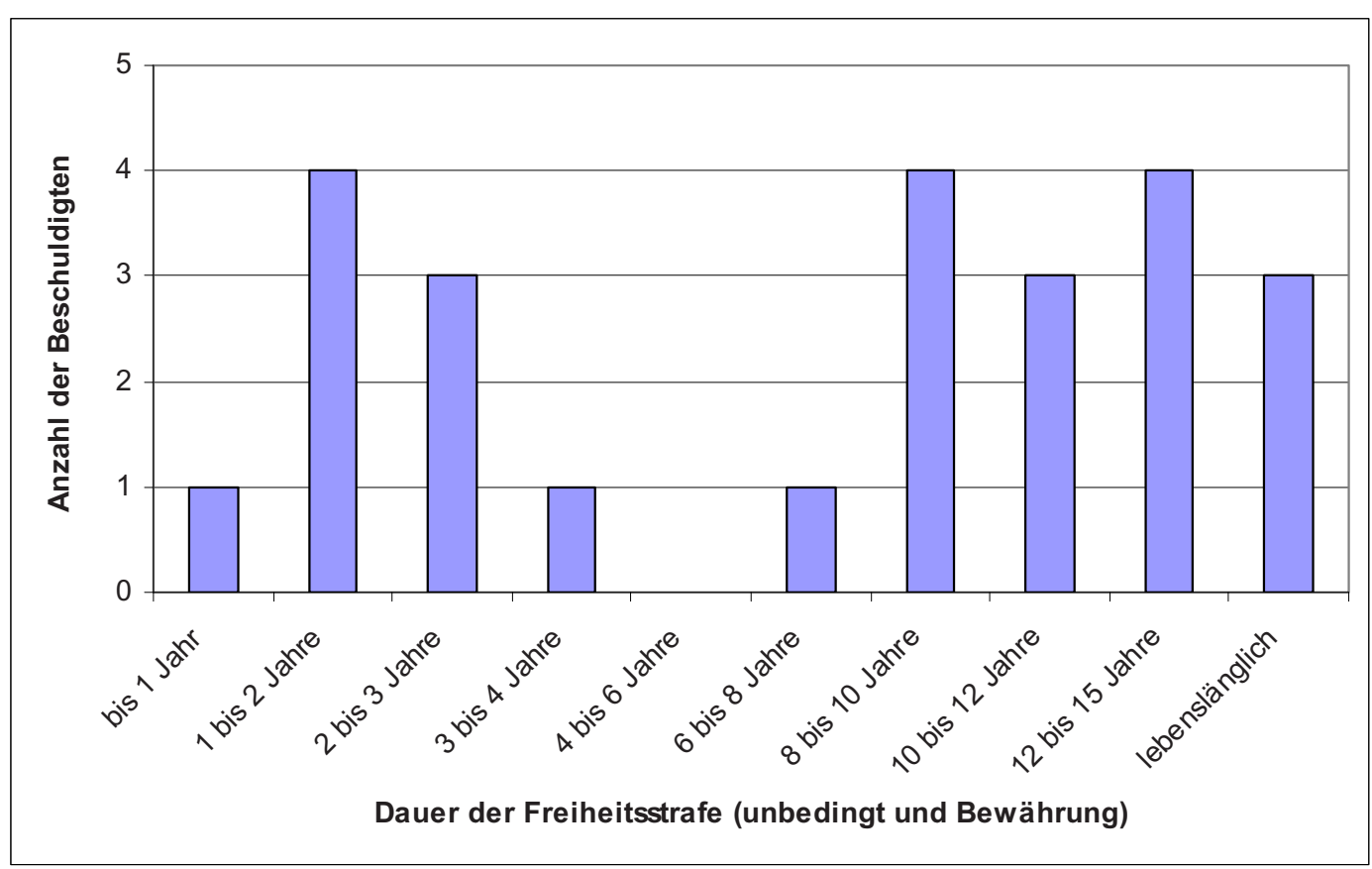

Bei der Betrachtung der Verteilung der Verurteilungen auf die Katalogdelikte fällt ebenfalls die Kategorie „Kombination aus mehreren Katalogdelikten“ auf. Diesbezüglich kann auf die Darstellungen unter Einstellungen verwiesen werden. 10 der 11 verurteilten Beschuldigten aus dieser Kategorie gehören dem betreffenden Verfahren an. Des Weiteren ergibt sich aus der Darstellung, dass zwei Drittel der aufgrund gemeingefährlicher Straftaten verfolgten Beschuldigten auch verurteilt wurden. Dagegen wurden keine der 13 Beschuldigten aus Verfahren wegen gewerbsund gewohnheitsmäßig begangenen Straftaten verurteilt. Letztlich sind lediglich 5 von 31 Personen, die der Begehung von Straftaten gegen Leib und beschuldigt wurden, verurteilt worden. 
Abbildung 19: Verurteilungen und Katalogdelikte

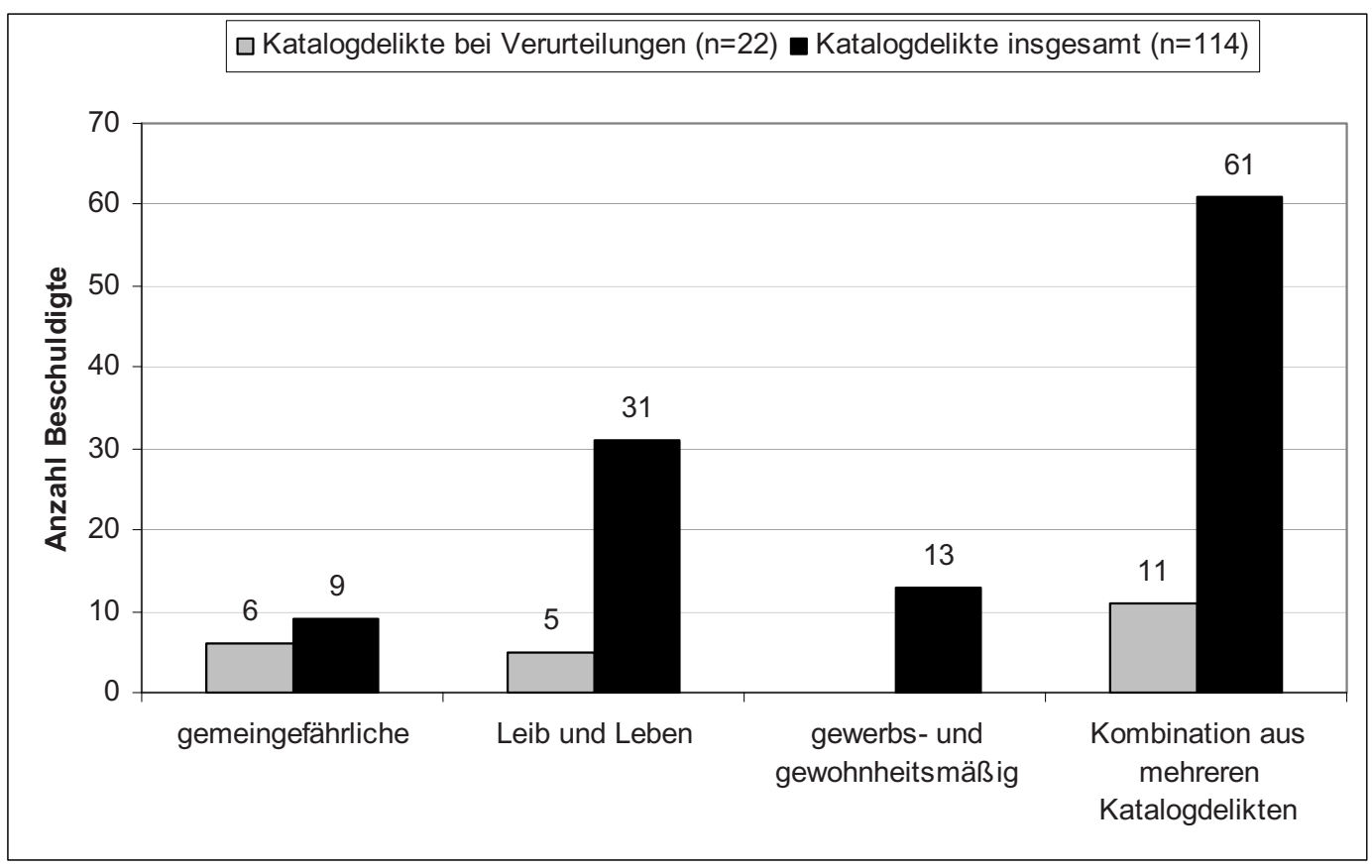





\section{Vierter Teil Erfolg und Effizienz}

Im Dritten Teil der Untersuchung standen die Grunddaten, der Verfahrensverlauf und Fragen nach der Überwachungsintensität sowie der Kontrolle der Rasterfahndung im Vordergrund. Demgegenüber befasst sich der folgende Teil der Untersuchung mit Fragen nach dem Erfolg und der Effizienz der Ermittlungsmaßnahme. Aufgrund der geringen Fallanzahl und der unterschiedlichen Charakteristik der untersuchten Verfahren war es für diesen Untersuchungsbereich notwendig, einen qualitativen Untersuchungsansatz zu wählen. Aufgrund dessen wurde bei der Datenerhebung in größerem Umfang auf Freitextvariablen zurückgegriffen. Die Auswertung basiert auf den Grundlagen der qualitativen Inhaltsanalyse, da es nur so möglich war, auf die Besonderheiten des Einzelfalles einzugehen. ${ }^{444}$

Inhaltlich gliedert sich dieser Teil der Untersuchung in drei Kapitel. Zunächst werden die Begriffe Erfolg und Effizienz erläutert und gegenüber verwandten Begriffen abgegrenzt. Nur auf der Grundlage einer solchen Bedeutungsanalyse ist es möglich, Aussagen über Erfolg und Effizienz der Ermittlungsmaßnahme Rasterfahndung zu treffen. Im zweiten Kapitel des Vierten Teils der Untersuchung steht die Analyse der einzelnen Verfahren im Mittelpunkt. Auf der Bedeutungsanalyse der Begriffe aufbauend werden die untersuchten Verfahren einzeln dargestellt und die Maßnahmen nach den $\S \S 98 \mathrm{a}, \mathrm{b}$ StPO analysiert. Dieses Vorgehen ermöglicht es, für jede Maßnahme nach den $\S \S 98 \mathrm{a}, \mathrm{b}$ StPO eine separate Erfolgseinschätzung abzugeben. Darüber hinaus kann auch das Zusammenspiel der Rasterfahndung mit weiteren Ermittlungsmaßnahmen analysiert werden. Das dritte Kapitel baut inhaltlich auf den Erkenntnissen der Einzelfallanalyse auf. Es sollen Gemeinsamkeiten und Unterschiede der Verfahren herausgestellt werden. Dabei stehen insbesondere die Auswirkungen der Maßnahme auf das weitere Verfahren im Vordergrund.

\section{A. Begriffsbestimmung}

Theoretische Begriffe wie Erfolg und Effizienz sind nicht direkt beobachtbar. Voraussetzung für die Beurteilung des Erfolges und der Effizienz der Rasterfahn-

${ }^{444}$ Siehe hierzu 2. Teil A. 
dung in den untersuchten Verfahren ist daher die Operationalisierung der Begriffe Erfolg und Effizienz. Unter Operationalisierung eines Begriffs ist die Angabe derjenigen Vorgehensweisen zu verstehen, mit deren Hilfe entscheidbar wird, ob und in welchem Ausmaß der mit dem Begriff bezeichnete Sachverhalt in der Realität vorliegt. ${ }^{445}$ Demnach müssen den Begriffen Effizienz und Erfolg zunächst beobachtbare Sachverhalte zugeordnet werden, um eine empirische Messung zu ermöglichen.

Grundlage der Operationalisierung bildet eine genaue Bedeutungsanalyse der zu operationalisierenden Begriffe. Vorrangig sind daher die Begriffe Erfolg und Effizienz zu erläutern und gegebenenfalls gegenüber anderen Begriffen abzugrenzen. Darüber hinaus wird auf ihre besondere Bedeutung im Zusammenhang mit der Polizeiarbeit eingegangen. Dies ist notwendig, da sich gerade hinsichtlich der Operationalisierung polizeilicher Ziele und der Messbarkeit ihrer Ergebnisse erhebliche Probleme ergeben. ${ }^{446}$

An die Bedeutungsanalyse der Begriffe Erfolg und Effizienz anschließend werden die im Rahmen der Aktenanalyse verwendeten Operationalisierungen dargestellt.

\section{Begriff des Erfolgs}

Unter Erfolg ist im Allgemeinen das positive Ergebnis einer Bemühung bzw. das Eintreten einer erstrebten Wirkung zu verstehen. ${ }^{447}$ Demnach steht im Rahmen des Erfolges lediglich das Ergebnis der Bemühung im Vordergrund. Erfolg ist dann gegeben, wenn das erstrebte Ergebnis erzielt wurde. Der Prozess bis zur Zielerreichung wird dabei nicht analysiert.

Während der generelle Begriff des Erfolges unstrittig ist, ist der Begriff des polizeilichen Erfolges schon seit längerer Zeit Gegenstand der Diskussion zwischen Wissenschaft und Praxis. ${ }^{448}$ Einigkeit besteht zumindest darin, dass sich der polizeiliche Erfolg am Ziel und an der Aufgabe, die der Polizei übertragen wurde bzw. welches sie zu erreichen hat, orientiert. Ziel der Polizei ist die Gewährleistung der inneren Sicherheit. Teilweise wird der polizeiliche Erfolg ausschließlich an der Aufklärungsquote gemessen. ${ }^{449}$ Die Praxis sieht dies als zu enge Sichtweise an und betont, dass die Aufklärungsquote zwar einer der wichtigsten, aber sicherlich nicht der einzige Indikator polizeilichen Erfolges darstellen kann. Direkte Indikatoren, an

\footnotetext{
445 Kromrey, S.183.

446 Büchler/Wagner/Grawert/Fiedler, S.33.

447 Brockhaus-Enzyklopädie, Band 6, S.514.

448 Siehe hierzu Störzer, in: Bundeskriminalamt (Hrsg.), Symposium: Der polizeiliche Erfolg, S.3ff, m.w.N.

${ }^{449}$ So von Lisken, NJW 1986, 175; Wehner, Kriminalistik 39 (1985), 112.
} 
welchen sich der polizeiliche Erfolg ablesen lassen soll, stellen u.a. die Straftatenziffer, die Aufklärungsquote und die Rate der erfolgten Verhaftungen dar. ${ }^{450}$ Dabei vermögen es diese Kriterien, sowohl einzeln als auch in Kombination miteinander, nicht zu überzeugen. Andere Indikatoren, wie beispielsweise das Sicherheitsgefühl der Bevölkerung, lassen sich dagegen nur schwer messen. ${ }^{451}$ Diese müssen aber vor dem Hintergrund der präventiven Aufgabe der Polizei auch ihren Eingang in den polizeilichen Erfolgsbegriff finden. Darüber hinaus wird der polizeiliche Erfolg maßgeblich durch die Rahmenbedingungen polizeilichen Handelns bestimmt. Dazu gehören gesetzliche Vorschriften, Personalstärke, materielle Ausstattung und die Organisationsform. ${ }^{452}$ Letztlich setzt das Täterverhalten zusätzliche Bedingungen, welche durch die Polizei ohne Einflussmöglichkeiten hingenommen werden müssen. ${ }^{453}$

Gegenstand der vorliegenden Untersuchung ist die Rasterfahndung nach den $\S \S 98 \mathrm{a}$, b StPO. Die Untersuchung ist demnach im repressiven Bereich polizeilicher Tätigkeit angesiedelt. Insofern können präventive Aufgaben und damit verbundene Ziele unberücksichtigt bleiben. ${ }^{454}$ Mithin ist für diese Untersuchung ausschließlich das als repressives Polizeiziel definierte Ziel der Aufklärung von Straftaten maßgeblich. Dieses Ziel wird der Polizei durch die $\S \S 161,163$ StPO übertragen. Danach wird eine Straftat als aufgeklärt angesehen, wenn die Polizei einen namentlich bekannten oder auf frischer Tat ergriffenen Tatverdächtigen ermittelt und Informationen und Beweismittel zusammengetragen hat, die eine gerichtliche Feststellung der Täterschaft erwarten lassen. ${ }^{455}$ An diesem Ziel ist im weiteren Verlauf dieses Abschnittes auch der Erfolg der Rasterfahndung zu messen.

\section{Begriff der Effizienz}

Auf der Bedeutungsanalyse des Begriffes Erfolg aufbauend, soll im Folgenden der Begriff Effizienz erläutert und gegenüber dem Begriff Effektivität abgegrenzt werden. Die Abgrenzung zur Effektivität ist notwendig, da die beiden Begriffe häufig synonym verwendet werden. ${ }^{456}$ Effektivität kennzeichnet die grundsätzliche Eignung einer Maßnahme, einer Organisationsform o.ä. ein angestrebtes Ziel zu erreichen. ${ }^{457}$ Bezogen auf die Polizeiarbeit stellt sich eine Maßnahme dann als ef-

\footnotetext{
450 Boeden, in: Bundeskriminalamt (Hrsg.), Symposium: Der polizeiliche Erfolg, S.67.

${ }^{451}$ In Betracht kämen Erhebungen in Form von Umfragen etc.

452 Störzer, in: Bundeskriminalamt (Hrsg.), Symposium: Der polizeiliche Erfolg, S.8.

453 Büchler/Wagner/Grawert/Fieler, S.34.

${ }^{454}$ Zur Generalprävention als Strafzweck siehe Eisenberg, § 41; Aufgrund der Untersuchungsanlage jedoch zu vernachlässigen.

${ }^{455}$ Dölling, in: Bundeskriminalamt (Hrsg.), Symposium: Der polizeiliche Erfolg, S.113.

${ }^{456}$ Büchler/Wagner/Grawert/Fieler, S.34; Albrecht/Dorsch/Krüpe, S.356.

${ }^{457}$ Büchler/Wagner/Grawert/Fiedler, S.33.
} 
fektiv dar, wenn sie bestimmte Effekte erzielt oder gewünschte Zustände erreicht. Darüber hinaus gibt es aber Situationen im polizeilichen Alltag, bei denen es nicht nur auf die Wirksamkeit der Maßnahme ankommt, sondern Fragen der Ökonomie des Mitteleinsatzes eine Rolle spielen. ${ }^{458}$

Diesbezügliche Fragen gehen über den Bereich der Effektivität hinaus und betreffen die Effizienz. Die Effizienz ist ein Prädikat, mit dem der eingeschlagene Weg zum Ziel qualifiziert wird. ${ }^{459}$ Dabei sind für die Beurteilung der Effizienz einer Maßnahme drei Komponenten maßgeblich. Zunächst enthalten Maßnahmen immer gewisse Zielvorstellungen, d.h. Vorstellungen darüber, was man erreichen will. Um die angestrebten Ziele erreichen zu können, müssen Mittel aufgewendet werden. Dieser Teil von Maßnahmen wird mit Input bezeichnet. Das Ergebnis der durchgeführten Maßnahme wird als Output bezeichnet. Der Effizienzbegriff gewinnt dann besonders an Aussagekraft, wenn es ihm gelingt, möglichst alle Facetten eines zu beurteilenden Sachverhalts in seine Betrachtung einzubeziehen. ${ }^{460}$

Zusammenfassend lässt sich der Begriff der Effizienz auf das Ausmaß der Zielerreichung unter Berücksichtigung der zur Verwirklichung der Ziele eingesetzten Mittel definieren. Die vorhandenen Mittel sollen so eingesetzt werden, dass die verfolgten Ziele in einem möglichst großen Ausmaß erreicht werden. Mithin beschreibt die Effizienz die Relation von Input zu Output. ${ }^{461}$ Dabei sind für das Qualitätsurteil die Beziehungen wesentlich, die zwischen den Elementen auftreten. ${ }^{462}$ Diesbezüglich dürfen, wie bereits im Rahmen der Bedeutungsanalyse zum Erfolg festgestellt, die Bedingungen im Umfeld, in welchem die Maßnahme getroffen wird, nicht unberücksichtigt bleiben. Diese Notwendigkeit rechtfertigt die eingehende Einzelfallbetrachtung zu Beginn dieses Untersuchungsabschnittes. Nur so konnte das Umfeld, in welchem die Entscheidung für die Durchführung der Maßnahme getroffen wurde, angemessen berücksichtigt werden.

Letztlich ist es notwendig, den Effizienzbegriff in Bezug zur Polizeiarbeit zu setzen. Dabei ist zunächst einmal der Eintritt des polizeilichen Erfolges Voraussetzung für die Effizienz der Polizeiarbeit. Eine erfolglose polizeiliche Maßnahme kann auch bei denkbar ressourcenschonenstem Einsatz der Mittel niemals als effizient bezeichnet werden. Demnach kommt dem polizeilichen Erfolg in der oben beschrieben Weise eine Schlüsselfunktion bei der Bestimmung der Effizienz zu und muss dieser immer vorausgehen. Darüber hinausgehend ist im Rahmen der Effizienz der Weg hin zu dem erstrebten Ergebnis zu untersuchen. Außerhalb der Polizeiarbeit wird zur Messung der Effizienz die Kosten- und Leistungsrechnung

\footnotetext{
${ }^{458}$ Schroller, Bundeskriminalamt (Hrsg.), Symposium: Der polizeiliche Erfolg, S.28.

${ }^{459}$ Störzer, in: Bundeskriminalamt (Hrsg.), Symposium: Der polizeiliche Erfolg, S.4.

${ }^{460}$ Schroller, Bundeskriminalamt (Hrsg.), Symposium: Der polizeiliche Erfolg, S.28.

${ }^{461}$ Albrecht/Dorsch/Krüpe, S.356.

${ }^{462}$ Schroller, Bundeskriminalamt (Hrsg.), Symposium: Der polizeiliche Erfolg, S.29.
} 
herangezogen. Eine Analyse des Verhältnisses von Kosten der Polizeiarbeit und deren Zielerreichung kann jedoch nicht ohne Weiteres durchgeführt werden. Im Rahmen der Polizeiarbeit gibt es zu viele Faktoren, die sich dem Einflussbereich der Polizei entziehen. Beispielhaft hierfür ist die Anzahl der begangenen Straftaten, welche aufzuklären sind. Demzufolge können nur beeinflussbare effizienzfördernde und effizienzmindernde Faktoren herausgestellt und untersucht werden. ${ }^{463}$ Es bleibt festzuhalten, dass, bezogen auf das Verhältnis von Input zu Output, im Rahmen der Polizeiarbeit untersucht werden muss, mit welchem Ressourceneinsatz die Aufklärung der Straftat erreicht wurde. ${ }^{464}$

\section{Erfolg und Effizienz der Rasterfahndung}

Im Folgenden werden die Begriffe Erfolg und Effizienz auf die Rasterfahndung im Sinne der $\S \S 98 \mathrm{a}, \mathrm{b}$ StPO übertragen. Von der vorangegangenen Bedeutungsanalyse ausgehend, soll zunächst dargestellt werden, wann eine Rasterfahndung als erfolgreich eingestuft werden kann. Im Anschluss daran wird dargelegt, wann die Maßnahme als effizient anzusehen ist.

Der Erfolg der Rasterfahndung bemisst sich an ihrem Einsatzziel. Dieses Ziel legt der $\S 98$ a I S.1 StPO fest. Demnach sollen durch die Rasterfahndung Nichtverdächtige ausgeschlossen oder Personen festgestellt werden, die weitere für die Ermittlungen bedeutsame Prüfungsmerkmale erfüllen. Mithin besteht das Ziel der Rasterfahndung darin, den Kreis möglicher Tatverdächtiger einzugrenzen, um anschließend weitere personenbezogene Ermittlungen führen zu können. ${ }^{465}$ Die Rasterfahndung könnte demnach als umso erfolgreicher eingestuft werden, je kleiner der Kreis der möglichen Tatverdächtigen nach Durchführung der Rasterfahndung wäre. Als Idealfall würde am Ende einer Rasterfahndung eine Person übrig bleiben, welche nach weiterer Abklärung als Täter überführt wird. Diese lediglich auf die Rasterfahndung konzentrierte Sichtweise stellt sich jedoch, gemessen am repressiven Polizeiziel, wie es sich aus den $\S \S 161,163$ StPO ergibt, als zu eng dar. Die Rasterfahndung kann auch dann als erfolgreich angesehen werden, wenn sie Erkenntnisse liefert, die sich nur entfernt auf die Aufklärung der betreffenden Straftat auswirkt. Hat der Datenabgleich z.B. keine Treffer zur Folge, können die vom Abgleich betroffenen Personen als Nichtverdächtige ausgeschlossen und die Ermittlungen auf einen anderen Personenkreis konzentriert werden. In diesem Fall könnte die Rasterfahndung als erfolgreich bewertet werden, obwohl sie keine Hinweise zur Überführung eines Täters geliefert hat. Für die Beurteilung des Erfolges der Rasterfahndung im Einzelfall muss zusätzlich die konkrete Zielsetzung miteinbezogen werden. Hierbei kommt der Begründung der Maßnahme innerhalb der polizeilichen

\footnotetext{
463 Albrecht/Dorsch/Krüpe, S.357.

464 Michels, in: Bäumler (Hrsg.), Polizei und Datenschutz, S.147.

465 Nack, in: Karlsruher Kommentar, § 98a, Rn.11.
} 
Anregung, des staatsanwaltschaftlichen Antrags und der richterlichen Anordnung besondere Bedeutung zu.

Bei der Beurteilung des Erfolgs muss darüber hinaus dem besonderen Charakter der Rasterfahndung Rechnung getragen werden. Die Rasterfahndung kann nicht als Beweismittel genutzt werden, sondern liefert nur Ermittlungsansätze. Auf der Basis dieser Ermittlungsansätze müssen im Anschluss weitere Ermittlungsmaßnahmen durchgeführt werden. Aus diesem Grund sind für die Beurteilung des Erfolgs der Rasterfahndung auch die Ergebnisse der weiteren Ermittlungsmaßnahmen zu berücksichtigen.

Für die Einordnung des Erfolges der Rasterfahndung über den Einzelfall hinaus müssen auch die Ziele miteinbezogen werden, welche der Gesetzgeber mit der Implementation der Maßnahme in die Strafprozessordnung verfolgt hat. Unmittelbarer Anlass für das OrgKG war die bedrohliche Zunahme der Organisierten Kriminalität. Es hatte sich gezeigt, dass die herkömmlichen Ermittlungs- und Aufklärungsmöglichkeiten im Hinblick auf die besonderen Strukturen der Organisierten Kriminalität und die fortschreitende Professionalisierung der Straftäter in diesem Bereich nicht ausreichen. ${ }^{466}$ In verfahrensrechtlicher Hinsicht sollte es den Strafverfolgungsorganen ermöglicht werden, über die Peripherie der kriminellen Organisationen hinaus in deren Kernbereich einzudringen, um ihre Strukturen zu erkennen. ${ }^{467}$ Aus diesem Grund ist über die Untersuchung der Anwendung in den Einzelfällen hinausgehend, die Rasterfahndung auch bezüglich ihres Anteils an der Bekämpfung der organisierten Kriminalität zu messen.

So wie der Begriff des Erfolges auf die Rasterfahndung übertragen wurde, muss auch der Begriff der Effizienz auf den Untersuchungsgegenstand übertragen werden. Mithin ist das Verhältnis von Input zu Output für die Ermittlungsmaßnahme Rasterfahndung zu untersuchen. Input sind in diesem Fall die Datenerhebung und der anschließende Datenabgleich, verbunden mit dem Eingriff in das Recht auf informationelle Selbstbestimmung der vom Abgleich betroffenen Personen. Bei der Untersuchung der Effizienz der Rasterfahndung müssen insbesondere der personelle, zeitliche und finanzielle Aufwand berücksichtigt werden. Auch technische Probleme und der Umfang der vom Abgleich betroffenen Daten sind zu berücksichtigende Faktoren bei der Beurteilung der Effizienz. Diese Faktoren müssen in Bezug zum Output gesetzt werden. Der Output ist, wie auch schon der Erfolg, am repressiven Polizeiziel, der Aufklärung von Straftaten, zu messen. Insofern ist die Analyse des Erfolgs der Rasterfahndung Voraussetzung für die Untersuchung der Effizienz und muss dieser vorangehen. Die Effizienz der Rasterfahndung ist jedoch nicht allein auf die Durchführung der Maßnahme zu beziehen. Möglich ist auch die Steigerung der Effizienz der gesamten Ermittlungen aufgrund der Durchführung

\footnotetext{
466 BT-Drs, 12/989, S.1.

${ }^{467}$ BT-Drs, 12/989, S.21.
} 
einer Rasterfahndung. Insofern muss bei der Beurteilung der Effizienz auch das Zusammenspiel der Rasterfahndung mit weiteren Ermittlungsmaßnahmen im Kontext mit dem repressiven Polizeiziel gesehen werden.

Die Operationalisierungen der Begriffe Erfolg und Effizienz, wie sie für die Untersuchung maßgeblich sind, werden den jeweiligen Untersuchungsabschnitten vorangestellt.

\section{B. Einzelfallanalyse}

Im Rahmen der Einzelfallanalyse werden die untersuchten Verfahren von der Verfahrensauslösung bis hin zum Abschluss des Verfahrens analysiert. Dabei werden zunächst der dem Verfahren zugrunde liegende Sachverhalt und der Stand der Ermittlungen bis zur Initialisierung der Rasterfahndung dargestellt. In einem zweiten Schritt werden die Maßnahmen von der Anregung, über die Antragstellung bis hin zur Anordnung analysiert. Anschließend werden die Durchführung, das Ergebnis der Rasterfahndung und seine Auswirkungen auf das Ermittlungsverfahren und den Verfahrensausgang beschrieben. Darauf aufbauend wird der Erfolg der Maßnahme einer Einschätzung unterzogen. Diese Erfolgseinschätzung basiert auf der Bedeutungsanalyse des Erfolgsbegriffs.

Die 27 untersuchten Verfahren werden anhand des Zeitpunktes ihrer Einleitung chronologisch angeordnet. In einem Exkurs wird darüber hinaus die präventive Rasterfahndung nach den Anschlägen des 11. Septembers 2001 in den Vereinigten Staaten von Amerika dargestellt.

\section{Verfahren 001}

\section{Sachverhalt}

In der Zeit vom 29.10.1990 bis zum 16.04.1992 versuchten ein oder mehrere unbekannte Täter, durch Anschläge auf das Schienennetz den Bahnhof in H und einen Zug der Deutschen Bahn Geld zu erpressen. Insgesamt wurden in sieben Fällen Stücke bis zu einer Länge von ca. fünf Metern aus Gleisen herausgetrennt. In einem der Fälle kam es zur Entgleisung eines Arbeitszuges. Der Sachschaden betrug 100.000 DM. Am 27.02.1992 kam es zu einem Sprengstoffanschlag auf den Hauptbahnhof in H. Personen wurden dabei nicht verletzt. Zeitgleich wurde in einem Regionalzug ein baugleicher Sprengsatz gefunden, welcher nicht detoniert war. Der oder die Täter forderten zunächst zwei Millionen DM. Nach den Sprengstoffanschlägen wurde die Forderung auf 3,5 Millionen DM erhöht. Modalitäten für die Geldübergabe wurden schriftlich und per Telefon mitgeteilt. Die Geldübergabeversuche scheiterten jedoch daran, dass sich der oder die Täter in den entscheidenden Momenten nicht mehr meldeten. Lediglich beim letzten Übergabever- 
such am 16.04.1992 konnte davon ausgegangen werden, dass der oder die Täter am Übergabeort anwesend waren.

\section{Die Rasterfahndung Nr.1}

\section{a. Ermittlungsstand und Ausgangslage}

Mit der Einleitung der Ermittlungen wurde eine Sonderkommission durch das Landeskriminalamt $\mathrm{H}$ gegründet. Es wurden Telefonüberwachungen für die Anschlüsse der Deutschen Bahn in H veranlasst. Darüber hinaus wurden die Schreiben der unbekannten Täter auf daktyloskopische Spuren untersucht. Die Ermittlungen verliefen jedoch erfolglos. Nach Einschätzungen der ermittelnden Sonderkommission musste es sich um mehrere Täter handeln, da ein einzelner Täter nicht in der Lage gewesen wäre, Gleisstücke von bis zu fünf Metern zu entfernen. Die Gleisstücke wurden mit Maschinen wie sie beim Gleisbau verwendet werden herausgetrennt. Dies ließ die Annahme zu, dass es sich um Täter mit Kenntnissen im Gleisbau oder zumindest in der Verarbeitung von Stahl handeln musste.

Im Rahmen des letzten Geldübergabeversuchs wurde festgestellt, dass ein Täter mit einem Geländemotorrad am Übergabeort gewesen sein musste. Ferner kam die ermittelnde Sonderkommission $\mathrm{zu}$ dem Schluss, dass die Täter über regionale Kenntnisse im Bereich des Übergabeortes verfügt haben müssen. Es wurde angenommen, dass die Täter folgende Voraussetzungen erfüllen würden:

- Täter verfügt über ein Kfz

- Täter verfügt über ein Geländemotorrad

- Täter verfügt über genaue Ortskenntnisse im Raum U

- Täter verfügt über Kenntnisse im metallverarbeitenden Handwerk

- Täter hat Zugang zu Sauer- und Wasserstoff sowie Spezialklebern

Aus diesem Grund wurde am 06.07.1992 der Datenabgleich einer im Bereich U ansässigen Stahlbaufirma mit Daten des Kraftfahrtbundesamtes angeregt. Es sollte festgestellt werden, welche Firmenangehörigen über ein Kfz und möglicherweise auch über ein Geländemotorrad verfügten. Als geltende Rechtsgrundlage wurden die $\S \S 94,103,110,96$ StPO herangezogen. Eine Stellungnahme des Landesdatenschutzbeauftragten befürwortete jedoch die Beantragung einer richterlichen Anordnung in Analogie zu den $\S \S 100 b, 163$ II StPO und im Vorgriff auf die Regelung des $\S$ 98a StPO. Ein entsprechender Antrag der Staatsanwaltschaft wurde am 12.07.1992 durch das Amtsgericht H abgelehnt. Das Amtsgericht begründete seine Entscheidung damit, dass die beantragte Anordnung in der StPO nicht vorgesehen sei und daher keine Notwendigkeit für eine Anordnung bestehen würde. Mithin sei die Maßnahme ohne richterliche Anordnung zulässig. Die Maßnahme wurde daraufhin am 14.07.1992 von der Staatsanwaltschaft angeordnet. 


\section{b. Begründung und Ziel}

Laut polizeilichem Vermerk konnte der Datenabgleich aufgrund technischer Probleme bis zum 23.09.1992 noch nicht durchgeführt werden. Da mittlerweile das OrgKG in Kraft getreten war, wurde die Einholung einer richterlichen Anordnung nach den $\S \S 98 \mathrm{a}, \mathrm{b}$ StPO in erweiterter Form angeregt. Die Daten des Kraftfahrtbundesamtes waren bereits mit den Daten der Firmenangehörigen der betreffenden Stahlbaufirma abgeglichen worden. Laut Antrag der Staatsanwaltschaft vom 24.09.1992 verfügten nahezu alle 1.300 Beschäftigten über ein Kfz. Aus diesem Grund sollten die Ergebnisse mit dem Kennzeichenbestand der im Ermittlungsverfahren angelegten Datei abgeglichen werden. In dieser Datei waren ca. 13.000 Kennzeichen gespeichert, welche in Ringfahndungen an den Geldübergabeorten erfasst worden waren. Ziel war es herauszufinden, welche Firmenangehörigen über ein Kfz verfügten und in den Ringfahndungen erfasst worden waren. Eine entsprechende richterliche Anordnung erging am 30.09.1992.

\section{c. Durchführung und Ergebnis}

In einem ersten Schritt wurden die von der Firma gelieferten Magnetbänder mit den Daten des Kraftfahrtbundesamtes abgeglichen. Dieser Abgleich wurde durch das Bundeskriminalamt durchgeführt und führte zu ca. 1.300 Treffern. Der Abgleich dieser Treffer mit der Kennzeichendatei des Ermittlungsverfahrens sollte ebenfalls durch das Bundeskriminalamt durchgeführt werden. Da die Datei jedoch nicht nach den erforderlichen Normierungsregeln erstellt worden war, lehnte das BKA einen Abgleich unter Hinweis auf einen zu hohen Umformatierungsaufwand ab. Aufgrund dessen wurde der Abgleich mit der Kennzeichendatei durch Einzeleingabe durch das zuständige LKA durchgeführt. Dieser Einzelabgleich erbrachte 26 Treffer.

\section{d. Auswirkungen auf das Ermittlungsverfahren}

Die 26 Personen wurden zunächst mit internen Unterlagen der Stahlbaufirma abgeglichen, weshalb 15 Personen direkt ausschieden. Die weiteren elf Personen wurden mit negativem Ergebnis überprüft. Ein Tatverdacht gegen eine dieser Personen ergab sich nicht. Mithin erbrachte die Rasterfahndung keine weiteren Ermittlungsansätze.

\section{Die Rasterfahndung Nr.2}

\section{a. Ermittlungsstand und Ausgangslage}

Weitere Ermittlungen ergaben, dass viele der im Umkreis um den letzten Geldübergabeort lebenden Personen bei einem großen Automobilkonzern tätig waren. Daher wurden die Ermittlungen in diese Richtung weitergeführt. 


\section{b. Begründung und Ziel}

Am 22.07.1993 wurde eine weitere Maßnahme nach den $\S \S 98 a$, b StPO angeregt. Auf der Annahme basierend, dass sich der Täter unter den ca. 55.000 Beschäftigten des betreffenden Werkes des Automobilkonzerns befinden würde, sollte herausgefunden werden, welche Arbeitnehmer zu den einzelnen Tatzeiten abwesend waren. Nach Auskunft der Datenverarbeitung des Unternehmens sei damit zu rechnen, dass es sich um einen kleinen Kreis von Personen handeln dürfte, welche zu allen Tatzeiten abwesend waren. Geplant wurde eine einzelne Überprüfung dieser Personen. Im Antrag der Staatsanwaltschaft vom 29.07.1993 wurde darauf verwiesen, dass die Beschäftigten des Unternehmens ebenfalls über Kenntnisse im metallverarbeitenden Handwerk besitzen würden. Aufgrund der großen Anzahl von Beschäftigten sei es darüber hinaus erforderlich, den Datenbestand maschinell abzugleichen. Die entsprechende richterliche Anordnung erging am 02.08.1993.

\section{c. Durchführung und Ergebnis}

Die Datenverarbeitung des Automobilkonzerns musste zunächst eine aufwendige Software erstellen, um die Recherche nach Fehlzeiten durchzuführen. Ein erster Durchlauf erbrachte eine Anzahl von 630 männlichen Personen, welche zu den Tatzeiten nicht im Werk waren. Da diese Anzahl nicht zu überprüfen war, wurde dieser Personenkreis auf solche Personen begrenzt, die ihren Wohnsitz in einem Umkreis von 20 Kilometern um die Geldübergabeorte hatten. Darüber hinaus wurde das Rastermerkmal „Führerschein Klasse I“ aufgenommen. Dieses Vorgehen basierte auf der Annahme, der Täter sei ein geübter Motorradfahrer. Der Abgleich erbrachte eine Anzahl von 22 Personen.

\section{d. Auswirkungen auf das Ermittlungsverfahren}

Die 22 herausgerasterten Personen wurden einzeln aufgesucht und überprüft. Gegen keine der Personen konnte ein Tatverdacht konkretisiert werden. Es gab keine Hinweise auf eine Täterschaft der Personen.

\section{Ausgang des Verfahrens}

Am letzten Geldübergabeort konnte ein Motorradhandschuh sichergestellt werden, welcher in Deutschland nur von einem einzigen Fachgeschäft vertrieben wurde. Im Umkreis des betreffenden Geschäfts wurden 52 männliche Personen mit Führerscheinen der Klasse I aufgesucht und überprüft. Auch diese Überprüfungen verliefen mit negativem Ergebnis. Eine weitere Richtung der Ermittlungen ergab sich im Bereich der Angestellten der Deutschen Bahn. Der oder die Täter mussten 
über Kontakte zur Bahn verfügen, da sie zur Mitteilung der Geldübergabemodalitäten auf Telefonnummern aus bahninternen Telefonbüchern zurückgriffen. Aber auch in dieser Richtung verliefen die Ermittlungen ohne Ergebnis. Das Verfahren wurde schließlich gem. § 170 II StPO eingestellt, da kein Täter zu ermitteln war. Nach dem letzten Geldübergabeversuch am 16.04.1992 hatten sich der oder die Täter nicht mehr gemeldet.

\section{Erfolgseinschätzung}

In Ermangelung von Hinweisen auf den oder die Täter bildete die Rasterfahndung zumindest die Möglichkeit, neue Ermittlungsansätze zu erlangen. Beide Maßnahmen erbrachten Hinweise auf mögliche Tatverdächtige und damit neue Ermittlungsansätze. Weitere Ermittlungen zu den Personen verliefen jedoch negativ. Grund hierfür war unter anderem, dass die Täter kaum Spuren hinterlassen hatten. Ferner war das Verhalten der Täter höchst widersprüchlich. Sie hatten nicht einen ernsthaften Versuch unternommen, um an das verlangte Geld zu gelangen.

\section{Verfahren 002}

\section{Sachverhalt}

Gegenstand von Verfahren 002 waren zwei Taten, welche in zwei gesonderten Verfahren verfolgt wurden. Da jedoch eine Maßnahme nach den $\S \S 98 \mathrm{a}$, b StPO für beide Verfahren durchgeführt wurde, beinhaltet die Auswertung beide Verfahren. Aufgrund des erheblichen Umfangs der beiden Verfahren konnte nur in ausgewählte Aktenbestandteile Einsicht genommen werden. Dies waren unter anderem eine Sonderband zur Rasterfahndung und polizeiliche Vermerke zu weiteren Ermittlungsmaßnahmen.

Bei der ersten Tat handelte es sich um einen Anschlag mit Schusswaffen auf eine Botschaft in B. Am 13.02.1991 gaben mehrere Personen Schüsse auf die betreffende Botschaft ab. Anschließend zündeten sie eine Nebelkerze und konnten mit einem Kfz unerkannt flüchten. Am Abschussort konnten ca. 250 Patronenhülsen und ein Bekennerschreiben einer linksextremistischen terroristischen Vereinigung sichergestellt werden. Die Botschaft wurde von ca. 65 Projektilen getroffen. Personen wurden nicht verletzt, aber unmittelbar gefährdet.

Bei der zweiten Tat handelt es sich um ein vollendetes und ein versuchtes Tötungsdelikt. Am 01.04.1991 wurde eine männliche Person durch ein Fenster seines Hauses erschossen. Seine zu Hilfe eilende Ehefrau wurde ebenfalls von einem Schuss getroffen. Sie wurde dabei aber nicht lebensgefährlich verletzt. Auch hier konnte am Schussabgabeort ein Bekennerschreiben der betreffenden Vereinigung sichergestellt werden. 


\section{Die Rasterfahndung Nr.1}

\section{a. Ermittlungsstand und Ausgangslage}

Die Ermittlungen wurden durch das Bundeskriminalamt geführt und durch den Generalbundesanwalt geleitet. Am Tatort der zweiten Tat konnten an einer Zigarettenkippe DNA-Spuren einer unbekannten männlichen Person sichergestellt werden. Eine Untersuchung der Bekennerschreiben beider Taten ergab Übereinstimmungen zu weiteren Bekennerschreiben der terroristischen Vereinigung in anderen Verfahren. Bei aufgrund anderer Taten inhaftierten Angehörigen der terroristischen Vereinigung wurden daraufhin die Hafträume durchsucht. Im Rahmen der Durchsuchungen wurde die Erkenntnis gewonnen, dass die inhaftierten Personen bei der Erstellung der Bekennerschreiben mitgewirkt haben mussten. Anhand von Untersuchungen der per Post versandten Bekennerschreiben wurden Hinweise über die Aufgabeorte erlangt. Die Bekennerschreiben waren in denselben Landkreisen aufgegeben worden.

Untersuchungen der in beiden Verfahren sichergestellten Patronenhülsen ergaben ebenfalls Übereinstimmungen. Danach war eine der im ersten Verfahren verwendeten Waffen auch als Tatwaffe im zweiten Verfahren verwendet worden. Bis auf diese Erkenntnisse konnten jedoch keine Hinweise auf mögliche Tatverdächtige erlangt werden.

\section{b. Begründung und Ziel}

Grundlage für die Anregung einer Maßnahme nach den $\S \S 98 \mathrm{a}, \mathrm{b}$ StPO waren die Erkenntnisse zu den Aufgabeorten der Bekennerschreiben, die per Post versandt worden waren. Diese Erkenntnisse ließen den Schluss zu, dass die Täter in den betreffenden Landkreisen über eine sog. „Langzeit Konspirative Wohnung (Langzeit KW)“ verfügen mussten. Aufgrund von Erkenntnissen aus vorangegangenen Verfahren gegen diese terroristische Vereinigung war davon auszugehen, dass die Bewohner solcher Langzeit KWs nicht amtlich gemeldet seien und darüber hinaus ihre Strom- und Wasserkosten bar begleichen würden. Daher sollten Daten der Einwohnermeldeämter der betroffenen Landkreise und Städte mit Daten von Energieversorgungsunternehmen und Stadtwerken abgeglichen werden. Ziel sollte es sein Personen herauszufiltern, die nicht gemeldet waren und ihre Stromrechnungen bar bezahlten. Die hierzu benötigten Daten der Einwohnermeldeämter waren bereits im April 1992 erhoben worden. Der maschinelle Abgleich wurde am 23.04.1992 durch den Generalbundesanwalt genehmigt, wurde aber bis zum Inkrafttreten des OrgKG am 22.09.1992 noch nicht durchgeführt. Aus diesem Grund wurde am 06.11.1992 die Beantragung einer Maßnahme angeregt. Zum Zeitpunkt der Anregung lagen die Daten von 12 Energieversorgungsunternehmen und fünf Einwohnermeldeämter vor. Der Generalbundesanwalt stellte am 26.11.1992 den 
Antrag, die Maßnahme anzuordnen. Dem Antrag entsprechend wurde der Abgleich der bereits vorliegenden Daten am 27.11.1992 angeordnet. Allerdings wurde der Umfang auf die Daten der Einwohnermeldeämter und Energieversorgungsunternehmen für den Zeitraum vom 01.07.1990 bis zum 30.06.1991 zeitlich begrenzt. Von zwei weiteren Energieversorgungsunternehmen sollte ebenfalls die Übermittlung von Kundendaten angeordnet werden. Von einem Ersuchen an diese beiden Unternehmen war zuvor aus kriminaltaktischen Überlegungen abgesehen worden. Eine entsprechende Anordnung wurde am 26.11.1992 durch das Bundeskriminalamt angeregt und am 30.11.1992 durch den Generalbundesanwalt beantragt.

Der zuständige Ermittlungsrichter am Bundesgerichtshof äußerte seine Bedenken gegen eine Übermittlung von Daten für den Zeitraum vor dem 01.01.1989. Nach Ansicht des Ermittlungsrichters würde die Vereinigung Konspirative Wohnungen nur für Zeiträume von einigen Monaten bis zu einem Jahr nutzen. Am 19.01.1993 erhob der Generalbundesanwalt, nach Rücksprache mit dem Bundeskriminalamt, Gegenvorstellung gegen die Anordnung des Datenabgleichs und die Bedenken des Ermittlungsrichters zu der Erweiterung auf die beiden weiteren Energieversorgungsunternehmen. Danach sei eine zeitliche Eingrenzung der bereits erhobenen Daten technisch nicht durchführbar. Darüber hinaus ließen aufgefundene Beweismittel in anderen Verfahren den Schluss zu, dass die Täter auch schon vor 1990 über eine konspirative Wohnung im betreffenden Bereich verfügt hatten. Ferner beantragte der Generalbundesanwalt den Wortlaut der Anordnung von „barzahlende Kunden“ in „Kunden, die nicht am Lastschriftverfahren teilnehmen“ zu ändern, um auch Personen zu erfassen, die ihre Rechnungen per Überweisung begleichen.

Die beantragte Erweiterung der Anordnung des Datenabgleichs auf den Zeitraum vom 01.01.1985 bis zum 31.12.1992 und die Änderung des Wortlauts, wurde am 05.02.1993 angeordnet. Die Übermittlung Daten der beiden weiteren Energieversorgungsunternehmen wurde am 08.02.1993 angeordnet.

\section{c. Durchführung und Ergebnis}

Die Daten wurden gemäß des Berichts des Bundeskriminalamtes vom 29.03.1993 in personal- und zeitintensiver Weise in abgleichfähige Strukturen gebracht. Der maschinelle Abgleich erbrachte 42.051 Prüffälle. Die sehr hohe Anzahl von Prüffällen resultierte aus der schlechten Datenqualität der angelieferten Daten. Aufgrund eines weiteren Anschlags der terroristischen Vereinigung am 27.03.1993 wurde die Maßnahme abgebrochen.

\section{d. Auswirkungen auf das Ermittlungsverfahren}

Demnach hatte die erste Rasterfahndung keine Auswirkungen auf die Ermittlungen. 


\section{Die Rasterfahndung Nr.2}

\section{a. Ermittlungsstand und Ausgangslage}

Am 27.03.1993 wurde ein erneuter Anschlag der terroristischen Vereinigung verübt. Danach wurde beschlossen, die Maßnahme mit einem verbesserten und aktualisierten Datenbestand nochmals durchzuführen. Mithin bildeten die im Rahmen der ersten Maßnahme erhobenen und strukturierten Daten die Grundlage für die neue Rasterfahndung.

\section{b. Begründung und Ziel}

Über die Anregung und den Antrag der neuen Rasterfahndung waren den Verfahrensakten keine Informationen zu entnehmen. Da diese sich inhaltlich jedoch mit der vorangegangenen Maßnahme deckte, kann insofern auf die Ausführungen zur ersten Maßnahme zurückgegriffen werden. Das Ziel der Maßnahme war die Lokalisierung einer „Langzeit KW“ in den betreffenden Landkreisen und Städten. Die erneute Durchführung der Maßnahme wurde am 07.05.1993 angeordnet. Darüber hinaus wurden zur Klarstellung die ersten Anordnungen aufgehoben.

\section{c. Durchführung und Ergebnis}

Insgesamt wurden durch die Einwohnermeldeämter 1.315.848 personenbezogene Datensätze übermittelt. Die Energieversorgungsunternehmen übermittelten 58.158 personenbezogene Datensätze. Eine Selektion dieser 58.158 Datensätze brachte eine Reduzierung auf 51.161 Datensätze. Die Datenaufbereitung wurde am 21.09.1993 abgeschlossen. Der maschinelle Abgleich erfolgte vom 22. - 27.09.1993. Danach blieb eine Anzahl von 36.885 Prüffällen übrig. Ein sog. Prüffall lag dann vor, wenn die Personalien eines Stromkunden nicht im betreffenden Einwohnermeldeamtsbestand erfasst waren. Aufgrund mangelnder Datenqualität war eine erneute Überarbeitung der Datenbestände notwendig. Es stellte sich heraus, dass den 65 Ortseinträgen der Einwohnermeldeämter 666 Ortseinträge der Energieversorgungsunternehmen gegenüberstanden. Dies war dem Umstand geschuldet, das die Energieversorgungsunternehmen zahlreiche Datensätze außerhalb des Fahndungsraumes und mit unterschiedlichen Schreibweisen übermittelt hatten. Nachdem die Stromkundendaten auf den Fahndungsraum reduziert worden waren, ergaben sich nur noch 17.291 Prüffälle. Ein modifizierter Datenabgleich erbrachte 13.656 Prüffälle. Nachdem diese 13.656 Prüffälle einer erneuten Überprüfung unterzogen wurden, blieben 2.636 Prüffälle übrig. Eine weitere Überprüfung reduzierte die Prüffälle auf eine Anzahl von 2.251 Personen. Anhand von Abklärungen bei den Energieversorgungsunternehmen reduzierte sich die Zahl schließlich auf 249 Personen. Das Ergebnis von 249 Personen auf der Basis der letzten Abklärung wurde erst am 14.07.1994 erlangt. 
Laut abschließendem Vermerk zur Rasterfahndung war trotz der Erkenntnisse aus der ersten Rasterfahndung ein zeitnaher Abschluss der Maßnahme nicht zu realisieren. Ausschlaggebend für dieses Fazit waren folgende Gründe:

- EDV-Probleme der übermittelnden Stellen

- mangelnde Datenqualität

- unterschiedliche Datenstrukturen, die aneinander anzugleichen waren

- und daraus resultierend notwendige manuelle, zeit- und personenintensive Arbeitsschritte

\section{d. Auswirkungen auf das Ermittlungsverfahren}

Für die Durchführung wurde eine Arbeitsleistung von insgesamt 544 „Manntagen“ benötigt. Im Anschluss an den Datenabgleich wurden die 249 Prüffälle zwischen dem 15.07.1994 und dem 29.09.1994 einer Überprüfung unterzogen. Hinweise auf eine Langzeit KW ergaben sich jedoch nicht.

\section{Ausgang des Verfahrens}

Das Verfahren war bis zum Zeitpunkt der Auswertung im November 2006 noch nicht eingestellt worden. DNA-Untersuchungen ergaben, dass ein Angehöriger der terroristischen Vereinigung, welcher bei seiner Verhaftung ums Leben kam, zumindest als einer der Täter des Tötungsdelikts identifiziert werden konnte. Eine weitere tatverdächtige Person wurde in Zusammenhang mit einer weiteren Tat der terroristischen Vereinigung zu einer Freiheitsstrafe verurteilt. Eine Täterschaft in diesem Verfahren konnte ihr jedoch nicht nachgewiesen werden.

\section{Erfolgseinschätzung}

Die Maßnahme nach den $\S \S 98 \mathrm{a}, \mathrm{b}$ StPO brachte in diesem Verfahren keine Erkenntnisse für die Ermittlung von Tatverdächtigen. Zur Erfolglosigkeit der Maßnahme gesellt sich zudem der erhebliche Zeit- und Arbeitsaufwand. Ein Testlauf der Daten mit Erkenntnissen zu Decknamen, welche der verstorbene Täter verwendet hatte, erbrachte ebenfalls keine Treffer. Es ist zudem bis zum heutigen Zeitpunkt fraglich, ob die terroristische Vereinigung über eine Langzeit $\mathrm{KW}$ in dem betreffenden Bereich verfügt hat. Aufgrund der mangelnden Qualität der abzugleichenden Daten sowohl der Einwohnermeldeämter als auch der Energieversorgungsunternehmen war der Datenabgleich zudem erheblich erschwert. 


\section{Verfahren 003}

\section{Sachverhalt}

Am 22.04.1992 wurde ein Brandanschlag auf ein Gebäude der Universität H verübt. Unbekannte Täter drangen in das Gebäude ein und entleerten ca. 200 Liter Vergaserkraftstoff in vier Stockwerken. Zur Auslösung des Brandes wurden in jedem Stockwerk Zündverzögerungseinrichtungen deponiert. Zwei der Zündverzögerungseinrichtungen wiesen jedoch einen technischen Defekt auf, weshalb der Brand nicht in allen Stockwerken ausbrach. An dem betroffenen Gebäude entstand ein Sachschaden in Höhe von einer Million DM. In den vier Stockwerken wurden durch die Täter Bekennerschreiben hinterlegt. Eine Tätergruppierung wurde jedoch nicht genannt.

In die Verfahrensakten von Verfahren 003 konnte aufgrund des Umfangs nicht in vollem Maße Einsicht genommen werden. Darüber hinaus handelt es sich bei Verfahren 003 um einen eigenständigen Teilkomplex des Verfahrens 004.

\section{Die Rasterfahndung}

a. Ermittlungsstand und Ausgangslage

Aufgrund des Verdachts der Mitgliedschaft in einer terroristischen Vereinigung wurden die Ermittlungen durch den Generalbundesanwalt übernommen. Die Ermittlungen wurden durch das Landeskriminalamt und den Landes-verfassungsschutz geführt. Eine Auswertung der Bekennerschreiben ließ den Schluss zu, dass die Täter der lokalen Antifa-Szene zuzurechnen seien. Darüber hinaus lagen Hinweise für die Zugehörigkeit der Täter zur Universität H vor. Diese Hinweise ergaben sich ebenfalls aus den Bekennerschreiben.

\section{b. Begründung und Ziel}

Diese Annahme war ursächlich für die Beantragung einer Maßnahme nach den $\S \S 98 \mathrm{a}, \mathrm{b}$ StPO am 24.11.1992 durch den Generalbundesanwalt. Eine Anregung der Maßnahme war in den Verfahrensakten nicht enthalten. Der Generalbundesanwalt führte aus, dass es sich nach der Art der Tatbegehung um eine Gruppe von mehr als zwei Personen handeln müsste, welche sich auf Dauer zur Verfolgung politischer Ziele mittels terroristischer Straftaten nach dem Vorbild der RAF zusammengeschlossen hätten. Ferner würden die Ortskenntnisse auf eine Angehörigkeit der Täter zur Universität und dort insbesondere zur juristischen Fakultät schließen lassen. In Ermangelung von Hinweisen gegen diesen Personenkreis wurde daher beantragt, die Daten der eingeschriebenen Studenten der juristischen Fakultät zu übermitteln. Diese Daten sollten mit Erkenntnissen über polizeibekannte gewaltbereite Mitglieder der RAF-Szene abgeglichen werden. Ziel war es, Ansatzpunkte für weiterführende Ermittlungen zu erlangen. Die beantragte Maßnahme wurde am 
25.11.1992 ohne Änderungen und Ergänzungen angeordnet. In dem Antrag und in der Anordnung wurde dabei nur von polizeilichen Erkenntnissen gesprochen. Geplant war jedoch ein Abgleich mit den Daten des Landesverfassungsschutzes $\mathrm{H}$. Dieses weigerte sich jedoch, den Datenabgleich im Wege der Amtshilfe durchzuführen.

Aufgrund dessen wurde am 10.12.1992 eine Erweiterung der Anordnung angeregt. Der Generalbundesanwalt beantragte am 14.12.1992 die Erweiterung der ersten Anordnung auf die Datenbestände des Landesverfassungsschutzes H. Darüber hinaus sollte ausdrücklich festgestellt werden, dass der Landesverfassungsschutz zu Amtshilfe verpflichtet sei. Eine entsprechende Erweiterung wurde am 17.12.1992 angeordnet.

\section{c. Durchführung und Ergebnis}

Die Universität H hat die angeforderten Daten am 07.12.1992 auf einem Magnetband übermittelt. Betroffen waren die personenbezogenen Daten von 6.481 Studenten. Ein erster Testlauf des Programms wurde am 10.12.1992 durchgeführt. Dabei wurden die Daten ohne Ergebnisse mit dem Datenbestand der Polizei H abgeglichen. Im Anschluss daran wurde das Magnetband für den weiteren Abgleich an das Bundeskriminalamt versandt.

Wann der weitere Abgleich durchgeführt wurde, ließ sich den Verfahrensakten nicht entnehmen. Das Ergebnis des Datenabgleichs wurde in einem polizeilichen Vermerk vom 29.08.1994 aufgeführt. Danach wurden die Daten der Universität mit den Datenbeständen POLAS, INPOL, KAN, ED, APIS und NADIS abgeglichen. Bei 45 der 6.481 personenbezogenen Datensätze war lediglich ein manueller Abgleich möglich. Der Abgleich erbrachte insgesamt 335 Treffer. Diese Treffer wurden nochmals manuell abgeglichen und Überscheidungen (Personenidentitäten) herausgefiltert. Letztlich verblieb eine Anzahl von 32 Personen, welche an der juristischen Fakultät der Universität $\mathrm{H}$ eingeschrieben waren und zu denen linksextremistische Erkenntnisse vorlagen.

\section{d. Auswirkungen auf das Ermittlungsverfahren}

Die 32 Personen wurden überprüft. Zwei der Personen wurden im weiteren Verlauf des Verfahrens als Beschuldigte geführt. Die übrigen 30 Personen schieden als Tatverdächtige aus. Aus dem Teil der Verfahrensakten, in welchen Einsicht genommen werden konnte, ergaben sich Hinweise auf veranlasste Telefonüberwachungen und Observationen. Mit welchem Ergebnis diese durchgeführt wurden und ob sie auf den Erkenntnissen der Rasterfahndung basierten, war nicht nachzuvollziehen. Nähere Informationen zu den beiden Beschuldigten konnten ebenfalls nicht erlangt werden. 


\section{Ausgang des Verfahrens}

Keiner der Ermittlungsansätze führte zur Identifizierung der Täter. Den beiden Beschuldigten konnte eine Tatbeteiligung nicht nachgewiesen werden, weshalb das Verfahren eingestellt wurde. Bei Verfahren 003 handelt es sich um einen Teilkomplex des Verfahrens 004. Im Rahmen von Verfahren 004 konnten Täter ermittelt, angeklagt und verurteilt werden. Dieses Verfahren richtete sich kurzzeitig auch gegen die Täter aus Verfahren 004. Untersuchungen von Bekennerschreiben aus beiden Verfahren kamen zu dem Ergebnis, dass die Verfasser der Schreiben identisch gewesen sein dürften. In der Anklage zu Verfahren 004 wird die dem Verfahren 003 zugrunde liegende Tat nicht aufgeführt. Sie findet jedoch eine Erwähnung im Urteil zu Verfahren 004. Dort wird sie unter der Rubrik Vorgeschichte der Tätergruppierung aufgelistet.

\section{Erfolgseinschätzung}

Die Maßnahme nach den $\S \S 98 \mathrm{a}, \mathrm{b}$ StPO isoliert betrachtet, kann durchaus als erfolgreich beurteilt werden. Sie lieferte zwei Beschuldigte und damit weiterführende Ermittlungsansätze. Welche Erkenntnisse aus den weiterführenden Ermittlungsansätzen gewonnen wurden, ließ sich jedoch nicht nachvollziehen. Letztlich wurde das Verfahren auch gegen die beiden Beschuldigten eingestellt. Damit kann festgehalten werden, dass die Rasterfahndung einerseits, gemessen an dem in Antrag und Anordnung aufgeführten Ziel erfolgreich war, andererseits aber auch nicht zur Aufklärung der Tat beitragen konnte.

\section{Verfahren 004}

\section{Sachverhalt}

In der Zeit vom 05.06.1994 bis zum 23.12.1995 verübte eine unbekannte Gruppe von Tätern fünf vollendete und einen versuchten Sprengstoffanschlag. Bis auf eine Tat in B ereigneten sich alle Taten in Nordrhein-Westfalen. Ziele der Sprengstoffanschläge waren die Geschäftsstellen von Parteien und die Wohnhäuser von Mitgliedern des Deutschen Bundestages. In einem siebten Fall kam es lediglich zur Verabredung der Vorbereitung eines Sprengstoffanschlages. Die Tätergruppierung hinterließ an allen Tatorten Positionspapiere und Bekennerschreiben.

Aufgrund des Umfangs des Verfahrens konnte nicht in die kompletten Verfahrensakten Einsicht genommen werden. Die Einsicht erstreckte sich auf die Verfahrensbestandteile zur Rasterfahndung, einige polizeiliche Vermerke sowie die Anklage und das Urteil. 


\section{Die Rasterfahndung}

\section{a. Ermittlungsstand und Ausgangslage}

Die Ermittlungen wurden durch das Bundeskriminalamt, das Landeskriminalamt Nordrhein-Westfalen und den Verfassungsschutz des Innenministeriums Nordrhein-Westfalen geführt. Geleitet wurden die Ermittlungen durch den Generalbundesanwalt. Nach den ersten Taten gerieten zwei Personen in den Fokus der Ermittlungen. Diese wurden im weiteren Verlauf des Verfahrens als Beschuldigte Nr.1 und Nr.2 geführt. Für die Telefonanschlüsse der beiden Beschuldigten wurden Telefonüberwachungen veranlasst. Darüber hinaus wurde das Wohnumfeld der beiden Personen mit Hilfe von Videokameras über eine längere Zeit beobachtet. Ferner wurden beide Personen gelegentlich observiert. Diese Maßnahmen hatten jedoch wenig Erfolg, da die beiden Beschuldigten mit Observationen etc. rechneten und sich daher konspirativ verhielten. Durch den Verfassungsschutz wurden verdeckte Ermittler eingesetzt. Einen Durchbruch in den Ermittlungen erreichten die Ermittlungsbehörden mit dem Einsatz von GPS Geräten. Die GPS-Sender wurden am Fahrzeug eines der Beschuldigten angebracht und lieferte ein detailliertes Bewegungsbild.

\section{b. Begründung und Ziel}

Am 22.02.1996 wurde durch die Ermittlungsbehörden eine Maßnahme nach den $\S \S 98 \mathrm{a}, \mathrm{b}$ StPO angeregt. Grund für die Anregung waren Hinweise, wonach einer der unbekannten Täter des letzten Anschlags vom 23.12.1995 in D kurz vor der Begehung der Tat von einer Polizeistreife kontrolliert worden sein sollte. Daher sei es erforderlich, die Protokollbänder der Zentralen-Polizeitechnischen-Dienste für den Bereich von D für den begrenzten Zeitraum vom 22.12.1995 20.00 Uhr bis zum 23.12.1995 0.38 Uhr auszuwerten. Es sollte herausgefunden werden, ob:

- bekannte Kontaktpersonen der Beschuldigten Nr.1 und Nr.2 bzw. deren Pkw

- oder sonstige Personen, die im bisherigen Ermittlungsverfahren bekannt geworden sind,

im tatrelevanten Zeitraum in D aufhältig waren. Bereits vier Tage nach der Anregung der Maßnahme wurden die beiden Beschuldigten festgenommen. Aus diesem Grund verzögerte sich die Durchführung der Maßnahme. Erst am 02.04.1996 wurde die Maßnahme durch den Generalbundesanwalt beantragt. Dieser führte in der Begründung aus, dass die Maßnahme erforderlich sei, um etwaige Mittäter identifizieren zu können. Eine Kontrolle der beiden Beschuldigten konnte aufgrund deren Ausschreibung zur Beobachtung ausgeschlossen werden. Da eine Vertrauensperson jedoch mitgeteilt hatte, dass die Täter vor der Tatausführung kontrolliert worden seien, konnte es sich bei diesen nur um weitere unbekannte Täter handeln. 
Darüber hinaus beantragte der Generalbundesanwalt den weiteren Abgleich der Daten aus den Protokollbändern mit polizeiinternen Datenbeständen zu Personen mit Erkenntnissen aus dem Bereich politisch motivierter Straftaten. Hierdurch sollten Strukturen innerhalb der Tätergruppierung erhellt werden. Am 15.04.1996 wurde die Maßnahme wie beantragt angeordnet.

\section{c. Durchführung und Ergebnis}

Die Daten der Zentralen-Polizeitechnischen-Dienste wurden am 24.04.1996 übermittelt. Danach waren 104 Personen und 72 amtlich registrierte Kennzeichen einer Überprüfung unterzogen worden. Ein Vermerk des Landeskriminalamtes vom 28.06.1996 enthielt das Ergebnis des darauf folgenden Abgleichs mit polizeiinternen Datenbeständen. Dieser Abgleich ergab, dass bei einer der 104 Personen Erkenntnisse über politisch motivierte Straftaten bestanden. Es konnte jedoch anhand weiterer Überprüfungen festgestellt werden, dass die betreffende Person dem rechtsradikalen Umfeld zuzurechnen sei. Eine weitere Recherche bzgl. eines festgestellten Kennzeichens verlief ebenfalls negativ.

\section{d. Auswirkungen auf das Ermittlungsverfahren}

Die Rasterfahndung brachte keine weiteren Erkenntnisse für das Ermittlungsverfahren. Durch die ermittelnden Polizeidienststellen konnte nicht verifiziert werden, welcher Wahrheitsgehalt der Aussage der Vertrauensperson beizumessen war. Letztlich konnte von der Vertrauensperson nicht in Erfahrung gebracht werden, ob die betreffenden Personen tatsächlich kontrolliert oder möglicherweise nur durch ein vorbeifahrendes Polizeifahrzeug kurzzeitig abgeschreckt worden waren. Mithin konnte durch die Rasterfahndung kein weiterer Tatverdächtiger festgestellt werden. Es konnte jedoch auch nicht gänzlich ausgeschlossen werden, dass weitere Personen beteiligt waren. Informationen über Strukturen innerhalb der Tätergruppierung konnten durch die Rasterfahndung ebenfalls nicht in Erfahrung gebracht werden.

\section{Ausgang des Verfahrens}

Im Rahmen der Festnahme der beiden Beschuldigten wurden deren Wohnungen durchsucht. Dabei konnten diverse belastende Beweismittel sichergestellt werden. Darüber hinaus führten insbesondere die Überwachung per GPS und die Observationen zur Überführung der Täter. Unter anderem konnten so Verstecke aufgefunden werden, in welchen die Beschuldigten Sprengstoff lagerten. Der Beschuldigte Nr.1 wurde zu zwölf Jahren und acht Monaten und der Beschuldigte Nr.2 zu neun Jahren Freiheitsentzug wegen des versuchten Mordes in Tateinheit mit der vorsätzlichen Herbeiführung einer Sprengstoffexplosion verurteilt. 


\section{Erfolgseinschätzung}

Die Rasterfahndung erbrachte keine Erkenntnisse und auch keine weiteren Ermittlungsansätze für das Verfahren. Die Maßnahme basierte zudem auf der vagen Aussage einer Vertrauensperson, die sich im Nachhinein als unwahr herausstellte. Der Datenabgleich bildete jedoch einen viel versprechenden Ansatz, um weitere möglicherweise kontrollierte Täter zu identifizieren.

\section{Verfahren 005}

\section{Sachverhalt}

Im Rahmen der Auswertung von Verfahren 005 konnte nicht in die gesamten Verfahrensakten Einsicht genommen werden. Gegenstand des Verfahrens war ein Rechtshilfeersuchen von Interpol Rom an ein Landeskriminalamt. Dieses wurde darüber in Kenntnis gesetzt, dass sich ein ranghohes Mitglied der italienischen Mafia möglicherweise bei Landsleuten aus der Stadt X in $M$ aufhalten könnte. Der Gesuchte war u.a. verdächtig, an mehreren Tötungsdelikten beteiligt gewesen zu sein.

\section{Die Rasterfahndung}

\section{a. Ermittlungsstand und Ausgangslage}

Die Ermittlungen wurden am 11.01.1993 eingeleitet und durch das Landeskriminalamt geführt. Neben den Informationen zur Rasterfahndung ließ sich den Verfahrensakten nur entnehmen, dass an bestimmten Grenzübergängen zusätzliche Beamte zur verstärkten Kontrolle eingesetzt wurden. Darüber hinaus waren keine Informationen über weitere Ermittlungsmaßnahmen verfügbar.

\section{b. Begründung und Ziel}

Die Maßnahme nach den $\S \S 98 a$, b StPO wurde durch das LKA am 18.01.1993 angeregt. Sie wurde mit Hinweisen von Interpol Rom begründet, wonach der Gesuchte Kontakte zu in $\mathrm{M}$ wohnhaften Landsleuten aus X unterhalten würde. Es sei daher erforderlich, die Einwohnermeldedaten von $\mathrm{M}$ einem Abgleich zu unterziehen. Anhand dieses Abgleichs sollten alle italienischen Staatsangehörigen, die in X geboren sind und in $\mathrm{M}$ wohnen oder wohnhaft waren, herausgefiltert werden. Anschließend sollten diese Daten mit polizeiinternen Dateien und mit Erkenntnissen der italienischen Polizei abgeglichen werden. Ziel war es, mögliche Verbindungen zu dem Gesuchten feststellen zu können. Letztlich gäbe es keine anderen Möglichkeiten, die Verbindungen des Gesuchten nach $\mathrm{M}$ zu ermitteln. Ein entsprechender 
Antrag der Staatsanwaltschaft M wurde am 19.01.1993 gestellt und am 25.01.1993 durch das Amtsgericht $\mathrm{M}$ angeordnet. In Antrag und Anordnung fehlt jedoch der angeregte Abgleich mit polizeiinternen Dateien und Erkenntnissen der italienischen Polizei. Diesbezüglich war den Verfahrensakten eine ergänzende Anordnung vom 29.03.1993 zu entnehmen. Hierzu fehlte jedoch ein Antrag der Staatsanwaltschaft.

\section{c. Durchführung und Ergebnis}

Zur Durchführung und zum Ergebnis der Maßnahme waren den Verfahrensakten keine Informationen $\mathrm{zu}$ entnehmen. Ob übersandte Datenträger zurückgegeben worden sind, war ebenfalls nicht nachvollziehbar. Die personenbezogenen Daten wurden am 10.11.1993 gelöscht.

\section{d. Auswirkungen auf das Ermittlungsverfahren}

Mangels Informationen muss davon ausgegangen werden, dass der Datenabgleich keine Treffer ergeben hatte, die auf konventionellem Wege abzuklären waren.

\section{Ausgang des Verfahrens}

Der Gesuchte wurde im Mai 1993 in Italien festgenommen. Aus diesem Grund waren weitere Ermittlungen in Deutschland im Rahmen dieses Verfahrens nicht mehr notwendig. Das Verfahren wurde am 10.11.1993 eingestellt.

\section{Erfolgseinschätzung}

Die Rasterfahndung bildete hier den einzig möglichen Ermittlungsansatz. Nur so konnte im Bestand des Einwohnermeldeamtes nach italienischen Staatsangehörigen mit Geburtsort X und Wohnsitz in M gefahndet werden. Welches Ergebnis die Rasterfahndung hatte, war nicht nachvollziehbar. Da sich der Gesuchte jedoch, wie sich später herausgestellt hat, nicht in $\mathrm{M}$ aufgehalten hatte, konnte die Rasterfahndung nicht zur Aufenthaltsermittlung des Gesuchten beitragen.

\section{Verfahren 006}

\section{Sachverhalt}

Ausgangspunkt für das Verfahren 006 war die Entführung, Vergewaltigung und anschließende Aussetzung eines neunjährigen Mädchens in H. Das Opfer wurde am 31.08.1994 entführt und einige Tage später ausgesetzt. 


\section{Die Rasterfahndung}

\section{a. Ermittlungsstand und Ausgangslage}

Mit den Ermittlungen wurde eine Sonderkommission betraut. Erste Vernehmungen des Opfers ergaben eine Beschreibung des Täters und seines Fahrzeuges. Im Laufe der Ermittlungen wurden drei Personen als Beschuldigte geführt und vernommen. Darüber hinaus wurden die Wohnungen der Beschuldigten durchsucht. Zusätzlich wurde auf einem Wochenmarkt im Umfeld des Ortes, an dem die Entführung des Opfers stattgefunden hatte, ein Infostand der Polizei errichtet und Flugblätter mit dem Phantombild des Täters verteilt. Der Fall war auch Gegenstand einer Sendung der Reihe „Aktenzeichen xy-ungelöst“. Die Ermittlungsmaßnahmen verliefen durchweg negativ.

Ein dreiviertel Jahr später wurde erneut ein Mädchen entführt und vergewaltigt. Die Beschreibung des Täters wies Übereinstimmungen zur ersten Tat auf, weshalb die Ermittlungen zur ersten Tat wieder intensiviert wurden. Das Opfer der zweiten Tat beschrieb jedoch ein anderes Fahrzeug. Aufgrund der Vorgehensweise des Täters wurde eine dritte Tat in die Untersuchungen mit einbezogen. Diese hatte sich zeitlich vor der ersten Tat ereignet, war aber bislang nicht aufgeklärt worden. Bei der dritten Tat handelt es sich um eine Entführung und versuchte Vergewaltigung. Alle Ermittlungen zu den drei Taten verliefen ergebnislos. Auch den drei Beschuldigten konnten die Taten nicht nachgewiesen werden, so dass die Verfahren gegen diese am 19.04.1995 eingestellt wurden.

\section{b. Begründung und Ziel}

Aufgrund dessen konzentrierten sich die Ermittlungen auf das Fahrzeug, welches der Täter genutzt hatte. Zur Ermittlung des Fahrzeugs und des Täters wurde eine Maßnahme nach den $\S \S 98 a$, b StPO am 12.06.1995 angeregt. Es sollte die Sexualstraftäterdatei mit der Halterdatei des Kraftfahrtbundesamtes und der Kundendatei eines Autoherstellers abgeglichen werden. Die Sexualstraftäterdatei wurde für den Abgleich ausgewählt, da davon ausgegangen wurde, dass der Täter mit hoher Wahrscheinlichkeit bereits als Sexualstraftäter in Erscheinung getreten sei. Der Abgleich mit der Halterdatei des KBA sollte durchgeführt werden, um einschlägige Vorstrafen von Haltern eines bestimmten Fahrzeugtyps festzustellen. Es handelte sich um den Fahrzeugtyp, welchen das Opfer Nr.2 beschrieben hatte. Darüber hinaus sollte das Ergebnis des ersten Abgleichs mit der Kundendatei des Autoherstellers abgeglichen werden. Dieser Abgleich sollte die Fahrzeuge auf Ausführungen mit bestimmten Ausstattungsmerkmalen begrenzen. Begründet wurde die Maßnahme mit der Erfolglosigkeit der bisherigen zeit- und personenaufwendigen Maßnahmen und dem Fehlen von weiteren Ermittlungsansätzen. 
Der Abgleich wurde von der Staatsanwaltschaft H am 12.06.1995 beantragt. Begründet wurde der maschinelle Abgleich mit dem Umfang der angeforderten Daten. Angeordnet wurde die Maßnahme am 14.06.1995 durch das Amtsgericht H.

\section{c. Durchführung und Ergebnis}

Magnetbänder mit den Datensätzen der Sexualstraftäterdatei wurden beim Bundeskriminalamt am 28.06.1995 abgeholt. Da auf diesen Geburtsname und Geburtsdatum fehlten, mussten sie erneut erstellt werden. Dies hatte zur Folge, dass am 29.06.1995 erneut Magnetbänder beim Bundeskriminalamt abgeholt werden mussten. Darüber hinaus stellte sich heraus, dass die Sexualstraftäterdatei erhebliche Lücken aufwies. Die Daten der Sexualstraftäterdatei umfassten 15.000 personenbezogene Datensätze. Auch bei den vom Kraftfahrtbundesamt angeforderten Daten kam es zu technischen Problemen. Aufgrund einer falschen Speicherung wurde eine Anzahl von 100.000 Fahrzeugen anstelle der veranschlagten 35.000 Fahrzeuge in den Abgleich einbezogen.

Das Ergebnis des Datenabgleichs lag am 07.07.1995 vor. Danach kam es zu 33 Treffern. Laut einem polizeilichen Vermerk traten jedoch einige Fehler auf, weshalb noch weitere Personen zu überprüfen waren. Der Abgleich mit der Kundendatei erbrachte die Erkenntnis, dass die gesuchte Ausführung des Fahrzeugtyps sowohl in Deutschland als auch den angrenzenden Staaten nicht vertrieben worden war. Aus diesem Grund war es nicht möglich die 33 Treffer weiter einzugrenzen.

\section{d. Auswirkungen auf das Ermittlungsverfahren}

Aufgrund eines Zufalls ergab sich zeitgleich eine neue Spur. Einem Polizeibeamten kam beim Einkaufen ein Fahrzeug auf dem Parkplatz eines Supermarktes verdächtig vor. Daraufhin getroffene Ermittlungsmaßnahmen erhärteten den Verdacht gegen den Halter des Fahrzeugs. Gegen diesen war zu einem früheren Zeitpunkt des Verfahrens bereits ermittelt worden. Vernehmungen der Angehörigen erhärteten den Verdacht nochmals, so dass am 12.07.1995 eine Festnahme der einschlägig vorbestraften Person erfolgte. Da es sich bei dem Fahrzeug des mittlerweile Beschuldigten um einen anderen Fahrzeugtyp als dem der Rasterfahndung zugrunde liegenden handelte, wurden die im Zuge der Rasterfahndung durchzuführenden Ermittlungen eingestellt. Insofern hatte die Rasterfahndung keine weiteren Auswirkungen auf das Ermittlungsverfahren.

\section{Ausgang des Verfahrens}

Die als Beschuldigter Nr.4 geführte Person legte weder vor noch während der Hauptverhandlung ein Geständnis ab. In einem Indizienprozess konnte der Be- 
schuldigte jedoch aufgrund von Zeugenaussagen, Augenscheinobjekten und Sachverständigengutachten zu zwölf Jahren Freiheitsstrafe verurteilt werden.

\section{Erfolgseinschätzung}

Letztlich war es die Beobachtung eines aufmerksamen Polizeibeamten, die zur Ermittlung des Täters führte. Der Datenabgleich konnte nicht zur Identifizierung des Täters beitragen. Zum Zeitpunkt der Anregung der Maßnahme bestanden jedoch keine weiteren Ermittlungsansätze, so dass die Rasterfahndung zur Ermittlung des Fahrzeugs und damit auch des Täters Erfolg versprechend erschien. Dem Opfer Nr.2 wurden diverse Fahrzeuge zur Ansicht vorgeführt, um sichergehen zu können, dass nicht nach einem falschen Fahrzeug gefahndet würde. Insofern kann nicht geschlussfolgert werden, dass die Grundlagen für den Datenabgleich mangelhaft ausgewählt worden waren. Vielmehr war auch die Annahme, der Täter wäre einschlägig vorbestraft, zutreffend. Auf der Basis der erlangten Erkenntnisse war die Rasterfahndung ein Erfolg versprechendes Mittel zur Ermittlung des Täters.

\section{Verfahren 007}

\section{Sachverhalt}

Gegenstand von Verfahren 007 waren Ermittlungen zur Aufklärung von zwei Tötungsdelikten. In der Nacht vom 08.10.1994 zum 09.10.1994 gegen 22.00 Uhr besuchten zwei sechzehnjährige Mädchen eine Diskothek in der Nähe von L. Gegen 4.00 Uhr wurden die beiden Mädchen beim Verlassen der Diskothek das letzte Mal lebend gesehen. Am 11.10.1994 wurden die Leichen der beiden Mädchen unbekleidet in einem Waldstück aufgefunden.

\section{Die Rasterfahndung}

\section{a. Ermittlungsstand und Ausgangslage}

Nach dem Auffinden der Leichen wurde umgehend eine Sonderkommission zur Durchführung der Ermittlungen eingesetzt. Erste Untersuchungen der Leichen ergaben erhebliche Verletzungen in den Brustbereichen der beiden Opfer. Für diese Verletzungen sollten „saugende Gegenstände“ wie sie auch in Sexshops vertrieben werden, verantwortlich gewesen sein. Ursächlich für den Todeseintritt bei beiden Opfern war eine Chloroformvergiftung. Anzeichen einer Vergewaltigung und insbesondere Spermaspuren konnten nicht festgestellt werden.

Aufgrund der Kontakte eines der Opfer zum örtlichen Drogen- und Prostitutionsmilieu wurden die Ermittlungen zunächst in diese Richtung geführt. Im Rahmen der Ermittlungen in diesem Milieu gerieten drei Personen in Tatverdacht. Diese wurden im weiteren Verlauf des Verfahrens als Beschuldigte Nr.1, Nr.2 und Nr.3 geführt. Tele- 
fonüberwachungen und Observationen verliefen ergebnislos. Die Beschuldigten wurden festgenommen und vernommen. Ein Tatnachweis gelang bzgl. der drei Personen jedoch nicht. Allerdings konnten den drei Beschuldigten Nr.1, Nr.2 und Nr.3 diverse Straftaten nachgewiesen werden, die in gesonderten Verfahren verfolgt wurden.

Die Auslobung von 25.000 DM brachte genauso wenig Hinweise auf den Täter wie eine Ausstrahlung des Falles in der Fernsehsendung „Aktenzeichen: xy ungelöst“". Knapp zwei Jahre nach der Tat wurde ein Gutachten bzgl. eines Täterprofils in Auftrag gegeben. Laut dem Gutachten ließ sich der Täter wie folgt beschreiben:

- Einzeltäter, Deutscher

- 20 - 30 Jahre alt

- Mittelschichtberuf, wahrscheinlich Handwerker oder Dienstleister „sauberer Beruf“, evtl. selbstständig

- intelligent, eloquent, sympathisch, sozial angepasst, unverdächtig

- lebt +/- $10 \mathrm{~km}$ um den Leichenfundort

- lebt in Ein-/Zweifamilienhaus mit Keller und Garage; optisch abgeschirmt

- lebt bei seiner Mutter oder in ihrer unmittelbaren Nähe

- besitzt einen Lieferwagen und eine Schusswaffe

- besitzt noch Teile der Opferbekleidung

- Wohnung und Fahrzeug des Täter sauber und aufgeräumt

- lebt bereits seit längerer Zeit in seiner angestammten Umgebung

- fällt im Diskomilieu nicht auf

- ist dezent leger gekleidet, trägt kurze Haare

- besitzt ein Bodybuilding Heimstudio oder ist Kraft- und Kampfsportler

- hat nach der Tat evtl. als Tippgeber Kontakt zur Polizei gesucht

- hat nach der Tat evtl. ein Alkoholproblem entwickelt und dadurch möglicherweise seinen Führerschein verloren

- hat den alten Wohnsitz evtl. kurzfristig verlassen

- hat evtl. zumindest eines der Opfergräber besucht

- hat sich auf eine Überprüfung durch die Polizei gedanklich vorbereitet

- dürfte bald nach der Tat überzeugend ruhig und unschuldig gewirkt haben

- dürfte heute aber erdrückende Schuldgefühle haben

- wird auf seine Festnahme erleichtert reagieren 


\section{b. Begründung und Ziel}

Auf der Basis dieser Erkenntnisse wurde die Maßnahme nach den $\S \S 98 \mathrm{a}, \mathrm{b}$ StPO am 14.11.1996 angeregt. In der Begründung der Anregung wurde angeführt, dass das Täterprofil von einem Einzeltäter ausgehe, welcher sich durch eine Vielzahl von charakteristischen Merkmalen von anderen Personen unterscheiden würde. Diese Merkmale sind geeignet, bei Durchführung einer Rasterfahndung den Täter zu ermitteln. Bei Verwendung verschiedener Fragestellungen mit unterschiedlichen Verknüpfungen ließen sich sowohl Nichtverdächtige ausschließen als auch Personen feststellen, die für die Ermittlungen bedeutsame Prüfungsmerkmale erfüllen. Wie im Vorfeld der Anregung festgestellt werden konnte, war es nicht möglich, die benötigten Daten $\mathrm{zu}$ trennen, weshalb eine komplette Übermittlung angeregt wurde. In den Abgleich sollten Einwohnermeldedaten aller Gemeinden der Leichenfundregion, Kfz-Daten und Daten bzgl. erteilter Fahrerlaubnisse einbezogen werden. Darüber hinaus wurde angeregt, die Anordnungen so allgemein zu halten, dass keine Rückschlüsse auf das Verfahren möglich wären. Begründet wurde dies damit, dass in diesem Verfahren in besonderem Maße öffentliches und Medieninteresse bestehen würde. Es seien deshalb Maßnahmen nötig, um Publikationen zu verhindern, da der Täter nicht gewarnt werden dürfe.

Die Maßnahme wurde am 14.11.1996 durch die Staatsanwaltschaft L beantragt. In ihrer Begründung stellte diese heraus, dass nahezu alle Ermittlungsansätze erschöpft seien. Darüber hinaus verwies die Staatsanwaltschaft auf die polizeiliche Anregung. Angeordnet wurde die Maßnahme am 03.12.1996. In den Ausfertigungen für die zur Übermittlung Verpflichteten wurden keine Angaben aufgenommen, die Rückschlüsse auf das Verfahren ermöglichten.

Am 04.12.1996 wurde eine Ergänzung der Anordnung durch die Staatsanwaltschaft beantragt. Grund für die Ergänzung war die Weigerung einer der verpflichteten Stellen, die Daten zu übermitteln. Die erste Anordnung sollte deshalb die zur Übermittlung verpflichteten Personen genau benennen, um im Falle einer erneuten Weigerung die Verhängung von Zwangsgeld in Höhe von 1000 DM oder ersatzweise Zwangshaft anordnen zu können. Die beantragte Erweiterung wurde am 04.12.1996 angeordnet.

Darüber hinaus wurde am 18.12.1996 eine Erweiterung der Maßnahme auf die Kundendateien eines Versandhandels angeregt. Begründet wurde diese Anregung mit der Möglichkeit, dass der Täter den Gegenstand, mit welchem er die Verletzungen der Opfer herbeigeführt hatte, über diesen Versandhandel bezogen haben könnte. Die Erweiterung wurde am 18.12.1996 beantragt und am 19.12.1996 angeordnet. Eine entsprechende Anordnung für einen weiteren Versandhandel wurde am 20.12.1996 angeregt und beantragt. Die diesbezügliche Anordnung erging am 21.12.1996. 


\section{c. Durchführung und Ergebnis}

Aufgrund der unterschiedlichen Formen der personenbezogenen Datenverarbeitung bei den Kommunen ergaben sich erhebliche Defizite bei der Recherche in den Datenbeständen. Darüber hinaus wurde der aktuelle Einwohnermeldebestand des Jahres 1997 übermittelt. Benötigt wurde jedoch der Bestand zur Tatzeit 1994, welcher nur vereinzelt und unter erschwerten Bedingungen beschafft werden konnte. Im Resultat führte dies dazu, dass Personen, die herausgerastert wurden, später ausgeschlossen werden mussten, da sie zur Tatzeit gar nicht in der Umgebung des Leichenfundortes wohnhaft waren. Auch die Informationen zur Wohnsituation, insbesondere was die Anzahl der Personen in den Haushalten anging, waren mangelhaft. Letztlich konnte auch das Kriterium „verfügt über ein $\mathrm{Kfz}$ “ nur unzureichend überprüft werden, da auch hier nur der aktuelle Datenbestand bekannt war. $\mathrm{Da}$ Kfz jedoch relativ häufig und zum Teil auch nach kurzer Zeit gewechselt wurden, war häufig nicht nachvollziehbar, über welches Kfz die betreffenden Personen zur Tatzeit verfügt haben.

Zusätzlich war eine mangelhafte Ausstattung der Sonderkommission aus den Verfahrensakten ersichtlich. So wurde vermerkt, dass der Aufbau und die Handhabung des zur Verfügung gestellten Rechercheprogramms nicht mehr zeitgemäß und in der praktischen Anwendung zu umständlich waren. Darüber hinaus hat sich mit dem Aufbau der Daten die Gefahr eines kompletten Datenverlustes potenziert, weshalb regelmäßig aufwendige Datenspeicherungen durchgeführt werden mussten. Aufgrund der Probleme wurden die Recherchen auf die dem Leichenfundort am nächsten gelegenen Gemeinden beschränkt. Aus der Gesamteinwohnerzahl von 22.602 Personen konnten 191 Personen herausgefiltert werden, welche den Recherchevorgaben entsprachen.

Die 191 Personen wurden durch zwei Teams mit je zwei Beamten überprüft. Insgesamt erstreckte sich die Bearbeitung der Spuren aus der Rasterfahndung auf einen Zeitraum von sechs Monaten. Vom geplanten Rechercheumfang konnten weniger als $50 \%$ bewältigt werden. Im Ergebnis führte die Rasterfahndung zur Ermittlung eines Tatverdächtigen, welcher im weiteren Verlauf des Verfahrens als Beschuldigter Nr.4 geführt wurde. Darüber hinaus wurden 36 Personen unter „Tatverdacht kann nicht ausgeschlossen werden“" eingestuft.

\section{d. Auswirkungen auf das Ermittlungsverfahren}

Der Tatverdacht gegen den Beschuldigten Nr.4 ergab sich allein aufgrund der Rasterfahndung. Allerdings konnte der Beschuldigte ein Alibi vorweisen. Er war zur Tatzeit nachweislich im Krankenhaus und schied daher als Täter aus. Die Ermittlungen gegen den Beschuldigten Nr.4 wurden am 25.08.1998 eingestellt. Die Verfolgung der weiteren Spuren aus der Rasterfahndung wurde zurückgestellt, da sich eine neue Leitspur ergab. 


\section{Ausgang des Verfahrens}

Da die sog. harten Daten, wie sie im Rahmen der Rasterfahndung abgeglichen wurden, das Täterprofil nur unzureichend abzubilden vermochten, wurde dazu übergegangen, Referenzpersonen in den betreffenden Gemeinden hinzuzuziehen. Als solche wurden ansässige Polizeibeamte, Postzusteller etc. hinzugezogen. Diese sollte Angaben über Aussehen, Arbeit und das persönliche Umfeld der zu überprüfenden Personen machen. Diese Ermittlungen verliefen jedoch mit negativem Ergebnis.

Zwischenzeitlich ergaben sich Hinweise auf einen weiteren Tatverdächtigen. Dieser war aufgrund einer vergleichbaren Tat bereits in Haft. Insbesondere der Modus Operandi der betreffenden Tat deutete auch auf eine Täterschaft in diesem Verfahren hin. Zusätzlich hatte der Tatverdächtige, der im weiteren Verlauf als Beschuldigter Nr.5 geführt wurde, seinen Wohnsitz zur Tatzeit in L. Die Ermittlungen bzgl. des Beschuldigten Nr.5 wurden von Ende 1997 bis zur Ergreifung des tatsächlichen Täters parallel weitergeführt.

Neue Hinweise aus dem Drogen- und Prostituiertenmilieu von L ergaben einen Tatverdacht gegen zwei weitere Personen. Diese wurden als Beschuldigte Nr.6 und Nr.7 geführt. Diesbezüglich stellte sich jedoch heraus, dass die Hinweise von konkurrierenden Personen des Milieus getätigt und haltlos waren. Während der Ermittlungen befanden sich die beiden Personen aufgrund anderer Delikte bereits in Untersuchungshaft. Die Ermittlungen gegen die beiden Beschuldigten Nr.6 und Nr.7 liefen ebenfalls bis zur Ergreifung des tatsächlichen Täters weiter.

Zu Beginn des Jahres 2001 wurden sichergestellte Gegenstände unter Zuhilfenahme neuer molekulargenetischer Untersuchungsmethoden erneut überprüft. Hierbei konnten DNA-Spuren entdeckt werden. Daraufhin wurden bei den 36 Personen, welche im Rahmen der Rasterfahndung unter „Tatverdacht kann nicht ausgeschlossen werden“ eingestuft wurden, Speichelproben genommen. Dabei konnte jedoch kein Treffer erzielt werden. Im Anschluss daran wurden bei allen männlichen Personen, die im Laufe der Ermittlungen bekannt geworden waren, Speichelproben genommen. Unter diesen befand sich auch der Täter, welcher aufgrund eines anonymen Hinweises kurzzeitig verdächtigt worden war. Eine freiwillig abgegebene Speichelprobe der Person stimmte mit dem sichergestellten DNA-Material überein. Unter den Fingernägeln eines der Opfer sichergestelltes DNA-Material stimmte darüber hinaus mit der DNA der Frau des Täters überein. Die beiden wurden daraufhin als Beschuldigte Nr.8 und Nr.9 geführt. In der ersten Vernehmung waren die beiden Beschuldigten geständig. Der Beschuldigte Nr.8 wurde angeklagt und zu fünfzehn Jahren Freiheitsstrafe und Unterbringung in einem psychiatrischen Krankenhaus verurteilt. Die Beschuldigte Nr.9 wurde angeklagt und zu lebenslanger Haft verurteilt. Das Urteil wurde am 26.03.2003 ausgesprochen. Die Revision der beiden Angeklagten wurde abgewiesen. 


\section{Erfolgseinschätzung}

Grundlage für die im Rahmen der Rasterfahndung erhobenen und abgeglichenen Daten war das erstellte Täterprofil. Wie dargestellt, führte die Rasterfahndung zur Identifizierung eines Tatverdächtigen und zur Identifizierung von 36 möglichen Tatverdächtigen. Die näheren Überprüfungen verliefen jedoch negativ. Eine isolierte Betrachtung der Rasterfahndung zeigt, dass sie zumindest neue Ermittlungsansätze erbracht hat.

Wie sich im Nachhinein jedoch herausgestellt hat, waren nahezu alle Merkmale des zugrunde gelegten Täterprofils nicht zutreffend. Insbesondere die Eingrenzung auf einen Umkreis von $10 \mathrm{~km}$ um den Leichenfundort stellte sich als falsch heraus. Der Täter hatte die Leichen über $50 \mathrm{~km}$ von seinem Wohnsitz und dem Tatort entfernt abgelegt. Darüber hinaus waren das Alter des Täters und die Tatsache, dass es sich nicht um einen Einzeltäter gehandelt hatte, von negativem Einfluss auf die Durchführung der Rasterfahndung. Letztlich kann hier festgehalten werden, dass die Maßnahme auf einem unzutreffenden Täterprofil aufgebaut war und dadurch von Beginn an keinen Erfolg haben konnte.

\section{Verfahren 008}

\section{Sachverhalt}

Auslöser für das Verfahren 008 war ein Überfall auf eine Bank in $\mathrm{P}$ am 16.02.1995. Der unbekannte Täter fuhr mit einem weißen VW-Golf, mit Kennzeichen der Stadt K, vor die Bank und stellte es dort ab. Der maskierte, mit einer Jeans und einer leuchtend orangefarbenen Jacke bekleidete Täter forderte unter Vorhalt einer Pistole den Kassierer zur Herausgabe von 49.000 DM auf. Hierzu übergab er dem Kassierer eine beigefarbene Leinentasche mit auffälligem Aufdruck. Nach der Tat bestieg der Täter das Motorrad, welches ca. 200 m Luftlinie vom Tatort aufgefunden wurde. Die weiteren Tatmittel und das Diebesgut wurden nicht aufgefunden.

\section{Die Rasterfahndung}

\section{a. Ermittlungsstand und Ausgangslage}

Die Ermittlungen konzentrierten sich zunächst auf die Erscheinung des Täters und dessen Tatfahrzeug. Um die Größe des Täters zu ermitteln, ließ die Polizeidienststelle $\mathrm{P}$ das Bildmaterial aus der Videoüberwachung der Bank analysieren und ein Gutachten erstellen. Das Ergebnis ergab eine Größe von 1,85 bis 1,90 m Größe. Auffallend war auch die leuchtend orangefarbene Jacke des Täters. Die 
Ermittlungen ergaben, dass er eine sehr teure Jacke trug, die in Geschäften in Schleswig-Holstein und im angrenzenden Niedersachsen nicht vertrieben wurde.

Am Tatfahrzeug wurden sämtliche Identifizierungshinweise entfernt, so dass eine Identifizierung nur aufgrund der Motornummer möglich war. Weitere Ermittlungen ergaben, dass das Fahrzeug von der in D wohnhaften Vorhalterin in einem lokalen Annoncenblatt im Raum B / D zum Verkauf angeboten wurde. Dort erstand der mutmaßliche Täter das Fahrzeug am 22.01.1995 von der Vorhalterin. Aufgrund der Beschreibung der Vorhalterin konnte ein Phantombild des Käufers und damit des mutmaßlichen Täters angefertigt werden. Die am Tatfahrzeug angebrachten Kennzeichenschilder wurden vom Täter am Tag vor dem Überfall bei der Zulassungsstelle in $\mathrm{K}$ entwendet und mit neuen Zulassungsstempeln versehen.

Weitere Hinweise erbrachten die Ermittlungen zu der im Rahmen des Überfalls verwendeten Leinentasche. Diese wurde für eine Supermarktkette hergestellt. Diese hatte die Leinentasche jedoch nur in ihren Märkten im Bereich D, M, D, G und S vertrieben. Wie schon die Ermittlungen bezüglich des Tatfahrzeugs ergab sich also auch diesbezüglich ein Bezug des Täters in das Ruhrgebiet und insbesondere nach D.

Darüber hinaus wurde durch die Kriminalpolizei P eine Öffentlichkeitsfahndung veranlasst. Hierzu wurden das Phantombild des Täters und weitere fahndungsrelevante Merkmale des Täters in der Presse veröffentlicht. Daraufhin meldete sich ein Bediensteter der Universität K. Dieser hatte auf dem Campus mehrfach eine männliche Person gesehen, welche die orangefarbene Jacke getragen haben sollte. Der Zeuge äußerte die Annahme, dass es sich bei der Person um einen Studenten, Doktorranden oder Mitarbeiter der Universität handeln könnte.

\section{b. Begründung und Ziel}

Diese Erkenntnisse bildeten die Grundlage für die Rasterfahndung. Insbesondere die Beziehung des Täters nach D und die Beobachtungen des Bediensteten der Universität waren für die Rasterfahndung ausschlaggebend. Diese Erkenntnisse nahm die Kriminalpolizei P am 14.03.1995 zum Anlass, das Rektorat der Universität K um einen Datenabgleich zu ersuchen. Es sollte festgestellt werden, ob und wie viele männliche Studenten mit Geburts- oder Wohnort D eingeschrieben waren.

Die Universität teilte daraufhin am 15.03.1995 mit, dass es möglich sei, dem kriminalpolizeilichen Ersuchen nachzukommen, jedoch aus datenschutzrechtlichen Gesichtspunkten Bedenken bestehen würden. Darüber hinaus wurde um eine richterliche Anordnung gem. der $\S \S 98 \mathrm{a}, \mathrm{b}$ StPO gebeten. Daraufhin regte die Kriminalpolizei die Beantragung eines entsprechenden Beschlusses bei der Staatsanwaltschaft an. Diese forderte allerdings am 16.03.1995 ihrerseits die Daten bei der Universität selbst an. Sie verlangte Auskunft über alle männlichen Studenten, Dokto- 
randen und Mitarbeiter im Alter zwischen 20 und 40 Jahren mit Geburts- oder Wohnort in D. In der Anforderung hat die Staatsanwaltschaft ausdrücklich auf den § 98a StPO Bezug genommen hat. Allerdings hat sie keine Eilanordnung im Sinne des $\S 98$ b I S.1 StPO getroffen. Diese Vorgehensweise veranlasste die Universität am 20.03.1995 erneut ihre Rechtsbedenken gegen die erbetene Auskunft zu äußern und den Datenabgleich abzulehnen. Nach ihrer Ansicht sei die Straftatbestimmung Raub / schwerer Raub gem. $\S \S 249,250$ StGB keine Straftat, die unter die in $§ 98 \mathrm{a}$ StPO aufgeführten Straftaten falle. Ferner wies die Universität darauf hin, dass die Anordnung durch die Staatsanwaltschaft nur bei Gefahr im Verzuge getroffen werden könne, was hier nicht vorliegen würde. Darüber hinaus bedürfe die Eilanordnung einer richterlichen Bestätigung innerhalb von drei Tagen, da sie ansonsten nicht in Kraft treten würde.

Am 24.03.1995 stellte die Staatsanwaltschaft einen entsprechenden Antrag auf Datenabgleich gem. $\S \S 98 \mathrm{a}, \mathrm{b}$ StPO beim Amtsgericht K. Hierin verwies sie zunächst auf die polizeiliche Begründung und ihre eigene Begründung vom 16.03.1995. Mithin wies sie in ihrem Antrag daraufhin, dass die schwere räuberische Erpressung den Katalogtaten des $\S$ 98a StPO zuzurechnen sei. Begründet wurde dies mit der Angehörigkeit des $\S 240$ StGB (Nötigung) zum 18. Abschnitt des StGB, auf welchen in $\S 98$ a StPO verwiesen werde. Ferner führte die Staatsanwaltschaft aus, dass Nötigung ein Element von Raub und räuberischer Erpressung sei. Wenn bereits die Nötigung zu den Katalogtaten gehören würde, dann müsste dies auch für das schwerere Delikt gelten. Ferner dürfe bei der angedrohten Mindeststrafe für schweren Raub / schwere räuberische Erpressung ohne weitere Begründung von einer Straftat von erheblicher Bedeutung ausgegangen werden. Letztlich sei die Fahndung nach einer Person mit Kräften der Polizei erheblich weniger Erfolg versprechend.

Der Antrag der Staatsanwaltschaft wurde am 28.03.1995 durch das Amtsgericht K abgelehnt. Dieses sah die Voraussetzungen der $\S \S 98 \mathrm{a}$, b StPO nicht gegeben. Insbesondere würde keine Katalogtat vorliegen. So nehme $\S 98 \mathrm{a}$ I Nr.4 StPO Bezug auf die Abschnitte 13, 16, 17 und 18 des Strafgesetzbuches, nicht aber auf den 20. Abschnitt über Raub und Erpressung. Mithin käme eine Anwendung der Katalogstraftaten durch analoge Anwendung auf ,zusammengesetzte“ Straftaten, die ein Element einer Katalogstraftat enthalten, nicht in Frage. Letztlich sei eine Anwendung des $\S 98$ a StPO im vorliegenden Verfahren nur über $\S 98$ a I Nr.5 oder Nr.6 StPO in Betracht zu ziehen. Anhaltspunkte für eine gewerbs- oder gewohnheitsmäBige und / oder in irgendeiner Form bandenmäßig oder sonst organisiert von mehreren Tätern begangene Straftaten würden jedoch nicht vorliegen.

Gegen diesen Beschluss legte die Staatsanwaltschaft am 31.03.1995 Beschwerde ein. Diese begründete sie damit, dass im Falle einer Beschränkung der Strafverfolgung gem. § 154a StPO auf die Nötigung die Voraussetzungen des § 98a StPO bei der Schwere der Tat gegeben sein würden. Ferner sei die Bedrohung der Personen in der Bank mit der Schusswaffe auch eine Tat, die sich gegen Leib oder Leben 
gerichtet hätte. Mit Beschluss vom 18.04.1995 wurde der Entscheidung nicht abgeholfen, da die Beschwerdebegründung keinen Anlass zu einer Abänderung des Beschlusses gegeben hätte.

Daraufhin stellte die Staatsanwaltschaft am 24.04.1995 beim Landgericht K den Antrag, unter Aufhebung der angefochtenen Entscheidung einen entsprechenden Beschluss gem. $\S \S 98 \mathrm{a}, \mathrm{b}$ StPO zu erlassen. Am 04.05.1995 hat das Landgericht den angefochtenen Beschluss aufgehoben. Des Weiteren ordnete es den Abgleich und die Übermittlung von Daten aller männlichen Studenten, Doktoranden und Mitarbeiter der Universität K im Alter zwischen 20 und 40 Jahren mit Geburtsort oder Wohnort D an. Das Landgericht sah nach dem Stand der Ermittlungen zureichende tatsächliche Anhaltspunkte dafür vorliegen, dass eine Straftat gegen die persönliche Freiheit, nämlich ein erpresserischer Menschenraub gem § 239a StGB begangen worden sei. Mit Blick auf die Mindeststrafe von 5 Jahren würde auch eine Straftat von erheblicher Bedeutung vorliegen.

\section{c. Durchführung und Ergebnisse}

Wie angeordnet, führte die Universität K den Abgleich durch. Die Recherche erfolgte in einem Datenbestand von ca. 24.000 personenbezogenen Datensätzen. Am 12.06.1995 ging bei der Kriminalpolizei P eine am 06.06.1995 erstellte Liste mit den Daten von 17 Personen ein.

\section{d. Auswirkungen auf das Ermittlungsverfahren}

Die übermittelte Aufstellung von 17 Personen bildete die Grundlage für die weiteren Ermittlungen. Zunächst wurden die Personen einer büromäßigen Überprüfung unterzogen. Dabei handelte es sich um eine Wohnortfeststellung sowie eine Abfrage bzgl. der polizeilichen Erkenntnisse. Keine der 17 Personen war bisher polizeilich in Erscheinung getreten. Aufgrund einer zwischenzeitlich zutage getretenen Ermittlungsrichtung wurden zunächst keine weiteren Ermittlungen in diese Richtung unternommen.

Erst in der Zeit von Februar bis April 1996 wurden die 17 Personen einer Überprüfung unterzogen. Diese erfolgte auf der Basis folgender Kriterien:

- Körperbau: sportlich, kräftig

- Körpergröße: $190-200 \mathrm{~cm}$

- Haarfarbe: dunkel

- Mundart

- Hände: Handhaltung beim Durchgreifen

- Ohren: angewachsene Ohrläppchen 
- Benutzte Pkw / Motorrad: Tatfahrzeuge Krad / VW Golf

- Alibi zu den Tattagen

Die Kriterien ergaben sich aus den bisherigen Ermittlungsergebnissen, insbesondere aus den Auswertungen der Kameraüberwachung und der Zeugenaussagen. Es wurden 14 der 17 Personen anhand dieser Kriterien überprüft. Dabei konnten alle Personen als Tatverdächtige ausgeschlossen werden. Die übrigen drei Personen waren inzwischen verzogen. Es wurde daher auf eine Überprüfung verzichtet.

\section{Ausgang des Verfahrens}

Zwischenzeitlich wurden drei weitere Banküberfälle in die Ermittlungen mit einbezogen. Einer der Überfälle hatte sich bereits am 31.07.1990 auf dieselbe Bank ereignet. Des Weiteren wurde eine Bank in W am 10.08.1995 und am 14.12.1995 überfallen. Bei diesen vier Taten wurden übereinstimmende Vorbereitungshandlungen vorgenommen. Auch das Vorgehen in der Bank wies Parallelen auf. So war der Wortlaut im Rahmen der Geldforderung identisch. Letztlich offenbarte auch das Nachtatverhalten deutliche Übereinstimmungen.

Im Rahmen einer Durchsuchung in einem anderen Verfahren erlangte die Polizei Erkenntnisse über mögliche Tatverdächtige. Es handelte sich bei diesen um Zwillinge, die dem Täter sehr ähnlich sahen. Im Rahmen einer Lichtbildvorlage wurde eine der Personen von der Verkäuferin des Tatfahrzeugs wieder erkannt. Die beiden Personen wurden im weiteren Verlauf des Verfahrens als Beschuldigte geführt. Da eine Täterschaft jedoch nicht nachgewiesen werden konnte, wurde das Verfahren gegen die beiden Beschuldigten am 24.02.1997 gem. § 170 II StPO eingestellt. Eine weitere Ermittlungsrichtung ergab sich aus Ermittlungen zu Pkw Diebstählen mit ähnlicher Vorgehensweise. Aber auch diese führten nicht zur Ermittlung eines Täters. Laut dem polizeilichen Abschlussbericht vom 29.01.1997 wurden die Ermittlungen erfolglos eingestellt.

\section{Erfolgseinschätzung}

Um die Erfolgsaussichten der Rasterfahndung in diesem Verfahren beurteilen zu können, muss zunächst das verwendete Raster genauer betrachtet werden. Dieses bezog alle zu diesem Zeitpunkt verwertbaren Erkenntnisse mit ein. Grundlage für die Entscheidung, einen Datenabgleich an der Universität K durchzuführen, war die Aussage eines Zeugen. Dieser wollte eine Person, welche eine Jacke mit Ähnlichkeiten zu der des Täters trug, gesehen haben. Aufgrund dieser Vermutung des Zeugen wurde beschlossen, den Datenbestand der Universität für einen Datenabgleich heranzuziehen. Die Auswertung der Verfahrensakten ergab keine Hinweise darauf, ob zunächst andere Ermittlungen durchgeführt worden sind. Auch eine Abwägung 
zwischen verschiedenen Ermittlungsmaßnahmen, welche zur Entscheidung geführt haben, eine Rasterfahndung durchzuführen, ist nicht ersichtlich geworden.

Darüber hinaus scheint auch die Begrenzung auf den Ortsbezug zu D als zu eng gewählt. Die Hinweise aus den Ermittlungen zum Tatfahrzeug und zur Leinentasche betrafen nicht nur D, sondern weitere Regionen in Nordrhein-Westfalen. Allein die Tatsache, dass das Tatfahrzeug in D erworben wurde, wurde herangezogen, um den Datenabgleich zu begrenzen. Diese Begrenzung ermöglichte sicherlich eine geringe Treffermenge. Die Wahrscheinlichkeit, dass der Wohn- oder Geburtsort des Täters in D und nicht angrenzenden Gemeinden liegen würde, war jedoch im Bereich des Zufalls anzusiedeln. Daher stellt sich die Frage, warum der Ortsbezug nicht weiträumiger gewählt wurde. Für den Fall, dass ein solcher Datenabgleich eine nicht zu überprüfende Trefferanzahl ergeben hätte, wäre in einem zweiten Rasterungsschritt eine Begrenzung auf D möglich gewesen.

Betrachtet man die 17 Treffer, welche das Ergebnis der Rasterfahndung darstellen, losgelöst vom Verfahrensausgang, kann durchaus von einem Erfolg der Rasterfahndung gesprochen werden. Der Erfolg besteht konkret in der Erlangung eines Ermittlungsansatzes für weitere konventionelle Ermittlungen. Bezieht man dagegen die Überprüfung der 17 Personen anhand konventioneller Ermittlungsmaßnahmen in die Erfolgseinschätzung mit ein, so ergibt sich ein anderes Bild. Gemessen am Verfahrensausgang lieferte die Rasterfahndung keine Erkenntnisse zur Ergreifung eines Täters.

\section{Verfahren 009}

\section{Sachverhalt}

Am 03.11.1995 wurde ein siebenjähriges Mädchen in $\mathrm{H}$ als vermisst gemeldet. Das Mädchen hatte das Haus der Eltern am Morgen verlassen, um zur Schule zu gehen. Dort war es jedoch nicht angekommen. Noch am gleichen Tag konnten die Schultasche und ein Regenschirm des Mädchens aufgefunden werden. Der Auffindeort der beiden Gegenstände befand sich in großer räumlicher Entfernung zum Schulweg des Mädchens. Aufgrund dessen ging die Polizei von einem Gewaltverbrechen aus.

\section{Die Rasterfahndung}

\section{a. Ermittlungsstand und Ausgangslage}

Eine umgehend eingeleitete Suche nach dem Mädchen verlief erfolglos. Am 05.11.1995 wurde durch die Polizeidirektion S eine 22-köpfige Sonderkommission gegründet. Aufgrund von Zeugenaussagen konnte festgestellt werden, dass das Mädchen in Begleitung eines ca. 40 Jahre alten Mannes gesehen worden war. Ferner wollte ein Zeuge das Mädchen in einem ihm unbekannten Kfz gesehen haben. 
Anhand der Zeugenbeobachtungen konnte ein Phantombild des Mannes erstellt werden. Dieses wurde umgehend veröffentlicht. Durch Taucheinsätze konnten in den folgenden Tagen ca. 20 Gewässer im näheren Umkreis um H durchsucht werden. Hierbei wurde am 15.11.1995 die Leiche des Mädchens aufgefunden. Im Rahmen der Obduktion konnte festgestellt werden, dass das Opfer erhebliche Verletzung erlitten hatte. Der Tod trat durch Verbluten ein. An der Kleidung des Mädchens konnten fremde Haare sichergestellt werden.

Bereits am 04.11.1995 war der Polizei in H mitgeteilt worden, dass auf einem Jagdhochstand in einem nahe gelegen Waldstück größere Blutspuren aufgefunden wurden. Erste Untersuchungen führten zu der Annahme, es würde sich dabei um Tierblut handeln. Erst nach dem Auffinden der Leiche und weiteren Beweismitteln kam die ermittelnde Sonderkommission zu dem Schluss, dass es sich um den Tatort handeln könnte. An diesem konnten weitere Spuren gesichert werden. Darunter befanden sich menschliche Haare, welche nicht dem Opfer zuzurechnen waren.

Es wurde eine Belohnung in Höhe von 5.000 DM für Hinweise zur Ergreifung des Täters ausgesetzt. Die eingegangenen Hinweise führten jedoch nicht zur Identifizierung eines Tatverdächtigen. Insgesamt wurden im Verlauf des Verfahrens 56 Personen als Beschuldigte geführt. Gegen diese wurden zum Teil strafprozessuale Maßnahmen durchgeführt. Diese verliefen jedoch durchweg negativ. Im Jahr 1997 wurde durch einen Gutachter ein psychologisches Täterprofil erstellt. Die Erkenntnisse aus dem Täterprofil führten genauso wie eine im Jahr 1999 durchgeführte Fallanalyse der Abteilung Operative Fallanalyse des Landeskriminalamtes nicht zur Identifizierung eines Tatverdächtigen.

Im Frühjahr 2000 stand dem Bundeskriminalamt eine neue Methode zur molekulargenetischen Typisierung menschlicher Haare zur Verfügung. Aufgrund dessen wurden dem Bundeskriminalamt am 09.04.2001 sämtliche Asservate mit geeignetem serologischem Spurenmaterial übergeben. Dabei handelte es sich um 17 Haarspuren mit Wurzeln. Die Untersuchung ergab, dass an einem Haar eine DNA-Spur einer männlichen Person festgestellt werden konnte. Ein Abgleich mit der DNAAnalyse-Datei des Bundeskriminalamtes verlief negativ. Aus diesem Grund wurde die Durchführung einer DNA-Reihenuntersuchung in Erwägung gezogen. Aufgrund einer erneuten Fallanalyse der OFA des LKA konnte zudem davon ausgegangen werden, dass der Täter im näheren Umkreis um den Tatort aufgewachsen und/oder wohnhaft sei.

\section{b. Begründung und Ziel}

Zur Grundlage für die DNA-Reihenuntersuchung wurde eine Maßnahme nach den $\S \S 98 \mathrm{a}, \mathrm{b}$ StPO angeregt. Ziel war es, personenbezogene Daten von allen in der Stadt H und den Ortschaften H, B und E im Zeitraum vom 09.11.1989 bis zum 03.11.1995 gemeldeten männlichen Personen, die zwischen dem 01.01.1950 und 
dem 31.12.1960 geboren wurden, zu erlangen. Begründet wurde die Maßnahme mit den Ortskenntnissen des Täters und der Erforderlichkeit der Daten als Grundlage für die geplante DNA-Reihenuntersuchung. Die Maßnahme wurde am 06.02.2003 durch die Staatsanwaltschaft M beantragt und am 14.02.2003 angeordnet.

\section{c. Durchführung und Ergebnis}

Die angeforderten Daten der drei betroffenen Einwohnermeldeämter gingen am 28.02.2003, am 11.03.2003 und am15.03.2003 bei der Kriminalpolizei in S ein. Die Dateien wurden aufbereitet und in ein EDV-Programm importiert. In diesem war die Verwaltung der 2.409 herausgefilterten Personen möglich.

\section{d. Auswirkungen auf das Ermittlungsverfahren}

Durch eine Pressekonferenz und anhand einer Plakataktion wurde die Öffentlichkeit über die Durchführung der DNA-Reihenuntersuchung informiert. Mithilfe der Plakate und verteilter Handzettel wurden alle männlichen Personen der vier Gemeinden, die zwischen dem 01.01.1950 und dem 31.12.1960 geboren wurden, zur freiwilligen Abgabe einer Speichelprobe aufgefordert. $\mathrm{Zu}$ den vorgesehenen Terminen erschienen mehr als 2.000 Personen. Bei weiteren Personen wurde auf die Entnahme einer Speichelprobe verzichtet, weil diese Alibis aufweisen konnten oder anderweitig als Täter ausschieden. 52 Personen verweigerten die Abgabe einer Speichelprobe. Für diese Personen wurden Anordnungen nach den $\S \S 81$ c, e StPO erwirkt.

\section{Ausgang des Verfahrens}

Die Untersuchungen ergaben Übereinstimmungen der Probe mit der laufenden Nummer 2089 und dem sichergestellten DNA-Material. Die betreffende Person hatte die Probe freiwillig abgegeben. Das Ergebnis wurde der ermittelnden Polizeidienststelle am 25.08.2005 übermittelt. Noch am selben Tag wurde der Tatverdächtige festgenommen und vernommen. Im Rahmen der Beschuldigtenvernehmung legte der Tatverdächtige ein umfassendes Geständnis ab. Weitere Ermittlungen ergaben drei weitere Fälle des sexuellen Missbrauchs von Kindern, welche dem Tatverdächtigen nachgewiesen werden konnten.

Der Tatverdächtige wurde angeklagt und mit rechtskräftigem Urteil vom 19.04.2006 zu lebenslanger Freiheitsstrafe wegen Mordes in Tateinheit mit Freiheitsberaubung mit Todesfolge, mit sexuellem Missbrauch eines Kindes mit Todesfolge, mit sexueller Nötigung mit Todesfolge und mit versuchter Vergewaltigung sowie des sexuellen Missbrauchs von Kindern in drei Fällen verurteilt. Ferner wurde die besondere Schwere der Schuld festgestellt und die Unterbringung in der Sicherungsverwahrung angeordnet. 


\section{Erfolgseinschätzung}

Die Anordnung nach den $\S \S 98 \mathrm{a}, \mathrm{b}$ StPO bildete die Grundlage für die erfolgreiche Durchführung der DNA-Reihenuntersuchung. Die erlangten Daten ermöglichten einen Abgleich der freiwillig erschienenen Personen. So konnte jederzeit nachvollzogen werden, welche Personen bereits eine Speichelprobe abgegeben hatten und welche noch nicht. Die Rasterfahndung ermöglichte insofern eine effiziente Durchführung der Reihenuntersuchung.

\section{Verfahren 010}

\section{Sachverhalt}

Gegenstand von Verfahren 010 waren Ermittlungen in Zusammenhang mit einer Serie von Raubüberfällen auf Spielbanken. Auslöser für das Ermittlungsverfahren war ein Überfall auf eine Spielbank in D am 11.05.1996. Drei maskierte Täter drangen in die Spielbank ein und erbeuteten unter Vorhalt von Schusswaffen ca. 450.000 DM. Anschließend entkamen sie unerkannt.

\section{Die Rasterfahndung}

\section{a. Ermittlungsstand und Ausgangslage}

Die Ermittlungen wurden von einer Sonderkommission übernommen. Aufgrund von Ähnlichkeiten im Modus Operandi und weiterer Übereinstimmungen in Bezug auf die Täter wurden vier weitere Überfälle in die Ermittlungen miteinbezogen. Die betreffenden Ermittlungsverfahren wurden am 03.07.1996 durch die Staatsanwaltschaft D übernommen. Bei den weiteren Verfahren handelte es sich um einen Überfall auf die Spielbank K am 20.10.1995. Zwei unbekannte Täter drangen in die Spielbank ein. Dort nahmen sie einen Angestellten als Geisel und erbeuteten 106.190 DM.

Ein weiterer Überfall wurde auf die Spielbank Bad H am 23.12.1995 verübt. Hierbei nahmen drei maskierte Männer einen Besucher als Geisel und betraten mit diesem die Spielbank. Die Geisel wurde mittels einer an den Kopf gehaltenen Schusswaffe bedroht. Die Täter erbeuteten 864.300 DM. Im Anschluss an die Tat flüchteten die Täter mit einem Pkw. Diesen Pkw ließen sie in einiger Entfernung stehen und nutzten vermutlich einen weiteren Pkw zur Fortsetzung der Flucht. In der Spielbank wurde ein Rucksack zurückgelassen.

Darüber hinaus wurde am 16.09.1995 die Spielbank Bad W überfallen, Zwei unbekannte Täter bedrohten die anwesenden Mitarbeiter und Gäste mit Waffen und erbeuteten 34.038 DM. Darüber hinaus wurde ein Überfall am 18.11.1995 auf einen Gast einer der Spielbanken, bei welchem 120.000 DM erbeutet wurden, ebenfalls der Tatserie zugerechnet. 
Aufgrund der Hinweise eines anonymen Anrufers wurden Ermittlungen gegen drei Personen geführt. Deren Wohnräume wurden durchsucht. Darüber hinaus wurden Telefonüberwachungen veranlasst und die Personen als Beschuldigte vernommen. Diese konnten jedoch ein Alibi für die Tatzeit vorweisen. Aufgrund dessen wurde das Verfahren gegen die Beschuldigten Nr.1, Nr.2 und Nr.3 am 29.04.1996 gem. $\S 170$ II StPO eingestellt.

Ermittlungen bzgl. des im Rahmen des Überfalls vom 11.05.1996 sichergestellten Fluchtfahrzeugs ergaben keine Hinweise auf mögliche Tatverdächtige. Es wurden Besucherbefragungen in den einzelnen Spielbanken durchgeführt. Für die Bereiche der Spielbanken wurden die in den Funkzellen angefallenen Verbindungsdaten erhoben. Im Rahmen der Sofortmaßnahmen nach den Überfällen wurden auch Ringalarmfahndungen ausgelöst.

\section{b. Begründung und Ziel}

Am 29.05.1996 wurde durch die ermittelnden Sonderkommission eine Maßnahme nach den $\S \S 98 \mathrm{a}, \mathrm{b}$ StPO angeregt. In der Anregung wurde ausgeführt, dass deutliche Parallelen im Hinblick auf die Begehungsweise und die jeweiligen Täterbeschreibungen zu erkennen seien. Insbesondere die guten Ortskenntnisse würden den Schluss zulassen, dass die Täter entweder der Spielerszene zuzurechnen seien oder die Tatorte zuvor zumindest begutachtet haben müssten. Daher sei davon auszugehen, dass die Täter bereits durch die Spielbanken registriert worden waren. Aus diesem Grund sei ein Abgleich von Besucherdaten der betroffenen Spielbanken notwendig. Ziel des Abgleichs sei die Überprüfung der Besucherdaten, um feststellen zu können, welche Personen wiederholt in allen Spielbanken, gegebenenfalls sogar an Tattagen, registriert wurden. Zeitlich sollte die Anordnung die jeweiligen Tattage und die davor liegenden 60 Kalendertage umfassen.

Noch am gleichen Tag wurde die Maßnahme durch die Staatsanwaltschaft D beantragt. Im Antrag wurden die Besucherlisten von 3 Spielbanken und die Verbindungsdaten von drei Netzanbietern für die Tatzeit und die Funknetzzellen des letzten Tatorts aufgelistet. Begründet wurde die zusätzliche Einbeziehung der Verbindungsdaten mit Erkenntnissen darüber, dass die Täter kurz vor Betreten der Spielbank von einer unbekannten Person über Mobiltelefon und möglicherweise über die Gegebenheiten in der Spielbank informiert worden sind. Diese Erkenntnisse hätten sich aus Beobachtungen von Zeugen ergeben. Mithin seien die Erforschung des Sachverhalts und die Ermittlung der Täter auf andere Weise nicht möglich, da praktisch keine weiteren objektiven Beweismittel vorhanden seien. Die Maßnahme wurde ohne Änderungen oder Ergänzungen am 30.5.1996 durch das Amtsgericht D angeordnet. 


\section{c. Durchführung und Ergebnis}

Die von den Spielbanken angeforderten Daten wurden auf insgesamt elf Disketten übersandt. Wann der Datenabgleich durchgeführt wurde, war den Verfahrensakten nicht zu entnehmen. Erst in einem Zwischenbericht der Sonderkommission vom 21.06.1996 findet das Ergebnis des Datenabgleichs eine Erwähnung. Nachdem die Daten eingegangen und die erforderliche Software installiert worden waren, konnte nach einem ersten Abgleich sofort die Information erlangt werden, dass eine Person am Tag des Überfalls auf die Spielbank Bad H als Besucher registriert worden war. Zudem wurde von seinem Mobiltelefon zur Tatzeit des Überfalls auf die Spielbank H am 11.05.1996 in der Funkzelle des Tatortes telefoniert. Diese Person wurde daraufhin als Beschuldigter Nr.4 geführt. Es wurde festgestellt, dass der Beschuldigte Nr.4 zur Tatzeit viermal die gleiche Nummer gewählt hatte. Der Inhaber des angerufenen Anschlusses wurde daraufhin als Beschuldigter Nr.5 geführt. Insgesamt ergaben sich in der Funkzelle des Tatortes für den Zeitraum des Überfalls neun Verbindungen von drei Personen in wechselseitigen Konstellationen. Der Beschuldigte Nr.5 und die Anschlussinhaberin des dritten Anschlusses, im weiteren Verlauf des Verfahrens als Beschuldigte Nr.6 geführt, waren jedoch nicht als Besucher in den Spielbanken registriert worden. Jedoch ergab der Nachname der Beschuldigten Nr.6 einen Treffer. Der Ehemann, der im weiteren Verlauf des Verfahrens als Beschuldigter Nr.7 geführt wurde, war am 11.05.1996 eine Stunde vor der Tat als Gast registriert worden. Eine Recherche nach Straßennamen in den Besucherdatenbanken ergab, dass unter derselben Anschrift wie der Beschuldigte Nr.4 zwei weitere Personen gemeldet und Besucher der Spielbanken waren. Diese beiden Personen wurden als Beschuldigter Nr.8 und Nr.9 geführt.

Eine Gesamtauswertung der Besucherdaten ergab, dass die Beschuldigten Nr.4, Nr.5, Nr.7 und Nr.8 in verschiedenen Konstellationen und teilweise alleine in allen drei Spielbanken registriert worden waren. Dabei waren die Registrierungszeiten teilweise identisch.

\section{d. Auswirkungen auf das Ermittlungsverfahren}

Aufgrund der Erkenntnisse aus der Rasterfahndung wurden Maßnahmen nach den $\S \S 100 \mathrm{a}, \mathrm{b}$ StPO durchgeführt. Darüber hinaus wurden für die betreffenden Anschlüsse auch Verbindungsdaten erhoben. Die getroffenen Maßnahmen erhärteten den Verdacht gegen die Beschuldigten Nr.4 bis Nr.8, so dass diese am 13.07.1997 festgenommen werden konnten.

\section{Ausgang des Verfahrens}

Die Beschuldigten Nr.4 bis Nr.8 wurden angeklagt und verurteilt. Die ausgesprochenen Freiheitsstrafen bewegten sich zwischen zweieinhalb und zwölf Jahren. 
In der Anklage wurde die Rasterfahndung nicht ausdrücklich als Beweismittel aufgeführt. Allerdings wurden die Ergebnis- bzw. Trefferlisten des Datenabgleichs als Beweismittel aufgeführt. Für das Urteil waren in erster Linie die Einlassungen der Beschuldigten maßgebend.

\section{Erfolgseinschätzung}

Im vorliegenden Verfahren führte die Rasterfahndung in den Besucherdatenbanken der drei Spielbanken und den aufgrund der Funkzellenabfrage erlangten Daten zur Identifizierung der Täter. Aufgrund dieser Erkenntnisse durchgeführte Ermittlungsmaßnahmen führten schließlich zur Festnahme und letztlich zur Verurteilung der Beschuldigten. Insofern kann die Maßnahme als erfolgreich angesehen werden. Es wurden Erkenntnisse für weitere Ermittlungsansätze erlangt. So wurde die Maßnahme auch von der Staatsanwaltschaft als belastend angesehen. Diese hielt in einem Vermerk vom 28.08.1996 fest, dass sich der Tatverdacht gegen die Beschuldigten aufgrund der Rasterfahndung und der Aufenthaltsermittlung im Funknetz ergeben und verdichtet habe.

\section{Verfahren 011}

\section{Sachverhalt}

Gegenstand von Verfahren 011 war eine Serie von Raubüberfällen auf kleinere Geldinstitute im Raum um B. Insgesamt handelte es sich dabei um 17 Taten im Zeitraum vom 17.09.1993 bis zum 17.06.2005. Die Überfälle verteilten sich auf 10 Geldinstitute. Es wurde ein Gesamtbetrag von über 766.000 € erbeutet. Zur Vorbereitung der Taten wurden diverse Logistikstraftaten begangen. Dabei wurden mehrere Fluchtfahrzeuge entwendet.

\section{Die Rasterfahndung}

\section{a. Ermittlungsstand und Ausgangslage}

Die einzelnen Taten wurden zunächst gesondert bearbeitet. Nach der siebten Tat, in der Zeit vom September bis Oktober 1997, wurde eine Ermittlungsgruppe eingerichtet. Am 10.01.2005 wurde anhand einer anlassunabhängigen Strafanzeige ein neues Ermittlungsverfahren eingeleitet und die einzelnen Verfahren hinzu verbunden. Da mit einem erneuten Auftreten zu rechnen war, wurde am 15.02.2005 eine Ermittlungskommission eingerichtet. Diese erhielt die folgenden Aufträge:

- Auswertung und Systematisierung der erfolgten Banküberfälle

- Aufarbeitung aller bisher aus diesen Ermittlungsverfahren gewonnenen Erkenntnisse und Datensätze 
- Zusammenführung der Vorgänge zu einem Verfahren

- Abarbeitung der vorhandenen Spuren zur Beweissicherung

- Übernahme weiterer der Serie zuzuordnender Ermittlungsverfahren

Nachdem die Ermittlungskommission die Verfahren übernommen und einer erneuten Auswertung unterzogen hatte, lagen die folgenden Erkenntnisse vor:

- es konnten Übereinstimmungen bzgl. der Tatobjekte festgestellt werden

- es konnten Übereinstimmungen bzgl. des Modus Operandi festgestellt werden

- es konnten Übereinstimmungen bzgl. der Fluchtfahrzeuge festgestellt werden

- die Tatobjekte liegen in einem geografisch begrenzten Raum (von einem gedachten Mittelpunkt aus befinden sich alle Tatobjekte in einer Entfernung von maximal 20 Kilometern)

- diese Entfernungsangaben treffen auch auf den größten Teil der Logistikstraftaten zu

- die Zeitabstände zwischen den Taten differieren teilweise erheblich

Die Größenangaben zu den Tätern ließen den Schluss zu, dass bis 2004 mindestens drei verschiedene Personen in vermutlich wechselnder Beteiligung die Taten durchgeführt hatten. Mindestens seit der letzten Tat am 08.04.2005 trat zusätzlich ein weiterer deutlich kleinerer Täter auf. Somit war von einer Beteiligung von mindestens vier Personen auszugehen. Die Erkenntnisse zu den Entfernungen der Tatorte ergaben sich aus einem Geoprofil, welches durch das Landeskriminalamt Abteilung Operative Fallanalyse erstellt wurde.

\section{b. Begründung und Ziel}

Nach der Übernahme der Ermittlungen durch die Ermittlungskommission und vor den letzten beiden Banküberfällen wurde am 07.03.2005 eine Maßnahme nach den $\S \S 98 \mathrm{a}, \mathrm{b}$ StPO angeregt. Begründet wurde die Anregung damit, dass die Täter bislang keinerlei verwertbare Spuren hinterlassen hatten und es daher notwendig war, im umfangreichen Maße Daten zu erheben und maschinell abzugleichen, um die Täter ermitteln zu können. Aufgrund der gewonnenen Erkenntnisse sollte das bisher vorliegende Datenmaterial aus den Einzelfällen mit Personen abgeglichen werden, die:

- in der Vergangenheit in den Kreisgebieten H, M und O polizeilich in Erscheinung getreten waren und innerhalb der Jahrgänge 1950 bis 1975 geboren wurden 
- bei denen kriminalpolizeiliche personengebundene Hinweise auf Bewaffnung und/oder Gewalttätigkeit vorlagen

- Die in polizeilichen Dateien der Länder NRW und Niedersachsen mit dem Vor- oder Spitznamen X gespeichert waren

- Männliche Personen deutscher Staatsangehörigkeit der Geburtsjahrgänge 1950 bis 1975, die in sieben Städten und Gemeinden gemeldet waren (Orte ergeben sich aus dem Geoprofil)

- männliche Personen der Jahrgänge 1950 bis 1975, die in den genannten Wohnbereichen von den dafür zuständigen Stellen für die Eignung zum Grundwehrdienst gemustert wurden

- männliche Personen der genannten Jahrgänge, die im bundesweit agierenden Verein $\mathrm{X}$ registriert waren

- beim Kraftfahrtbundesamt bekannte, innerhalb des Wohnbereichs gemeldete Fahrzeughalter von Krafträdern der Marke $\mathrm{X}$ und von Pkws des Typs Y

- Kunden sind, die sich aus der Kundendatei des in den Fällen 14 und 15 geschädigten Motorradfachgeschäfts ergaben

- Kunden, die sich aus entsprechenden Kundendateien weiterer Fachhändler aus dem näheren Umkreis ergaben

Dem lagen die Annahmen zugrunde, dass es sich mit hoher Wahrscheinlichkeit um einschlägig vorbestrafte Täter handeln müsste, welche im näheren Umkreis um die Tatobjekte wohnhaft seien. Ein entsprechender Antrag wurde am 14.03.2005 durch die Staatsanwaltschaft B gestellt. Diese verwies dabei auf das erstellte Täterund Geoprofil des LKA. Die Maßnahme wurde am 14.03.2005 durch das Amtsgericht $\mathrm{B}$ angeordnet.

Am 16.03.2005 wurde eine Erweiterung und Änderung der Anordnung angeregt. Grund war, dass einer der verpflichteten Motorradhändler sein Geschäft mittlerweile aufgegeben hatte und unter Mitnahme seiner Kundendatei eine Anstellung bei einem weiteren Motorradhändler gefunden hatte. Verpflichtet wurde deshalb der neue Motorradhändler. Zusätzlich wurde angeregt, Führerscheindaten von männlichen Personen deutscher Staatsangehörigkeit der Geburtsjahrgänge 1950 bis 1975, welche in drei betreffenden Landkreisen einen Führerschein für Motorräder erworben hatten oder ein solcher entzogen wurde, zu erheben. Hierfür war die Benutzung von Motorrädern während der Tatserie maßgeblich. Diese Anregung ging von der Polizei direkt an das Amtsgericht und wurde von diesem am 16.03.2005 angeordnet.

Eine erneute Erweiterung der Anordnung wurde am 24.03.2005 angeregt. Es sollten bereits erhobene Funkzellendaten aus den Fällen 11, 13, 15 und 16 in den Datenabgleich mit einbezogen werden. Ferner sollten die erstellten Ringalarmlisten 
aus den Fällen 11, 12 und 13 ebenfalls einbezogen werden. Die Einbeziehung der Funkzellendaten war notwendig, da die Täter im Vorfeld der elften Tat einen Pkw entwendet und dessen Fahrer als Geisel genommen hatten. Die Geisel gab später an, dass die Täter während der Fahrt telefoniert hätten. Die Erweiterung der Anordnung wurde am 24.03.2005 beantragt und angeordnet.

Im Rahmen einer Tatortbegehung wurden die Beamten auf einen Wohnblock im Stadtgebiet S aufmerksam, dessen Einwohner ebenfalls in den Datenabgleich einbezogen werden sollten. Aufgrund des häufig in einem solchen Wohnblock anzutreffenden sozialen Gefüges war es aus kriminalpolizeilicher Sicht nicht auszuschließen, dass die Täter zu einem früheren Zeitpunkt unter dieser Anschrift gewohnt oder eine Garage angemietet hatten oder ggf. sogar noch haben und von daher die Ortskenntnisse stammen dürften. Aus diesem Grund sollten alle Personen erfasst werden, die seit 1986 ein Mietverhältnis mit der zu verpflichtenden Wohnungsgesellschaft eingegangen waren. Die Erweiterung wurde am 30.03.2005 beantragt und am 31.03.2005 angeordnet.

Nachdem am 08.04.2005 erneut ein der Serie zuzuordnender Banküberfall stattgefunden hatte, wurde noch am selben Tag eine Erweiterung der Maßnahme auf weitere Funkzellendaten angeregt. Begründet wurde dies mit der Annahme, dass die Täter mit hoher Wahrscheinlichkeit auch zu dieser Tat Absprachen über Mobiltelefone getätigt haben müssten. Die Erweiterung wurde am 12.04.2005 beantragt und beschlossen.

\section{c. Durchführung und Ergebnis}

Aus den betreffenden Quellen wurden ca. 225.000 Datensätze erhoben und in einer durch den Datenschutzbeauftragten genehmigten Datenbank zusammengeführt. Eine Zugriffsberechtigung auf die Datenbank hatten nur die Mitarbeiter der Ermittlungskommission. Da die Daten aufgrund verschiedener Formatierungen teilweise nicht kompatibel waren, musste sich die Auswertung auf die Kriterien Vor- und Nachname beschränken. Probleme ergaben sich bei Namensgleichheiten von tatsächlich verschiedenen Personen.

Auf der Grundlage der Recherche wurden aus den Daten insgesamt 818 Personendatensätze von im weitesten Sinne verdächtigen Personen herausgefiltert. Eine nähere Überprüfung bzgl. Mehrfachtreffern etc. ergab eine Reduzierung der Personenzahl auf 228 Personen. Zu diesen 228 Personen wurden Spurenakten angelegt. Im Abschlussbericht zur Rasterfahndung wurde ausdrücklich angeführt, dass die Einbeziehung der Ringalarmlisten und der Funkzellendaten keinen Treffer ergab, so dass die Täter nicht im Umkreis der Tatorte telefoniert hätten und nicht mit einem Kfz an den Kontrollpunkten vorbeifuhren. Dies würde im Umkehrschluss bedeuten, dass sich die Täter nicht außerhalb der Kontrollpunkte bewegten, sondern vielmehr innerhalb dieses Kreises geblieben waren. 
Von den 228 überprüften Personen waren 29 innerhalb des vom Geoprofil benannten Gebietes wohnhaft. Der größte Teil dieser Personen konnte nach Überprüfungen als unverdächtig ausgeschlossen werden. Eine der Personen hat jedoch stets im Zielgebiet des Geoprofils gelebt und war mehrfach einschlägig vorbestraft. Bei der aktuellen Adresse der Person handelte es sich um ein sehr unübersichtliches bebautes Anwesen mit mehreren Häusern, Schuppen und einem ehem. Bauernhaus. Diese Örtlichkeit lag, aufgrund der bekannten Fluchtrichtungen und den Ergebnissen des Geoprofils im Kerngebiet der Ermittlungen. Der Verlust des Sichtkontakts zu den Flüchtigen auf einer Verfolgungsfahrt sprach ebenfalls für dieses Objekt. Ergebnis des Datenabgleichs war somit die Identifizierung eines Tatverdächtigen, der im weiteren Verlauf der Ermittlungen als Beschuldigter geführt wurde.

\section{d. Auswirkungen auf das Ermittlungsverfahren}

Aufgrund der Identifizierung des Tatverdächtigen und dessen Wohnsitz wurde zur Erlangung von weiteren Erkenntnissen die längerfristige Observation gem. $§ 163 \mathrm{f}$ StPO angeordnet. Es wurde unter Mitwirkung eines Mobilen Einsatzkommandos ein Bewegungsbild des Tatverdächtigen erstellt. Darüber hinaus wurde eine Telefonüberwachung gem. der $\S \S 100 a, b$ StPO veranlasst. Die Rasterfahndung lieferte folglich einen Tatverdächtigen und Ansätze für weitere Ermittlungsmaßnahmen.

\section{Ausgang des Verfahrens}

Am 17.06.2005 kam es zum bislang letzten Raubüberfall auf ein Geldinstitut, welcher der Serie zugeordnet werden konnte. Aufgrund der Observation des Tatverdächtigen konnte dessen direkte Beteiligung als handelnder Täter an der Tat ausgeschlossen werden. Inwieweit der Tatverdächtige an früheren Taten beteiligt war, konnte nicht ermittelt werden. Das Verfahren wurde am 15.07.2005 gem. § 170 II StPO eingestellt. Im Abschlussvermerk wurde festgehalten, dass mit einem weiteren Auftreten der Täter zu rechnen sei. Dem unregelmäßigen Auftreten der Täter sei es geschuldet, dass durchgehende Maßnahmen der Polizei nicht möglich sind. Mithin dürften aktuelle Erkenntnisse zu den Tätern erst nach neuen Straftaten erlangt werden.

\section{Erfolgseinschätzung}

Laut Begründung der Maßnahme durch die Ermittlungskommission und die Staatsanwaltschaft gab es vor der Rasterfahndung keine Hinweise auf mögliche Tatverdächtige. Die Rasterfahndung lieferte demnach den einzigen Tatverdächtigen. Insofern kann die Rasterfahndung durchaus als erfolgreich angesehen werden. Sie ermöglichte weitere Ermittlungsmaßnahmen gegen den Tatverdächtigen, welche jedoch dazu führten, dass dieser als Täter der letzten Tat ausgeschlossen werden konnte. Zusammenfassend erbrachte die Rasterfahndung demnach einen Be- 
schuldigten und neue Ermittlungsansätze und kann somit isoliert betrachtet als erfolgreich bezeichnet werden. Zur Aufklärung der Serie konnte sie jedoch nicht beitragen. Es bleibt abzuwarten, ob es zu einer erneuten Tat kommt und die Ermittlungen bzgl. des Beschuldigten wieder aufgenommen werden.

\section{Verfahren 012}

\section{Sachverhalt}

Im Rahmen der Auswertung von Verfahren 012 konnte nicht in die gesamten Verfahrensakten Einsicht genommen werden. Dies war dem Umstand geschuldet, dass der Täter noch nicht ermittelt und das Verfahren nicht eingestellt war. Es wurde durch die Staatsanwaltschaft F lediglich der Sonderband Rasterfahndung zur Einsichtnahme überlassen. Daraus ließen sich alle Informationen die Rasterfahndung und den Sachverhalt betreffend erheben.

Am 26.03.1998 wurde ein 13-jähriger Junge tot aufgefunden. Der Täter hat das Opfer nach vorangegangener massiver stumpfer Gewalteinwirkung gegen den Kopf bis zur Bewusstlosigkeit gewürgt und mit einem Halsschnitt getötet. Anschließend trennte der Täter Körperteile des Opfers ab und nahm diese mit.

\section{Die Rasterfahndung}

\section{a. Ermittlungsstand und Ausgangslage}

Für die Ermittlungen wurde eine Sonderkommission eingesetzt. Aufgrund der Tatortsituation und der durchgeführten Ermittlungen lag der Verdacht nahe, dass der Täter die abgetrennten bzw. entnommenen Körperteile mit dem vom Opfer mitgeführten und zuvor unweit des Leichenfundortes entleerten Rucksack abtransportiert hatte. Unter den ausgeleerten Gegenständen befand sich unter anderem ein Schulbuch, an dessen rückwärtigen Einband ein mit Blut gelegter Fingerabdruck gesichert werden konnte.

Der Rucksack selbst wurde ein Jahr später am 25.03.1999, durch einen Hinweis aus der Bevölkerung, in einem ca. $35 \mathrm{~km}$ entfernten Waldstück aufgefunden. Trotz wiederholter Überprüfung der gesicherten Fingerspur sowohl im bundesweiten AFIS-Datenbestand als auch in vergleichbaren Fingerabdruck-Erfassungs- und Auswertungssystemen von 72 weiteren Ländern konnte bislang kein Treffer erzielt werden. Auch die Überprüfung und der Fingerabdruckvergleich einschlägig polizeilich in Erscheinung getretener Straftäter und psychisch auffällig gewordener Personen führten nicht zur Ergreifung des Täters.

Zusätzlich wurde durch das BKA Abteilung Operative Fallanalyse ein Täterprofil erstellt. Danach war der männliche Täter im engeren Umkreis um den Tatort zu 
suchen. Vor diesem Hintergrund und in Anlehnung an das Täterprofil wurde beschlossen, eine verdachtsunabhängige Reihenuntersuchung von Vergleichsfingerabdrücken durchzuführen. Es sollten Vergleichsfingerabdrücke von allen in sechs genau bezeichneten Stadtteilen in F gemeldeten männlichen Personen im Alter von 15 bis 45 genommen werden.

\section{b. Begründung und Ziel}

Grundlage für die Erhebung der Einwohnermeldedaten und den anschließenden Abgleich mit polizeiinternen Datenbeständen bildete eine Maßnahme nach den $\S \S 98 \mathrm{a}, \mathrm{b}$ StPO. Ziel der Rasterfahndung war eine 100\%-ige Erfassung der Zielgruppe. Die Erfassung der Personengruppe durch eine Rasterfahndung und die anschließende Vergleichsuntersuchung waren laut polizeilicher Anregung vom 24.08.2001, zur Weiterführung des Ermittlungsverfahrens zwingend erforderlich, da die Ermittlung des unbekannten Täters auf andere Weise wesentlich erschwert wäre. Die personenbezogenen Daten sollten Name, Vorname, Geburtsort, Geburtstag, Geschlecht und Wohnsitz beinhalten. Zur systematischen Erfassung der eigentlichen Zielgruppe sei es darüber hinaus notwendig den erhobenen Datenbestand mit dem Datenbestand von POLAS zu vergleichen, um bereits erkennungsdienstlich behandelte Personen ausschließen zu können.

Die Staatsanwaltschaft F stellte den Antrag auf Anordnung der Maßnahme am 27.08.2001. Hierbei verwies sie auch auf die polizeiliche Anregung. In ihrer Begründung führte sie darüber hinaus an, dass sich Anhaltspunkte dafür ergeben haben, dass der Täter aus dem Bereich der genannten Stadtteile stammen und seinen Wohnsitz auch dort haben könnte. Ohne die Maßnahme seien die Erforschung des Sachverhalts und die Ermittlung des Täters und seines Aufenthaltsortes auf andere Weise erheblich weniger Erfolg versprechend, aussichtslos oder wesentlich erschwert. Letztlich sei der Datenabgleich geeignet, weitere Ermittlungsgrundlagen zur Überprüfung des betreffenden Personenkreises zu erbringen. Im Antrag wurde jedoch nicht aufgeführt, mit welchen Dateien die Daten des Einwohnermeldeamtes abgeglichen werden sollten. Laut polizeilicher Anregung sollten die erlangten Daten mit dem POLAS-Datenbestand abgeglichen werden. Der staatsanwaltschaftliche Antrag spricht nur von einem maschinellen Abgleich mit anderen Daten.

Der von der Staatsanwaltschaft gefertigte Entwurf der Anordnung wurde durch das Amtsgericht F ohne Änderungen oder Ergänzungen am 27.08.2001 erlassen. Zusammenfassend lässt sich, die 100\%-ige Erfassung aller männlichen Personen im Alter von 15 bis 45 der sechs Stadtteile als Grundlage für die geplante Reihenuntersuchung von Vergleichsfingerabdrücken als Ziel festhalten.

\section{c. Durchführung und Ergebnis}

Wann der Datenabgleich durchgeführt wurde, war den Unterlagen nicht zu entnehmen. Ende August 2001 war die Soko jedoch schon im Besitz der personenbe- 
zogenen Daten der KIV, wie aus einem Vermerk ersichtlich war. Der Gesamtdatenbestand umfasste 19.731 Personen. Diese wurden unterteilt in die Gruppen ,aktuell gemeldet“" und ,verzogen“. Die Zielgruppe umfasste danach 14.442 noch aktuelle gemeldete und 5.289 verzogene Personen.

Zunächst wurde für den Stadtteil A ein Probelauf durchgeführt. Hierzu wurde der Datenbestand von 5.053 in A gemeldeten Personen in einem Zeitaufwand von drei Monaten manuell mit den Datenbeständen von HEPOLIS, INPOL und der für das Verfahren errichteten Datenbank abgeglichen. Dabei ergab sich ein Restbestand von 4.204 Personen. Als Fazit dieser Vorabüberprüfung wurde festgehalten, dass ein auf die übrigen fünf Stadtteile ausgeweiteter manueller Datenabgleich aufgrund des erheblichen Personal- und Zeitaufwandes nicht im Verhältnis zum gewünschten Erfolg stehen würde und eine zeitnahe Durchführung der angedachten Maßnahme unrealistisch erscheinen ließe.

Letzte Informationen über den Stand des Datenabgleichs und der darauf aufbauenden Reihenuntersuchung ließen sich einem polizeilichen Vermerk vom 03.03.2003 entnehmen. Auffällig waren dabei die erheblichen Schwankungen der Zahlen im Vergleich zu den bisherigen Informationen. So wurden für den Stadtteil A 2.166 Personen (ohne verzogene Personen) als Datengrundlage herangezogen. Die Anzahl der verzogenen Personen betrug 258 Personen. Diese wurden durch die Behörden vor Ort abgearbeitet. Von den 2.166 Personen waren 1.687 bereits erkennungsdienstlich behandelt worden. 222 wurden auf andere Weise abgearbeitet. Die übrigen 257 Personen waren noch in Bearbeitung der Soko. Es handelte sich dabei unter anderem um Personen, die eine Abgabe von Vergleichsfingerabdrücken verweigert hatten. Für den Stadtteil B betrug die Ausgangszahl 2.465 gemeldete und 154 verzogene Personen. Von den 2.465 Personen wurden 2.058 bereits erkennungsdienstlich behandelt. 213 Personen wurden auf anderem Wege aus den Ermittlungen ausgeschlossen. Demnach verblieb eine Anzahl von 194 offenen Spuren.

Bei den beiden Stadtteilen A und B handelt es sich um die Stadtteile, welche dem Tatort am nächsten lagen, weshalb die Ermittlungen zunächst hierauf konzentriert wurden.

\section{d. Auswirkungen auf das Ermittlungsverfahren}

Die Maßnahme nach den $\S \S 98 \mathrm{a}, \mathrm{b}$ StPO war in diesem Verfahren nicht isoliert zu sehen. Vielmehr lieferte sie die Grundlage für die Reihenuntersuchung von Vergleichsfingerabdrücken. In Verbindung mit dieser bildete die Rasterfahndung den einzigen verbleibenden Ermittlungsansatz. Aus dem Vermerk vom 03.03.2003 ließ sich entnehmen, dass die Soko noch 865 offene Spuren abzuarbeiten hatte. Diese 865 offenen Spuren setzten sich aus den noch abzuarbeitenden Spuren aus den Stadtteilen A und B und den aus diesen Stadtteilen verzogenen Personen zusammen. 


\section{Ausgang des Verfahrens}

Die Ermittlungen waren zur Zeit der Einsichtnahme in die Verfahrensakten noch nicht abgeschlossen. Laut dem Vermerk vom 03.03.2003 waren unter den 865 offenen Spuren einige interessante Spuren, die weiterer intensiver Ermittlungen bedurften. Darüber hinaus gäbe es bundesweit einige Verfahren, die teilweise markante Übereinstimmungen im Modus Operandi aufweisen würden. Eines dieser Verfahren würde erst am Anfang stehen, so dass weitergehende Ermittlungen eine Vielzahl brisanter Spuren liefern könnten. Daher wurde die Erweiterung der Reihenuntersuchung von Vergleichsfingerabdrücken auf die übrigen vier Stadtteile als nicht angebracht eingestuft. Insgesamt wurden im Verfahren 012 bisher 21 Personen als Beschuldigte geführt. Mittlerweile wurde jedoch gegen alle 21 Beschuldigten gem. $§ 170$ II StPO verfahren.

\section{Erfolgseinschätzung}

Das Ziel, eine Grundlage für die Reihenuntersuchung zu schaffen, wurde durch die Maßnahme nach $\S \S 98 \mathrm{a}, \mathrm{b}$ StPO erreicht. Nur durch die Datenerhebung bei der KIV war es möglich, die Zielgruppe für die geplante Reihenuntersuchung zu erfassen. Darüber hinaus ermöglichte der Abgleich mit polizeiinternen Daten sowohl die Reduzierung des Personenkreises als auch die Priorisierung von bestimmten Personen. Demnach kann die Maßnahme, gemessen an ihrem Ziel, als erfolgreich beurteilt werden. Inwieweit die Maßnahme, gemessen am polizeilichen Ziel der Aufklärung der Straftat, als erfolgreich beurteilt werden kann, bleibt aufgrund der zur Zeit noch andauernden Ermittlungen und der großen Anzahl von Spuren, die noch abgearbeitet werden müssen, abzuwarten.

\section{Verfahren 013}

\section{Sachverhalt}

Gegenstand von Verfahren 013 waren Ermittlungen gegen eine Bande, die Betäubungsmittel in die BRD eingeführt und vertrieben hat. Die Betäubungsmittel wurden auf dem Luftweg von Thailand nach F gebracht. Mit den eingeführten Betäubungsmitteln wurden Prostituierte aus dem Milieu von F gefügig gemacht. Darüber hinaus wurden die Prostituierten dazu angehalten, die Betäubungsmittel an ihre Kundschaft weiter zu veräußern. Insgesamt waren 27 einzelne Fälle des Handels und der Einfuhr von Betäubungsmitteln Gegenstand der Ermittlungen.

\section{Die Rasterfahndung Nr.1}

\section{a. Ermittlungsstand und Ausgangslage}

Die Ermittlungen wurden seit dem 01.10.1998 durch die Kriminalpolizei F geführt. Auslöser für das Verfahren waren Erkenntnisse aus Telefonüberwachungen 
in einem anderen Verfahren. Aus diesen resultierten Erkenntnisse für Observationsmaßnahmen. Im Rahmen der Observationen konnte eine Geldübergabe am Flughafen in F beobachtet werden. Getätigte Durchsuchungen bei Beschuldigten führten zum Auffinden von mehreren hundert Tabletten. Im Verlauf des Verfahrens konnten über 6.500 Tabletten mit Amphetaminen sichergestellt werden. Aus Hinweisen und Beschuldigtenvernehmungen wurde bekannt, dass es sich bei den Betäubungsmittelkurieren um thailändische Flugbegleiter einer deutschen und einer thailändischen Fluggesellschaft handeln sollte.

\section{b. Begründung und Ziel der ersten Rasterfahndung}

Aus diesem Grund wurde am 16.03.1999 eine Maßnahme nach den $\S \S 98 \mathrm{a}, \mathrm{b}$ StPO angeregt. Ziel war es, in den Datenbeständen der beiden Fluggesellschaften zu recherchieren. Es sollte in Erfahrung gebracht werden, ob die Fluggesellschaften thailändische Angestellte hatten, welche auf Flügen zwischen Deutschland und Thailand eingesetzt worden sind. Darüber hinaus sollten Informationen darüber erlangt werden, ob die betreffenden Personen einen Zweitwohnsitz in Deutschland hatten. Da es sich dabei um einen maschinellen Datenabgleich handelte, wurde eine richterliche Anordnung angeregt. Einen entsprechenden Antrag stellte die Staatsanwaltschaft F am 17.03.1999. Der Antrag enthielt jedoch nur den Datenabgleich innerhalb der Datenbestände der deutschen Fluglinie. Der Abgleich innerhalb der Datenbestände der thailändischen Fluglinie wurde ohne Begründung zurückgestellt. Eine entsprechende Anordnung des Amtsgerichts F erging am 18.03.1999. Als Katalogstraftaten des $§ 98$ a I StPO wurden Straftaten auf dem Gebiet des Betäubungsmittelgesetzes, gewerbsmäßig begangene Straftaten und in anderer Weise organisierte Straftaten aufgeführt.

\section{c. Durchführung und Ergebnis der ersten Rasterfahndung}

Eine Liste mit zwei Treffern wurde der ermittelnden Polizeidienststelle im Mai 1999 zugesandt. Es standen jedoch noch Daten bzgl. eines weiteren Fluges aus. Diese sollten zu einem späteren Zeitpunkt übermittelt werden. Allerdings widerrief die Fluggesellschaft ihre Bereitschaft die Daten des betreffenden Flugs zu übermitteln, da die betreffenden Daten nach ihrer Ansicht nicht von der Anordnung umfasst gewesen seien. Hiervon wurde die Staatsanwaltschaft aufgrund organisatorischer Unzulänglichkeiten im Bereich der ermittelnden Polizeidienststelle erst am 13.09.1999 in Kenntnis gesetzt.

\section{Die Rasterfahndung Nr.2}

a. Begründung und Ziel der zweiten Rasterfahndung

Aufgrund dessen wurde durch die Staatsanwaltschaft F am 27.09.1999 erneut eine Maßnahme nach den $\S \S 98 \mathrm{a}, \mathrm{b}$ StPO beantragt. Inhaltlich umfasste diese Maß- 
nahme lediglich die Daten eines genau bezeichneten Fluges der deutschen Fluggesellschaft. Eine entsprechende Anordnung erging am 28.09.1999.

b. Durchführung und Ergebnis der zweiten Rasterfahndung

Die Ergebnisse des zweiten Datenabgleichs wurden der ermittelnden Polizeidienststelle am 06.10.1999 übermittelt. Danach war für den betreffenden Flug kein thailändischer Flugbegleiter eingesetzt worden.

c. Auswirkungen beider Maßnahmen auf das Ermittlungsverfahren

Ermittlungen zu den beiden im Rahmen des ersten Datenabgleichs bekannt gewordenen Personen verliefen negativ. Beide Personen besaßen die thailändische Staatsbürgerschaft und hatten einen zweiten Wohnsitz in Deutschland. Es gab jedoch keine Hinweise darauf, dass die beiden Personen in irgendeinem Zusammenhang mit den Personen und Vorgängen des Ermittlungsverfahrens standen. Der zweite Datenabgleich hatte keine Treffer zur Folge und brachte damit keine weiteren Ermittlungsansätze.

\section{Ausgang des Verfahrens}

Insgesamt wurde in diesem Verfahren gegen 65 Personen ermittelt. Davon wurden 56 Personen im Verlauf des Verfahrens als Beschuldigte geführt. Von diesen 56 Personen wurden lediglich neun Beschuldigte angeklagt und verurteilt. Gegen die restlichen Beschuldigten wurde das Verfahren eingestellt, weil kein hinreichender Tatverdacht bestand oder die Beschuldigten abgetrennt und in gesonderten Verfahren verfolgt wurden. Das Strafmaß für die neun Beschuldigten bewegte sich zwischen einer Geldstrafe und dreieinhalb Jahren Freiheitsstrafe. Als Beweismittel dienten in erster Linie die im Rahmen von Durchsuchungen sichergestellten Beweismittel (6.500 Tabletten BtM), die Protokolle der Telefonüberwachungen und die Einlassungen der Beschuldigten. Die Verurteilungen erfolgten aufgrund von $\S 29$ I Nr.1, III Nr.1 BtmG, § 29a I Nr.1 BtmG, § 95 I Nr.4 AMG und § 98 AMG.

\section{Erfolgseinschätzung}

Im vorliegenden Verfahren handelte es sich bei der Maßnahme nach den $\S \S 98 \mathrm{a}, \mathrm{b}$ StPO mehr um ein Auskunftsersuchen als um eine klassische Rasterfahndung, bei welcher mehrere Datenbestände miteinander abgeglichen werden. Es wurde nach Personen mit bestimmten Merkmalen in einem Datenbestand gesucht. Die richterliche Anordnung wurde erwirkt, da der Abgleich maschinell erfolgen sollte. Auf das Ermittlungsverfahren hatte die Maßnahme keine Auswirkungen. Fraglich ist, warum eine Recherche in den Datenbeständen der thailändischen 
Fluggesellschaft zurückgestellt wurde. Die Wahrscheinlichkeit, dass durch diese thailändische Flugbegleiter eingesetzt worden sind, wäre deutlich höher gewesen. Hierdurch hätten weitere Ermittlungsansätze erlangt werden können. Insgesamt lässt sich festhalten, dass die Maßnahme nach den $\S \S 98 \mathrm{a}, \mathrm{b}$ StPO im vorliegenden Verfahren eine lediglich untergeordnete Rolle gespielt hat. Dies wurde auch durch die Verzögerung der Weiterleitung von Ergebnissen an die Staatsanwaltschaft deutlich.

\section{Verfahren 014}

\section{Sachverhalt}

Im Zeitraum von Dezember 1999 bis zum Juni 2002 kam es in L zu zwei vollendeten und zwei versuchten Vergewaltigungen. Am 13.12.1999 wurde am Rande einer Kirmesveranstaltung ein 13 Jahre altes Mädchen vergewaltigt. Weiterhin kam es am 23.09.2000 zur Vergewaltigung eines 16 Jahre alten Mädchens. Darüber hinaus kam es am 22.06.2002 zu zwei versuchten Vergewaltigungen.

\section{Die Rasterfahndung}

\section{a. Ermittlungsstand und Ausgangslage}

Die im Rahmen der ersten Tat sichergestellten DNA-Spuren wurden in die DNA-Analyse-Datei eingestellt. Dieses Vorgehen führte zu einem Treffer mit den Spuren aus der zweiten Tat. Aufgrund der festgestellten Übereinstimmungen konnte somit von einem Täter ausgegangen werden. Ähnlichkeiten im Modus Operandi ließen die Annahme zu, dass der Täter auch für die beiden versuchten Vergewaltigungen verantwortlich war. Da sich die erste Tat am Rande einer Kirmesveranstaltung ereignet hatte, wurde nach möglichen Tätern zunächst im Schaustellerumfeld gefahndet. Im Rahmen der Ermittlungen wurden von diversen Personen Speichelproben genommen und mit negativem Ergebnis abgeglichen. Auch im Rahmen der Ermittlungen zur zweiten Tat wurden mehrfach Speichelproben genommen, welche jedoch nicht zur Ergreifung des Täters führten. Aufgrund von Zeugenaussagen wurden darüber hinaus Maßnahmen nach den $\S \S 100 \mathrm{~g}$, h StPO getroffen, die ebenfalls ergebnislos verliefen.

Da zunächst alle Ermittlungen erfolglos verliefen, wurde im September 2002 die Abteilung Operative Fallanalyse (OFA) des zuständigen Landeskriminalamtes um eine vergleichende Fallanalyse der betreffenden Verfahren ersucht. Am 05.11.2002 wurde das Ergebnis der Fallanalyse vorgestellt. Danach waren die Taten aus verhaltensanalytischer Sicht mit hoher Wahrscheinlichkeit einem Täter zuzuordnen. Neben dem Motiv hatten sich in allen Fällen eingeschränkte Fähigkeiten des Täters herausgestellt. Es sollte sich um einen Täter mit niedriger Intelligenz handeln, der wahrscheinlich bei seinen Eltern, in einem Wohnheim oder in betreutem Wohnen 
leben würde. Sexuelle Erfahrungen dürfte er ausschließlich oder überwiegend aus Medien bezogen haben. Ferner sei der Täter ohne qualifizierten Beruf und würde in Laufdistanz zu den Tatorten wohnen oder arbeiten. Es ließen sich folgende Ermittlungsansätze zusammenfassen:

- Aufgrund der Opferangaben konnte das Alter des Täters auf 20 bis 40 Jahre geschätzt werden

- Er dürfte ledig sein

- in welchen Institutionen in L sind minderbegabte/psychisch Kranke untergebracht

- in welchen Häusern sind Sozialhilfeempfänger der Stadt L und der angrenzenden Stadt D untergebracht

- Der Täter dürfte sich vermehrt in Videotheken und Sexkinos/ Erotikshops aufhalten

Für die weiteren Ermittlungen wurde eine Ermittlungskommission eingesetzt.

\section{b. Begründung und Ziel}

Auf der Grundlage der Erkenntnisse aus der Fallanalyse wurde am 11.11.2002 eine Maßnahme nach den $\S \S 98 \mathrm{a}$, b StPO angeregt. Begründet wurde die Maßnahme mit den Übereinstimmungen der einzelnen Taten und den Erkenntnissen aus der Fallanalyse. Ein entsprechender Antrag der Staatsanwaltschaft D wurde am 13.11.2002 an das Amtsgericht D gerichtet. Als Begründung wurde der Text des $\S 98 \mathrm{a}$ I StPO verwandt. Mithin sollten Nichtverdächtige ausgeschlossen und Personen festgestellt werden, die weitere für die Ermittlungen bedeutsame Prüfungsmerkmale erfüllen. Darüber hinaus sei die Erforschung des Sachverhalts oder die Ermittlung des Aufenthaltsortes des Täters auf andere Weise erheblich weniger Erfolg versprechend oder wesentlich erschwert. Inhaltlich sollte der Abgleich die Datenbestände der Stadt D, der Stadt L, die Daten von drei Einrichtungen, in welchen psychisch kranke Personen untergebracht waren, und die Kundendaten von vier Videotheken und Sexkinos umfassen. Eingegrenzt wurde die Erhebung durch die Altersangabe von 20 bis 40 Jahren und den Familienstand ledig. Die Maßnahme wurde am 14.11.2002 durch das Amtsgericht D ohne Änderungen oder Ergänzungen angeordnet.

Bereits am 15.11.2002 wurde eine Erweiterung der Anordnung auf den Datenbestand des Arbeitsamtes der Stadt L angeregt. Begründet wurde dies damit, dass in Erfahrung gebracht wurde, dass das Arbeitsamt persönliche Daten von Arbeitslosen vorrätig hält und automatisiert verwaltet. Da laut Täterprofil die Wahrscheinlichkeit groß war, dass der Täter zeitweilig arbeitslos oder in Arbeitsbeschaffungsoder Schulungsmaßnahmen des Arbeitsamtes untergebracht war, sollten die vor- 
handenen Daten in die Rasterfahndung integriert werden. Die betreffende Erweiterung wurde am 18.11.2002 beantragt und am 19.11.2002 angeordnet.

Am 21.11.2002 wurde eine erneute Erweiterung der Anordnung angeregt. Im Rahmen der Datenerhebung wurde festgestellt, dass weitere Suchkriterien erhoben werden müssten, um die mehrere tausend Personen umfassende Treffermenge weiter zu verkleinern. Aus den Angaben der Opfer waren Größenangaben bekannt. Dieses Merkmal war recherchefähig, da es im Ausweisregister erfasst war. Um eine Erfolg versprechende Durchführung zu gewährleisten, sollten aus dem Ausweisregister Nationalität, Geburtsort und die Größenangabe erhoben werden. Die Erweiterung wurde am 21.11.2002 durch die Staatsanwaltschaft beantragt und am 22.11.2002 angeordnet. Da in der richterlichen Anordnung das Merkmal Nationalität nicht enthalten war, wurde am 25.11.2002 eine Ergänzung beantragt und auch angeordnet.

Letztlich wurde am 11.12.2002 eine zusätzliche Erweiterung angeregt. Danach sollten die Datenbestände mit polizeiinternen Datenbeständen abgeglichen werden, um den Personenkreis weiter eingrenzen zu können. Diese Erweiterung wurde am 12.12.2002 beantragt und angeordnet. Insgesamt setzt sich die Maßnahme damit aus fünf richterlichen Anordnungen zusammen. Inhaltlich lässt sie sich jedoch als eine Maßnahme ansehen. Als Ziele der Maßnahme wurden in den Anträgen und den Beschlüssen lediglich die im Gesetz verwendeten Formulierungen angeführt.

\section{c. Durchführung und Ergebnis}

Für den ersten Abgleich der Daten der Einwohnermeldeämter der Stadt L und D, der Videotheken und der Einrichtungen, in welchen psychisch Kranke untergebracht waren oder betreut wurden, dienten die folgenden Vorgaben:

- männliche Person

- Wohnanschrift in L

- Geburtsdatum zwischen 01.01.1967 und 31.12.1982

- Körpergröße $170 \mathrm{~cm}$ bis $182 \mathrm{~cm}$

Dieser Abgleich ergab einen Personenkreis von 3.925 Personen. Um diesen Personenkreis weiter eingrenzen zu können, wurden folgende Merkmale in den Abgleich mit einbezogen:

- Kriminalaktennachweis in D

- Ausleiher von pornografischen Videofilmen

- Arbeitsloser 
- Bezieher von Sozialleistungen

- psychiatrisch untergebrachte oder betreute Person

Nachdem doppelte Datensätze ausgeschlossen wurden, blieb eine Treffermenge von 808 Personen übrig. Um eine weitere Eingrenzung zu ermöglichen, wurde den einzelnen Prüfungsmerkmalen eine Wertigkeit zugeordnet. Dabei wurde folgende Rangfolge festgelegt:

- Personen in psychiatrischer Unterbringung/Betreuung

- Kunden der Videotheken

- Personen mit Kriminalaktennachweis in D

- Leistungsbezieher (Arbeitsamt/Sozialamt in L und D)

Den Prüfungsmerkmalen wurden Punkte gemäß ihrer Wertigkeit zugeordnet, um eine Rangfolge der Personen festlegen zu können. Mithilfe weiterer Auswertungen konnte der Personenbestand auf 715 Personen reduziert werden. Diese 715 Personen wurden entsprechend der erfüllten Merkmale und deren Wertigkeit in eine Prioritätenliste eingeordnet. Das Ergebnis der Rasterfahndung lag laut einem polizeilichen Vermerk am 09.12.2002 vor. Bemerkenswert erscheint hier, dass der Abgleich mit polizeiinternen Datenbeständen jedoch erst am 12.12.2002 angeordnet wurde. Folglich wurde die richterliche Anordnung erst nach Durchführung des Abgleichs eingeholt.

\section{d. Auswirkungen auf das Ermittlungsverfahren}

Von den 715 Personen waren 36 Personen bereits verzogen. Diese wurden von auswärtigen Dienststellen überprüft und gegebenenfalls zur Abgabe einer Speichelprobe aufgefordert. Die übrigen 679 Personen wurden entsprechend ihrer Rangfolge auf der Prioritätenliste zur Abgabe einer Speichelprobe aufgefordert.

Zusätzlich wurden alle in den Akten aufgeführten männlichen Personen, die ebenfalls dem Täterprofil entsprachen, aufgelistet und durch weitere Personen ergänzt, auf die Hinweise aus den laufenden Ermittlungen eingingen. Bei diesen weiteren 168 Personen sollten ebenfalls Speichelproben entnommen werden. Da sich der Täter jedoch unter den 715 Personen befand und freiwillig eine Speichelprobe abgab, konnte auf die weiteren Speichelproben verzichtet werden.

\section{Ausgang des Verfahrens}

Nachdem die Speichelprobe des mutmaßlichen Täters mit den sichergestellten DNA-Spuren eindeutige Übereinstimmungen aufwies, wurde die betreffende Person festgenommen. In der ersten Vernehmung ließ sich der Beschuldigte zu den Vorwürfen ein und gestand die beiden Vergewaltigungen. Die beiden versuchten Vergewaltigungen stritt er jedoch ab. Lichtbildvorlagen bei den Opfern der ver- 
suchten Vergewaltigungen ließen den Schluss zu, dass der Beschuldigte als Täter dieser beiden Taten nicht in Betracht kam. Der Beschuldigte wurde angeklagt und am 08.09.2003 zu sieben Jahren und sechs Monaten Freiheitsstrafe verurteilt.

\section{Erfolgseinschätzung}

Im vorliegenden Verfahren 014 wurde der Täter aufgrund einer DNAReihenuntersuchung identifiziert. Grundlage für die Reihenuntersuchung waren die Ergebnisse der Rasterfahndung. Anhand der Rasterfahndung war es möglich den Personenkreis für die Reihenuntersuchung einzugrenzen. Insofern ermöglichte die Rasterfahndung eine effiziente Durchführung der Reihenuntersuchung. Aufgrund welcher der verwendeten Merkmale der Täter herausgerastert wurde, ließ sich den Verfahrensakten nicht entnehmen. Er hatte zwar Einträge im KAN-Datenbestand, diese beinhalteten mit Diebstahl und unerlaubter Einfuhr von Betäubungsmitteln jedoch keine einschlägigen Straftaten. Es kann festgehalten werden, dass die Rasterfahndung in diesem Verfahren erfolgreich war und die Grundlage für die Identifizierung des Täters bildete.

\section{Verfahren 015}

\section{Sachverhalt}

Aufgrund noch andauernder Ermittlungen konnte in Verfahren 015 keine Akteneinsicht genommen werden. Es wurde durch die ermittelnde Staatsanwaltschaft N eine Kopie der Anregung, des Antrags und der Anordnung der Rasterfahndung zur Auswertung übersandt. Darüber hinaus wurde ein Kurzfragebogen, der die für die Auswertung wichtigsten Fragen enthielt, durch die Staatsanwaltschaft ausgefüllt.

Gegenstand von Verfahren 015 waren sieben Tötungsdelikte. Im Zeitraum vom 09.09.2000 bis einschließlich 15.06.2005 wurden in den Städten N, M, R und H insgesamt sieben männliche Gewerbetreibende, davon sechs türkische und ein griechischer Staatsangehöriger, durch unbekannte Täter ermordet. Der bzw. die Täter haben in allen Fällen die gleiche Tatwaffe benutzt. In zwei Fällen wurde eine zusätzliche Pistole verwandt. Ein Tatmotiv war nicht ersichtlich. Auch waren bisher keinerlei Verbindungen aller sieben Fälle untereinander feststellbar. Die beiden letzten Fälle fanden am 09.06.2005 in N und am 15.06.2005 in M statt.

\section{Die Rasterfahndung}

a. Ermittlungsstand und Ausgangslage

Informationen zum Stand der Ermittlungen waren nur der Anregung und dem Antrag der Rasterfahndung zu entnehmen. Im Rahmen der Ermittlungen wurde bekannt, dass sich bei der vorletzten Tat in N am 09.06.2005 zwei Täter mit Fahrrädern im Nahbereich des Tatortes aufgehalten haben sollen. Anschließend sollen 
diese Personen die Fahrräder auf einem frei zugänglichen Parkplatz in einen dunklen Van mit ausländischem Kennzeichen eingeladen haben.

b. Begründung und Ziel

Die Rasterfahndung wurde am 29.07.2005 angeregt und am 25.08.2005 durch die Staatsanwaltschaft N beantragt. Der Antrag der Staatsanwaltschaft wurde durch das Amtsgericht $\mathrm{N}$ lediglich unterschrieben. Datum der Anordnung war der 30.08.2005. Der Maßnahme lag die Annahme zugrunde, dass die unbekannten Täter mit einem Pkw zu den jeweiligen Tatorten anreisten und Deutschland anschließend wieder verließen. Zu diesem Zweck hätten sie allein für Benzin Bargeld benötigt oder hätten entsprechende Tankrechnungen mittels Kreditkarte bezahlt. Um nun den bei den Taten vom 09.06.2005 und 15.06.2005 übereinstimmenden Gebrauch von Zahlungs- oder Kreditkarten festzustellen, seien die Bankauskünfte und deren maschineller Abgleich erforderlich.

Ziel war es, sämtliche Kreditkartentransaktionen, die im Zeitraum 08.06.2005 0.00 Uhr bis 10.06.2005 24.00 Uhr und 14.06.2005 0.00 Uhr bis 16.06.2005 24.00 Uhr an Geldausgabeautomaten oder sonstigen Terminals in den Postleitzahlenbezirken $\mathrm{X}, \mathrm{Y}, \mathrm{Z}$ etc. angefallen waren, zu erheben. Insgesamt sind zwölf Postleitzahlenbezirke von der Erhebung erfasst. Die Anordnung betrifft 45 Geldinstitute.

\section{c. Durchführung und Ergebnis}

Die Anordnung enthielt im Anhang ein vorgefertigtes Formblatt der ermittelnden Polizeidienststelle mit Informationen über die Art des geplanten Abgleichs, eine genaue Bezeichnung der benötigten Daten und deren Format. Informationen darüber, welche Geld- und Kreditinstitute der Anordnung nachgekommen sind und von welchen die Datenanlieferung noch aussteht, waren nicht zu erlangen. Darüber hinaus lagen keine Informationen darüber vor, ob und mit welchem Ergebnis der Datenabgleich durchgeführt worden ist.

\section{d. Auswirkungen auf das Ermittlungsverfahren}

Da keine Informationen über Durchführung und Ergebnis der Maßnahme zum Zeitpunkt der Auswertung vorgelegen haben, können keine Angaben zur Auswirkung der Maßnahme auf die Ermittlungen gemacht werden.

\section{Ausgang des Verfahrens}

Nach der Aufnahme des Verfahrens in die Auswertung kam es Mitte des Jahres 2006 zu zwei weiteren Tötungsdelikten. Dabei verwandten der oder die Täter wiederum die gleiche Tatwaffe. Weitere Informationen über den Stand der Ermittlungen lagen nicht vor. 


\section{Erfolgseinschätzung}

Da die Maßnahme vermutlich nicht abgeschlossen ist und sich der Datenabgleich noch in der Durchführung befindet, können keine Angaben zum Erfolg der Maßnahme gemacht werden. Es ist jedoch festzuhalten, dass eine vermutlich sehr große Anzahl von Daten in den Abgleich einbezogen wird und die Konvertierung der Daten auf ein einheitliches Format, mit erheblichen Schwierigkeiten verbunden sein dürfte. Dies könnte auch den langen für den Abgleich benötigten Zeitraum erklären.

\section{Verfahren 016}

\section{Sachverhalt}

Gegenstand von Verfahren 016 waren Ermittlungen zur Aufklärung eines versuchten Tötungsdelikts in D. Am 03.03.2000 griff ein unbekannter Mann zwei Polizeibeamte mit einem Messer an. Diese befanden sich in ihrer Freizeit auf dem Weg von einer Karnevalsfeier nach Hause. Sie wurden dabei so schwer verletzt, dass ihnen nur durch sofort durchgeführte Notoperationen das Leben gerettet werden konnte. Dem Angriff war ein kurzer Wortwechsel mit dem Täter vorausgegangen, innerhalb dessen sich die beiden als Polizeibeamte zu erkennen gaben. Der Täter flüchtete zu Fuß. Er wurde bei der Tatausführung von einem Pkw-Fahrer gesehen, der den Opfern zu Hilfe eilte.

\section{Die Rasterfahndung}

\section{a. Ermittlungsstand und Ausgangslage}

Die Ermittlungen wurden von der Mordkommission der Polizei in D geführt. Es wurde eine große Anzahl von Personen als Zeugen vernommen. Am Tatort konnten mehrere DNA-Spuren gesichert werden, die nicht den Geschädigten zuzuordnen waren. Auch an der Kleidung der Geschädigten konnten fremde DNA-Spuren gesichert werden. Diese stimmten mit den Spuren vom Tatort überein. Durch die Verteilung von Handzetteln wurde die Öffentlichkeit dazu aufgerufen, verdächtige Beobachtungen und Hinweise der Polizei mitzuteilen. Ermittelte verdächtige Personen wurden alibimäßig überprüft und mit den Angaben zum Aussehen der Person, welche die Geschädigten gemacht hatten, verglichen. Ein Tatverdächtiger konnte nicht ermittelte werden.

Nach der Abarbeitung der konkreten Hinweise auf mögliche Tatverdächtige wurde mit der Durchführung einer DNA-Reihenuntersuchung begonnen. Grundlage für die Reihenuntersuchung und den hierzu heranzuziehenden Personenkreis bildeten folgende Überlegungen: 
„Am Donnerstag 2. März 2000 wurde in D Weiberfastnacht gefeiert. Die Feierlichkeiten fanden überwiegend in der Altstadt statt. Die Feierlichkeiten beginnen traditionell um 11.11 Uhr und ziehen sich dann bis in die darauf folgende Nacht hin. Gegen 00.30 Uhr waren schon viele der seit etlichen Stunden feiernden Menschen wieder zu Hause oder auf dem Weg dorthin. Wegen des vorangegangenen Alkoholkonsums waren viele Menschen ohne Pkw unterwegs. Für den Heimweg nutzten sie somit, wenn längere Wege zu überwinden waren, öffentliche Verkehrsmittel wie Straßenbahnen, Bus oder Taxi. Fußgänger, die zur Tatzeit in Stadtteilen unterwegs waren, die nicht zu den Zentren der Weiberfastnacht zählten, befanden sich überwiegend auf dem Fußweg nach Hause, also in der Regel schon in der Nähe ihres Wohnsitzes. Diese Vermutung galt auch für den unbekannten Täter. Unter Berücksichtigung der Haltestellen von Bussen und Bahnen im Umkreis um den Tatort wurde unter Verfolgung dieser Überlegung ein Bezirk abgesteckt, in dem jemand wohnen dürfte, der nach Nutzung öffentlicher Verkehrsmittel das letzte Stück des Heimwegs zurücklegte und dabei am Tatort vorbeigekommen sein müsste. “468

In Anlehnung an die Personenbeschreibung sollten nunmehr männliche Personen der Geburtsjahrgänge 1955 bis 1975 überprüft werden, die im zuvor festgelegten Wohnbezirk amtlich gemeldet waren. Zur Vorbereitung der Reihenuntersuchung wurde das Einwohnermeldeamt D am 5.4.2000 ersucht, die betreffenden Daten zu übermitteln. Diesem Ersuchen kam das EMA nach und übermittelte 4.202 Datensätze in digitaler Form. Wegen der unerwartet hohen Anzahl der vorzuladenden Personen für eine DNA-Reihenuntersuchung wurde das LKA im Vorfeld der Maßnahme kontaktiert. Der aufgezeigte Zeitrahmen für die anstehenden Untersuchungen erwies sich als zu hoch, Gleiches galt auch für alternative kriminalpolizeiliche Überprüfungen (Vergleich mit Personenbeschreibungen, Alibi). Aufgrund dessen sollten die Datensätze nach Prioritäten gestaffelt werden, wobei folgende Überlegungen zugrunde gelegt wurden:

„Das Tatgeschehen zeugte von großer Aggressivität und nicht unerheblicher krimineller Energie. Der Täter führte ein Messer bei sich, das er, ohne zu zögern, und zwar auf eine Art und Weise benutzte, die zwanglos den Schluss zuließ, dass er nicht nur stechen, sondern töten wollte. Diese Tatbegehung lässt die Vermutung aufkommen, dass der Täter nicht zum ersten Mal gegen andere gewalttätig geworden ist. Er könnte also zu dem Personenkreis gehören, der bereits in der Vergangenheit kriminalpolizeilich in Erscheinung getreten ist und für den entsprechende kriminalpolizeiliche Unterlagen geführt werden. Diese Annahme wird noch untermauert durch verbale Äußerungen des Täters bei der Tat. “469

${ }^{468}$ Dieses Zitat entstammt einem Ermittlungsvermerk der ermittelnden Mordkommission.

${ }^{469}$ Dieses Zitat entstammt dem gleichen Ermittlungsvermerk. 
Daher sollten von den 4.204 relevanten Personen zuerst diejenigen mit der höchsten Priorität versehen werden, die bereits kriminalpolizeilich in Erscheinung getreten waren. Als einzige adäquate Möglichkeit bot sich hier ein automatisierter Datenabgleich zwischen dem angelieferten Datenbestand und dem Datenbestand des Kriminalaktennachweises (KAN) an. Für die Priorität I der Abarbeitung ergab sich so ein Datenbestand in Höhe von 523 Datensätzen, der sich aufgrund der Streichungen von Mehrfachnennungen auf 503 Datensätze reduzierte.

\section{b. Begründung und Ziel}

Nach einer erneuten Prüfung der Sach- und Rechtslage sowie einer Erörterung mit der Staatsanwaltschaft bestanden hinsichtlich der ursprünglichen Einschätzung, dass es sich bei dem Datenabgleich lediglich um die Schaffung einer Prioritätenliste zur Abarbeitung handeln würde, nunmehr Bedenken. Vielmehr hätte eine richterliche Entscheidung gem. $\S \S 98 \mathrm{a}$, b StPO eingeholt werden müssen. Um die weiteren Maßnahmen (Weiterverwertbarkeit der erhobenen Daten, weitere freiwillige Abgabe von Speichelproben und deren Auswertung etc.) mit einer entsprechenden Rechtssicherheit zu versehen, wurde daher am 06.06.2000 eine entsprechende Maßnahme bei der Staatsanwaltschaft D angeregt.

Die Staatsanwaltschaft D stellte am 07.06.2000 einen Antrag beim Amtsgericht D. In der Begründung der Maßnahme verwies sie auf die polizeiliche Anregung. Als Ziel wurde die Schaffung einer Prioritätenliste für die DNA-Reihenuntersuchung angeführt. Das Amtsgericht D ordnete die Maßnahme ohne Änderungen oder Ergänzungen am 09.06.2000 an. Am 19.06.2000 wurde die Anordnung durch das Amtsgericht D berichtigt, da eine der in der Anordnung aufgeführten Straßen falsch geschrieben worden war.

\section{c. Durchführung und Ergebnis}

Die Daten des Einwohnermeldeamtes lagen bereits am 06.04.2000 vor. Wie bereits dargestellt wurde der angelieferte Datenbestand des EMA durch den Abgleich mit dem KAN-Bestand von 4.204 Personen auf 503 Personen der ersten Priorität reduziert. Der Datenabgleich wurde durch den Zentralen Polizeitechnischen Dienst des betreffenden Bundeslandes durchgeführt.

\section{d. Auswirkungen auf das Ermittlungsverfahren}

Die 503 Personen der ersten Priorität wurden schriftlich zur Abgabe einer freiwilligen Speichelprobe eingeladen. Insofern stellt das Ergebnis der Rasterfahndung den Ansatzpunkt für die DNA-Reihenuntersuchung dar. 


\section{Ausgang des Verfahrens}

Insgesamt erschienen 381 der 503 Personen zu den vorgegebenen Terminen. Bei elf Personen, deren Erscheinungsbild deutlich abwich, wurde auf eine Speichelprobe verzichtet. Fünf Personen weigerten sich, machten aber Angaben zur Alibiüberprüfung. 116 Personen erschienen überhaupt nicht $\mathrm{zu}$ den Terminen im Mai und Juni 2000. Die Personen, die zur DNA-Reihenuntersuchung erschienen waren und freiwillig eine Speichelprobe abgegeben haben, wurden mit Schreiben vom 7.9.2000 über das Ergebnis, die Löschung ihrer Daten und die Vernichtung des Speichelmaterials, die am 5.9.2000 erfolgte, in Kenntnis gesetzt.

Die Personen, welche nicht $\mathrm{zu}$ den Terminen erschienen waren, wurden $\mathrm{zu}$ Hause aufgesucht und um die Abgabe einer Speichelprobe gebeten. Hierzu zählte auch der spätere Beschuldigte. Dieser gab nach Aufforderung durch Polizeibeamte eine Speichelprobe ab. Das Ergebnis war identisch mit den am Tatort aufgefunden DNA-Spuren. Der Beschuldigte wurde am 05.07.2000 festgenommen. Er ließ sich zunächst nicht zur Sache ein. Im Rahmen von Vernehmungen weiterer Zeugen aus dem Umfeld des Beschuldigten konnte der Tatverdacht erhärtet werden. Der Beschuldigte hatte sich gegenüber diesen Zeugen selbst der Tat bezichtigt. Den vernehmenden Beamten gegenüber ließ er sich daraufhin teilweise ein, machte dabei jedoch Erinnerungslücken geltend. Der Beschuldigte wurde angeklagt und wegen versuchten Mordes in zwei Fällen zu achten Jahren und sechs Monaten Freiheitsstrafe verurteilt.

\section{Erfolgseinschätzung}

In diesem Verfahren führte die DNA-Reihenuntersuchung zur Überführung des Täters. Um diese effizienter zu gestalten, wurde im Vorfeld eine Rasterfahndung durchgeführt, um den Personenkreis einzuschränken. Diese Priorisierung war erfolgreich, da sich der Täter unter den 503 herausgerasterten Personen befand. Durch den Abgleich der angelieferten Einwohnermeldedaten mit dem KANBestand konnte die Reihenuntersuchung somit deutlich effizienter gestaltet werden. Mithin kann die Rasterfahndung als erfolgreich bewertet werden. Sie hatte eine erhebliche Zeit- und Kostenersparnis zur Folge. Ferner waren die getroffenen Überlegungen im Vorfeld der Reihenuntersuchung, welche in den Datenabgleich mündeten, durchweg zutreffend. Einzig der Zeitpunkt für die Einholung der richterlichen Entscheidung nach der Durchführung des Datenabgleichs stellt sich als fragwürdig dar. Darüber hinaus hätten schon die Einwohnermeldedaten nur aufgrund einer richterlichen Anordnung nach den $\S \S 98 \mathrm{a}, \mathrm{b}$ StPO aussortiert und übermittelt werden dürfen. 


\section{Verfahren 017}

\section{Sachverhalt}

Grund für die Ermittlungen im Verfahren 017 war eine Serie von bewaffneten Banküberfällen im gesamten Bundesgebiet. Die erste der Serie zuzurechnende Tat wurde am 22.12.1988 begangen. Zu Beginn der Ermittlungen in diesem Verfahren waren bereits 28 Taten zu zählen. Während der Ermittlungen kamen noch drei weitere Taten hinzu. Im Rahmen der 31 Taten erbeuteten die Täter insgesamt ca. acht Millionen DM. Darüber hinaus wurde den unbekannten Tätern ein versuchtes Tötungsdelikt an einem Polizeibeamten zugerechnet.

\section{Die Rasterfahndung}

a. Ermittlungsstand und Ausgangslage

Die Ermittlungen zu den einzelnen Überfällen wurden zunächst durch die zuständigen Staatsanwaltschaften und Polizeidienststellen geführt. Am 15.11.2000 bat die Staatsanwaltschaft B das LKA um Übernahme der gesamten Ermittlungen. Die Zusage erging am 04.12.2000. Das LKA gründete für die Ermittlungen eine Ermittlungskommission. Im Rahmen einer Gesamtschau der Taten zu Ermittlungsbeginn wurden folgende Übereinstimmungen festgestellt:

- Modus Operandi

- Die Täter betreten zu zweit oder zu dritt die Geldinstitute; teilweise mit Geländemotorrädern

- immer wird der Haupttresor angegangen

- Täter sind schwer bewaffnet

- in fast allen Fällen wurden die Raumüberwachungsanlagen angegangen

- an den aufgefunden Fluchtfahrzeugen wurden intensive Spurenvernichtungsmaßnahmen betrieben.

- Täterbeschreibungen

- Täter Nr.1 über 190cm groß, Bodybuildertyp, in fast allen Fällen dabei

- Täter Nr.2 ca. 180 - 185cm groß, kräftig

- Täter Nr.3 wird durchgängig kleiner beschrieben (seit Fall Nr. 16 agieren nur noch zwei Täter) 
- Maskierung

- $\quad$ in einem Zeitraum von 6 Jahren wurden in 6 Fällen die gleichen Masken getragen

- korrespondierende Tatorte von Vor- und Haupttaten

- Fluchtfahrzeuge und verwendete Kennzeichen werden an den gleichen Orten entwendet, an denen später die Tat ausgeführt wird

Von Beginn der Ermittlungen an wurden zwei Tathypothesen erstellt und verfolgt. Die erste Tathypothese befasste sich mit Parallelen zwischen der Serie und einer bereits aufgeklärten Bankraubserie Anfang der 90er Jahre. Die zweite Tathypothese beschäftigte sich mit der Frage danach, welche kriminellen Personengruppen am ehesten in der Lage seien, den praktizierten logistischen Aufwand zu betreiben. Es wurde die Täterschaft sesshaft gewordener Landfahrer in Betracht gezogen. Erste Ermittlungen konzentrierten sich insbesondere auf Täter-TatortBeziehungen. Beide Hypothesen wurden zunächst büromäßig verfolgt, ergaben jedoch keine konkreten Hinweise. Noch während der Überlegungen, welche der beiden Hypothesen zu favorisieren sei, kam es zu Hinweisen auf eine Gruppe von Landfahrern. Insbesondere ergaben sich Hinweise auf eine Person, die im weiteren Verlauf des Verfahrens als Beschuldigter Nr.1 geführt wurde. Aus diesem Grund wurde die zweite Hypothese priorisiert. Auffällig waren die erheblichen finanziellen Mittel der Gruppe um den Beschuldigten Nr.1. Es wurden diverse strafprozessuale Maßnahmen, darunter auch Telefonüberwachungen, veranlasst.

\section{b. Begründung und Ziel}

Am 12.03.2002 wurde eine Maßnahme nach den $\S \S 98 \mathrm{a}, \mathrm{b}$ StPO durch das LKA angeregt. Diese richtete sich ausdrücklich gegen den Beschuldigten Nr.1 und weitere unbekannte Täter.

Im Rahmen der Ermittlungen waren bereits Datenmengen geschaffen bzw. erhoben worden und sollten noch erhoben werden. Ziel war es, diese zusammenzuführen und nach bestimmten Prüfungsmerkmalen miteinander abzugleichen. Bei den Daten handelte es sich im Einzelnen um:

- die Datenbank der Ermittlungskommission

- es handelt sich um die Arbeitsdatei der Ermittlungskommission; sie enthält alle Daten, die im Rahmen der polizeilichen Ermittlungsarbeit festgestellt worden sind (z.B. aus TÜ, Verbindungsdaten, Personendaten, Objektdaten etc.)

- Daten aus den Funkzellenabfragen gem. § 12 FAG in Fall 28 und Fall 29

- Daten aus den Ringalarmlisten der Fälle 22, 25-30 
- Daten des Kraftfahrtbundesamtes (KBA)

- Vom KBA wurden am 18.11.2001 aus 20 Zulassungsbereichen bestimmte Halterdaten angefragt. Es wurden daraufhin alle Halter von Enduromaschienen eines bestimmten Herstellers mitgeteilt.

- Diese Daten sollten anschließend nach vorgegebenen Kriterien, insbesondere nach Geschlecht und Größe, mit Einwohnermeldedaten bestimmter Gemeinden abgeglichen werden. Hintergrund war die Annahme, dass der große Täter die Enduromaschine auch privat nutzen und in einer der Gemeinden wohnen würde.

- KBA-Daten der Halter, der im Rahmen der Ringalarmfahdung erfassten Kennzeichen

- Ziel hierbei war die Feststellung von sog. Doppeltreffern, d.h. ob ein Fahrzeug bzw. Halter an mehreren Tatorten in den Ringalarmlisten erfasst wurde.

- Daten aus der L-Gruppen-Recherche

- hierbei handelte es sich um ca. 2.000 Personen mit einer Körpergröße zwischen $190 \mathrm{~cm}$ und $200 \mathrm{~cm}$, deren Daten bei den Einwohnermeldeämtern erhoben worden sind.

- Daten aus dem INPOL-Datenbestand zu Krad-Entwendungen im betreffenden Bundesland, da davon ausgegangen werden konnte, dass das für die Tat benutzte Kraftrad entwendet worden war.

- Daten der Zentralen Polizeilichen Dienste (ZPD)

- Diese teilten der EK auf Anfrage die Teilnehmerdaten zu den im Rahmen der Funkzellenbeschlüsse erhobenen Verbindungsdaten mit.

- Die betreffenden Personendaten sollten mit den übrigen Personendaten auf Doppeltreffer abgeglichen werden.

- Alle Personendaten, die im Rahmen der Ermittlungen einer Sonderkommission, welche zwischen 1990 und 1995 die Ermittlungen führte, erhoben worden sind.

- KBA-Daten von Haltern eines bestimmten Fahrzeugtyps, welches bei einigen Überfällen benutzt worden ist.

- Daten die im Rahmen von Ermittlungen in einer anderen Bankraubserie, welche Übereinstimmungen aufweist, erhoben worden sind

- Alle Daten, die in einem Ermittlungsverfahren der Staatsanwaltschaft $\mathrm{K}$ gegen den Beschuldigten erhoben worden sind. 
Einen Antrag mit entsprechendem Inhalt stellte die Staatsanwaltschaft B am 15.03.2002 beim zuständigen Amtsgericht. In ihrer Begründung führt sie dabei aus, dass bei dem letzten der Serie zuzurechnenden Banküberfall mit hoher Wahrscheinlichkeit eine Enduromaschine eines bestimmten Typs benutzt wurde. Dieses Fluchtfahrzeug wurde auch bei vorhergehenden Überfällen benutzt. Die Täter fuhren mit der Enduromaschine direkt in die Bankfilialen hinein. Bis zum Zeitpunkt der Antragstellung konnte das Fahrzeug nicht aufgefunden werden. Ferner sei für die gesamte Serie signifikant, dass der Täter, welcher die Enduromaschine benutzte, als auffällig groß beschrieben und auch fotografiert wurde. Ziel des Datenabgleichs sei es, Nichtverdächtige auszuschließen oder Personen festzustellen, die weitere für die Ermittlungen relevante Prüfungsmerkmale erfüllen. Darüber hinaus sei die Erforschung des Sachverhalts auf andere Weise nicht aussichtsreich und wesentlich erschwert. Letztlich würde es sich bei den Tätern um eine Bande handeln, die sich durch die fortgesetzte Begehung von Banküberfällen eine fortlaufende Einnahmequelle von einiger Dauer und einigem Umfang verschafft habe und weiterhin verschaffen wolle.

Die Maßnahme wurde am 22.03.2002 durch das Amtsgericht B angeordnet. Hierzu wurde die Ausfertigung der Staatsanwaltschaft lediglich unterschrieben.

\section{c. Durchführung und Ergebnis}

Aus den Dateien sollten identische Namen, Kennzeichen und Telefonnummern herausgefiltert werden, die in zwei oder mehr Dateien gespeichert waren. Hierzu mussten die Namen, Kennzeichen und Telefonnummern, die in unterschiedlichster Art und Weise in den Originaldateien erfasst worden waren, in eine einheitliche Form gebracht werden.

Laut einem polizeilichen Vermerk vom 18.04.2002 musste die Durchführung des Datenabgleichs aufgrund aufwendiger technischer Vorarbeiten mehrfach verschoben werden. So war es unter anderem notwendig, im Rahmen des automatisierten Kennzeichenabfrage- und Auskunftsdienstes des KBA ca. 4.000 Kennzeichen aus Ringalarmlisten manuell mit den entsprechenden Halterdaten zu versehen. Ferner kam es zu erheblichen technischen Schwierigkeiten im Vorfeld des Datenabgleichs. Die an das KBA gesandten Daten mussten aufgrund unterschiedlicher nicht kompatibler Software an eine private Softwarefirma weitergeleitet werden, bevor sie durch die ermittelnde Polizeibehörde verwandt werden konnten. Da es bei der privaten Softwarefirma ebenfalls zu technischen Problemen kam, infolge derer die Daten vernichtet wurden, mussten die Daten des KBA erneut angefordert werden. Dieser Vorgang hatte eine erneute Verzögerung von 3 Wochen zur Folge.

Erst am 10.06.2002 lagen alle Datensätze in recherchefähiger Form vor. Insgesamt handelte es sich dabei um 35.000 personenbezogene Datensätze. Am 11.06.2002 wurde mit dem Abgleich begonnen und die Treffer aufgelistet. Der 
Abgleich erbrachte 431 Treffer aufgrund gleicher Familien und Vornamen. Die Treffer wurden bewertet und in drei Prioritäten geordnet. Dabei konnten 132 Treffer durch Recherchen in den Ursprungsdateien sofort erledigt werden, da keine Personenidentität vorlag. Sieben weitere Treffer wurden im Rahmen von Büroermittlungen mit negativem Ergebnis abgearbeitet. Die verbleibenden Treffer erhielten eine Spurennummer und wurden separat betrachtet. Es handelte sich um 183 Spuren der ersten und zweiten sowie 116 Spuren der dritten Priorität. Davon wurden die Spuren der dritten Priorität aufgrund schlechter Datenqualität zunächst zurückgestellt.

Unter Zuhilfenahme einer neuen Software wurden die Datensätze erneut abgeglichen. Diese Software ermöglichte es im Rahmen einer Schnittpunktsuche, Entitätsentsprechungen zu finden. Dabei handelt es sich um eine Art phonetische Abfrage. Es wurden Entitäten gefunden, die „fast identisch“ geschrieben wurden. Mit dieser Funktion wurden 169 ,fast identische“ Entitäten gefunden, welche von der Ermittlungskommission protokolliert und bewertet wurden.

\section{d. Auswirkungen auf das Ermittlungsverfahren}

Die Überprüfung der Spuren aus der Rasterfahndung wurde Ende Juli 2002 vorläufig gestoppt. Die letzte Spurenbearbeitung aus der Rasterfahndung erfolgte bereits am 09.07.2002. Von insgesamt 433 Spuren waren bis zu diesem Zeitpunkt 199 mit negativem Ergebnis erledigt worden. 234 Spuren waren noch offen. Grund für die in Absprachen mit der Staatsanwaltschaft getroffene Entscheidung, die Überprüfung abzubrechen, war eine neue Leitspur. Diese resultierte jedoch nicht aus den Erkenntnissen der Rasterfahndung.

\section{Ausgang des Verfahrens}

Während die Daten der Rasterfahndung ausgewertet und die erlangten Spuren abgearbeitet wurden, führte eine beim Beschuldigten Nr.1 geschaltete Telefonüberwachung zu dessen Entlastung. Er konnte während einer weiteren Tat nachweislich nicht am Tatort gewesen sein. Aus diesem Grund wurden die Ermittlungen gegen den Beschuldigten Nr.1 eingestellt.

Daraufhin wurde der zweiten Tathypothese der Vorrang eingeräumt. Es gab auffällige Übereinstimmungen zu einer Serie von Banküberfällen Anfang der 90er Jahre in den neuen Bundesländern. Bei dieser Serie wurden die Fluchtfahrzeuge ebenfalls im Raum B beschafft. Die Täter konnten damals jedoch ermittelt werden und verbüßten ihre Haftstrafen teilweise zur Zeit der ersten Taten dieser Serie. Insofern schieden sie als Tatverdächtige aus.

Die signifikanten Parallelen der beiden Serien führten dazu, dass im Rahmen der Ermittlungen zur aufgeklärten Serie sichergestellte Kennzeichendubletten mit sol- 
chen aus dem versuchten Tötungsdelikt verglichen wurden. Kriminaltechnische Gutachten kamen zu dem Schluss, dass die Kennzeichendubletten identische Fälschungsmerkmale aufwiesen. Aufgrund dieser Feststellung wurden zeitgleich zur Rasterfahndung die Ermittlungen im Umfeld der Täter aus der aufgeklärten Serie intensiviert. Diese brachten Erkenntnisse über eine 1997 bereits verstorbene Person. Diese hatte zusammen mit einem der Täter der ersten Serie eine Haftstrafe verbüßt. Die verstorbene Person hatte während der Haft ihrerseits intensive Kontakte zu zwei weiteren Personen. Dies wurde aus dem Hinweis einer Vertrauensperson bekannt. Dieser Hinweis war es auch, der zur vorläufigen Einstellung der Überprüfung der Spuren aus der Rasterfahndung führte. Die weiteren Ermittlungen richteten sich nun gegen die beiden Personen, welche im weiteren Verlauf des Verfahrens als Beschuldigte Nr.2 und Nr.3 geführt wurden. Aufgrund der Telefonüberwachungen und der Maßnahmen nach $\S 100 \mathrm{c}$ StPO konnte der Aufenthaltsort der Beschuldigten ermittelt werden. Weitere verdeckte Ermittlungsmaßnahmen führten zu der Erkenntnis, dass sich die Beschuldigten Nr.2 und Nr.3 in der Planungsphase für einen weiteren Banküberfall befanden. Deshalb kam es zum Zugriff. Im Rahmen von Durchsuchungen bei den Beschuldigten Nr.2 und Nr.3 wurden diverse Kennzeichendubletten und Siegel zu deren Fertigung, Tatfahrzeuge, Waffen, Waffenzubehör, Munition, Handgranaten, Sprengstoff, Gesichtsmasken und Tatbekleidung aufgefunden. Aufgrund von DNA-Untersuchungen konnte zudem die Täterschaft im Rahmen des versuchten Tötungsdeliktes nachgewiesen werden.

Die aufgefundenen Beweismittel und die Ergebnisse der DNA-Untersuchung führten schließlich zur Anklage. Erst am 13. Verhandlungstag, nachdem 88 Zeugen und Sachverständige angehört wurden, legten die beiden ein Geständnis ab. Neben zehn angeklagten Taten gestanden Nr.2 13 und Nr.3 14 weitere Taten. Aussagen über den dritten Beteiligten machten sie jedoch nicht. Beide wurden zu jeweils 15 Jahren Freiheitsstrafe verurteilt.

\section{Erfolgseinschätzung}

Im vorliegenden Verfahren bildete die Rasterfahndung sicherlich einen geeigneten Ansatzpunkt, um die im Rahmen der Ermittlungen über mehrere Jahre gesammelten Daten sinnvoll zu nutzen. Es ist jedoch auch deutlich geworden, welche technischen Schwierigkeiten bei einem so umfangreichen Abgleich so unterschiedlicher Datensätze auftreten können. Leider waren den Verfahrensakten keine Informationen darüber zu entnehmen, ob die Beschuldigten Nr.2 und Nr.3 in der Treffermenge der Rasterfahndung enthalten waren. Auch Informationen über das weitere Vorgehen mit den Datensätzen waren nicht zu erlangen. Aussagen über den Erfolg der Maßnahme können vor dem Hintergrund dessen, dass lediglich die Hälfte der Treffer überprüft wurden, nicht gemacht werden. Auffällig ist hier lediglich der hohe personelle und technische Aufwand im Vorfeld der Maßnahme. Die tech- 
nischen Schwierigkeiten hatten zur Folge, dass zwischen richterlicher Anordnung und eigentlichem Datenabgleich fast drei Monate vergingen.

\section{Verfahren 018}

\section{Sachverhalt}

Gegenstand von Verfahren 018 waren Ermittlungen zur Aufklärung eines versuchten Tötungsdeliktes in M. Am 06.04.2001 befand sich das Opfer nach einem Gaststättenbesuch auf dem Heimweg. Vor seinem Wohnanwesen begegnete ihm eine unbekannte Person. Nachdem diese an ihm vorübergegangen war, verspürte er plötzlich einen Schlag von hinten auf seine linke Schulter. Der Täter flüchtete darauf in unbekannte Richtung. Kurz darauf bemerkte das Opfer, dass es stark blutete. Im Krankenhaus wurde festgestellt, dass das Opfer eine $2 \mathrm{~cm}$ breite und 7-8 $\mathrm{cm}$ tiefe Stichverletzung davongetragen hatte.

\section{Die Rasterfahndung}

\section{a. Ermittlungsstand und Ausgangslage}

Am 07.04.2001 wurde ein Ermittlungsverfahren eingeleitet. Die Ermittlungen wurden durch die Mordkommission der Polizei in M geführt. Ermittlungen im Umfeld des Opfers ergaben keine Hinweise auf mögliche Tatverdächtige. Eine Plakataktion und diverse Presseveröffentlichungen brachten nur wenige Hinweise, deren Überprüfungen zudem ausnahmslos negativ verliefen. Im Tatortbereich wurden zivile Streifen durchgeführt. Im Rahmen derer sollte es möglich sein, alle angetroffenen Personen zu befragen und ggf. auch zu überprüfen. Dabei haben sich weder verwertbare Erkenntnisse ergeben, noch sind verdächtige Personen angetroffen bzw. überprüft worden.

\section{b. Begründung und Ziel}

Bereits am 19.04.2001 wurde durch die Mordkommission eine Maßnahme nach den $\S \S 98 \mathrm{a}, \mathrm{b}$ StPO bei der zuständigen Staatsanwaltschaft in M angeregt. Begründet wurde die Maßnahme mit den bisher erfolglos verlaufenen Ermittlungen. Es sei kein Motiv für die Tat erkennbar. Der Tat sei weder eine Auseinandersetzung mit dem Opfer vorausgegangen, noch wurde versucht, den Geschädigten zu berauben. Vielmehr habe der Täter überraschend, heimtückisch und brutal agiert.

Aufgrund dessen sei davon auszugehen, dass der Täter bereits einschlägig in Erscheinung getreten sei. Zudem sei zu vermuten, dass der Täter seinen Wohnsitz in der Nähe des Tatortes habe. Daher sei der Abgleich der folgenden Daten notwendig: 
- männliche Personen im Alter von 20 bis 40 Jahren,

- die im Regional-, Landes- oder Bundes KAN-Bestand als Täter oder Tatverdächtige eingetragen sind,

- mit Wohnsitz in M in bestimmten Stadtbezirken und dort in 39 betreffenden Straßen bzw. Straßenabschnitten.

Ein entsprechender Antrag wurde am 20.04.2001 durch die Staatsanwaltschaft beim Amtsgericht $\mathrm{M}$ gestellt und durch dieses am 24.04.2001 angeordnet. Mit der Anordnung wurde das Kreisverwaltungsreferat der Stadt M zur Übermittlung der Einwohnermeldedaten verpflichtet. Am 27.04.2001 wurde durch die ermittelnde Polizeidienststelle eine Erweiterung des Beschlusses angeregt. Bei der ersten Anregung wurde versehentlich eine Straße übersehen. Diese befindet sich im betreffenden Bereich und sei daher mit einzubeziehen. Darüber hinaus hätte eine Zeugenvernehmung Hinweise auf einen möglicherweise jüngeren Täter ergeben, weshalb die Altersuntergrenze von 20 auf 18 Jahre herabzusetzen war. Auf diesbezüglichen Antrag der Staatsanwaltschaft vom 03.05.2001 wurde die Erweiterung des ersten Beschlusses am 09.05.2001 angeordnet. Durch die Maßnahme nach den $\S \S 98 \mathrm{a}$, b StPO sollten Personen herausgerastert werden, die einschlägig in Erscheinung getreten und im Tatortbereich wohnhaft waren. Mit welchen Delikten im Rahmen der KAN-Bestände abgeglichen werden sollte, war den Verfahrensakten nicht zu entnehmen.

\section{c. Durchführung und Ergebnis}

Der Beschluss des Amtsgerichts $M$ wurde zur Umsetzung an das zuständige Landeskriminalamt weitergeleitet. Dieses leitete den Beschluss an das Einwohnermeldeamt weiter. Die vom Einwohnermeldeamt übermittelten Daten für die im Beschluss aufgeführten Straßen und Straßenabschnitte wurde dann im LKA mit dem KAN-Datenbestand abgeglichen. Wann der ermittelnden Polizeidienststelle die Ergebnisse des Datenabgleichs durch das LKA mitgeteilt wurden, war nicht ersichtlich. Darüber hinaus waren den Verfahrensakten keine Angaben über die Anzahl der herausgerasterten Personen zu entnehmen.

\section{d. Auswirkungen auf das Ermittlungsverfahren}

Die als Treffermenge herausgerasterten Personen wurden überprüft und teilweise als Zeugen vernommen. Die Überprüfungen verliefen durchweg negativ. Zeitlich liefen die Überprüfungen bis August 2001. Informationen über die Rückgabe der Datenträger und die Löschung der Daten waren nicht verfügbar.

\section{Ausgang des Verfahrens}

Im Anschluss an die Rasterfahndung und die damit verbundenen Zeugenvernehmungen wurde das Verfahren am 29.04.2005 gem. § 170 II StPO eingestellt. Die Einstellung wurde mit fehlenden Ermittlungsansätzen begründet. 


\section{Erfolgseinschätzung}

Auffällig an der dem Verfahren zugrunde liegenden Tat war, dass es keine Hinweise auf ein mögliches Tatmotiv gab. Darüber hinaus konnte das Opfer keine Angaben zu dem unbekannten Täter machen, da es diesen nicht gesehen hatte. Nachdem die Ermittlungen im Umfeld des Opfers ohne Ergebnis verliefen, blieb letztlich eine Recherche in den betreffenden Datenbeständen als letzte Möglichkeit. Diese lieferte eine unbekannte Anzahl von zu überprüfenden Personen und damit zumindest neue Ermittlungsansätze. Gemessen daran kann die Maßnahme nicht als erfolglos bezeichnet werden. Zur Aufklärung der Tat konnten aber auch die Rasterfahndung und die erlangten Ermittlungsansätze nicht beitragen.

\section{Verfahren 019}

\section{Sachverhalt}

Gegenstand des Verfahrens 019 waren Ermittlungen bzgl. des Verdachts des schweren Raubes, der gefährlichen Körperverletzung und des erpresserischen Menschenraubes. Das Opfer wurde am 21.01.02 von Täter Nr.1 unter dem Vorwand eines Gesprächs in ein Fahrzeug gelockt. Im Rahmen dessen sollten Verabredungen über Schwarzarbeit getroffen werden. Im Verlauf des Gesprächs stiegen zwei weitere Personen in das Fahrzeug und hielten das Opfer fest. Nach kurzer Fahrt wurde das Opfer auf einem Parkplatz aus dem Auto gezogen und von allen Beteiligten körperlich misshandelt. Im Anschluss wurde das Opfer in den Kofferraum des Fahrzeuges verbracht.

Nach einer weiteren halben Stunde Fahrt wurde das Opfer aus dem Kofferraum geholt und erneut misshandelt. Ihm wurden diverse Gegenstände abgenommen, darunter Bargeld und eine EC-Karte. Das Opfer wurde gezwungen, die Geheimnummer seiner EC-Karte zu nennen. Letztlich wurde das Opfer nach längerer Fahrt an der polnischen Grenze freigelassen. Ihm wurde gesagt, dass er die ihm abgenommenen Gegenstände wiederbekäme, wenn er $2.500 €$ auf sein eigenes Konto überweisen oder einzahlen würde.

\section{Die Rasterfahndung}

\section{a. Ermittlungsstand und Ausgangslage}

Ausschlaggebend für die Rasterfahndung waren Erkenntnisse aus der Befragung des Opfers. Dieses kannte Täter Nr.1 und wusste, dass dieser ca. einen Monat vor der Tat mit seinem Auto von der Polizei kontrolliert worden war. Er konnte auch angeben, wo die betreffende Kontrolle stattgefunden hatte. Nachforschungen ergaben, dass sich der zuständige Polizeibeamte zwar an die Kontrolle erinnern konnte, aber keine Aufzeichnungen über die Kontrolle gefertigt hatte. Die Personen und 
das Fahrzeug waren jedoch über Funk, im polizeilichen Fahndungsbestand abgefragt worden. Zudem war dem Polizeibeamten erinnerlich, dass zu einer der Personen Notierungen im System vorlagen (sog. Positiv-Kontrollierung). Mithin waren die polizeiliche Kontrolle des mutmaßlichen Täters und die damit einhergehende Funkabfrage als Ansatzpunkt für die Rasterfahndung anzusehen.

\section{b. Begründung und Ziel}

Die Maßnahme wurde am 15.02.2002 durch die ermittelnde Polizeidienststelle bei der Staatsanwaltschaft in B angeregt. In dieser Anregung wird ausgeführt, dass die Funküberprüfung regelmäßig eine Rechnerabfrage beim Landeskriminalamt Abteilung Zentrale Polizeitechnische Dienste nach sich ziehen würde. Derartige Überprüfungen werden langfristig gespeichert und seien daher recherchierbar. Allerdings sei ein Beschluss nach $\S \S 98 \mathrm{a}, \mathrm{b}$ StPO notwendig, um die betreffende Recherche durchzuführen. Die Anregung betraf die Verpflichtung der ZPD, die dort vorhandenen Unterlagen und Datenträger darauf zu überprüfen, welche Personen und Sachen am 03.12.2001 in der Zeit von 17.00 bis 23.30 Uhr von einem bestimmten Abfrageterminal der KPD in G abgefragt worden waren. Daten mit entsprechenden Kriterien sollten an die KPD in G übermittelt werden.

Ein Antrag der Staatsanwaltschaft B mit entsprechendem Inhalt wurde am 08.05.2002 beim Amtsgericht in D gestellt. Dabei nahm die Staatsanwaltschaft ausdrücklich Bezug auf die polizeiliche Anregung. Sie stellte ferner fest, dass eine Straftat von erheblicher Bedeutung im Sinne des § 98a I S.2 Nr.4 StPO vorliegen würde. Ziel der Maßnahme sei die Feststellung des Aufenthaltsortes des Täters und seiner vollständigen Personalien.

Ein Beschluss des Amtsgerichts in D erging am 27.05.2002. Begründet wurde die Anordnung mit der Erforderlichkeit der zu übermittelnden Daten für die Ermittlung der Täter. Zusammenfassend lassen sich aus Anregung, Antrag und Anordnung die Ermittlung des Kfz-Kennzeichens, die Feststellung der Personalien des mutmaßlichen Täters und die Ermittlung seines Aufenthaltsortes als Ziele festhalten.

\section{c. Durchführung und Ergebnis}

Das Ergebnis des Datenabgleichs wurde der ermittelnden Polizeidienststelle am 20.06.2002 übermittelt. Die übermittelten Daten für den fraglichen Zeitraum umfassten 80 Abfragen, welche vom betreffenden Terminal getätigt worden waren. Die Treffer wurden als Ausdruck übermittelt. Aus den 80 Abfragen konnte unter Mithilfe des Polizeibeamten die gesuchte Abfrage herausgefunden werden. Als Ergebnis brachte die Rasterfahndung damit die Identifikation eines möglichen Täters und des fraglichen Kfz-Kennzeichens. 


\section{d. Auswirkungen auf das Ermittlungsverfahren}

Die mithilfe der Rasterfahndung identifizierte Person wurde im weiteren Verlauf des Verfahrens als Beschuldigter geführt. Im Rahmen einer Lichtbildvorlage wurde die betreffende Person durch das Opfer nicht eindeutig wiedererkannt. Der Beschuldigte ist polnischer Staatsbürger und hält sich in Polen auf. Im Rahmen der Ermittlungen wurden diverse Rechtshilfeersuchen gestellt und durchgeführt. Die im Umfeld des Beschuldigten getätigten Ermittlungen erbrachten Hinweise auf zwei weitere Personen. Bei diesen handelte es sich ebenfalls um polnische Staatsbürger. Eine weitere Lichtbildvorlage erbrachte jedoch keine Widererkennung durch das Opfer.

Auf der Grundlage des nach § 98a StPO getätigten Datenabgleichs konnten ein Täter und zwei weitere tatverdächtige Personen ermittelt werden. Ohne die Rasterfahndung wäre es nicht möglich gewesen, den Beschuldigten und die beiden Tatverdächtigen zu identifizieren und darüber hinausgehende Ermittlungen durchzuführen.

\section{Ausgang des Verfahrens}

Auf einem neuen im Rahmen von Rechtshilfeersuchen erlangten Bild konnte das Opfer den Beschuldigten eindeutig als Täter wieder erkennen. Die betreffende Lichtbildvorlage wurde am 31.01.2006 durchgeführt. Das Ermittlungsverfahren ist zum Zeitpunkt der Auswertung im Frühjahr 2006 noch nicht abgeschlossen. Die als Beschuldigte geführte Person hält sich weiterhin in Polen auf. Eine Auslieferung wurde nicht beantragt. Eine Strafverfolgung kommt nur in Polen in Betracht. Dort wird ein gesondertes Strafverfahren geführt. Weitere Ermittlungsmaßnahmen werden von den polnischen Behörden durchgeführt.

\section{Erfolgseinschätzung}

In diesem Verfahren war es nur durch den Datenabgleich nach § 98a StPO möglich, Tatverdächtige zu ermitteln. Durch die Rasterfahndung konnte das KfzKennzeichen des Tatfahrzeugs ermittelt werden. Darüber hinaus brachte die Rasterfahndung die Identifikation des Beschuldigten, der im weiteren Verlauf des Verfahrens als Täter identifiziert werden konnte. Letztlich wurde durch die weiteren Ermittlungen auch der Aufenthaltsort des Beschuldigten festgestellt. Ohne die Identifikation des Beschuldigten aufgrund der Rasterfahndung wäre dies nicht möglich gewesen. Insofern ist mittelbares Ergebnis der Maßnahme auch die Feststellung des Aufenthaltsortes des Beschuldigten.

Betrachtet man die mit der Rasterfahndung verfolgten Ziele, so muss festgestellt werden, dass diese durchweg erreicht worden sind. Mithin kann die Rasterfahn- 
dung in diesem Verfahren als erfolgreich beurteilt werden. Dass bis heute keine Festnahme des Beschuldigten, keine Anklage und keine Verurteilung erfolgt sind, ist den länderübergreifenden Ermittlungen und der Übernahme des Verfahrens durch die polnischen Behörden geschuldet.

\section{Verfahren 020}

\section{Sachverhalt}

Gegenstand von Verfahren 020 sind Ermittlungen zur Aufklärung eines Tötungsdeliktes an einem zwölfjährigen Mädchen aus G. Am 12.02.2002 wurde das Opfer in seinem Kinderbett liegend mit mehreren Messerstichen getötet. Zur Tatzeit befanden sich die Eltern des Kindes auf einer Karnevalsfeier. Der jüngere Bruder des Opfers schlief im Nachbarzimmer.

\section{Die Rasterfahndung}

\section{a. Ermittlungsstand und Ausgangslage}

Noch am 12.02.2002 wurde die Soko V. mit 30 Beamten gegründet. Befragungen der nächsten Angehörigen und des Umfeldes des Opfers erbrachten keine Erkenntnisse. Noch am Tattag wurde das Tatmesser auf einem Grundstück in derselben Straße gefunden und sichergestellt. DNA-Untersuchungen ergaben Spuren des Opfers an der Klinge. Aufgrund der Persönlichkeit des Opfers konnte kein sicheres Tatmotiv erkannt werden. Die Tötungshandlung hätte sich auch als Verdecken einer Straftat oder aus sexuellem Antrieb heraus ergeben können. Bzgl. der letzteren Möglichkeit fanden sich an der Leiche jedoch keinerlei Anhaltspunkte, die diese Vermutung hätten bestätigen können.

Aufgrund der Medienberichte über den Fall meldete sich am 17.02.2002 eine Zeugin. Diese gab an, dass sie in der Tatnacht um 0.05 Uhr in der Nähe des Tatortes aus einem Bus gestiegen sei. Anschließend sei sie von einem komplett in schwarz gekleideten und mit einer Totenkopfmaske maskierten Mann verfolgt worden. An ihrem Ziel angekommen habe sie die Person mit den Worten „Was willst Du?" angefahren, worauf dieser sich entfernt hätte. Da es Rosenmontag gewesen sei, habe sie dieser Begebenheit zunächst keine Bedeutung zugemessen. Laut Schlussvermerk der ermittelnden Polizeibehörde war dieser Hinweis entscheidend für die Aufklärung der Tat.

Am 16.02.2002 teilte ein weiterer Zeuge mit, dass er ebenfalls eine Begegnung mit einem als Tod maskierten Mann gehabt habe. Der Zeuge gab an, mit der Person in einem Lokal zusammengesessen und sich unterhalten zu haben. In diesem Gespräch habe die maskierte Person unter anderem erzählt, wo er einer Ausbildung 
nachginge. Gegen Mitternacht habe der Maskierte dann das Lokal verlassen. Auf dem Weg nach Hause habe der Zeuge die Person gegen ein Uhr erneut gesehen. Die beiden Zeugenaussagen gewannen an Gewicht, da feststand, dass sich die maskierte Person zur Tatzeit zwischen Mitternacht und ein Uhr im näheren Tatortbereich aufgehalten hatte. Auf einen Presseaufruf hin meldete sich die unbekannte Person jedoch nicht. Ferner wurde für den Telefonanschluss der Eltern des Opfers eine Telefonüberwachung veranlasst. Dieser lag die Annahme zugrunde, der Täter käme aus dem Umfeld und würde in telefonischen Kontakt zu den Hinterbliebenen treten.

\section{b. Begründung und Ziel}

Die Maßnahme nach $\S \S 98 \mathrm{a}, \mathrm{b}$ StPO wurde am 19.02.2002 durch die ermittelnde Polizeibehörde bei der Staatsanwaltschaft A angeregt. Es sollten die bereits beim Einwohnermeldeamt der Stadt G erhobenen Daten von allen aktuell registrierten männlichen Personen zwischen 10 und 70 Jahren mit Daten der Protokolldatei des LKA und dem Datenbestand des Landes KAN abgeglichen werden. Begründet wurde die Anregung mit der Notwendigkeit des Abgleichs für weitere Recherchen. Darüber hinaus wurde angeregt, personenbezogene Daten des einschlägig in Erscheinung getretenen Intensivtäters X zu erheben und abzugleichen. Dieses Vorgehen sei angezeigt, um zurückliegende Aufenthaltsorte festzustellen und dadurch ein Bewegungsbild zu erstellen.

Ein Antrag mit entsprechendem Inhalt der Staatsanwaltschaft A wurde am 20.02.2002 beim Amtsgericht A gestellt. Die Staatsanwaltschaft begründete den Antrag mit der Annahme, der Täter sei zwischen 10 und 70 Jahren und wäre im Stadtgebiet G ansässig. Der maschinelle Abgleich dieser Personen mit einem weiteren Personenkreis, der bereits in ähnlicher Weise strafrechtlich in Erscheinung getreten ist, sei zur Erforschung des Sachverhalts von erheblicher Bedeutung. Ferner sei die Ermittlung des Täters auf andere Weise erheblich weniger Erfolg versprechend. Die Ausfertigung der Staatsanwaltschaft wurde am 20.02.2002 durch den Ermittlungsrichter unterschrieben.

\section{c. Durchführung und Ergebnis}

Neben Anregung und Antrag/Anordnung der Maßnahme enthielten die Verfahrensakten nur noch einen Vermerk des LKA mit Informationen bzgl. der Rasterfahndung. Dieser ist datiert vom 20.02.2002 und betrifft Informationen aus dem Protokolldatenbestand. Laut diesem Vermerk wurde die Auswertung mit den genannten Kriterien durchgeführt und die erzielten Treffer in einer Liste per Mail zugesandt. Die betreffende Liste war jedoch in den Akten nicht enthalten, so dass keine Angaben über die Trefferanzahl vorlagen. Darüber hinaus war nicht ersicht- 
lich, ob lediglich mit dem Protokolldatenbestand oder auch mit dem Landes-KAN abgeglichen worden war. Über die Vernichtung der Trefferliste und entstandene Kosten waren den Verfahrensakten ebenfalls keine Informationen zu entnehmen.

\section{d. Auswirkungen auf das Ermittlungsverfahren}

Da der Täter zwischenzeitlich gefasst wurde und geständig war, entfiel die Notwendigkeit einer konventionellen Abklärung der Treffer aus der Rasterfahndung. Darüber hinaus war nicht ersichtlich, mit welchen Straftatbeständen die EMADaten abgeglichen worden sind. Da jedoch von einschlägigen Straftaten ausgegangen werden musste und der Täter lediglich zweimal wegen Diebstahls in Erscheinung getreten war, ist davon auszugehen, dass er nicht von der Trefferliste erfasst wurde. Allerdings können diesbezüglich nur Mutmaßungen angestellt werden. Auswirkungen auf das Ergebnis der Ermittlungen hatte die Maßnahme nicht.

\section{Ausgang des Verfahrens}

Aufgrund der Zeugenaussagen und der daraus resultierenden Ermittlungsansätze konnte der am Tattage als Tod maskierte Mann ermittelt werden. In seiner ersten Vernehmung als Zeuge am 22.02.2002 verschwieg er die Verfolgung der Frau und das zweite Zusammentreffen mit dem Zeugen Nr.2. Nachdem ihm dies vorgehalten wurde, gestand der Mann auch die Tötung des Kindes. Seine Behauptung er habe das Tatmesser nicht mit sich geführt, sondern erst im Haus an sich genommen, konnte durch Zeugenaussagen widerlegt werden. Des Weiteren konnte seine Behauptung, er hätte nur zugestochen, weil das Kind um Hilfe gerufen hätte, anhand der Obduktion ebenfalls widerlegt werden. Bezüglich des Tatmotivs ließ sich der Täter sehr wechselhaft ein.

Der Täter wurde mit Urteil vom 13.02.2003 wegen Mordes zu zehn Jahren Jugendstrafe verurteilt. Auch im Urteil wird ausgeführt, dass kein plausibles Tatmotiv erkennbar geworden ist. Nicht ausgeschlossen wurde, dass der Täter durch häufiges Anschauen von Horrorfilmen einen Tatimpuls erfahren habe. Diesbezüglich wurden Gutachten eingeholt, welche die Annahme jedoch nicht belegen konnten.

\section{Erfolgseinschätzung}

Im vorliegenden Verfahren ist festzustellen, dass die Maßnahme nach den $\S \S 98 \mathrm{a}, \mathrm{b}$ StPO außerordentlich früh angeordnet und durchgeführt wurde. Dies ist vermutlich dem Umstand geschuldet, dass von Anfang an kein Tatmotiv ersichtlich war und dadurch keine Ermittlungsansätze gegeben waren. Neben den Ermittlungen bzgl. der bis dahin unbekannten maskierten Person bot der Datenabgleich von Einwohnermeldedaten mit polizeilichen Datenbeständen zu einschlägigen Delikten 
den einzigen Ermittlungsansatz. Aufgrund der schnellen Ergreifung des Täters waren die Ergebnisse der Rasterfahndung für das Ermittlungsverfahren obsolet. Daher ließen sich den Verfahrensakten nur sehr wenige Informationen über das Ergebnis des Datenabgleichs entnehmen. Aussagen über den Erfolg der Maßnahme können aus diesem Grund nicht gemacht werde.

\section{Verfahren 021}

\section{Sachverhalt}

Das Verfahren 021 hatte Ermittlungen zur Aufklärung eines Tötungsdeliktes zum Gegenstand. Am 25.04.2002 verschaffte sich ein unbekannter Täter Zutritt zum Haus des Opfers. Er vergewaltigte das Opfer und legte es im Anschluss in eine Badewanne und stellte das Wasser an. In der Badewanne trat der Tod des Opfers durch Ertrinken ein. Anschließend durchsuchte der Täter das Haus und nahm diverse Wertgegenstände an sich.

In dem Moment, als der Täter das Haus verließ, trafen die Kinder des Opfers ein. Als der Täter diese sah, kehrte er zurück und bat eines der beiden Kinder, unter dem Vorwand, er habe Gartenarbeit auf dem Grundstück verrichtet, eine von ihm vergessene Wasserflasche und ein Glas aus dem Haus zu holen. Nach Erhalt der Gegenstände verließ der Täter den Tatort, wobei er von keiner weiteren Person gesehen wurde.

\section{Die Rasterfahndung}

\section{a. Ermittlungsstand und Ausgangslage}

$\mathrm{Zu}$ Beginn der Ermittlungen wurde eine Sonderkommission durch die Polizei M eingesetzt. Auf den Beschreibungen der beiden Kinder basierend, wurde ein Phantombild des unbekannten Täters gefertigt und sowohl in lokalen Medien als auch im Internet veröffentlicht. Darüber hinaus wurden Funkzellendaten gem. §§ 100g, h StPO für den Bereich des Tatortes erhoben. Ferner wurden Verbindungsdaten vom Anschluss des Opfers erhoben. Letztlich wurde eine Belohnung in Höhe von $10.000 €$ für Hinweise, die zur Ergreifung des Täters führen, ausgesetzt. Auch sichergestellte daktyloskopische und molekulargenetische Spuren brachten keine Hinweise auf den unbekannten Täter.

\section{b. Begründung und Ziel}

Zum Zeitpunkt der Anregung der Maßnahme nach den $\S \S 98 \mathrm{a}, \mathrm{b}$ StPO am 10.05.2002 waren die Sonderkommission bereits aufgelöst und die Ermittlungen durch 
die Mordkommission der Polizei M übernommen worden. Die ermittelnde Polizeidienststelle führte in ihrer Begründung aus, dass die Wahrscheinlichkeit, da es sich um eine sexuell motivierte Tat handelte und der Täter Maßnahmen zur Spurenbeseitigung getroffen hatte, groß sei, dass der Täter bereits kriminalpolizeilich in Erscheinung getreten sei. Allerdings seien weder seine Fingerabdrücke noch DNA-Material in den entsprechenden Dateien eingestellt gewesen. Es würde jedoch die Möglichkeit bestehen, dass der Täter bereits aus der Fingerabdruckdatei gelöscht und noch nicht in die DNA-Datei eingestellt worden sei. Für diese Annahme würde auch das Alter des unbekannten Täters sprechen, welches von den beiden Kindern mit ca. 35 Jahren angegeben wurde. Nach Ansicht der Mordkommission wäre daher eine Recherche beim Bundeszentralregister angezeigt, da es möglich ist, dass Straftäter dort bereits registriert, aber noch nicht in die DNA-Datei eingestellt worden sind.

Die Staatsanwaltschaft M richtete daraufhin ein Auskunftsersuchen an das Bundeszentralregister. Dieses sollte Auskunft darüber erteilen,

- welche männlichen Personen

- geboren 1952 - 1972

- in den Jahren $1966-2001$

- wegen Delikten des Mordes, Totschlags, versuchten Totschlags, sexueller Nötigung und sexueller Nötigung mit Todesfolge, bei den Landgerichten $\mathrm{M}, \mathrm{K}, \mathrm{M}, \mathrm{D}, \mathrm{F}, \mathrm{F}$ und $\mathrm{K}$ verurteilt worden sind

Das Bundeszentralregister forderte für diese Auskunft jedoch eine richterliche Anordnung nach den $\S \S 98 \mathrm{a}, \mathrm{b}$ StPO. Aus diesem Grund stellte die Staatsanwaltschaft $\mathrm{M}$ einen entsprechenden Antrag beim Amtsgericht M. Diesen begründete sie damit, dass es notwendig sei, Auskunft über Verurteilungen mit bestimmten Eckdaten zu erlangen. Der unbekannte Täter sei bei der Tatausführung so umsichtig vorgegangen, dass davon auszugehen sei, dass es sich nicht um einen Ersttäter handeln und eine Verurteilung vorliegen würde. Das Amtsgericht erließ am 27.06.2002 eine entsprechende Anordnung. Diese war in ihrem Wortlaut identisch mit dem Antrag der Staatsanwaltschaft. Lediglich ergänzt wurde der Antrag durch die Feststellung, dass andere Ermittlungsansätze nicht ersichtlich seien.

\section{c. Durchführung und Ergebnis}

Am 01.08.2002 wurden die angeforderten Daten durch das Bundeszentralregister ausgesondert und an die ermittelnde Mordkommission übersandt. Die zunächst in Papierform übermittelte Auskunft enthielt 1503 Personendatensätze. Mit der Bearbeitung der Spuren aus der Rasterfahndung konnte aufgrund Personalmangels erst im November 2002 begonnen werden. Am 13.11.2002 wurde beim Bundeszentralregister angefragt, ob die betreffenden Daten erneut und diesmal als Datei übersandt werden könnten. Die Anfrage erfolgte unter Hinweis auf einen geplanten Abgleich der Daten mit anderen Daten nach § 98c StPO. Nachdem das Bundes- 
zentralregister eine erneute Begründung verlangt und erhalten hatte, wurden die Daten übersandt. Die 1503 Datensätze wurden daraufhin mit den Daten aus der Funkzellenabfrage nach Übereinstimmungen abgeglichen. Da sich den Verfahrensakten keine Informationen über Treffer entnehmen ließen, muss davon ausgegangen werden, dass es keine Treffer gegeben hat.

\section{d. Auswirkungen auf das Ermittlungsverfahren}

Die 1.503 Datensätze aus der Maßnahme nach $\S \S 98 \mathrm{a}, \mathrm{b}$ StPO wurden daraufhin mit dem im Folgenden dargestellten Raster konventionell abgearbeitet.

- Sind die Personen bereits in Fingerabdruck- oder DNA-Datenbank erfasst?

- wenn ja, dann werden sie aus dem Kreis der tatverdächtigen

Personen ausgeschlossen

- Haben die übrigen Personen ein Alibi?

- Personen, die noch immer nicht ausgeschlossen werden können, werden einer gezielten Überprüfung unterzogen. Von diesem Personenkreis werden auf freiwilliger Basis ein Lichtbild, Fingerabdrücke und eine Speichelprobe erhoben, um sie mit dem vorhandenen Spurenmaterial überprüfen zu können.

Durch Abgleich mit POLIS konnte ein Großteil der 1503 Personen ausgeschlossen werden. Die übrigen 298 Personen wurden mit dem AZR abgeglichen, woraufhin noch 262 Personen übrig blieben. Bis auf 11 Personen haben davon alle Speichelproben und Fingerabdrücke abgegeben. Die anschließende Überprüfung hatte keinen Treffer zur Folge. Gegen die 11 Personen wurden durch die Staatsanwaltschaft M Anordnungen nach $\S \S 81 \mathrm{a}$ III, 81c, 81e StPO beantragt und am 01.12.2002 durch das Amtsgericht M erlassen. Auch deren Durchführung brachte keinen Treffer.

\section{Ausgang des Verfahrens}

Neben den bereits genannten Ermittlungsmaßnahmen wurde ein Rechtshilfeersuchen an niederländische Behörden gestellt. Diese hatten einen Abgleich der DNASpuren mit den dortigen DNA-Datenbanken zum Gegenstand. Dieser Abgleich verlief ebenfalls negativ. In den Verfahrensakten war ausdrücklich vermerkt, dass nach Abgleich der Spuren und Daten aus der Rasterfahndung kein Verdächtiger übrig geblieben war. Da die weiteren Ermittlungen erfolglos verlaufen sind, wurde das Verfahren am 11.11.2005 nach $\S 170$ II StPO eingestellt.

\section{Erfolgseinschätzung}

Aufgrund der schlechten Beweislage ergaben sich neben der Rasterung unter Zuhilfenahme der verwandten Rasterkriterien nur wenig andere Ermittlungsansät- 
ze. Insofern kann festgehalten werden, dass die Rasterfahndung zumindest den Erfolg versprechendsten Ansatz für weitere Ermittlungen lieferte. Anders ist auch nicht zu erklären, dass die Maßnahme in diesem Verfahren so früh durchgeführt wurde. Mithin lieferte die Rasterfahndung einen Personenkreis möglicher Tatverdächtiger, der einer weiteren konventionellen Abklärung bedurfte. In Anbetracht dessen kann die Maßnahme nicht als erfolglos bewertet werden. Ohne die erlangte Datengrundlage wären weitere Ermittlungen nur in sehr begrenztem Maße möglich gewesen. Allerdings darf nicht außer Betracht bleiben, dass der Täter nicht ermittelt werden konnte. Wird die Rasterfahndung allein am Ergebnis der gesamten Ermittlungen gemessen, so ist auch sie letztlich erfolglos geblieben.

\section{Verfahren 022}

\section{Sachverhalt}

Gegenstand von Verfahren 022 waren Ermittlungen zur Aufklärung eines Tötungsdelikts. Am 19.05.2002 wurde auf einem unbefestigten Feldweg eine männliche Leiche gefunden. Diese wies eine tödliche Schussverletzung auf. Der Fundort der Leiche befand sich in der Nähe einer Landstraße im Umkreis der Stadt O.

\section{Die Rasterfahndung}

\section{a. Ermittlungsstand und Ausgangslage}

Noch am selben Tag wurde der Einsatz der Mordkommission angeordnet. Diese setzte sich aus Polizeibeamten der Kommissariate $\mathrm{M}$ und $\mathrm{P}$ sowie des Zentralen Kriminaldienstes der Polizeiinspektion E zusammen. Die Ermittlungen wurden zunächst im Umfeld des Opfers geführt. Es stellte sich heraus, dass das Tötungsdelikt im Zusammenhang mit illegalen Whiskygeschäften des Opfers gestanden haben dürfte. Im Rahmen der Ermittlungen zu diesen Geschäften geriet eine Person in den Fokus der Ermittlungen. Bei der Person handelte es sich um den vermeintlichen Whiskylieferanten. Als solcher hatte die als Beschuldigter geführte Person am Vorabend der Tat eine Fahrt von über $800 \mathrm{Km}$ gemeinsam mit dem Opfer durch Norddeutschland unternommen. Im Rahmen dieser Fahrt sollte, wie sich aus Zeugenvernehmungen ergab, eine Whiskylieferung übergeben werden, wozu es jedoch nicht kam. Aus diesem Grund war für die Tatnacht ein erneuter Übergabeversuch geplant. Alle Zeugenaussagen deuteten zu diesem Zeitpunkt daraufhin, dass es sich bei dem Täter um den Whiskylieferanten handeln dürfte.

Für die Telefonanschlüsse des Beschuldigten wurden Maßnahmen nach den $\S \S 100 \mathrm{a}, \mathrm{b}$ StPO veranlasst sowie Verbindungsdaten nach den $\S \S 100 \mathrm{~g}$, h StPO erhoben. Am 23.05.2002 wurde der Beschuldigte festgenommen und vernommen. Er legte jedoch kein Geständnis ab, so dass die Festnahme am 24.05.2002 mangels 
dringenden Tatverdachts aufgehoben wurde. In der Wohnung und dem Geschäft des Beschuldigten durchgeführte Durchsuchungsmaßnahmen erbrachten keine Hinweise auf die Täterschaft des Beschuldigten. Im Pkw des Beschuldigten wurde eine Abhöreinrichtung eingebaut. Aufgrund technischer Probleme erbrachte diese jedoch keine Erkenntnisse. Darüber hinaus wurde der Beschuldigte observiert.

Am 30.05.2002 übergab ein Zeuge eine vom Beschuldigten erhaltene Waffe an die Polizei. Bei dieser Waffe handelte es sich um die Tatwaffe. Um die Glaubwürdigkeit des Zeugen zu überprüfen und den Beschuldigten in ein Gespräch über die Waffe zu verwickeln, sollte der Zeuge den Beschuldigten auf dessen Mobiltelefon anrufen und auf die Waffe ansprechen. Das Gespräch sollte dabei mithilfe einer Telefonüberwachung aufgezeichnet werden. Im Rahmen dieses Gesprächs forderte der Beschuldigte den Zeugen auf, die Waffe für ihn verschwinden zu lassen. Aufgrund der Sicherstellung der Tatwaffe und Erkenntnisse aus der Telefonüberwachung wurde am 30.05.2002 ein Haftbefehl gegen den Beschuldigten ausgestellt und vollstreckt.

\section{b. Begründung und Ziel}

Die Maßnahme nach den $\S \S 98 \mathrm{a}, \mathrm{b}$ StPO wurde erst am 03.06.2002 durch die Mordkommission angeregt. Ziel war es festzustellen, wo sich das Opfer und der Beschuldigte ab Tagesanfang des 17.05.2002 bis Tagesende des 18.05.2002 aufgehalten hatten. Es lagen Erkenntnisse darüber vor, dass die beiden Personen zumindest am 17.05.2002 gemeinsam im Raum um $\mathrm{O}$ und im angrenzenden Nordrhein-Westfalen unterwegs gewesen sein mussten. Dabei hatten sie zwei bekannte Fahrzeuge genutzt. Da Daten über möglicherweise durchgeführte Fahrzeug- bzw. Personenkontrollen durch den Zentralen Polizeitechnischen Dienst NordrheinWestfalen gespeichert werden, sei ein Abgleich dieses Datenbestandes mit den Kennzeichen und Personendaten vom Opfer und dem Beschuldigten notwendig. Durch den Abgleich sei es möglich, gemeinsame Aktivitäten vom Opfer und dem Beschuldigten im fraglichen Zeitraum belegen zu können. Aufgrund landesgesetzlicher Vorschriften war die Möglichkeit einer Recherche in dem Datenbestand nur nach Erlass einer richterlichen Anordnung gegeben. Für das Land Niedersachsen war eine solche Recherche aufgrund landesgesetzlicher Vorschriften ohne richterliche Anordnung möglich.

Ein entsprechender Antrag wurde durch die Staatsanwaltschaft O am 03.06.2002 gestellt. Die Maßnahme wurde daraufhin am 04.06.2002 durch das Amtsgericht $\mathrm{O}$ angeordnet. Ziel war es, möglichst vollständige Erkenntnisse über den Aufenthalt der beiden Personen im betreffenden Zeitraum zu erlangen. In Zusammenhang mit dieser Maßnahme wurde auch ein Rechtshilfeersuchen an die Niederländische Polizei gerichtet. Es sollte festgestellt werden, ob die Fahrzeuge der beiden Personen im fraglichen Zeitraum in den angrenzenden Niederlanden kontrolliert worden waren. 


\section{c. Durchführung und Ergebnis}

Die Ergebnisse der Maßnahme haben am 26.06.2002 vorgelegen. Danach sind die Personen und Fahrzeuge im fraglichen Zeitraum weder durch die niedersächsische noch durch die nordrhein-westfälische und die niederländische Polizei kontrolliert worden. Eine Übermittlung von Daten wurde ausdrücklich nicht angefordert. Vielmehr sollte lediglich eine Trefferliste übersandt werden.

\section{d. Auswirkungen auf das Ermittlungsverfahren}

Anhand der Maßnahme war es nicht möglich die Aufenthaltsorte und die Fahrtstrecken des Opfers und des Beschuldigten am Tag vor der Tat zu rekonstruieren.

\section{Ausgang des Verfahrens}

Der Beschuldigte wurde angeklagt und am 15.05.2003 wegen Mordes zu einer lebenslangen Freiheitsstrafe verurteilt. Er hat sich vor und während der Hauptverhandlung nicht zur Sache eingelassen. Die Verurteilung erfolgte auf der Grundlage von belastenden Zeugenaussagen und Gutachten zu Beweisstücken und Tatortgegebenheiten.

\section{Erfolgseinschätzung}

Da die beiden Personen und Fahrzeuge im fraglichen Zeitraum nicht kontrolliert wurden, erbrachte der Datenabgleich keine Erkenntnisse. Mithin konnten der Aufenthaltsort und die Fahrtstrecken der beiden Personen nicht rekonstruiert werden. Folglich kann die Maßnahme nach den $\S \S 98 \mathrm{a}, \mathrm{b}$ StPO im vorliegenden Verfahren als nicht erfolgreich beurteilt werden. Darüber hinaus erscheint die generelle Eignung der Maßnahme zur Erstellung eines vollständigen Bewegungsbildes fraglich.

\section{Verfahren 023}

\section{Sachverhalt}

Gegenstand eines weiteren Verfahrens, in welchem die Rasterfahndung eingesetzt wurde, waren Ermittlungen zur Aufklärung einer Serie von Briefbombenanschlägen. Dabei wurden im Zeitraum von April 2004 bis November 2004 insgesamt neun Briefbomben an Kommunalpolitiker in B und weitere Personen des öffentlichen Lebens versandt. Die Anschlagsserie begann mit der ersten Öffnung einer Briefbombe am 06.04.2004. Die letzte Briefbombe erreichte ihren Empfänger am 10.11.2004. Nur bei der Öffnung der Briefbombe Nr.6 am 30.08.2004 kam es 
zu einer Explosion. Dabei wurde eine Person leicht verletzt. In den weiteren acht Fällen wurden die Briefbomben entschärft oder waren defekt.

\section{Die Rasterfahndung Nr.1}

Im Verfahren 023 wurden zwei Maßnahmen nach den $\S \S 98 \mathrm{a}$, b StPO angeordnet und durchgeführt. Diese werden im Folgenden als Rasterfahndung Nr. 1 und Rasterfahndung Nr. 2 bezeichnet.

\section{a. Ermittlungsstand und Ausgangslage}

Die Ermittlungen wurden durch das Bayerische Landeskriminalamt geführt. Das LKA richtete eine „Arbeitsgruppe Briefbombe“ ein. Die Ermittlungen waren in mehrere Ermittlungskomplexe unterteilt. Es wurden verdeckte Ermittler eingesetzt und ein Beschuldigter wurde durch ein Mobiles Einsatzkommando observiert. Daneben wurden Telefonüberwachungen veranlasst und Wohnungen von weiteren Beschuldigten durchsucht. Diese Ermittlungsmaßnahmen, die sich gegen insgesamt sieben Beschuldigte richteten, führten nicht zur Ermittlung des Täters. Das Verfahren wurde gegen die sieben Beschuldigten eingestellt.

Bereits nach der zweiten Briefbombe wurde die Abteilung Operative Fallanalyse (OFA) des Polizeipräsidiums $\mathrm{M}$ in die Ermittlungen miteinbezogen. Diese erhielt den Auftrag, eine fallanalytische Bewertung durchzuführen. Hierbei sollten folgende Unterpunkte berücksichtigt werden:

- Fallcharakteristik

- Bewertung des Aufbaus der Briefbomben

- Motivbewertung

- Täterprofil

- Ermittlungsstrategie

Die Ergebnisse der Bewertung durch die OFA wurden am 06.05.2004 vorgestellt. Grundlage für die Bewertung waren Erkenntnisse, welche aus dem Aufbau der Bomben gezogen werden konnten. Der Bombenaufbau wurde als ineffektiv und simpel strukturiert beschrieben, wobei sich eine allgemeine Frust und Politikverdrossenheit in der Motivlage des Täters widerspiegeln sollte. Darüber hinaus wurden auch aus der Auswahl der Empfänger (Opfer) der Briefsendungen Rückschlüsse auf den geografischen Ankerpunkt eines möglichen Täters gezogen. Aufgrund der gewonnenen Erkenntnisse wurde das folgende Täterprofil erstellt.

- Männlicher Täter zwischen 40 und 60 Jahren

- Einzeltäter 
- Geografischer Ankerpunkt im Großraum A

- Lebt mit weiblicher Person im Haushalt

- Zugriffsmöglichkeit auf ein Fahrzeug (Mobilität)

- Vermutlich akuter Lebensstress im Zeitraum Ende 2003 bis zur ersten Briefbombe

- Trennung vom Partner

- Verlust des Arbeitsplatzes

- Finanzielle Schwierigkeiten

- Arbeitslos oder geht einer untergeordneten Tätigkeit nach

- Handwerkliche Fähigkeiten, ohne jedoch eine handwerkliche Ausbildung beendet zu haben

- Evtl. finanziell angespannte Situation

- Bezug zu Pyrotechnik

- Minderleister (Täter bleibt hinter seinen Fähigkeiten zurück und steht sich selbst im Weg)

- Abbruch von Ausbildungen denkbar

- Eigenes Versagen wird nicht reflektiert und angenommen

- Soziale Randständigkeit, nur oberflächlich in der Gemeinschaft integriert (,dabei statt mittendrin“)

- Lebt tendenziell zurückgezogen, er fühlt sich subjektiv etwas isoliert

- Fehlende soziale Anerkennung aufgrund der Randständigkeit führt zu resignierender Verbitterung

- Täter fühlt sich legitimiert zur Tatbegehung

- Durchschnittlich intelligent, eher „Bauernschläue“, Defizite im intellektuellen Bereich

- Improvisationsvermögen

- Polizeiliche Erkenntnisse nicht zwingend erforderlich

- Negativabgrenzung

- Keine Sprengausbildung

- Kein Zugang zu Sprengmitteln

- Keine elektrotechnische Ausbildung

Der vermeintliche Ortsbezug zur Gemeinde A ergab sich aus der Absenderangabe auf der Briefbombe Nr.2. 


\section{b. Begründung und Ziel}

Anlass für die Rasterfahndung war eine Empfehlung der OFA der Polizeiinspektion M. Diese empfahl die Durchführung einer Rasterfahndung auf der Grundlage des erstellten Täterprofils. Es wurden zunächst folgende Hauptkriterien für die Rasterfahndung festgelegt:

- Ortsbezug

- Männlich

- Alter zwischen 40 und 60 Jahren

- KAN-Eintrag (sozialschädliche Delikte)

Am 12.05.2004 wurde die Maßnahme durch die AG-Briefbombe angeregt. In der Anregung wurde Bezug auf das durch die OFA erstellte Täterprofil genommen. Die herausgearbeiteten Kriterien wie z.B. Geschlecht, Alter, Wohnsitz und weitere Merkmale wie Straffälligkeit sollten durch eine Selektion der Daten der Einwohnermeldeämter der Gemeinden A, B, C und D erlangt werden. Der angestrebte Abgleich mit dem polizeilichen Datenbestand sollte dem Ausschluss von Nichtverdächtigen und zur Gewinnung weiterer Erkenntnisse dienen. Als Begründung wurde angegeben, dass die Abarbeitung der bisher vorliegenden Spuren nicht zur Feststellung eines Tatverdächtigen geführt hätte.

Ein entsprechender Antrag wurde durch die Staatsanwaltschaft P am 13.05.2004 gestellt. Der dem Antrag zugrunde liegende Entwurf einer Anordnung wurde ohne Änderungen und Ergänzungen durch das Amtsgericht übernommen und am 13.05.2004 erlassen. Die Anordnung enthielt die an die Einwohnermeldeämter der Gemeinden A, B, C und D gerichtete Verpflichtung, die betreffenden Daten auszusondern und zu übermitteln. Der Abgleich dieser Daten mit dem KAN-Bestand wurde dem LKA aufgetragen. Als Ziel wurde unter Rückgriff auf den Gesetzeswortlaut die Feststellung tatverdächtiger bzw. der Ausschluss nichtverdächtiger Personen angeführt. Darüber hinaus seien Ermittlungen auf andere Weise erheblich weniger Erfolg versprechend gewesen.

Am 13.05.2004 regte das LKA - AG Briefbomben eine Erweiterung des Beschlusses an. Die Anregung war in ihrem Wortlaut identisch mit der ersten Anregung. Nur die zu erhebenden Daten unterschieden sich. Es sollten Daten des Arbeitsamtes $\mathrm{P}$, der Sozialämter der Stadt und des Landkreises P sowie des Landkreises F-G erhoben werden. Eine entsprechende Anordnung wurde durch das Amtsgericht P am 14.05.2005 getroffen. Deren Wortlaut war, bis auf die zu erhebenden Daten, ebenfalls mit der ersten Anordnung vom 13.05.2004 identisch. Ein Antrag der Staatsanwaltschaft bzgl. des zweiten Beschlusses war in den Verfahrensakten nicht enthalten. 


\section{c. Durchführung und Ergebnis}

Die angeforderten Daten der Einwohnermeldeämter, des Arbeitsamtes P (auch zuständig für den Landkreis F-G) und des Sozialreferats F-G wurden in ExcelTabellen aufbereitet, so dass der Datenabgleich am 27.05.2004 begann. Insgesamt lagen dem Datenabgleich 10.834 personenbezogene Datensätze zugrunde. An diese Gesamtmenge wurden unter Berücksichtigung der erstellten Täterprofilmerkmale folgende Filter angelegt:

- alle Sterbefälle wurden ausgeschieden

- alle weiblichen Personen wurden ausgeschieden

- es wurden alle männlichen Personen ausgeschieden, die nicht innerhalb des Zeitraumes vom 01.01.1944 bis 31.12.1964 geboren sind

- anschließend wurden alle Personen ausgeschieden, die nicht aktuell in den vier Gemeinden als dort wohnhaft gemeldet sind, soweit dies anhand der Daten möglich war

- anhand der KAN-Einträge wurden alle sog. Konfrontationsdelikte (Körperverletzung, Raub u.ä., 17., 18. und 20. Abschnitt des StGB) sowie alle Btm-Delikte, Ausländerdelikte und Beleidigungen ausgeschlossen

- Ausgrenzung aller Personen, die KAN-Einträge vor dem 01.01.2003 hatten, außer diejenigen, welche beim Arbeitsamt und/oder Sozialverwaltung des Landratsamtes F-G gemeldet waren.

Nachdem der Grunddatensatz von 10.834 einzelnen Datensätzen mit diesen Filterkriterien abgeglichen worden war, verblieb eine Restmenge von 48 personenbezogenen Datensätzen.

\section{d. Auswirkungen auf das Ermittlungsverfahren}

Die 48 auf diese Weise herausgerasterten Personen wurden anschließend anhand einer von der OFA erstellten Benehmens- und Verhaltensanalyse überprüft. Hierzu wurden fünf Ermittlungsteams eingesetzt, welche vorher durch Beamte der OFA eingewiesen wurden. Nach Abschluss der Befragungsaktion ergaben sich keine konkreten Anhaltspunkte gegen eine der 48 Personen.

\section{Die Rasterfahndung Nr.2}

a. Ermittlungsstand und Ausgangslage

Im Rahmen von Untersuchungen an der Briefbombe Nr.4, welche in der Zwischenzeit sichergestellt worden war, wurde ein vollständiges DNA-Muster aufge- 
funden. Der anschließende Abgleich mit der DNA-Datenbank des Bundeskriminalamtes ergab einen Treffer. Das DNA-Muster war identisch mit einer gesicherten DNA-Spur aus einem Einbruch am 07.05.2002 in der Gemeinde H. Nach dem Eingang der Briefbombe Nr.6 und dem DNA-Spurentreffer aus dem Einbruch in ein Anwesen in $\mathrm{H}$ am 07.05.2002 hat die OFA ihre fallanalytische Bewertung aktualisiert und überarbeitet. Demnach ergaben sich folgende Änderungen im Täterprofil:

- Männlicher Einzeltäter im Alter zwischen

- $\quad 30$ - 50 Priorität I

- 51 - 60 Priorität II

- 25 - 29 Priorität III

- Geografischer Ankerpunkt im Großraum H

- Bereits polizeilich in Erscheinung getreten und erkennungsdienstlich behandelt

- Eingeschränkte Stressresistenz

- Defizite im Bereich Frustrationstoleranz

- Introvertierte Persönlichkeit

- Täter gewinnt Sicherheit aus nicht-kommunikativen Beschäftigungen (Stressabbau)

- Kein aktives Interesse an Kommunikation

- Aber: Bedürfnis der Korrektur von Fehldarstellungen

- Täter hat Zugriff auf eine Werkstatt

\section{b. Begründung und Ziel}

Auf der Grundlage der Änderungen im Täterprofil wurde von der OFA eine erneute Rasterfahndung empfohlen. Ziel war es, einen Personenkreis für eine DNAReihenuntersuchung herauszufiltern. Die Maßnahme wurde am 27.08.2004 durch die AG-Briefbombe angeregt.

Es sollten bei den zuständigen Einwohnermeldeämtern von 25 Gemeinden die Daten von sämtlichen männlichen Einwohnern im Alter von 16 bis 70 Jahren erhoben werden. Die erhobenen Daten sollten darüber hinaus mit polizeilichen Datenbeständen zu einschlägig in Erscheinung getretenen Personen abgeglichen werden. Begründet wurde dies damit, dass der bislang unbekannte Täter des Einbruchs in $\mathrm{H}$ auch wahrscheinlich der Täter der Anschlagsserie sei. Aus den Ermittlungen zu dem Einbruch in $\mathrm{H}$ habe sich darüber hinaus die Erkenntnis ergeben, dass der Täter 
aus dem näheren Bereich von H stammen dürfte, da er über sehr gute Ortskenntnisse zu verfügen schien.

Unter Verwendung der gleichen Begründung stellte die Staatsanwaltschaft P am 01.09.2004 einen entsprechenden Antrag. Angeordnet wurde die Maßnahme ebenfalls am 01.09.2004 durch das Amtsgericht P. Dieses nutzte seinerseits die Begründung der ermittelnden AG-Briefbombe.

\section{c. Durchführung und Ergebnis}

Insgesamt wurden 50.931 Einwohnermeldeamt-Daten, die durch die 25 Gemeinden angeliefert wurden, mit dem KAN-Bestand und dem IGVP-Bestand (Eigentumsdelikte) abgeglichen. Hierbei wurden 7.947 Personen herausgefiltert, die aktuell gemeldet oder zurück bis 1998 in den Gemeinden wohnhaft waren und bei denen zudem noch kein DNA-Muster vorhanden war.

Personen, von denen eine Speichelprobe genommen werden sollte, wurden gemäß den unterschiedlichen Prioritäten in verschiedene Phasen unterteilt. Ausgangspunkt für die anschließenden Speicheltests war die Gemeinde $\mathrm{H}$, in welcher der Einbruch stattgefunden hatte. Die DNA-Tests erfolgten in zwölf Phasen.

Den Ausgangsdatenbestand für Phase Nr.1 bildeten alle männlichen Personen im Alter von 17 bis 70 Jahren, welche im Bereich der Gemeinde H aktuell oder inaktuell gemeldet waren. Merkmal für den Datenabgleich war ein KAN-Eintrag Eigentumsdelikte Straftatenschlüssel 2 (Raubdelikte), 3 (Diebstahlsdelikte) und 4 (Einbruch, also besonders schwere Fälle des Diebstahls) oder Hehlerei oder Waffen/Sprengstoffdelikte. Nach Anlegung dieser Kriterien blieben 129 Personen übrig, welche einem DNA-Test unterzogen werden sollten.

Grundmenge für Phase Nr. 2 waren ebenfalls alle männlichen Personen im Alter von 17 bis 70 Jahren, welche im Bereich der Gemeinde $\mathrm{H}$ aktuell oder inaktuell gemeldet waren. Auswahlkriterium waren in dieser Phase das Vorliegen von erkennungsdienstlichen Unterlagen und ein KAN-Eintrag erweitert auf Delikte, außer Körperverletzungsdelikte, Beleidigung und Verkehrsdelikte. Hiernach sollten 225 Personen einem DNA-Test unterzogen werden.

Wie Phase Nr.1 und Nr.2 wurde in Phase Nr.3 die identische Grundmenge gewählt. Abgeglichen wurden alle restlichen Delikte des KAN-Bestandes. Hier blieb eine Restmenge von 105 Personen übrig.

In Phase Nr.4 dienten alle männlichen Personen im Alter von 17 bis 70 Jahren, welche aktuell oder inaktuell in der Gemeinde F gemeldet waren, als Grundbestand. Auswahlkriterien waren in dieser Phase ein KAN-Eintrag oder IGVPDiebstahls-Eintrag. Betroffen waren in dieser Phase 70 Personen.

Für Phase Nr.5 wurden als Grunddaten alle männlichen Personen im Alter von 17 bis 70 Jahren, welche aktuell oder inaktuell in der Gemeinde W gemel- 
det waren, gewählt. Auch hier wurde als weitere Einschränkung ein KANEintrag oder IGVP-Diebstahls-Eintrag herangezogen. Die Restmenge betrug hier 108 Personen.

In Phase Nr.6 wurden wie bei den Phasen Nr.1 bis Nr.3 auch hier die entsprechenden Personen aus Gemeinde $\mathrm{H}$ herangezogen. Gerastert wurde jetzt mit einem IGVP-Diebstahls-Eintrag. 49 Personen wurden so herausgefiltert.

Die Ausgangsdatenmenge für Phase Nr.7 wird durch männliche Personen im Alter von 17 bis 70 Jahren, welche aktuell oder inaktuell in der Gemeinde B gemeldet waren, gebildet. Abgeglichen wurde dieser Datenbestand mit KAN-Eintrag oder IGVP-Diebstahls-Eintrag. Im Rahmen von Phase Nr.7 blieb eine Restmenge von 286 Personen übrig.

Als Ausgangsdatenmenge für Phase Nr.8 wurden alle männlichen Personen im Alter von 17 bis 70 Jahren, welche aktuell oder inaktuell in der Gemeinde E gemeldet waren, gewählt. Ein Abgleich erfolgte anhand des KAN-Bestandes und des IGVP-Diebstahls-Bestandes. Die Restmenge betrug 121 Personen.

In Phase Nr.9 bildeten alle männlichen Personen im Alter von 17 bis 70 Jahren, welche aktuell oder inaktuell in der Gemeinde F gemeldet waren, die Ausgangsdatenmenge. Der Abgleich erfolgte ebenfalls anhand des KAN-Bestandes und des IGVP-Diebstahls-Bestandes. Nach dem Abgleich verblieb eine Restmenge von 245 Personen.

Die Phasen Nr.10 und Nr.11 betrafen Personenkreise, die nicht mittels der Rasterfahndung ermittelt wurden. Betroffen von Phase Nr.10 waren 74 Personen und von Phase Nr.11 waren es 159 Personen.

Im Rahmen von Phase Nr.12 bildeten alle männlichen Personen im Alter von 17 bis 70 Jahren, welche aktuell oder inaktuell in der Gemeinde T gemeldet waren, die Ausgangsdatenmenge. Betroffen waren hier 193 Personen.

\section{d. Auswirkungen auf das Ermittlungsverfahren}

Auf der Grundlage des Datenabgleichs sollten von insgesamt 1764 Personen Speichelproben entnommen werden. Darüber hinaus wurde in der Gemeinde H vom 26.11.2004 bis zum 28.11.2004 eine DNA-Reihenuntersuchung durchgeführt. Hierzu wurden alle aktuellen und inaktuellen (bis1998) männlichen Einwohner der Gemeinde $\mathrm{H}$ im Alter zwischen 17 und 70 Jahren eingeladen. Hierbei handelte es sich um 2302 Personen. Zum Zeitpunkt der Täterermittlung wurden von der im Rahmen des Datenabgleichs ermittelten Gruppe 1445 Speichelproben genommen. Von den für den 26.11.2004 geladenen 697 Personen aus H waren 594 Personen zur Abgabe einer Speichelprobe erschienen. Die Auswertung verlief durchweg negativ. 


\section{Ausgang des Verfahrens}

Zeitgleich zur Reihenuntersuchung in H wurde am 26.11.2004 eine verbrannte männliche Leiche auf einem Feld in der Nähe von H aufgefunden. Erste Ermittlungen ergaben, dass die Person mittels eines selbst gebauten Sprengsatzes Suizid begangen haben dürfte. Ein durchgeführter Vergleich der DNA mit der DNA des Täters der Briefbombenserie ergab eindeutige Übereinstimmungen. Aus diesem Grund wurde die DNA-Reihenuntersuchung in $\mathrm{H}$ abgebrochen. Der Täter war für den 27.11.2004 zur Reihenuntersuchung eingeladen. Laut Abschlussbericht der AG-Briefbomben sah er vermutlich keinen anderen Ausweg als den Suizid. Er wurde aufgrund von DNA-Untersuchungen und aufgefundenen Beweismitteln als Täter identifiziert. Letztlich wurden umfangreiche Ermittlungen im Umfeld des Täters durchgeführt, welche einen nahezu kompletten Lebenslauf des Täters zum Ergebnis hatte. Ein mögliches Tatmotiv konnte jedoch nicht ermittelt werden. Die Ermittlungen wurden daraufhin eingestellt.

\section{Erfolgseinschätzung}

Ursächlich für die Entscheidung des Täters, Suizid zu begehen, dürfte der durch die Einladung zur Abgabe einer Speichelprobe ausgeübte Druck gewesen sein. Insofern führte die DNA-Reihenuntersuchung in H zur Identifizierung des Täters. Im Abschlussbericht des LKA wurde ausdrücklich festgehalten, dass die DNAReihenuntersuchung in der Gemeinde $\mathrm{H}$ die einzige Möglichkeit war, den Täter zu ermitteln.

Die auf der Grundlage des Datenabgleichs durchgeführte DNA-Untersuchung konnte jedoch nicht zur Identifizierung führen, da dieser nicht von den betreffenden polizeilichen Datenbeständen erfasst war. Sie war lediglich dazu geeignet, einen Personenkreis für die Reihenuntersuchung zu priorisieren, so dass nicht gleich zu Beginn alle männlichen Einwohner eingeladen werden mussten. Mithin eignet sich die Rasterfahndung zur Steigerung der Effizienz einer DNAReihenuntersuchung. Darüber hinaus wurden die Daten der männlichen Einwohner von $\mathrm{H}$ aufgrund der Anordnung gem. § 98a StPO erhoben. Folglich führte zumindest dieser Teil der Rasterfahndung mittelbar zur Identifizierung des Täters.

Auch die Rasterfahndung Nr.1, an deren Ende 48 Personen mit negativem Ergebnis überprüft worden sind, kann nicht als erfolglos angesehen werden. Sie brachte zu einem Zeitpunkt der Ermittlungen, an dem kaum Spuren vorhanden waren, zumindest neue Ermittlungsansätze. Allerdings muss auch festgehalten werden, dass diese Maßnahme keinen Beitrag zur Identifizierung des Täters lieferte. 


\section{Verfahren 024}

\section{Sachverhalt}

Das Verfahren 024 hatte eine Serie von 19 Einbruchsdiebstählen zum Gegenstand. Dabei handelte es sich ausschließlich um Einbrüche in Wohnungen von Angestellten und Betreibern von chinesischen und vietnamesischen Restaurants. Zur Beute ließen sich den Verfahrensakten keine Informationen entnehmen. Die Taten wurden zwischen dem 29.04.2004 und dem 07.08.2004 in zwei Bundesländern begangen.

\section{Die Rasterfahndung}

\section{a. Ermittlungsstand und Ausgangslage}

Eingeleitet wurde dieses Ermittlungsverfahren durch die Staatsanwaltschaft D am 21.06.2004. Die Ermittlungen ergaben bei allen Einbrüchen einen ähnlichen Modus Operandi. Zunächst wurden die Restaurants seitens der Täter observiert, um Hinweise auf die Wohnverhältnisse der Opfer zu erlangen. Anschließend erfolgten mehrere Testanrufe auf den Festnetzanschlüssen der Wohnungsinhaber. Diese wurden auch unmittelbar vor der Tatbegehung durchgeführt. Letztlich wurden die Einbrüche immer in der Mittagszeit verübt, während sich die Wohnungsinhaber in ihren Restaurants befanden. Die Wohnungstüren wurden aufgebrochen und in den Wohnungen wurden alle Behältnisse nach Bargeld und Goldschmuck durchsucht. Als Fluchtfahrzeuge dienten ältere Pkws, die unter falschem Namen gekauft und nicht umgemeldet worden waren.

Aufgrund der Testanrufe wurden Maßnahmen nach den $\S \S 100 \mathrm{~g}$, h StPO durchgeführt. Darüber hinaus konnte an einem Tatort eine Sohlenabdruckspur sichergestellt werden. Zeugen konnten drei verschiedene Pkw- Kennzeichen und Modelle beobachten und beschreiben. Letztlich konnte die Beschuldigte Nr.1 aufgrund einer Zeugenaussage als Käuferin eines der Pkws identifiziert werden. Ihr Aufenthaltsort war jedoch unbekannt. Insgesamt bestand die Gruppe aus vier bis sechs Personen.

\section{b. Begründung und Ziel}

Am 24.08.2004 wurde durch die ermittelnde Polizeibehörde eine Maßnahme nach den $\S \S 98 \mathrm{a}, \mathrm{b}$ StPO bei der Staatsanwaltschaft D angeregt. Begründet wurde die Anregung mit Hinweisen auf die Beschuldigte Nr.1. Um Anhaltspunkte für die Tatbeteiligung der Beschuldigten erlangen zu können, sei die Auswertung der Protokolldatei der Zentralen Polizeitechnischen Dienste (ZPD) geeignet. Es sei denkbar und, wie die Erfahrung zeigen würde, wahrscheinlich, dass die Beschuldigte Nr.1 sowie die seitens der Tätergruppe benutzten Pkws im Rahmen polizeilicher Kontrollen überprüft und diese Vorgänge datenmäßig erfasst worden sein könnten. Eine Auswertung der Protokolldatei könnte demnach Aufschluss über die Reise- 
wege der Beschuldigten Nr.1, deren Mittäter, die Struktur der Tätergruppe und eine Zuordnung weiterer Einbruchdiebstähle ermöglichen. Daher sollte die Protokolldatei auf Daten im Zusammenhang mit der Beschuldigten und den drei KfzKennzeichen ausgewertet werden. Als Begründung wurde darüber hinaus angeführt, dass eine Sachverhaltsermittlung auf andere Art und Weise nicht möglich und die Durchführung der Maßnahme angesichts der Schwere der Tatvorwürfe auch verhältnismäßig sei.

Noch am 24.08.2004 wurde die Maßnahme beim Amtsgericht D beantragt. Dabei waren Anregung und Antrag nahezu wortgleich. Lediglich die Einordnung der Anlassstraftat unter die Katalogdelikte gewerbsmäßige Begehung und Mitglied einer Bande, waren in der polizeilichen Anregung noch nicht enthalten.

Die Maßnahme wurde durch das Amtsgericht D am 25.08.2004 angeordnet. Dabei wurde der abzufragende Zeitraum auf die Zeit vom 20.04.2004 bis 08.08.2004 begrenzt. Über die Begründung der Staatsanwaltschaft hinaus führte das Amtsgericht in seiner Anordnung an, dass die Beweislage sehr dünn sei und andere tatrelevante Spuren, die einen Rückschluss auf bestimmte Personen zulassen würden, bisher nicht ermittelt worden seien.

Als Ziele der Maßnahme waren die Rückverfolgung der Reisewege der Beschuldigten Nr.1, die Identifizierung von Mittätern, Erkenntnisse über die Struktur der Tätergruppe und eine Zuordnung weiterer Einbruchsdiebstähle festzuhalten.

\section{c. Durchführung und Ergebnis}

Mit Schreiben vom 02.09.2004 wurde der ermittelnden Polizeidienststelle eine Trefferliste zugesandt. Diese befand sich zum Zeitpunkt der Auswertung noch in den Verfahrensakten. Die drei Fahrzeuge wurden mehrfach in verschiedenen Datenbanken abgefragt. So unter anderem in ZEVIS, INPOL und POLAS.

\section{d. Auswirkungen auf das Ermittlungsverfahren}

Laut polizeilichem Vermerk vom 08.09.2004 konnten keine relevanten Daten zur Aufklärung der Taten erlangt werden. Auf die weiteren Ermittlungen hatte die Maßnahme daher keinen Einfluss.

\section{Ausgang des Verfahrens}

Am 14.10.2004 konnte eines der Fluchtfahrzeuge aufgefunden werden. Untersuchungen ergaben drei verwertbare DNA-Spuren. Eine Zuordnung der Spuren konnte bislang nicht erfolgen. Angefertigte und veröffentlichte Phantombilder erbrachten keine Hinweise auf die Täter. Es ergaben sich daher keine weiteren Ermitt- 
lungsansätze. Das Verfahren wurde am 04.07.2005 analog § 205 StPO eingestellt und die Beschuldigte Nr.1 zur Aufenthaltsermittlung ausgeschrieben.

\section{Erfolgseinschätzung}

Die Einschätzung der anregenden Polizeidienststelle, die Pkws könnten kontrolliert oder in den betreffenden Datenbanken abgefragt worden sein, erwies sich als richtig. Allerdings erbrachten die erlangten Daten keine neuen Ermittlungsansätze. Insofern konnten die angeführten Ziele, wie unter anderem die Aufenthaltsermittlung der Beschuldigten, nicht erreicht werden. Mithin war die Maßnahme nicht erfolgreich. Diese Einschätzung der ermittelnden Polizeidienststelle wurde so auch in den Verfahrensakten festgehalten.

\section{Verfahren 025}

\section{Sachverhalt}

Gegenstand von Verfahren 025 waren Ermittlungen zur Aufklärung eines vollendeten und eines versuchten Tötungsdeliktes. Auslöser für dieses Verfahren war das versuchte Tötungsdelikt. Am 19.10.2004 wurde eine Prostituierte von einem LKW-Fahrer mitgenommen. Sie begaben sich mit seinem LKW auf eine Autobahn. Nachdem eine längere Strecke zurückgelegt worden war, fuhr der LKWFahrer an einer Ausfahrt von der Autobahn ab und vergewaltigte das Opfer. Anschließend verletzte er das Opfer mit einem Messer lebensgefährlich. Das Opfer flüchtete über ein Feld in Richtung Autobahn. Dort wurde es von einem PkwFahrer aufgenommen.

Aufgrund des Modus Operandi wurde dem Täter eine weitere Tat, welche sich ein Jahr zuvor ereignet hatte, zugerechnet. Hierbei wurde eine Prostituierte von einem LKW-Fahrer aufgenommen, vergewaltigt und anschließend mit mehreren Messerstichen getötet. Auch diese Tat war in größerer Entfernung zum Aufnahmeort begangen worden.

\section{Die Rasterfahndung}

\section{a. Ermittlungsstand und Ausgangslage}

Die Ermittlungen wurden durch die Kriminalpolizei K und das Landeskriminalamt geführt. Aufgrund der Beschreibungen des Opfers konnte ein Phantombild des Täters gefertigt werden, welches veröffentlicht wurde. Darüber hinaus beschrieb das Opfer eine körperliche Auffälligkeit des Täters. Diesbezüglich wurden Veröffentlichungen in einschlägigen Ärzteblättern getätigt. An den Opfern sichergestellte 
DNA-Spuren des Täters wurden mit den betreffenden Dateien abgeglichen. Darüber hinaus wurden diese Spuren im Rahmen von Rechtshilfeersuchen auch mit ausländischen Dateien abgeglichen. Die gesamten Ermittlungsmaßnahmen verliefen jedoch ohne Erfolg. Letztlich war das Verfahren Gegenstand der Fernsehsendung „Aktenzeichen: xy ungelöst“. Die aufgrund der Ausstrahlung erhaltenen Hinweise erbrachten jedoch auch keine weiteren Ermittlungsansätze.

Zeitgleich wurde durch die Abteilung Operative Fallanalyse (OFA) des Landeskriminalamtes eine vergleichende Untersuchung der beiden Taten durchgeführt. Das Ergebnis bestätigte die Annahme, dass es sich um den gleichen Täter handeln dürfte. Auf diesen Erkenntnissen basierend, wurde von der OFA eine Maßnahme nach den $\S \S 98 \mathrm{a}, \mathrm{b}$ StPO vorgeschlagen.

\section{b. Begründung und Ziel}

Angeregt wurde die Maßnahme am 08.11.2004 durch die ermittelnde Mordkommission. Mithilfe eines automatisierten Datenabgleichs sollten bereits erhobene und noch zu erhebende Daten abgeglichen werden. Sollte es bei dem Abgleich zu Überschneidungen kommen, so sollten diese als Spur konventionell ausermittelt werden. In den Datenabgleich sollten die folgenden Daten einbezogen werden:

- Daten von Speditionsunternehmen über Fahrten zu beiden Tatzeiten

- Daten von Geldautomaten im Umfeld der Aufnahme- und Tatorte in einem Zeitraum von sechs Stunden um die Taten

- Tankquittungen von Tankstellen in den Bereichen der Aufnahmeund Tatorte im betreffenden Zeitraum (Frage: Wer hat Diesel getankt und mit EC-Karte gezahlt?)

- Auswertungen des polizeilichen Fahndungssystems

- operative Maßnahmen eines Ermittlungstrupps

- Daten aus der Überwachung von Kreuzzungen in der Nähe der Aufnahmeorte. Es sollten LKW-Kennzeichen mit einer Videokamera aufgezeichnet werden.

- Eine solche Aufzeichnung sollte auch von einer Autobahnbrücke aus, auf einer Autobahn durchgeführt werden. Diese Daten sollten auch in den Abgleich einbezogen werden.

- Funkzellendaten der Aufnahme- und Tatorte in den betreffenden Zeiträumen

- Daten aus einer Recherche in der VICLAS-Datenbank

- Halterdaten des Kraftfahrtbundesamtes 
- Angedacht war auch die Einbeziehung von Daten der LKWMautstellen von Toll Collect

Den operativen Maßnahmen an den betreffenden Straßenkreuzungen und der Autobahn lag die Annahme zugrunde, dass der Täter im Rahmen seiner beruflichen Tätigkeit als LKW-Fahrer diese Stellen häufig passieren würde. Ein entsprechender Antrag der Staatsanwaltschaft K wurde am 10.11.2004 gestellt. Am 12.11.2004 informierte das Amtsgericht die Staatsanwaltschaft, dass die beantragte Anordnung so nicht getroffen werden könnte und verlangte Ergänzungen. So sah sich das Amtsgericht K nicht für die Daten aus der ersten Tat zuständig und verlangte einen entsprechenden Antrag an das Amtsgericht D. Darüber hinaus waren im Antrag der Staatsanwaltschaft die zur Übermittlung der Daten Verpflichteten nicht ausdrücklich bezeichnet worden. Nachdem die Staatsanwaltschaft die betreffenden Ergänzungen vorgenommen hatte, wurde die Maßnahme am 25.11.2004 angeordnet. In der Anordnung nicht enthalten waren jedoch die Daten, welche im Rahmen der operativen Maßnahmen noch erhoben werden sollten.

Um diese Daten einbeziehen zu können, richtete die Staatsanwaltschaft K am 17.12.2004 einen erneuten Antrag an das Amtsgericht. Die Einbeziehung der Daten in die Maßnahme nach den $\S \S 98 \mathrm{a}$, b StPO wurde am 30.12.2004 angeordnet. Darüber hinaus wurde am 06.01.2005 durch das Amtsgericht D die Einbeziehung der Daten aus der ersten Tat angeordnet.

\section{c. Durchführung und Ergebnis}

Über die Durchführung und das Ergebnis der Maßnahme waren den Verfahrensakten nur wenige Informationen $\mathrm{zu}$ entnehmen. Dies ist dem Umstand geschuldet, dass die Maßnahme noch in der Durchführung begriffen war, als die Aktenanalyse erfolgte. Die Durchführung der Maßnahme erstreckt sich aufgrund erheblicher technischer Probleme im Rahmen der operativen Maßnahmen auf der Autobahn und den betreffenden Straßenkreuzungen über einen längeren Zeitraum.

Allein vom Kraftfahrtbundesamt wurden zwischen 500.000 und 800.000 personenbezogene Datensätze übermittelt. Nach Ansicht des KBA hat die Übermittlung eines Teils der Daten einem Anordnungsverbot unterlegen. Trotz dieser Bedenken wurden die betreffenden Daten dennoch übermittelt. $\mathrm{Zu}$ den Geldabhebungen an Geldautomaten lagen Daten von 150 Personen vor. Von den Speditionen konnten 481 Personen, welche in den beiden Tatnächten Fahrten durchgeführt hatten, ermittelt werden. Letztlich ergaben sich aus einer Recherche im POLAS-Datenbestand Hinweise auf 1.830 Personen. Diese 1.830 Personen sollten als Grundlage für die geplanten Abgleiche dienen. Inwieweit ein Abgleich durchgeführt wurde und ob die Daten aus den Observationen bereits vorgelegen haben, konnte den Verfahrensakten mit Stand 30.11.2005 nicht entnommen werden. 


\section{d. Auswirkungen auf das Ermittlungsverfahren}

Zum Zeitpunkt der Auswertung der Verfahrensakten lagen noch keine Informationen über Treffer vor. Insofern konnten die Auswirkungen auf das Ermittlungsverfahren noch nicht beurteilt werden. Den Verfahrensakten zufolge bildete die Rasterfahndung jedoch den Mittelpunkt der Ermittlungen.

\section{Ausgang des Verfahrens}

Wie bereits dargelegt, war das Verfahren zum Zeitpunkt der Aktenanalyse noch nicht abgeschlossen. Mitte des Jahres 2006 konnte jedoch aus Medienberichten in Erfahrung gebracht werden, dass der Täter, nachdem er eine weitere Tat begangen hatte, gefasst wurde. Ursächlich für die Ergreifung waren Hinweise aufgrund eines veröffentlichten neuen Phantombildes. Insgesamt waren dem Täter drei vollendete und ein versuchtes Tötungsdelikt zuzurechnen. Eine erneute Akteneinsicht konnte aufgrund der weiteren Ermittlungen nicht mehr erfolgen. Demnach konnte nicht in Erfahrung gebracht werden, ob und mit welchem Ergebnis die Rasterfahndung weiter durchgeführt worden ist.

\section{Erfolgseinschätzung}

Da die Maßnahme zum Zeitpunkt der Akteneinsicht nicht beendet war, konnten keine Einschätzungen bzgl. des Erfolges getätigt werden. Aufgrund der Informationen aus den Medien wurde jedoch bekannt, dass es sich bei dem Täter tatsächlich um einen LKW-Fahrer gehandelt hat. Insofern bestand durchaus die Möglichkeit, dass dieser die betreffenden Punkte mit den Observationseinrichtungen auch im Nachhinein passiert haben könnte. Mithin war die Maßnahme, gerade vor dem Hintergrund der wenigen Hinweise auf den Täter, ein Erfolg versprechender Ermittlungsansatz.

\section{Verfahren 026}

\section{Sachverhalt}

Am 5.12.2004 wurde die Leiche einer Prostituierten in G aufgefunden. Diese lag unbekleidet vor einem Gebäude, in dem bekanntermaßen der Prostitution nachgegangen wurde. Aufgrund der Untersuchungen stellte sich heraus, dass das Opfer zunächst gewürgt und anschließend aus einem Fenster im fünften Obergeschoss geworfen worden war. Am Tatort konnten Blut und ein benutztes Kondom mit DNA-Material sichergestellt werden. Die gleiche DNA wurde auch unter den Fingernägeln des Opfers sichergestellt. 


\section{Die Rasterfahndung}

a. Ermittlungsstand und Ausgangslage

Am 6.12.2004 wurde eine Sonderkommission gegründet. Die Ermittlungen konzentrierten sich auf vier Richtungen. Diese waren das Umfeld des Opfers, das Umfeld des Tatortes, das Vorliegen einer Millieustraftat und die Tathypothese „letzter Freier“. Zunächst wurden Maßnahmen nach den $\S \S 100 a$, b StPO bei sämtlichen Prostituierten im betreffenden Wohnobjekt veranlasst. Darüber hinaus wurden Maßnahmen nach den $\S \S 100 \mathrm{~g}$, h StPO für den näheren Umkreis um den Tatort getroffen.

Ferner wurde durch die Abteilung Operative Fallanalyse des Landeskriminalamtes eine Fallanalyse durchgeführt. Im Rahmen der Fallanalyse wurde der Täter wie folgt beschrieben:

- kein Serienmörder

- war vermutlich nicht das erste Mal im Tatobjekt

- Temperamentsprobleme i.V.m.

- Genussmittelmissbrauch

- er hasst nichts mehr als Widerstand

- häufiger Wechsel der Arbeitsstelle / Wohnung

- interagiert mit anderen Menschen, zieht aber die eigene Gesellschaft vor

- unternimmt Handlungen, ohne die Konsequenzen zu bedenken (selbstsüchtig)

- arbeitet in einer Position, welche es ihm erlaubt, seine Aggressionen abzureagieren

- tendenzielle Allmachtsvorstellungen

- allgemeine sexuelle Funktionsstörung ist die verzögerte Ejakulation

Auf den Einschätzungen zum Täter basierend, ergaben sich für die OFA folgende Rasterparameter:

- der Täter ist männlich

- sein Alter liegt zwischen 17 und 53 Jahren

- der Wohnort liegt in einem Umkreis von $21 \mathrm{~km}$ um den Tatort

- er hat kriminelle Vorerfahrungen; entweder Hellfeld oder Dunkelfeld (Diebstahl, Körperverletzungsdelikte, Betäubungsmittel- 
delikte, Trunkenheitsfahrten, Fahren ohne Fahrerlaubnis, Sexualdelikte, Tötungsdelikte, Beleidigung)

Bis auf die Erkenntnisse aus der Fallanalyse lagen keine Hinweise auf einen möglichen Täter vor. Von entscheidender Bedeutung für die weiteren Ermittlungen war daher, dass die sichergestellte DNA-Spur als vom Täter stammend gewertet wurde. Dies hatte zur Folge, dass die Tathypothese ,letzter Freier“ zu priorisieren war.

\section{b. Begründung und Ziel}

Für die ermittelnde Polizeibehörde bildete die Fallanalyse der OFA die Grundlage für die Anregung der Rasterfahndung. Die Maßnahme wurde am 3.02.2005 angeregt. Danach sollten alle männlichen Personen, welche im Umkreis von $20 \mathrm{~km}$ um den Tatort wohnhaft waren, erfasst werden.

Hierzu sollte die Kommunale Informationsverarbeitung (KIV) von 42 Gemeinden die Daten von:

- allen männlichen Personen / Einwohnern, die 1990 oder früher geboren wurden und deren Daten im aktuellen Datenbestand enthalten sind;

- allen männlichen Personen / Einwohnern, die 1990 oder früher geboren wurden und deren Daten nicht im aktuellen Datenbestand enthalten sind, weil sie in der Zeit vom 1.07.2004 bis zum Erfassungszeitpunkt verzogen sind;

- allen männlichen Personen / Einwohnern, die 1990 oder früher geboren wurden und deren Daten nicht im aktuellen Datenbestand enthalten sind, weil sie in der Zeit vom 5.12.2004 bis zum Erfassungszeitpunkt verstorben sind, übermitteln.

Die personenbezogenen Daten sollten Familiennamen, frühere Namen, Vornamen, Tag der Geburt, Geburtsort, Staatsangehörigkeit, Straße, Hausnummer, Postleitzahl, Ort und Stadtteil enthalten. Darüber hinaus wurden Beschlüsse desselben Inhaltes für zwei weitere Gemeinden, welche nicht der KIV angehörten, aber innerhalb der $20 \mathrm{~km}$ lagen, angeregt. Außer der Erfassung der Daten als Datengrundlage für weitere Ermittlungen wurden keine Begründung und auch kein weiteres mit der Maßnahme verfolgtes Ziel aufgeführt. Ein möglicherweise geplanter Abgleich mit weiteren personenbezogenen Daten hat in den Verfahrensakten keine Erwähnung gefunden.

Drei entsprechende Anträge wurden durch die Staatsanwaltschaft am 7.02.2005 gestellt. Als einzige Begründung führte die Staatsanwaltschaft die Erkenntnis aus der Fallanalyse an, wonach der Täter in einem Umkreis von $20 \mathrm{~km}$ um den Tatort wohnhaft sei. Das Amtsgericht G erließ am 11.02.2005 die beantragten Anordnun- 
gen bzgl. der 42 der KIV angehörenden Gemeinden und der beiden weiteren Gemeinden. Die richterlichen Anordnungen enthielten die Erforschung des Sachverhaltes und die Ermittlung des Aufenthaltsortes als Ziele.

Laut richterlicher Anordnung war die Maßnahme unerlässlich, „da die Erforschung des Sachverhalts und die Ermittlung des Aufenthaltsortes des Beschuldigten auf andere Weise aussichtslos oder wesentlich erschwert wäre“. Insofern gab die richterliche Begründung lediglich den Wortlaut des § 98a I StPO als Begründung wieder. Wertet man diese Begründung gleichzeitig als Ziel der Maßnahme, können die Schaffung einer Datengrundlage für weitere Ermittlungen, die Erforschung des Sachverhaltes und die Ermittlung des Aufenthaltsortes des Beschuldigten als Ziele festgehalten werden

Darüber hinaus wurden bei zwei amerikanischen Militärstandorten, die sich im 20-km-Umkreis befanden, ebenfalls Daten erhoben. Dieser Erhebung lag ein staatsanwaltschaftliches Ermittlungsersuchen zugrunde. Ein formelles Rechtshilfeersuchen war nicht notwendig. Begründet wurde das Ersuchen mit einem Verweis auf die $\S \S 98$ a, b StPO.

\section{c. Durchführung und Ergebnis}

Wann die Aussonderung der Daten bei der KIV durchgeführt wurde, ließ sich den Verfahrensakten nicht entnehmen. Aus einem polizeilichen Vermerk konnte jedoch die Information erlangt werden, dass die Ergebnisse am 19.04.2005 bei der ermittelnden Polizeidienststelle vorlagen. Die angeforderten Daten hatten eine Größenordnung von ca. 280.000 personenbezogenen Datensätzen.

\section{d. Auswirkungen auf das Ermittlungsverfahren}

Bevor die Übermittlung der Daten am 19.10.2005 an die ermittelnde Polizeidienststelle stattfand, wurde der Täter bereits ermittelt. Dieser war bereits am 31.03.2005 geständig. Insofern wurden die erlangten Daten nicht weiter benötigt. Ob die erhaltenen Datenträger zurückgegeben und die Daten gelöscht wurden, war den Verfahrensakten nicht zu entnehmen.

\section{Ausgang des Verfahrens}

Aufgrund der Priorisierung der Tathypothese „letzter Freier“ in Verbindung mit der DNA-Spur bestand die Notwendigkeit, DNA-Proben von männlichen Personen zu entnehmen, die im Rahmen der Ermittlungen in Erscheinung getreten waren. Hierzu wurden alle erlangten Erkenntnisse in sog. Personenlisten aufgenommen. Diese ermöglichten eine Gewichtung innerhalb der in Erscheinung getreten Perso- 
nen. Insgesamt wurden neun Listen für die Ermittlungen angefertigt. In den Listen 1 bis 8 wurden die Personen aufgeführt, die beispielsweise aufgrund der Maßnahmen nach $\S \S 100 \mathrm{~g}$, h StPO und der weiteren Ermittlungen im Umfeld des Tatortes in Erscheinung getreten waren. Hieraus wurden 1678 Personen herausgefiltert, von denen nach weiteren kriminalistischen Überlegungen 616 Personen in eine DNAListe aufgenommen wurden. Liste Nr.9 enthielt die 280.000 aufgrund der Rasterfahndung erlangten Datensätze. Der Täter war in den erhobenen Datensätzen zweimal enthalten. Zum einen hielt er sich zum tatkritischen Zeitpunkt in einer Gaststätte in der Nähe des Tatortes auf und zum anderen telefonierte er mit einem Mobiltelefon in der Funkzelle des Tatortes. Aus diesem Grund wurde er auch in die Liste für den DNA-Abgleich aufgenommen.

Er wurde im Rahmen der Ermittlungen angeschrieben und zur Abgabe einer Speichelprobe aufgefordert. Dieser Aufforderung kam er jedoch nicht nach. Im weiteren Verlauf der Ermittlungen wurden alle Personen, welche dieser Aufforderung nicht nachgekommen waren, aufgesucht und erneut um die Abgabe einer Speichelprobe gebeten. Im Rahmen dessen gab der Täter schließlich eine Speichelprobe $a b$, welche zur Überführung führte. Von den 616 Personen auf der Liste, welche als Grundlage zur DNA-Erhebung diente, gaben bis zu diesem Zeitpunkt 410 Personen freiwillig eine DNA-Probe ab. 67 Personen waren bereits in der DNADatenbank enthalten und 15 Personen verweigerten die Abgabe. In der ersten Beschuldigtenvernehmung am 31.03.2005 legte der Täter ein umfassendes Geständnis ab. Mit rechtskräftigem Urteil vom 8.12.2005 wurde er zu neun Jahren Freiheitsstrafe verurteilt.

\section{Erfolgseinschätzung}

In Bezug auf die Ergreifung des Täters lieferte die Rasterfahndung keine Erkenntnisse. Insofern kann die Rasterfahndung nicht als erfolgreich bezeichnet werden. Sie brachte keine Informationen zur Erforschung des Sachverhaltes und trug auch nicht zur Ermittlung des Aufenthaltsortes des Beschuldigten bei.

Bezieht man allerdings das Ziel „Erlangung einer Datengrundlage für weitere Ermittlungen“ in die Betrachtung mit ein, so muss festgehalten werden, dass dieses erreicht wurde. Inwiefern die erlangten und in Liste Nr. 9 gespeicherten Daten benutzt worden wären, wenn der Täter nicht bereits ermittelt worden wäre, lässt sich den Verfahrensakten nicht entnehmen. Es kann nur spekuliert werden, wozu die Datengrundlage dienen sollte. Ersichtlich wäre hier nur ein Abgleich mit polizeiinternen und / oder mit den aufgrund von $\S \S 100 \mathrm{~g}$, h StPO erhobenen Daten. Ein entsprechender Datenabgleich wäre auf der Grundlage der von der OFA erstellten Rasterparameter durchaus erfolgreich gewesen, da der Täter mehrfach enthalten war. Ein solches Vorgehen wäre jedoch nur mit einer zusätzlichen richterlichen Anordnung möglich gewesen. 
Es bleibt festzuhalten, dass die Maßnahme nur sehr allgemein und unter Verwendung des Gesetzeswortlautes begründet wurde. Konkrete mit der Maßnahme verfolgte Ziele waren nicht zu erkennen. Letztlich ist ein Datenbestand in der Größenordnung von 280.000 Personen kaum sinnvoll in die Ermittlungen einzubeziehen.

\section{Verfahren 027}

\section{Sachverhalt}

Das Verfahren 027 hatte Ermittlungen bzgl. des Verdachts eines versuchten Tötungsdeliktes zum Gegenstand. Die Geschädigte, eine Richterin am Zivilgericht, war am 28.07.2005 mit dem Fahrrad auf dem Weg zu ihrer Dienststelle, als sich ihr von hinten der unbekannte Täter, ebenfalls auf einem Fahrrad, näherte. Im Vorbeifahren schlug der Täter mit einem Schwert, Säbel oder ähnlich scharfen Gegenstand in den Nacken des Opfers. Nach der Tat stoppte der Täter in einiger Entfernung und schaute sich um. Anschließend fuhr er weiter, wobei er von Zeugen gesehen wurde. Die Verletzungen des Opfers waren nur aufgrund schneller ärztlicher Versorgung nicht lebensgefährlich.

\section{Die Rasterfahndung}

\section{a. Ermittlungsstand und Ausgangslage}

Erste Ermittlungen durch eine gegründete Sonderkommission ergaben keine Hinweise auf einen beruflichen oder privaten Hintergrund für die Tat. Dass der Täter nach der Tat gestoppt und sich umgeschaut habe, wurde als Hinweis darauf gewertet, dass es sich um keine geplante Tat, sondern eher um einen Unfall gehandelt habe. Daher wurde der Tathergang rekonstruiert und ein Gutachten bzgl. der Frage erstellt, ob es sich auch um einen Unfall gehandelt haben könnte. Darüber hinaus wurden Maßnahmen nach $\S \S 100 \mathrm{~g}$, h StPO für die Tatortumgebung veranlasst. Es wurden eine Belohnung in Höhe von 5.000€ ausgesetzt und Überwachungsposten und Kontrollstellen im Tatortbereich eingerichtet. Letztlich wurde der Fall am 27.10.2005 in der Fernsehsendung „Aktenzeichen: xy ungelöst“ ausgestrahlt. All diese Ermittlungsmaßnahme erbrachten jedoch keine Erkenntnisse, die zur Ergreifung eines Täters führten.

\section{b. Begründung und Ziel}

Bereits am 27.07.2005 wurde eine Maßnahme nach $\S \S 98 a$, b StPO durch die ermittelnde Polizeidienststelle angeregt. Die Anregung enthielt keine Begründung. Es wurde angeregt die Daten von allen männlichen Personen zwischen 25 und 45 Jahren, die im Bestand des Einwohnermeldeamtes (EMA) aktuell registriert waren, 
zu erheben. Für die weiteren Recherchen sei es darüber hinaus erforderlich, diese personenbezogenen Daten mit den gespeicherten Daten in der Protokolldatei des LKA und dem Datenbestand des Landes-Kriminalaktennachweises (KAN) abzugleichen.

Ein entsprechender Antrag der Staatsanwaltschaft A wurde am gleichen Tag gestellt. Begründet wurde die Maßnahme durch die Staatsanwaltschaft nicht. Lediglich der Sachverhalt wurde in einem kurzen Satz dargelegt. Darüber hinausgehende konkrete mit der Maßnahme verfolgte Ziele enthielt der Antrag nicht. Die Anordnung durch das Amtsgericht A erging am 01.08.2005. Hierzu wurde lediglich eine Ausfertigung der Staatsanwaltschaft unterschrieben und mit einem neuen Datum versehen. Ein identischer Vorgang, d.h. Anregung, Antrag und Anordnung mit gleichem Datum und Inhalt, wurde für die Daten des Einwohnermeldeamtes der Stadt $\mathrm{S}$ durchgeführt.

Darüber hinaus wurde auf Antrag der Staatsanwaltschaft vom 18.08.2005, der Abgleich von Daten der beim Landratsamt A - Gesundheitsamt registrierten männlichen Personen im Alter zwischen 25 und 45 Jahren mit der Protokolldatei des LKA und dem Datenbestand des Landes-KAN am 19.08.2005 angeordnet. Auch hier wurde die Ausfertigung der Staatsanwaltschaft durch das Amtsgericht lediglich unterschrieben. Eine Begründung und die Angabe von verfolgten Zielen waren den Verfahrensakten nicht zu entnehmen. Diese Maßnahme dürfte jedoch im Zusammenhang mit der vormaligen Tätigkeit des Opfers beim Familiengericht, insbesondere mit Unterbringungssachen gestanden haben. Darüber hinaus wurde eine identische Maßnahme für Daten des Gesundheitsamtes der Stadt S beantragt. Ein Beschluss bzgl. dieser Maßnahme war in den Verfahrensakten jedoch nicht enthalten. Insgesamt bleibt festzuhalten, dass in diesem Verfahren vier Anordnungen nach den $\S \S 98 \mathrm{a}, \mathrm{b}$ StPO beantragt und getroffen worden sind. Konkrete Ziele wurden jedoch nicht angegeben und die angeführten Begründungen waren als formelhaft zu bezeichnen.

\section{c. Durchführung und Ergebnis}

Neben den aufgrund der Maßnahmen nach $\S \S 98 \mathrm{a}$, b StPO erlangten Daten wurden zusätzlich und ohne richterliche Anordnung alle Daten von Vormundschaftssachen, mit denen das Opfer befasst war, beim betreffenden Gericht erhoben. Die Daten des Vormundschaftsgerichtes umfassten 116 personenbezogene Datensätze. Letztlich wurden auch Daten des Zivilgerichtes, bei dem das Opfer zur Tatzeit tätig war, ohne Anordnung erhoben.

Wann die von den Einwohnermeldeämtern angeforderten Daten vorgelegen haben, war den Verfahrensakten nicht zu entnehmen. Allerdings richtete die ermittelnde Polizeidienststelle am 03.08.2005 einen Antrag an das LKA, die aufgrund der Beschlüsse Nr.1 und Nr.2 erhobenen Daten mit den Daten des Vormundschaftsgerichtes, des Zivilgerichtes und dem Datenbestand des KAN abzugleichen. 
Im Rahmen des KAN sollten Erkenntnisse zu Gewaltdelikten, Waffendelikten und Schlagwaffen herangezogen werden. Welchen Umfang die im Rahmen von Anordnung Nr.1 und Anordnung Nr.2 durch die Einwohnermeldeämter übermittelten Daten hatten, war nicht ersichtlich. Die Ergebnisse des vom LKA vorgenommenen Abgleichs wurden der ermittelnden Polizeidienststelle mit Schreiben vom 12.08.2005 zugesandt.

Wann die aufgrund von Anordnung Nr.3 und Nr.4 zu erhebenden Daten übermittelt wurden, war den Verfahrensakten nicht zu entnehmen. Angaben über den Umfang der Daten ließen sich jedoch finden. Auf Anordnung Nr.3 hin wurden personenbezogene Daten von 76 Personen und auf die fehlende Anordnung Nr.4 hin wurden personenbezogene Daten von 27 Personen übermittelt.

Wie und mit welchem Ergebnis die Daten miteinander abgeglichen wurden, ist im Folgenden dargestellt.

- Daten des Gesundheitsamtes A mit relevantem Ortsbezug

- 17 Personen

- Daten des Gesundheitsamtes S mit relevantem Ortsbezug - acht Personen

- Daten des Vormundschaftsgerichtes mit Ortsbezug zu A

- 39 Personen

- Daten des Vormundschaftsgerichtes mit Ortsbezug zu S

- zwei Personen

- Personen mit relevanten KAN-Einträgen und Ortsbezug zu A

- 21 Personen

- Personen mit relevanten KAN-Einträgen und Ortsbezug zu S

- drei Personen

Insgesamt erbrachten die durchgeführten Datenabgleiche damit eine Treffermenge von 90 Personen.

\section{d. Auswirkungen auf das Ermittlungsverfahren}

Die 90 Personen wurden im Anschluss unter Zuhilfenahme herkömmlicher Ermittlungsmethoden überprüft. Demnach lieferte die Rasterfahndung Ansatzpunkte für weitere Ermittlungen. Bei den gegen die 90 Personen getroffenen Ermittlungsmaßnahmen handelt es sich sowohl um weitere verdeckte als auch offene Maßnahmen. Es ergaben sich jedoch keine Verdachtsmomente gegen eine der herausgerasterten Personen. 


\section{Ausgang des Verfahrens}

Insgesamt wurden im Verlauf des Verfahrens vier Personen als Beschuldigte geführt. Die Beschuldigten waren u.a. durch Hinweise des Opfers mit Bezug auf ihre richterliche Tätigkeit in den Fokus der Ermittlungen geraten. Es konnte jedoch keine der Personen als Täter überführt werden. Gegen den Beschuldigten Nr.1 wurde das Verfahren am 23.09.2005 gem. § 170 II StPO eingestellt. Die Verfahren gegen die Beschuldigten Nr.2 und Nr.3 wurden am 21.10.2005 gem. § 170 II StPO und gegen den Beschuldigten Nr.4 am 29.11.2005 ebenfalls gem. § 170 II StPO eingestellt. Die Alibis der Beschuldigten Nr.2, Nr.3 und Nr.4 konnten durch die Ermittlungen nicht widerlegt werden. Darüber hinaus wurde sie durch einen Tatzeugen nicht wiedererkannt. Der Beschuldigte Nr.1 hatte mehrfach beleidigende Schreiben an das Opfer geschickt. Der mutmaßlich schuldunfähige Beschuldigte kam jedoch nicht als Täter in Betracht.

Das weiterhin gegen unbekannt gerichtete Verfahren ist laut dem vorläufigen polizeilichen Abschlussbericht vom 30.01.2006, noch nicht eingestellt.

\section{Erfolgseinschätzung}

Die Raster wurden im vorliegenden Verfahren so gewählt, dass nach dem $\mathrm{Ab}$ gleich eine verhältnismäßig geringe Treffermenge übrig blieb. Die Anzahl von 90 Treffern stellt eine Menge dar, die durchaus mit konventionellen Ermittlungsmaßnahmen zu überprüfen möglich war. Verglichen mit den weiteren Ermittlungen, die unabhängig von der Rasterfahndung geführt wurden, erbrachte die Rasterfahndung die mit Abstand meisten Ermittlungsansätze.

Der vorliegende Sachverhalt bildet insofern eine Ausnahme, als dass nicht mit Sicherheit ausgeschlossen werden kann, dass es sich um einen Unfall handelte. Es wurde angenommen, dass das Opfer von einem anderen Radfahrer überholt wurde, welcher einen Rucksack mit darin befindlichem scharfem Gegenstand trug, der das Opfer streifte. Für diesen Fall wären jedoch die verwendeten Raster nur durch großen Zufall zutreffend gewesen.

Der einzige Ermittlungsansatz, der verfolgt werden konnte, war derjenige, dass von einem Anschlag auf das Opfer auszugehen war. In diesem Fall war es die Rasterfahndung in den betreffenden Datenbeständen, die in der Lage war, weitere Ansätze zu liefern.

\section{Die präventive Rasterfahndung nach dem 11. September 2001}

In diesem Exkurs werden der Ablauf und die Ergebnisse der Rasterfahndung nach sog. „Schläfern“ nach den Anschlägen des 11. Septembers 2001 dargestellt. Die Ausführungen basieren auf Recherchen in den Tätigkeitsberichten der Daten- 
schutzbeauftragten der Bundesländer und des Bundes. Dabei ist zu beachten, dass den Tätigkeitsberichten zum Teil noch keine abschließenden Informationen entnommen werden konnten. Beispielsweise lag der Bericht des Bundesbeauftragten für Datenschutz für die Jahre 2005-2006 noch nicht vor. Neben den Tätigkeitsberichten war es möglich, aus mehreren kleinen und großen Anfragen in den Parlamenten der Bundesländer Informationen über die Rasterfahndung nach dem 11. September zu entnehmen. Anfragen an die Innenminister der Länder mit der Bitte um Einsichtnahme in die Unterlagen zur Rasterfahndung wurden dagegen durchgängig negativ beschieden. Einer Einsichtnahme standen entweder ermittlungstaktische Bedenken oder die Tatsache entgegen, dass die betreffenden Unterlagen bereits vernichtet worden waren. Zunächst werden die Ziele der Maßnahme dargestellt. Daran anschließend werden die Ergebnisse der Rasterfahndung am Beispiel von Bayern und Berlin dargestellt. Anschließend werden die Ergebnisse zusammengefasst und anhand von Erkenntnissen aus den übrigen Bundesländern angereichert.

\section{Grundlagen und Ziele}

Den Berichten der Datenschutzbeauftragten war zu entnehmen, dass zunächst die Durchführung der Maßnahme beschlossen und im Anschluss nach einer Ermächtigungsgrundlage gesucht wurde. Dabei stand zunächst eine Maßnahme nach den $\S \S 98 \mathrm{a}, \mathrm{b}$ StPO im Fokus der Diskussion. Allerdings lehnte der Generalbundesanwalt eine solche ab, weshalb es zur präventiv polizeilichen Anordnung der Maßnahme kam. Damit griffen die Ermittlungsbehörden erstmals seit der Fahndung nach Mitgliedern der RAF in großem Umfang auf dieses Ermittlungsinstrument zurück. ${ }^{470}$ Die Rasterfahndung nach dem 11. September 2001 stellt die bislang einzige präventive Rasterfahndung auf der Grundlage der Polizei- und Sicherheitsgesetze der Bundesländer dar. ${ }^{471}$

Aufgrund der Ermittlungserfolge in den USA stand fest, dass einige der Attentäter des 11. Septembers in Deutschland gelebt und die Anschläge vorbereitet hatten. Dies führte bei den Ermittlungsbehörden zu der Annahme, dass es in Deutschland noch mehr potenzielle Attentäter geben würde. Ziel der Rasterfahndung war es diese sog. „Schläfer“ aufzuspüren. Auf der Grundlage der Eigenschaften der Attentäter wurde durch die Abteilung Operative Fallanalyse des Bundeskriminalamtes ein Täterprofil erstellt. In diesem Täterprofil wurden die

${ }^{470}$ Zur Anwendung der Ermittlungsmaßnahme im Rahmen der Suche nach RAFMitgliedern siehe 1. Teil A.

${ }^{471}$ Lisken, NvwZ 2002, 513. 
im Folgenden dargestellten Rasterkriterien für einen bundesweiten Datenabgleich festgelegt. ${ }^{472}$

- männlich

- 18-40 Jahre

- islamische Religionszugehörigkeit

- Wohnung im jeweiligen Bundesland

- Student bzw. ehemaliger Student

- legaler Aufenthaltsstatus

- keine Sozialhilfe

- Geburtsland und/oder Nationalität folgender Staaten: Afghanistan, Ägypten, Algerien, Bahrain, Bangladesh, Eritrea, Indonesien, Irak, Iran, Jemen, Jordanien, Oman, Pakistan, Palästina, Saudi Arabien, Somalia, Sudan, Syrien, Tunesien, Vereinigte Arabische Emirate, Israel (Erfassungskriterien für Palästinenser) bzw. Staatenlose, Staatsangehörigkeit „ungeklärt" oder ,unbekannt"

Neben diesen Kriterien wurden weitere Feinrasterkriterien verwendet, welche aus ermittlungstaktischen Gesichtspunkten jedoch nicht veröffentlicht wurden. Die Datenerhebung wurde durch die Landeskriminalämter durchgeführt. Als Rechtsgrundlage dienten die jeweiligen Polizei- und Sicherheitsgesetze. Erhoben wurden die Daten bei:

- Einwohnermeldeämtern

- Hochschulen und Fachhochschulen mit Schwerpunkt technischer/naturwissenschaftlicher Ausrichtung

- Sozialämtern

- Sprachschulen

- Flugschulen

- Luftfahrtämtern

- Betreibern kerntechnischer Anlagen und Forschungseinrichtungen

- Industrie- und Handelskammern

Im Anschluss an die Datenerhebung wurden die Daten abgeglichen und die Treffer in einer separaten Datei abgespeichert. Darüber hinaus wurden die Treffer an das BKA übermittelt und dort in der Verbunddatei „Schläfer“" abgespeichert.

${ }^{472}$ Aufgeführt in: Bayerischer Landtag-Drs, 14/9221, S.2. 


\section{Die Rasterfahndung am Beispiel von Bayern ${ }^{473}$}

Das Bayerische Landeskriminalamt hat mit Zustimmung des Staatsministeriums des Innern am 22.09.2001 eine Rasterfahndungsanordnung nach Artikel 44 Polizeiaufgabengesetz erlassen. Weitere Anordnungen erfolgten am 01.10.2001, 04.10.2001, 05.10.2001, 15.10.2001 und am 19.12.2001. Beim Bayerischen Landeskriminalamt wurde am 26.09.2001 eine Fahndungskoordinierungsstelle eingerichtet. Dieser gehörten 26 Beamte des Landeskriminalamtes, aller Präsidien der Landespolizei und des Bayerischen Landesamtes für Verfassungsschutz an. Die Fahndungskoordinierungsstelle wurde mit der Vorbereitung und Durchführung der Datenerhebung betraut. Auch die Koordinierung und Umsetzung der Maßnahme oblag dieser Stelle. Zum 31.12.2001 wurde die Fahndungskoordinierungsstelle um 16 Beamte reduziert.

Wann die Daten von den einzelnen Stellen übermittelt wurden, ließ sich nicht nachvollziehen. Die Daten wurden auch retrospektiv angefordert (z.B. frühere Meldeanschriften oder Studiengänge). Aus diesem Grund kam es auch zu Mehrfachnennungen in den einzelnen Datenbeständen. Insgesamt wurden folgende Daten erhoben: ${ }^{474}$

- Einwohnermeldeämter bayerischer Städte und Gemeinden 52.980 Personendatensätze (ca. 91.000)

- Ausländerämter bayerischer Städte und Landkreise 7.309 Personendatensätze (ca. 12.000)

- Bayerische Universitäten bzw. Fachhochschulen mit Schwerpunkt technischer/naturwissenschaftlicher Ausrichtung 2.566 Personendatensätze (4.823)

- Industrie- und Handelskammern der bayerischen Regierungsbezirke 23.342 Personendatensätze (ca.43.000)

- Betreiber kerntechnischer Anlagen und Forschungseinrichtungen 52 Personendatensätze

- Luftfahrtämter Nord- und Südbayern 8.515 Personendatensätze (ca.24.000)

Der komplette Datenbestand wurde an das Bundeskriminalamt übermittelt. Dort wurden die Daten in die Verbunddatei „Schläfer“ eingestellt und mit weiteren Da-

473 Die Informationen zur Rasterfahndung in Bayern sind dem 20. und dem 21. Tätigkeitsbericht des Bayerischen Landesbeauftragten für den Datenschutz, Bayerischer Landtag-Drs, 14/991 und Bayerischer Landtag-Drs, 14/992 entnommen.

${ }^{474}$ Die in Klammern gesetzten Zahlen geben den Ursprungsdatenbestand an, die ohne Klammersetzung die Anzahl der Personendatensätze nach Bereinigung von Mehrfachnennungen. Quelle: Bayerischer Landtag-Drs, 14/9221, S.3. 
tenbeständen abgeglichen. Nach der Durchführung des Datenabgleichs verblieb eine Anzahl von 1.939 Personen. Dieses Ergebnis wurde an das Bayerische Landeskriminalamt zurückübermittelt. Die 1.939 Prüffälle wurden durch die örtlich zuständigen kriminalpolizeilichen Staatsschutzdienststellen abgeklärt. Wenn sich bei der Abarbeitung der Prüffälle herausstellte, dass die betreffende Person nicht dem Grundraster unterfiel, wurde diese aus dem Datenbestand gelöscht. Die Überprüfung der 1.939 Personen wurde Anfang März 2004 abgeschlossen. Mit der Beendigung der Überprüfungen wurden auch die Datenbestände gelöscht.

Als vorrangiges Ziel der Rasterfahndung wurden nicht Festnahmen und strafprozessuale Ermittlungen, sondern die Gefahrenabwehr angeführt. Nach Ansicht des Innenministeriums sei deshalb schon dann von einem Erfolg der Maßnahme zu sprechen, wenn potenzielle islamistische Extremisten/Terroristen durch die polizeilichen Überprüfungsmaßnahmen verunsichert und $\mathrm{zu}$ einer Verhaltensänderung veranlasst wurden, auch wenn einzelne Verdächtige von den Sicherheitsbehörden letzten Endes nicht enttarnt werden konnten. ${ }^{475}$

\section{Die Rasterfahndung am Beispiel von Berlin ${ }^{476}$}

In Berlin wandte sich das Landeskriminalamt am 17.09.2001 mit der Bitte an die Technische Universität und die Humboldt Universität, die Personalien von allen ausländischen Studierenden aus 14 arabischen Staaten zu übermitteln. Diese informierten daraufhin den Berliner Beauftragten für Datenschutz und Informationsfreiheit. In der Zeit vom 17. bis zum 19. September 2001 richtete das Landeskriminalamt insgesamt 44 Anfragen an private und öffentliche Stellen mit der Bitte um Übermittlung personenbezogener Daten. Diesen Anfragen wurde nur zum Teil nachgekommen. Überwiegend verweigerten die betroffenen Stellen eine Übermittlung von Daten ohne richterliche Anordnung.

Die auf $\S 47$ ASOG basierende Rasterfahndung wurde am 20. September 2001 durch das Amtsgericht Tiergarten angeordnet. In der Zeit bis zum 24. Oktober 2001 ergingen weitere Ergänzungsanordnungen und Beschlussneufassungen. Diese wurden zum Teil auf Anregung des Berliner Beauftragten für Datenschutz und Informationsfreiheit beantragt. Seit der Benachrichtigung vom 17. September war der Berliner Beauftragte für Datenschutz und Informationsfreiheit in die Maßnahme mit einbezogen.

475 Bayerischer Landtag-Drs, 14/9221, S.5.

476 Die Daten und Informationen zur Rasterfahndung in Berlin entstammen dem Sonderbericht des Berliner Beauftragten für Datenschutz und Informationsfreiheit, über die Durchführung besonderer Formen des Datenabgleichs (Rasterfahndung) durch den Polizeipräsidenten in Berlin nach dem 11. September 2001, vom 10.Dezember 2002. 
Auf der Grundlage der Anordnungen ersuchte das Landeskriminalamt insgesamt 45 öffentliche und private Stellen um die Übermittlung personenbezogener Daten. Dabei wurden die durch das Bundeskriminalamt erstellten Rasterkriterien herangezogen. Zu den im Folgenden aufgeführten Stellen lagen genaue Angaben über den Umfang der Datenübermittlung vor, da diese einer Kontrolle durch den Berliner Beauftragten für Datenschutz und Informationsfreiheit unterzogen wurden.

- Technische Universität Berlin 1.481 Datensätze

- Freie Universität Berlin 3.174 Datensätze

- Humboldt-Universität zu Berlin 836 Datensätze

- BEWAG 48 Datensätze

- IHK für den Bereich Sicherheitsunternehmen und Wachschutz ca. 2.500 Datensätze und für den Bereich Gefahrguttransporte ca. 13.000 Datensätze

Genaue Angaben über den Umfang der Einwohnermeldedaten waren nicht zu erlangen. Im Rahmen der Rasterfahndung wurden in Berlin insgesamt 58.032 Datensätze erhoben. Nach der Durchführung des Datenabgleichs blieben 3.641 Prüffälle übrig. Hierbei handelt es sich um Personen, die in mindestens zwei Dateien enthalten waren. Die Liste mit den 3.641 Treffern wurde daraufhin manuell gesichtet, um Namensidentitäten durch unterschiedliche Schreibweisen feststellen zu können. Die Prüffälle wurden anhand einer Prioritätenliste überprüft.

Am 15.01.2002 wurde die Überprüfung der Trefferfälle eingestellt, da das Landgericht Berlin die Rasterfahndung für unzulässig erklärt hatte. Nach Ansicht des Landgerichtes habe es an einer gegenwärtigen Gefahr als Voraussetzung für die Rasterfahndung gefehlt. Der 1. Zivilsenat des Kammergerichtes Berlin hob am 16. April 2002 die Entscheidung des Landgerichtes auf. Das Kammergericht stellte fest, dass die Entscheidung des Landgerichtes auf einer rechtsfehlerhaften Auslegung und Anwendung des unbestimmten Rechtsbegriffs der ,gegenwärtigen Gefahr" in $\S 47$ ASOG und auf einer Überspannung der Anforderungen an die Wahrscheinlichkeitsprognose im Hinblick auf das Bestehen eine solchen Gefahr beruht habe. Es habe sich um eine Dauergefahr gehandelt. Diese sei gerade dadurch gekennzeichnet, dass Wahrscheinlichkeitsprognosen zum Zeitpunkt und zum Ort sowie zur Art und Weise der erneuten Verwirklichung nach Art der Gefahr nicht möglich seien, sondern nur zum Bestehen der Gefahr überhaupt und zum in Betracht kommenden Schaden. Je größer und folgenschwerer der Schaden sei, desto geringer seien die Anforderungen an die Wahrscheinlichkeit des Schadenseintritts. $^{477}$

${ }^{477}$ Kammergericht Berlin, Beschluss vom 16.04.2002. 
Aufgrund der Entscheidung des Kammergerichts wurden die Ermittlungen wieder aufgenommen. Von den 3.641 Prüffällen wurden 114 Personen eingehenden Überprüfungen unterzogen. Bei diesen handelte es sich in erster Linie um solche, bei denen die Merkmale „Student“ und „im sicherheitsrelevanten Bereich tätig“ in besonderen Kombinationen vorlagen. Für alle Prüffälle erfolgte eine Abfrage der Datenbestände ISVB, EWW, INPOL, APIS, Schengen, Ausländerbehörde und eine Nachfrage bei der Abteilung Verfassungsschutz der Senatsbehörde für Inneres. Am 12. Juli 2002 wurden die übermittelten Datensätze öffentlich vernichtet.

Im Rahmen der Berliner Rasterfahndung wurden darüber hinaus Daten an das Bundeskriminalamt übermittelt. Dabei handelte es sich um 199 personenbezogene Datensätze, welche in die Verbunddatei „Schläfer“ eingestellt wurden. Die Speicherung beim Bundeskriminalamt erfolgte am 15. Januar 2002. Am 31. Januar 2002 wurden die Daten beim Bundesbeauftragten aufgrund des Beschlusses des Landgerichts Berlin gelöscht. Allerdings erfolgte am 4. Juni eine erneute Übermittlung der Datensätze, da die Entscheidung des Landgerichtes in der Zwischenzeit wieder aufgehoben wurde.

Die Rasterfahndung hatte in Berlin keinen Fahndungstreffer zur Folge. Es konnte kein sog. Schläfer ermittelt werden. Dennoch wurde durch den Polizeipräsidenten eine positive Bilanz gezogen. Nach dessen Ansicht sei „der generalpräventive Effekt nicht zu unterschätzen“. Darüber hinaus sei durch die intensive Medienbegleitung ein „Abschreckungseffekt für mögliche Attentäter“ erzielt worden. Letztlich seien sicherheitsempfindliche Bereiche sensibilisiert worden, so dass dort auch eigeninitiativ die bis dahin bestehen Sicherheitsmaßnahmen überprüft wurden. Letztlich habe das Ansprechen relevanter Personen im Anschluss an die Rasterfahndung ebenfalls einen präventiven Effekt zur Folge gehabt. ${ }^{478}$

\section{Das Ergebnis der Rasterfahndung nach dem 11. September 2001}

Genau Informationen darüber, wie viele Datensätze im Rahmen der Rasterfahndung bundesweit erhoben wurden, waren nicht verfügbar. Neben den Darstellungen zu Berlin und Bayern konnten Angaben zu den Bundesländern Niedersachsen, Baden-Württemberg, Brandenburg, Bremen und Nordrhein-Westfalen erlangt werden.

Von den niedersächsischen Universitäten wurden ca. 3.800 Datensätze übermittelt. Die Einwohnermeldeämter übermittelten ca. 40.000 Datensätze. Der Datenabgleich erbrachte 1.677 Prüffälle. Diese wurden gleichzeitig in die Verbunddatei „Schläfer“" beim Bundeskriminalamt eingestellt. ${ }^{479}$

\footnotetext{
478 Pressemeldung des Polizeipräsidenten in Berlin vom 12.07.2002.

479 Niedersächsischer Landtag-Drs, 14/3339, S.5.
} 
In Baden-Württemberg wurden ca. 1,8 Millionen Datensätze von mehr als 250 Stellen übermittelt. Zwei Drittel der Daten entsprachen nicht den Rasterkriterien und wurden deshalb gelöscht. Mit den übrigen 600.000 Datensätzen wurde der maschinelle Datenabgleich durchgeführt. Der Datenabgleich hatte 551 Prüffälle zum Ergebnis. Davon konnten 180 Prüffälle relativ schnell ausgeschlossen werden. Die verbleibenden 371 Prüffälle wurden eingehend überprüft und abschließend direkt angesprochen. Dabei ergaben sich keine Hinweise auf sog. Schläfer. Im Rahmen des Datenabgleichs wurden ca. 25.000 Datensätze an das Bundeskriminalamt übermittelt und dort zum Teil in die Verbunddatei Schläfer eingestellt. ${ }^{480}$

In Brandenburg wurden dem Landeskriminalamt 460.270 Datensätze übermittelt. Dabei handelte es sich überwiegend um Datensätze, die nicht den Rasterkriterien entsprachen. Nach Löschung der nicht benötigten Datensätze verblieben 27.683 Datensätze. Angaben über die Anzahl der Prüffälle waren nicht verfügbar. Die Maßnahme führte nicht zur Einleitung strafprozessualer Ermittlungsverfahren. ${ }^{481}$

Im Rahmen der Rasterfahndung in Bremen wurden ca. 100.000 Datensätze abgeglichen. Dieser Abgleich erbrachte 589 Prüffälle. ${ }^{482}$ Diese Daten wurden auch an das Bundeskriminalamt übermittelt. Am 11. April 2003 wurden die durch das Bremer Landeskriminalamt übermittelten Daten beim Bundeskriminalamt gelöscht. Die beim Landeskriminalamt gespeicherten Daten wurden, bis auf wenige am 10. September 2003 gelöscht. Einige Daten wurden herausgenommen und der konventionellen Datenverarbeitung der Staatsschutzabteilung zugeführt. Es handelte sich dabei um ca. 40 Prüffälle, welche einer weiteren polizeilichen Abklärung bedurften. $^{483}$

Auf der Grundlage der angeordneten Rasterfahndung wurden von den Einwohnermeldeämtern Nordrhein-Westfalens und den übrigen verpflichteten Stellen ca. 5,2 Millionen personenbezogene Datensätze übermittelt. Diese 5,2 Millionen Datensätze wurden unter Zugrundelegung der bundesweiten Rasterkriterien gefiltert. Im Ergebnis blieben 11.004 Datensätze übrig. Diese wurden an das Bundeskriminalamt zur Einstellung in die Verbunddatei „Schläfer“ übermittelt. Aufgrund falsch erhobener Daten wurde das Bundeskriminalamt angewiesen, 1.187 dieser Datensätze zu löschen. Dieser Aufforderung kam es am 4. Juli 2002 nach. Im weiteren Verlauf der Maßnahme kamen noch 165 Datensätze hinzu, so dass insgesamt 9.982 Datensätze aus Nordrhein-Westfalen in der Verbunddatei enthalten waren. Alle ca. 11.000 im Zuge der Rasterfahndung überprüften Personen wurden durch das Polizeipräsidium Düsseldorf schriftlich über die Datenerhebung informiert. Gegen acht Personen wurden weitere Ermittlungsmaßnahmen nach dem Polizeigesetz Nord-

480 24. Tätigkeitsbericht des Landesbeauftragten für den Datenschutz BadenWürttemberg (2003), 1. Abschnitt, Nr.1.

${ }^{481}$ Brandenburger Landtag-Drs, 3/4023, S.2.

482 25. Jahresbericht des Landesbeauftragten für den Datenschutz Bremen (2003); S.53.

483 26. Jahresbericht des Landesbeauftragten für den Datenschutz Bremen (2004); S.65. 
rhein-Westfalen getätigt. Zur Einleitung eines Strafverfahrens kam es jedoch nicht. $^{484}$

Im Zuge der Rasterfahndung nach dem 11. September wurden demnach mehrere Millionen personenbezogener Datensätze erhoben und miteinander abgeglichen. Dem Bundeskriminalamt wurden aus allen Bundesländern Datensätze zur Einstellung in die Verbunddatei „Schläfer“ übermittelt. Nach Angaben des Bundeskriminalamtes übermittelten die Bundesländer insgesamt 31.988 Datensätze. ${ }^{485}$ Die Verbunddatei „Schläfer“ wurde nach Durchführung der Abgleichsserien am 30. Juni 2003 gelöscht. Mithin zogen sich die Erfassung und der Abgleich der Daten durch das Bundeskriminalamt fast zwei Jahre hin. Im Ergebnis konnten keine sog. Schläfer festgestellt werden. Von den beteiligten Stellen wurden jedoch die mit der Maßnahme verbundene Abschreckungswirkung und der gesteigerte Informationsstand hervorgehoben. ${ }^{486}$ Von den Datenschutzbeauftragten wurde dagegen auf erhebliche datenschutzrechtliche Mängel verwiesen. ${ }^{487}$ Zudem wurde als Kritik angeführt, dass keine konkreten Verdachtsfälle aufgedeckt wurden, auf die die Polizei auch nicht ohne die Rasterfahndung gestoßen wäre. ${ }^{488}$ Letztlich würde auch eine Betrachtung der Maßnahme unter ökonomischen Gesichtspunkten zu erheblichen Bedenken führen.

Die begrenzten Informationen zur Rasterfahndung nach dem 11. September machten es notwendig, Beamte des Staatsschutzes der Bundesländer in die Expertengespräche mit einzubeziehen. So war es möglich detaillierte Informationen über den Ablauf der Maßnahme zu erlangen. Mithin war die Evaluation von Umsetzungsschwierigkeiten ausschließlich im Rahmen der Expertengespräche möglich, da Berichte zum Ablauf der Maßnahme nicht zugänglich waren. Zudem konnten Einschätzungen der mit der Maßnahme betrauten Beamten des Staatsschutzes erhoben werden. ${ }^{489}$

\section{Zusammenfassung}

Die vorangegangene Einzelfallanalyse bildet einen Schwerpunkt dieser Untersuchung. Die Untersuchung der 27 Verfahren und der präventiven Rasterfahndung im Zuge des 11. Septembers 2001 anhand einer eingehenden Einzelfallanalyse ermöglichte eine Bestimmung des Stellenwerts der Rasterfahndung für das einzelne Ver-

484 Die Informationen zur Rasterfahndung in Nordrhein-Westfalen entstammen BVerfGE 115, 320, 331ff.

485 BVerfGE 115, 320, 324.

486 Bayerischer Landtag-Drs, 14/9221, S.5; Hessischer Landtag-Drs, 16/2042, S.2.

487 Eine Auflistung der festgestellten Mängel enthält: Sonderbericht des Berliner Beauftragten für Datenschutz und Informationsfreiheit, über die Durchführung besonderer Formen des Datenabgleichs (Rasterfahndung) durch den Polizeipräsidenten in Berlin nach dem 11. September 2001, vom 10.Dezember 2002, S.46.

488 25. Jahresbericht des Landesbeauftragten für den Datenschutz Bremen (2003); S.55f.

${ }^{489}$ Siehe 5. Teil. 
fahren. Dabei waren erhebliche Unterschiede festzustellen. Teilweise bildete die Rasterfahndung zumindest zu einem bestimmten Verfahrenszeitpunkt den Mittelpunkt der Ermittlungen. Dabei handelte es sich insbesondere um die Verfahren, in welchen die Ermittlungsmaßnahme auf Anregung der Operativen Fallanalyse durchgeführt wurde. In diesen Verfahren wurden umfangreiche Täterprofile erstellt und in einer Vielzahl von Datenbeständen recherchiert. Beispielhaft sind hier insbesondere die Ermittlungsverfahren zu nennen, in welchen die Rasterfahndung zur Vorbereitung von DNA-Reihenuntersuchungen eingesetzt wurde. Dagegen wurde die Maßnahme in anderen Verfahren nur in Randbereichen der Ermittlungen eingesetzt. Hierbei handelt es sich um Verfahren, in denen lediglich in einzelnen Datenbeständen recherchiert wurde.

Neben dem Stellenwert der Rasterfahndung konnte im Rahmen der Einzelfallanalyse auch die Charakteristik der einzelnen Verfahren dargestellt werden. Auch diesbezüglich waren nur in begrenztem Umfang Übereinstimmungen festzustellen. Diese beziehen sich lediglich auf die zugrunde liegenden Straftaten. Den Ermittlungen lagen in mehr als zwei Dritteln der Verfahren Straftaten gegen Leib oder Leben, die sexuelle Selbstbestimmung und die persönliche Freiheit zugrunde. In Bezug auf den Stand der Ermittlungen und die Ausgangslage für die Rasterfahndungen unterschieden sich die Verfahren erheblich.

Ferner war es nur im Rahmen der Einzelfallanalyse möglich, die Auswirkungen der Maßnahme auf den Verlauf der Ermittlungen zu untersuchen. Von besonderem Interesse war insofern das Zusammenspiel der Rasterfahndung mit weiteren Ermittlungsmaßnahmen. Auch konnte analysiert werden, inwiefern die Rasterfahndung dazu führte, dass andere Spuren nicht oder nur unzureichend verfolgt wurden. Diesbezüglich waren ebenfalls erhebliche Unterschiede festzustellen, sodass keine verallgemeinerungsfähigen Aussagen gemacht werden können.

Im Ergebnis ist festzuhalten, dass eine Typisierung von Rasterfahndungsverfahren nicht möglich ist. Es bieten sich vielmehr bestimmte Fallkonstellationen für die Anwendung der Rasterfahndung an. Zu diesen Fallkonstellationen sind insbesondere die Verfahren zu zählen, in welchen die Rasterfahndung zu Vorbereitung einer DNA-Reihenuntersuchung durchgeführt wird. Letztlich bilden die Erkenntnisse der Einzelfallanalyse die Grundlage für die Operationalisierung des Erfolgsbegriffs und damit für die anschließende Analyse des Erfolgs und der Effizienz der Rasterfahndung.

\section{Die Ergebnisse der Untersuchung von Erfolg und Effizienz}

Im dritten Kapitel der Untersuchung von Erfolg und Effizienz werden Gemeinsamkeiten und Unterschiede der untersuchten Verfahren zusammenfassend dargestellt und analysiert. Aufbauend auf der Einzelfallanalyse stellt dieser Teil die eigent- 
liche Untersuchung von Erfolg und Effizienz der Rasterfahndung nach den $\S \S 98 \mathrm{a}$, b StPO dar. Um jedoch generelle Aussagen über den Erfolg und die Effizienz von Rasterfahndungen zu treffen, müssen diese Begriffe zunächst operationalisiert werden. Es müssen Variablen gefunden werden, anhand derer die vorgefundenen Sachverhalte verglichen und zusammengefasst werden können. Die Operationalisierung basiert auf der vorgenommenen Bedeutungsanalyse der Begriffe Erfolg und Effizienz, wie sie zu Beginn des Dritten Teils der Untersuchung vorgenommen wurde.

\section{Erfolg}

\section{Operationalisierung des Erfolgs}

Unter Erfolg wurden alle Hinweise erfasst, die Erkenntnisse für das Ermittlungsverfahren erbracht haben. Von besonderer Bedeutung waren hierfür die teilweise in den Akten enthaltenen Auswertungsberichte der Polizeibehörden. Darüber hinaus konnten auch den polizeilichen Zwischen- und Abschlussberichten Informationen über die Rasterfahndung entnommen werden. Zugeordnet wurden die Erfolge der jeweiligen Maßnahme. Eine Zuordnung zum einzelnen Beschluss war nicht möglich, da sich der Datenabgleich häufig aus mehreren Beschlüssen zusammensetzte. In den Fällen, in welchen der Datenabgleich aufgrund mehrerer zusammenhängender Beschlüsse und Ergänzungsbeschlüsse durchgeführt wurde, hätte eine Zuordnung zu den einzelnen Beschlüssen zu Unübersichtlichkeit geführt.

Bei der Operationalisierung des Erfolgs muss dem Charakter der Ermittlungsmaßnahme in besonderem Maße Rechnung getragen werden. Die Übertragung von Operationalisierungen, wie sie im Rahmen von empirischen Untersuchungen zu anderen Ermittlungsmaßnahmen der Strafprozessordnung verwendet worden sind, ist daher nicht ohne weiteres möglich. Die bislang einzige empirische Untersuchung, die sich unter anderem mit Fragen nach dem Erfolg und der Effizienz einer Ermittlungsmaßnahme befasst hat, ist eine Untersuchung des Max-Planck-Institutes für ausländisches und internationales Strafrecht zur Telefonüberwachung nach den $\S \S 100 \mathrm{a}, \mathrm{b}$ StPO. ${ }^{490}$ Insofern bilden die dort vorgenommen Operationalisierungen des Erfolgsbegriffs einen Ausgangspunkt für diese Untersuchung.

In der betreffenden Untersuchung wurde der Erfolg der Telefonüberwachung in die Kategorien unmittelbarer und mittelbarer Erfolg eingestuft. Ein unmittelbarer Erfolg wurde dann angenommen, wenn er unmittelbare Auswirkungen auf das Ermittlungsverfahren zur Folge hatte. Dagegen sollten mittelbare Erfolge einen weitergehenden Ermittlungsaufwand erfordern. Als unmittelbare Erfolge wurden beispielsweise die „Identifizierung des Aufenthaltsortes des Beschuldigten“, die „Selbstbelastung“ des Beschuldigten und „Aussagen eines Dritten wegen einer Katalogstraftat" angesehen. In die Kategorie mittelbare Erfolge wurden unter ande-

490 Albrecht/Dorsch/Krüpe, S.360ff. 
rem „Hinweise auf Straftaten Dritter“, „Hinweise auf neue Straftaten eines Beschuldigten“ und „mittelbare Ermittlungsansätze wegen einer Katalogstraftat“ aufgenommen. ${ }^{491}$

Aufgrund des Charakters der Rasterfahndung war eine solche Einteilung in unmittelbare und mittelbare Erfolge nicht möglich. Im Gegensatz zur Telefonüberwachung kann eine Rasterfahndung immer nur Ermittlungsansätze liefern und nicht als Beweismittel dienen. Eine Rasterfahndung erfordert in jedem Fall weitere Ermittlungen. Im Erfolgsfall liefert die Rasterfahndung lediglich neue Ermittlungsansätze, welche ihrerseits zur Aufklärung der verfolgten Straftat führen. Auf die Kategorisierung der Untersuchung zur Telefonüberwachung bezogen, würde sich die Rasterfahndung damit nur im Bereich von mittelbaren Erfolgen bewegen. Insofern mussten andere Kategorien gefunden werden, unter welche die Ergebnisse der einzelnen Maßnahmen eingeordnet werden konnten.

Wie bereits dargestellt, liefert die Rasterfahndung lediglich neue Ermittlungsansätze. Folglich müssen für die Beurteilung einer Rasterfahndung als erfolgreich zunächst neue Ermittlungsansätze erlangt werden. Insofern war es notwendig die Ergebnisse der durchgeführten Rasterfahndungen nach neuen Ermittlungsansätzen zu untersuchen. Daran anknüpfend wurden die Ermittlungsansätze nach der Art der ihr folgenden Ermittlungsmaßnahmen untersucht. Die aufgrund neuer Ermittlungsansätze eingeleiteten Maßnahmen wurden in die Kategorien „offene Ermittlungsmaßnahmen“ und ,verdeckte Ermittlungsmaßnahmen“ unterteilt.

Für die Beurteilung des Erfolges der Rasterfahndung waren, neben dem Vorliegen von neuen Ermittlungsansätzen, auch die Ergebnisse der daraufhin durchgeführten Ermittlungen maßgebend. Diese wurden in die Kategorien „Identifizierung eines Beschuldigten“, „Identifizierung des Aufenthaltsortes des Beschuldigten“ und daran anknüpfend „Festnahme des Beschuldigten“ sowie „Entlastung eines Beschuldigten“ eingeteilt. Darüber hinaus wurden „Hinweise auf neue oder bislang unbekannte Straftaten des Beschuldigten“, „Hinweise auf neue Tatverdächtige“ und wenn es zur Identifizierung neuer Tatverdächtiger kam, die „Anzahl der neuen Tatverdächtigen“ aufgenommen. Ferner wurden Erkenntnisse, welche zur Einleitung ,neuer Ermittlungsverfahren“ führten, erfasst. Diesbezüglich wurde auch danach gefragt, ob es sich bei den der neuen Ermittlungsverfahren zugrunde liegenden Straftaten „um Katalogdelikte des § 98a I StPO“ handelte. Letztlich wurden auch ,Zufallsfunde“ aufgenommen.

Unter Zugrundelegung dieser Erkenntnisse wurden die Maßnahmen einer abschließenden Beurteilung unterzogen. Dabei bilden die Kombinationen der gewonnenen Erkenntnisse die Grundlage für die Beurteilung der Maßnahme. Als Kategorien für die abschließende Einstufung der jeweiligen Rasterfahndung wurden „Rasterfahndung erfolgreich“, „Rasterfahndung bedingt erfolgreich“, „Rasterfahndung

${ }^{491}$ Albrecht/Dorsch/Krüpe, 360 ff. 
nicht erfolgreich“ und „Keine Angaben“ gewählt. Die Voraussetzungen für die Einstufung der Maßnahmen in diese Kategorien werden im Folgenden dargestellt.

\section{a. „Rasterfahndung erfolgreich“}

Eine Rasterfahndung wurde dann als erfolgreich eingestuft, wenn aufgrund der erlangten Ermittlungsansätze ein Beschuldigter identifiziert oder der Aufenthaltsort eines Beschuldigten ermittelt werden konnte und daraufhin eine Festnahme erfolgte. Eine weitere Voraussetzung war, dass diese Ergebnisse zur Aufklärung der Tat führten. Diese Voraussetzung ermöglichte die Einbeziehung des repressiven Polizeiziels in die Erfolgsbeurteilung. ${ }^{42}$ Zusammenfassend musste die Rasterfahndung demnach Ermittlungsansätze erbracht haben, welche wiederum erfolgreich zur Aufklärung der Tat beigetragen haben. Nur in diesem Fall wurde die Maßnahme als erfolgreich eingestuft.

\section{b. „Rasterfahndung bedingt erfolgreich“}

Die Grundvoraussetzungen für die Einstufung einer Maßnahme als bedingt erfolgreich war ebenfalls das Erlangen von Ermittlungsansätzen. Darüber hinaus mussten diese Ermittlungsansätze auch zu Ermittlungsergebnissen führen. Im Gegensatz zur erfolgreichen Rasterfahndung führten die neuen Ermittlungsansätze und die darauf aufbauenden Ermittlungen letztendlich aber nicht zur Aufklärung der Tat. Beispielsweise wurden Maßnahmen als bedingt erfolgreich eingestuft, wenn deren Ermittlungsansätze zur Identifizierung von Beschuldigten führten, die Verfahren gegen die Beschuldigten aber in Ermangelung eines Tatverdachts eingestellt wurden. Bei einer bedingt erfolgreichen Rasterfahndung handelt es sich demnach um eine Maßnahme, deren Ermittlungsansätze unter isolierter Betrachtung Ermittlungserfolge erbrachten, jedoch nicht zur Aufklärung der verfolgten Tat führten. Der Unterschied zur erfolgreichen Rasterfahndung ist folglich im Nichteintritt des repressiven Polizeiziels zu sehen.

\section{c. „Rasterfahndung nicht erfolgreich“}

In der Kategorie „Rasterfahndung nicht erfolgreich“ wurden alle Maßnahmen nach den $\S \S 98 \mathrm{a}, \mathrm{b}$ StPO erfasst, welche keine neuen Ermittlungsansätze liefern konnten. Es handelt sich um Maßnahmen, die keine Erkenntnisse für die jeweiligen Verfahren erbrachten. Mithin fehlt bei diesen Rasterfahndungen schon die Grundvoraussetzung für die Einstufung in die Kategorien „erfolgreich“ und „bedingt erfolgreich“.

${ }^{492}$ Zum repressiven Polizeiziel siehe 4. Teil A.I. 


\section{d. „Keine Angaben“}

Unter der Klassifizierung „Keine Angaben“ wurden alle Rasterfahndungen erfasst, über die nur Grundinformationen vorgelegen haben. Beispielsweise konnte in einigen Verfahren nur Einsicht in die Anregung, den Antrag und die Anordnung der Rasterfahndung genommen werden, da die Verfahren und die Rasterfahndungen noch nicht abgeschlossen waren. Ferner war mit der Durchführung einiger Rasterfahndungen zum Zeitpunkt der Akteneinsicht noch nicht begonnen worden.

\section{Die Untersuchungsergebnisse}

\section{a. Ermittlungsansätze}

Wie bereits dargestellt, war als Voraussetzung für die Erfolgsanalyse zunächst zu untersuchen, ob die Maßnahmen nach den $\S \S 98 \mathrm{a}$, b StPO zu neuen Ermittlungsansätzen geführt hatten. Als neue Ermittlungsansätze waren alle Erkenntnisse zu verstehen, die als Ausgangspunkt für weiterführende Ermittlungsmaßnahmen dienten. Bei den weiterführenden Ermittlungsmaßnahmen handelte es sich beispielsweise um Telefonüberwachungen, Zeugenvernehmungen und Durchsuchungen.

Von den 31 erfassten Maßnahmen nach den $\S \S 98 \mathrm{a}$, b StPO erbrachten 22 Maßnahmen neue Ermittlungsansätze, die weiterverfolgt wurden. In fünf Fällen wurden durch die Rasterfahndungen keine neuen Ermittlungsansätze erlangt. Bzgl. weiterer vier Maßnahmen konnten aus den Verfahrensakten keine Angaben über neue Ermittlungsansätze erlangt werden. Bei diesen Maßnahmen handelte es sich um solche, bei denen sowohl die Ermittlungen als auch die Rasterfahndungen noch nicht abgeschlossen waren. Es ist festzuhalten, dass die Rasterfahndung in mehr als zwei Dritteln der Fälle zu neuen Ermittlungsansätzen geführt hat.

\section{b. Weiterführende Ermittlungsmaßnahmen}

Von den 22 Maßnahmen nach den $\S \S 98 \mathrm{a}, \mathrm{b}$ StPO konnten in 20 Fällen weiterführende Ermittlungsmaßnahmen genau identifiziert werden. Bei den beiden übrigen Maßnahmen konnte den Verfahrensakten entnommen werden, dass die neuen Ermittlungsansätze zu weiteren Ermittlungen führten. Welcher Art die weiteren Ermittlungen in den beiden Fällen waren, konnte jedoch nicht festgestellt werden.

c. Verteilung auf offene und verdeckte Ermittlungsmaßnahmen

Die Basis für die Untersuchung der weiterführenden Ermittlungsmaßnahmen bildeten die 20 Rasterfahndungen, bei denen festgestellt wurde, zu welchen weiteren Ermittlungsmaßnahmen es kam. Die neuen Ermittlungsansätze führten in sechs 
Fällen zu verdeckten und in zehn Fällen zu offenen Ermittlungsmaßnahmen. In vier weiteren Fällen wurden sowohl offene als auch verdeckte Ermittlungsmaßnahmen veranlasst.

Abbildung 20: Neue Ermittlungsansätze verteilt auf die Maßnahmen ( $n=31)$

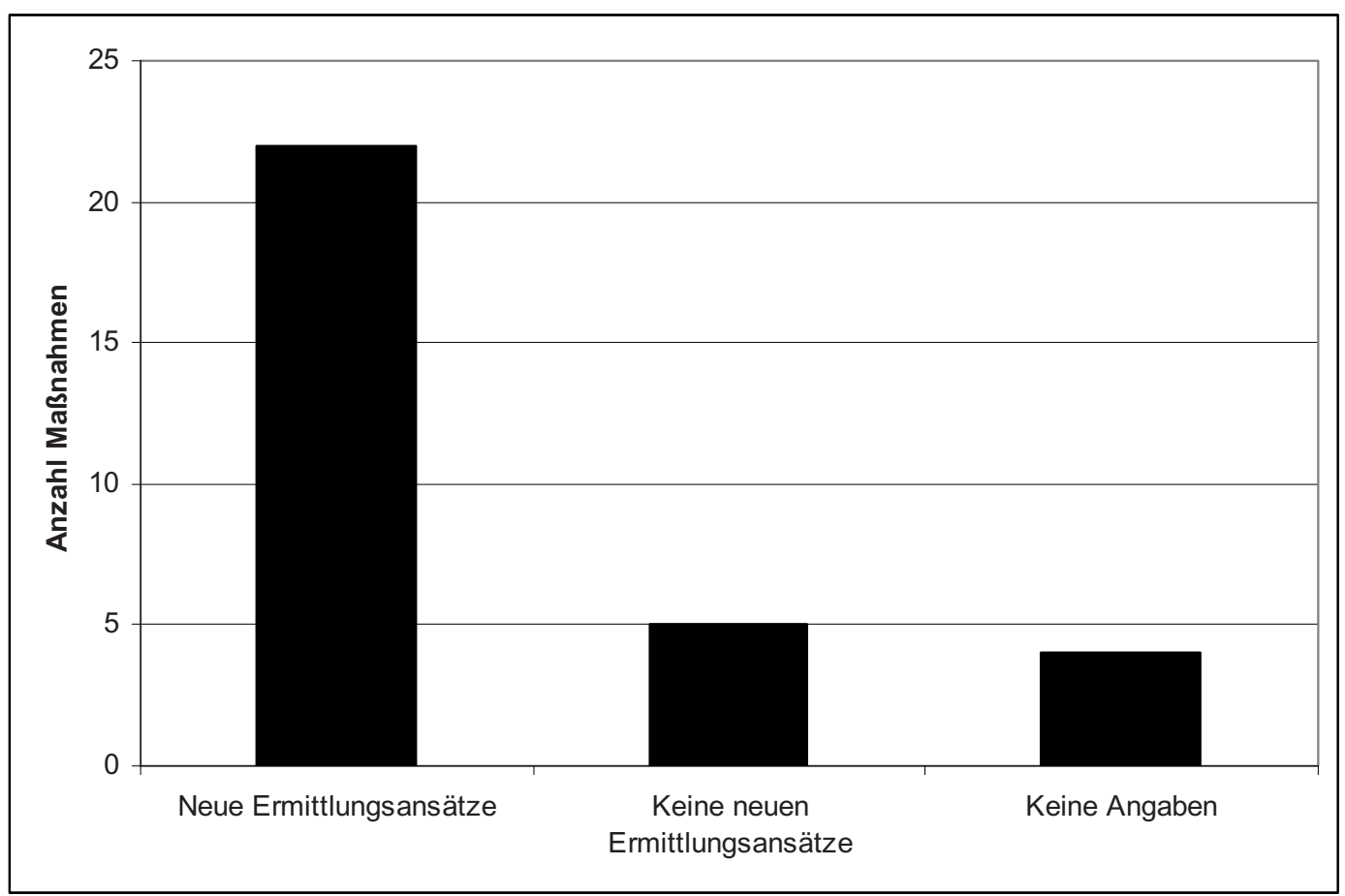

Bei den aufgrund der Erkenntnisse aus der Rasterfahndung veranlassten offenen Ermittlungsmaßnahmen handelte es sich um Zeugenvernehmungen, Durchsuchungen, DNA-Reihenuntersuchungen und eine Reihenuntersuchung von Vergleichsfingerabdrücken. Zur Anzahl der durchgeführten Durchsuchungen und Zeugenvernehmungen ließen sich den Verfahrensakten keine Angaben entnehmen. Auffällig ist jedoch die Anzahl von fünf DNA-Reihenuntersuchungen und einer Reihenuntersuchung von Vergleichsfingerabdrücken. Diese Maßnahmen erfordern einen hohen Arbeits- und Zeitaufwand und damit verbunden auch den Einsatz erheblicher finanzieller Mittel. In den betreffenden Verfahren wurde die Rasterfahndung gezielt zur Vorbereitung der Reihenuntersuchungen eingesetzt. So war es möglich innerhalb der ermittlungsrelevanten Personenkreise Priorisierungen vorzunehmen.

Als verdeckte Ermittlungsmaßnahmen waren Telefonüberwachungen, die Erhebung von Telekommunikationsverbindungsdaten und Observationen festzustellen. Die größte Gruppe von verdeckten Ermittlungsmaßnahmen machten büromäßige Abklärungen der Treffer aus. Dabei wurden durch Recherche in polizeiinternen und anderen Dateien Personen aus den Trefferlisten ausgeschlossen. So konnten 
die aus den maschinellen Abgleichen erhaltenen Trefferlisten manuell weiter eingegrenzt werden.

\section{d. Anzahl der Prüffälle / Treffer}

Zur Beurteilung des Erfolgs der Rasterfahndungen war darüber hinaus die Anzahl der Prüffälle bzw. der Treffer nach der Durchführung der Datenabgleiche heranzuziehen. Als Prüffälle bzw. als Treffer wurden beispielsweise die bei einem Abgleich herausgerasterten Personen bezeichnet. Diese bildeten die Grundlage für die weiteren konventionellen Ermittlungen. Angaben über die Treffer konnten nur für 24 der 31 Maßnahmen erlangt werden. Bei zwei Maßnahmen kam es zu keinen Treffern. Eine weitere Maßnahme hatte dagegen 42.051 Treffer zur Folge. Der Mittelwert liegt bei 2.357 Treffern und der Median bei 85 Treffern. Aus der erheblichen Abweichung von Mittelwert und Median lässt sich entnehmen, dass es eine schiefe Verteilung gibt. Diese ist im Zusammenhang mit der hohen Anzahl von Treffern in vier Maßnahmen zu sehen. Bei diesen kam es zu 42.051, 5.043, 4.066 und 2.409 Treffern.

Der Wert des Median von 85 besagt, dass es in $50 \%$ der Maßnahmen weniger als 85 Treffer gab. In einem Viertel der Fälle liegt die Anzahl der Treffer sogar unter 22. Mithin erbrachten 50\% der Maßnahmen handhabbare Trefferzahlen. Bei der Maßnahme mit 42.051 Treffern handelt es sich um die Maßnahme aus dem Verfahren 002. Diese wurde aufgrund der hohen Trefferzahl eingestellt.

\section{e. Identifizierung von Beschuldigten}

Von besonderer Bedeutung für den Ausgang der jeweiligen Verfahren und die Beurteilung des Erfolges der Rasterfahndung war es, ob durch die weiteren Ermittlungsmaßnahmen aus den Prüffällen bzw. Treffern Beschuldigte identifiziert werden konnten. Als Beschuldigte wurden nur solche Personen aufgenommen, die aufgrund der Ermittlungsansätze aus der Rasterfahndung identifiziert und im weiteren Verlauf der Verfahren ausdrücklich als Beschuldigte geführt worden sind. Insgesamt wurden aufgrund der weiteren Ermittlungsmaßnahmen in acht Verfahren Beschuldigte ermittelt. Dabei handelte es sich um sechs Verfahren, in denen jeweils ein Beschuldigter identifiziert wurde. In einem Verfahren wurden zwei und in einem weiteren fünf Personen als Beschuldigte identifiziert. Mithin wurden insgesamt 13 Beschuldigte verteilt auf acht Verfahren identifiziert. Ein Zusammenhang zwischen der Anzahl der Prüffälle bzw. der Treffer und der Anzahl der Beschuldigten besteht nicht. ${ }^{493}$ Von den 13 Beschuldigten wurden im Verlauf der

${ }^{493}$ Der Korrelationskoeffizient der beiden Variablen beträgt $r=-0,1$ und ist statistisch nicht signifikant. 
betreffenden Verfahren zehn festgenommen. In einem Fall kam es zu Erkenntnissen über weitere bislang unbekannte Straftaten des Beschuldigten.

\section{f. Identifizierung von Tatverdächtigen}

Neben der Identifizierung von Beschuldigten waren auch neue Tatverdächtige von besonderem Interesse für die Untersuchung. Als Tatverdächtige wurden nur solche Personen aufgenommen, die in den Verfahrensakten ausdrücklich als tatverdächtig bezeichnet, aber nicht als Beschuldigte geführt wurden. Neben den Beschuldigten wurden nur in zwei Verfahren Tatverdächtige aufgrund der veranlassten Ermittlungsmaßnahmen identifiziert. Dabei wurden in einem Verfahren zwei Personen und im zweiten Verfahren 36 Personen ausdrücklich als Tatverdächtige geführt.

\section{g. Neue Ermittlungsverfahren}

Von Bedeutung für die Erfolgsbeurteilung der Rasterfahndung war darüber hinaus, ob die Erkenntnisse aus den Rasterfahndungen zu neuen Ermittlungsverfahren geführt haben. Im Rahmen der Untersuchung der $31 \mathrm{Maßnahmen} \mathrm{nach} \mathrm{den} \S \S 98 \mathrm{a}, \mathrm{b}$ StPO konnten keine Informationen über neue Ermittlungsverfahren erlangt werden. Insofern ist davon auszugehen, dass es aufgrund der Erkenntnisse aus den Rasterfahndungen nicht zu neuen Ermittlungsverfahren gekommen ist.

\section{h. Zufallsfunde}

Die analysierten Verfahren wurden nach Erkenntnissen zu sog. Zufallsfunden untersucht. Dabei handelt es sich dem $\S 98$ b III, S.3 StPO zufolge um eine Verwendung der erlangten Erkenntnisse im Rahmen von anderen Verfahren. Zu dieser Untersuchungsfrage konnten den Verfahrensakten jedoch keine Informationen entnommen werden. Insofern kann darauf geschlossen werden, dass es in den 31 Maßnahmen zu keinen Zufallsfunden kam.

\section{i. Aufklärung aufgrund der Erkenntnisse aus der Rasterfahndung}

Wie bereits dargestellt basiert die Untersuchung auf der Analyse von 27 Verfahren. In 15 Fällen wurden die den Verfahren zugrunde liegenden Taten aufgeklärt. In elf Fällen wurden die Taten nicht und in einem weiteren Fall nur teilweise aufgeklärt. Es handelte sich hierbei um Verfahren 019. In diesem Verfahren wurden ein Beschuldigter und zwei Tatverdächtige ermittelt und bzgl. des Beschuldigten ein Tatnachweis erbracht. Die weitere Strafverfolgung wurde jedoch durch polni- 
sche Behörden übernommen. Aufgrund des besonderen Sachverhalts konnte das Verfahren in keine der beiden Kategorien aufgenommen werden.

In vier der 15 aufgeklärten Verfahren waren die aufgrund der Rasterfahndung erlangten neuen Ermittlungsansätze ursächlich für die Aufklärung. Auch in Verfahren 019 waren es die Erkenntnisse aus der Rasterfahndung, die zur teilweisen Aufklärung führten. In einem weiteren Verfahren hatte die Rasterfahndung ebenfalls einen Anteil an der Aufklärung. Dabei handelt es sich um Verfahren 023. Hier waren Daten für einen Abgleich erhoben worden. Der Abgleich führte zwar zu neuen Ermittlungsansätzen, jedoch nicht zur Aufklärung. Allerdings wurde ein Teil der Daten als Grundlage für eine DNA-Reihenuntersuchung genutzt, welche zur Aufklärung der Tat führte. Insofern trug die Rasterfahndung, wenn auch nicht wie vorgesehen, zur Aufklärung der Tat bei.

Es kann festgehalten werden, dass die aufgrund der Rasterfahndung erlangten Ermittlungsansätze in vier Fällen zur Aufklärung der Tat beitrugen. In weiteren zwei Fällen trug die Rasterfahndung teilweise zur Aufklärung der Taten bei. Auf die übrigen neun aufgeklärten Taten hatte die Rasterfahndung keinen Einfluss.

\section{j. Erfolgseinschätzung}

Der Operationalisierung des Erfolgsbegriffs entsprechend wurden die Rasterfahndungen in die Kategorie „erfolgreich“, „,bedingt erfolgreich“, „nicht erfolgreich“ und „Keine Angaben“ eingestuft. Eine auf diesen Kategorien basierende Erfolgseinschätzung war für alle 31 untersuchten Maßnahmen möglich.

Von den 31 Maßnahmen nach den $\S \S 98 \mathrm{a}$, b StPO wurden vier als „erfolgreich“ eingestuft. Aufgrund dieser vier Maßnahmen wurden neue Ermittlungsansätze erlangt, die nach weiteren Ermittlungen zur Aufklärung der Taten führten. Weitere 18 Maßnahmen konnten als „bedingt erfolgreich“ eingestuft werden. Diese hatten neue Ermittlungsansätze zur Folge, welche jedoch nicht zur Aufklärung der Taten führten. Fünf durchgeführte Rasterfahndungen mussten in die Kategorie „nicht erfolgreich“" aufgenommen werden. Diese erbrachten keine neuen Ermittlungsansätze. Letztlich waren vier Rasterfahndungen in der Kategorie „Keine Angaben“ einzustufen.

Es kann festgehalten werden, dass sich erfolgreiche und nicht erfolgreiche Rasterfahndungen ungefähr zu gleichen Anteilen gegenüberstehen. Die bedingt erfolgreichen Rasterfahndungen bilden mit fast $60 \%$ die größte Gruppe. Das heißt jedoch, dass von den mehr als zwei Dritteln der Maßnahmen, welche neue Ermittlungsansätze zur Folge haben, nur wenige letztendlich zur Aufklärung der Taten beitragen. 
Abbildung 21: Art der Erfolge in Prozent ( $n=31)$

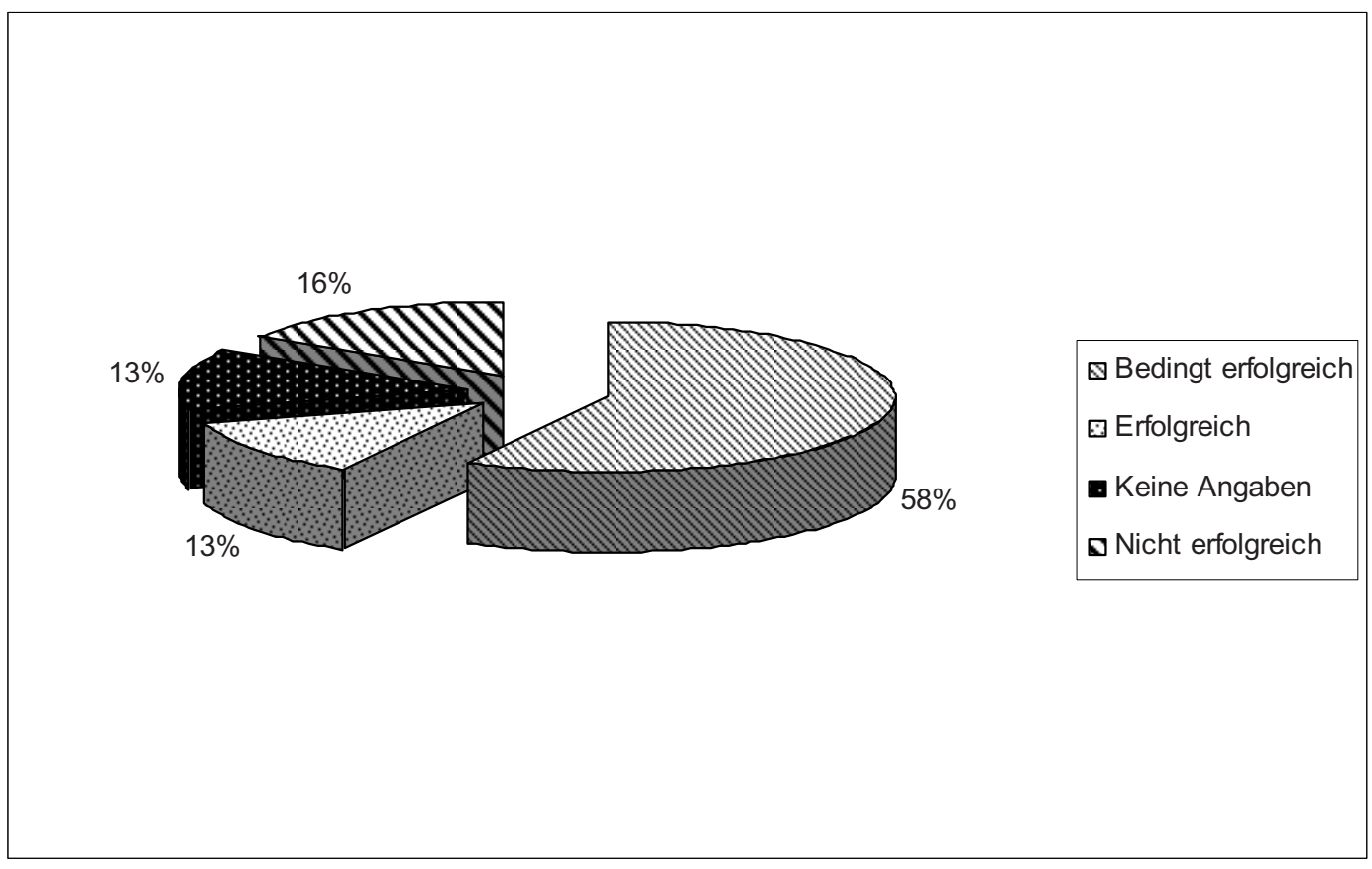

\section{Einschätzung des Erfolges}

Im Anschluss an die Untersuchung des Erfolges war es von besonderem Interesse, wie die jeweilige Maßnahme von den mit der Durchführung befassten Personen beurteilt wurde. Hierzu wurden die Verfahrensakten nach Aussagen von Polizeibeamten, Staatsanwälten und Richtern untersucht. Eine Einstufung der in den Verfahrensakten vorgefundenen Aussagen wurde ebenfalls unter die Kategorien „Rasterfahndung erfolgreich“, „Rasterfahndung bedingt erfolgreich“, „Rasterfahndung nicht erfolgreich“ und „Keine Angaben“ vorgenommen. So war es möglich die Ergebnisse der Untersuchung mit den in den Verfahrensakten enthaltenen Aussagen zu überprüfen, um gegebenenfalls Unterschiede und Gemeinsamkeiten herauszustellen.

\section{Erfolgseinschätzungen in den Verfahrensakten}

Zur weiteren Analyse des Erfolges der Rasterfahndung wurden die Verfahrensakten nach Einschätzungen von ermittelnden Polizeidienststellen und Staatsanwälten untersucht. Basis für die Untersuchung bildeten die $31 \mathrm{Maßnahmen} \mathrm{nach} \mathrm{den}$ $\S \S 98 \mathrm{a}, \mathrm{b}$ StPO. Für $17 \mathrm{Maßnahmen} \mathrm{konnten} \mathrm{„keine} \mathrm{Angaben“} \mathrm{festgestellt} \mathrm{werden.}$ Es wurden darüber hinaus drei Maßnahmen als „erfolgreich“ und ebenfalls drei Maßnahmen als „,bedingt erfolgreich“ beurteilt. Letztlich wurden acht Maßnahmen als ,nicht erfolgreich“ angesehen. 
Abbildung 22: Erfolgseinschätzungen in den Verfahrensakten ( $n=14)$

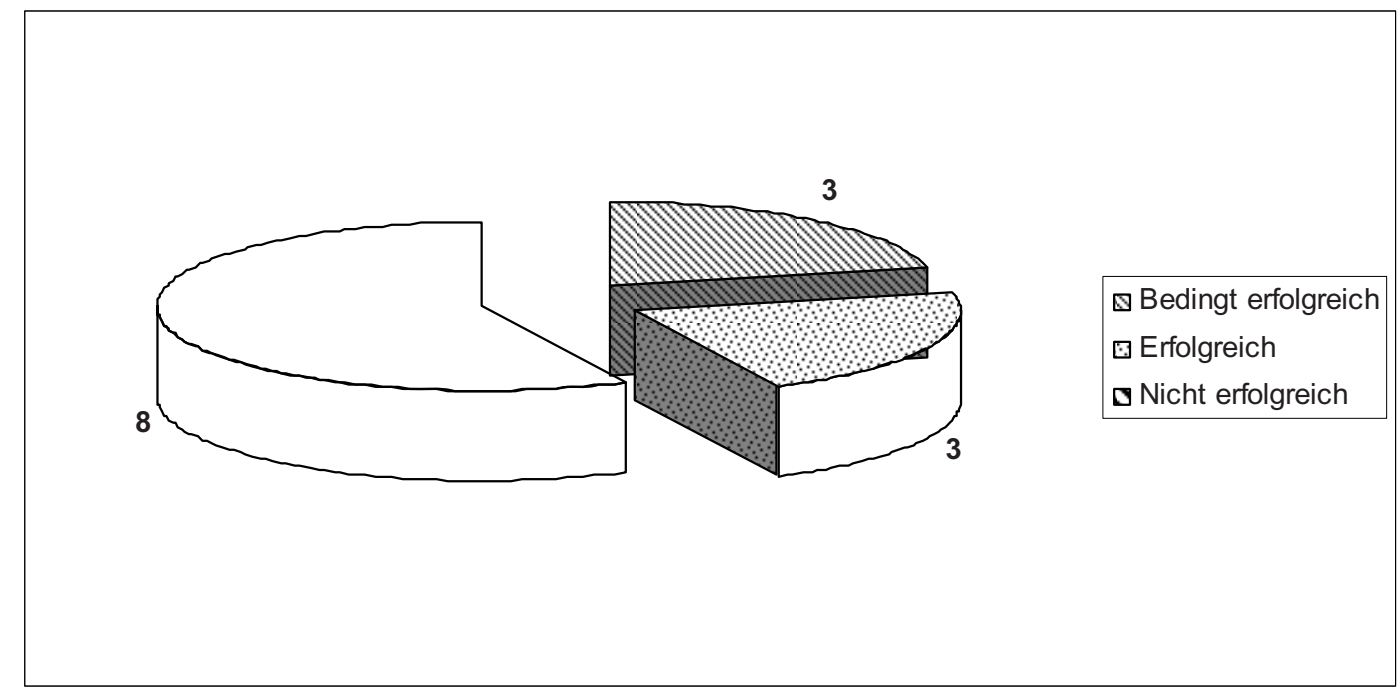

Von den 14 Maßnahmen, zu denen Erfolgseinschätzungen den Verfahrensakten entnommen werden konnten, wurden fast $60 \%$ als „nicht erfolgreich“ eingestuft. Mithin bilden die negativen Erfolgseinschätzungen die Mehrheit in den Verfahrensakten. Die Erfolgseinschätzungen basierten in allen 14 Fällen auf Aussagen der ermittelnden Polizeidienststellen. In zwei Fällen wurden die Aussagen ergänzt durch die Staatsanwaltschaft und in einem Fall durch das zuständige Amtsgericht.

\section{Vergleich der Erfolgseinschätzungen}

Für den Vergleich der aus den Verfahrensakten entnommenen Erfolgseinschätzungen mit den Erfolgseinschätzungen dieser Untersuchung werden nur die 14 Maßnahmen herangezogen, für die den Verfahrensakten eine Erfolgseinschätzung entnommen werden konnte.

Es zeigt sich, dass die drei Maßnahmen, die in den Verfahrensakten als „,erfolgreich“ bewertet wurden, auch im Rahmen der Untersuchung als „erfolgreich“ bewertet worden sind. Insofern stimmen die Kriterien für eine erfolgreiche Bewertung überein. Auffällig sind die auseinanderfallenden Werte in den Kategorien „bedingt erfolgreich“ und ,nicht erfolgreich“. Zunächst war festzustellen, dass die in den Verfahrensakten als „,bedingt erfolgreich“ eingestuften Maßnahmen in den ebenso eingestuften Maßnahmen der Untersuchung enthalten sind. Ferner waren die in der Untersuchung als ,nicht erfolgreich“ eingestuften Maßnahmen in den ebenso in den Verfahrensakten eingestuften Maßnahmen enthalten. Bzgl. dieser Verfahren stimmen die Erfolgseinschätzungen der Untersuchung und der ermittelnden Polizeidienststellen überein. 
Abbildung 23: Vergleich der Erfolgseinschätzungen ( $n=14)$

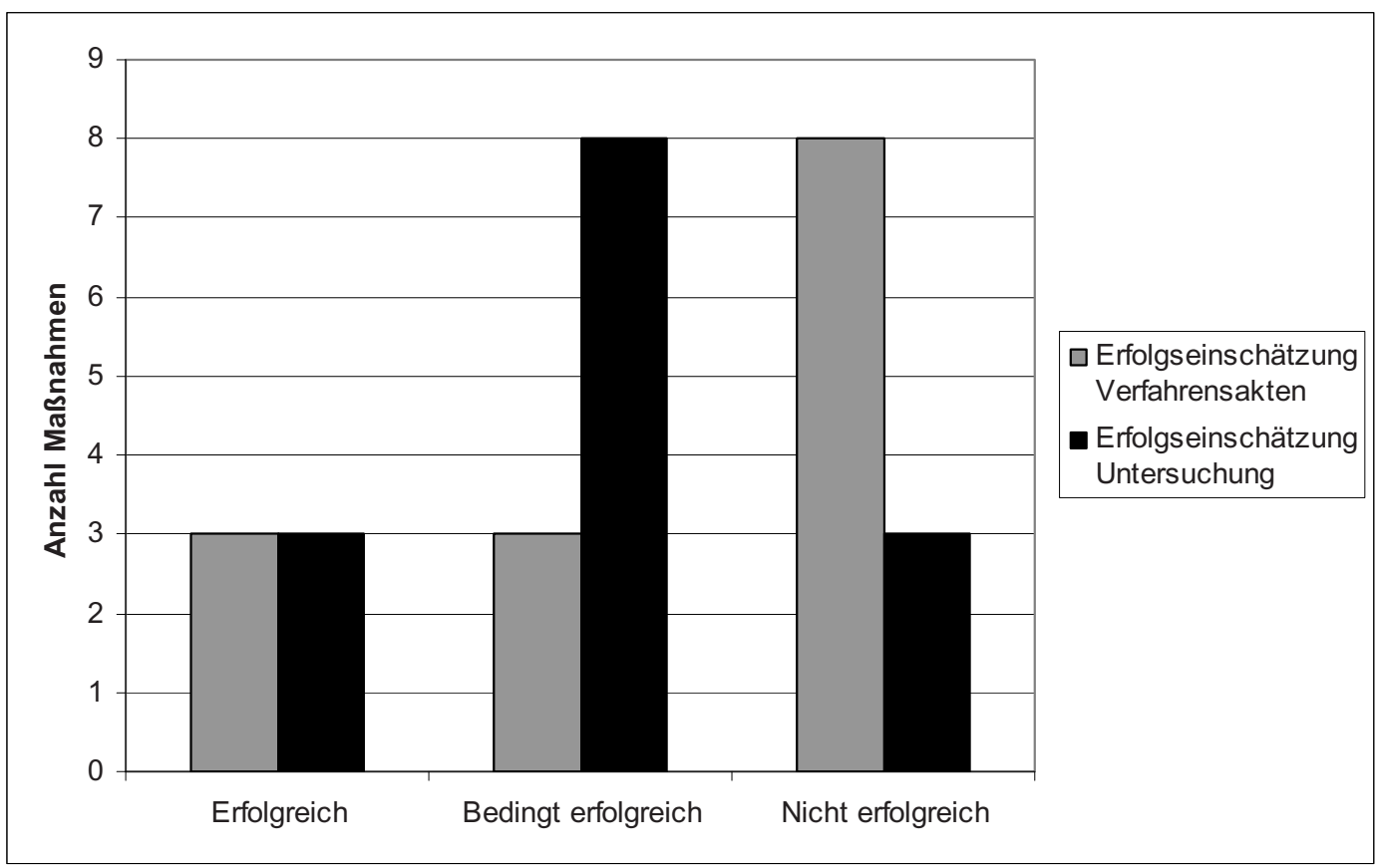

Daraus ergibt sich, dass fünf Maßnahmen unterschiedlich bewertet worden sind. Als Grund für das Auseinanderfallen der unterschiedlichen Erfolgseinschätzungen kommt die Einstufung einer Maßnahme als „,bedingt erfolgreich“ in Betracht. Wie bereits dargestellt, wurden im Rahmen der Untersuchung die Maßnahmen als bedingt erfolgreich eingestuft, die neue Ermittlungsansätze zur Folge hatten, aber letztendlich nicht zur Aufklärung der Tat beitragen konnten. In den Verfahrensakten orientiert sich die Beurteilung jedoch ausschließlich an der Aufklärung der Tat. Das Erlangen neuer Ermittlungsansätze wurde bei den betreffenden Maßnahmen nicht in die Bewertung einbezogen. Dieser Umstand erklärt das Auseinanderfallen der Erfolgseinschätzungen in den beiden Kategorien.

\section{Effizienz}

\section{Operationalisierung des Effizienzbegriffs}

Im Rahmen der Bedeutungsanalyse der Begriffe Erfolg und Effizienz wurde bereits dargestellt, dass für die Effizienz das Verhältnis von Input zu Output maßgebend ist. Im Rahmen des Outputs ist wiederum der Eintritt eines Erfolgs maßgebend. Folglich muss der Erfolg, wie er zuvor untersucht wurde, auch für die Untersuchung der Effizienz herangezogen werden. 
$\mathrm{Zu}$ beachten ist, dass im vorangegangenen Abschnitt allein der Erfolg der Maßnahme im Ermittlungsverfahren untersucht worden ist. Der Output der Rasterfahndung kann sich jedoch auch auf den weiteren Verlauf des Verfahrens beziehen. Aus diesem Grund ist der Verfahrensausgang in die Untersuchung mit einzubeziehen. In diesem Zusammenhang sind auch die erzielten Erfolge in Bezug zu den Katalogdelikten und den verfolgten Zielen zu setzen. Darüber hinaus ist die Rasterfahndung auf ihre Auswirkungen auf Anklage, Hauptverhandlung und Urteil zu untersuchen. Zudem ist die Rolle der Rasterfahndung im Rechtsmittelverfahren in die Untersuchung mit einzubeziehen.

Neben der Untersuchung des Outputs ist für die Beurteilung der Effizienz der Bereich des Inputs zu betrachten. Es soll festgestellt werden, welche Mittel im Rahmen der Rasterfahndung aufgewendet worden sind. Insofern sind der technische, personelle und zeitliche Aufwand in Bezug zum Ergebnis der Maßnahme zu setzen. Neben dem Erfolg der Maßnahme, wie er im vorangegangenen Abschnitt analysiert worden ist, bilden demnach die folgenden Kriterien eine Möglichkeit, die Effizienz der Rasterfahndung zu untersuchen.

- Der Ausgang der Verfahren

- Die Rolle der Rasterfahndung als Beweismittel in Anklage, Hauptverhandlung und Urteil

- Die Rolle der Rasterfahndung im Rechtsmittelverfahren

- Aufgewendete Ressourcen

\section{Die Untersuchungsergebnisse}

a. Verfahrensausgang

Bei der Untersuchung des Verfahrensausgangs in Bezug auf den Erfolg der Rasterfahndung waren nur die Verfahren zugrunde zu legen, die zum Zeitpunkt der Einsichtnahme bereits abgeschlossen waren. Demnach wurden von den 27 untersuchten Verfahren nur die neun eingestellten und 13 aufgrund von Verurteilungen abgeschlossenen Verfahren einbezogen. Der Verfahrensausgang wurde in Bezug zum Erfolg der in diesen Verfahren durchgeführten Rasterfahndungen gesetzt. Dabei wurden die im vorhergehenden Abschnitt verwendeten Kategorisierungen des Erfolgs herangezogen.

aa. Einstellungen erfolgsbezogen

Wie bereits dargestellt wurden die Ermittlungen in neun Verfahren eingestellt. ${ }^{494}$ Dabei konnte allerdings in einem Verfahren ein Täter ermittelt werden, welcher sich jedoch durch Suizid der weiteren Strafverfolgung entzogen hatte. Insofern

${ }^{494}$ Siehe 3.Teil A. 
dienten hier die acht Verfahren als Grundlage, in denen kein Täter ermittelt werden konnte und die Ermittlungen erfolglos eingestellt wurden. In diesen acht Verfahren wurden insgesamt neun Rasterfahndungen durchgeführt. Von diesen Maßnahmen wurden acht als bedingt erfolgreich und eine Maßnahme als nicht erfolgreich eingestuft. Die bedingt erfolgreichen Maßnahmen hatten zwar einerseits neue Ermittlungsansätze zur Folge, zeigten andererseits jedoch keine Auswirkungen auf den erfolgreichen Abschluss der Ermittlungen.

bb. Verurteilungen erfolgsbezogen

In den 13 Verfahren, welche Verurteilungen zur Folge hatten, wurden 14 Maßnahmen nach den $\S \S 98 \mathrm{a}, \mathrm{b}$ StPO durchgeführt. Davon waren fünf Maßnahmen als bedingt erfolgreich einzustufen. Ferner waren vier Maßnahmen als erfolgreich und drei Maßnahmen als nicht erfolgreich einzustufen. Für zwei der Maßnahmen war keine Einstufung möglich. Daraus ergibt sich, dass die Rasterfahndung nur in vier Verfahren einen Einfluss auf die Aufklärung der Tat und die Verurteilung des Täters hatte. In den übrigen zehn Verfahren hatte die Rasterfahndung keinen Anteil an der Aufklärung der Taten.

\section{b. Verteilung der Erfolge auf die Katalogstraftaten}

Bei der Verteilung der Erfolge auf die Katalogstraftaten zeigt sich, dass die vier Maßnahmen, denen gemeingefährliche Straftaten als Katalogtaten zugrunde lagen, lediglich bedingt erfolgreich waren. Demnach lieferte die Rasterfahndung in allen Fällen neue Ermittlungsansätze. Allerdings war die Ermittlungsmaßnahme nicht in der Lage zur Aufklärung gemeingefährlicher Straftaten beizutragen. Nur wenig ändert sich dieses Bild bei der Betrachtung von Maßnahmen, denen gewerbs- und gewohnheitsmäßig begangene Straftaten als Katalogtaten zugrunde lagen. Auch hier handelte es sich um vier Maßnahmen. Zwei dieser Maßnahmen erbrachten neue Ermittlungsansätze und eine verlief erfolglos. Allerdings konnte auch eine Maßnahme festgestellt werden, die erfolgreich zur Aufklärung der Tat beitragen konnte.

Bei den Kombinationen aus mehreren Katalogtaten handelte es sich in zwei Fällen um eine Kombination aus den Kategorien Straftaten auf dem Gebiet des BtmG, gewerbs- und gewohnheitsmäßig und als Bandenmitglied oder in anderer Weise organisiert begangene Straftaten. Die weiteren sechs Kombinationen setzten sich in verschiedenen Variationen aus Straftaten gegen Leib und Leben, Straftaten auf dem Gebiet des Staats- und Verfassungsschutzes und gemeingefährlichen Straftaten zusammen. Die Maßnahmen mit Kombinationen waren in vier Fällen bedingt erfolgreich. Darüber hinaus verliefen zwei dieser Maßnahmen ohne Erfolg.

Bei den Maßnahmen zur Aufklärung von Straftaten gegen Leib und Leben ließen sich mit drei Maßnahmen die am meisten erfolgreichen feststellen. Hierbei 
handelte es sich ausschließlich um Rasterfahndungen, die als Grundlage von DNA-Reihenuntersuchungen durchgeführt worden sind. ${ }^{495}$ Diese Reihenuntersuchungen führten in den drei Fällen zur Ergreifung und Verurteilung eines Täters. Daraus lässt sich ableiten, dass sich die Rasterfahndung in besonderem Maße zur Vorbereitung einer DNA-Reihenuntersuchung eignet.

Abbildung 24: Verteilung der Erfolge auf die Katalogtaten $(n=31)$

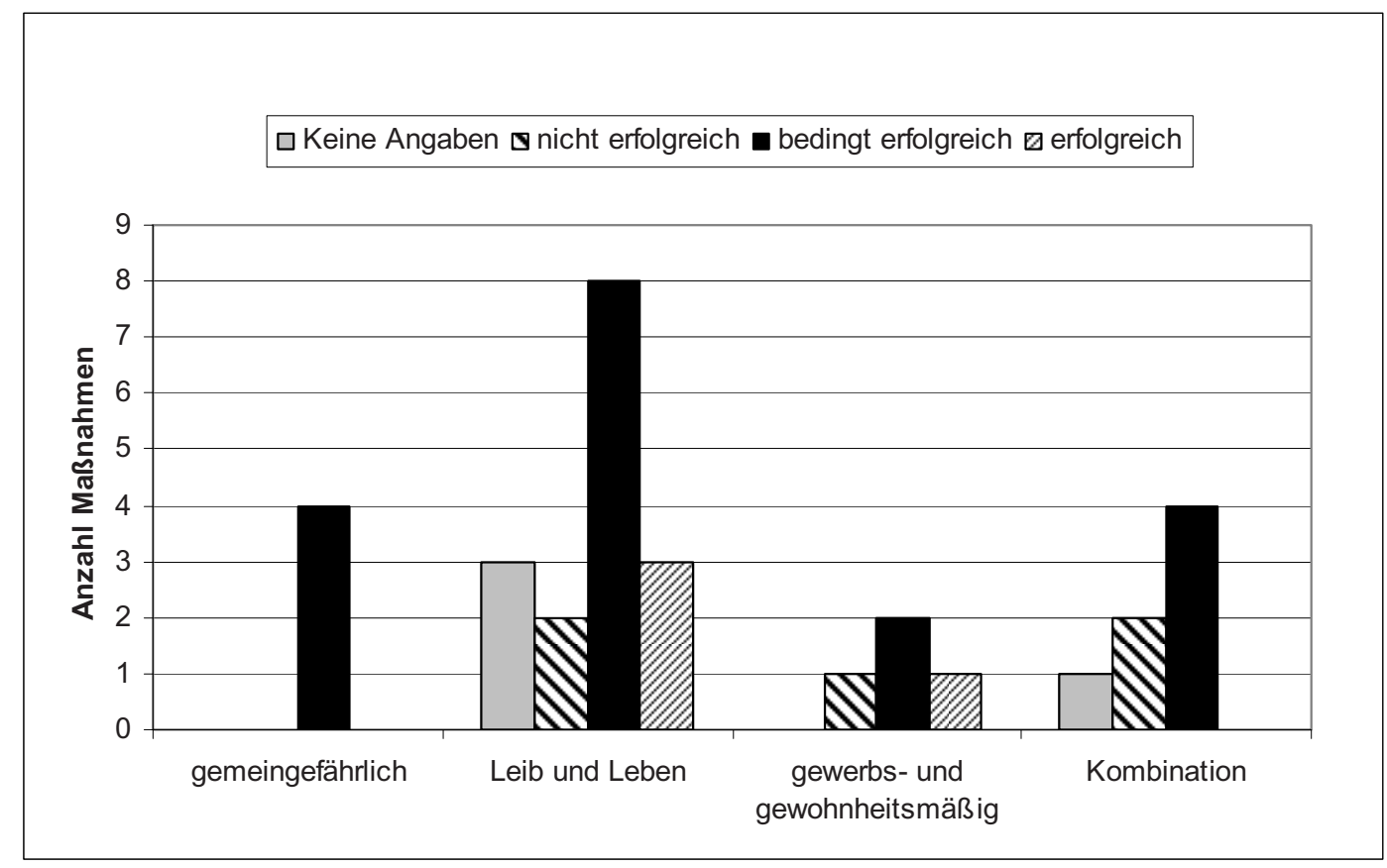

In acht weiteren Fällen konnten Maßnahmen in dieser Kategorie als bedingt erfolgreich eingestuft werden. $\mathrm{Zu}$ diesen acht Maßnahmen zählte eine Maßnahme, die ebenfalls zur Vorbereitung einer Reihenuntersuchung durchgeführt worden ist. Das betreffende Verfahren war zum Zeitpunkt der Einsichtnahme in die Verfahrensakten noch nicht abgeschlossen. Aus diesem Grund wurde die Maßnahme nach den $\S \S 98 \mathrm{a}, \mathrm{b}$ StPO nur als bedingt erfolgreich eingestuft. ${ }^{496}$ Zieht man lediglich die bereits abgeschlossenen drei Verfahren im Bereich der Straftaten gegen Leib und Leben heran, in denen die Rasterfahndung als Grundlage einer Reihenuntersuchung durchgeführt wurde, so kann festgehalten werden, dass die Rasterfahndung in diesen Fällen immer erfolgreich zur Ergreifung der Täter beigetragen hat. Daraus folgt, dass sich Verfahren, welche Straftaten gegen Leib und Leben (insbesondere sexuell motivierte Straftaten) zum Gegenstand haben, dann für die Anwendung einer Rasterfahndung eignen, wenn eine vergleichsfähige Tatortspur gesichert werden konnte und eine Reihenuntersuchung geplant wird.

495 Die drei Maßnahmen wurden in den Verfahren 009, 014 und 016 durchgeführt.

496 Bei dem betreffenden Verfahren handelt es sich um Verfahren 012. 
c. Verteilung der Erfolge auf die verfolgten Ziele

Im Dritten Teil der Untersuchung wurden die mit den einzelnen Maßnahmen verfolgten Ziele aufgezeigt. Dabei wurde zunächst zwischen positiver und negativer Rasterfahndung differenziert. Im Anschluss daran wurden weitere mit den Maßnahmen verfolgte Ziele aufgezeigt. ${ }^{497}$ An dieser Stelle soll dargestellt werden, wie sich die Erfolge auf die mit den Maßnahmen verfolgten Ziele verteilen. Hierdurch war es möglich Aussagen über den Umfang der Zielerreichung und damit auch über die Effizienz der Rasterfahndung zu treffen.

aa. Verteilung der Erfolge auf die Differenzierung zwischen positiver und negativer Rasterfahndung

Bei der Verteilung der Erfolge auf die Kategorien „Positive Rasterfahndung“, „beide Alternativen“ und „keine der beiden Alternativen“ fällt auf, dass die Maßnahmen, bei denen lediglich die „Positive Rasterfahndung“ als Ziel angeführt wurde, nicht so erfolgreich waren. Die Maßnahmen, bei denen beide Alternativen als Ziele angeführt wurden, waren somit erfolgreicher. In dieser Kategorie waren von den elf Maßnahmen drei als erfolgreich einzustufen. Lediglich eine Maßnahme war nicht erfolgreich und sieben Maßnahmen waren bedingt erfolgreich.

Abbildung 25: Verteilung der Erfolge auf die verfolgten Ziele ( $n=30)$

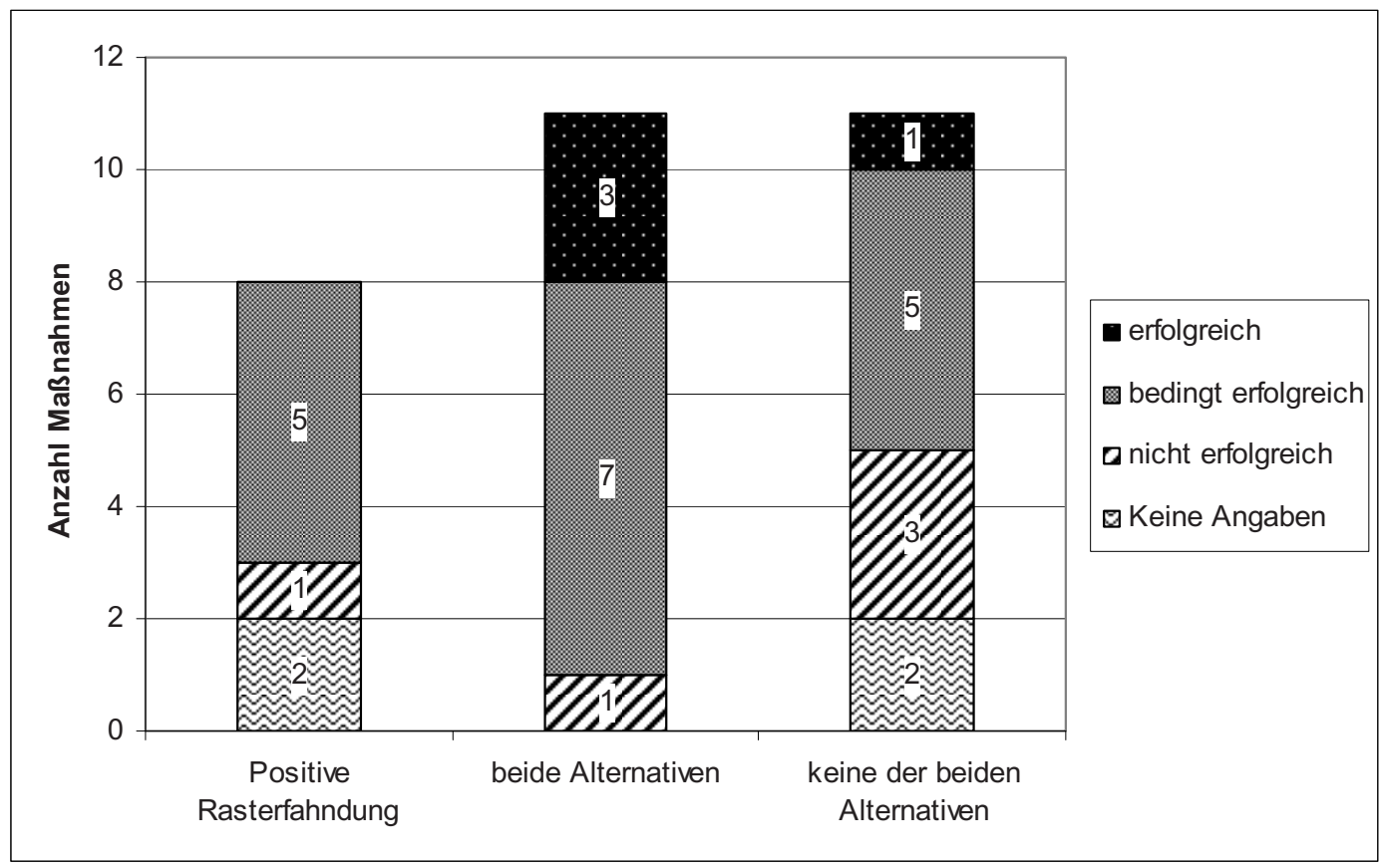

497 Siehe 3.Teil.B.II.3. 
Die breiteste Verteilung über die Kategorien wiesen die Maßnahmen auf, welche lediglich konkrete Ziele enthielten. Hier waren eine Maßnahme als erfolgreich, fünf Maßnahmen als bedingt erfolgreich und drei Maßnahmen als nicht erfolgreich einzustufen. Daraus ergibt sich die Annahme, dass Maßnahmen mit konkreten Zielen nicht so erfolgreich sind wie die Maßnahmen, welche beide Alternativen des § 98a I StPO als Ziel enthalten. Um diese Annahme näher zu untersuchen, war es jedoch notwendig, die Verteilung der Erfolge auf die weiteren mit den Maßnahmen verfolgten Ziele zu betrachten. Wie bereits dargestellt, wurden die beiden Alternativen häufig ergänzend zu anderen Zielen in die Anträge aufgenommen. Insofern war zu beachten, dass in 6 der 11 Maßnahmen, in denen beide Alternativen als Ziele angeführt wurden, auch weitere Ziele enthalten waren.

bb. Verteilung der Erfolge auf die weiteren Ziele

Neben den elf Maßnahmen, welche keine der beiden Alternativen des $\S 98 \mathrm{a} I$ StPO enthielten, konnten in acht Maßnahmen der beiden anderen Kategorien weitere Ziele festgestellt werden. Insgesamt enthielten damit 19 Maßnahmen weitere Ziele. Unter Berücksichtigung von Mehrfachnennungen verteilen sich 26 Ziele auf diese 19 Maßnahmen. Fünf der Maßnahmen enthalten mehr als ein weiteres Ziel. Sie bilden die Kategorie „Kombination mehrerer Ziele“. Sie enthalten die „Feststellung von Bandenstrukturen“, die Bestimmung des "Aufenthaltsortes des Beschuldigten“, die „Identifizierung von Mittätern“, die „Allgemeine Erforschung des Sachverhalts“ und ,sonstige Ziele“ in verschiedenen Kombinationen.

Bei der Betrachtung der Verteilung der Erfolge auf die weiteren Ziele zeigt sich, dass lediglich zwei erfolgreiche Einstufungen zu finden sind. In einem Fall konnte das Ziel der Identifizierung von Mittätern und einem weiteren Fall konnten neue Ermittlungsansätze erfolgreich erreicht werden. Betrachtet man die sonstigen Ziele, so fällt auf, dass diese in der Regel nicht erreicht wurden. Dies ist insofern überraschend, als dass sich daraus ergibt, dass die Rasterfahndung dann nicht erfolgreich war, wenn ganz konkrete Ziele verfolgt wurden. Demnach bestätigt dieses Ergebnis die zuvor aufgestellte These zumindest in Teilen. Allerdings bedürfen die Ergebnisse einer eingehenden Analyse im Rahmen der Expertengespräche.

\section{cc. Zusammenfassung der Verteilung der Erfolge auf die verfolgten Ziele}

Um eine aussagekräftige Darstellung zu erlangen, müssen die Ergebnisse der beiden vorangegangenen Untersuchungsschritte miteinander kombiniert werden. Wie bereits dargestellt worden ist, konnten 4 der 31 Maßnahmen als erfolgreich eingestuft werden. Das Ziel von zwei der Maßnahmen war der Ausschluss Nichtverdächtiger Personen und die Feststellung von Personen, die weitere für die Ermittlungen bedeutsame Prüfungsmerkmale erfüllen. Eine Maßnahme ergänzte die- 
Abbildung 26: Verteilung der Erfolge auf die weiteren Ziele ( $n=19)$

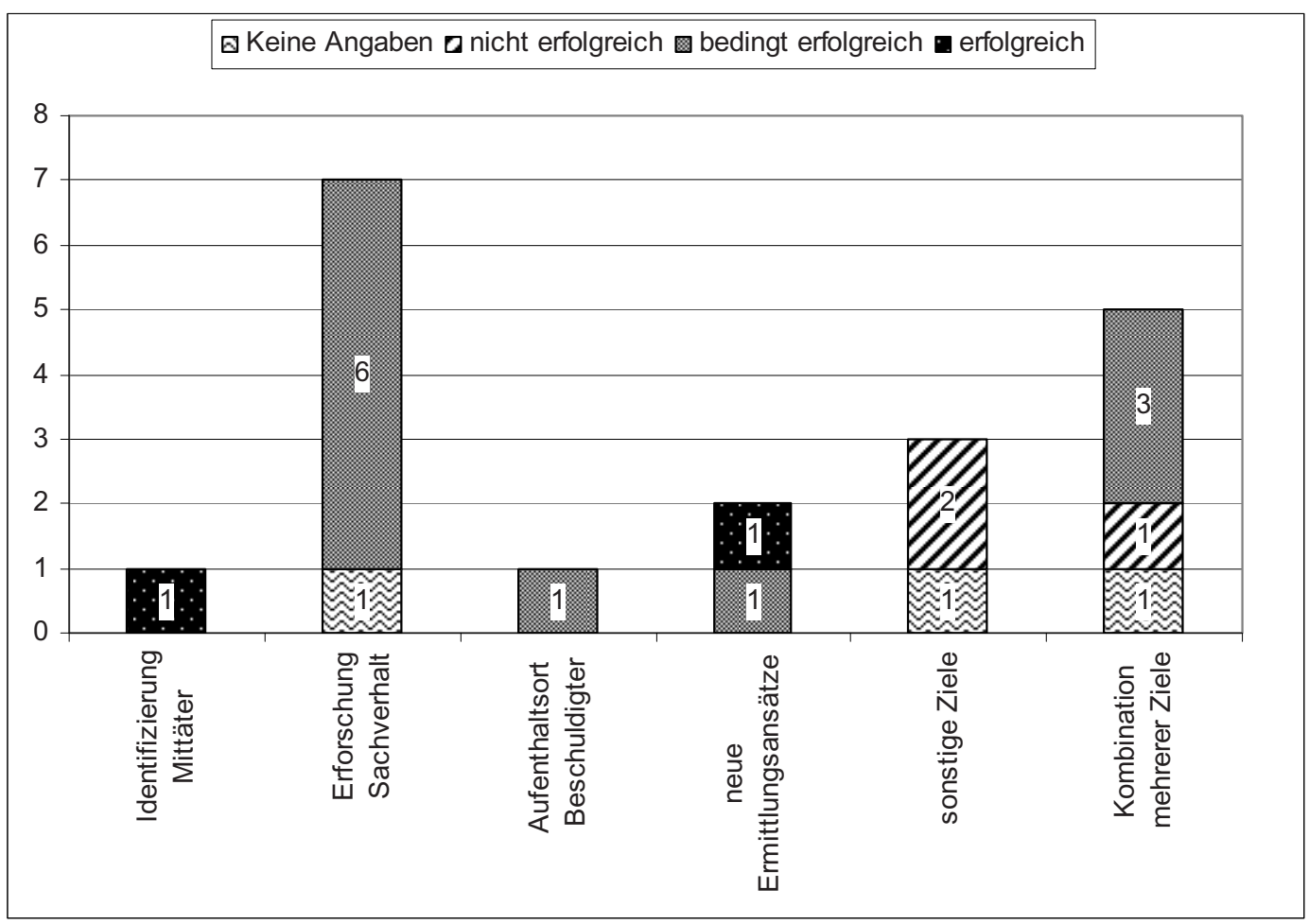

se Ziele durch die Identifizierung von Mittätern. Die vierte erfolgreiche Maßnahme enthielt lediglich die Erlangung neuer Ermittlungsansätze als Ziel.

Bezieht man jedoch in die Betrachtung mit ein, dass es sich bei drei der erfolgreichen Maßnahmen um solche handelt, die zur Vorbereitung einer DNAReihenuntersuchung veranlasst wurden, so liegt der Schluss nahe, dass die tatsächlich mit der Maßnahme verfolgten Ziele nicht in den Anträgen aufgeführt werden. Die drei Anträge der betreffenden Maßnahmen enthielten keine Angaben über die geplanten Reihenuntersuchungen.

\section{d. Die Rasterfahndung in Anklage, Hauptverhandlung und Urteil}

aa. Die Rolle der Rasterfahndung in der Anklage

In den Anklageschriften gegen die 28 Beschuldigten wurde die Rasterfahndung in fünf Fällen als Beweismittel aufgeführt. Diese Personen waren in einem der 27 Verfahren beschuldigt. Allerdings wurde die Rasterfahndung nicht ausdrücklich, sondern nur eine Trefferliste als Gegenstand des richterlichen Augenscheins aufgeführt.

In einer weiteren Anklage wurde die Rasterfahndung nur beiläufig erwähnt. Dabei handelte es sich um den folgenden Satz. „Nach einer Fallanalyse wurde eine Sonderkommission gebildet, die nach einer Rasterfahndung 808 Männer aufforder- 
te, eine Speichelprobe abzugeben." Ferner war in einer weiteren Anklage folgender Satz enthalten. „Aufgrund der Rasterfahndung wurde ein Personenkreis erlangt, welcher durch eine DNA-Reihenuntersuchung weiter ermittelt werden konnte.“ In beiden Verfahren wurde die Rasterfahndung als erfolgreich eingestuft.

Es zeigt sich deutlich, dass die Ermittlungsmaßnahme lediglich ein Mittel zum Erkenntnisgewinn ist und sich nur in Ausnahmefällen auch als Beweismittel eignet. Im Gegensatz zur Rasterfahndung genießen Einlassungen, Augenscheinsobjekte und Gutachten den größten Stellenwert in den Anklageschriften. Aber auch Protokolle von Telefonüberwachungen, Verbindungsdaten und Zeugen werden als Beweismittel aufgeführt.

bb. Die Rolle der Rasterfahndung in der Hauptverhandlung

Bei der Analyse der Hauptverhandlungsprotokolle konnten in 13 Fällen Beweisanträge der Verteidigung festgestellt werden. Lediglich einer dieser Beweisanträge tangierte die Rasterfahndung in Randbereichen. Es wurde beantragt, einen Zeugen bzgl. des Sachverhalts zu vernehmen, welcher zur Rasterfahndung geführt hatte. Das Ergebnis der Rasterfahndung oder die Rasterfahndung an sich waren nicht Gegenstand des Antrags.

Für die Staatsanwaltschaft waren insgesamt zwei Beweisanträge festzustellen. Einer der beiden Anträge bezog sich auf den zuvor beschriebenen Antrag der Verteidigung. Es wurde beantragt, den Antrag der Verteidigung zurückzuweisen. Mit diesem Antrag hatte die Staatsanwaltschaft Erfolg. Weitere Informationen über die Rolle der Rasterfahndung in der Hauptverhandlung konnten den Protokollen nicht entnommen werden.

cc. Die Rolle der Rasterfahndung im Urteil

Lediglich in einem Urteil wurde die Rasterfahndung im Rahmen der Beweiswürdigung aufgegriffen. Bei dem betreffenden Verfahren handelte es sich um jenes, in dessen Hauptverhandlung die zuvor beschriebenen Anträge gestellt worden sind. Die Rasterfahndung wurde jedoch ohne Beweiskraft erörtert. Demnach kann festgehalten werden, dass die Rasterfahndung in keinem Urteil mit Beweiskraft aufgegriffen wurde. Dieses Ergebnis bestätigt die Annahme, dass es sich bei der Rasterfahndung lediglich um ein Mittel zum Erkenntnisgewinn handelt.

e. Die Rolle der Rasterfahndung im Rechtsmittelverfahren

Von den 28 Beschuldigten, die angeklagt und verurteilt wurden, lagen von 26 Personen Informationen über Rechtsmittel vor. 19 der Personen legten keine Rechtsmittel gegen das Urteil ein. Ferner legten sieben Beschuldigte das Rechtsmittel der Revision ein. Von diesen zogen zwei Beschuldigte die Revision wieder 
zurück. Über den Inhalt der Revision der fünf Beschuldigten waren keine Informationen verfügbar. Es ist jedoch davon auszugehen, dass die Rasterfahndung in diesen Fällen keine Rolle gespielt hat.

\section{f. Sonstige Effizienzkriterien}

Als sonstige Kriterien waren der mit der Durchführung von Rasterfahndungen verbundene zeitliche, personelle und finanzielle Aufwand zu berücksichtigen. Wie bereits im Dritten Teil der Untersuchung dargestellt worden ist, waren den Verfahrensakten nur in sehr begrenztem Umfang Informationen über den mit den Maßnahmen verbundenen Aufwand zu entnehmen. Diesbezügliche Informationen waren nur in polizeilichen Vermerken enthalten. Ausführliche Auseinandersetzungen mit der Maßnahme waren nur in wenigen Verfahren festzustellen. Detaillierte Informationen bildeten die Ausnahme. Es waren lediglich Sätze wie: „Der Datenabgleich musste aufgrund von Problemen bei der Formatierung der Daten um zwei Wochen verschoben werden" enthalten.

Aufgrund dieser Angaben kann darauf geschlossen werden, dass im Rahmen der Ermittlungsmaßnahme in besonderem Maße technische Probleme auftreten und zur Lösung dieser Probleme in größerem Umfang Ressourcen eingesetzt werden. Insbesondere der personelle Aufwand und die mit diesem verbundene Bindung von Mitarbeitern dürfen in diesem Zusammenhang nicht unberücksichtigt bleiben. Der personelle Aufwand schlägt sich wiederum in den mit einer solchen Maßnahme verbundenen Kosten nieder. Letztlich darf auch der für die Durchführung einer Rasterfahndung benötigte Zeitaufwand nicht unberücksichtigt bleiben. $\mathrm{Zu}$ diesen Punkten waren den Verfahrensakten jedoch nur in sehr begrenztem Umfang Informationen $\mathrm{zu}$ entnehmen. Mithin war eine Untersuchung der Effizienz unter Anwendung der Kosten-Nutzen-Analyse nicht möglich. Unter ausschließlicher Zugrundelegung der Erkenntnisse der Aktenanalyse wäre allerdings davon auszugehen, dass der mit einem Datenabgleich verbundene Aufwand bei der Anregung, der Beantragung und bei der Anordnung nur eine untergeordnete Rolle spielt. Dies würde bedeuten, dass bei der Anordnung und der Durchführung einer Maßnahme nach den $\S \S 98 \mathrm{a}, \mathrm{b}$ StPO nur begrenzt wirtschaftliche Überlegungen angestellt werden. Diese Annahme bedarf einer eingehenden Untersuchung im Rahmen der Expertengespräche.

\section{Erfolg und Effizienz der präventiven Rasterfahndung nach dem 11. September}

Zum Abschluss des Vierten Teils dieser Untersuchung werden auch der Erfolg und die Effizienz der Rasterfahndung nach dem 11. September in die Betrachtung miteinbezogen. Wie bereits bei der Darstellung der Maßnahme wird auch hier auf 
Informationen aus den Tätigkeitsberichten von Datenschutzbeauftragten der Bundesländer und des Bundes zurückgegriffen. ${ }^{498}$

\section{Erfolg}

Im Rahmen der Rasterfahndung nach sog. Schläfern wurden bundesweit erhebliche Datenmengen erhoben und miteinander abgeglichen. Im Zuge der Maßnahme wurde beim Bundeskriminalamt die Verbunddatei „Schläfer“ errichtet. Zwischenzeitlich waren in dieser Datei ca. 32.000 Datensätze enthalten. ${ }^{499}$ Übereinstimmend berichteten Vertreter der Innenministerien und Datenschutzbeauftragte darüber, dass die Maßnahme nicht zur Einleitung von Strafverfahren gegen sog. „Schläfer“ geführt habe. ${ }^{500}$ Gemessen am verfolgten Ziel, muss die Maßnahme damit als nicht erfolgreich beurteilt werden. Allerdings kann nicht sicher davon ausgegangen werden, dass es in Deutschland weitere „Schläfer“ gegeben hat oder noch gibt. Insofern ist eine Beurteilung der Maßnahme allein an der Identifikation sog. „Schläfer“ nicht möglich.

Von den ermittelnden Stellen wurde mehrfach hervorgehoben, dass die Rasterfahndung auch dann erfolgreich sei, wenn sie dazu führe, dass potenzielle Terroristen durch den Fahndungsdruck zur Aufgabe ihrer Ziele veranlasst würden. In diesem Zusammenhang wurde angeführt, dass die Rasterfahndung dazu geführt habe, dass die Erkenntnisse über das islamistische Potenzial in Deutschland bei den Sicherheitsbehörden verbessert wurden. ${ }^{501}$ Die von den Sicherheitsbehörden angeführte Abschreckungswirkung ist schwer zu evaluieren. Diesbezüglich wurde angemerkt, ,dass niemand abschätzen könne, inwieweit der erzeugte Fahndungsdruck weitere Terroranschläge verhindert, potenzielle Terroristen von ihrem Vorhaben abgebracht oder sie in ihrem Aktionsfeld eingeschränkt habe. Daneben könne jedoch vermutet werden, dass diese Maßnahme bei einigen Personen den Wegzug bewirkt bzw. einen geplanten Zuzug beschränkt habe. “502 Von der Ausreise herausgerasterter Personen auf deren Eigenschaft als „Schläfer“ zu schließen und dies mit der Abschreckungswirkung der Rasterfahndung zu begründen, erscheint mehr als fraglich. Im Ergebnis ist eine Einstufung der Rasterfahndung nach dem 11. September als erfolgreich allein in Bezug auf ihre Abschreckungswirkung schwer nachvollziehbar.

498 Siehe 4. Teil B. XXVIII.

${ }^{499}$ BVerfGE 115, 320, 324.

500 Siehe beispielsweise: Hessischer Landtag-Drs, 16/2042, S.2; 25. Jahresbericht des Landesbeauftragten für den Datenschutz Bremen (2003); S.55f.

${ }^{501}$ Bayerischer Landtag-Drs, 14/9222, S.5.

${ }^{502}$ Hetger, zitiert in: Kube/Schneider/Stock (Hrsg.), Kriminologische Spuren in Hessen, S.75. 
Aufgrund der unzureichenden Informationen über erlangte Ermittlungsansätze und die weiteren Ermittlungen kann an dieser Stelle keine Erfolgsbeurteilung erfolgen. Insofern ist es angebracht, Einschätzungen und Erfahrungen der mit der Rasterfahndung nach dem 11. September 2001 befassten Mitarbeiter des Staatsschutzes im Rahmen der Expertengespräche zu erheben.

\section{Effizienz}

Im Rahmen der Untersuchung der Effizienz der Maßnahme ist es notwendig, das erzielte Ergebnis in Bezug zu den eingesetzten Ressourcen zu setzen. Im Rahmen der eingesetzten Ressourcen sind insbesondere der technische, der finanzielle und der personelle Aufwand zu berücksichtigen. Darüber hinaus darf auch der zeitliche Aufwand nicht unberücksichtigt bleiben. Allerdings ist zu beachten, dass bzgl. dieser Kriterien nur in sehr begrenztem Umfang Informationen verfügbar waren. Auch hier sei darauf hingewiesen, dass es nicht möglich war, Einsicht in die betreffenden Vorgänge zu erlangen.

Zeitlich nahm die Maßnahme ca. zwei Jahre in Anspruch. Dieser lange Zeitraum ist bedingt durch den erheblichen Umfang der abzugleichenden Datenbestände. Darüber hinaus kam es in einigen Bundesländern zu richterlichen Überprüfungen der Maßnahme, was ebenfalls zu zeitlichen Verzögerungen führte. In Anbetracht des Ergebnisses der Maßnahme und des zeitlichen Aufwandes bestehen erhebliche Zweifel an der Effizienz der Maßnahme.

Lediglich für Schleswig-Holstein war es möglich, Erkenntnisse über Kosten der Maßnahme zu erlangen. So wurden im Jahr 2001 für Software und Kosten des Datenabgleichs insgesamt 125.374,51 DM aufgewandt. In welchem Umfang die übrigen Bundesländer finanzielle Mittel aufgewandt haben, war nicht zu evaluieren. Es ist davon auszugehen, dass der mit der Maßnahme verbundene finanzielle Aufwand erheblich war. Im Zusammenhang mit dem finanziellen Aufwand ist auch der personelle Aufwand zu sehen. Dieser wirkt sich indirekt auf die Kosten der Maßnahme aus. Durch den Datenabgleich wurden erhebliche personelle Ressourcen gebunden. Beispielsweise waren in Bayern zeitweise 26 Beamte und in Hessen bis zu 30 Beamte mit der Erhebung und dem Abgleich der Daten beschäftigt. ${ }^{503}$ Bei diesen Zahlen handelt es sich jedoch ausschließlich um die Personen, welche mit dem Abgleich befasst waren. Eine vermutlich deutliche größere Anzahl von Beamten war jedoch mit der Abarbeitung der Prüffälle betraut. Bezieht man das Ergebnis der Maßnahme in die Betrachtung mit ein, so muss festgehalten werden, dass erhebliche finanzielle und personelle Ressourcen aufgewendet, aber keine konkreten Ergebnisse erzielt worden sind. Mithin verstärken sich die Zweifel an der Effizienz der Maßnahme.

${ }^{503}$ Bayerischer Landtag-Drs, 14/9221, S.4; Hessischer Landtag-Drs, 16/2042, S.2. 
Wie bereits im Rahmen der Untersuchung der repressiven Rasterfahndung festgestellt, ergibt sich auch hier die Annahme, dass die Maßnahme keiner Effizienzkontrolle unterliegt. Vielmehr ist davon auszugehen, dass wirtschaftliche Gesichtspunkte eine begrenzte Bedeutung im Rahmen der präventiven Rasterfahndung genießen. Zu diesem Ergebnis kommen auch die Kritiker der Maßnahme. Nach diesen führt eine Betrachtung der Maßnahme unter ökonomischen Gesichtspunkten zu erheblichen Bedenken. ${ }^{504}$ Aufgrund der eingeschränkten Informationen, die zur Beurteilung der Effizienz der Maßnahme herangezogen werden konnten, muss auch auf die Effizienz der Maßnahme im Rahmen der Expertengespräche eingegangen werden. Ohne diese zusätzliche Evaluation ist es nicht möglich, eine Beurteilung der Maßnahme abzugeben.

504 25. Jahresbericht des Landesbeauftragten für den Datenschutz Bremen (2003); S.55. 


\section{Fünfter Teil \\ Die Ergebnisse der Expertengespräche}

Ziel der Expertengespräche war es, die Ergebnisse der Aktenanalyse zu ergänzen und zu hinterfragen. Insbesondere Abläufe im Rahmen des Anordnungsvorgangs konnten im Rahmen der Aktenanalyse nicht umfassend analysiert werden. In diesem Zusammenhang waren informelle Erledigungsstrukturen von besonderem Interesse. Ferner war es nur vereinzelt möglich, Informationen über die Durchführung der Maßnahme aus den Verfahrensakten zu entnehmen. Insofern wurden Fragen nach dem mit der Maßnahme verbundenen finanziellen, personellen und zeitlichen Aufwand gestellt. Letztlich sollten Einschätzungen von mit der Durchführung von Rasterfahndungen betrauten Personen erhoben werden. Dabei standen Fragen nach dem Erfolg von Rasterfahndungen und der Ausgestaltung der gesetzlichen Regelungen im Vordergrund.

Wie bereits im Rahmen des Zweiten Teils dargestellt, liegt diesem Teil der Untersuchung die Befragung von Kriminalbeamten, von Mitarbeitern der Abteilungen Operative Fallanalyse und Staatsschutz der Landeskriminalämter und des Bundeskriminalamtes sowie von Staatsanwälten zugrunde. ${ }^{505}$ Bei der Befragung von Mitarbeitern der Operativen Fallanalyse der Landeskriminalämter war zu beachten, dass diese die Maßnahme in der Regel gegenüber der ermittelnden Polizeidienststelle anregten, aber nur selten mit der tatsächlichen Durchführung betraut waren. Bis auf fünf Personen verfügten die Gesprächsteilnehmer aus dem repressiven Bereich lediglich über Erfahrungen aus einer Maßnahme nach den $\S \S 98 \mathrm{a}, \mathrm{b}$ StPO. Insofern können die Angaben nur begrenzt verallgemeinert werden. Die übrigen fünf Gesprächsteilnehmer haben bis zu sieben Maßnahmen nach den $\S \S 98 \mathrm{a}, \mathrm{b}$ StPO betreut und durchgeführt.

Von den Gesprächsteilnehmern aus dem Bereich des Staatsschutzes konnten lediglich Angaben zur Rasterfahndung nach dem 11. September 2001 gemacht werden. Im Hinblick auf Fragen zur gesetzlichen Ausgestaltung und damit verbundene Umsetzungsschwierigkeiten wurde Bezug auf die jeweilige Gesetzeslage des betreffenden Bundeslandes genommen.

${ }^{505}$ Zur Auswahl der Gesprächsteilnehmer siehe 2. Teil C. II. 1. 


\section{A. Der Anordnungsvorgang}

\section{Entscheidungskriterien für die Anregung, Beantragung und Anordnung einer Rasterfahndung}

Die Teilnehmer der Expertengespräche wurden zunächst danach befragt, welche Entscheidungskriterien für die Anregung und Anordnung der Rasterfahndung erheblich und von Bedeutung seien. Die im repressiven Bereich tätigen Polizeibeamten und die Staatsanwälte gaben an, dass zunächst einmal recherchierbare personenbezogene Merkmale des Täters vorliegen müssten. Insofern sei das Vorliegen eines Täterprofils, welches im Rahmen einer Fallanalyse durch die OFA erstellt wird, eine entscheidende Voraussetzung für die Anregung bzw. Anordnung der Ermittlungsmaßnahme. Darüber hinaus seien sichergestellte und abgleichsfähige Spuren, die dem Täter zugeordnet werden können, von besonderer Bedeutung. Neben der Schwere des Delikts und einer Gefährlichkeitsprognose sei auch die Wiederholungsgefahr ein Entscheidungskriterium.

Im Rahmen der Befragung von Beamten des Staatsschutzes wurde im Hinblick auf die Rasterfahndung nach dem 11. September 2001 mehrfach darauf verwiesen, dass es sich um eine politische Entscheidung handeln würde. Dabei wurde von mehreren Befragten aus unterschiedlichen Bundesländern angegeben, dass die Entscheidung aufgrund bundespolitischen Drucks getroffen wurde und ,man nicht als einziges Bundesland nicht dabei sein wollte“.

Ferner wurden in erster Linie die gesetzlichen Voraussetzungen als Entscheidungskriterien angeführt. Letztlich sei jedoch, wie auch bei der repressiven Rasterfahndung, das Vorliegen belastbarer Rasterkriterien die wichtigste Voraussetzung. Diesbezüglich bestünden jedoch die größten Unterschiede der präventiven zur repressiven Rasterfahndung. Die repressiven Rasterkriterien seien „fassbarer“ und die Täterprofile „sauberer“. Im Rahmen der präventiven Rasterfahndung würden die Täterprofile zu schnell und zu unsauber erstellt. Aus diesem Grund sei die Treffermenge zu groß und die weiteren Ermittlungen erheblich erschwert. Die Aussagen wurden unter Verweis auf die Ergebnisse der Rasterfahndung nach sog. Schläfern getätigt.

\section{Das Vorliegen der gesetzlichen Voraussetzungen}

\section{Einordnung einer Straftat unter den Katalog des § 98a I StPO}

Im Zusammenhang mit der Anregung und der Anordnung der Rasterfahndung stellte sich die Frage, ob die Einordnung einer Straftat unter den Katalog des $\S$ 98a I StPO in der Praxis Schwierigkeiten bereite. Die befragten Kriminalbeamten sahen hier ebenso wenige Schwierigkeiten, wie die Mitarbeiter der Abteilungen Operative Fallanalyse der Landeskriminalämter. Der Grund hierfür lag bei 
den OFA-Mitarbeitern darin, dass die OFA ausschließlich bei Tötungsdelikten, sexuell motivierten Straftaten und Serien in die Ermittlungen einbezogen wird. Von den befragten Staatsanwälten wurden ebenfalls keine Schwierigkeiten bei der Einordnung unter den Katalog des § 98a I StPO gesehen.

Die Mitarbeiter der Abteilung Staatsschutz der Landeskriminalämter konnten zu dieser Frage keine Auskünfte geben, da die betreffenden gesetzlichen Regelungen in den Ländergesetzen keine Straftatenkataloge vorsehen. Schwierigkeiten bereitet dagegen die Subsumtion unter den jeweiligen Gefahrenbegriff. Insbesondere die Gegenwärtigkeit der Gefahr bereitete erhebliche Probleme und war in einigen Bundesländern Anlass richterlicher Überprüfungen der Rasterfahndung nach dem 11. September 2001.

\section{Begründungsaufwand für das Merkmal der ,,Straftat von erheblicher Bedeutung "}

Im theoretischen Teil dieser Untersuchung wurde bereits auf die Schwierigkeiten bei der Auslegung des Merkmals der „Straftat von erheblicher Bedeutung“ hingewiesen. Die befragten Kriminalbeamten sahen hierin jedoch keine Probleme, wenn es sich um ein Gewaltdelikt handle. Je schwerer die Tat sei, desto geringer sei der Begründungsaufwand. Wie bei der Einordnung der Straftat unter den Katalog des § 98a I StPO bereite auch die Auslegung der Straftat von erheblicher Bedeutung für die Mitarbeiter der OFA keine Schwierigkeiten. Die Staatsanwälte sahen zwar hohe Anforderungen an das Vorliegen dieses Merkmals geknüpft, in den betreffenden Verfahren war die Auslegung jedoch nicht mit Schwierigkeiten verbunden.

In der Ausgestaltung der Rasterfahndung in den Polizeigesetzen der Länder ist dieses Merkmal mehrheitlich enthalten. Die Mitarbeiter des Staatsschutzes sahen bei der Auslegung des Merkmals in ihrem Aufgabenbereich jedoch keine Probleme.

\section{Die praktische Relevanz des Anordnungsverbots des $\S 98 b$ I S.6 und S.7 StPO}

Zur Frage nach der praktischen Relevanz des Anordnungsverbots des $\S 98$ b I S.6 und S.7 StPO konnten durch die befragten Personen keine Angaben gemacht werden. In den von diesen Personen durchgeführten Maßnahmen spielte das Anordnungsverbot keine Rolle.

\section{Informelle Abläufe im Rahmen des Anordnungsvorgangs}

Aufgrund der Erkenntnisse aus der Aktenanalyse war es von besonderem Interesse für die Untersuchung, in welchem Umfang informelle Abläufe einen Einfluss 
auf den Anordnungsvorgang nehmen. Sowohl der kurze Zeitraum zwischen Anregung und Antrag als auch der kurze Zeitraum zwischen Antrag und Anordnung der Rasterfahndung deuteten daraufhin, dass die Ermittlungsbehörden im Vorfeld der Maßnahme auf informellem Wege in Kontakt standen. ${ }^{506}$ Darüber hinaus deutete auch der hohe Anteil von Anordnungen, welche identisch mit den Anträgen waren, auf solche Erledigungsstrukturen hin. ${ }^{507}$

Von den befragten Kriminalbeamten gaben alle an, dass sie sich im Vorfeld der Maßnahme mit den Staatsanwaltschaften beraten würden. Es würden die rechtlichen Voraussetzungen auf informellem Weg zunächst abgeklärt. Erst im Anschluss daran würde die Maßnahme auf schriftlichem Weg angeregt. Des Weiteren berichteten die ermittelnden Kriminalbeamten davon, dass sich auch die Staatsanwaltschaften mit den Amtsgerichten in Verbindung setzen würden.

Die Mitarbeiter der OFA regten die Maßnahme gegenüber den ermittelnden Kriminalbeamten an. In den weiteren Anordnungsvorgang waren sie in der Regel jedoch nicht eingebunden. Insofern konnten nur wenige Angaben über informelle Erledigungsstrukturen erlangt werden. In einigen Fällen begleitete die OFA jedoch die Maßnahme und war in die Umsetzung mit eingebunden. War dies der Fall, so wurden auch die Staatsanwaltschaften bereits in die Vorstellung der Fallanalyse miteinbezogen. So sollten Ressentiments gegenüber der Rasterfahndung abgebaut werden.

Alle befragten Staatsanwälte gaben an, die Entscheidung, eine Rasterfahndung durchzuführen, gemeinsam mit der ermittelnden Polizeidienststelle zu treffen und die Gerichte frühzeitig in diesen Prozess einzubinden. Es wurde betont, dass es mit Polizei und Gericht eine „enge und qualifizierte Zusammenarbeit“ gäbe. Demnach bestätigen sich die im Rahmen der Aktenanalyse aufgestellten Annahmen. Die Zeiträume zwischen Anregung und Antrag, zwischen Antrag und Anordnung und die von den Amtsgerichten ausgefertigten Anordnungen, weisen auf informelle Erledigungsstrukturen hin. Die schriftlichen Anregungen, Anträge und Anordnungen stellen demnach lediglich einen formalen Akt dar. Sie spiegeln den tatsächlich betriebenen Begründungsaufwand nur unzureichend wider.

Im präventiven Bereich machten die Gesprächsteilnehmer ähnliche Angaben. In den Bundesländern, in welchen die Gesetzeslage eine richterliche Anordnung vorsah, wurde die Maßnahme ebenfalls im Vorfeld abgeklärt. Dabei „tastete man sich gemeinsam an das Neuland heran“. Es wurde mit den Amtsgerichten ,eine Art Nachhilfe" betrieben.

${ }^{506} \mathrm{Zu}$ den Zeiträumen siehe 3. Teil B. II. 2. und B. III. 1.

${ }^{507} \mathrm{Zu}$ den Anordnungsbegründungen siehe 3. Teil B. IV. 2. 


\section{Durchführung der Rasterfahndung aufgrund staatsanwaltschaftlicher Eilanordnung}

Bei der Beantwortung der Frage nach der Möglichkeit einer Eilanordnung waren sich die befragten Personen einig, dass eine Eilanordnung in der Regel nicht sinnvoll sei. Insbesondere der zeitliche und technische Aufwand stehe einer Eilanordnung entgegen. Nach Aussagen der Kriminalbeamten und der OFA-Mitarbeiter bedürfe die elektronische Verarbeitung der angelieferten Daten so viel Zeit, dass eine Eilanordnung nicht in Betracht käme. Auch die für die Anlieferung der Daten beanspruchte Zeit widerspräche einer Eilanordnung. Innerhalb von drei Tagen seien nach Ansicht eines OFA Mitarbeiters niemals genug Daten für einen Abgleich vorhanden. Mithin sei eine Rasterfahndung unter Druck nicht realisierbar. Letztlich würde die Erstellung eines Täterprofils zu viel Zeit in Anspruch nehmen. Einer der befragten Staatsanwälte gab an, dass die Annahme von Gefahr im Verzuge im Rahmen der Rasterfahndung unmöglich sei. Ferner käme der Verhältnismäßigkeitsprüfung und dem Richtervorbehalt in diesem datenschutzrechtlich sensiblen Bereich erhöhte Bedeutung zu. Unter den aufgezeigten Schwierigkeiten sei eine Rasterfahndung aufgrund einer Eilanordnung nach Ansicht von im repressiven Bereich tätigen Polizeibeamten und Staatsanwälten nur sehr schwer vorstellbar. Mithin erklärt dies, dass im Rahmen der Aktenanalyse kein Verfahren festgestellt werden konnte, in welchem eine Rasterfahndung aufgrund einer staatsanwaltschaftlichen Eilanordnung durchgeführt worden ist. ${ }^{508}$

Von den Mitarbeitern des Staatsschutzes konnte nur ein Gesprächsteilnehmer zu diesem Bereich Angaben machen. In dem betreffenden Bundesland wurde die Rasterfahndung nach dem 11. September 2001 zunächst aufgrund einer staatsanwaltschaftlichen Eilanordnung durchgeführt. Der Grund für dieses Vorgehen sei der ausgeübte politische Druck gewesen. Nach drei Tagen wurde die richterliche Anordnung nachgeholt. Dieses Vorgehen wurde durch den zuständigen Landesdatenschutzbeauftragten gerügt. Der betreffende Beamte gab an, dass der technische Aufwand einer Eilanordnung entgegenstehen würde.

\section{Hierarchieverhältnis von Ermittlungsmaßnahmen und Standort der Rasterfahndung}

Bei der Frage nach dem Verhältnis der Ermittlungsmaßnahmen zueinander und der Einordnung der Rasterfahndung in dieses Verhältnis waren unterschiedliche Ansichten von Kriminalbeamten und OFA Mitarbeitern zu verzeichnen. So sahen die ermittelnden Kriminalbeamten die Rasterfahndung als Ultima Ratio an. Sie sollte nur nach erfolglosem Verlauf aller anderen Ermittlungsmaßnahmen einge-

${ }^{508}$ Siehe hierzu 3. Teil B. II. 1. 
setzt werden. Demgegenüber sahen die Mitarbeiter der OFA die Rasterfahndung nicht durchweg als Ultima Ratio an.

Bei den Gesprächen mit Mitarbeitern der OFA konnten unterschiedliche Ansichten dokumentiert werden. Teilweise wurde die Rasterfahndung auch von diesen Personen als Ultima Ratio angesehen. Ein befragter OFA-Mitarbeiter bezeichnete die Durchführung der Rasterfahndung zu einem frühen Verfahrenszeitpunkt als den „Tod jeder kriminalistischen Arbeit“. Die Mitarbeiter der OFA aus Bundesländern, in denen die Rasterfahndung bereits mehrfach erfolgreich zur Anwendung kam, hatten ein deutlich differenzierteres Bild. Nach einer Hierarchie und der Einstufung der Rasterfahndung gefragt, antwortete ein Gesprächsteilnehmer, dass zunächst Tatortnahbereichsermittlungen, Opferumfeldermittlungen und Ermittlungen zum Täterverhalten durchzuführen seien. Auf der Grundlage der so gewonnenen Erkenntnisse sei eine Rasterfahndung auch schon zu einem frühen Verfahrenszeitpunkt Erfolg versprechend. Darüber hinaus wiesen die OFA-Mitarbeiter auf die Ursachen für die unterschiedlichen Ansichten der ermittelnden Kriminalbeamten hin. So würden ihrer Meinung nach die mit der Maßnahme verbundenen Möglichkeiten von den ermittelnden Behörden nicht ausreichend erkannt. Darüber hinaus würden diese auch den mit der Maßnahme verbundenen Aufwand scheuen. Einige OFA-Dienststellen bieten sachliche und personelle Unterstützung bei der Durchführung der Maßnahme an. Somit soll den ermittelnden Dienststellen die Durchführung der Maßnahme erleichtert werden. Den Ermittlern soll so „die Scheu vor der Rasterfahndung“ genommen werden. Es kann festgehalten werden, dass die Rasterfahndung bei den Mitarbeitern der OFA eine deutlich höhere Akzeptanz genießt als bei den ermittelnden Polizeidienststellen.

Im Gegensatz zu den OFA-Mitarbeitern sahen die befragten Staatsanwälte die Rasterfahndung durchweg als Ultima Ratio an. Der mit der Rasterfahndung verbundene Aufwand sei nur gerechtfertigt, wenn andere Ermittlungsmaßnahmen nicht schneller und effizienter zum Ziel führen würden.

Ein differenzierteres Bild in Bezug auf das Verhältnis der Rasterfahndung zu anderen Ermittlungsmaßnahmen zeigt sich bei den Beamten des Staatsschutzes. Während ein Teil der befragten Personen die Rasterfahndung ebenfalls als Ultima Ratio ansahen, maßen andere die Maßnahme am verfolgten Ermittlungsziel. Demnach kann die Rasterfahndung sowohl als erstes als auch als letztes Ermittlungsinstrument eingesetzt werden. Die Rasterfahndung stellt demzufolge das „Mittel der Wahl“" dar.

\section{Vorzüge der Rasterfahndung gegenüber anderen Ermittlungsmaßnahmen}

In Anbetracht der vorhergehenden Frage zum Verhältnis der Rasterfahndung zu anderen Ermittlungsmaßnahmen sollten die befragten Personen angeben, welche Vorzüge die Rasterfahndung gegenüber anderen Ermittlungsmaßnahmen habe. Die 
Antworten der Experten waren aufgrund der gemachten Erfahrung sehr differenziert. Dabei spielen die gemachten Erfahrungen eine entscheidende Rolle. Ein Angehöriger des Staatsschutzes gab an, dass ihm ,tausend negative Sachen einfallen würden, aber nicht ein positives Argument für eine Rasterfahndung“". Ein weiterer Staatsschützer sagte, ,wenn wir nicht mehr weiter wissen, machen wir eine Rasterfahndung“" In diesen Aussagen spiegeln sich die negativen Erfahrungen der Staatsschützer mit der Ermittlungsmaßnahme nach dem 11. September 2001 wieder. Jedoch sahen nicht alle Mitarbeiter des Staatsschutzes die Rasterfahndung so negativ. So wurde auch hervorgehoben, dass ohne die Rasterfahndung eine solch große Datenmenge nicht erfasst worden wäre. Ferner ermögliche es die Rasterfahndung, aus einer Menge von Massendaten systematisch Erkenntnisse herauszufiltern.

Die ermittelnden Kriminalbeamten verbanden mit der Rasterfahndung die Möglichkeit Einsicht in Datenbestände zu erlangen, in welchen ohne die Rasterfahndung nicht ermittelt werden könnte. Ähnlich pragmatisch sahen dies die befragten Staatsanwälte. Die Rasterfahndung habe keine konkreten Vorzüge gegenüber anderen Ermittlungsmaßnahmen. Greift man jedoch zur Rasterfahndung, so stelle diese das notwendige Ermittlungsinstrument dar. Letztlich sei die Rasterfahndung „eine Ermittlungsmaßnahme unter vielen“.

Positive Aussagen über die Vorzüge der Ermittlungsmaßnahme waren bei den befragten OFA-Mitarbeitern zu verzeichnen. Die Rasterfahndung habe dann Vorteile, wenn die Spuren zunächst herkömmlich abgearbeitet worden sind und sich aus den Ermittlungen keine Täter-Opfer-Beziehung ergeben hat. Die Rasterfahndung ermögliche eine „Selektion bei einem großen Verdächtigenkreis“. Durch die mit einer Rasterfahndung verbundene Priorisierung und Gewichtung in einem relevanten Personenkreis können „Ermittlungen zielgerichteter geführt werden“. Darüber hinaus sei die Rasterfahndung dazu geeignet, DNA-Reihenuntersuchungen praktikabler zu gestalten.

Es kann festgehalten werden, dass die Rasterfahndung bei den befragten Personen einen höchst unterschiedlichen Stellenwert besitzt. Grund hierfür sind die von den Staatsschützern im Zuge der Rasterfahndung nach sog. Schläfern gemachten negativen Erfahrungen und die positiven Erfahrungen der OFA-Mitarbeiter.

\section{Typisierung von Fallkonstellationen für die Durchführung einer Raster- fahndung}

Unter Einbeziehung der Angaben zu den Vorzügen der Ermittlungsmaßnahme, wie sie insbesondere die OFA-Mitarbeiter herausgestellt haben, wurden die Interviewpartner nach typischen Fallkonstellationen gefragt, bei denen die Rasterfahndung zur Anwendung kommen könnte. Die ermittelnden Kriminalbeamten sahen keine typische Fallkonstellation, welche sich für die Durchführung einer Rasterfahndung eignen würde. Ebenso fielen die Antworten der Staatsanwälte aus. Dage- 
gen hielten fast alle OFA-Mitarbeiter die nachfolgend beschriebene Fallkonstellation für typisch:

Es wurde ein Tötungs- oder Sexualdelikt begangen. Am Tatort oder am Opfer konnten tatrelevante Spuren sichergestellt werden, welche dem Täter zugeordnet werden können. Ferner sind die Ermittlungsmethoden ausgeschöpft und führten nicht zur Identifizierung eines Tatverdächtigen. Im Rahmen einer Fallanalyse wurden Merkmale des Täters im Sinne eines Täterprofils herausgearbeitet. Dabei ist von besonderer Bedeutung, dass es sich um einen ortsansässigen Täter handelt. Nur so kann eine örtliche Eingrenzung erfolgen. Anhand herausgearbeiteter Rasterkriterien werden die betreffenden Dateien miteinander abgeglichen. Ziel ist es, die herausgerasterten Personen beispielsweise einer DNA-Reihenuntersuchung zu unterziehen.

Wie sich bereits im Rahmen der Untersuchung von Erfolg und Effizienz der Rasterfahndung im vorhergehenden Teil herausgestellt hat, handelt es sich bei dieser Fallkonstellation um diejenige, in welcher die Rasterfahndung erfolgreich zur Anwendung gekommen ist.

Im Hinblick auf die Frage nach typischen Fallkonstellationen konnten den Antworten der Mitarbeiter des Staatsschutzes keine Übereinstimmungen entnommen werden. Während eine der befragten Personen die Gefährdungslage nach den Anschlägen vom 11. September als typisch kennzeichnete, war der überwiegende Teil der Befragten der gegenteiligen Auffassung. Vielmehr würde die Anwendung der Rasterfahndung vom Einzelfall abhängen. Zwei Staatsschützer nannten die Bereiche Organisierte Kriminalität und islamischer Terrorismus als typische Verbrechensbereiche, die sich für die Anwendung der Rasterfahndung eignen würden. Im Hinblick auf die Ermittlungen im Zusammenhang mit der RAF nannte einer der Befragten ,die Suche nach Personen, von denen ich weiß, dass es sie gibt" als typische Fallkonstellation.

\section{Die Rolle der Rasterfahndung bei der Planung und Durchführung von DNA-Reihenuntersuchungen}

Aufgrund der von den OFA-Mitarbeitern angeführten typischen Fallkonstellation wurden die Teilnehmer der Befragung nach der Rolle der Rasterfahndung im Rahmen der Durchführung von DNA-Reihenuntersuchungen befragt. Während die Mitarbeiter des Staatsschutzes hierzu keine Angaben machen konnten, bejahten alle im repressiven Bereich tätigen Personen die Notwendigkeit der Rasterfahndung für die Durchführung von DNA-Reihenuntersuchungen. Insbesondere die OFA-Mitarbeiter definierten die Rasterfahndung als unbedingte Voraussetzung für die Durchführung von DNA-Reihenuntersuchungen. Nach deren Ansicht komme es $\mathrm{zu}$ einem Wechselspiel zwischen Rasterfahndung und DNA-Reihenuntersuchung. Durch die Rasterfahndung würden Personengruppen priorisiert. So sei es möglich 
die Zahl der in die Reihenuntersuchung einzubeziehenden Personen zunächst auf diejenigen zu beschränken, die dem Täterprofil am nächsten kämen. Insofern stellt die Rasterfahndung ein Mittel dar, welches die DNA-Reihenuntersuchung effizienter gestaltet. Nach Ansicht aller Befragten wird die Rasterfahndung in diesem Bereich in der Zukunft häufiger zum Einsatz kommen. Diese Annahme beruht auf den ständig steigenden Möglichkeiten im Bereich biologischer Untersuchungen von Tatortspuren.

\section{Die Rolle technischer, zeitlicher und wirtschaftlicher Erwägungen im Rahmen der Entscheidung}

\section{Technischer Aufwand}

In den Entscheidungsprozess zur Durchführung einer Rasterfahndung werden auch technische Komponenten miteinbezogen. So gaben die ermittelnden Kriminalbeamten an, dass die Bearbeitung der Datenbestände und das Einpflegen von Daten bereits in der Anregungsphase thematisiert wurden. In einem Fall musste sich das zur Übermittlung von Daten verpflichtete Einwohnermeldeamt zunächst mit neuer Software ausstatten, um die angeforderten Daten übermitteln zu können. Auch von den Mitarbeitern der OFA werden technische Fragen im Vorfeld der Anregung diskutiert. Dabei steht insbesondere die Verknüpfung der Daten im Mittelpunkt. In einigen Fällen wurde der ermittelnden Polizeidienststelle ein sachkundiger OFA-Mitarbeiter zur Seite gestellt, um die technischen Probleme zu lösen. Diese Dienstleistung wird in einigen Bundesländern von der OFA bereits im Rahmen der Vorstellung der jeweiligen Fallanalyse angeboten. So solle den Dienststellen die „Scheu“ vor der Rasterfahndung genommen werden.

Die befragten Staatsanwälte gaben an, dass technische Probleme nur von untergeordneter Bedeutung bei der Entscheidung seien. „Wenn die Maßnahme notwendig sei, dürfe die technische Umsetzung nicht entgegenstehen." Ferner gäbe es für die Lösung technischer Probleme Spezialisten. Lediglich ein Staatsanwalt führte an, dass bei der Auswahl der Kriterien überprüft werde, ob die Abfrage technisch durchführbar sei. Allerdings sei dies ein gemeinsamer Entscheidungsfindungsprozess mit den ermittelnden Polizeidienststellen, in welchen auch EDV Spezialisten miteinbezogen werden.

Von den befragten Staatsschützern wurde zwar angeführt, dass technische Probleme und die Durchführbarkeit des geplanten Datenabgleichs thematisiert würden, eine Maßnahme aber nicht aufgrund technischer Probleme abgesagt werde. Es wird davon ausgegangen, dass alle technischen Probleme gelöst werden könnten. Die Aussage „Notfalls müsse der Abgleich per Hand erfolgen“ verdeutlicht dies. 


\section{Zeitlicher Aufwand}

Im Gegensatz zum technischen Aufwand wird der zeitliche Aufwand nur in Einzelfällen thematisiert. Die befragten Kriminalbeamten gaben an, dass beispielsweise bei einem Tötungsdelikt Zeit keine Rolle spiele. Letztlich sei bis zur Entscheidung eine Rasterfahndung durchzuführen ohnehin viel Zeit vergangen. Auch von den OFA-Mitarbeitern wird der zeitliche Aufwand thematisiert. Er stellt jedoch kein Entscheidungskriterium dar. Letztlich sei gerade die Priorisierung einer Personengruppe mithilfe der Rasterfahndung eine erhebliche Zeitersparnis für geplante DNA-Reihenuntersuchungen. Von den befragten Staatsanwälten wurde die Bedeutung des zeitlichen Aufwands als Entscheidungskriterium ebenfalls als gering angesehen. „Letztlich müsse getan werden, was getan werden müsse. Dafür würde man schließlich vom Steuerzahler bezahlt".

Von den Mitarbeitern des Staatsschutzes wurde die Bedeutung des zeitlichen Aufwandes ebenfalls als gering eingeschätzt. Unter Hinweis auf die Rasterfahndung nach dem 11. September 2001, welche beinahe zwei Jahre in Anspruch genommen habe, wurde dargelegt, dass man um den zeitlichen Aufwand wisse, dieser jedoch ,Zweitrangig“ sei. Es wurde darüber hinaus darauf hingewiesen, dass es sich um eine politische Entscheidung gehandelt habe und auch in ähnlichen Fallkonstellationen und Gefährdungslagen der zeitliche Aufwand nicht als Entscheidungskriterium herangezogen werden würde.

\section{Wirtschaftlicher Aufwand}

Die Frage, ob im Rahmen der Entscheidung, eine Rasterfahndung durchzuführen, auch wirtschaftliche Erwägungen eine Rolle gespielt haben, bejahten die ermittelnden Kriminalbeamten durchgängig. Allerdings wurden auch Folgemaßnahmen, wie beispielsweise DNA-Reihenuntersuchungen, in diese Überlegungen miteinbezogen. Im Rahmen der Entscheidungen der OFA werden dagegen wirtschaftliche Überlegungen vernachlässigt. Wenn die Fallanalyse der OFA zu dem Ergebnis kommt, dass eine Rasterfahndung durchgeführt werden sollte, wird diese auch angeregt, egal welche Kosten entstehen. Ein OFA-Mitarbeiter gab an, dass nach Abschluss des betreffenden Verfahrens eine Überprüfung unter wirtschaftlichen Gesichtspunkten stattfinden würde. Diese sei jedoch nicht exakt, diene aber als Überlegungsgrundlage für zukünftige Fälle.

Bei der Befragung von Mitarbeitern des Staatsschutzes zeigte sich ein widersprüchliches Bild. So gaben alle Befragten an, dass wirtschaftliche Überlegungen einen herausgehobenen Stellenwert genießen würden. Andererseits wurde jedoch deutlich, dass eine notwendige Rasterfahndung nicht an wirtschaftlichen Erwägungen scheitern würde. Diesbezüglich wurde mehrfach auf die Rasterfahndung nach dem 11. September 2001 und den politischen Druck hingewiesen. 
Als Ergebnis lässt sich festhalten, dass bei der OFA im Gegensatz zu den übrigen repressiv tätigen Staatsanwälten und Polizeidienststellen wirtschaftliche Überlegungen nur in begrenztem Umfang als Entscheidungskriterium herangezogen werden. Im Tätigkeitsbereich des Staatsschutzes werden wirtschaftliche Überlegungen zwar in den Entscheidungsprozess miteinbezogen, dabei wurde aber auch einhellig vertreten, dass „eine Rasterfahndung nicht am Geld scheitern würde.“

\section{Häufigkeit der Erwägung einer Rasterfahndung vor dem Hintergrund des wirtschaftlichen, zeitlichen oder technischen Aufwands}

Im Anschluss an die Fragen nach der Entscheidungserheblichkeit von wirtschaftlichen, zeitlichen und technischen Gesichtspunkten wurden die Experten nach der Häufigkeit der Erwägung von Rasterfahndungen gefragt. Die ermittelnden Kriminalbeamten gaben an, dass die Durchführung der Maßnahme nur sehr selten erwogen werde. Insbesondere bei sehr schweren Straftaten würde die Rasterfahndung in Betracht gezogen. Einer der Befragten sagte, dass im Falle der Erwägung die Maßnahme auch durchgeführt würde.

Die OFA-Mitarbeiter verfügen nicht immer über Rückmeldungen, ob die von ihnen angeregten Rasterfahndungen tatsächlich von den ermittelnden Polizeidienststellen auch durchgeführt wurden. Teilweise wurde bekannt, dass der von der OFA angeregte Datenabgleich nur mit den Daten durchgeführt worden ist, die den Ermittlungsbehörden ohne richterliche Anordnung übermittelt worden sind. Von den OFA-Mitarbeitern wurde unter anderem angeführt, dass sie sich in einem ,Argumentationsnotstand" befänden, wenn sie der ermittelnden Polizeidienststelle eine Maßnahme mit hohen Kosten vorschlagen würden.

Die befragten Staatsanwälte konnten keine Angaben darüber machen, wie häufig die Ermittlungsmaßnahme Gegenstand von Überlegungen sei. Es wurde ausdrücklich dargelegt, dass Ermittlungsmaßnahmen aus gemeinsamen Überlegungsprozessen mit den ermittelnden Polizeidienststellen erwogen werden. Allerdings seien die bisherigen Rasterfahndungen ausschließlich auf Initiative der Polizei durchgeführt worden.

Von den befragten Staatsschützern wurde angegeben, dass die Ermittlungsmaßnahme häufig Gegenstand von Überlegungen sei. Insbesondere nach jedem neuen terroristischen Anschlag im In- und vor allem im Ausland werde die Durchführung einer Rasterfahndung erwogen. Allerdings scheitere diese nicht an wirtschaftlichen, zeitlichen oder technischen Problemen. Vielmehr seien es ungenaue und fehlende Erkenntnisse über mögliche weitere „Schläfer“, die dazu führten, dass die Rasterfahndung nicht zur Anwendung komme. 


\section{B. Der Datenabgleich und das weitere Verfahren}

\section{Zusammenarbeit zwischen den datenführenden Stellen und den Strafverfol- gungsbehörden im Hinblick auf die Akzeptanz der Maßnahme}

Von den ermittelnden Kriminalbeamten wurde dargelegt, dass im Vorfeld der Maßnahme bereits auf informellem Weg Kontakt zu den datenführenden Stellen aufgenommen wurde. Im Rahmen der informellen Kontaktaufnahme würde zudem abgeklärt, ob sogenannte Überhangdaten erhoben werden müssten. ${ }^{509}$ Darüber hinaus gäbe es keine Schwierigkeiten, da die Erhebung auf einer richterlichen Anordnung beruhen würde.

Die Mitarbeiter der OFA führten an, dass es nur zu Akzeptanz-Schwierigkeiten bei den datenführenden Stellen käme, wenn bei diesen ein großer technischer Aufwand betrieben werden müsste. Ansonsten gehöre insbesondere die Zusammenarbeit mit den Einwohnermeldeämtern und dem Kraftfahrtbundesamt bereits zum Alltagsgeschäft. Auch die Gesprächsteilnehmer aus den Staatsanwaltschaften konnten keine Angaben über Schwierigkeiten mit den datenführenden Stellen machen.

Die Gesprächsteilnehmer aus dem Bereich des Staatsschutzes zeichneten ein ähnliches Bild wie ihre im repressiven Bereich tätigen Kollegen. Der größte Teil der zur Übermittlung von Daten verpflichteten Stellen und insbesondere Einrichtungen mit hoher Gefährdungslage (Flughäfen) waren zur Übermittlung von Daten bereit. Lediglich einige Universitäten und Fachhochschulen akzeptierten die Maßnahme nicht und führten richterliche Entscheidungen herbei. Erhebliche Schwierigkeiten verursachten auch in diesem Bereich die technischen Ausstattungen der datenführenden Stellen. Es war vor allem die Datenqualität, welche den Ermittlungsbehörden technische Probleme bereitet habe.

\section{Für die Rasterfahndung prädestinierte Datenbestände}

Auf die Frage nach Datenbeständen, welche für einen Abgleich im Rahmen einer Rasterfahndung geradezu prädestiniert wären, nannten alle Befragten die Bestände der Einwohnermeldeämter. An zweiter Stelle wurden häufig die Datenbestände des Kraftfahrtbundesamtes genannt. Aber auch polizeiinterne Dateien, wie der Kriminalaktennachweis, seien nach Ansicht aller befragten Personen für einen Abgleich im Rahmen von Rasterfahndungen geeignet. Letztlich eigne sich auch das Auslän-

509 Bei den Überhangdaten handelt es sich um solche, die nicht benötigt und von der Anordnung nicht umfasst, allerdings übermittelt werden, weil eine Trennung von den benötigten Daten einen unverhältnismäßigen Aufwand bedeuten würde. Siehe auch 1. Teil E.V. 
derzentralregister für einen Abgleich mit anderen Dateien. Allerdings wurde insbesondere von den Mitarbeitern des Staatsschutzes darauf hingewiesen, dass ein Abgleich mit Daten des Ausländerzentralregisters Schwierigkeiten berge. Es seien vor allem die unterschiedlichen Schreibweisen ausländischer Namen, welche zu Schwierigkeiten führen würden.

\section{Die Bedeutung des Datenschutzes im Rahmen der Durchführung einer Rasterfahndung}

Die befragten Personen gaben auf die Frage nach der Bedeutung des Datenschutzes im Rahmen einer Rasterfahndung durchweg an, dass dieser eine große und wichtige Bedeutung habe. Allerdings seien Fragen des Datenschutzes kein Entscheidungskriterium für die Durchführung. Die gesetzliche Ausgestaltung des Datenschutzes sei insofern ausreichend. Bei der Umsetzung der Rasterfahndung sei nach Angaben eines OFA-Mitarbeiters der Datenschutzbeauftragte des betreffenden Bundeslandes einzubeziehen.

Die Gesprächsteilnehmer aus dem Bereich des Staatsschutzes gaben ebenfalls an, dass der Datenschutz einen hohen Stellenwert habe. Im polizeilichen Alltag werde dieser im Allgemeinen immer wichtiger. Auf die Rasterfahndung nach dem 11. September hin befragt, gaben alle Experten an, dass die Datenschutzbeauftragten von Beginn an in die Rasterfahndung miteinbezogen worden sind. Allerdings sei auch im präventiven Bereich die Frage danach, ob eine Rasterfahndung durchgeführt wird, nicht an datenschutzrechtliche Gesichtspunkte geknüpft.

\section{Die Benachrichtigungspflicht des § 98b IV StPO}

Auf die Frage, wer nach der Durchführung einer Rasterfahndung zu benachrichtigen sei, äußerten sich die Gesprächsteilnehmer sehr unterschiedlich. Die ermittelnden Kriminalbeamten setzten sich mit dieser Frage gar nicht auseinander. Es wurde die Meinung geäußert, dass die Benachrichtigung nicht im Zuständigkeitsbereich der Polizei liegen würde. Vielmehr müsse die Staatsanwaltschaft entscheiden, wer und wann zu benachrichtigen sei. Von den OFA-Mitarbeitern konnten keine Angaben zu dieser Fragestellung erlangt werden. Diese regen die Maßnahme an und betreuen sie gegebenenfalls. Die Durchführung obliegt jedoch den ermittelnden Polizeidienststellen. Aus diesem Grund habe die OFA nichts mit der Benachrichtigung zu tun.

Von den befragten Staatsanwälten sah ein Staatsanwalt die Möglichkeit von Benachrichtigungen gegeben, wenn der Ermittlungszweck nicht gefährdet sei. Dabei stellte er jedoch insofern auf das verwendete Raster ab, als ein weit gefasstes Raster kaum einen Eingriff darstelle und in diesen Fällen eine Benachrichtigung unterbleiben könne. Nach der Ansicht eines weiteren Staatsanwalts sei die Benachrichti- 
gung von Betroffenen der Maßnahme im Aufgabenfeld der Polizei angesiedelt. Angaben über die Personen, die zu benachrichtigen seien, wurden nur vereinzelt gemacht. So sollten teilweise die Datenschutzbeauftragten und in einem Fall alle in den Abgleich einbezogenen Personen benachrichtigt werden. Diese unterschiedlichen Auffassungen und auch die für die Befragten unklare Frage der Zuständigkeit für die Benachrichtigung erklären die Erkenntnisse aus der Aktenanalyse. ${ }^{510}$ Folglich ist davon auszugehen, dass die Benachrichtigung von Betroffenen und der Datenschutzbeauftragten in der Regel unterbleibt.

Die im präventiven Bereich tätigen Personen setzten sich dagegen mit der Frage der Benachrichtigung deutlich intensiver auseinander. Alle Befragten waren sich einig, dass der Datenschutzbeauftragte so früh wie möglich in die Durchführung der Rasterfahndung miteinbezogen werden sollte. „Er sei eher hilfreich, als dass er der Maßnahme schaden würde“. Die Frage danach, wer darüber hinaus zu benachrichtigen sei, wurde dagegen unterschiedlich beantwortet. Ein Gesprächsteilnehmer sah keine Notwendigkeit für eine Benachrichtigung von Betroffenen der Rasterfahndung nach dem 11. September 2001, da die Rasterkriterien zureichend über die Medien bekannt gegeben worden seien. Die betreffenden Personen müssten daher wissen, ob sie in das Raster gefallen seien oder nicht. Während das Landesgesetz in einem Bundesland die Benachrichtigung von Betroffenen gar nicht vorsah, gaben die übrigen Gesprächsteilnehmer an, dass alle Personen benachrichtigt werden müssten, die mit weiteren Ermittlungsmaßnahmen belegt worden seien.

\section{Löschung und Rückgabe der Datenträger}

Zur Frage nach der Löschung und der Rückgabe von Datenträgern konnten nur sehr wenige Informationen aus den Expertengesprächen gewonnen werden. Insofern deckt sich das Bild mit den Ergebnissen der Aktenanalyse. Auch im Rahmen der Aktenanalyse konnten nur in begrenztem Umfang Angaben über Löschung und Rückgabe von Datenträgern erlangt werden. ${ }^{511}$ Den befragten Kriminalbeamten war nicht mehr erinnerlich, ob die Datenträger gelöscht und zurückgegeben wurden. Von den OFA-Mitarbeitern wurden diesbezüglich gar keine Angaben gemacht, da diese, wie bereits dargestellt, nur in begrenztem Umfang mit der Durchführung der Rasterfahndung befasst waren. Von den Staatsanwälten wurde darauf hingewiesen, dass es sich bei der Löschung und Rückgabe von Datenträgern um Vorgänge im Bereich der Polizei handle. Lediglich die Gesprächsteilnehmer aus dem Bereich des Staatsschutzes berichteten, dass sämtliche im Rahmen der Rasterfahndung nach dem 11. September erhobenen und abgeglichenen Daten gelöscht worden seien. Diesbezüglich wiesen sie auf die enge Zusammenarbeit mit den Datenschutzbeauftragten hin. Es kann festgehalten werden, dass die Löschung und die

510 Siehe 3. Teil C. III. 5.

${ }^{511}$ Siehe zu Rückgabe und Löschung 3. Teil C. III. 1. und 2. 
Rückgabe von Datenträgern im Rahmen von repressiven Rasterfahndungen einen untergeordneten Stellenwert haben.

\section{Die Rolle der Rasterfahndung in der Hauptverhandlung}

Keiner der Gesprächsteilnehmer aus dem repressiven Bereich war der Meinung, dass sich die Rasterfahndung als Beweismittel eignen würde. Vielmehr sei sie ein Mittel zum Erkenntnisgewinn. Letztlich hat keiner der Gesprächsteilnehmer an einer Hauptverhandlung teilgenommen, in welche die Ergebnisse der Rasterfahndung eingeführt worden sind. Insofern bestätigen die Expertengespräche die im Rahmen der Aktenanalyse gewonnenen Erkenntnisse, dass es sich bei der Rasterfahndung lediglich um ein Mittel zum Erkenntnisgewinn handelt.

\section{Das gesetzliche Regelungskonzept}

\section{Unklarheiten bzgl. der gesetzlichen Ausgestaltung der Rasterfahndung}

Die Frage nach Unklarheiten in Bezug auf die gesetzliche Ausgestaltung der Rasterfahndung wurde von allen Gesprächsteilnehmern verneint. Von einem OFAMitarbeiter wurde lediglich angeführt, dass der Begriff Rasterfahndung zu negativ beladen sei. Der Begriff müsste aus der politischen Diskussion herausgehalten werden, um eine größere Akzeptanz der Maßnahme zu erreichen. Schließlich sei sie ein legitimes Mittel zur Strafverfolgung.

Im Rahmen der Gespräche mit den Gesprächsteilnehmern aus dem Bereich des Staatsschutzes wurde auf die Frage nur am Rande eingegangen, da sich die betreffenden Ländergesetze teilweise erheblich unterscheiden. Jedoch wurde deutlich, dass der in einigen Ländergesetzen verwendete Gefahrenbegriff erhebliche Probleme bereitet. Im Rahmen dessen wurde darauf hingewiesen, dass die Regelung in der StPO deutlich ,einfacher“" sei.

\section{Verbesserungsvorschläge}

Im Anschluss an die Frage nach Unklarheiten in Bezug auf die gesetzliche Ausgestaltung wurden die Gesprächsteilnehmer nach Verbesserungsvorschlägen gefragt. Dabei war der größte Teil der befragten Personen der Meinung, die gesetzliche Ausgestaltung sei ausreichend und bedürfe keiner Verbesserungen. Allerdings würden jedoch ausreichende Erfahrungswerte, die Umsetzung der Regelung betreffend, fehlen. Lediglich im Hinblick auf den Katalog des § 98a I S.1 StPO wurden Verbesserungsvorschläge gemacht. Nach der Ansicht eines ermittelnden Kriminalbeamten sei insbesondere $\S 98$ a I S.1 Nr.4 StPO sehr weit gegriffen. Sowohl für den $\S$ 98a I S.1 Nr.4 StPO als auch für den gesamten Katalog des $\S$ 98a I S.1 StPO 
wäre ein konkret ausformulierter Katalog vorteilhafter als die bestehende Regelung. Von einem Staatsanwalt wurde vertreten, dass der Katalog eher wieder einzugrenzen sei, als zusätzliche Delikte aufzunehmen. Ein weiterer Gesprächspartner regte an, die einzelnen Kataloge von Ermittlungsmaßnahmen einander anzugleichen. Ferner war ein OFA-Mitarbeiter der Meinung, dass der letzte Satz des § 98a I StPO Schwierigkeiten für Begründung der Maßnahme zur Folge habe. Die Rasterfahndung würde dadurch, in der Hierarchie der Ermittlungsmaßnahmen nach hinten rutschen“. Diese Ausführung deutet daraufhin, dass der Subsidiarität der Maßnahme keine große Bedeutung beigemessen wird. Ansonsten hätte sich der betreffende Gesprächsteilnehmer nicht darüber beklagt, dass sich die Ermittlungsbehörden im Rahmen der Anordnung einer Rasterfahndung mit anderen Ermittlungsmaßnahmen auseinandersetzen müssen.

Von den Gesprächsteilnehmern aus dem Bereich des Staatsschutzes wurden die jeweiligen gesetzlichen Regelungen in den Ländergesetzen durchweg als ausreichend angesehen. Lediglich bzgl. des Gefahrenbegriffs sei in einigen Bundesländern eine Gesetzesinitiative wünschenswert. Diesbezüglich müssten die Ländergesetze der Rechtsprechung des Bundesverfassungsgerichtes angepasst werden.

\section{Einschätzungen der Gesprächsteilnehmer}

\section{Erfolg der Rasterfahndung}

Im Rahmen der Aktenanalyse wurde bereits dargelegt, dass die Rasterfahndung in der Regel neue Ermittlungsansätze liefert, denen mithilfe weiterer Ermittlungsmaßnahmen nachgegangen werden muss. Es war für die Untersuchung von besonderem Interesse, ob dies von den Ermittlungsbehörden ähnlich gesehen wird. Daher wurden die Gesprächsteilnehmer danach gefragt, wann sie eine Rasterfahndung als erfolgreich beurteilen würden.

Als Erfolg wurde durch die ermittelnden Kriminalbeamten in erster Linie die Eingrenzung des Kreises von Personen angesehen, aus dem der Täter vermutlich stamme. Eine erfolgreiche Rasterfahndung liefere neue Ermittlungsansätze, um in diesem eingegrenzten Personenkreis zu ermitteln. Je kleiner dabei der herausgerasterte Personenkreis sei, desto erfolgreicher sei die Maßnahme. Gerade im Hinblick auf die Vorbereitung und Durchführung von DNA-Reihenuntersuchung diene die Rasterfahndung zudem als Mittel zur effektiveren Polizeiarbeit.

Auch von den Mitarbeitern der OFA wurde in erster Linie die Reduzierung des Personenkreises möglicher Täter auf ein Minimum als der Erfolg einer Rasterfahndung angesehen. Dabei wurde jedoch darauf hingewiesen, dass die Rasterfahndung nur in Zusammenhang mit einem eindeutig dem Täter zuzuordnenden Sachbeweis durchgeführt werden sollte. Mithin sei „die Anzahl der Treffer in Zusammenhang mit der objektiven Überprüfbarkeit“" entscheidend für die Beurteilung des Erfolgs. 
Auch die befragten Staatsanwälte sahen insbesondere das Erlangen neuer Ermittlungsansätze, die nach weiteren Ermittlungen zur Ergreifung des Täters führen, als Erfolg an. Aber auch der Ausschluss einer Personengruppe aus den Ermittlungen aufgrund der Rasterfahndung und die damit einhergehende Konzentration der weiteren Maßnahmen auf eine kleinere Gruppe wird als Erfolg gewertet. Letztlich wurde eine Rasterfahndung auch dann als erfolgreich beurteilt, wenn der Täter auf andere Weise ermittelt wurde, er jedoch im Rückblick in der Treffermenge der Rasterfahndung enthalten war.

Dem gefahrenabwehrrechtlichen Tätigkeitsfeld entsprechend beurteilen die im Bereich des Staatsschutzes tätigen Gesprächsteilnehmer den Erfolg einer Rasterfahndung unter anderen Gesichtspunkten. Zunächst war jedoch festzustellen, dass auch im präventiven Bereich eine Rasterfahndung als erfolgreich beurteilt wird, wenn sie zu einer möglichst kleinen Zahl von Treffern führt und die weiteren Ermittlungen in der Treffermenge zur Ergreifung von Tätern führen. Insofern unterscheidet sich die Erfolgseinschätzung nicht von den Gesprächsteilnehmern aus dem repressiven Bereich. Als Erfolg wird aber auch die „Durchleuchtung der Strukturen von Organisationen und Vereinen" angesehen. Darüber hinaus wurde auch die „Ausgrenzung eines Personenpotenzials“ als Erfolg gewertet. Letztlich ist im präventiven Bereich auch die mit der Öffentlichkeitswirksamkeit der Maßnahme verbundene Abschreckung als Erfolg einzustufen. Es kann festgehalten werden, dass über das Erlangen von Ermittlungsansätzen hinaus im präventiven Bereich auch der reine Gewinn von Informationen als Erfolg angesehen wird.

\section{Die praktische Bedeutung der Maßnahme für die Tätigkeit der Ermittlungsbehörden}

Abschließend wurden die Teilnehmer der Befragung darum gebeten, die praktische Bedeutung der Rasterfahndung für ihre Tätigkeit zu beurteilen. Von den ermittelnden Kriminalbeamten wurde angegeben, dass es sich um eine wichtige, aber selten zur Anwendung kommende Ermittlungsmaßnahme handeln würde. Die Rasterfahndung ermögliche es, ,einen Strich zu ziehen und zu sagen in der Gruppe befindet sich der Täter". So sei es möglich die Ermittlungen auf eine Personengruppe zu bündeln. Es wurde jedoch auch darauf hingewiesen, dass die Maßnahme in der Regel von der OFA angeregt werde.

Bei den Mitarbeiten der OFA hingegen hat die Rasterfahndung einen sehr hohen Stellenwert. Die Maßnahme kam zwar bislang nur vereinzelt zur Anwendung, wird aber nach Angaben der Mitarbeiter der OFA in Zukunft vermehrt zum Einsatz kommen. Nach Aussagen der Gesprächsteilnehmer wird die Rasterfahndung bundesweit in den OFA-Dienststellen kontrovers diskutiert. Insbesondere bei der OFA des Landeskriminalamtes Nordrhein-Westfalen genießt die Maßnahme einen hohen Stellenwert. Die betreffende OFA hat einen Ablaufplan für die im Rahmen einer 
Rasterfahndung durchzuführenden Schritte erarbeitet. Zudem wurde in Zusammenarbeit mit einer Universität eine mathematische Methode ausgewählt, die eine Priorisierung von Personen innerhalb von Treffermengen ermöglicht. Mithin erklärt dieses Vorgehen die vermehrte Anwendung der Rasterfahndung in NordrheinWestfalen. $^{512}$

Darüber hinaus wird die Rasterfahndung aufgrund gestiegener Möglichkeiten im Bereich von DNA-Untersuchungen in Zukunft in größerem Umfang zur Anwendung kommen. Ferner stellte ein OFA-Mitarbeiter heraus, dass die Maßnahme im Zusammenhang mit erstellten Täterprofilen zwingend erforderlich sei. Insofern erklärt gerade der gesteigerte Stellenwert der Ermittlungsmaßnahme bei den OFAMitarbeitern die zunehmende Anwendung in den letzten Jahren. ${ }^{513}$

Ganz im Gegensatz zu den Gesprächsteilnehmern aus dem Bereich der OFA beurteilen die befragten Staatsanwälte den Stellenwert der Rasterfahndung für ihre Tätigkeit als sehr gering. Sie messen der Maßnahme keine Relevanz im Vergleich mit anderen Ermittlungsmaßnahmen bei. Ferner sei sie unbedeutend, gehöre jedoch als Ultima Ratio dazu.

Auch die Befragten aus dem Bereich des Staatsschutzes beurteilen die praktische Relevanz der Rasterfahndung als nicht sehr hoch. Es handle sich um eine Maßnahme mit hohem finanziellem, personellem und technischem Aufwand, die sich nur lohnen würde, „wenn gar nichts mehr geht“. Bezogen auf die Rasterfahndung nach dem 11. September gab ein Staatsschützer an, dass man sich vor der nächsten Rasterfahndung genau überlegen müsse, was man mit den Daten anfangen wolle und ob man die dafür notwendigen Mittel habe. Letztlich wurde auch auf die aus Amtsleitersicht große Öffentlichkeitswirksamkeit der Maßnahme hingewiesen, die in keinem Verhältnis zu den erzielten Ergebnissen stehe. Vor diesem Hintergrund wurden die Gesprächsteilnehmer nach der Eignung der Maßnahme für zur Gefahrenabwehr gefragt. Nach übereinstimmender Ansicht sei die Rasterfahndung nur bedingt und in Einzelfällen zur Gefahrenabwehr geeignet. Es wurde eher die abschreckende Wirkung herausgestellt. Allerdings wurden Zweifel dahingehend geäußert, dass sich die Rasterfahndung dazu eigne, Straftaten zu verhindern.

Es kann festgehalten werden, dass die Rasterfahndung insbesondere im Bereich der OFA einen stetig steigenden Stellwert genießt, während die übrigen Gesprächsteilnehmer der Maßnahme eher negativ gegenüberstehen.

512 Zur Verteilung der Verfahren mit Maßnahmen nach den $\S \S 98 \mathrm{a}, \mathrm{b}$ StPO siehe 3.Teil A. I. 3.

513 Zur Entwicklung der Rasterfahndung im Zeitraum seit Einführung in die StPO siehe 3.Teil A. I. 2. 


\section{Sechster Teil \\ Zusammenfassung und Schlussfolgerungen}

A. Zusammenfassung

\section{Ausgangspunkt und Fragestellungen}

Die Rasterfahndung befindet sich seit vielen Jahren im Blickpunkt rechtspolitischer Diskussionen, wobei sie sich häufig starker Kritik ausgesetzt sieht. Im Mittelpunkt steht dabei zumeist die präventive Rasterfahndung. Im Schatten der präventiven Rasterfahndung wurde die Ermittlungsmaßnahme aber auch in die Strafprozessordnung eingeführt. Mittlerweile ist die Rasterfahndung seit 15 Jahren in der Strafprozessordnung enthalten. Sie bewegt sich im Spannungsfeld zwischen dem Recht auf informationelle Selbstbestimmung des Einzelnen und dem Allgemeininteresse in Form einer effizienten Strafverfolgung.

Im Gegensatz zur präventiven Regelung war die Rasterfahndung im Bereich der Strafverfolgung nur vereinzelt Gegenstand von Untersuchungen. Dies begründet den begrenzten Umfang empirischer Informationen zur Rasterfahndung. Aus diesem Grund lagen nur in begrenztem Maße empirische Informationen vor. Zur Behebung des defizitären Informationsstandes verfolgte die vorliegende Untersuchung die im Folgenden dargestellten Ziele und Fragestellungen.

\section{Ziele der Untersuchung}

Schwerpunkt der Untersuchung war es, empirische Grundinformationen über die Einsatzpraxis der Rasterfahndung zu erlangen und darzustellen. Mit dieser Darstellung des tatsächlichen Rechtszustandes ist die Möglichkeit gegeben, zukünftige rechtspolitische Diskussionen und Entscheidungen mit einer ausreichenden empirischen Grundlage zu versorgen.

Darüber hinaus wurden auch die Auswirkungen der Rasterfahndung auf das Ermittlungsverfahren untersucht. In diesem Zusammenhang war es das Ziel der Untersuchung, Erfolge und Schwierigkeiten des maschinellen Datenabgleichs aufzuzeigen und zu analysieren. Im Anschluss an die Evaluation des Erfolgs der Ermittlungsmaßnahme war es notwendig den Einfluss einzelner Faktoren auf die Effizienz der Ermittlungsmaßnahme zu untersuchen. 


\section{Untersuchungsinhalt}

Im Mittelpunkt des rechtstatsächlichen Teils der Untersuchung stand eine Bestandsaufnahme der Einsatzpraxis. Es wurde ein grundlegender Überblick über die Anwendung und die praktische Umsetzung der $\S \S 98 \mathrm{a}, \mathrm{b}$ StPO gegeben. Im Rahmen dieses Teils standen Fragen nach der Häufigkeit, der Intensität, der Dauer und des Zeitpunktes der Maßnahme innerhalb der einzelnen Verfahren im Vordergrund.

Daran anschließend wurde der Anordnungsvorgang untersucht. Hierbei standen Fragen nach dem Einfluss von Polizei, Staatsanwaltschaft und Ermittlungsrichter im Entscheidungsprozess im Vordergrund. Von besonderem Interesse war in diesem Zusammenhang die Begründung der Maßnahme durch die Beteiligten. Insbesondere die Kontrolle der Maßnahme in Form der Umsetzung des Richtervorbehalts wurde eingehend untersucht.

Darüber hinaus war auch die Durchführung der Maßnahme Gegenstand des rechtstatsächlichen Teils der Untersuchung. In diesem Zusammenhang standen Fragen zum Durchführungszeitraum, zu technischen Problemen und zu den mit der Rasterfahndung verbundenen Kosten im Fokus der Untersuchung. Daneben wurden auch die einbezogenen Datenbestände und der weitere Umgang der Ermittlungsbehörden mit den erlangten Daten untersucht. Ferner wurde auch die Einhaltung von Rückgabe- und Löschungspflichten analysiert. Letztlich wurde auch der Ausgang der betreffenden Verfahren einer eingehenden Analyse unterzogen.

Dagegen befasste sich der evaluative Teil der Untersuchung mit Fragen nach den Auswirkungen der Ermittlungsmaßnahme auf die weiteren Ermittlungen und den Ausgang des Ermittlungsverfahrens. Die Grundlage für diesen Teil bildete eine einzelfallbezogene Erfolgsanalyse. Darauf aufbauend wurde die Effizienz der Rasterfahndung im Zusammenhang mit dem Einfluss einzelner Faktoren untersucht.

\section{Die bisherige Forschung zur Rasterfahndung}

Die Rasterfahndung zur Strafverfolgung war nur vereinzelt Gegenstand von Untersuchungen. Bis auf eine Untersuchung wurden dabei ausschließlich sekundäranalytische Zugänge gewählt. Gegenstand waren zunächst die Diskussion bzgl. des Eingriffscharakters und die Suche nach einer Ermächtigungsgrundlage. Nach der Aufnahme der Maßnahme in die Strafprozessordnung im Jahr 1992 befassten sich lediglich drei Untersuchungen mit der Ermittlungsmaßnahme. Zwei dieser Untersuchungen datieren aus dem Jahr 1996. Die dritte Untersuchung stammt aus dem Jahr 2003.

In der ersten Untersuchung stand die Verfassungsmäßigkeit der Maßnahme im Mittelpunkt. Dabei wurde insbesondere auf das Recht auf informationelle Selbstbestimmung eingegangen. Im Rahmen der zweiten Untersuchung wurde die Rasterfahndung in Bezug auf ihre Eignung zur Bekämpfung organisierter Kriminalität 
untersucht. Hierbei handelt es sich um die bisher einzige Untersuchung zur Rasterfahndung, welche sich zumindest zum Teil empirischer Methoden bediente. Die dritte Untersuchung, welche aus dem Jahr 2003 stammt, befasst sich ausschließlich mit der Verfassungsmäßigkeit der Ermittlungsmaßnahme. Es war festzustellen, dass es bislang nur in begrenztem Umfang gesicherte empirische Erkenntnisse zur Rasterfahndung gibt. Seit der einzigen Untersuchung, die teilweise auf empirischen Untersuchungen basierte, sind zudem mehr als zehn Jahre vergangen. Insofern bestätigt sich die Annahme, dass die rechtspolitische Diskussion jeglicher empirischer Grundlage entbehrt.

\section{Konzept und Durchführung der Untersuchung}

Im Rahmen der Untersuchung wurde zunächst der Stand der Forschung zur Rasterfahndung ausgewertet. Darüber hinaus wurden die Anordnungsvoraussetzungen des $\S 98 \mathrm{a}$ StPO und die verfahrensrechtlichen Vorkehrungen des $\S 98 \mathrm{~b}$ StPO einer eingehenden Analyse unterzogen.

Im Mittelpunkt der Untersuchung steht eine empirische Studie. Diese besteht aus drei Teilen, die inhaltlich aufeinander aufbauen und sich gegenseitig ergänzen. Die ersten beiden Teile der empirischen Studie basieren auf den Erkenntnissen einer als Vollerhebung angelegten Analyse staatsanwaltschaftlicher Ermittlungsverfahren. Dabei handelt es sich ausschließlich um Verfahren, in denen eine oder mehrere Maßnahmen nach den $\S \S 98 \mathrm{a}, \mathrm{b}$ StPO angeordnet und durchgeführt worden sind. Den zeitlichen Anknüpfungspunkt für die Erhebung bildete die Aufnahme der Rasterfahndung in die Strafprozessordnung im Jahr 1992.

Im Rahmen der Aktenanalyse kam ein standardisierter Fragebogen zum Einsatz. So war es möglich eine einheitliche Datenerhebung zu gewährleisten. An Stellen, welche für den Untersuchungsgegenstand von besonderem Interesse waren, wurden vermehrt Freitextvariablen verwendet. Hierdurch war es möglich, dem qualitativen Ansatz der Untersuchung gerecht zu werden.

Dem dritten Teil der empirischen Untersuchung liegen die Erkenntnisse einer Befragung von Experten aus dem Bereich der Strafverfolgungsbehörden zugrunde. In die Expertengespräche wurden insgesamt 24 Personen einbezogen. Die Gespräche wurden anhand eines Interviewleitfadens geführt, um eine Vergleichbarkeit der Ergebnisse zu gewährleisten.

\section{Die Erkenntnisse der rechtstatsächlichen Untersuchung}

\section{Entwicklung der Rasterfahndung}

Insgesamt konnten 30 Verfahren mit Maßnahmen nach den $\S \S 98 \mathrm{a}, \mathrm{b}$ StPO identifiziert werden. Der Untersuchung liegen 27 dieser Verfahren zugrunde. In drei 
Verfahren konnte aufgrund noch andauernder Ermittlungen keine Einsicht genommen werden. Daraus ergibt sich, dass die Ermittlungsmaßnahme seit ihrer Einführung in die Strafprozessordnung nur vereinzelt zur Anwendung gekommen ist. Bei der Verteilung der 27 Verfahren auf die Zeitspanne seit Einführung der Maßnahme in die Strafprozessordnung ist jedoch eine deutliche Zunahme von Verfahren mit Anordnungen nach den $\S \S 98 \mathrm{a}, \mathrm{b}$ StPO seit dem Jahr 2002 zu erkennen. Gründe für die Zunahme von Verfahren mit Rasterfahndungen liegen unter anderem in einer gesteigerten Akzeptanz der Maßnahme, insbesondere bei den Abteilungen Operative Fallanalyse der Landeskriminalämter, erheblich verbesserter technischer Möglichkeiten und der Zunahme von Datensammlungen in allen Bereichen des Lebens.

Im präventiven Bereich kam die Rasterfahndung lediglich einmal flächendeckend zur Anwendung. Dabei handelt es sich um die Rasterfahndung nach sog. Schläfern im Zuge der Anschläge des 11. Septembers 2001. Im Rahmen der Analyse des bisherigen Forschungsstandes konnten Informationen über weitere Anwendungen der Maßnahme erlangt werden. Es war jedoch nicht möglich diese Informationen einer eingehenden Überprüfung zu unterziehen, da sowohl die Datenschutzbeauftragten und die Innenminister der Bundesländer unisono mitteilten, dass die Rasterfahndung lediglich im Zuge des 11. Septembers 2001 zur Anwendung gekommen sei.

\section{Charakter der untersuchten Verfahren}

Einen Schwerpunkt der Untersuchung bildete die Einzelfallanalyse der 27 Verfahren. Dieses Vorgehen ermöglichte es, den Stellenwert der Maßnahme für das einzelne Verfahren zu bestimmen. Darüber hinaus bildete die Einzelfallanalyse die Grundlage für die Untersuchung des Erfolges und der Effizienz der Rasterfahndung.

Verallgemeinerungsfähige Erkenntnisse in Bezug auf die Charakteristik der Verfahren ergaben sich im Rahmen der Einzelfallanalyse nicht. Vielmehr wiesen die Verfahren nur im begrenzten Umfang Übereinstimmungen auf. Lediglich in Bezug auf die verfolgten Straftaten war festzustellen, dass den Ermittlungen in mehr als zwei Dritteln der Verfahren ausschließlich oder in Kombination mit anderen Katalogdelikten Straftaten gegen Leib oder Leben, die sexuelle Selbstbestimmung und die persönliche Freiheit zugrunde lagen.

Auch der Stellenwert der Rasterfahndung für die Ermittlungen in den einzelnen Verfahren war sehr unterschiedlich. In einigen Verfahren kam die Ermittlungsmaßnahme lediglich in Randbereichen der Ermittlungen zum Einsatz. Dagegen bildete die Rasterfahndung in anderen Verfahren zumindest zu bestimmten Verfahrenszeitpunkten den Mittelpunkt der Ermittlungen. In diesen Verfahren wurden teilweise umfangreiche Täterprofile erstellt und eine Vielzahl von Datenbeständen in den Abgleich miteinbezogen. 
Im Ergebnis ist festzuhalten, dass es kein typisches Rasterfahndungsverfahren gibt. Vielmehr bieten sich bestimmte Fallkonstellationen für die Anwendung der Rasterfahndung an. $\mathrm{Zu}$ diesen Fallkonstellationen sind insbesondere die Verfahren zu zählen, in welchen die Rasterfahndung zu Vorbereitung einer DNA-Reihenuntersuchung durchgeführt wird.

\section{Allgemeine Verteilung}

Bei der Verteilung der Verfahren auf die einzelnen Bundesländer war zu beobachten, dass es in erster Linie drei Bundesländer und die Bundesanwaltschaft waren, in denen die Rasterfahndung vermehrt zum Einsatz kam. Insgesamt verteilten sich 22 der 27 Verfahren auf die Länder Nordrhein-Westfalen, Bayern und Hessen sowie auf die Bundesanwaltschaft. Im Rahmen der Expertengespräche konnte festgestellt werden, dass sich insbesondere die Abteilung Operative Fallanalyse des Landeskriminalamtes Nordrhein-Westfalen verstärkt mit den Möglichkeiten der Rasterfahndung auseinandergesetzt hat.

Der Einsatz der Abteilungen Operative Fallanalyse der Landeskriminalämter erklärt auch die überwiegende Anordnung der Rasterfahndung in Verfahren mit Straftaten gegen Leib und Leben. Insgesamt lagen 19 der 27 Verfahren Straftaten gegen Leib und Leben, teilweise in Kombination mit anderen Katalogdelikten, zugrunde. Die operative Fallanalyse wird nur bei schwersten Kapitaldelikten und Serien von Straftaten hinzugezogen.

Bei der Analyse der 27 Verfahren konnten 31 Maßnahmen nach den $\S$ 98a, b StPO festgestellt werden. In 23 der Verfahren wurde jeweils eine und in den übrigen vier Verfahren wurden jeweils zwei Maßnahmen angeordnet. Die Maßnahmen setzten sich überwiegend aus mehreren Beschlüssen zusammen. Insgesamt konnten den $31 \mathrm{Maß-}$ nahmen 62 Beschlüsse zugeordnet werden. Dabei variierte die Anzahl der Beschlüsse pro Maßnahme zwischen einem und fünf Beschlüssen.

Bei der Verteilung der Katalogtaten auf die Maßnahmen und Beschlüsse spiegelte sich das gleiche Bild wieder, wie bei der Verteilung auf die Verfahren. In fast $65 \%$ der Maßnahmen und in über $70 \%$ der Beschlüsse wurden die Straftaten gegen Leib und Leben, einzeln oder in Kombination mit anderen Katalogdelikten, angeführt.

In den untersuchten Verfahren konnten insgesamt 135 Beschuldigte festgestellt werden. Diese verteilten sich auf 22 der 27 Verfahren. Die Zahl der Beschuldigten pro Verfahren variierte zwischen einem und 56 Beschuldigten.

\section{Der Anordnungsvorgang}

a. Ermittlungsstand und Initiative

Von besonderem Interesse für die Untersuchung war der Stand der Ermittlungen zum Zeitpunkt der Anregung der Rasterfahndung. Die untersuchten Verfahren 
konnten diesbezüglich in drei Kategorien eingeteilt werden. Die erste Kategorie bildeten die Verfahren, in denen bislang alle Ermittlungen erfolglos verliefen und die Rasterfahndung das letzte zur Verfügung stehende Ermittlungsinstrument darstellte. Die zweite Kategorie bildeten die Verfahren, in denen zwar ebenfalls alle Ermittlungen erfolglos verliefen, aber beispielsweise aufgrund von erstellten Täterprofilen genaue Anhaltspunkte für eine Rasterfahndung vorgelegen haben. In der dritten Kategorie von Verfahren waren die Ermittlungen bereits weit fortgeschritten. Die Rasterfahndung diente in diesen Verfahren dazu, eine konkrete Fragestellung zu beantworten. Die Verfahren verteilten sich zu gleichen Teilen auf die drei Kategorien.

Aufgrund des unterschiedlichen Ermittlungsstandes war auch der Zeitpunkt der Anregung der Rasterfahndung innerhalb der Verfahren höchst unterschiedlich. Der Zeitraum zwischen dem Beginn der Ermittlungen und der Anregung der Rasterfahndung variiert zwischen einem und 1.247 Tagen. Durchschnittlich beträgt der Zeitraum 291 Tage. Der aufgrund der schiefen Verteilung aussagekräftigere Median liegt bei 62 Tagen.

Es war festzustellen, dass die Anordnungsinitiative in der Regel von der ermittelnden Polizeidienststelle oder der in einigen Fällen auch von der eingeschalteten Abteilung Operative Fallanalyse der Landeskriminalämter ausging. Ferner beruhte keine der 31 in die Analyse einbezogenen Maßnahmen auf einer staatsanwaltschaftlichen Eilanordnung. Diesbezüglich konnte aus den Expertengesprächen die Ansicht bestärkt werden, dass der mit einer Rasterfahndung verbundene technische, personelle und finanzielle Aufwand einer Eilanordnung entgegensteht. Mithin sei „eine Rasterfahndung unter zeitlichem Druck, von vornherein zum Scheitern verurteilt."

Inhaltlich stimmten die Anträge und Anordnungen zu über $80 \%$ überein. In zwei Fällen wurde die Maßnahme mit Änderungen und in weiteren zwei Fällen mit Ergänzungen angeordnet. Lediglich in einem Fall kam es zur Ablehnung einer beantragten Maßnahme durch den zuständigen Richter. In Folge der Anfechtung wurde der ablehnende Beschluss durch das zuständige Landgericht aufgehoben und die Maßnahme angeordnet. Demnach ist festzuhalten, dass zwischen den Beteiligten Konsens bestand. Ablehnungen bildeten die Ausnahme. Im Rahmen der Expertengespräche wurde als Begründung der vorhergehende Kontakt auf informellem Wege angeführt.

\section{b. Ziele}

Von besonderem Interesse waren die mit der Rasterfahndung verfolgten Ziele. Bei der Untersuchung der Ziele konnte festgestellt werden, dass in keinem Antrag der Ausschluss Nichtverdächtiger als alleiniges Ziel genannt worden war. Dies dürfte dem Umstand geschuldet sein, dass der Ausschluss Nichtverdächtiger einen genau umgrenzten Personenkreis voraussetzt. Die Feststellung von Personen, die 
weitere für die Ermittlungen bedeutsame Prüfungsmerkmale erfüllen, wurde in etwas weniger als einem Drittel der Anträge als Ziel angeführt. Beide Alternativen gemeinsam wurden ebenfalls in etwa einem Drittel der Anträge genannt. Bei der Nennung beider Alternativen handelte es sich vor allem um formelhafte Verwendungen des Gesetzestextes in den Anträgen. Letztlich enthielten etwas mehr als ein Drittel der Anträge keine der beiden Alternativen.

Die Anträge wurden darüber hinaus auf die Nennung weiterer Ziele untersucht. In 19 Anträgen, also in mehr als $60 \%$ aller Anträge, wurden weitere Ziele angeführt. Dabei ist zu beachten, dass es zu Mehrfachnennungen kam. Insgesamt wurden in den 19 Anträgen 26 weitere Ziele angeführt. Mit zehn Nennungen bildete die Erforschung des Sachverhalts die größte Gruppe unter den weiteren Zielen. Mithin war die Erforschung des Sachverhalts in einem Drittel aller Anträge als Ziel enthalten. Die übrigen Nennungen verteilten sich gleichmäßig auf die Gruppen, Identifizierung von Mittätern, Feststellung von Bandenstrukturen, Feststellung des Aufenthaltsortes des Beschuldigten, neue Ermittlungsansätze und sonstige Ziele. Bei den sonstigen Zielen handelte es sich beispielsweise um die Vorbereitung einer DNA-Reihenuntersuchung.

Unter Betrachtung dieser Ergebnisse ist festzustellen, dass die mit der Rasterfahndung verfolgten Ziele nur in Ausnahmefällen konkret formuliert werden. In der Regel enthalten die Anträge nur Teile des Gesetzestextes als Zielformulierung.

\section{c. Begründungen}

Im Rahmen der Untersuchung der Begründungen der Rasterfahndung, wie sie die polizeilichen Anregungen, den staatsanwaltschaftlichen Anträgen und den richterlichen Anordnungen zugrunde liegen, war eine stetige Abnahme der Begründungstätigkeit zu verzeichnen. Es war festzustellen, dass die Begründungstätigkeit in erster Linie durch die Polizei erfolgte. Über 96 \% der polizeilichen Anregungen waren substanziell begründet. Lediglich eine Anregung war als formelhaft zu beurteilen. Demgegenüber enthielten nur noch zwei Drittel der staatsanwaltschaftlichen Anträge eine substanzielle Begründung. Die richterlichen Anordnungen der Ermittlungsmaßnahme waren nur noch zu weniger als $20 \%$ substanziell begründet. Bedenklich ist die große Zahl an Beschlussausfertigungen. So wurde die Maßnahme in mehr als $60 \%$ der Fälle durch die Ausfertigung eines von der Staatsanwaltschaft formulierten Beschlusses angeordnet. Eine eigenständige Begründungstätigkeit durch die anordnenden Gerichte war in diesen Fällen nicht gegeben. Zudem konnte im Rahmen der Analyse der Anordnungen eine Auseinandersetzung mit der Subsidiarität der Rasterfahndung nur in Einzelfällen festgestellt werden. Es muss davon ausgegangen werden, das entweder keine diesbezügliche Überprüfung erfolgt oder dass diese nicht dokumentiert wird.

Diese Annahmen werden durch die Betrachtung der zwischen den einzelnen Anordnungsschritten liegenden Zeiträume erhärtet. Der Median des Zeitraums zwi- 
schen Anregung und Antrag beträgt 1,5 Tage, der Median des Zeitraums zwischen Antrag und Anordnung beträgt zwei Tage und der Median des Zeitraums zwischen Anregung und Anordnung beträgt sechs Tage. ${ }^{514}$ Die kurzen Zeiträume deuten auf eine informelle Erörterung der Ermittlungsmaßnahme im Vorfeld des Anordnungsvorgangs hin. Folglich kann der tatsächliche Begründungsaufwand nicht ausschließlich anhand der Aktenanalyse ermittelt werden.

In Bezug auf den Umfang der Begründungen waren zwischen den staatsanwaltschaftlichen Anträgen und den richterlichen Anordnungen keine signifikanten Abweichungen festzustellen. Dies ist dem Umstand geschuldet, dass in 60 \% der Fälle eine Beschlussausfertigung durch das anordnende Gericht übernommen worden ist.

Der tatsächliche Begründungsaufwand war im Rahmen der Aktenanalyse nicht festzustellen. Aufgrund dessen war es notwendig diesen Bereich auch im Zuge der Expertengespräche zu thematisieren. Von den Experten wurde dargelegt, dass im Vorfeld der Maßnahme ein informeller Kontakt zwischen den Beteiligten erfolgt. Allerdings sei nicht der anordnende Richter die ,größte Hürde auf dem Weg zur Rasterfahndung, sondern die zuständige Staatsanwaltschaft.“ Eine genaue Einschätzung, den tatsächlichen Umfang der richterlichen Kontrolle betreffend, konnte jedoch auch auf der Basis der Expertengespräche nicht erfolgen. Allerdings bestehen erhebliche Zweifel an der Ausübung der richterlichen Kontrollpflicht. Insofern zeichnet sich bei der Rasterfahndung nach den $\S \S 98 \mathrm{a}$, b StPO ein ähnliches Bild, wie es schon im Rahmen von Untersuchungen $\mathrm{zu}$ anderen besonderen Ermittlungsmaßnahmen hervorgetreten ist. ${ }^{515}$

\section{Der Datenabgleich}

Beeinflusst von technischen Problemen und der Einholung von Ergänzungs- und Erweiterungsbeschlüssen variierte der Zeitraum zwischen Anordnung und Durchführung der Maßnahme erheblich. Der betreffende Zeitraum konnte für 22 der 31 Maßnahmen festgestellt werden. Er liegt zwischen 69 und 209 Tagen. Der Minuswert bildet eine Ausnahme, da in dem betreffenden Verfahren der Datenabgleich

514 Der Wert des Medians für den Zeitraum zwischen Antrag und Anordnung liegt sowohl bei allen $30 \mathrm{Maßnahmen,} \mathrm{für} \mathrm{welche} \mathrm{ein} \mathrm{Antrag} \mathrm{erfasst} \mathrm{werden} \mathrm{konnte,} \mathrm{bei} \mathrm{sechs} \mathrm{als}$ auch bei den $26 \mathrm{Maßnahmen} \mathrm{für} \mathrm{welche} \mathrm{Anregungen} \mathrm{festzustellen} \mathrm{waren.} \mathrm{Auffällig} \mathrm{ist,}$ dass eine Addition der Medianwerte für die Zeiträume zwischen Anregung und Antrag auf der einen Seite und zwischen Antrag und Anordnung auf der anderen Seite nicht den Median des Zeitraums zwischen Antrag und Anordnung ergibt. Eine solche Addition der Medianwerte ist jedoch nicht möglich. Dies ist durch die schiefen Verteilungen innerhalb der einzelnen Zeiträume begründet. Eine solche Addition ist lediglich bei den weniger aussagekräftigeren Mittelwerten möglich. Hier liegt der Mittelwert für den Zeitraum zwischen Anregung und Antrag bei zehn Tagen. Der Mittelwert für den Zeitraum zwischen Antrag und Anordnung liegt bei vier Tagen und der Mittelwert für den Zeitraum zwischen Anregung und Antrag liegt bei 14 Tagen.

${ }^{515}$ Albrecht/Dorsch/Krüpe, S.446ff.; Meyer-Wieck, S.33. 
durchgeführt und erst im Anschluss eine richterliche Anordnung eingeholt worden ist. $50 \%$ der Maßnahmen wurden innerhalb von 26 Tagen nach der Anordnung durchgeführt. Es ist festzuhalten, dass die Rasterfahndung einer längeren Vorbereitungszeit bedarf. Insofern erklärt sich auch, dass es in keinem Fall zu einer Eilanordnung gekommen ist.

Für den eigentlichen Datenabgleich wurde dagegen in der Regel ein Tag benötigt. Der längste Zeitraum betrug eine Woche. Folglich wird für die Aufbereitung der angelieferten Daten deutlich mehr Zeit benötigt als für den eigentlichen Datenabgleich.

In zwei Dritteln der Maßnahmen wurde der Datenabgleich von den ermittelnden Polizeidienststellen durchgeführt. Von den ermittelnden Polizeidienststellen wurden die Daten teilweise an die zuständigen Landeskriminalämter weitergeleitet, um den Datenabgleich durch diese durchführen zu lassen. Die übrigen Datenabgleiche führten die datenführenden Stellen selbst durch.

Nicht unerheblich waren die im Rahmen der Datenabgleiche auftretenden technischen Probleme. Bei mehr als $20 \%$ der Maßnahmen waren diese ausdrücklich in den Verfahrensakten vermerkt. Da jedoch nicht zu allen Maßnahmen diesbezügliche Informationen festgestellt werden konnten, muss davon ausgegangen werden, dass es deutlich häufiger zu technischen Problemen gekommen sein muss. Diese Annahme bestätigte sich im Rahmen der Expertengespräche. Insbesondere die Formatierung der angelieferten Daten auf ein einheitliches abgleichfähiges Format bereitete die größten Schwierigkeiten. Im Rahmen einer Maßnahme kam es bei der Formatierung zu einem vollständigen Datenverlust. Die technischen Schwierigkeiten betreffen darüber hinaus auch die teilweise mangelhafte Ausstattung der Polizei und der datenführenden Stellen. Von den Experten wurde angeführt, dass insbesondere die Einwohnermeldeämter mit veralteter Software arbeiten würden.

Die Übermittlung von sog. Überhangdaten im Sinne des $\S 98$ a III S.1 StPO musste in keinem Fall angeordnet werden. Darüber hinaus wurden keine Ordnungsoder Zwangsmittel angeordnet. Allerdings wurden diese im Zuge einer Maßnahme angedroht.

Lediglich im Rahmen einer Maßnahme konnten Hinweise auf ein Anordnungsverbot festgestellt werden. Nach Ansicht des Kraftfahrtbundesamtes (die durch die betreffende Maßnahme verpflichtete Stelle) würde die Übermittlung der angeforderten Daten der Zweckbestimmung des ZFER entgegenstehen und gem. § 52 StVG unzulässig sein. Nach Zurückweisung einer Beschwerde durch das zuständige Amtsgericht wurden die angeforderten Daten jedoch übermittelt. Es war demnach festzustellen, dass insbesondere der Streit über freiwillige Herausgabe von Daten durch Zeugnisverweigerungsberechtigte einen rein theoretischen Charakter hat. Die geringe praktische Relevanz der Anordnungsverbote des $\S 98$ b I S.6 und S.7 StPO basiert auf den für die Maßnahme herangezogenen Datenbeständen. 


\section{Intensität des Eingriffs}

In $50 \%$ der Rasterfahndungen wurden Daten von Einwohnermeldeämtern in den Datenabgleich einbezogen. Auch die Datenbestände des Kraftfahrtbundesamtes waren mehrfach von Rasterfahndungen betroffen. Die am häufigsten betroffene Gruppe von Datenbeständen bilden jedoch die polizeiinternen Datenbanken. Hier sind insbesondere die KAN-Bestände von Bund und Ländern, der IGVPDatenbestand, die POLAS-Datenbank, die VICLAS-Datenbank und die Sexualstraftäterdatei des Bundeskriminalamtes zu nennen. Ferner wurden auch Daten, die im Rahmen von anderen Ermittlungsmaßnahmen wie beispielsweise Telefonüberwachungen erlangt wurden, in die Datenabgleiche einbezogen. Letztlich wurde auch in Datenbeständen von Banken und Versandhandelsfirmen recherchiert.

Zum Umfang der angeforderten Daten waren den Verfahrensakten kaum Informationen zu entnehmen. Die Informationen beschränkten sich in der Regel auf die Anzahl der übermittelten Datensätze. Die Anzahl variierte zwischen elf und 1.374.006 übermittelten Datensätzen.

Allerdings lagen nicht zu allen einbezogenen Datensätzen Informationen über den Umfang vor. Folglich konnte nicht ermittelt werden, wie viele Personen von den Maßnahmen betroffen waren. Insgesamt konnten 2.633.721 einbezogene Datensätze festgestellt werden. Dabei konnten jedoch keine Mehrfachnennungen berücksichtigt werden. Aufgrund der Erkenntnisse und der fehlenden Informationen zu Teilen der einbezogenen Datenbanken dürfte die Zahl der Betroffenen jedoch deutlich höher liegen.

\section{Weiteres Vorgehen nach dem Datenabgleich}

In Bezug auf die Rückgabe der Datenträger waren den Verfahrensakten nur zu zehn Maßnahmen Informationen zu entnehmen. Dabei wurden in drei Fällen die Datenträger an die betreffenden Stellen zurückgegeben. In den übrigen sieben Fällen wurden teilweise nur Trefferlisten übermittelt, so dass eine Rückgabe nicht notwendig war. Darüber hinaus wurde von den Speicherstellen zum Teil auch auf die Rückgabe der Datenträger verzichtet.

Für zwölf Verfahren konnten Informationen über die Löschung von Daten erlangt werden. Davon hat in sechs Fällen eine Löschung stattgefunden. Diese fand jedoch in keinem Verfahren unter Aufsicht der Staatsanwaltschaft statt. Eine Niederschrift über die Löschung wurde nur in einem Fall gefertigt. In den weiteren sechs Maßnahmen konnte die Information erlangt werden, dass die Daten zum Zeitpunkt der Einsichtnahme in die Verfahrensakten noch nicht gelöscht worden waren. Dies war zum Teil durch die noch andauernden Ermittlungen bedingt. Es kann nicht sicher davon ausgegangen werden, dass die Daten in den übrigen 19 Verfahren nicht gelöscht worden sind. Auch im Rahmen der Expertengespräche 
konnten keine Erkenntnisse zu diesem Themenbereich erlangt werden. Es war festzustellen, dass sowohl die Löschung als auch die Rückgabe der Datenträger eine lediglich untergeordnete Rolle spielen.

In keiner der in die Untersuchung einbezogenen Maßnahmen konnte festgestellt werden, dass die Daten zu Beweiszwecken in anderen Verfahren verwendet worden sind. Durch die Gesprächsteilnehmer wurde die Ansicht vertreten, dass einer solchen Verwendung der stark einzelfallbezogene Charakter der Daten in der Regel entgegenstehe.

Im Rahmen der Untersuchung war lediglich in drei Fällen festzustellen, dass die von der Maßnahme betroffenen Personen benachrichtigt worden sind. Bei weiteren elf Maßnahmen war eine Benachrichtigung nicht notwendig, da die betreffenden Personen vernommen oder zur Abgabe einer Speichelprobe aufgefordert wurden. Insofern war eine Benachrichtigung obsolet. Bedenklich ist die große Anzahl von Maßnahmen, nach deren Abschluss eine Benachrichtigung unterblieben ist. Im Zuge der Expertengespräche wurde deutlich, dass zwischen Staatsanwaltschaften und Polizei Uneinigkeit über Inhalt und Umfang der Benachrichtigungspflicht besteht. Während von der Polizei die Ansicht geäußert wurde, dass die Staatsanwaltschaft den Benachrichtigungszeitpunkt zu bestimmen und die Betroffenen zu benachrichtigen habe, wurde von den Staatsanwaltschaften teilweise angeführt, dass die Benachrichtigung im Aufgabenbereich der Polizei liegen würde. Dies erklärt, weshalb es in fast zwei Dritteln der Maßnahmen nicht zu einer Benachrichtigung der Betroffenen gekommen ist.

Den Verfahrensakten waren nur für vier Maßnahmen Erkenntnisse über die Meldung der Maßnahme an den Datenschutzbeauftragten zu entnehmen. Dem steht die Aussage der Experten entgegen, dass der Datenschutz eine wichtige Rolle bei der Durchführung einer Rasterfahndung spielt. Sowohl aus der Aktenanalyse als auch aus den Expertengesprächen ergibt sich der Eindruck, dass die Meldung an den Datenschutzbeauftragten in der Regel unterbleibt. Demnach würde eine Kontrolle der Einhaltung von datenschutzrechtlichen Vorschriften nicht erfolgen.

Zum Umfang der mit einer Rasterfahndung verbundenen Kosten waren den Verfahrensakten in der Regel keine Informationen zu entnehmen. Lediglich in einem Fall war die Rechnung eines Einwohnermeldeamtes über 225 DM für die Datenübermittlung in den Verfahrensakten enthalten. Es ist in erster Linie der mit einer Maßnahme verbundene personelle Aufwand, der Kosten verursacht. Insbesondere wenn technische Probleme auftreten, führt dies zu einer regelrechten Kostenexplosion. In einem Verfahren erforderte die Formatierung der Daten einen Zeitaufwand von 554 „Manntagen“. Zudem werden vereinzelt die an die Rasterfahndung anschließenden Folgemaßnahmen (z.B. DNA-Reihenuntersuchungen) in das Kostencontrolling miteinbezogen. 


\section{Verfahrensausgang}

Zum Zeitpunkt der Akteneinsicht dauerten die Ermittlungen in 5 der 27 untersuchten Verfahren noch an. In neun Verfahren wurden die Ermittlungen eingestellt, weil kein Täter ermittelt werden konnte. In einem dieser Verfahren entzog sich der Täter der Festnahme durch Suizid. Die Ermittlungen in den übrigen 13 Verfahren führten zur Ergreifung und Verurteilung von Tätern.

Bezogen auf die Beschuldigten, zu denen Informationen über den Verfahrensausgang vorlagen, war festzustellen, dass die Verfahren gegen fast $70 \%$ dieser Personen eingestellt worden sind. Insgesamt wurden 35 Beschuldigte angeklagt. $\mathrm{Zu}$ 28 dieser Personen lagen Informationen bzgl. der Anklage, der Hauptverhandlung und dem Urteil vor. Diese 28 Personen wurden alle verurteilt. 19 der Angeklagten wurden zu unbedingten Freiheitsstrafen verurteilt. Weitere fünf Angeklagte wurden zu Bewährungsstrafen und die übrigen vier Angeklagten zu Geldstrafen verurteilt. Durchschnittlich lagen die Freiheitsstrafen bei acht Jahren. Allerdings lagen $50 \%$ der Strafen bei neun und mehr Jahren. Daraus ergibt sich, dass die Rasterfahndung hauptsächlich in Verfahren der schweren Kriminalität zur Anwendung kommt.

\section{Die Ergebnisse der Evaluation von Erfolg und Effizienz}

Im Rahmen der Untersuchung wurden die Begriffe Erfolg und Effizienz einer grundlegenden Bedeutungsanalyse unterzogen. Anschließend wurden diese Begriffe in Bezug zur Polizeiarbeit im Allgemeinen und zur Rasterfahndung gesetzt. Letztlich wurden den Begriffen beobachtbare Sachverhalte zugeordnet, um eine empirische Überprüfung zu ermöglichen.

Diese Operationalisierung wurde zunächst für den Begriff Erfolg vorgenommen. Dabei standen die Erlangung neuer Ermittlungsansätze und die weiteren Ermittlungsergebnisse im Mittelpunkt der Untersuchung. Auf diesen Erkenntnissen aufbauend wurden die Maßnahmen einer abschließenden Beurteilung unterzogen. Diese Ergebnisse wurden anschließend mit aus den Verfahrensakten entnommenen Erfolgseinschätzungen der Ermittlungsbehörden verglichen.

Bei der Untersuchung der Effizienz der Maßnahme wurden die Auswirkungen der Erfolge auf das Ermittlungsverfahren analysiert und in Beziehung zu verschiedenen effizienzfördernden und effizienzhemmenden Faktoren gesetzt. Dabei wurde die Rasterfahndung zunächst in Bezug zum Verfahrensausgang gesetzt. Hierzu war es notwendig, die Rolle der Rasterfahndung in Anklage, Hauptverhandlung und Urteil zu untersuchen. Zudem wurde die Rolle der Rasterfahndung im Rechtsmittelverfahren in die Untersuchung einbezogen. Im Rahmen der Effizienz wurde darüber hinaus der Umfang der Zielerreichung analysiert. Letztlich wurden Effizienzkriterien wie finanzieller, zeitlicher und personeller Aufwand untersucht. 


\section{Erfolge der Rasterfahndung}

Die Beurteilung der Erfolge der Maßnahmen basiert auf der Einteilung der Maßnahmen in die Kategorien „Rasterfahndung erfolgreich“, „Rasterfahndung bedingt erfolgreich“, „Rasterfahndung nicht erfolgreich“ und „Keine Angaben“. 516 Danach waren $13 \%$ der Maßnahmen als erfolgreich und $58 \%$ als bedingt erfolgreich einzustufen. $\mathrm{Zu} 13 \%$ waren keine Angaben möglich und $16 \%$ wurden als nicht erfolgreich eingestuft. Insgesamt erbrachten mehr als zwei Drittel der durchgeführten Rasterfahndungen neue Ermittlungsansätze. Diese führten jedoch nur vereinzelt zu Ermittlungserfolgen. Lediglich aufgrund von Erkenntnissen aus vier Maßnahmen konnten Ermittlungsansätze erlangt werden, die erfolgreich zur Ergreifung der Täter geführt haben.

In einem Exkurs wurde die präventiv polizeiliche Rasterfahndung nach dem 11. September 2001 in die Untersuchung miteinbezogen. Aus den erlangten Informationen war zu erkennen, dass auch die präventive Rasterfahndung neue Ermittlungsansätze geliefert hat. Allerdings kam es im Rahmen der weiteren Ermittlungen nicht zur Ergreifung sog. „Schläfer“. An den im Rahmen der repressiven Rasterfahndung verwendeten Kategorien gemessen, kann die Maßnahme damit als bedingt erfolgreich eingestuft werden. Aufgrund des bundesweiten Einsatzes der Maßnahme und der groben Rasterkriterien waren die Trefferzahlen und die neuen Ermittlungsansätze deutlich größer als im repressiven Bereich.

\section{Ermittlungsansätze}

Von den 31 Maßnahmen erbrachten 22 neue Ermittlungsansätze. Für 20 der 22 Maßnahmen konnten die Ermittlungsansätze genau identifiziert werden. Insgesamt hatten zehn Maßnahmen offene, sechs Maßnahmen verdeckte und sechs Maßnahmen sowohl offene als auch verdeckte Ermittlungsmaßnahmen zur Folge. Bei den offenen Ermittlungsmaßnahmen handelt es sich beispielsweise um DNAReihenuntersuchungen, Durchsuchungen und Vernehmungen. Die verdeckten setzten sich aus Telefonüberwachungen, der Erhebung von Telekommunikationsverbindungsdaten, Observationen und büromäßigen Abklärungen zusammen.

Durchschnittlich hatten die Maßnahmen 2.357 Treffer zur Folge. Allerdings wird dieser Wert durch vier überdurchschnittlich hohe Treffermengen beeinflusst. Der aussagekräftigere Median liegt bei 85 Treffern. Daraus folgt, dass $50 \%$ der Maßnahmen weniger als 85 Treffer erbrachten. Bei einem Viertel der Maßnahmen lag die Anzahl der Treffer sogar unter 22. Mithin erbrachte die Hälfte der Rasterfahndungen handhabbare Trefferzahlen.

${ }^{516}$ Zur Einteilung und den dafür notwendigen Voraussetzungen siehe 5.Teil C.I.1. 
In acht Verfahren kam es aufgrund der Rasterfahndung zur Identifizierung von Beschuldigten. Verteilt auf diese Verfahren wurden 13 Personen als Beschuldigte geführt. Ein Zusammenhang zwischen Treffern und Beschuldigten ließ sich jedoch nicht herstellen. Über die Beschuldigten hinaus wurden aufgrund der Rasterfahndung in einem Verfahren zwei und in einem weiteren Verfahren 36 Personen als Tatverdächtige identifiziert.

Neue Ermittlungsverfahren wurden aufgrund der Erkenntnisse aus den Rasterfahndungen nicht eingeleitet. Darüber hinaus lagen keine Erkenntnisse über sog. Zufallsfunde vor.

\section{Erfolgseinschätzungen der Ermittlungsbehörden}

Zu 14 der 31 Maßnahmen ließen sich den Verfahrensakten Erfolgs-einschätzungen der Ermittlungsbehörden entnehmen. Von diesen wurden drei als erfolgreich und drei als bedingt erfolgreich eingestuft. Die restlichen acht Maßnahmen wurden als nicht erfolgreich beurteilt. Die Erfolgseinschätzungen basieren auf den Aussagen der ermittelnden Polizeidienststellen und wurden in zwei Fällen durch Staatsanwaltschaften und in einem Fall durch einen Richter ergänzt. Unter den Ermittlungsbehörden überwiegen damit die negativen Einschätzungen deutlich. Bei einem Vergleich der Einschätzungen mit den im Rahmen der Untersuchung vorgenommenen Einschätzungen zeigt sich, dass für die Ermittlungsbehörden die Erlangung von neuen Ermittlungsansätzen nicht automatisch einen Erfolg darstellt.

\section{Verteilung der Erfolge auf Katalogdelikte und verfolgte Ziele}

Bei der Verteilung der Erfolge auf die Katalogdelikte zeigte sich, dass insbesondere die Maßnahmen in Verfahren mit Straftaten gegen Leib und Leben zu Erfolgen geführt haben. Drei der vier erfolgreichen Rasterfahndungen lagen Straftaten gegen Leib und Leben als Katalogdelikt zugrunde. Bei den drei Maßnahmen handelt es sich um solche, die als Grundlage für eine DNA-Reihenuntersuchung durchgeführt worden sind. Die DNA-Reihenuntersuchungen führten in den drei Fällen zur Identifizierung des Täters. Mithin eignet sich die Rasterfahndung in besonderem Maße zur Priorisierung eines Personenkreises im Vorfeld einer Reihenuntersuchung. $\mathrm{Zu}$ den gleichen Erkenntnissen gelangten auch die Gesprächsteilnehmer, welche in der Kombination mit einer DNA-Reihenuntersuchung das Hauptanwendungsfeld der Rasterfahndung sehen. Nach Ansicht der Experten sei zu erwarten, dass die Rasterfahndung in diesem Bereich in Zukunft häufiger zum Einsatz komme, da sie die Effizienz von Reihenuntersuchung zu steigern vermag.

Bei der Betrachtung der verfolgten Ziele im Zusammenhang mit den Erfolgen zeigt sich, dass die Maßnahmen welche konkrete Ziele verfolgen nicht so erfolgreich sind, wie solche, die in ihrer Formulierung ganz allgemein gehalten sind. Von 
den vier erfolgreichen Rasterfahndungen enthielten zwei Maßnahmen lediglich die Formulierung „Ausschluss Nichtverdächtiger Personen und die Feststellung von Personen, die weitere für die Ermittlungen bedeutsame Prüfungsmerkmale erfüllen“ als Ziel. Die dritte Maßnahme ergänzte diese Formulierung durch die Identifizierung von Mittätern als weiteres Ziel. Ziel der vierten Maßnahme war die Erlangung neuer Ermittlungsansätze. Bezieht man in die Betrachtung mit ein, dass drei der vier Maßnahmen zur Vorbereitung einer DNA-Reihenuntersuchung durchgeführt worden sind, ergibt sich die Schlussfolgerung, dass die tatsächlich verfolgten Ziele nicht in den Anträgen genannt worden sind. Vielmehr gegeben die erfolgreichen Maßnahmen lediglich die im Gesetz formulierten Ziele wieder. Mithin bestätigt sich, dass der Anordnungsvorgang lediglich formellen Charakter besitzt.

\section{Die Rolle der Rasterfahndung im Verfahrensausgang}

Lediglich in der Anklageschrift eines Verfahrens wurde die Rasterfahndung als Beweismittel aufgeführt. Dabei wurde nicht ausdrücklich die Rasterfahndung, sondern die Trefferliste aufgeführt. In diesem Verfahren wurden fünf Beschuldigte angeklagt und verurteilt. Darüber hinaus wurde die Rasterfahndung in zwei weiteren Anklagen in anderen Verfahren jeweils mit einem Satz erwähnt. Bei den drei Rasterfahndungen handelt es sich um solche, die als erfolgreich eingestuft worden sind. Daraus ergibt sich, dass die Rasterfahndung lediglich ein Mittel zum Erkenntnisgewinn ist und sich nur in Ausnahmefällen als Beweismittel eignet.

Diese Annahme erhärtete sich im Rahmen der Untersuchung der Hauptverhandlungsprotokolle. Lediglich in einem Fall wurde durch die Verteidigung ein Beweisantrag gestellt, welcher sich auf die Rasterfahndung bezog. Beweisanträge von Staatsanwaltschaften die Rasterfahndung betreffend, konnten nicht festgestellt werden. In den untersuchten Urteilen wurde die Rasterfahndung in einem Fall im Rahmen der Beweiswürdigung aufgegriffen. Allerdings erfolgte dies ohne Beweiskraft. Ferner spielte die Rasterfahndung in den untersuchten Verfahren keine Rolle in den Rechtsmittelverfahren. Diese Erkenntnisse decken sich mit den Informationen aus den Expertengesprächen. Auch die Gesprächsteilnehmer sahen in der Rasterfahndung lediglich ein Mittel zum Erkenntnisgewinn. Eine Beweiskraft wurde dagegen nur in Einzelfällen für möglich gehalten.

\section{Sonstige Effizienzkriterien}

Im Rahmen der Aktenanalyse konnten nur in begrenztem Umfang Informationen über den mit den Maßnahmen verbundenen finanziellen, personellen und zeitlichen Aufwand erlangt werden. Aus den Expertengesprächen ergab sich, dass im Rahmen von Rasterfahndungen wirtschaftliche Erwägungen eine untergeordnete Rolle spielen. Allerdings wurde dargelegt, dass die ermittelnden Polizeidienststellen in 
der Regel nicht über ausreichende technische Ausrüstung für den Datenabgleich verfügen. Von nahezu allen Gesprächsteilnehmern wurde von Problemen bei der Formatierung der Daten berichtet. Der personal- und zeitaufwendigste Arbeitsschritt ist demnach die Formatierung der Daten auf ein einheitliches abgleichfähiges Datenformat. Allerdings würde eine notwendige Rasterfahndung nach einhelliger Auffassung der Experten nicht an technischen Problemen scheitern.

\section{B. Schlussfolgerungen}

Als Schlussfolgerungen können folgende Punkte festgehalten werden:

- Seit Einführung der Rasterfahndung in die Strafprozessordnung im Jahr 1992 wurde die Ermittlungsmaßnahme nur vereinzelt eingesetzt.

- Seit dem Jahr 2002 ist eine deutliche Zunahme von Verfahren mit Maßnahmen nach den $\S \S 98 \mathrm{a}$, b StPO zu verzeichnen. Diese beruht auf einer gesteigerten Akzeptanz der Maßnahme bei den Ermittlungsbehörden, verbesserte technische Möglichkeiten und der Zunahme von Datensammlungen.

- Die Anzahl der Rasterfahndung wird maßgeblich durch den Entwicklungsstand der Abteilungen Operative Fallanalyse der Landeskriminalämter mitbestimmt. In den Bundesländern, in welchen die betreffenden Abteilungen über größere Erfahrungswerte im Umgang mit der Rasterfahndung verfügen und entsprechende Konzepte erstellt haben, kommt die Maßnahme häufiger zur Anwendung als in den übrigen Bundesländern.

- Die Rasterfahndung hat bei den Abteilungen Operative Fallanalyse der Landeskriminalämter und des Bundeskriminalamtes einen großen Stellenwert. Einige Landeskriminalämter und das Bundeskriminalamt haben sich intensiv mit der Maßnahme und den mit ihr verbundenen Möglichkeiten beschäftigt. Insofern ist davon auszugehen, dass die Maßnahme in Zukunft vermehrt zur Anwendung kommen wird.

- Die Rasterfahndung kommt in erster Linie bei der Aufklärung von Tötungsdelikten, sexuell motivierten Straftaten und in Serie begangen Straftaten zum Einsatz. Damit ist ihr Einsatz auf die Bereiche schwerster Kriminalität limitiert.

- Die Rasterfahndung wurde in den 15 Jahren seit Einführung in die Strafprozessordnung erst in zwei Verfahren zur Bekämpfung der Organisierten Kriminalität eingesetzt. Dabei sind Strukturermittlungen im Bereich organisierter Kriminalität, wie sie der Gesetzgeber mit der Einführung der Maßnahme vorgesehen hat, bislang nicht durchgeführt worden. Inso- 
- fern wurden die vom Gesetzgeber mit der Implementation der Maßnahme in die Strafprozessordnung verfolgten Ziele nicht erreicht.

- Die Stärken der Ermittlungsmaßnahme liegen im Bereich der Vorbereitung von DNA-Reihenuntersuchungen. In diesem Zusammenhang ermöglicht sie die Priorisierung von Personenkreisen und damit eine effiziente Durchführung von Reihenuntersuchungen. Ausschließlich in diesem Bereich ist die Rasterfahndung bislang erfolgreich zur Anwendung gekommen.

- Eine Differenzierung zwischen negativer und positiver Rasterfahndung hat in der Praxis keinerlei Bedeutung.

- Die mit den einzelnen Maßnahmen konkret verfolgten Ziele lassen sich den Anträgen und den Anordnungen nur begrenzt entnehmen. Bei der Formulierung der Ziele orientieren sich Staatsanwaltschaften und Gerichte lediglich am Gesetzestext.

- Insbesondere die Staatsanwaltschaften und die Gerichte setzen sich mit der Subsidiarität der Maßnahme nur in unzureichendem Umfang auseinander.

- Aufgrund der Schwere der Delikte, die den untersuchten Verfahren zugrunde liegen, bildet die Feststellung des Vorliegens der gesetzlichen Voraussetzungen keinerlei Schwierigkeiten.

- Die richterliche Anordnung ist lediglich ein formaler Akt. Mithin stellt sich die Umsetzung der richterlichen Kontrolle als mangelhaft dar und bedarf einer deutlichen Steigerung.

- Einer staatsanwaltschaftlichen Eilanordnung steht der mit einer Rasterfahndung verbundene technische und zeitliche Aufwand entgegen.

- Die Hälfte der untersuchten Rasterfahndungen hat handhabbare Trefferzahlen zum Ergebnis.

- Die Ermittlungsmaßnahme ermöglicht die Erlangung neuer Ermittlungsansätze. Erfolge, die sich direkt an der Identifizierung von Straftätern oder der Aufklärung von Straftaten ablesen lassen, bilden dagegen die Ausnahme.

- Die größten Schwierigkeiten bei der Durchführung von Rasterfahndungen liegen im Bereich der Formatierung von Daten auf ein einheitliches Datenformat. Dieser Arbeitsschritt erfordert je nach Umfang des Datenabgleichs einen hohen personellen und zeitlichen Aufwand. In diesem Bereich besteht erhebliches Verbesserungspotenzial. Insbesondere die Datenverarbeitung bei den Einwohnermeldeämtern sollte sich bundesweit auf eine einheitliche Software stützen. 
- Aufgrund der geringen Anwendungshäufigkeit erscheint es nicht sinnvoll, die ermittelnden Polizeidienststellen mit dem notwendigen technischen Material auszustatten. Die Rasterfahndung wird niemals zum polizeilichen Alltagsgeschäft gehören. Aus diesem Grund sollten ausschließlich bei den Landeskriminalämtern Abteilungen geschaffen werden, die personell und materiell zur Durchführung von Rasterfahndung ausgestattet werden.

- Die Benachrichtigung von Datenschutzbeauftragten und betroffenen Personen findet in der Regel nicht statt. In der gesetzlichen Ausgestaltung der Rasterfahndung fehlt es an einer eindeutigen Zuständigkeitsregelung. Zwischen den beteiligten Ermittlungsbehörden besteht Dissens bzgl. der Zuständigkeit zur Benachrichtigung. Darüber hinaus bedarf die Frage einer Klärung, welche vom Datenabgleich betroffenen Personen zu benachrichtigen sind. Eine Initiative des Gesetzgebers zur Behebung dieser Missstände wäre wünschenswert.

- Die mit einer Rasterfahndung verbundenen Kosten spielen bei der Entscheidung, eine Rasterfahndung durchzuführen nur eine untergeordnete Rolle. Vielmehr wird der mit den Folgemaßnahmen, wie beispielsweise den DNA-Reihenuntersuchungen, verbundene finanzielle Aufwand in die Entscheidung einbezogen. Ferner findet eine rückwirkende Beurteilung anhand ökonomischer Gesichtspunkte nur vereinzelt statt. 


\section{Abbildungsverzeichnis}

$\begin{array}{lll}\text { Abbildung 1: } & \text { Struktur des Fragebogens } & 83\end{array}$

Abbildung 2: $\quad$ Entwicklung der Verfahren mit Anordnungen nach $\S \S 98 \mathrm{a}, \mathrm{b}$ stopp $(\mathrm{n}=27)$

Abbildung 3: $\quad$ Verteilung der Verfahren auf die

Bundesländer $(\mathrm{n}=27)$

Abbildung 4: $\quad$ Verteilung der Katalogdelikte auf die Verfahren $(\mathrm{n}=34)$

Abbildung 5: $\quad$ Beschlüsse pro Maßnahme $(\mathrm{n}=31)$

Abbildung 6: $\quad$ Altersstruktur der Beschuldigten in Jahren $(\mathrm{n}=96)$

Abbildung 7: $\quad$ Differenzierung zwischen positiver und negativer Rasterfahndung $(\mathrm{n}=30)$

Abbildung 8: $\quad$ weitere Ziele $(\mathrm{n}=26)$

Abbildung 9: $\quad$ Kategorien und Kriterien für die

Beurteilung der Begründungen

Abbildung 10: $\quad$ Begründungen der Staatsanwaltschaften nach

Kategorien in \% $(\mathrm{n}=30)$

Abbildung 11: Umfang der staatsanwaltschaftlichen

Begründungen $(n=30)$

Abbildung 12: $\quad$ Erweiterung der Begründungskategorien aus Abbildung 9

Abbildung 13: $\quad$ richterliche Begründungen nach Kategorien in $\%(n=31)$

Abbildung 14: Übersicht über die Zeiträume zwischen Anregung und Antrag, Antrag und Anordnung und Anregung und Anordnung

Abbildung 15: $\quad$ Prozentuale Verteilung der Begründungskategorien bei polizeilicher Anregung $(n=26)$, staatsanwaltschaftlichem Antrag $(\mathrm{n}=30)$ und richterlicher Anordnung $(\mathrm{n}=31)$ 
Abbildung 16: $\quad$ Umfang staatsanwaltschaftlicher und richterlicher Begründungen im Vergleich

Abbildung 17: $\quad$ Einstellungen und Katalogtat

Abbildung 18: $\quad$ Dauer der Freiheitsstrafen $(\mathrm{n}=24)$

Abbildung 19: $\quad$ Verurteilungen und Katalogdelikte

Abbildung 20: Neue Ermittlungsansätze verteilt auf die Maßnahmen $(n=31)$

Abbildung 21: Art der Erfolge in Prozent $(\mathrm{n}=31)$

Abbildung 22: $\quad$ Erfolgseinschätzungen in den Verfahrensakten $(\mathrm{n}=14)$

Abbildung 23: $\quad$ Vergleich der Erfolgseinschätzungen ( $\mathrm{n}=14)$

Abbildung 24: Verteilung der Erfolge auf die Katalogtaten $(\mathrm{n}=31)$

Abbildung 25: $\quad$ Verteilung der Erfolge auf die verfolgten

Ziele $(\mathrm{n}=30)$

Abbildung 26: $\quad$ Verteilung der Erfolge auf die weiteren Ziele ( $\mathrm{n}=19)$ 


\section{Literaturverzeichnis}

Albrecht, Hans-Jörg, Rechtstatsachenforschung zum Strafverfahren, Neuwied 2005.

Albrecht, Hans-Jörg/Dorsch, Claudia/Krüpe, Christiane, Rechtswirklichkeit und Effizienz der Überwachung der Telekommunikation nach $\S \S 100 \mathrm{a}, 100 \mathrm{~b}$ StPO und anderer verdeckter Ermittlungsmaßnahmen, Freiburg 2003.

Albrecht, Hans-Jörg, Strafzumessung und Vollstreckung bei Geldstrafen, Berlin 1980.

Albrecht, Hans-Jörg, Organisierte Kriminalität - Theoretische Erklärungen und empirische Befunde, In: Deutsche Sektion der Internationalen JuristenKommission (Hrsg.), Organisierte Kriminalität und Verfassungsstaat, Heidelberg 1998, S.1-40.

Amelung, Knut, Die Entscheidung des BVerfG zur „Gefahr im Verzug“ i.S. des Art. 13 II GG, NStZ 2001, S.337-343.

Bär, Wolfgang, Der Zugriff auf Computerdaten im Strafverfahren, Köln/Berlin/ Bonn/München 1992.

Belz, Reiner/Mußmann, Eike, Polizeigesetz für Baden-Württemberg, 6. Auflage, Stuttgart//München/Hannover/ Berlin/Weimar/Dresden 2001.

Berg, Günter/Knape, Michael/Kiworr, Ulrich, Allgemeines Polizei- und Ordnungsrecht für Berlin, 8. Auflage, Hilden/Rhld. 2000.

Bernsmann, Klaus/Jansen, Kirsten, Heimliche Ermittlungsmethoden und ihre Kontrolle - Ein systematischer Überblick, StV 1998, S.217-231.

Blankenburg, Erhard, Die Aktenanalyse. In: Erhard Blankenburg (Hrsg.), Empirische Rechtssoziologie, München 1975, S.193-198.

Boeden, Gerhard, Die Rahmenbedingungen polizeilichen Handelns und polizeilicher Erfolg, In: Bundeskriminalamt (Hrsg.), Symposium: Der polizeiliche Erfolg, Wiesbaden 1988, S. 67-73.

Bölsche, Jochen, Der Weg in den Überwachungsstaat, Reinbek bei Hamburg 1979. 
Bottke, Wilfried, Polizeiliche Ermittlungstätigkeit und Legalitätsprinzip, In: Geppert, Klaus/Dehnicke, Diether (Hrsg.), Gedächtnisschrift für Karlheinz Meyer, Berlin/New York 1990, S.37-59.

Brockhaus-Enzyklopädie, Band 6 Ds-Ew und erster Nachtrag, 19. Auflage, Mannheim 1988.

Brockhaus-Enzyklopädie, Band 18 Rad-Rüs, 19. Auflage, Mannheim 1992.

Bruns, Hans-Jürgen, Tatverdacht und Schlüssigkeitsprüfung im Ermittlungsverfahren, In: Hirsch, Hans-Joachim/Kaiser, Günther/Marquardt, Helmut (Hrsg.), Gedächtnisschrift für Hilde Kaufmann, Berlin/New York 1986, S.863-873.

Büchler, Heinz/Wagner, Dieter/Grawert, Achim/Fiedler, Katrin, Effektivität und Effizienz kriminalpolizeilicher Organisationsformen auf Zeit, Wiesbaden 1997.

Bull, Hans Peter, Datenschutz oder die Angst vor dem Computer, München 1984.

Denninger, Erhard, Das Rechts auf informationelle Selbstbestimmung, In: Hohmann, Harald (Hrsg.), Freiheitssicherung durch Datenschutz, Frankfurt am Main 1987, S.127-172.

Dessecker, Axel, Gewinnabschöpfung im Strafrecht und in der Strafrechtspraxis, Freiburg 1992.

Dreier, Horst, Grundgesetz Kommentar Band I, 2. Auflage, Tübingen 2004.

Dölling, Dieter, Probleme der Aktenanalyse in der Kriminologie. In: Helmut Kury (Hrsg.), Methodologische Probleme in der kriminologischen Forschungspraxis, Köln/Berlin/Bonn/München 1984, S.265-286.

Dölling, Dieter, Effizienzsteigerung durch Beurteilung der Aufklärungswahrscheinlichkeit, In: Bundeskriminalamt (Hrsg.), Symposium: Der polizeiliche Erfolg, Wiesbaden 1988, S.113-137.

DRiZ Informationen..., Neues aus der „Mottenkiste“: Rasterfahndung, DRiZ 2002, 9-10.

Eisenberg, Ulrich, Kriminologie, 6. Auflage, München 2005.

Eisenberg, Ulrich/Conen, Stefan, § 152 II StPO Legalitätsprinzip im gerichtsfreien Raum, NJW 1998, S.2241-2249.

Ermisch, Günter, Fahndung und Datenschutz - aus Sicht der Polizei. In: Bundeskriminalamt (Hrsg.), Möglichkeiten und Grenzen der Fahndung, Wiesbaden 1980, S.63-72.

Friedrichs, Jürgen, Methoden empirischer Sozialforschung, 12. Auflage, Opladen 1980. 
Garz, Detlef/Kraimer, Klaus, Qualitativ-Empirische Sozialforschung, Opladen 1991.

Gehm, Volker/Link, Martina, Organisierte Kriminalität, Kriminalistik 1992, S.491-496.

Gehrken, Jan, BKA rastert illegal, FoR 2003, S.28.

Gerling, Rainer W./Langer, Cordula/Roßmann, Ray, Rechtsgrundlagen zur Rasterfahndung, DuD 25 (2001), S.1-10.

Göppinger, Hans, Kriminologie, München 1997.

Graf, Walther, Rasterfahndung und organisierte Kriminalität, Mönchengladbach 1997.

Grunst, Bettina, Moderne Gesetzgebungstechniken in StGB und StPO aus kritischer Sicht der juristischen Methodenlehre, GA 149 (2002), S.214-227.

Hassemer, Winfried, Stellungnahme zum Entwurf eines Gesetzes zur Bekämpfung des illegalen Rauschgifthandels und anderer Erscheinungsformen der organisierten Kriminalität (OrgKG), KJ 1992, S.64-80.

Heidelberger Kommentar zur Strafprozessordnung, Lemke, Michael/Julius, Karl-Peter/Krehl, Christoph/Kurth, Hans-Joachim/Rautenberg, Erardo Christoforo/Temming, Dieter (Hrsg.), 2. Auflage, Heidelberg 1999.

Hetger, Erwin, 21. GdP-Tagung Verbrechensbekämpfung 2002, Zitiert in: Kube, Erwin/Schneider, Hans/Stock, Jürgen (Hrsg.), Kriminologische Spuren in Hessen, Frankfurt 2003.

Hermann, Dieter, Die Aktenanalyse als kriminologische Forschungsmethode. In: Günther Kaiser/Helmut Kury/Hans-Jörg Albrecht (Hrsg.), Kriminologische Forschung in den 80er Jahren, Freiburg 1988, S.863-877.

Herold, Horst, Polizeiliche Datenverarbeitung und Menschenrechte, RuP 1980, S.79-86.

Hilger, Hans, Neues Strafverfahrensrecht durch das OrgKG, NStZ 1992, S.457463 und S.523-526.

Himmelreich, Manfred, Die Schranken der Wahrheitsermittlung bei der Strafverfolgung und neue Ermittlungsmethoden der Polizei, Frankfurt 1993.

Hucke, Jochen/Wollmann, Hellmut, Methodenprobleme der Implementationsforschung. In: Renate Mayntz (Hrsg.), Implementation politischer Programme, Hanstein 1980, S.216-235.

Joerden, Jan C., Der Bandendiebstahl und seine Mitwirkenden - BGH NJW 2001, S.2266, JuS 2002 S.329-332.

Kaiser, Günther, Kriminologie, 3. Auflage, Heidelberg 1996. 
Kaleth, Hans, Die elektronische Datenverarbeitung - ein kriminalpolizeiliches Hilfsmittel, Die Polizei 1962, S.179-182.

Kammann, Nicola, Der Anfangsverdacht, Hamburg 2003.

Kanther, Manfred, Die Entwicklung der organisierten Kriminalität in der Bundesrepublik Deutschland und geplante Maßnahmen zu ihrer Bekämpfung, In: Deutsche Sektion der Internationalen Juristen-Kommission (Hrsg.), Organisierte Kriminalität und Verfassungsstaat, Heidelberg 1998, S.57-72.

Karlsruher Kommentar, hrsg. von Pfeiffer, Gerd, 5. Auflage, München 2003.

Kersten, Ulrich, Die Bekämpfung der Organisierten Kriminalität unter besonderer Berücksichtigung der Zusammenarbeit von Polizei und Justitz, ZFIS 1998, S.131-138.

Kinzig, Jörg, Die rechtliche Bewältigung von Erscheinungsformen organisierter Kriminalität, Berlin 2004.

Kleinknecht/Müller/Reitberger Kommentar zur Strafprozessordnung, HeintschelHeinegg, Bernd von/Stöckel, Heinz (Hrsg.), Band $1 \S \S 1-149$ StPO, Loseblattsammlung, Neuwied/Kriftel, 44. Lfg. 2006.

Klever, Stefan, Die Rasterfahndung nach § 98a StPO, Münster 2003.

Koch, Martin, Datenerhebung und -verarbeitung in den Polizeigesetzen der Länder, Baden-Baden 1999.

Krey, Volker/Haubrich, Edgar, Zeugenschutz, Rasterfahndung, Lauschangriff, Verdeckte Ermittler, JR 1992, S.309-315.

Kromrey, Helmut, empirische Sozialforschung, 10. Auflage, Opladen 2002.

Krüger, Ralf, Die Gestaltung strafprozessualer Ermittlungsbefugnisse durch den Gesetzgeber, In: Fachhochschule Villingen-Schwenningen, Hochschule für Polizei (Hrsg.), Gedächtnisschrift für Hagen Gülzow, Konstanz 1999, S.33-44.

Kruse, Gesine, Landesbericht Bundesrepublik Deutschland. In: Walter Groop (Hrsg.), Besondere Ermittlungsmaßnahmen zur Bekämpfung organisierter Kriminalität, Freiburg 1993.

Kühne, Hans-Heiner, Strafprozesslehre, 4. Auflage, Heidelberg 1993.

Kühne, Hans-Heiner, Die Definition des Verdachts als Voraussetzung strafprozessualer Zwangsmaßnahmen, NJW 1979, S.617-622.

Kürzinger, Josef, Kriminologie, 2. Auflage, Stuttgart 1996.

Leipziger Kommentar Strafgesetzbuch, Jähnke, Burhard/Laufhütte, Heinrich Wilhelm/Odersky, Walter (Hrsg.), Vierter Band $\S \S 80-145 d, 11$. Auflage, Berlin 2005. 
Lilie, Hans, Verwicklungen im Ermittlungsverfahren, ZStW 111 (1999), S.807826.

Lisken, Hans, Zur polizeiliche Rasterfahndung, NVwZ 2002, S.513-519.

Lisken, Hans/Denninger, Erhard, Handbuch des Polizeirechts, 3. Auflage, München 2001.

Lisken, Hans, Kube/Störzer/Brugger (Hrsg.), Wissenschaftliche Kriminalistik, Band 16 BKA-Forschungsreihe, Teilband 1, Wiesbaden 1983, Teilband 2, Wiesbaden 1984 (Buchbesprechung), NJW 1986, S.175-176.

Löwe-Rosenberg, Die Strafprozessordnung und das Gerichtsverfassungsgesetz, Zweiter Band, Rieß, Peter (Hrsg.), 25. Auflage, Berlin 2004.

Löwe-Rosenberg, Die Strafprozessordnung und das Gerichtsverfassungsgesetz, Dritter Band, Rieß, Peter (Hrsg.), 25. Auflage, Berlin 2004.

Mayntz, Renate, Implementation politischer Programme, Hanstein 1980.

Mayring, Philipp, Qualitative Inhaltsanalyse, 8. Auflage, Weinheim 2003.

Meister, Johannes, Die gefahrenabwehrrechtliche Rasterfahndung, JA 2003, S.83-88.

Meixner, Kurt/Martell, Jörg-Michael, Gesetz über die öffentliche Sicherheit und Ordnung des Landes Sachsen-Anhalt, 3. Auflage, Stuttgart 2001.

Meyers enzyklopädisches Lexikon, Band 19 Pole-Renc und 6. Nachtrag 1977, 9. Auflage, Mannheim 1977.

Meyer-Goßner, Lutz, Strafprozessordnung, 49. Auflage, München 2006.

Meyer-Goßner, Lutz, Theorie ohne Praxis und Praxis ohne Theorie im Strafverfahren, ZRP 2000, S.345-351.

Meyer-Wieck, Hannes, Der große Lauschangriff - Eine empirische Untersuchung zu Anwendung und Folgen des $\S 100$ c Abs. 1 Nr. 3 StPO, Freiburg 2005.

Michels, Yves, Maßstäbe für eine effiziente Polizei. In: Helmut Bäumler (Hrsg.), Polizei und Datenschutz, Neuwied 1999, S.146-158.

Mitsch, Wolfgang, Strafrecht Besonderer Teil, Vermögensdelikte (Randbereich)/Teilband 2, Berlin/Heidelberg/New York 2001.

Möhrenschlager, Manfred, Das OrgKG - eine Übersicht nach amtlichen Materialien, wistra 1992, S.281-289 und S.326-333.

Münchner Kommentar zum Strafgesetzbuch, Joecks, Wolfgang/Miebach, Klaus (Hrsg.), Band $3 \S \S$ 185-262 StGB, München 2003.

Nelles, Ursula, Kompetenzen und Ausnahmekompetenzen in der Strafprozeßordnung. Zur organisationsrechtlichen Funktion des Begriffs „Gefahr im Verzug“ im Strafverfahrensrecht, Berlin 1980. 
Oswald, Katharina, Die Implementation gesetzlicher Maßnahmen zur Bekämpfung der Geldwäsche in der Bundesrepublik Deutschland, Freiburg 1997.

Pfeiffer, Gerd, Strafprozessordnung, 5. Auflage, München 2005.

Rehbinder, Manfred, Rechtssoziologie, 4. Auflage, München 2000.

Riegel, Reinhard, Rechtsprobleme der Rasterfahndung, ZRP 1980, S.300-306.

Rieß, Peter, Über Subsidiaritätsverhältnisse und Subsidiaritätsklauseln im Strafverfahren, In: Geppert, Klaus/Dehnicke, Diether (Hrsg.), Gedächtnisschrift für Karlheinz Meyer, Berlin/New York 1990, S.367-390.

Plöse, Michael, Panik als Rechtsgrundlage. Berliner Kammergericht erklärt Rasterfahndung für rechtmäßig (Anmerkung zu KG 16.04.2002), Betrifft Justiz 2002, S.332-334.

Rogall, Klaus, Moderne Fahndungsmethoden im Lichte gewandelten Grundrechtsverständnisses, GA 132 (1985), S.1-27.

Ruder, Karl-Heinz/Schmitt, Steffen, Polizeirecht Baden-Württemberg, 6. Auflage, Baden-Baden 2005.

Ruwe, Heinz, Stand und Entwicklung der elektronischen Datenverarbeitung bei der Polizei, Die Polizei 1968, S.373-379.

Schnarr, Karl Heinz, Zur Verknüpfung von Richtervorbehalt, staatsanwaltschaftlicher Eilanordnung und richterlicher Bestätigung, NStZ 1991, S.209-216.

Schneider, Hans, Gesetzgebung, 3. Auflage, Heidelberg 2002.

Schnell, Rainer/Hill, Paul B./Esser, Elke, Methoden der empirischen Sozialforschung, 7. Auflage, München 2005.

Schönke, Adolf/Schröder, Horst, Kommentar zum Strafgesetzbuch, Lenckner, Theodor/Eser, Albin/Stree, Walter/Eisele, Jörg/Heine, Günter/Perron, Walter/ Sternberg-Lieben, Detlev (Hrsg.), 27. Auflage, München 2006.

Schroller, Gerhard, Der polizeiliche Erfolg: Messbarkeit und Messung, In: Bundeskriminalamt (Hrsg.), Symposium: Der polizeiliche Erfolg, Wiesbaden 1988, S.27-38.

Seel, Lothar, Die präventiv polizeiliche Rasterfahndung - Bestandsaufnahme, Problemfelder und Lösungswege, Die Polizei 2002, S.192-202.

Sieber, Ulrich/Bögel, Marion, Logistik der Organisierten Kriminalität, Wiesbaden 1993.

Siebrecht, Michael, Rasterfahndung - Eine EDV-gestützte Massenfahndungsmethode im Spannungsfeld zwischen einer effektiven Strafverfolgung und dem Recht auf informationelle Selbstbestimmung, Berlin 1997.

Siebrecht, Michael, Rechtsprobleme der Rasterfahndung, CR 1996, S.545-555. 
Simitris, Spiros, Die informationelle Selbstbestimmung - Grundbedingungen einer verfassungskonformen Informationsordnung, NJW 1984, S.398-405.

Simon, Jürgen/Taeger, Jürgen, Rasterfahndung, Baden-Baden 1981.

Simon, Jürgen/Taeger, Jürgen, Grenzen kriminalpolizeilicher Rasterfahndung, JZ 1982, S.140-145.

Sokol, Bettina, Rasterfahndung vor 20 Jahren und heute. In: Helmut Bäumler (Hrsg.), Polizei und Datenschutz, Neuwied 1999, S.188-198.

Steffen, Wiebke, Analyse polizeilicher Ermittlungstätigkeit aus der Sicht des späteren Strafverfahrens, Wiesbaden 1976.

Störzer, Udo, Ziele des Symposiums, In: Bundeskriminalamt (Hrsg.), Symposium: Der polizeiliche Erfolg, Wiesbaden 1988, S.3-26.

Systematischer Kommentar zur Straprozeßordnung und zum Gerichtsverfassungsgesetz, Rudolphi, Hans-Joachim/Frisch, Wolfgang/Paeffgen, Hans-Ulrich/ Rogall, Klaus/Schlüchter, Ellen/Wolter, Jürgen (Hrsg.), Band 1 vor $\S 1$ bis $\S 100 \mathrm{~b}$, Loseblattsammlung, Frankfurt am Main, 33.Lfg. September 2003.

Wanner, Stephan, Die negative Rasterfahndung - Eine moderne und umstrittene Methode der repressiven Verbrechensbekämpfung, München 1985.

Wanner, Stephan, Die negative Rasterfahndung, CR 1986, S.216-223, S.274-283 und S.403-414.

Wassermann, Rudolf, Kommentar zum Strafgesetzbuch, Reihe Alternativkommentare, Band 2/Teilband $1 \S \S 94-212 b$, Neuwied/Kriftel/Berlin 1992.

Wehner, Bernd, Kube/Störzer/Brugger (Hrsg.), Wissenschaftliche Kriminalistik, Band 16 BKA-Forschungsreihe, Teilband 1, Wiesbaden 1983, Teilband 2, Wiesbaden 1984 (Buchbesprechung), Kriminalistik 39 (1985), S.111-112.

Weichert, Thilo, Informationelle Selbstbestimmung und strafrechtliche Ermittlung, Paffenweiler 1990.

Welp, Jürgen, Zur Legalisierung der Rasterfahndung, In: Erichsen, HansUwe/Kollhosser, Helmut/Welp, Jürgen (Hrsg.), Recht der Persönlichkeit, Berlin 1996, S.389-414.

Wittig, Petra, Schleppnetzfahndung, Rasterfahndung und Datenabgleich, JuS 1997, S.961-970.

Wittkämper, Gerhard W./Krevert, Peter/Kohl, Andreas, Europa und die innere Sicherheit, Wiesbaden 1996.

Wolter, Jürgen, Heimliche und automatisierte Informationseingriffe wider Datengrundrechtsschutz, GA 135 (1988), S.49-90 und S.129-142. 